Earth and Environmental Science Transactions of the Royal Society of Edinburgh

http://journals.cambridge.org/TRE

Additional services for Earth and Environmental Science Transactions of the Royal Society of Edinburgh:

Email alerts: Click here

Subscriptions: Click here

Commercial reprints: Click here

Terms of use : Click here

\title{
The wasps, bees and ants (Insecta: Vespida=Hymenoptera) from the Insect Limestone (Late Eocene) of the Isle of Wight, UK
}

Alexander V. Antropov, Sergey A. Belokobylskij, Stephen G. Compton, Gennady M. Dlussky, Andrey I. Khalaim, Victor A. Kolyada, Mikhail A. Kozlov, Ksenia S. Perfilieva and Alexandr P. Rasnitsyn

Earth and Environmental Science Transactions of the Royal Society of Edinburgh / Volume 104 / Issue 3-4 / May 2014, pp 335 - 446 DOI: 10.1017/S1755691014000103, Published online: 30 May 2014

Link to this article: http://journals.cambridge.org/abstract_S1755691014000103

How to cite this article:

Alexander V. Antropov, Sergey A. Belokobylskij, Stephen G. Compton, Gennady M. Dlussky, Andrey I. Khalaim, Victor A. Kolyada, Mikhail A. Kozlov, Ksenia S. Perfilieva and Alexandr P. Rasnitsyn (2014). The wasps, bees and ants (Insecta:

Vespida=Hymenoptera) from the Insect Limestone (Late Eocene) of the Isle of Wight, UK . Earth and Environmental Science Transactions of the Royal Society of Edinburgh, 104, pp 335-446 doi:10.1017/S1755691014000103

Request Permissions : $\underline{\text { Click here }}$ 


\title{
The wasps, bees and ants (Insecta: Vespida $=$ Hymenoptera) from the Insect Limestone (Late Eocene) of the Isle of Wight, UK
}

\author{
Alexander V. Antropov ${ }^{1}$, Sergey A. Belokobylskij ${ }^{2,7}$, Stephen G. Compton ${ }^{3}$, \\ Gennady M. Dlussky ${ }^{4}$, Andrey I. Khalaim ${ }^{2}$, Victor A. Kolyada ${ }^{1}$, \\ Mikhail A. Kozlov ${ }^{\dagger}$, Ksenia S. Perfilieva ${ }^{4}$ and Alexandr P. Rasnitsyn ${ }^{5,6}$ \\ ${ }^{1}$ Zoological Museum of Moscow Lomonosov State University. Bol'shaya Nikitskaya Str. 6. Moscow, 125009, \\ Russia. Emails: antropov@zmmu.msu.ru; proctos@mail.ru \\ ${ }^{2}$ Zoological Institute of the Russian Academy of Sciences, Universitetskaya nab. 1, St. Petersburg 199034, Russia. \\ Email: sb@zin.ru; doryctes@gmail.com \\ ${ }^{3}$ Faculty of Biological Sciences, University of Leeds, Leeds LS2 9JT, UK. Email: s.g.a.compton@leeds.ac.uk. \\ ${ }^{4}$ Biological Faculty of Moscow State University, Moscow 119992 Russia. \\ Email dlusskye@mail.ru; ksenperf@mail.ru. \\ ${ }^{5}$ Palaeontological Institute, Russian Academy of Sciences, 117997 Moscow, Russia. Email: alex.rasnitsyn@gmail.com \\ ${ }^{6}$ Natural History Museum, Cromwell Road, London SW7 5BD, UK. \\ ${ }^{7}$ Museum and Institute of Zoology, Polish Academy of Sciences, Wilcza 64, Warszawa 00-679, Poland. \\ ${ }^{\dagger}$ Deceased
}

\begin{abstract}
The types and undescribed material of the hymenopteran fossils of the Insect Bed of the Bembridge Marls from the Isle of Wight (UK) are critically revised and studied. A total of 1460 fossils are recorded and attributed to 20 families: Gasteruptiidae s.l. (1); Proctotrupidae (3); Diapriidae (24); Cynipidae (7); Figitidae (6); Pteromalidae (1); Agaonidae (3); Scelionidae (12); Platygastridae (2); Ichneumonidae (32); Braconidae (75); Bethylidae (3); Crabronidae (2); Sphecidae (1); Apidae (2); Scoliidae (1); Tiphiidae (2); Vespidae (4); and Formicidae (1220). Described as new are 51 species, 13 genera, two tribes and two subfamilies. Minimum number of species recorded (either as described species or representing higher taxa with no described species in the assemblage) is 118 . The composition of the hymenopteran assemblage is most similar to that of Baltic amber and indicative of a well forested territory, as well as of a humid, equable (aseasonal but not very hot) climate, more typically equable than in the Baltic amber source area, judging from the absence of Aphidiinae and scarcity of aphids.
\end{abstract}

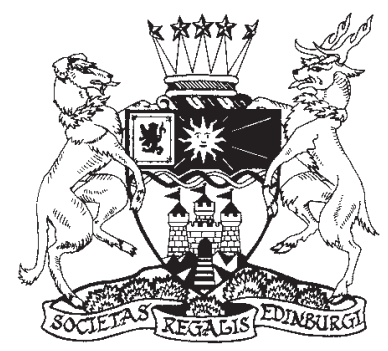

KEY WORDS: Bembridge Marls, Eocene, fossil insects, new combinations, new taxa

Material for the present study comprises the hymenopteran fossils preserved in concretions or tabular bands of very finegrained micrite, known as Insect Limestone. The unit where these concretions/bands occur is known as the Insect Bed, which lies towards the base of the Bembridge Marls Member (Solent Group: Bouldnor Formation). The Bembridge Marls are dated as the latest Eocene (Hooker et al. 2009). The deposits outcrop in several sites along the north coast of the Isle of Wight near the south coast of Great Britain.

Most of the specimens studied are kept at the Natural History Museum (NHMUK). The majority of them belong to the collections of A'Court Smith (purchased 1877, 1883), P.B. Brodie (purchased 1898) and R.W. Hooley (purchased 1924). They are labelled 'Gurnard Bay' or 'Gurnet Bay' (which is an old name for Gurnard Bay). However, Smith collected specimens all the way from West Cowes to Newtown River on the northwest side of the Isle of Wight (Jarzembowski 1980). Most of the specimens probably came from Thorness Bay (Jarzembowski 1976). Brodie and Hooley acquired parts of Smith's collection, so parts and counterparts of individual insects have turned up in all three collections. The parts and counterparts often have different numbers, because they were registered at different times. An additional collection was recently discovered at the Sedgwick Museum, Cambridge, by A.J. Ross. This collection has also yielded counterparts of specimens at the NHMUK which indicates that this is another part of the Smith collection. A label with ' 1883 ' on it suggests that the Sedgwick Museum acquired this collection in 1883, the same year in which the NHMUK purchased specimens from Smith.

A small collection of the fossils studied, referred to as USNM, is kept at the National Museum of Natural History, Smithsonian Institution, Washington, DC, USA. These are mostly the type material described by Cockerell (1915). They come from the same deposits.

Hymenopterans are the second most common insect order (after dipterans) in the Bembridge assemblage. Even if their high participation depends in part on the hyper-abundance of two species of a single ant genus (Oecophylla Smith, 1860 which is responsible for at least 40 per cent of the hymenopteran fossils), the order diversity is impressive, with its 20 families, over 100 genera and more than 120 species recorded conservatively after this non-exhaustive study of the available fossil material. 
Table 1 Current taxonomic position of the previously described species of the Bembridge fossil hymenopterans

\begin{tabular}{|c|c|}
\hline Taxa as described & Current taxonomic position \\
\hline Acourtia perplexa Cockerell, 1921, Ichneumonidae & Ichneumonidae: Townesitinae: Acourtia perplexa Cockerell, 1921 \\
\hline Andricus vectensis Cockerell, 1921, Cynipidae & not revised \\
\hline Aneurhynchus conservatus Cockerell, 1915, Diapriidae & not studied \\
\hline Bathystomus peritus Cockerell, 1921, Braconidae & Braconidae: Opiinae: Biosteres peritus (Cockerell, 1921) \\
\hline Calyptoides veternus Cockerell, 1921, Braconidae & Braconidae: Helconinae: Calyptoides veternus Cockerell, 1921 \\
\hline $\begin{array}{l}\text { Camponotus (Colobopsis) brodiei Donisthorpe, } 1920, \\
\text { Formicidae }\end{array}$ & Formicidae incertae sedis: "Camponotus" brodiei Donisthorpe, 1920: \\
\hline Coleocentrus gurnetensis Cockerell, 1921, Ichneumonidae & Ichneumonidae: subfam. indet.: “Coleocentrus” gurnetensis Cockerell, 1921 \\
\hline Cremastus? arcuatus Cockerell, 1921, Ichneumonidae & Ichneumonidae: Orthocentrinae, Microleptini: Eusterinx arcuatus (Cockerell, 1921) \\
\hline Dacnusites reductus Cockerell, 1921, Braconidae & Braconidae: Microgastrinae: Dacnusites reductus Cockerell, 1921 \\
\hline Dacnusites sepultus Cockerell, 1921, Braconidae & Braconidae: Microgastrinae: Dacnusites sepultus Cockerell, 1921 \\
\hline Diospiloides hooleyi Cockerell, 1921, Braconidae & Braconidae: Orgilinae: Microtypus hooleyi (Cockerell, 1921) \\
\hline Diospilus acourti Cockerell, 1921, Braconidae & Braconidae: Helconinae: Diospilus acourti Cockerell, 1921 \\
\hline Dolichoderus anglicus Cockerell, 1915, Formicidae & Formicidae: Aneuretinae: Britaneuretus anglicus (Cockerell, 1915) \\
\hline Dolichoderus britannicus Cockerell, 1915, Formicidae & Formicidae: Dolichoderinae: Emplastus britannicus (Cockerell, 1915) \\
\hline Dolichoderus gurnetensis Donisthorpe, 1920, Formicidae & Formicidae: Dolichoderinae: Emplastus gurnetensis (Donisthorpe, 1920) \\
\hline Dolichoderus ovigerus Cockerell, 1915, Formicidae & Formicidae: Dolichoderinae: Emplastus britannicus (Cockerell, 1915) \\
\hline Dolichoderus vectensis Donisthorpe, 1920, Formicidae & Formicidae: Dolichoderinae: Dolichoderus vectensis Donisthorpe, 1920 \\
\hline Emplastus emeryi Donisthorpe, 1920, Formicidae & Formicidae: Dolichoderinae: Emplastus britannicus (Cockerell, 1915) \\
\hline Euponera crawleyi Donisthorpe, 1920, Formicidae & Formicidae: Ponerinae: Ponerites crawleyi (Donisthorpe, 1920) \\
\hline Holomeristus? vectensis Cockerell, 1921, Ichneumonidae & Ichneumonidae: Orthocentrinae, Microleptini: Eusterinx vectensis (Cockerell, 1921) \\
\hline Ichneumon acourti Cockerell, 1921, Ichneumonidae & Ichneumonidae: Cryptinae: "Hemiteles" acourti (Cockerell, 1921) \\
\hline Ipobracon? micrarche Cockerell, 1921, Braconidae & Braconidae: Braconinae: Bracon micrarche (Cockerell, 1921) \\
\hline Ipobracon? vectensis Cockerell, 1921, Braconidae & Braconidae: Braconinae: Cyanopterus vectensis (Cockerell, 1921) \\
\hline Itoplectis saxosus Cockerell, 1921, Ichneumonidae & Ichneumonidae: Pimplinae: "Itoplectis" saxosa (Cockerell, 1921) \\
\hline Lampronota disrupta Cockerell, 1921, Ichneumonidae & Ichneumonidae: Townesitinae: Marjorietta disrupta (Cockerell, 1921) \\
\hline Leptothorax gurnetensis Cockerell, 1915, Formicidae & Formicidae: Formicinae: Leucotaphus gurnetensis (Cockerell, 1915) \\
\hline Leucotaphus cockerelli Donisthorpe, 1920, Formicidae & Formicidae: Formicinae: Camponotus cockerelli (Donisthorpe, 1920) \\
\hline Leucotaphus permaneus Cockerell, 1927, Formicidae & not studied (type lost) \\
\hline Lithapechtis fumosus Cockerell, 1921, Ichneumonidae & Ichneumonidae: subfam. indet.: Lithapechtis fumosus Cockerell, 1921 \\
\hline Lithobelyta reducta Cockerell, 1921, Diapriidae & Chalcidoidea: Lithobelyta reducta Cockerell, 1921 \\
\hline Macroteleia veterna Cockerell, 1921, Scelionidae & Scelionidae: Scelioninae: Calliscelio veternus (Cockerell, 1921) \\
\hline Mesitius? rectinervis Cockerell, 1921, Bethylidae & not revised \\
\hline Miota? strigata Cockerell, 1921, Diapriidae & not revised \\
\hline Oecophylla atavina Cockerell 1915, Formicidae & Formicidae: Formicinae: Oecophylla atavina Cockerell 1915 \\
\hline Oecophylla megarche Cockerell, 1915, Formicidae & Formicidae: Formicinae: Oecophylla megarche Cockerell, 1915 \\
\hline Oecophylla perdita Cockerell, 1915, Formicidae & Formicidae: Formicinae: Oecophylla atavina Cockerell 1915 \\
\hline Phanomeris? colenutti Cockerell, 1921, Chalcidoidea & not revised \\
\hline Philoponites clarus Cockerell, 1915, Sphecidae & Tiphiidae: Tiphiinae: Philoponites clarus Cockerell, 1915 \\
\hline Polybia oblita Cockerell, 1921, Vespidae & Vespidae: Polistinae: Protopolistes oblitus (Cockerell, 1921) \\
\hline Polybia? anglica Cockerell, 1921, Vespidae & Vespidae: Polistinae: Palaeopolybia anglica (Cockerell, 1921) \\
\hline Polyclistus anglicus Cockerell, 1921, Ichneumonidae & Ichneumonidae: Metopiinae: Hypsicera anglica (Cockerell, 1921) \\
\hline Polysphincta? atavina Cockerell, 1921, Ichneumonidae & Ichneumonidae: subfam. \& gen. indet.: "Polysphincta" atavina Cockerell, 1921 \\
\hline Ponera hypolitha Cockerell, 1915, Formicidae & Formicidae: Dolichoderinae: Emplastus hypolithus (Cockerell, 1915) \\
\hline Ponera minuta Donisthorpe, 1920, Formicidae & Agaonidae: "Ponera" minuta Donisthorpe, 1920 \\
\hline Pteromalus? vectensis Cockerell, 1921, Pteromalidae & not revised \\
\hline Rhodites vetus Cockerell, 1921, Cynipidae & not revised \\
\hline Sceliphron? brevior Cockerell, 1921, Sphecidae & Sphecidae: Protosceliphrini: Protosceliphron brevior (Cockerell, 1921) \\
\hline Sigalphus cervicalis Cockerell, 1921, Braconidae & Braconidae: Helconinae: Taphaeus cervicalis (Cockerell, 1921) \\
\hline Stilpnus oligocenus Cockerell, 1921, Ichneumonidae & Ichneumonidae: Cryptinae: "Stilpnus" oligocenus \\
\hline Syntaphus wheeleri Donisthorpe, 1920, Formicidae & Braconidae: Cheloninae: Ascogaster (Syntaphus) wheeleri (Donisthorpe, 1920) \\
\hline Vectevania vetula Cockerell, 1922, (Evaniidae) & Gasteruptiidae: Aulacinae?: Vectevania vetula Cockerell, 1922 \\
\hline Xenarcha? distracta Cockerell, 1921 Braconidae & Braconidae: Doryctinae: Ontsira distracta (Cockerell, 1921) \\
\hline Zygota? filicornis Cockerell, 1921, Diapriidae & not revised \\
\hline
\end{tabular}

The taxonomic history of the Bembridge hymenopteran fossils is short, in the sense that all descriptions predating the present project were made during a short interval of twelve years (Cockerell 1915-1927; Donisthorpe 1920) (Table 1).

In the framework of the present project, the following hymenopteran taxa recorded from the Bembridge Marls are thoroughly studied: aculeate wasps (except Chrysidoidea) by
Dlussky and Prefilieva (ants) and Antropov (all others); Ichneumonoidea by Belokobylskij (Braconidae) and Khalaim (Ichneumonidae); Gasteruptiidae by Rasnitsyn; and Proctotrupidae by Kolyada. Diverse Proctotrupomorpha were being studied by the late Mikhail Kozlov, whose untimely death on 11 September 2006 has left this important group without thorough description (except for Proctotrupidae). For the groups 
left unattended, there are preliminary identifications made by Kozlov and completed in part by Kolyada and Compton. Because of different styles in description, and particularly in morphological terminology, including symbols denoting various structures employed in different hymenopteran taxa, unification throughout has not been attempted.

The general compilation and editing of manuscripts by other participants, as well as this introduction, are by Rasnitsyn. The closing Discussion is written by Rasnitsyn, based on the results by other participants in the project.

\section{Overview of the hymenopteran taxa found in the Bembridge Marls}

Symphyta were not found. The absence of Tenthredinoidea is indicative of a warm climate (possibly warmer than in both Baltic amber and Florissant).

The only record of Evaniomorpha is Vectevania vetula Cockerell, 1922 (Gasteruptiidae: Aulacinae), a supposed parasite of xylophilous insect larvae, indicative of forested territory.

Proctotrupomorpha are moderately rich but unfortunately poorly studied. Proctotrupoidea are known from Proctotrupidae (three fossils, described Oxyserphus kozlovi Kolyada, sp. nov. and Mischoserphus sp., both in the tribe Cryptoserphini, parasitising curculionoid beetles and dipteran larvae, respectively, mainly in mesic forests; see below) and Diapriidae (24 fossils). Earlier described Diapriidae are Zygota? filicornis Cockerell, 1921a and Miota? strigata Cockerell, 1921a; additional identifications (by Masner and Kolyada in 2006) are Ambositrinae? gen. sp., Basalys sp., Belyta? sp., Lyteba (?) sp., Pantoclis (?) sp., Spilomicrini gen. sp. and Trichopria sp. Diapriidae are parasites of dipteran larvae preferring mesic environments; Ambositrinae are mainly Gondwanan in their distribution (Australasian and Neotropical with one Afrotropical species known in southern Africa and Madagascar), with one species in North America, and known also in Baltic amber, with one Baltic species hardly distinguishable from an extant African one (Masner 1969).

Cynipoidea are known from 9-11 Cynipidae fossils, including Andricus vectensis Cockerell, 1921a and Rhodites vetus Cockerell, 1921a, and 6-8 Figitidae. Cockerell's generic identifications are not reliable enough to be used for further inferences.

Platygastroidea are found with both living families Platygastridae (two fossils, including Inostemma sp., a genus of gall midge parasites, identified by both Kozlov and Masner) and Scelionidae. The latter comprise 12 fossils, including "Macroteleia" veterna Cockerell, 1921a = Calotelea, a widespread genus of orthopteran parasites; an undescribed genus (determined by Kozlov) near Apegus Foerster, 1856, a Palaearctic and Oriental genus whose relatives parasitise tettigoniid eggs on trees; Gryon sp., a widespread genus attacking heteropteran eggs; Scelionini gen. sp., parasites on acridid eggs; Baeinae gen. sp. a group of spider egg parasites, and Calliscelio sp. (all determined by Masner). Scelionidae are a more xerophylous group than Diapriidae, and the modest participation of this family compared to the latter indicates generally mesic past environments.

Chalcidoidea fossils (15-16 specimens) remain poorly known. Three species are described, one originally as an ant Ponera minuta Donisthorpe, 1920, another as a diapriid Lithobelyta reducta Cockerell, 1921a, and only the third as a chalcidoid Pteromalus? vectensis Cockerell, 1921a. The latter might be a pteromalid, whilst the former, along with two other fossils, are redescribed below as representatives of the family of fig pollinators, Agaonidae (first identified by Kozlov). The family identity of Lithobelyta reducta needs clarification.
The superfamily Ichneumonoidea is particularly rich in the Bembridge Marls, yielding more than one hundred fossils (minimum 32 Ichneumonidae and 75 Braconidae) of more than 60 species (minimum 25 and 36, respectively). Detailed information about these insects is presented below.

Aculeate hymenopterans other than ants are not very diverse. This is particularly true for Chrysidoidea, represented by only three fossils of the family Bethylidae, which remain mostly unstudied. One described is Mesitius? rectinervis Cockerell, 1921a.

The higher wasps and bees (Aculeata s. str.) are fully revised here (see below). Except for ants, they are only moderately diverse. Apoid wasps and bees are known from two bees (one Apidae: Apinae, another unidentifiable Megachilidae) and three wasps (one Sphecidae and two Crabronidae, the latter indicative of a forested landscape). Vespoid (s.1.) wasps are recorded from three families: Tiphiidae (two fossils), Scoliidae (one) and Vespidae (four; one of these shows (sub)tropical affinities). See below for details.

Ants (Formicidae) are the most abundant and most indicative group in the Bembridge hymenopteran assemblage and the third most diverse one (some 1220 fossils, 20 species and ten genera). They comprise both thermophilous and temperate species, whose co-existence implies most convincingly the equable climate, and the high proportion of dendrobiotic or otherwise forest-dwelling ants infers a well forested source area. The ant assemblage is undoubtedly more related to the Baltic amber fauna than to Florissant, but this similarity might be geographically rather than geochronologically driven (for details see below).

Institutional repository abbreviations. CAMSM, Sedgwick Museum of Earth Sciences, University of Cambridge; IWCMS, Isle of Wight County Museum Service; NHMUK, Department of Palaeontology, Natural History Museum, London; USNM, Department of Paleobiology, National Museum of Natural History, Smithsonian Institution, Washington DC.

\section{Material and methods}

The fossils were studied using the usual observation under a stereomicroscope, except that the application of any liquid was avoided because of salt crystals in the rock matrix, often within the fossil itself. Instead of liquid, polarising illumination was used to enhance visibility of the fossilised organic material when preserved. A.V. Antropov used Carl Zeiss Stemi SV 6 and Leica MZ 9.5 stereomicroscopes for study of the fossils, and Nikon Coolpix 885 / Nikon Coolpix 4500 digital cameras to make photographs, which were subsequently improved when necessary using Adobe Photoshop 7.0 software. The line drawings were prepared using CorelDRAW 7 software. All measurements were made with the help of an ocular-micrometer. G. M. Dlussky and K. S. Perfilieva used the Olympus C-4000 Zoom digital camera, and enlarged prints were hand-traced with a pen with the visual control of the specimen under a Leica S6E stereomicroscope. The resulting draft drawing was scanned with ScanExpress 6000 PS and improved finally using the program CorelDRAW 8. V.A. Kolyada used the Wuzhou XTL-3400E stereomicroscope and a Canon PowerShot S50 camera, with photographs automontaged with Helicon Focus software and adjusted with Adobe Photoshop 6.0; line drawings were made with Adobe Illustrator 10 software. A. P. Rasnitsyn examined the fossils using LOMO MPS-2 and Leica MZ 9.5 microscopes and prepared photographs using a Nikon Coolpix4500 camera automontaged with Helicon Focus software, and the line drawings were prepared using CorelDRAW 11 software. 


\section{Systematic palaeontology}

\subsection{Superfamily Evanioidea Latreille, 1802}

[By Alexandr P. Rasnitsyn.]

Vectevania vetula Cockerell, 1922 has been very briefly described based on the unique holotype collected in the Bembridge Marls. Cockerell (1922) ascribed the fossil to the family Evaniidae, which at that time was equivalent to the current superfamily Evanioidea, and compared it with Hyptiogaster, which is now attributed to the family Gasteruptiidae s.str. and subfamily Hyptiogastrinae (Jennings \& Austin 2000). This fossil remains the only Cenozoic record of Gasteruptiidae s.str. (Nel et al. 2004) and so deserves close attention.

The unique holotype (obverse part only) NHMUK In.20535 is kept at the Natural History Museum, London. As usual in the Bembridge Marls, the fossil (Text-fig. 1A) is perfectly threedimensional, with the body cavity empty, and a split within the body more or less along the wing plane. The counterpart is lost, and the only part at hand shows the internal ventral surface of the insect seen from above. The head cavity is only slightly open dorsally, showing no details. The antennae, legs and metasomal apex are not preserved, nor is practically all of the dorsal surface, except for the 1st metasomal acrosegment seen from above and sidewise, and a small subterminal tergal surface of the metasoma. This restricts the availability of taxonomically meaningful structures mainly to wing venation.

\section{Family Gasteruptiidae Ashmead, 1900 \\ Subfamily Aulacinae Hedicke, 1939 \\ Genus Vectevania Cockerell, 1922}

Type species. $V$. vetula Cockerell, 1922 (by monotypy).

Diagnosis. Propleura short. Forewing not folded longitudinally as preserved, with cell $1 \mathrm{mcu}$ reversely triangular $(\mathrm{RS}+\mathrm{M}$ meeting basal vein at its lower corner, $1 \mathrm{~m}-\mathrm{cu}$ short but distinct), $2 \mathrm{r}-\mathrm{m}$ spectral, $3 \mathrm{r}-\mathrm{m}$ apparently lost but leaving signs of its former position in slight angulation of RS and $\mathrm{M}, 2 \mathrm{~m}-\mathrm{cu}$ tubular. Hind wing with $\mathrm{C}$ tubular. Metasomal sterna flat, indicating depressed metasoma, with apparent metasomal segment 1 triangular with sides slightly convex (fore part not forming petiole). No trace of possible fusion of two primary sterna discernible.

Remark. Taxonomic position of the genus deserves an extensive discussion which is not appropriate herein (cf. Rasnitsyn 2013).

\section{Vectevania vetula Cockerell, 1922 Text-fig. 1}

1922 Vectevania Cockerell, p. 34, fig. 1.

1992 Vectevania Carpenter, p. 474.

Holotype. NHMUK In.20535, Bembridge Marls, NW Isle of Wight, UK, Smith Coll.; ventral body interior and left wing pair, no appendages; sex unknown.

Description. Head apparently large, transverse. Pronotum as preserved arching, not armed. Propleurae short, at most slightly extending beyond fore pronotal contour. Mesopectus with internal surface smooth with few and ordinary features (discrimen, pleural sutures, and bend delimiting anterior (coxae-faced) surface). Forewing with pterostigma large semicircular. Basal vein composed almost entirely of long 1RS slightly arching in lower half; $1 \mathrm{M}$ rudimentary, aligned with $1 \mathrm{RS}+\mathrm{M}$ thus making $1 \mathrm{mcu}$ cell reversal triangular (with narrow end directed basally), $2 \mathrm{RS}+\mathrm{M}$ short (about as long as $1 \mathrm{~m}-\mathrm{cu}$ ), with RS and $\mathrm{M}$ diverging almost symmetrically at its distal end. Cross-vein $2 \mathrm{r}-\mathrm{rs}$ c. $0 \cdot 7$ times as long as pterostigma width, meeting pterostigma at its midlength, slightly inclined posterodistally, meeting RS at about its length basal of $2 r-m$, $2 \mathrm{r}-\mathrm{m}$ spectral, meeting $\mathrm{M}$ slightly basal of $2 \mathrm{~m}-\mathrm{cu}$. Cell $2 \mathrm{rm}$ subtriangular, almost twice as long as wide. Cell $3 \mathrm{r}-\mathrm{m}$, as defined by angulations of RS and $\mathrm{M}$ at junctions with former $3 \mathrm{r}-\mathrm{m}$, subquadrate. $\mathrm{M}$ getting thinner beyond former $3 \mathrm{r}-\mathrm{m}$, but apparently persist tubular and coloured. Cell $2 \mathrm{~m}-\mathrm{cu}$ receiving $\mathrm{Cu}$ at its midhight basally, $2 \mathrm{~m}-\mathrm{cu}$ c. half as long as $2 \mathrm{~m}-\mathrm{cu}$ maximum height. Crossvein $\mathrm{cu}-\mathrm{a}$ mirroring $1 \mathrm{RS}$ in meeting $\mathrm{Cu}$ close to $\mathrm{M}+\mathrm{Cu}$ fork and being inclined posterodistally at similar angle. Anal vein thick (apparently thicker than R), slightly sinuate. Hind wing with $\mathrm{C}$ and $\mathrm{R}$ tubular and the rest veins spectral and of usual form. Metasoma elongate tear-shaped, with sterna flat, six in number, implying either no sternal fusion or male sex in case of traceless fusion of sterna 1 and 2. Metasomal 1st acrotergite small and not much modified in side view, 1st apparent sternum beyond acrosternite of subequal length and width, longer than two following sterna combined; following sterna short but of irregular length, possibly being telescoped irregularly. No distinct surface sculpture or colouration of ventral body integuments preserved. Forewing length $c .4 .7 \mathrm{~mm}$, body length might be $c .5-6 \mathrm{~mm}$ (body parts are too incomplete to be worth measuring).

\subsection{Superfamily Proctotrupoidea Latreille, 1802 [By Victor A. Kolyada.]}

Family Proctotrupidae Latreille, 1802

Tribe Cryptoserphini Kozlov, 1970

Genus Oxyserphus Masner, 1961

Oxyserphus kozlovi Kolyada, sp. nov.

Plate 1, fig. 1; Text-fig. 2

Etymology. In memory of Mikhail A. Kozlov.

Holotype. NHMUK I.9769, Bembridge Marls, NW Isle of Wight, UK, Brodie Collection; female, side view of insect lacking mid leg and most of antenna,

Diagnosis. The new species is similar to $O$. capitatus Townes, in Townes \& Townes 1981 in ovipositor form which differs in details: the latter species has sheaths shorter $(1.0$ as long as hind femur), and additionally, unlike the new species, it has the ultimate female flagellomere distinctly incrassate. Incomplete preservation of the holotype makes the diagnosis tentative.

Description. Body slender, length $2.9 \mathrm{~mm}$, forewing 1.35 $\mathrm{mm}$. Head slightly transversal, 1.6 times as high as wide. Apical antennal segments of usual thickness, c. 2.5 (penultimate) 3 times (ultimate) as long as wide, ultimate 1.2 times as long as penultimate. Mesosoma of usual form, not depressed. Horizontal groove across mesopleurum complete. Propodeum with strong reticulation. Forewing with pterostigma of usual form, 1.9 times as long as wide. Vertical part of pterostigma twice as long as wide, with radial vein originating from it. Radial vein slightly arched, joining costal vein at $40^{\circ}$. Costal section of radial cell 0.6 times as long as depth of pterostigma. Costal vein not extending beyond marginal cell. Hind tibia with spur not reaching midlength of basitarsus. Metasoma without a stalk. Ovipositor sheath somewhat widened toward widely rounded apex, 7.5 times as long as wide, c. 1.2 times as long as hind tibia.

Remarks. Oxyserphus is known to be widespread over Australia and New Zealand (Townes \& Townes 1981); however, there are unpublished records from most of the Oriental region, including SE Asia up to Japan, and also for Central America. Apparently only one fifth of the world fauna is 

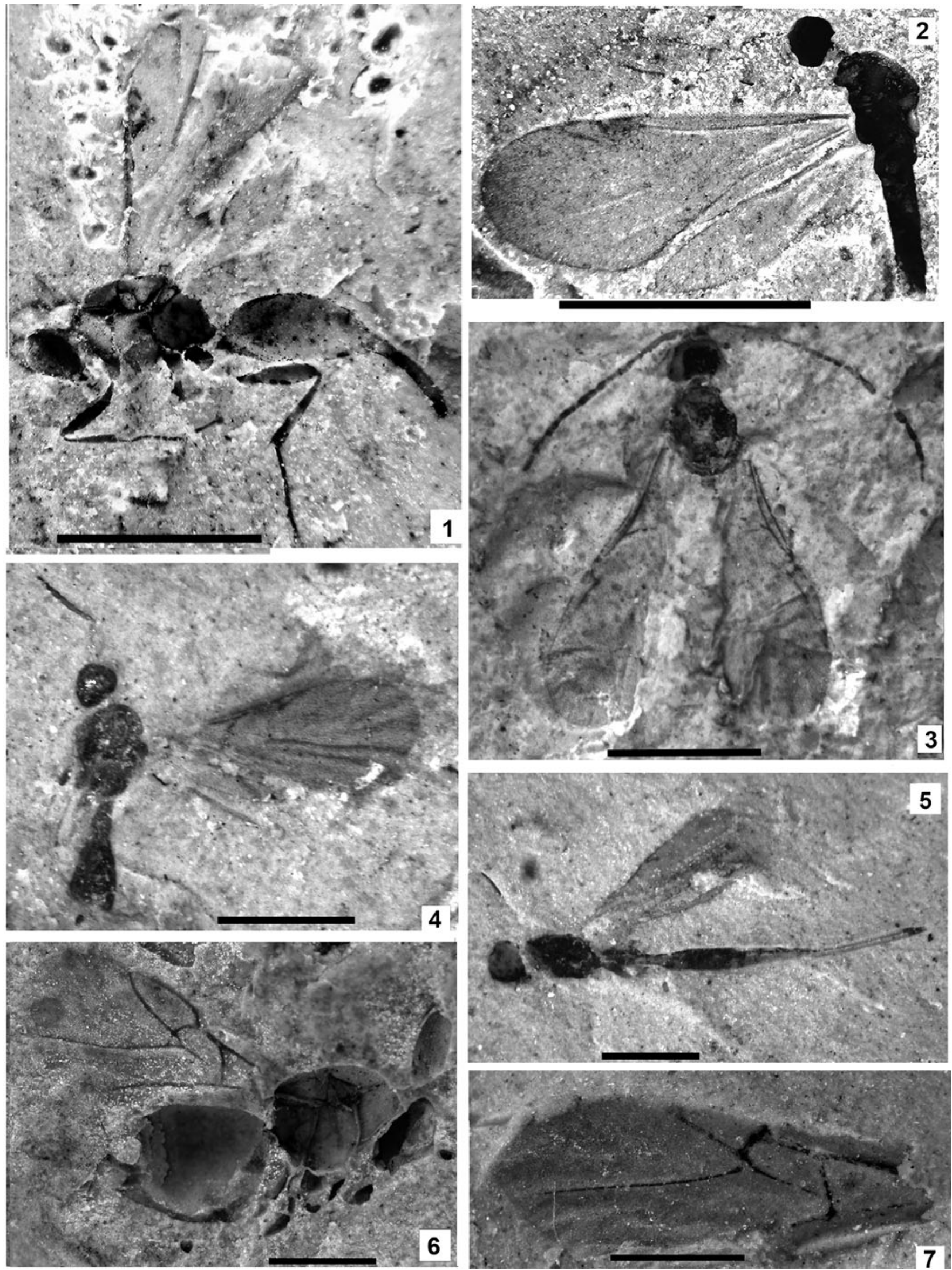

Plate 1 (1) Oxyserphus kozlovi Kolyada, sp. nov. NHMUK I.9769, holotype. (2) Mischoserphus sp., specimen NHMUK I.9142. (3) Zygota? filicornis Cockerell, NHMUK I.9269, holotype. (4) Miota? strigata Cockerell, NHMUK I.9312, holotype. (5) Macroteleia veterna Cockerell, NHMUK In.17262, holotype. (6) Andricus vectensis Cockerell, NHMUK I.8923, holotype. (7) Rhodites vetus Cockerell, NHMUK In.24341, holotype. Scale bars $=1 \mathrm{~mm}$. 
(a)

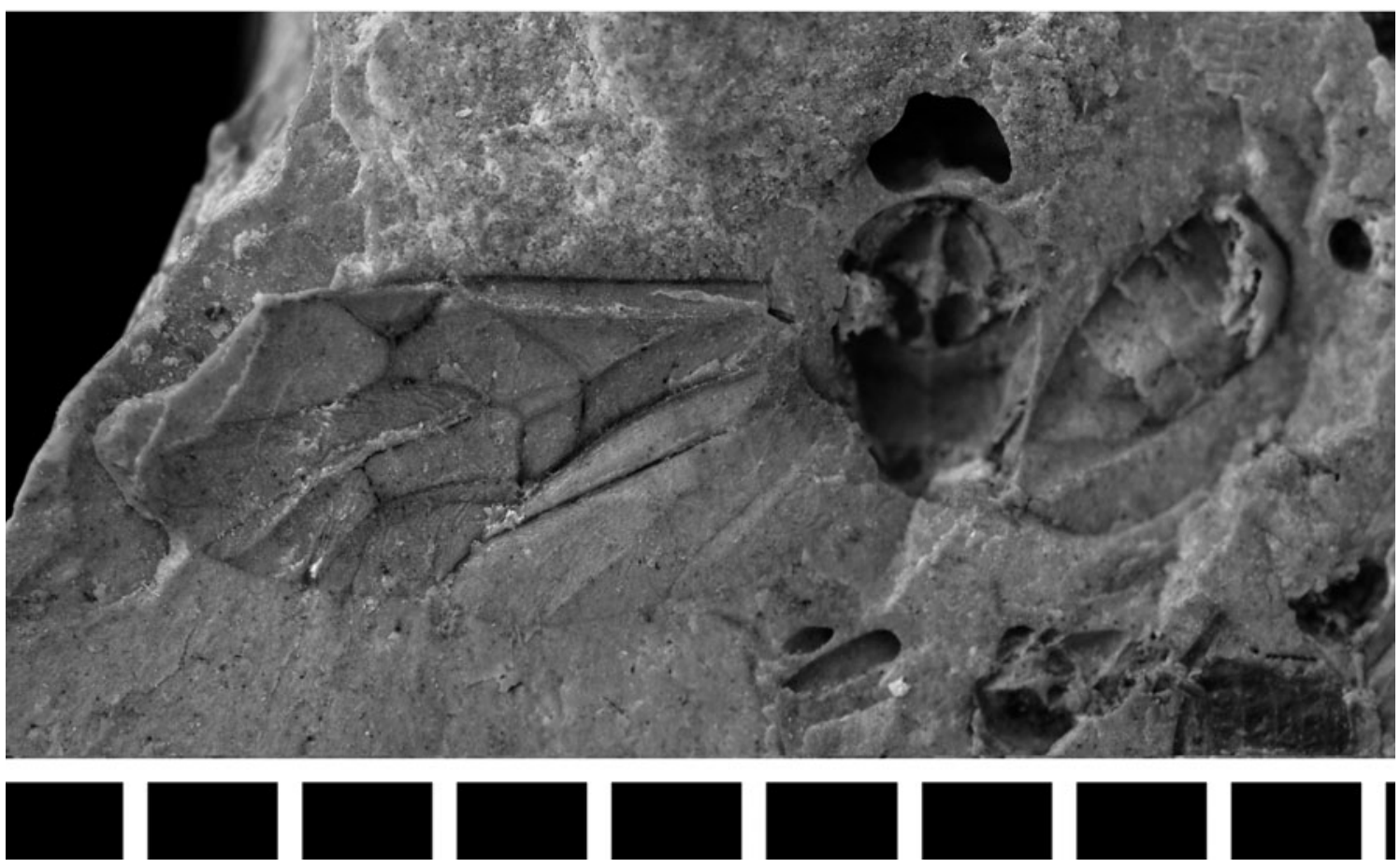

(b)
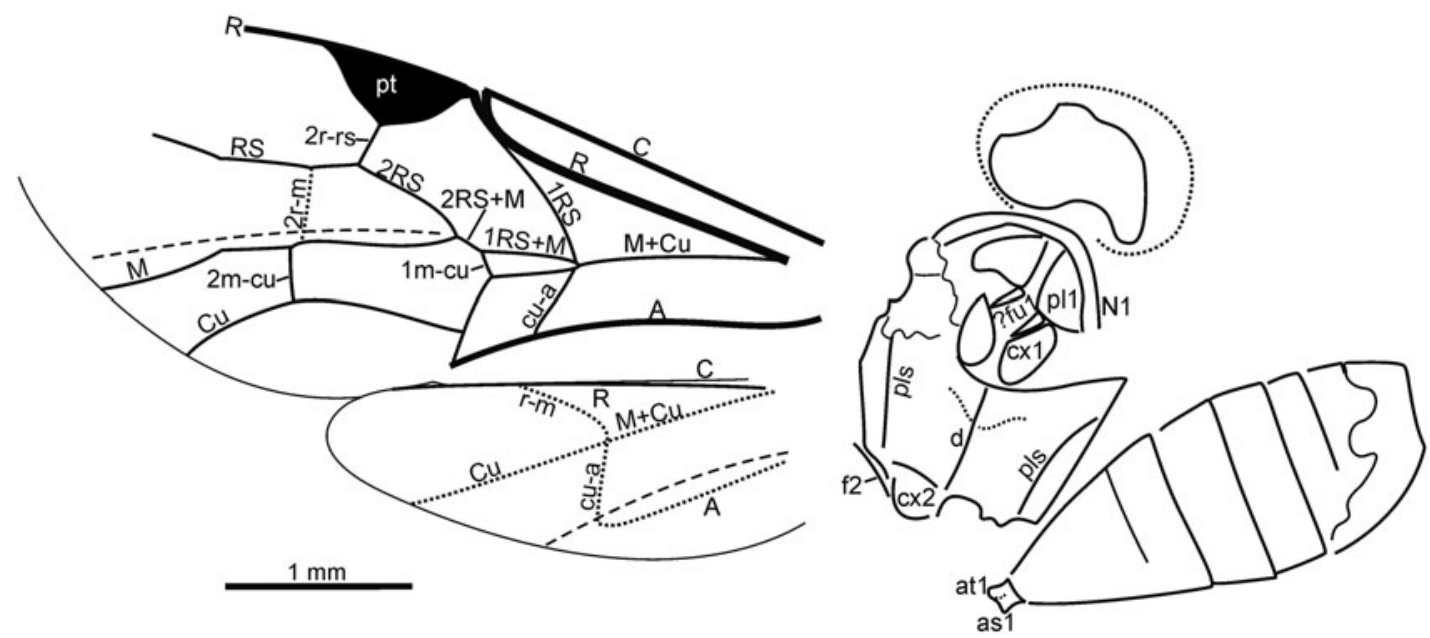

Text-figure 1 Vectevania vetula Cockerell, holotype NHMUK In.20535, Bembridge Marls, Isle of Wight, England: (A) photograph of the fossil. Ruler units equal to $1 \mathrm{~mm}$; (B) line drawing. For wings, spectral veins are shown by dots, membrane folds by dashes; for body, dot lines indicate the very tentative head contour and the bend between lower and anterior faces of mesopectus. The vein nomenclature is standard. Other abbreviations: at1, as 1 = acrotergite and acrosternite of the 1st metasomal segment; $d=$ discrimen (line of invagination of the mesothoracic sternum); $\mathrm{f} 2=$ margin of mid femur; ?fu1 = supposedly parts of prothoracic furca; $\mathrm{N} 1$ = fore margin of pronotum; pls = pleural suture; $\mathrm{cx} 1, \mathrm{cx} 2, \mathrm{pl}=$ entrances into cavities of, respectively, fore and mid coxae and of propleura.

described so far. The genus is thermophilous, preferring humid and shadowed forests. Known to be larval endoparasite of Curculionidae and Anthribidae (Townes \& Townes 1981).

Genus Mischoserphus Townes, in Townes \& Townes 1981 Mischoserphus sp.

Plate 1, fig. 2; Text-fig. 3

Material. NHMUK I.9142, Bembridge Marls, NW Isle of Wight, UK, Brodie Collection; partial body with no characters worth to study preserved, and complete wings.
Description. Forewing length $1.47 \mathrm{~mm}$. Costal vein extending beyond apex marginal cell for 0.9 times of costal length of marginal cell.

Remarks. The generic position of the fossil is due to its costal vein extending beyond the apex of the marginal cell, which is characteristic of Mischoserphus, supported by the slender body and small, round head. Comparison with other congeners is impossible based on the characters available. Mischoserphus is a widespread genus parasitising fungus gnats (Mycetophilidae). 


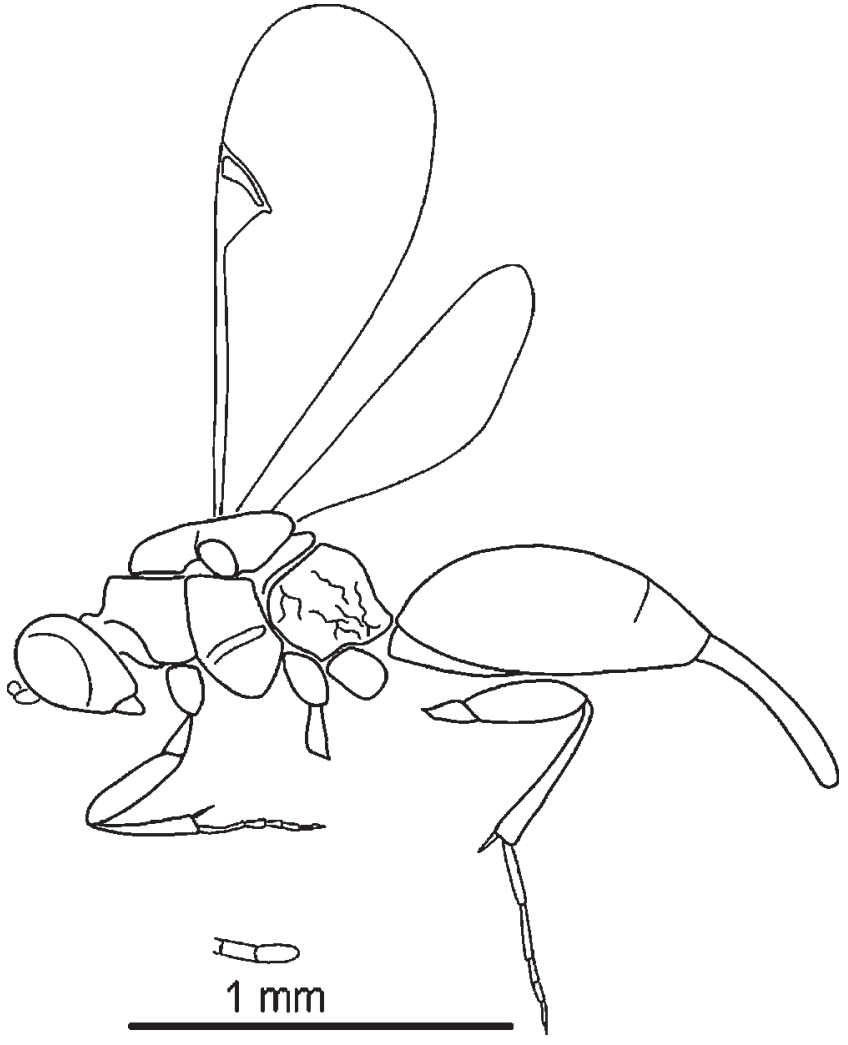

Text-figure 2 Oxyserphus kozlovi Kolyada, sp. nov., NHMUK I.9769, holotype.

\subsection{Superfamily Diaprioidea Haliday, 1833}

Family Diapriidae Haliday, 1833

Genus Zygota Foerster, 1856

Zygota? filicornis Cockerell, 1921

Plate 1, fig. 3

1921a Zygota? filicornis Cockerell, p. 23, fig. 29.

Holotype. NHMUK I.9269, Bembridge Marls, NW Isle of Wight, UK, coll. P. B. Brodie.

Remark. The type was not revised. The genus is limited to the cool part of the Holarctic, ranging from tundra to mixed forests, occurring further southward on mountains only. Host unknown.

Genus Miota Foerster, 1856

Miota? strigata Cockerell, 1921

Plate 1, fig. 4

1921a Miota? strigata Cockerell, p. 22, fig. 28.

Holotype. NHMUK I.9312, Bembridge Marls, NW Isle of Wight, UK, coll. P. B. Brodie.

Remark. The type was not revised. The genus is distributed worldwide, prefers temperate, mesic, forested environments and parasitises fungus gnats.

\subsection{Superfamily Platygastroidea Haliday, 1833}

Family Scelionidae Haliday, 1839

Genus Calotelea Westwood, in Hope, 1837

Calotelea veterna (Cockerell, 1921), comb. nov. Plate 1, fig. 5

1921a Macroteleia veterna Cockerell, p. 21, fig. 26.

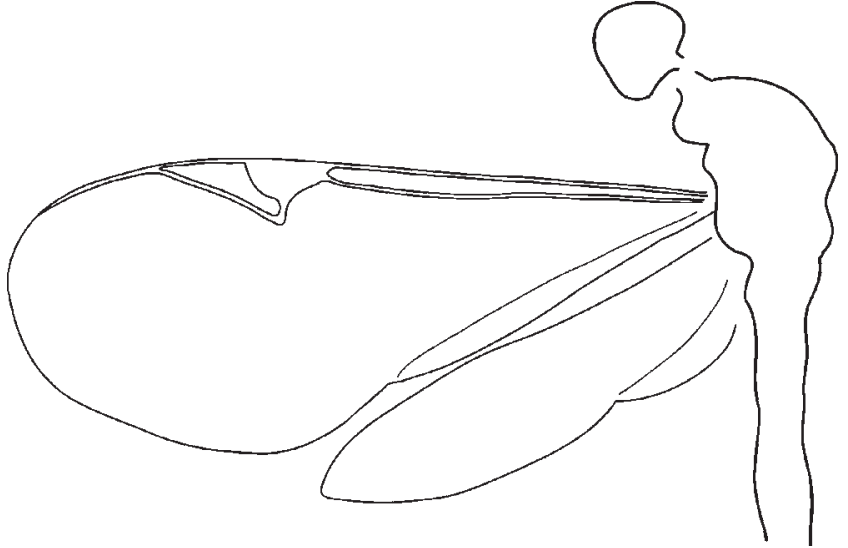

Text-figure 3 Mischoserphus sp., NHMUK I.9142.

Holotype. NHMUK In.17262, Bembridge Marls, NW Isle of Wight, UK, Smith Collection.

Remark. Generic attribution is by L. Masner (pers. comm., 2006) based on examination of the type. The genus populates mainly tropics and subtropics, the only host record is Aeshna dragonfly.

\subsection{Superfamily Cynipoidea Latreille, 1802} [By Alexandr P. Rasnitsyn.]

Family Cynipidae Latreille, 1802

Genus Andricus Hartig, 1840

Andricus vectensis Cockerell, 1921

Plate 1, fig. 6

1921a Andricus vectensis Cockerell, p. 23, fig. 30

Holotype. NHMUK I.8923, Bembridge Marls, NW Isle of Wight, UK, Collection P. B. Brodie.

Remark. The type has not been revised, so its taxonomic position is not confirmed.

Genus Rhodites Hartig, 1840

Rhodites vetus Cockerell, 1921

Plate 1, fig. 7

1921a Rhodites vetus Cockerell, p. 24, fig. 31

Holotype. NHMUK In.24341, Bembridge Marls, NW Isle of Wight, UK, Hooley Collection.

Remark. The type has not been revised, so its taxonomic position is not confirmed.

\subsection{Superfamily Chalcidoidea Latreille, 1817; Family Agaonidae Walker, 1846}

[By Stephen G. Compton.]

Donisthorpe (1920) described Ponera minuta as a new species of ant (Formicidae) based on a specimen housed in the NHMUK. Two further specimens are present in the collection of the Sedgwick Museum, Cambridge. They display characters that were unclear in the original specimen; in particular, a strongly reduced wing venation and the presence of an exserted ovipositor. Clearly they are not a species of ant. The forewing venation is typical of a chalcid (Hymenoptera, Chalcidoidea) type, but with a pigmented basal vein. Additional features are characteristic of adult female fig wasps that enter figs (the inflorescences of Ficus species, Moraceae) to oviposit. These features include a long flattened head, an enlarged fore femur with a reflexed short stout tibia, and the form of the ovipositor. 
Fig wasps form an artificial assemblage of several unrelated chalcidoid lineages of gallers, parasitoids and inquilines (Rasplus et al. 1998). The best known group are the pollinating fig wasps (Agaonidae sensu Rasplus et al. 1998) that are partners in a highly co-evolved mutualism with their plant hosts. Figs are shaped like a hollow ball, lined on the inside by hundreds or thousands of tiny flowers. Adult female agaonids enter the figs through a narrow bract-lined ostiole, losing their wings and part of their antennae on entry. Once inside, they lay their eggs down the styles of the female flowers, while at the same time pollinating other female flowers (Weiblen 2002). The length of their ovipositor closely corresponds to the average length of these styles (Nefdt \& Compton 1996).

Agaonidae are one of several lineages with females that can enter figs to oviposit (in addition there are fig wasps with much longer ovipositors that oviposit into the flowers from the outside of the fig). All such females have flattened heads and strong, spiny legs, an example of convergence in response to the difficulties associated with fig entry (van Noort \& Compton 1996). Bouček (1997) proposed three synapomorphies for female Agaonidae: a unique ridged or toothed mandibular appendage, unusual antennae, and a head with channels to accommodate the scapes of the antennae during fig entry. Unfortunately, none of these features are clearly visible in the three available specimens. The antennae are absent and the tops of the heads are obscured. Flattened mandibles with several transverse ridges are nonetheless present, and are similar in appearance to those of some agaonids. Furthermore, what appears to be a ridged appendage, extending backwards below the head is also present. More conclusively, thoracic pollen pockets, unique to some Agaonidae, are present. The specimens can therefore be placed in Agaonidae, rather than one of the other groups of fig wasps, a conclusion supported by their non-thickened marginal vein, wing shape and the slightly curved exserted ovipositor.

\section{Genus Archaeagaon Compton, gen. nov.}

Etymology. After archaios, the Greek for ancient, and genus Agaon. Gender neuter.

Type species. Ponera minuta Donisthorpe, 1920.

Diagnosis. Archaeagaon can be distinguished from other genera of Agaonidae by the presence of a strongly pigmented basal vein.

Archaeagaon minutum (Donisthorpe) 1920, comb. nov. Plate 2, figs 1-4

\section{Ponera minuta Donisthorpe, p. 85, plate 5, figure 4.}

Holotype. NHMUK I.9734, Bembridge Marls, NW Isle of Wight, UK, Brodie Collection; adult female in side view.

Other material. CAMSM X.50140.47a (TN 98) and X.50140.97c (TN 152), Bembridge Marls, Isle of Wight, UK; adult females.

Diagnosis. As for genus.

Description. Length of body approximately $1.7 \mathrm{~mm}$, mesosoma and metasoma approximately equal in length. Head elongate and flattened, about 2.5 times as long as high. Eyes situated towards rear of head, clearly shorter than the genae.

Thorax with pollen pockets (Compton et al. 2010). Fore femur enlarged, elongate and broadened, length about four times maximum width. Tibia short and broad, much shorter than the narrow tarsus. Forewing broad, less than twice as long as wide, with relatively sparse, evenly-spaced setation, reaching proximally to (at least) the basal vein. Marginal, postmarginal and stigmal veins about equal in length, about half the length of the sub-marginal vein. Stigmal vein curved, with stigma not strongly demarcated. Basal vein pigmented, straight for most of its length, meeting the submarginal vein at a relatively acute angle. Ovipositor exserted, slightly downcurved, with sheaths about $0.33 \mathrm{~mm}$ in length. Antennae, mid and hind legs not visible in the three available specimens, hind wing venation also unclear. Male unknown.

3.6.1. Discussion. Fossil agaonids are well known in midMiocene amber from the Dominican Republic in the Caribbean, which dates from about $20 \mathrm{Ma}$, but they have not been recorded in amber from elsewhere. Three species were recently described from Dominican amber in the extant genera Tetrapus Mayr and Pegoscapus Cameron, reflecting their essentially modern appearance (Peñalver et al. 2006). Brues (1910) also described a supposed Tertiary agaonid, Tetrapus mayri, from the Florissant Formation in Colorado, USA. This specimen has not been examined recently, but on the basis of the original drawing and a photograph (Weiblen 2002) it is clearly not a species of Tetrapus, nor an agaonid. It may belong to Torymidae. Archaeagaon minutum is therefore the earliest confirmed species of fig wasp.

Based on molecular evidence, the association between fig trees and their pollinator fig wasps is believed to date back at least 60 million years (Machado et al. 2001; Rønsted et al. 2005), and so had been in place for tens of millions of years before the appearance of Archaeagaon minutum. The physical structure of this fig wasp reflects the anatomical adaptations for entry into figs that can be seen in modern species, with a similar size, with head, mandibles and legs that are adapted for entry via its tight bract-lined ostiole, and with an ovipositor of similar length. This suggests that the key anatomical features that underpin the fig tree-fig wasp relationship were fully in place during the Eocene, and perhaps well before; a finding consistent with the presence of fruits that are recognisably from figs in Eocene England (Collinson 1989). Modern species of fig trees display both monoecious and functionally dioecious breeding systems, with the former assumed to be ancestral.

Fig wasps are largely tropical or sub-tropical in distribution, though one species (Blastophaga psenes $(\mathrm{L})$ ) is present in Mediterranean Europe. The habitat associations of modern species are extremely varied, from rainforests to deserts, so their presence in the Isle of Wight deposits provides little information about likely conditions at the time, other than that they were warmer than today. Fig wasps are also exceptionally good dispersers, travelling distances of tens or even hundreds of kilometres between host plants (Ahmed et al. 2009), so their host plants could have been some distance away from where they were deposited. A fossil fig leaf has nonetheless been described from the Insect Bed, though its identification is considered doubtful (Compton et al. 2010).

\subsection{Family ? Pteromalidae Dalman, 1820}

[By Alexandr P. Rasnitsyn]

Genus ? Pteromalus Swederus, 1795

Pteromalus? vectensis Cockerell, 1921

Plate 2, fig. 5

1921a Pteromalus? vectensis Cockerell, p. 25, fig. 32.

Holotype. NHMUK I.9472, Bembridge Marls, NW Isle of Wight, UK, Collection P. B. Brodie. 

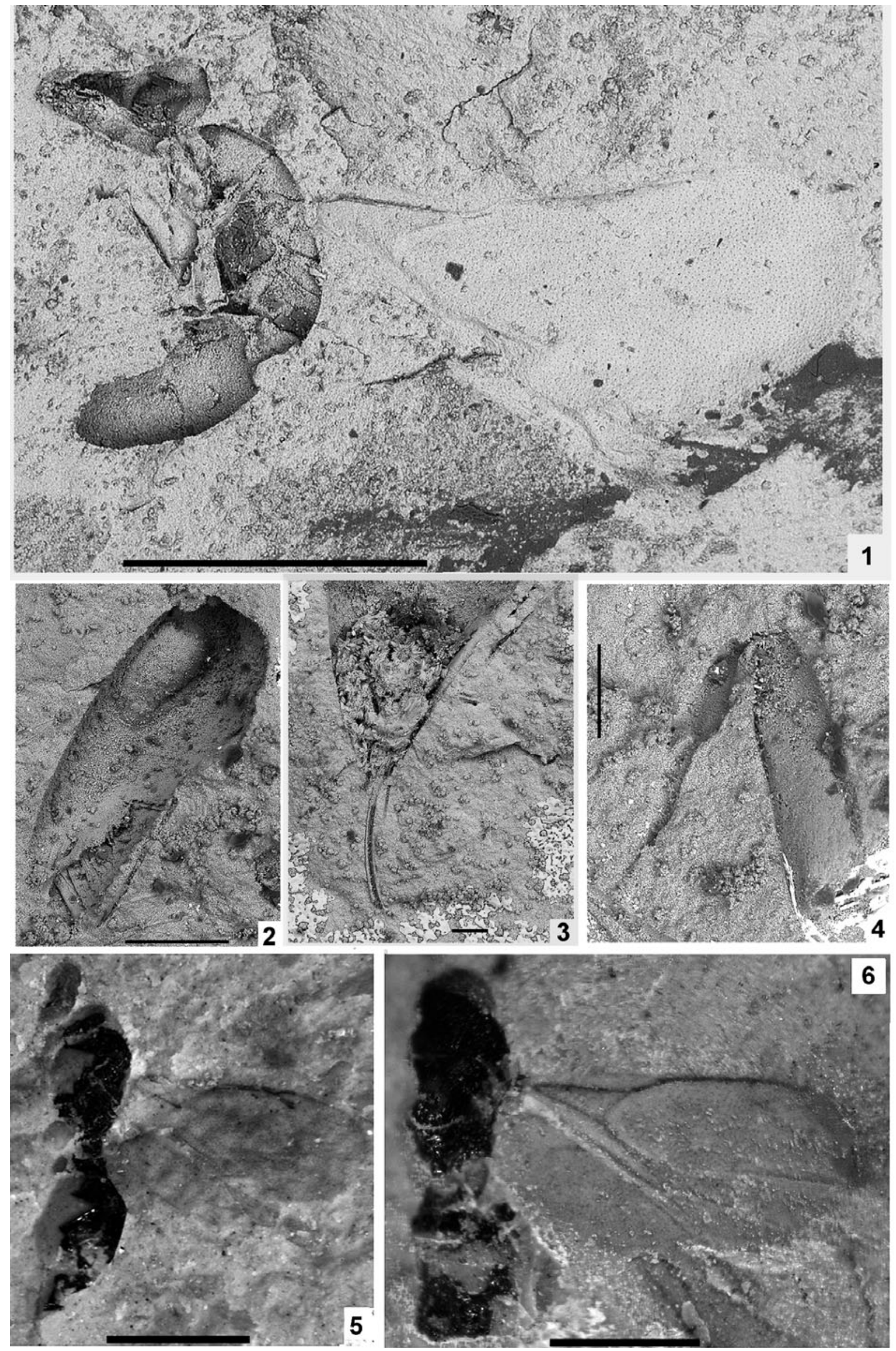

Plate 2 (1-4) Archaeagaon minutum (Donisthorpe): (1) NHMUK I.9734, holotype; (2) CAMSM X.50140.97c (TN 152), head; (3) CAMSM X.50140.47a (TN 98), metasomal apex with ovipositor; (4) CAMSM X.50140.97c (TN 152), fore leg. (5) Pteromalus? vectensis Cockerell, NHMUK I.9472, holotype. (6) Lithobelyta reducta Cockerell, NHMUK In.17091, holotype. Scale bars $=1 \mathrm{~mm}$. 
Remark. The fossil was not revised, its taxonomic position needs to be proven.

Family indet

Genus Lithobelyta Cockerell, 1921

Type species. L. reducta Cockerell, 1921.

Other species. None.

Remark. Taxonomic position is obscure (originally described as Diapriidae, identified as Chalcididea by M. A. Kozlov, in litt., 2004).

Lithobelyta reducta Cockerell, 1921

Plate 2, fig. 6

1921a Lithobelyta reducta Cockerell Cockerell, p. 22, fig. 27.

Holotype. NHMUK In.17091, Bembridge Marls, NW Isle of Wight, UK, Smith coll.

Remark. The type was not revised and requires re-study.

\subsection{Superfamily Ichneumonoidea Latreille, 1802 [By Andrey I. Khalaim.]}

3.8.1. Family Ichneumonidae Latreille, 1802. Ichneumonidae are one of the largest animal families, including over 30,000 described Recent species; although the real number of species is much greater. Most ichneumonids fly well and are common in all terrestrial biotopes from Arctic tundra to equatorial rainforests. Ichneumonidae are solitary or gregarious parasitoids, their larvae developing inside (endoparasitoids) or on (ectoparasitoids) living arthropod hosts. Most ichneumonids attack eggs, larvae or pupae of holometabolous insects, but some species oviposit on or in spiders and spider egg sacs. Hyperparasitoids (secondary parasites) are also known. They lay eggs into a primary parasite developing in the host.

The oldest representatives of Ichneumonidae are recorded from the uppermost Jurassic or Lower Cretaceous, and belong to the fossil subfamily Tanychorinae Rasnitsyn, 1980 (Zhang \& Rasnitsyn 2003). In the Eocene and Oligocene, the family Ichneumonidae began to flourish, and fossil subfamilies Townesitinae and Pherhombinae, and Recent subfamilies and genera appeared.

Thirty-two specimens of the family Ichneumonidae from the collection of the Natural History Museum are studied. 11 species described by Cockerell (1921a) are revised. Taxonomic changes are shown in Table 1.

The Bembrige Marls ichneumonid fauna is represented by the subfamilies Cryptinae, Pimplinae, Townesitinae, Orthocentrinae, Metopiinae and Paxylommatinae, and three specimens of the genus Lithapechtis Cockerell, which is undetermined to subfamily. Cryptinae are the largest Recent subfamily, which are richly represented in many Cenozoic deposits, and very abundant in Florissant (Brues 1910) and Baltic amber (Kasparyan 1994). The subfamily Cryptinae has a world-wide distribution and a broad range of hosts of various orders (Lepidoptera, Hymenoptera, Coleoptera, Diptera, etc.). All Bembridge Marls Cryptinae belong to the tribe Phygadeuontini Foerster.

Another numerous Bembridge Marls subfamily is Pimplinae. This subfamily has a world-wide distribution and a broad range of hosts. The genera Exeristes Foerster and Scambus Hartig parasitise hosts hidden within plant tissues (in leaves, galls, buds) or cocoons and use their long ovipositor to reach such hosts. Pimplines are abundant in most Cenozoic deposits, but not recorded from Baltic amber.

Townesitinae is a fossil subfamily known only from the Bembridge Marls and Baltic amber. This subfamily is very numerous in both deposits, and in Baltic amber it is second only to Cryptinae (Kasparyan 1994). Townesitinae of the Bembridge Marls and Baltic amber are very similar morphologically, with two out of three Bembridge Marls species belonging to the genus Marjorietta Kasparyan described from Baltic amber.

Orthocentrinae are world-wide in distribution and predominantly occur in rainforests and humid forests of the temperate zone. They are mostly small in size and parasitise fungus gnats (Diptera). Orthocentrinae were recorded from Florissant (Brues 1910), Baltic amber (Kasparyan \& Humala 1995) and some other Cenozoic deposits. Three species from the genus Eusterinx Foerster are recorded in the Bembridge Marls. Species described from Baltic amber also belong to Recent genera (A. E. Humala pers. comm. 2000).

Other Bembridge Marls subfamilies are represented by single specimens only. Metopiinae parasitise various Lepidoptera, oviposit in the larval instar and emerge always from the pupa; distributed world-wide. Metopiinae are first known from the lowermost Eocene Oise amber (Kasparyan \& Humala 1995), but are not common there.

Paxylommatinae are a small and morphologically distinct subfamily. Recent species are rare and only occur in the Holarctic region, and fossil species are known from Baltic and Rovno amber (Kasparyan 1988a, 2001; Tolkanitz et al. 2005) and the Bembridge Marls only. They are probably parasites of ants.

Ichneumonid specimens are represented most often by isolated forewings and fragments. Sometimes head, meso- and metasoma and parts of legs are present. The body in wellpreserved specimens is usually not or weakly deformed and preserves its three-dimensional structure. Wings are complete or sometimes crumpled, so real sizes and measurements may not be equal to such in photos and figures. The sex of the overwhelming majority of specimens is unknown.

Taxonomy is accepted as in the catalogue TaxaPad ( $\mathrm{Yu}$ et al. 2005). The following guides and monographs were used for identification: Kasparyan (1981), Townes (1969, 1970a, b, 1971) and Humala (2003). Morphological terminology predominantly follows Townes.

3.8.2. Subfamily Pimplinae Wesmael, 1845. Large worldwide subfamily with an extremely wide range of hosts. Well represented in most of the Cenozoic deposits.

\section{Exeristes gurnetor Khalaim, sp. nov.} Plate 3, figs 1, 2, 3; Text-fig. 4

Etymology. After Gurnet Bay, old name of Gurnard Bay where some of the Bembridge insect fossils were collected

Holotype. IWCMS 2012.574, part and counterpart, Thorness Bay; dorsoventral aspect of body with incomplete head, left pair of wings and incomplete hind wings; sex unknown. Yule Coll.

Diagnosis. Diagnostic characters of the new species are the shorter discocubital and brachial cells, and first tergite longer than in Recent species. It also differs from all Pimplinae described from the Bembridge Marls in having forewing with the first intercubitus subequal to the second one, and the postnervulus intercepted low.

Description. Body length as measured from anterior head margin to apex of metasoma) $5 \mathrm{~mm}$, forewing $4.3 \mathrm{~mm}$, mesosoma $1.5 \mathrm{~mm}$, mesosoma width $1 \mathrm{~mm}$. Mesosoma short and stout; notaulus, sternaulus and postpectal carina absent, prepectal carina present. Pterostigma and veins dark-brown. Pterostigma wide, almost three times as long as wide, receiving radius near its middle. First section of radius curved near pterostigma. Second section of radius straight, almost 2.5 


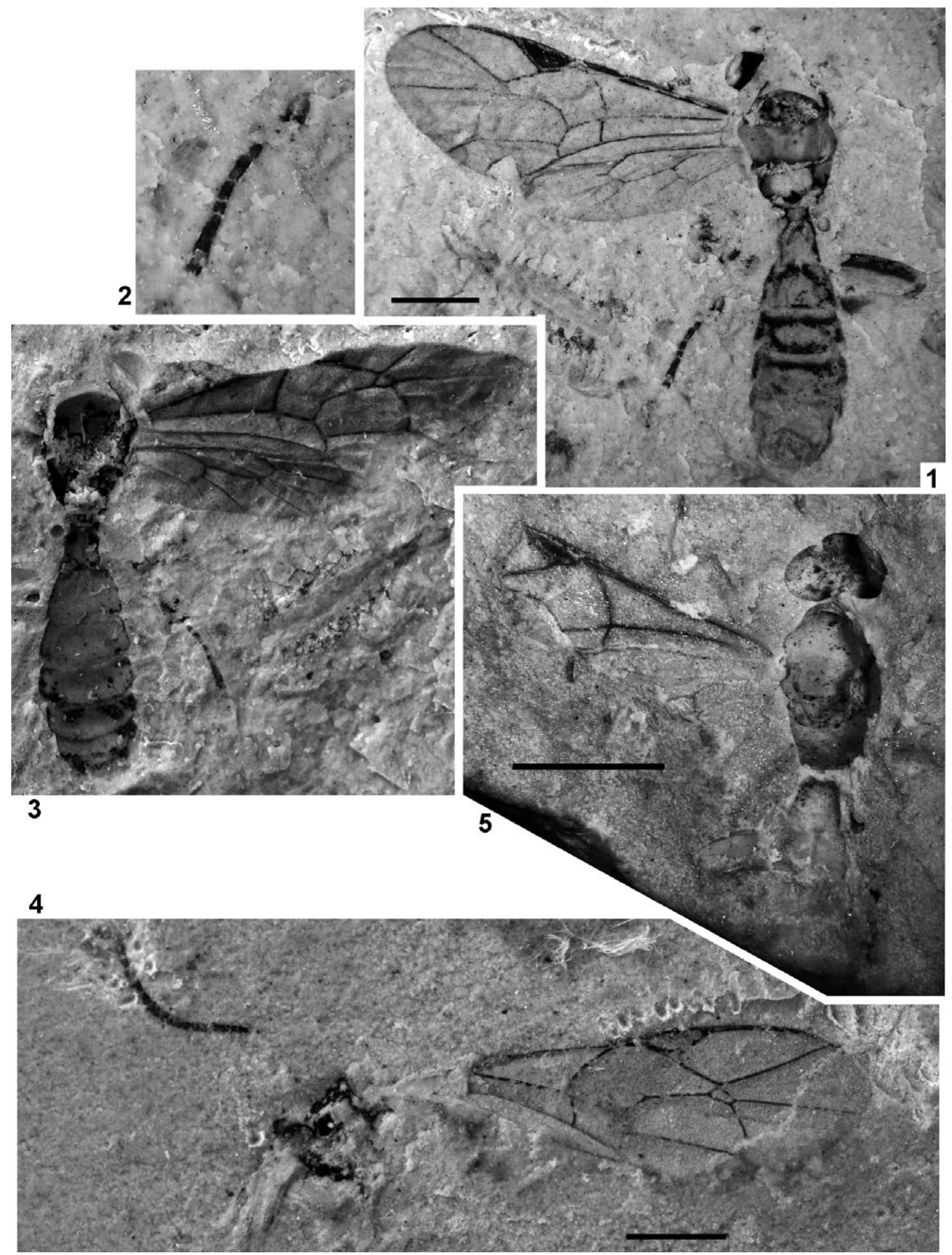

Plate 3 (1-3) Exeristes gurnetor sp. nov., holotype, IWCMS $2012.574(1,2)$ and its counterpart (3). (4) Itoplectis saxosa Cockerell, NHMUK In.24334, holotype. (5) Pimplinae genus and species indet. 2, NHMUK I.9965. Scale bars $=1 \mathrm{~mm}$. 


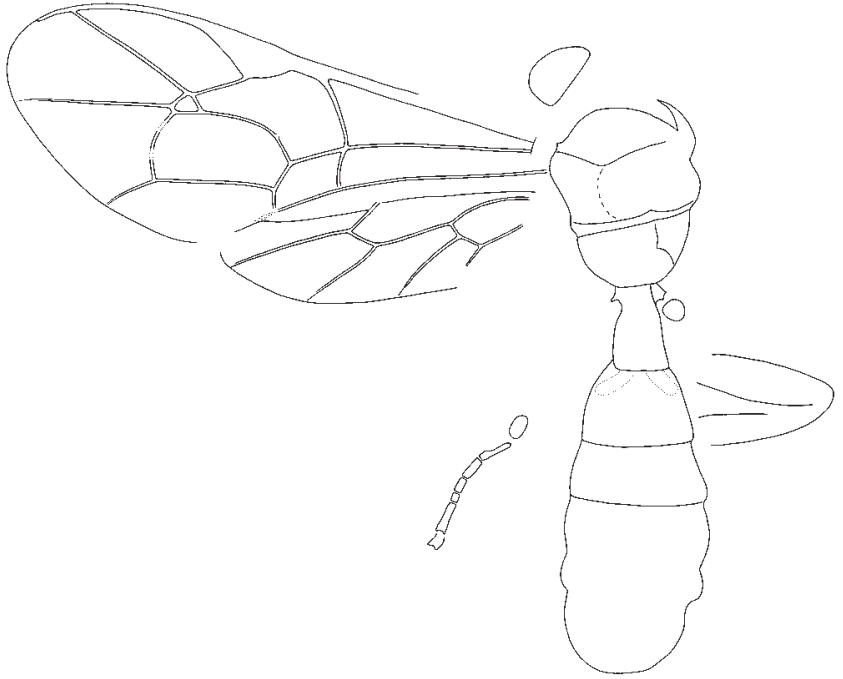

Text-figure 4 Exeristes gurnetor sp. nov., IWCMS 2012.574, holotype.

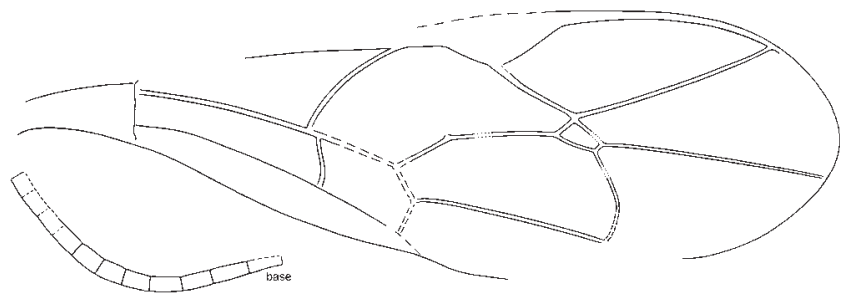

Text-figure 5 Itoplectis saxosa Cockerell, NHMUK In.24334, holotype.

times as long as first section. Metacarp not reaching apex of forewing. Areolet subtriangular, wider than high, receiving second recurrent vein before its outer corner. Second recurrent vein evenly and roundly curved, with two bullae. Discocubitus moderately curved, with ramulus in its $0 \cdot 36$. Second discoidal cell comparatively short. Nervulus hardly postfurcal, slightly inclivous. Postnervulus intercepted below middle; posterior section slightly inclivous. Brachial cell short. Nervellus intercepted in its 0.6. Mediella weakly curved. Hind femur and tibia moderately thick. Hind tibia darkened basally (or subbasally) and apically. 5th segment of hind tarsus 1.34 times as long as 2 nd segment. Length ratio of 2-5 tarsal segments 12:8:5:16. Metasoma dark, strongly depressed. First tergite distinctly elongate, with pair of dorsal keels extending for about half length of tergite. Following tergites strongly transverse. 2 nd tergite with pair of oblique basal grooves, $1 \cdot 3$ times as wide as long.

Remarks. Short and transverse second and following tergites, long fifth segment of hind tarsus and the intercepted high nervellus indicate that this species belongs to the genus Exeristes Foerster.

Pimplinae indet.

"Itoplectis" saxosa Cockerell, 1921

Plate 3, fig. 4; Text-fig. 5

1921a Itoplectis saxosus Cockerell, 7, fig. 5 (Pimplinae).

Holotype. NHMUK In.24334, Bembridge Marls, NW Isle of Wight, UK, Hooley Collection; forewing, part of antenna and mesosoma fragment; sex unknown.

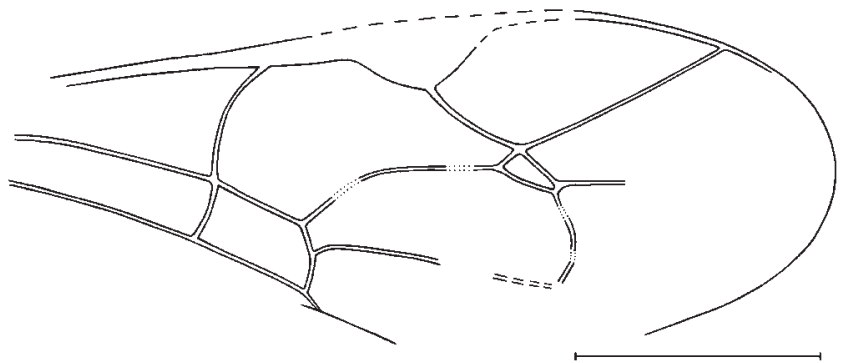

Text-figure 6 Scambus fossilis sp. nov., NHMUK In.64644, holotype. Scale bar $=1 \mathrm{~mm}$

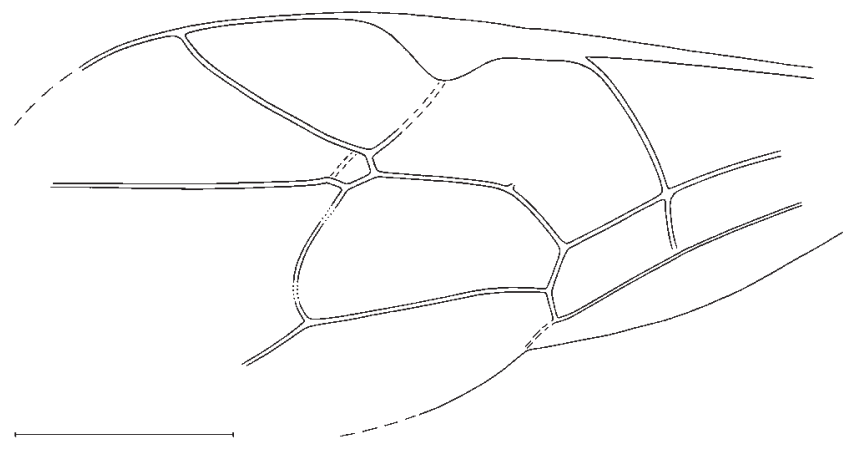

Text-figure 7 Pimplinae gen. et sp. indet., NHMUK In.24417. Scale bar $=1 \mathrm{~mm}$.

Diagnosis. Differs from other Pimplinae in the Bembridge Marls in having forewing with nervulus postfurcal, distinctly inclivous, and discocubitus very weakly curved.

Description. Forewing length $5.1 \mathrm{~mm}$. Basal flagellar segments about twice as long as wide, mid flagellar segments elongate. Pterostigma dark-brown with small yellowish mark, veins brown to dark-brown. Pterostigma wide, 2.9 times as long as wide, receiving radius near its middle. Radius very slightly curved. Second section of radius 2.2 times as long as first section. Areolet pointed, wider than high, receiving second recurrent vein before its outer corner. Second recurrent vein roundly curved, with two bullae. Discocubitus slightly curved, with ramulus. Nervulus curved, distinctly postfurcal, inclivous. Postnervulus intercepted near its middle; posterior section slightly inclivous.

Remarks. The species probably belongs to Pimplinae, but cannot be identified closer because many genera of this subfamily (as well as some genera of other subfamilies, in particular of Orthocentrinae) have a similar wing venation.

\section{"Scambus" fossilis Khalaim, sp. nov.} Plate 3, fig. 5; Text-fig. 6

Etymology. After fossilis, the Latin for fossil.

Holotype. NHMUK In.64644, Bembridge Marls, Isle of Wight, UK, Coll. Jarzembowski; forewing and dorsal aspect of poorly preserved head, mesosoma and base of metasoma; sex unknown.

Diagnosis. Differs from other Pimplinae from the Bembridge Marls in having the forewing with nervulus interstitial, subvertical, and areolet large, strongly oblique.

Description. Length of forewing $3.8 \mathrm{~mm}$, mesosoma $1.7 \mathrm{~mm}$. Pterostigma and veins dark brown. Pterostigma wide, receiving radius near its middle. First section of radius evenly curved. Second section of radius straight, $2 \cdot 15$ times as long as first section. Areolet large, subtriangular, receiving second recurrent vein a little before its outer corner. Second recurrent vein 
roundly curved, with two bullae. Discocubitus moderately curved, probably without ramulus. Nervulus inclivous, vertical. Postnervulus intercepted high; posterior section inclivous. First tergite with distinct dorsal keels basally.

Remarks. This is an evident Pimplinae. Scambus is a large and rather polymorphic Recent genus, which corresponds morphologically with this specimen. However, it is possible that the real position of the fossil within the subfamily is somewhat different.

\section{Genus and species indet. 1} Text-fig. 7

Material. NHMUK In.24417(1), Bembridge Marls, NW Isle of Wight, UK, Hooley Collection, incomplete forewing.

Description. Forewing length as preserved about $4.0 \mathrm{~mm}$, full length over $5.0 \mathrm{~mm}$. Pterostigma and veins brown. Pterostigma wide. Areolet present; second intercubitus unclear. Second recurrent vein roundly curved, with two bullae. Discocubitus slightly curved, with ramulus. Nervulus not curved, interstitial, slightly inclivous. Postnervulus intercepted somewhat below its middle; posterior section slightly inclivous.

Genus and species indet. 2

Plate 3, fig. 5

Material. NHMUK I.9965, Bembridge Marls, NW Isle of Wight, UK, Brodie Collection; ventral aspect of head, mesosoma and base of metasoma, with base of forewing and leg fragments, sex unknown.

Description. Mesosoma length $1.2 \mathrm{~mm}$. Notaulus absent. Propodeum without carinae. Pterostigma and veins dark-brown. Pterostigma wide, receiving radius somewhat basal of its middle. First section of radius curved near pterostigma. Nervulus interstitial, slightly inclivous. Metasoma depressed, first tergite short, about as long as wide, spherically and evenly prominent dorsally, without conspicuous dorsal keels, probably densely and coarsely punctuate, following tergites distinctly transverse.

3.8.3. Subfamily Orthocentrinae Foerster, 1869. Large, world-wide subfamily that includes small and moderate-sized ichneumonids, predominantly occuring in humid forests. Orthocentrinae are parasitoids of primitive Diptera, mainly of the superfamily Sciaroidea. Orthocentrinae are also found in Baltic amber (Kasparyan \& Humala 1995), Florissant (Brues 1910), Green River (Cockerell 1941) and other Cenozoic deposits. Three species from the Bembridge Marls probably belong to the large and rather polymorphic genus Eusterinx Foerster, 1869. Holomeristus Foerster, 1869 is considered a subgenus of Eusterinx by Humala (2003), and mentioned as a synonym in catalogues of Townes (1971) and Yu et al. (2005). Fossil species of this genus are known from the Bembridge Marls only.

Eusterinx vectensis (Cockerell, 1921), comb. nov. Plate 4, fig. 1; Text-fig. 8

1921a Holomeristus (?) vectensis Cockerell, p. 8, fig. 6 (Orthocentrinae).

Holotype. NHMUK I.9370, Bembridge Marls, NW Isle of Wight, UK, Brodie collection; lateral aspect of head with partial antennae, mesosoma, forewing and leg fragments; sex unknown.

Diagnosis. Differs from E. arcuatus in having the forewing with areolet large, first intercubitus long, and discocubitus moderately curved. Differs from E. humalai in having the forewing with areolet.
Description. Head and mesosoma combined $1.9 \mathrm{~mm}$ long. Forewing length $3.4 \mathrm{~mm}$. Occipital carina present. Scape of antenna suboval. Basal flagellar segments thin and long, proportions of $1-5$ segments 19:10:8:8:7-5. Ocelli of moderate size; distance between lateral and frontall ocellus subequal to diameter of ocellus. Clypeus separate from face. Notaulus deep. Postpectal carina probably absent. Hind coxa and femur slender. Pterostigma wide, receiving radius near its middle. First section of radius distinctly curved. Second section of radius almost straight, 2.3 times longer than first section. Areolet large, wider than high. Second recurrent vein inclivous, straight. Discocubitus strongly curved, probably without ramulus. Nervulus interstitial, very slightly inclivous. Postnervulus intercepted in its $0 \cdot 7$; posterior section inclivous.

Eusterinx arcuatus (Cockerell, 1921), comb. nov. Plate 4, fig. 2; Text-fig. 9

\section{1a Cremastus (?) arcuatus Cockerell, p. 8, fig. 7 (Cremas- tinae).}

Holotype. NHMUK I.9374/I.9246, part and counterpart, Bembridge Marls, NW Isle of Wight, UK, Brodie collection, 1898; lateral aspect of body with scape, forewing and hind leg fragments (counterpart poorly preserved), sex unknown.

Diagnosis. Differs from E. vectensis in having forewing with small, oblique areolet, very short first intercubitus, and strongly curved discocubitus. Differs from E. humalai in having the forewing with areolet.

Description. Body length $4.1 \mathrm{~mm}$, forewing $3.5 \mathrm{~mm}$, mesosoma $1.18 \mathrm{~mm}$, mesosoma height $0.86 \mathrm{~mm}$, first tergite length $0.46 \mathrm{~mm}$. Clypeus separate from face. Notaulus deep and short. Prepectal carina and mesopleural fovea present. Postpectal carina present only crossing mesosternal furrow. Propodeum areolate. Pterostigma and veins brown to dark-brown. Pterostigma wide, almost three times as long as wide, receiving radius near its middle. First section of radius curved. Second section of radius slightly curved, $2 \cdot 2$ times as long as first section. Areolet narrow, oblique, first intercubitus very short. Second recurrent vein curved, slightly inclivous, with two bullae. Discocubitus curved, without ramulus. Nervulus interstitial, vertical. Postnervulus intercepted in its 0.6 ; posterior section very slightly inclivous. First tergite slightly and evenly curved, subcylindrical anteriorly and somewhat depressed posteriorly, with spiracle near its $0 \cdot 6$; dorsal keels week, but distinct, reaching about 0.7 tergite length; dorsolateral keel about 0.4 of tergite length, not reaching spiracle; ventrolateral keel distinct and complete. Glymma absent.

Remark. The counterpart of the holotype (NHMUK I.9246) was incorrectly identified as an ant (Leucotaphus gurnetensis) by Donisthorpe (1920).

Eusterinx humalai Khalaim, sp. nov. Plate 4, fig. 3; Text-fig. 10

Etymology. In honour of Dr. Andrey E. Humala, expert in Orthocentrinae.

Holotype. NHMUK In.25730, Bembridge Marls, NW Isle of Wight, UK, Hooley collection; dorso-lateral aspect of female meso- and metasoma with wings.

Diagnosis. Differs from other congeners in the Bembridge Marls in having the forewing without areolet and with the first section of radius straight, discocubitus very slightly curved, nervulus inclivous, and postnervulus intercepted low. It differs from Recent Eusterinx lacking areolet in having the second discoidal cell unusually long. 


\section{1}
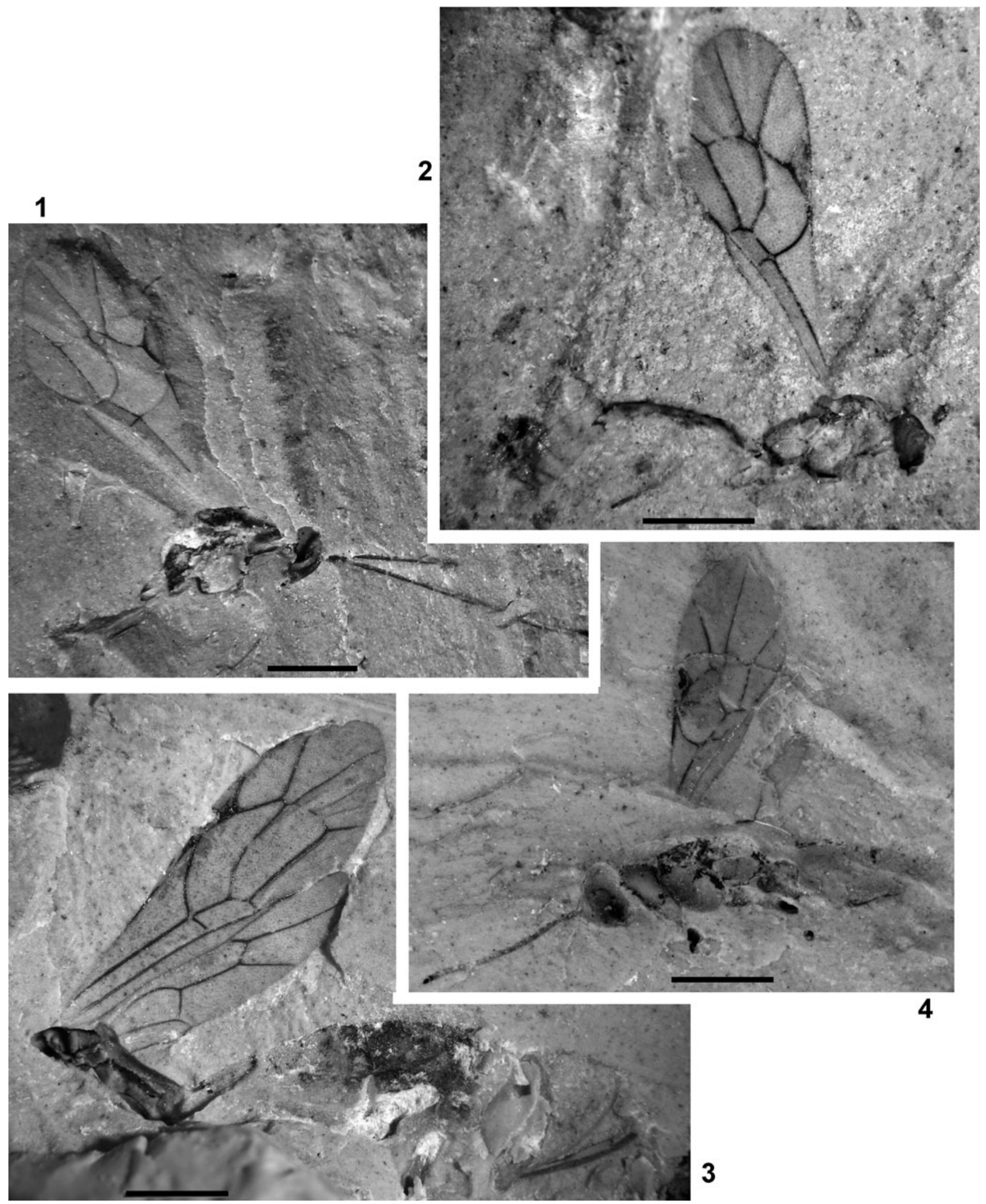

Plate 4 (1) Eusterinx vectensis (Cockerell), NHMUK I.9370, holotype. (2) Eusterinx arcuatus (Cockerell), NHMUK I.9374, holotype. (3) Eusterinx humalai sp. nov., NHMUK In.25730, holotype. (4) Hypsicera anglica (Cockerell), NHMUK I.9292, holotype. Scale bars $=1 \mathrm{~mm}$.

Description. Body length over $6 \mathrm{~mm}$, forewing $4.4 \mathrm{~mm}$, first tergite $c .1 \mathrm{~mm}$; sheath length $1.6 \mathrm{~mm}$. Notaulus deep, long, reaching centre of mesonotum. Prepectal carina present. Sternaulus deep, reaching from anterior margin to midlength of mesopleuron. Postpectal carina absent. Mesopleural fovea present. Propodeum areolate. Pterostigma and veins brown to dark-brown. Pterostigma moderately wide, about 3.5 times as long as wide, receiving radius near its middle. First section of radius straight. Second section of radius almost straight, 1.55 times as long as first section. Areolet absent. Second recurrent 

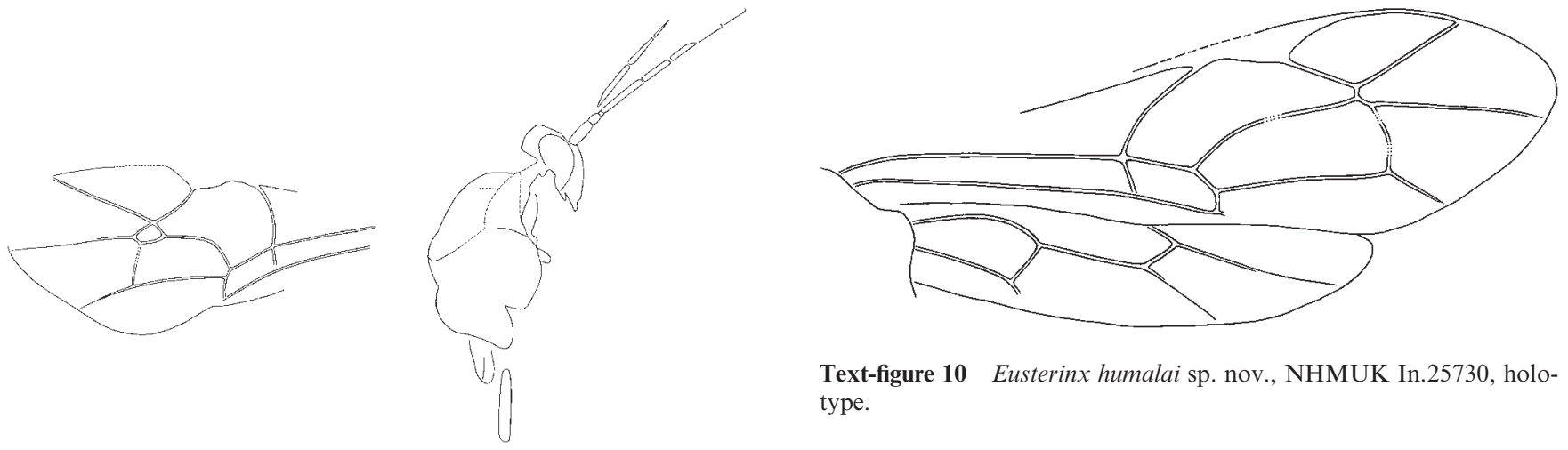

Text-figure 10 Eusterinx humalai sp. nov., NHMUK In.25730, holotype.

Text-figure 8 Eusterinx vectensis (Cockerell), NHMUK I.9370, holotype.

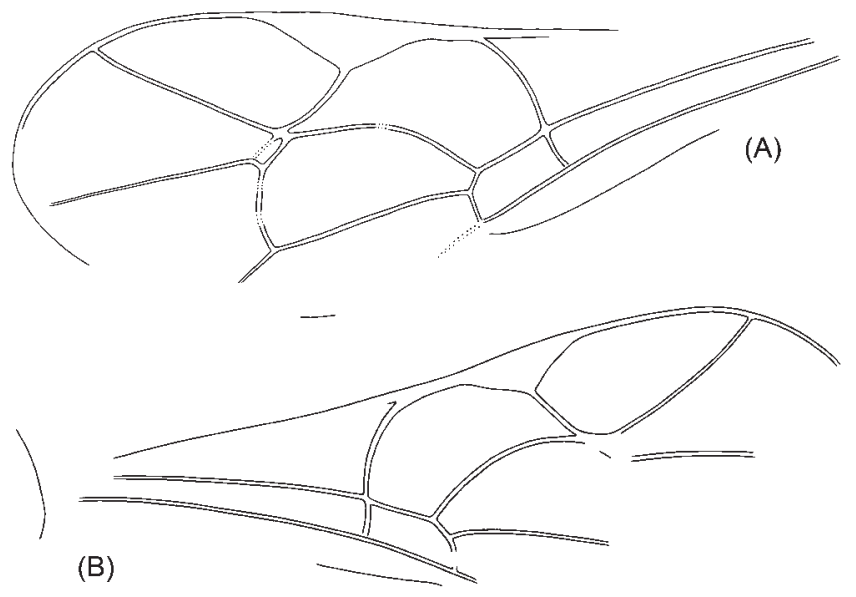

Text-figure 9 Eusterinx arcuatus (Cockerell): (A) NHMUK I.9374, holotype; (B) NHMUK I.9246, counterpart.

vein curved, slightly inclivous, with two bullae. Discocubitus very weakly and evenly curved, without ramulus. Second discoidal cell elongate, $2 \cdot 3$ times as long as wide. Nervulus interstitial, inclivous. Postnervulus intercepted in its 0.4 ; posterior section slightly inclivous. Nervellus not intercepted. Mediella distinctly curved. Metasoma behind first segment subcylindrical or slightly compressed. First tergite weakly and evenly widened toward apex, with weak ventro-lateral carina, with spiracle probably before middle. Ovipositor thin, slightly upcurved.

3.8.4. Subfamily Metopiinae Foerster, 1869. Moderatesized, Recent subfamily, parasites of Lepidoptera. Fossil Metopiinae are registered in some Cenozoic deposits, such as the lowermost Eocene Oise amber (Menier et al. 2004), the uppermost Eocene of Florissant (Brues 1910), the uppermost Eocene or lowermost Oligocene of Biamo in the Russian Far East (Khalaim 2008), and Miocene Brick Yard in NW USA (Lewis et al. 1990).

\section{Hypsicera anglica (Cockerell, 1921), comb. nov} Plate 4, fig. 4; Text-fig. 11

1921a Polyclistus (?) anglicus Cockerell, p. 10, fig. 10 (Metopiinae).

Holotype. NHMUK I.9292, Bembridge Marls, NW Isle of Wight, UK, Brodie collection; lateral aspect of body with metasoma incomplete, antenna, almost complete forewing, and leg fragments; sex unknown.

Diagnosis. Differs from recent species by the combination of the strongly inclivous, postfurcal nervulus, the broad pteros-

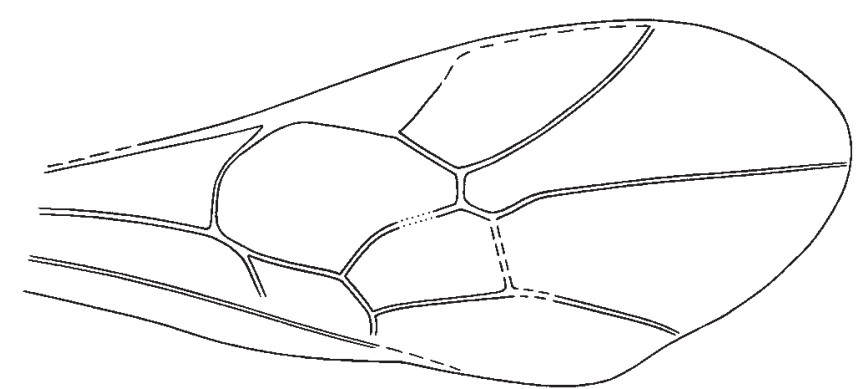

Text-figure 11 Hypsicera anglica (Cockerell), NHMUK I.9292, holotype.

tigma, and the subvertical, almost straight second recurrent vein.

Description. Body length c. $3.6 \mathrm{~mm}$, forewing $2.9 \mathrm{~mm}$, mesosoma $1.4 \mathrm{~mm}$, height $0.75 \mathrm{~mm}$. Head widened downward, rather abruptly sloping vertically just behind rear margin of hind ocelli. Ocelli of moderate size. Occipital carina absent dorsally and laterally. Scape of antenna short, oval. Flagellomeres at least 18 in number, visible slightly elongate and of subequal width. Mesosoma. Pronotum distinctly swollen, strongly and widely impressed. Notaulus probably absent. Prepectal carina present, indistinct in upper part of mesopleuron. Sternaulus and postpectal carina absent. Mesopleural fovea present. Propodeum areolate. Pterostigma and veins darkbrown. Pterostigma wide, over 2.5 times as long as wide, receiving radius in the middle. First section of radius straight, second section gradually curved. Areolet absent. Second recurrent vein not curved, slightly inclivous. Discocubitus slightly curved, without ramulus. Nervulus distinctly postfurcal and strongly inclivous. Postnervulus intercepted in its lower 0.38. Hind coxa and femur very thick. Metasoma cylindrical or depressed.

Remarks. This species belongs to Metopiinae as is justified by a robust, cylindrical body, globose head, thick legs, and characteristic venation of forewing (Text-fig. 11). It belongs most likely to the genus Hypsicera Latreille, 1829 which is characterised by the head abruptly sloping vertically just behind rear margin of hind ocelli. Hypsicera is a large, world-wide genus comprising over 60 Recent species, most common in tropics, and parasitising various Lepidoptera.

3.8.5. Subfamily Cryptinae Kirby, 1837. A large and very diverse subfamily of worldwide distribution. Cryptinae are recorded from any Cenozoic deposits with minimally diverse Ichneumonidae, and always most numerous there. All fossil Cryptinae belong to the tribe Phygadeuontini Foerster, 1869 because of having the second recurrent vein inclivous and propodeum completely areolate. Generic identification of Phygadeuontini is very difficult, and characters available in fossils are usually insufficient for reliable generic identification. I 

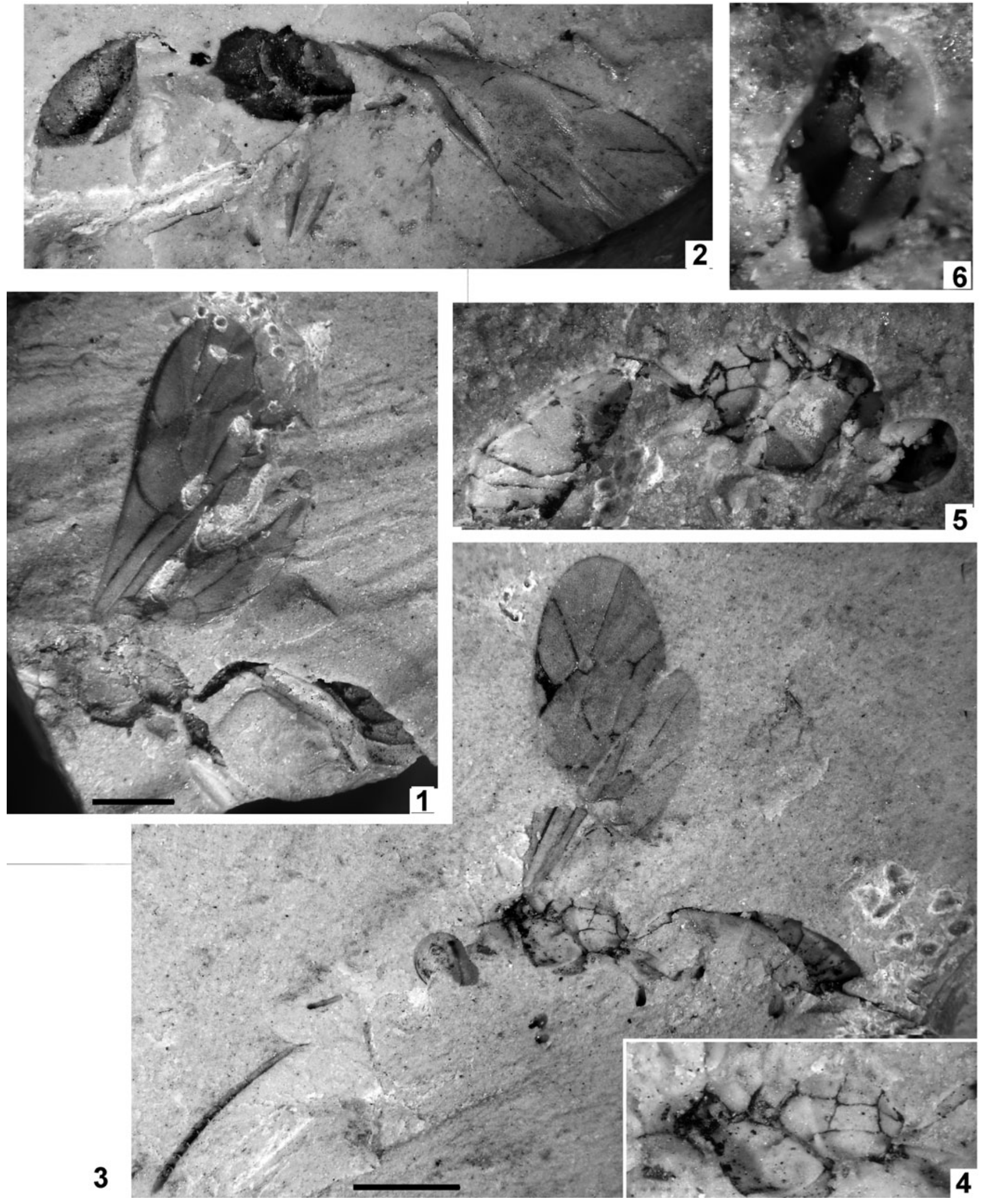

Plate 5 (1) "Hemiteles" acourti (Cockerell), NHMUK In.24332, holotype. (2) "Hemiteles" dirus sp. nov.,

NHMUK I.9244, holotype. (3-6) "Hemiteles" protervus sp. nov.: (1-2) NHMUK I.9609, holotype; (3-4) NHMUK In.25765, paratype; (5-6) NHMUK In.25765, paratype. Scale bars $=1 \mathrm{~mm}$.

retain Cockerell's original attribution of the fossil using the quotation marks for the generic name to note the very preliminary character of the attribution. New species are described as "Hemiteles" because this attribution looks likely but cannot be well grounded at present.
"Hemiteles" acourti (Cockerell, 1921), comb. nov. Plate 5, fig. 1; Text-fig. 12

1921a Ichneumon (s. latiss.) acourti Cockerell, 5, fig. 2 (Ichneumoninae). 


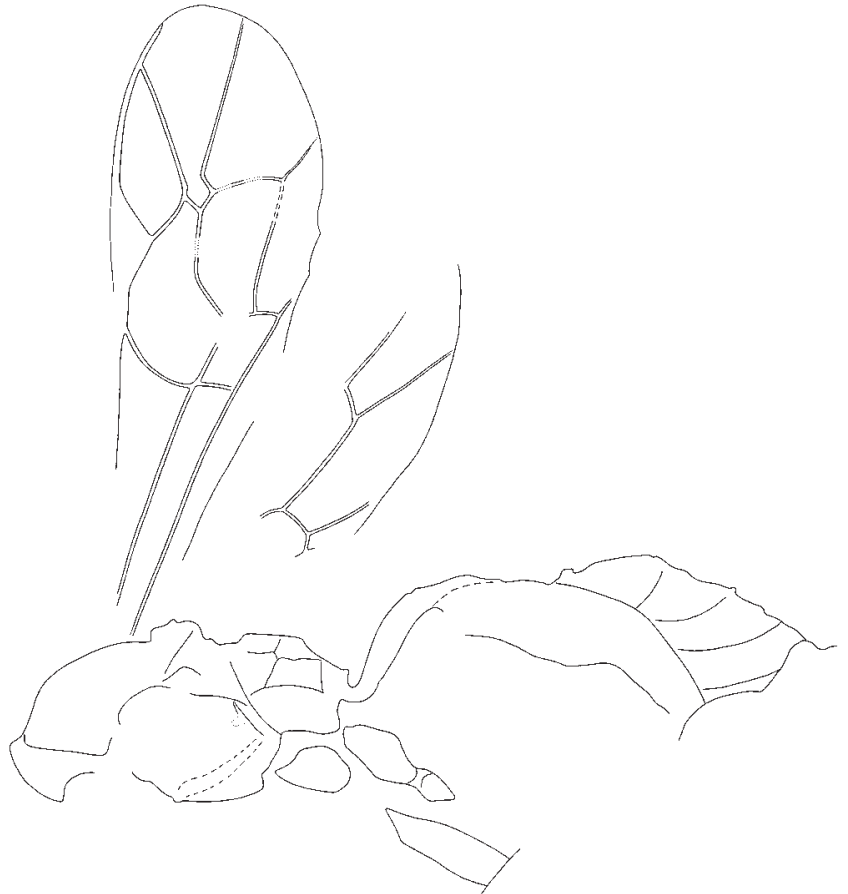

Text-figure 12 Hemiteles acourti (Cockerell), NHMUK In.24332, holotype.

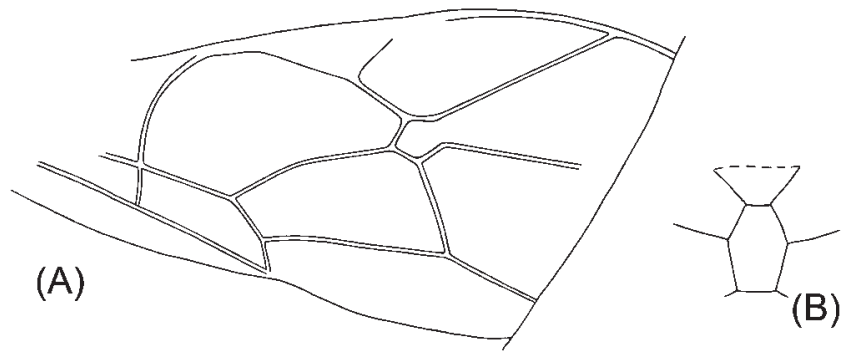

Text-figure 13 Hemiteles dirus sp. nov., NHMUK I.9244, holotype: $(\mathrm{A})=$ forewing; $(\mathrm{B})=$ areola of propodeum.

Holotype. NHMUK In.24332, Bembridge Marls, NW Isle of Wight, UK, Hooley collection; lateral view of mesosoma and metasoma (lacking apex) with wings and leg bases, sex unknown.

Diagnosis. This species differs from "Hemiteles" protervus in having the forewing with discocubitus almost straight anteriorly and posteriorly, and strongly curved near the middle, nervulus very slightly inclivous and postfurcal, and radial and second discoidal cells longer, and from "Hemiteles" dirus and from "Stilpnus" oligocenus in having the second section of postnervulus weakly inclivous.

Description. Size medium, mesosoma length $1.2 \mathrm{~mm}$, forewing $4.4 \mathrm{~mm}$, first metasomal tergite $c .1 \mathrm{~mm}$. Prepectal carina present. Sternaulus deep, spanning along whole mesopleuron length. Mesopleural fovea present. Pterostigma and veins brown. Pterostigma wide, $2 \cdot 6$ times as long as wide, receiving radius in the middle. Radius very slightly curved. Radial cell 2.5 times as long as wide. Metacarp not reaching apex of forewing. Areolet pentagonal, second intercubitus unpigmented. Second recurrent vein inclivous, with two bullae. Discocubitus curved, without ramulus. Second discoidal cell $2 \cdot 15$ times as long as wide. Nervulus postfurcal, slightly inclivous. Postnervulus intercepted at somewhat below its middle, posterior section distinctly inclivous. Hind wing with nervellus intercepted below middle. Hind legs of moderate thickness. Metasoma depressed behind first segment. First tergite long, petiolate, with
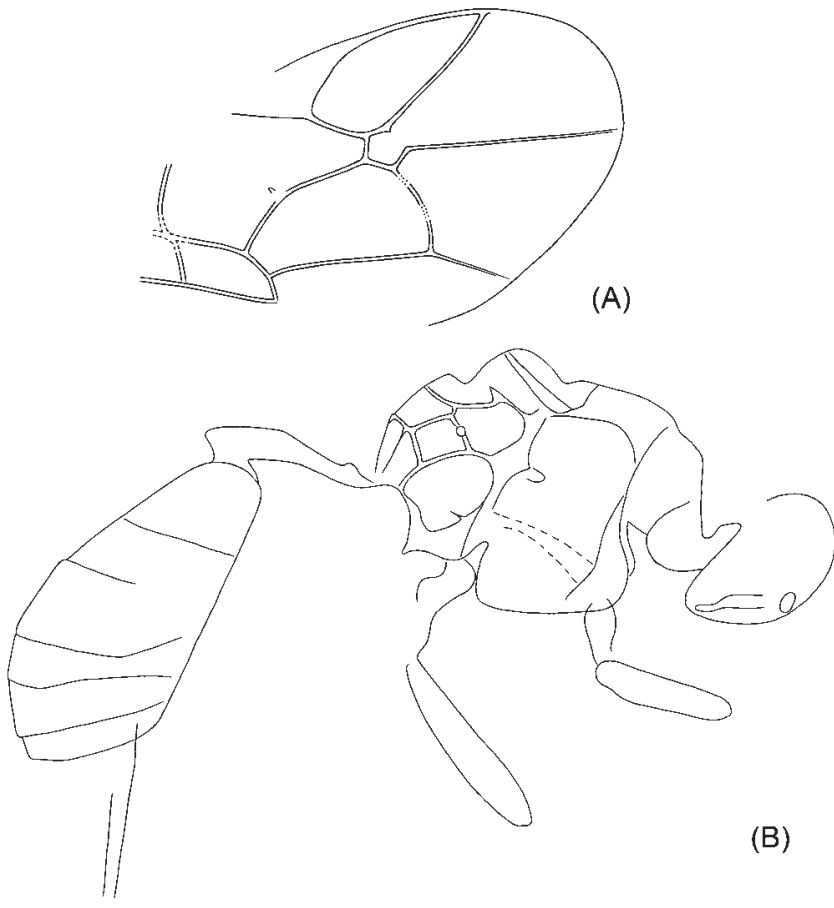

Text-figure 14 Hemiteles protervus sp. nov.: (A) NHMUK I.9609, holotype; (B) NHMUK In.25765, paratype.

ventro-lateral carinae and probably with dorso-lateral carinae. Glymma probably absent. Posterior tergites strongly transverse.

Remarks. Strong and long sternaulus which is never present in Ichneumoninae confirms attribution of the species to Cryptinae.

\section{"Hemiteles" dirus Khalaim, sp. nov.} Plate 5, fig. 2; Text-fig. 13

Etymology. After dirus, the Latin for terrible.

Holotype. NHMUK I.9244, Bembridge Marls, NW Isle of Wight, UK, Brodie collection, posteroventral aspect of posterior part of mesosoma, side view of metasoma, forewing, and detached leg parts. Sex unknown.

Diagnosis. This species differs from "Hemiteles" protervus and "Hemiteles" acourti in having forewing with second recurrent vein strongly inclivous and almost straight, nervulus interstitial, and postnervulus strongly inclivous; and from Stilpnus oligocenus in having the postnervulus with posterior section inclivous, discocubitus distinctly curved, and size larger.

Description. Forewing length $3.8 \mathrm{~mm}$. Notaulus present. Mesopleural fovea present. Propodeum areolate; areola hexagonal, elongate. Pterostigma wide, receiving radius near its middle. Radius slightly curved. Areolet pentagonal. Second recurrent vein strongly inclivous, almost straight, not curved near subdiscoideus, bullae indistinct. Discocubitus slightly and evenly curved, without ramulus. Nervulus interstitial, slightly inclivous. Postnervulus intercepted approximately in its 0.35 (posterior part of wing deformed), strongly inclivous, angle between posterior section and brachius $50^{\circ}$. Legs slender. Metasoma behind first segment depressed. Mid and posterior tergites strongly transverse.

"Hemiteles" protervus Khalaim, sp. nov. Plate 5, figs 3-6; Text-fig. 14

Etymology. After protervus, the Latin for bold.

Holotype. NHMUK I.9609, Bembridge Marls, NW Isle of Wight, UK, Brodie collection, best preserved female wasp in side view, with legs fragmentary. 

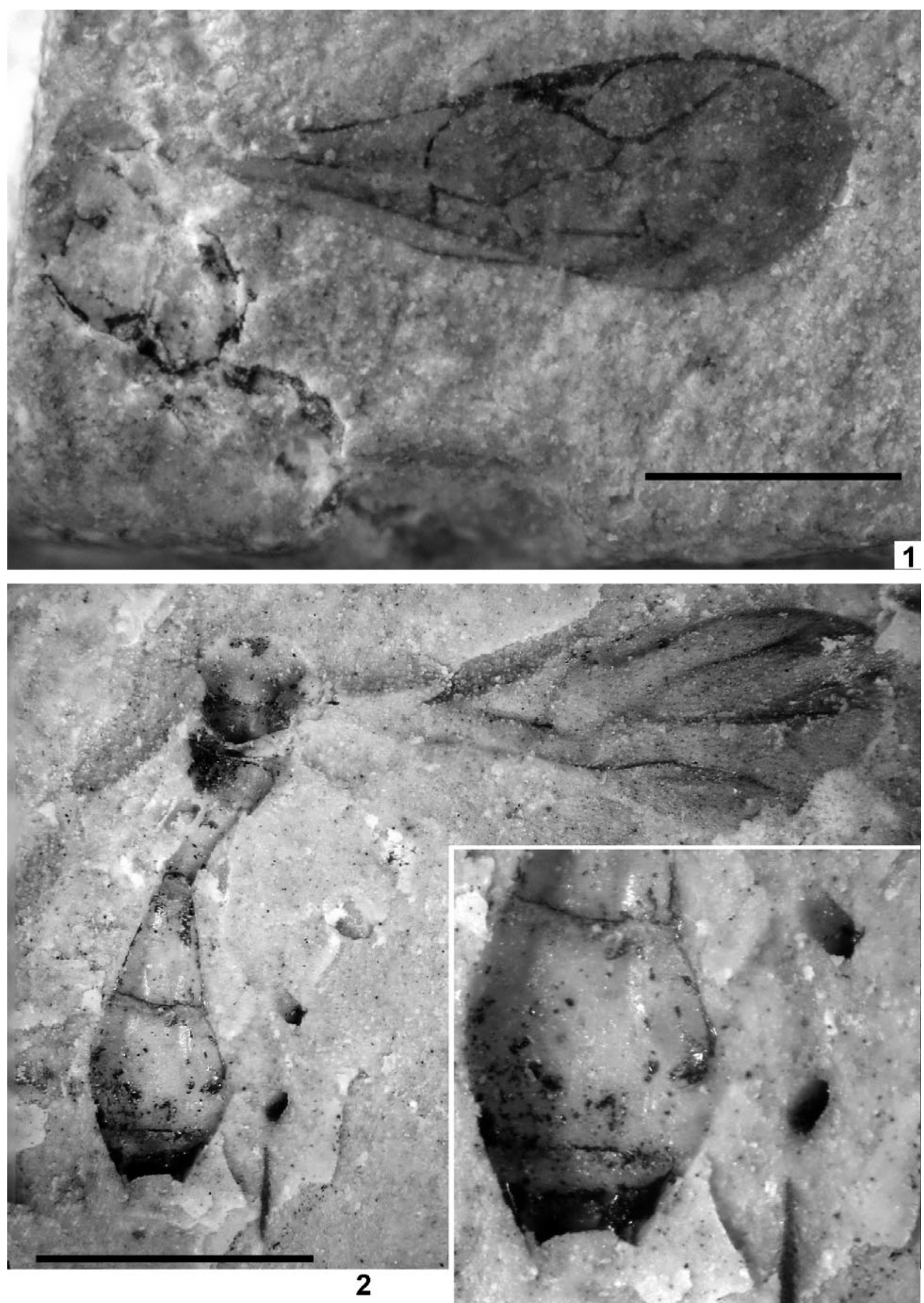

3

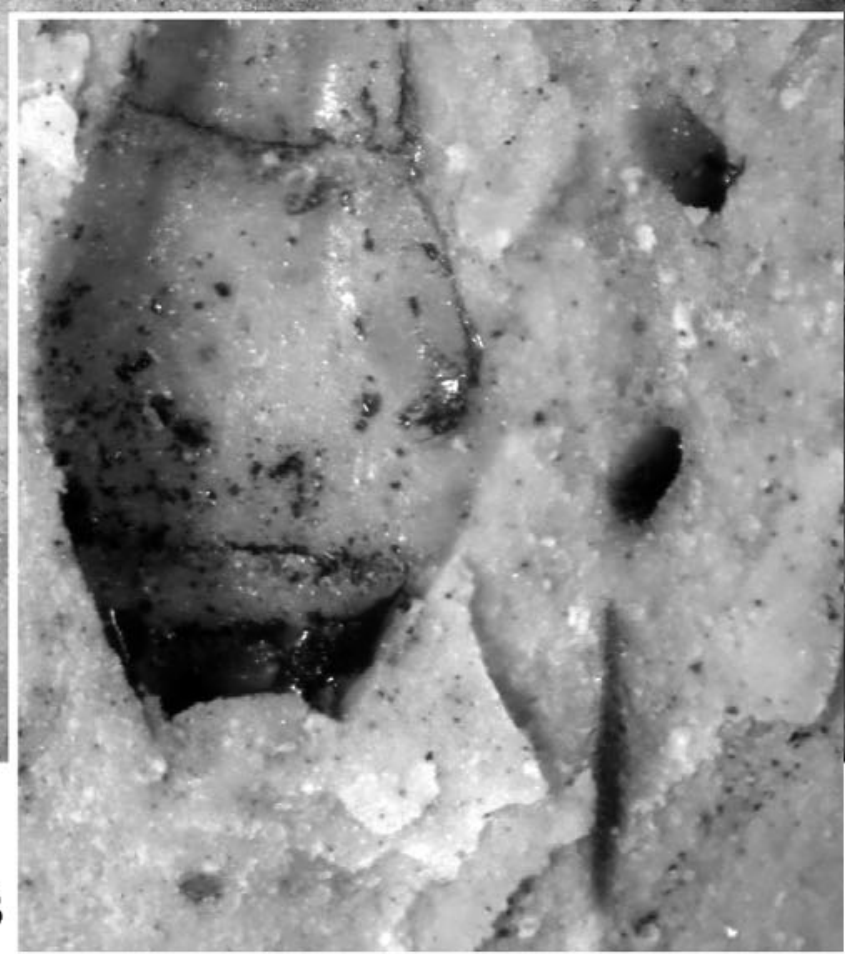

Plate 6 (1) "Stilpnus" oligocenus Cockerell, NHMUK In.24331, holotype. (2-3) Paxylobembra kozlovi gen. et sp. nov., IWCMS 2012.575, holotype. Scale bars $=1 \mathrm{~mm}$. 


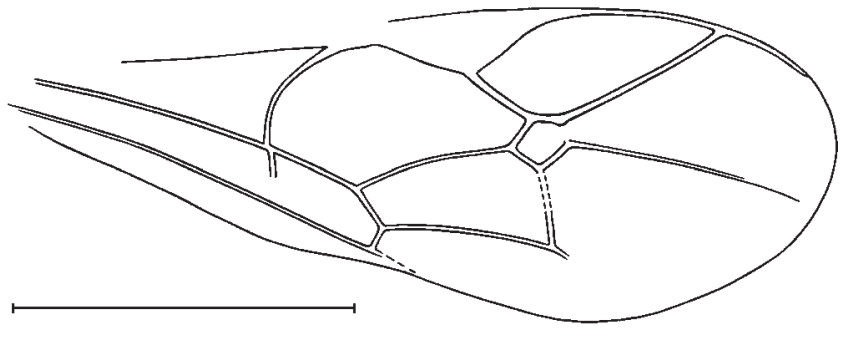

Text-figure 15 Stilpnus oligocenus Cockerell, NHMUK In.24331, holotype. Scale bar $=1 \mathrm{~mm}$.

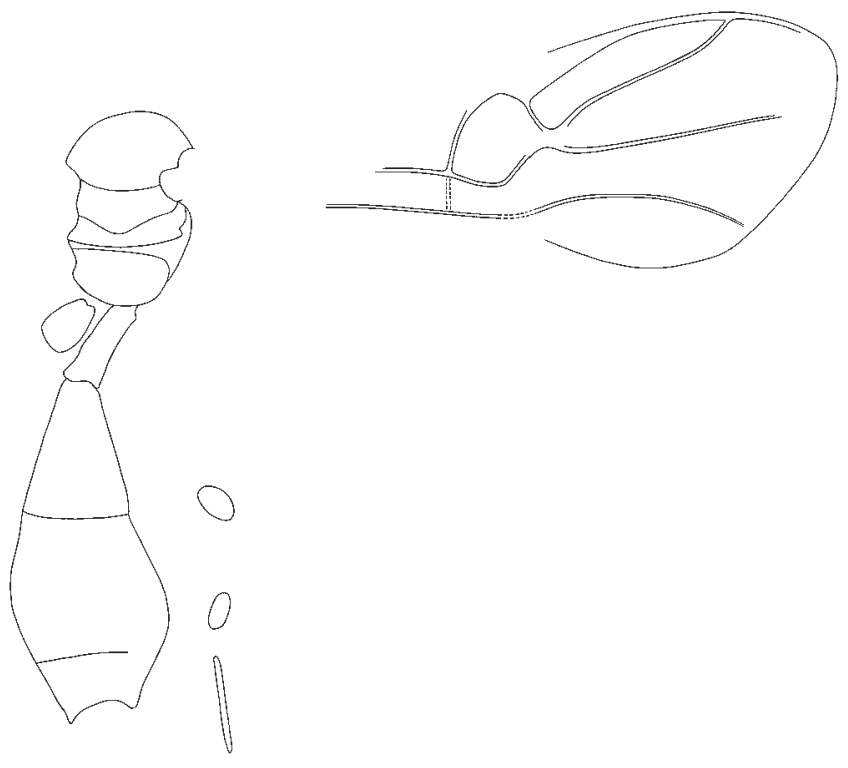

Text-figure 16 Paxylobembra kozlovi gen. et sp. nov., IWCMS 2012.575, holotype.

Paratype. NHMUK In.25765, Bembridge Marls, NW Isle of Wight, UK, Hooley collection, lateral aspect of almost complete female body lacking appendages.

Diagnosis. Differs from "Hemiteles" acourti in having the forewing with discocubitus weaker curved, and radial and second discoidal cells shorter; from "Stilpnus" oligocenus in having the second section of postnervulus inclivous; and from "Hemiteles" dirus in having the second recurrent vein arcuate and stronger curved near subdiscoideus, nervulus slightly postfurcal, and posterior section of postnervulus less inclivous .

Description. Body length $4.3 \mathrm{~mm}$, mesosoma $1.4 \mathrm{~mm}$, height $0.86 \mathrm{~mm}$. forewing length $3.3 \mathrm{~mm}$, first tergite $0.7 \mathrm{~mm}$. Antenna filiform; basal flagellar segment strongly elongate, more than five times as long as wide; mid flagellar segments $1 \cdot 6-2 \cdot 2$ times as long as wide. In paratype, frons with pair of longitudinal impressions behind antennal sockets, face with noticeable large longitudinal ridge. Temple wide, in lower part about of half eye width. Prepectal carina and mesopleural fovea present. Sternaulus long, reaching along whole mesopleuron length from its lower anterior part to posterior margin. Propodeum areolate. Pterostigma and veins dark-brown. Pterostigma wide, receiving radius at midlength. Radius slightly curved. Radial cell 2.2 times as long as wide. Areolet pentagonal, approximately equilateral, second intercubitus absent or unpigmented. Second recurrent vein inclivous, roundly and evenly curved, with two bullae. Discocubitus slightly and evenly curved, with ramulus. Second discoidal cell 1.8 times as long as wide. Nervulus somewhat postfurcal, distinctly inclivous. Postnervulus intercepted hardly below its middle, posterior sec- tion inclivous. Legs slender. First tergite long, petiolate, petiole rectangular in cross-section, its dorsolateral and ventrolateral carinae distinct, extending along whole petiole length. Glymma absent, lateral area of first tergite flat. Metasoma depressed, widened backward, second and following tergites distinctly transverse. Ovipositor straight, almost as long as first tergite; length $0.6 \mathrm{~mm}$.

Remarks. Paratype has no wings, but body is almost identical to that of the holotype, and apparently represents the same species. Paratype has a noticeable longitudinal ridge on the face, but face of holotype is not visible.

\section{"Stilpnus" oligocenus Cockerell, 1921}

Plate 6, fig. 1; Text-fig. 15

\section{1a Stilpnus oligocenus Cockerell, 4, fig. 5 (Cryptinae).}

Holotype. NHMUK In.24331, Bembridge Marls, NW Isle of Wight, UK, Hooley collection, forewing and poorly preserved mesosoma and base of metasoma. Sex unknown.

Diagnosis. This species differs from other Cryptinae in Bembridge Marls in having shorter forewing with postnervulus intercepted low (its posterior section vertical), and with discocubitus very slightly curved.

Description. Small wasp with forewing length $2.7 \mathrm{~mm}$. Pterostigma wide, $2 \cdot 8$ times as long as wide, receiving radius at midlength. Radius slightly curved. Metacarp long, but not reaching apex of forewing. Areolet pentagonal, outer side open or second intercubitus unpigmented. Second recurrent vein inclivous. Discocubitus very slightly curved, without ramulus. Nervulus very slightly postfurcal, inclivous. Postnervulus intercepted in its $0 \cdot 36$, its posterior section vertical.

3.8.6. Subfamily Paxylommatinae Foerster, 1862. Small subfamily known from Holarctic (Tobias 1988), fossils only known from the Upper Eocene Baltic and Rovno ambers (Kasparyan 1988a, 2001; Tolkanitz et al. 2005). Probably parasites of ants.

Paxylobembra Khalaim, gen. nov.

Etymology. After genus name Paxylomma and Bembridge Marls. Gender feminine.

Type species. P. kozlovi sp. nov. (by monotypy and present designation).

Diagnosis. New genus differs from all recent Paxylommatinae in having brachial cell not widened (as wide as submedian cell). It belongs to the tribe Tobiasitini because of lack of notauli. It differs from Tobiasites Kasparyan, 1988a and Paxylommites Kasparyan, 1988a in having flattened hind tibia and postnervulus intercepted very low (from hind outer corner of brachial cell or somewhat above it). Similarly flattened hind tibia (and hind basitarsus) are known also in the recent genus Eurypterna Foerster, 1862.

Paxylobembra kozlovi Khalaim, sp. nov. Plate 6, figs 2, 3; Text-fig. 16

Etymology. In memory of Mikhail Kozlov, specialist in Proctotrupoidea.

Holotype. IWCMS 2012.575, Jarzembowski collection; ventral view of headless body, forewing with poorly preserved venation, and leg fragments; sex unknown.

Diagnosis. As for genus.

Description. Body length without head about $2 \mathrm{~mm}$, forewing $2.25 \mathrm{~mm}$. Notaulus absent. Propodeum short, without carinae. Pterostigma moderately wide, receiving radius close 
to its base. Second section of radius S-curved, over five times as long as first section. Vein Rs-m short and probably thick. Second recurrent vein absent. Nervulus hardly discernible, interstitial, very slightly inclivous. Postnervulus indiscernible, intercepted at hind outer corner of brachial cell or somewhat above it. Brachial cell not widened (as wide as submedian cell). Hind tibia strongly compressed in cross-section, maximum width near apex about 2.5 times minimum width. Metasoma cylindrical. First metasomal segment slender, at least twice as long as wide, almost not widening rearward. Second metasomal segment almost 1.5 times as long as posterior width.

3.8.7. Subfamily Townesitinae Kasparyan, 1994. Small, extinct subfamily described from Baltic amber (Kasparyan 1994). Two Bembridge Marls species undoubtedly belong to the genus Marjorietta Kasparyan, 1994 because they have the frons with a keel between impressions (unknown for $M$. gigantea sp. nov.), long sternaulus, characteristic impressions on mesopleuron, and characteristic wing venation, and are very similar to M. minor Kasparyan. The third species (Acourtia perplexa) is known only from the forewing, which is similar to the wings of the genus Marjorietta, but the lack of the body prevents checking other important characters and makes synonymisation of Marjorietta under Acourtia premature. Accordingly, the genus Acourtia is retained for the present. Body length of the three Bembridge species varies from $6 \mathrm{~mm}$ to $8.5 \mathrm{~mm}$, far above that in both species from Baltic amber $(2 \cdot 5-4 \cdot 1 \mathrm{~mm})$ and in Townesitinae in general (maximum $5 \mathrm{~mm}$ ).

Acourtia perplexa Cockerell, 1921

Plate 7, fig. 3; Text-fig. 17

1921a Acourtia perplexa Cockerell, p. 11, fig. 11 (subfamily not specified).

1971 Acourtia perplexa Cockerell: Townes, p. 235 (Cremastinae?).

1992 Acourtia perplexa Cockerell: Carpenter, p. 474.

1994 Acourtia perplexa Cockerell: Kasparyan, p. 87 (Townesitinae?).

Holotype. NHMUK In.24336, Bembridge Marls, NW Isle of Wight, UK, Hooley collection, detached forewing.

Diagnosis. Differs from two other species of Townesitineae in Bembridge Marls in having the forewing with vein Rs-m very short and very thick, nervulus slightly postfurcal, and posterior section of postnervulus reclivous.

Description. Forewing length $4.9 \mathrm{~mm}$. Pterostigma and veins dark-brown. Pterostigma almost $3 \cdot 3$ times as long as wide, receiving radius in its middle. First section of radius not curved near pterostigma. Second section of radius straight, 4.4 times as long as first section. Metacarp short, not reaching wing apex. Vein Rs-m very short and very thick. Second recurrent vein subtending obtuse angle with first section of subdiscoideus, straight, with single bulla slightly above middle. Discocubitus curved, without ramulus. Second discoidal cell 1.5 as long as wide. Nervulus slightly postfurcal, inclivous. Postnervulus intercepted approximately in its $0 \cdot 7$; posterior section distinctly reclivous. Brachial cell short.

Marjorietta disrupta (Cockerell, 1921), comb. nov. Plate 7, fig. 1; Text-fig. 18

1921a Lampronota disrupta Cockerell, p. 10, fig. 9 (Banchinae).

Holotype. NHMUK I.9711, Bembridge Marls, NW Isle of Wight, UK, Brodie collection, lateral aspect of almost complete female wasp lacking antennal apex and most of legs and with metasoma detached, obscured by wings basally, and lacking ovipositor apex.

Diagnosis. Differs from A. gigantea in having the forewing with the first section of radius curved near pterostigma, vein Rs-m moderately thick, second recurrent vein subtend angle $95^{\circ}$ with the first section of subdiscoideus, the second discoidal cell longer and postnervulus intercepted lower. Differs from A. perplexa in having the vein $\mathrm{Rs}-\mathrm{m}$ longer and thiner, nervulus almost interstitial, and posterior section of postnervulus inclivous.

Description. Body length about $6 \mathrm{~mm}$, forewing $5 \mathrm{~mm}$, mesosoma length $2.1 \mathrm{~mm}$, width $1.5 \mathrm{~mm}$, forewing length $5 \mathrm{~mm}$. Antenna filiform as preserved; scape elongate, oval. Inner margins of eyes convergent ventrally. Temple about one third as wide as eye. Frons with pair of longitudinal impressions behind antennal sockets and with longitudinal keel between these impressions. Impressions deep, with slight slope to frontal ocellus and reaching about its level. Keel high and narrow, higher near antennal sockets and decreasing towards frontal ocellus. Notaulus absent. Prepectal and postpectal carinae distinct. Mesopleuron with obvious longitudinal impression in upper part near tegula, wider and more shallow anteriorly, deeper and more narrow posteriorly, and with more shallow oblique impression extending through mesopleuron from upper anterior to lower posterior corners. Sternaulus strong, deep, crenulate, extending for entire mesopleuron length in its lower part, joining its posterior margin below level of mid coxa. Mesopleural fovea absent. Mesopleural suture straight. Propodeum areolate. Mid and hind coxa and hind femur very slender. Pterostigma and veins dark-brown. Pterostigma narrow, almost five times as long as wide, receiving radius near its middle. First section of radius curved near metacarp. Second section of radius almost straight, 3.5 times as long as first section. Metacarp short, not reaching apex of forewing. Vein Rs-m moderately thickened. Second recurrent vein subtending obtuse angle with first section of subdiscoideus, not curved, with single bulla in the middle. Discocubitus slightly curved, without ramulus. Second discoidal cell 1.65 times longer than wide. Nervulus hardly postfurcal, inclivous. Postnervulus intercepted in its $0 \cdot 6$; posterior section slightly inclivous. Brachial cell short. Nervellus intercepted obviously below middle. Mediella moderately curved. Metasoma cylindrical (first segment not preserved). Ovipositor as preserved straight, longer than height of metasoma.

\section{Marjorietta gigantea Khalaim, sp. nov.} Plate 7, fig. 2; Text-fig. 19

Etymology. After giganteus, the Latin for giant.

Holotype. NHMUK In.43477(1), Bembridge Marls, NW Isle of Wight, UK, Hooley collection, ventrolateral aspect of wasp with head poorly preserved, mesosoma incomplete posteriorly, antenna and legs incomplete; sex unknown.

Diagnosis. Differs from $A$. disrupta in having forewing with the first section of radius not curved near pterostigma, vein Rs $-\mathrm{m}$ thick, second recurrent vein subtending angle of $105^{\circ}$ with first section of subdiscoideus, second discoidal cell shorter, and postnervulus intercepted higher. Differs from $A$. perplexa in having the vein Rs-m longer and thinner, nervulus almost interstitial, and posterior section of postnervulus inclivous.

Description. Body length $8.5 \mathrm{~mm}$, forewing c. $5 \mathrm{~mm}$. Flagellar base slender; 1st and 2nd flagellomeres at least twice as long as wide. Mesosoma very similar to that of Marjorietta disrupta. Prepectal carina distinct. Mesopleuron with distinct subtegular impression, and with oblique impression extending from upper anterior to lower posterior corner of mesopleuron. Sternaulus deep, begining from anteroventral margin of mesopleuron 


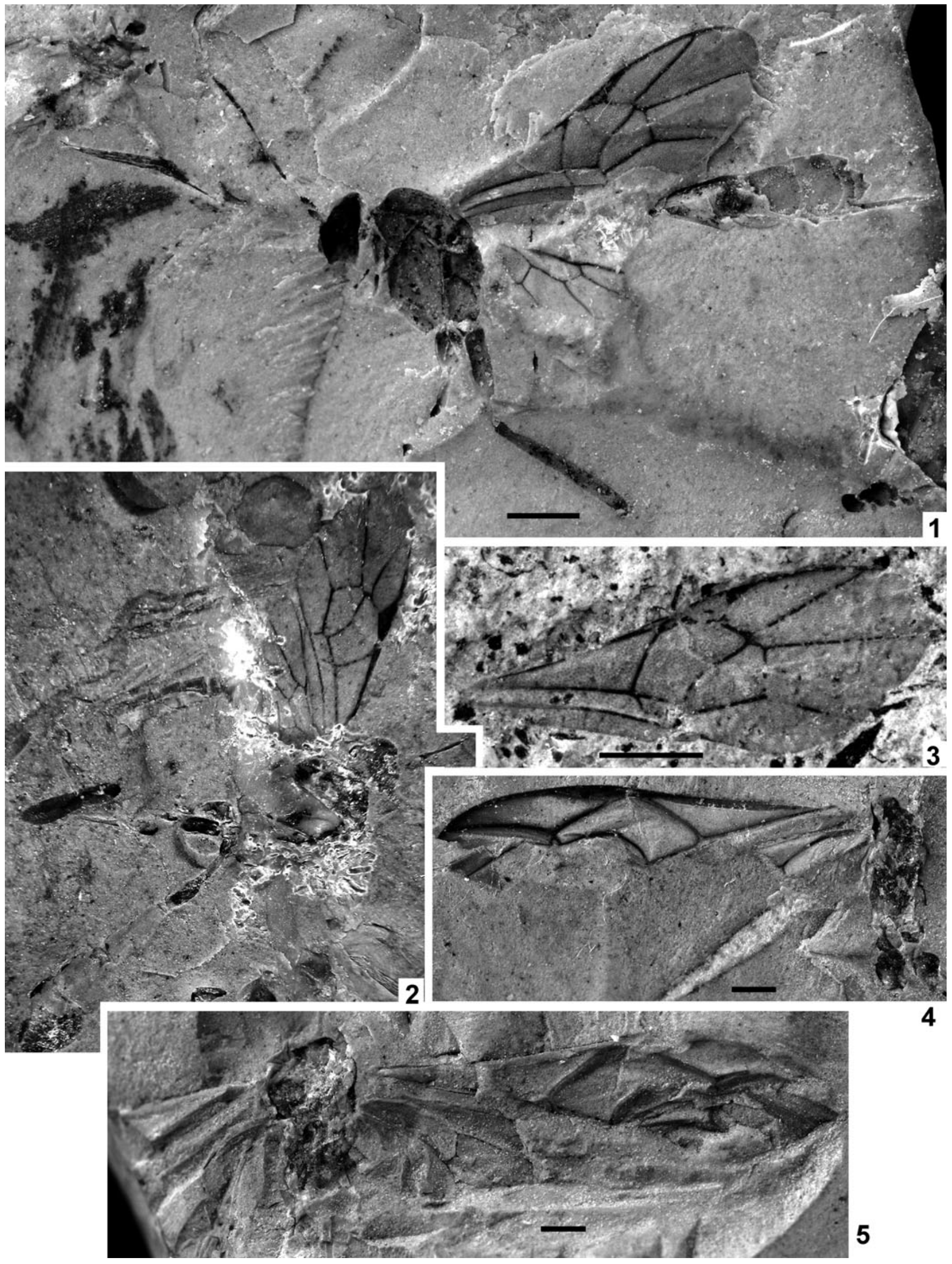

Plate 7 (1) Marjorietta disrupta (Cockerell), NHMUK I.9711, holotype. (2) Marjorietta gigantea sp. nov., NHMUK In.43477, holotype. (3) Acourtia perplexa Cockerell, NHMUK In. 24336, holotype. (4-5) "Coleocentrus" gurnetensis Cockerell: (4) NHMUK In.17079, holotype; (5) NHMUK In.17296, counterpart. Scale bars = $1 \mathrm{~mm}$. 


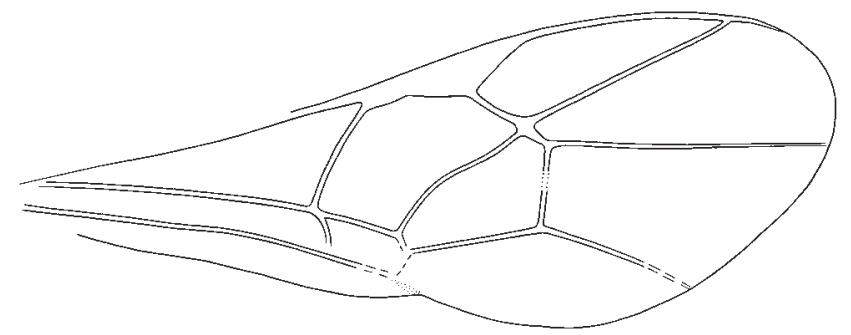

Text-figure 17 Acourtia perplexa Cockerell, NHMUK In.24336, holotype.

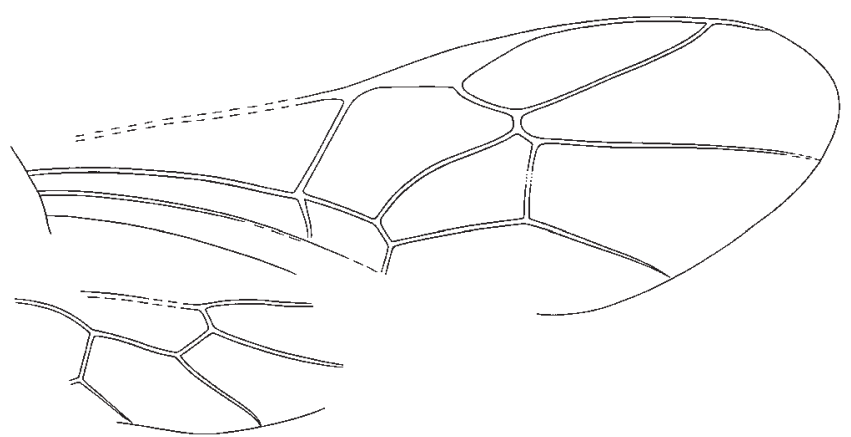

Text-figure 18 Marjorietta disrupta (Cockerell), NHMUK I.9711, holotype.

(posterior part not preserved). Mesopleural fovea absent. Mesopleural suture straight. Pterostigma and veins dark-brown. Pterostigma wide, 3.4 times as long as wide, receiving radius near its middle. First section of radius not curved near metacarp. Second section of radius almost straight, 4.5 times as long as first section. Vein Rs-m short and thick. Second recurrent vein subtending rather obtuse angle with first section of subdiscoideus, not curved, with single bulla somewhat above the middle. Discocubitus slightly curved, without ramulus. Second discoidal cell 1.35 times as long as wide. Nervulus strongly interstitial, inclivous. Postnervulus intercepted in its $0 \cdot 7$; posterior section hardly inclivous (almost vertical). Brachial cell short. Nervellus probably intercepted in the middle. Mediella slightly curved. Metasoma cylindrical, wider posteriorly. First segment thin and long, with distinct petiole and postpetiole. Second segment distinctly elongate. Third segment about as long as wide.

Ichneumonidae incerta sedis

"Coleocentrus" gurnetensis Cockerell, 1921

Plate 7, figs 4, 5; Text-fig. 20

1921a Coleocentrus gurnetensis Cockerell, p. 6, fig. 3 (Acaenitinae).

Holotype. NHMUK In.17079/In. 17296, Bembridge Marls, NW Isle of Wight, UK, Smith collection; crumpled wings, poorly preserved mesosoma; sex unknown.

Diagnosis. Differs from other Bembridge Marls ichneumonids in having the pterostigma very narrow, long and large.

Description. Forewing length $10 \mathrm{~mm}$. Pterostigma narrow, receiving radius basally. First section of radius not curved. Areolet present. Discocubitus curved, ramulus present. Nervulus distinctly postfurcal. Nervellus intercepted in its lower 0.4 . Mediella curved.

Remarks. Areolet and narrow pterostigma receiving radius basally are characteristic for the tribe Coleocentrini, but the nervellus intercepted low excludes this species from the genus

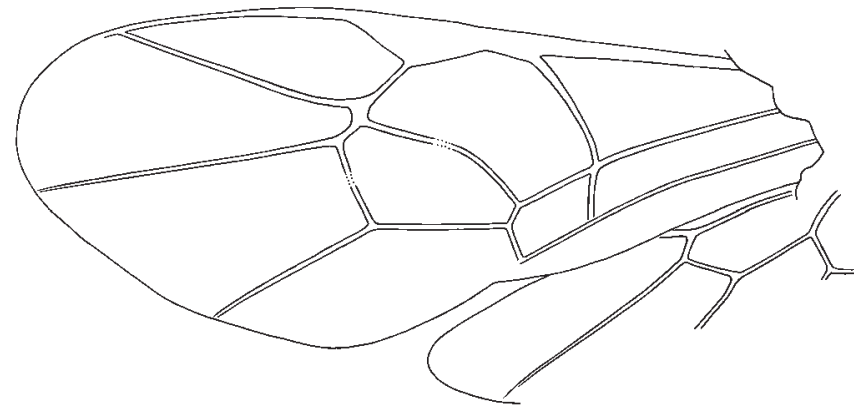

Text-figure 19 Marjorietta gigantea sp. nov., NHMUK In.43477, holotype.
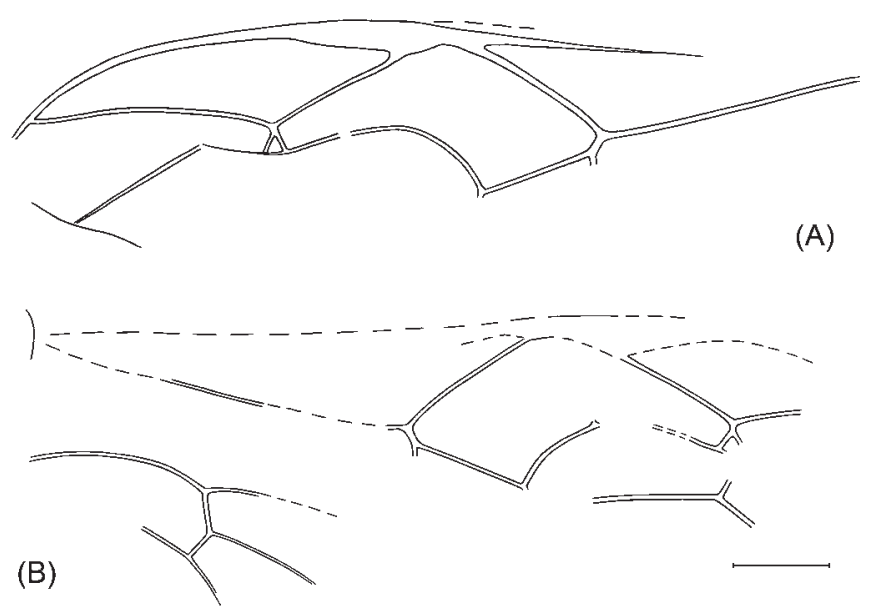

Text-figure 20 Coleocentrus gurnetensis Cockerell: (A) NHMUK In.17079 (holotype); (B) NHMUK In.17296 (counterpart). Scale bar $=1 \mathrm{~mm}$.

Coleocentrus, and from this tribe that has the nervellus intercepted in the upper 0.32 or higher.

"Polysphincta" atavina Cockerell, 1921

Plate 8, fig. 1; Text-fig. 21

1921a Polysphincta (?) atavina Cockerell, p. 9, fig. 8 (Pimplinae).

Holotype. NHMUK In.24335, Bembridge Marls, NW Isle of Wight, UK, Hooley collection, poorly preserved forewing, sex unknown.

Diagnosis. Differs from other Bembridge Marls ichneumonids in the unusual shape of areolet which adjoins broadly to the radius (Text-fig. 21).

Description. Forewing length over $4 \mathrm{~mm}$. Pterostigma and veins predominantly brown, stigma yellowish medially. Pterostigma wide, almost three times as long as wide, receiving radius near its middle. First section of radius curved. First intercubitus very short. Second intercubitus probably present, unpigmented. Second recurrent vein moderately curved, with two bullae. Discocubitus curved, ramulus absent. Nervulus interstitial or hardly postfurcal, inclivous. Postnervulus intercepted near its middle.

Remarks. Forewing venation generally similar to venation in Pimplinae, but areolet is not typical for this subfamily (second intercubitus unclear).

Genus Lithapechtis Cockerell, 1921

Type species. Lithapechtis fumosus Cockerell, 1921 (by monotypy). 

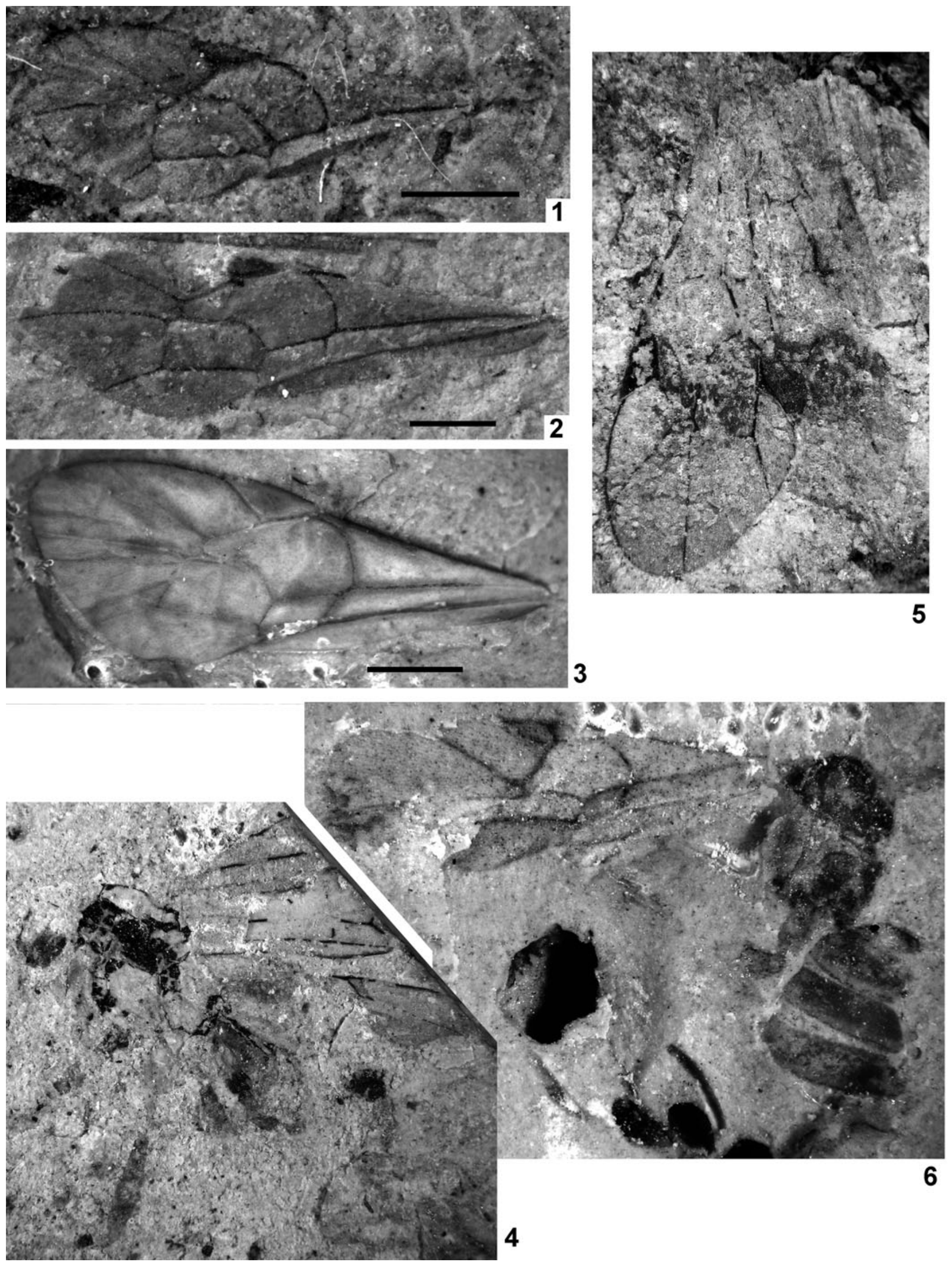

Plate 8 (1) "Polysphincta" atavina Cockerell, NHMUK In.24335, holotype. (2) Lithapechtis fumosus Cockerell, NHMUK In.24333, holotype. (3) Lithapechtis salmacidus sp. nov., NHMUK In.24839, holotype. (4-6) Ichneumonidae indet.: (4) NHMUK I.9311; (5) NHMUK I.9354; (6) NHMUK I.9812. Scale bars $=1 \mathrm{~mm}$. 


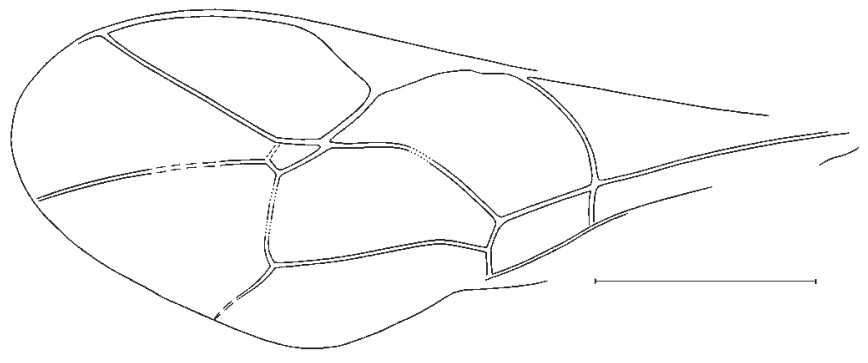

Text-figure 21 Polysphincta atavina Cockerell, NHMUK In.24335, holotype. Scale bar $=1 \mathrm{~mm}$.

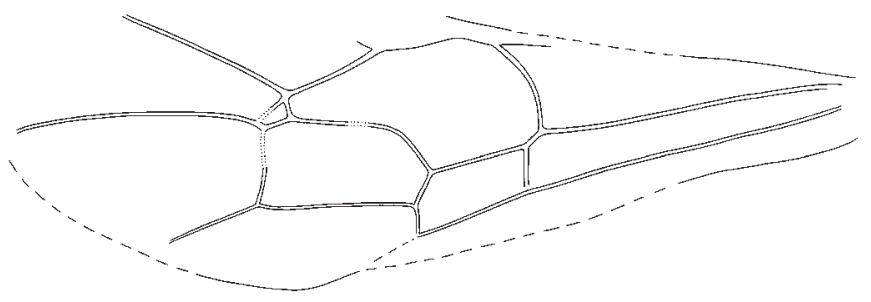

Text-figure 22 Lithapechtis fumosus Cockerell, NHMUK In.24333, holotype.

Diagnosis. Pterostigma more or less wide, receiving radius near its middle. Areolet small, oblique, with long petiole; first intercubitus shorter than second intercubitus; second intercubitus unpigmented. Second recurrent vein almost straight, slightly curved in middle, probably with two bullae (Text-fig. 23 ), inclivous or subvertical. Discocubitus rather strongly curved, without ramulus. Second discoidal cell short, 1.7-1.9 times as long as wide. Nervulus postfurcal, distance between basal vein and nervulus is half the length of nervulus. Postnervulus intercepted near or below its middle.

Remarks. Cockerell supposed that this genus belongs to Pimplinae. I have studied the type and two additional specimens which I refer to the same genus, all known from isolated forewings. Lithapechtis is well distinguishable from other ichneumonid genera found in the Bembridge Marls, mainly by the combination of the narrow pedunculate areolet, characteristic form of the second recurrent vein, and postfurcal nervulus, but I cannot recognise its subfamily. Similar forewing venation can be found in extant specimens of the subfamilies Ctenopelmatinae, Tryphoninae, Metopiinae and Banchinae.

\section{Lithapechtis fumosus Cockerell, 1921} Plate 8, fig. 2; Text-fig. 22.

1921a Lithapechtis fumosus Cockerell, p. 6, fig. 4 (Pimplinae). 1992 Lithapechtis fumosus Cockerell: Carpenter, p. 481.

Holotype. NHMUK In.24333, Bembridge Marls, NW Isle of Wight, UK, Hooley collection, poorly preserved forewing; sex unknown.

Diagnosis. Differs from $L$. salmacidus sp. nov. in having the forewing with the second recurrent vein subvertical, areolet with shorter petiole, second discoidal cell longer, discocubitus moderately curved, and nervulus weakly inclivous.

Description. Forewing length over $6.5 \mathrm{~mm}$. Pterostigma and veins predominantly brown; costa and veins in basal part of wing dark-brown to black; stigma yellowish basally. Pterostigma more or less wide, receiving radius near its middle. Areolet petiolate, first intercubitus shorter than second inter-

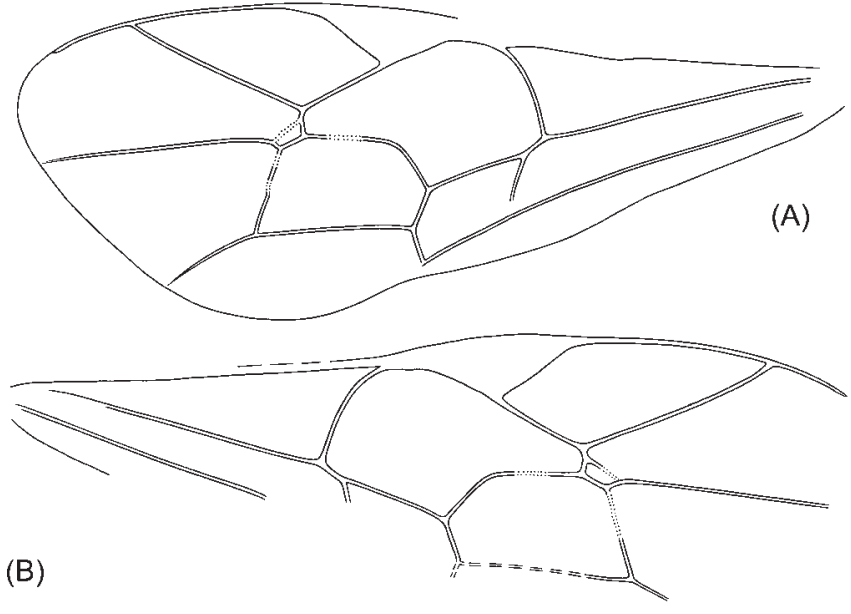

Text-figure 23 Lithapechtis salmacidus sp. nov., holotype: (A) part, NHMUK In.24839; (B) counterpart, NHMUK In.24791.
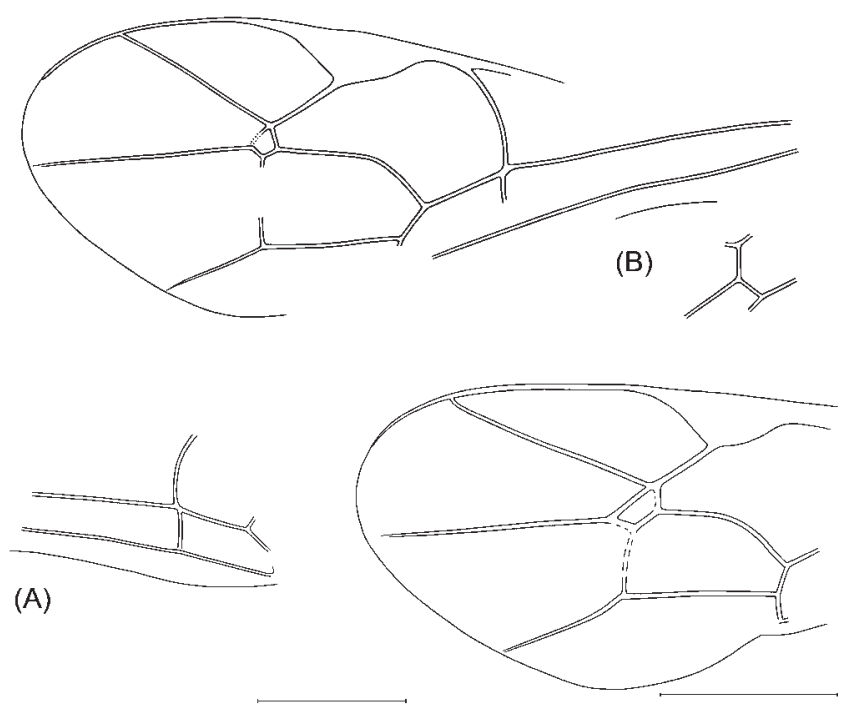

(C)

Text-figure 24 Ichneumonidae indet.: (A) NHMUK I.9311; (B) NHMUK I.9354; (C) NHMUK In.17430. Scale bars $=1 \mathrm{~mm}$.

cubitus. Second recurrent vein slightly curved, subvertical. Discocubitus curved, without ramulus. Second discoidal cell 1.9 times as long as wide. Nervulus weakly inclivous, postfurcal (distance between basal vein and nervulus equal to half nervulus length). Postnervulus intercepted in its middle.

\section{Lithapechtis salmacidus Khalaim, sp. nov. Plate 8, fig. 3; Text-fig. 23}

Etymology. After salmacidus, the Latin for salty sour.

Holotype. NHMUK In.24839, NHMUK In. 24791 (part and counterpart), Bembridge Marls, NW Isle of Wight, UK, Hooley collection; well-preserved complete forewing. Sex unknown.

Diagnosis. Differs from L. fumosus in having the forewing with the second recurrent vein distinctly inclivous, areolet with long petiole, second discoidal cell shorter, discocubitus stronger curved, and nervulus strongly inclivous.

Description. Forewing length $5.5 \mathrm{~mm}$. Veins yellowish; pterostigma whitish. Pterostigma wide, receiving radius near 
its middle. Metacarp not reaching apex of forewing. Radius more or less straight; second section $2 \cdot 2$ times longer than first section. Areolet petiolate, with long petiole; first intercubitus shorter than second intercubitus. Second intercubitus unpigmented. Second recurrent vein almost straight, slightly curved in the middle, inclivous. Discocubitus strongly curved, without ramulus. Second discoidal cell 1.7-1.75 times longer than wide. Nervulus strongly inclivous, postfurcal (distance between basal vein and nervulus half as long as nervulus). Postnervulus intercepted somewhat below its middle.

\section{Ichneumonidae indet.}

Remarks. Additionally found are six unnamed ichneumonid fossils which cannot be identified even up to subfamily level: NHMUK I.9214, NHMUK I.9311 (Plate 8, fig. 4); NHMUK I.9354 (Plate 9, fig. 5, Text-fig. 24B); NHMUK I.9812 (Plate 8, fig. 6); and NHMUK In.17430, some of which are worth further discussion.

Specimen NHMUK I.9311: Bembridge Marls, NW Isle of Wight, UK, Brodie collection, dorsal view of poorly preserved mesosoma and base of metasoma, wing bases and parts of mid and hind legs (Plate 8, fig. 4, Text-fig. 24A). Nervulus and postnervulus in forewing are similar to these in Hemiteles acourti, but those characters are insufficient to identify the position of the fossil.

Specimen NHMUK I.9812: Bembridge Marls, NW Isle of Wight, UK, Brodie collection, poorly preserved mesosoma, part of metasoma and crumpled forewing (Plate 8, fig. 6). Strongly transverse mid-metasomal segments might indicate Pimplinae.

Specimen NHMUK In.17430: Bembridge Marls, NW Isle of Wight, UK, Smith collection, poorly preserved apical half of forewing (Fig. 24C), possibly Pimplinae.

\subsubsection{Key to species of Bembridge Marls Ichneumonidae}

1 - Forewing with second recurrent vein entirely absent (Text-fig. 16); second section of radius S-curved, over five times as long as first section; small species with forewing $2.25 \mathrm{~mm}$; brachial cell not widened (as wide as submedian cell); notauli absent; hind tibia strongly compressed in cross-section, maximum width near apex about 2.5 times minimum width. (Paxylommatinae) $=$ Paxylobembra kozlovi sp. nov.

- Forewing with second recurrent vein present. Second section of radius straight or arcuate, usually much shorter...... go to 2 .

2 - Second recurrent vein straight, with one bulla, distinctly reclivous (Text-figs 17-19); areolet absent, vein Rs-m moderately to very thick; second section of radius $3 \cdot 5-$ 4.5 times as long as first section; postnervulus intercepted always distinctly above its middle. (Townesitinae)......go to 3 .

- Second recurrent vein often arcuate, with one or two bullae, usually inclivous or rarely subvertical; areolet absent or present, vein Rs-m thin; second section of radius usually shorter; postnervulus intercepted near or below, or rarely above its middle...... go to 6 .

3 - Body length 2.5-4.0 mm; forewing length at the most $3.3 \mathrm{~mm}=$ Baltic amber species of Marjorietta Kasparyan.

- Body length 6.5-8.5 mm; forewing about $5 \mathrm{~mm}$. Bembridge Marls...... go to 4 .

4 - Vein Rs-m very short and very thick (Text-fig. 17); nervulus slightly postfurcal; posterior section of postnervulus reclivous $=$ Acourtia perplexa Cockerell.

- Vein Rs-m longer and thinner; nervulus almost interstitial; posterior section of postnervulus more or less inclivous....... go to 5 .
5 - First section of radius not curved near pterostigma (Text-fig. 19); vein Rs-m thick; second recurrent vein subtend angle $105^{\circ}$ with first section of subdiscoideus; second discoidal cell 1.35 times as long as wide; postnervulus intercepted in its $0 \cdot 7=$ Marjorietta gigantea sp. nov.

- First section of radius distinctly curved near pterostigma (Text-fig. 18); vein Rs-m moderately thick; second recurrent vein subtend angle $95^{\circ}$ with first section of subdiscoideus; second discoidal cell 1.5 times as long as wide; postnervulus intercepted in its $0 \cdot 6=$ Marjorietta disrupta (Cockerell).

6 - Areolet quadrangular, strongly oblique, with long petiole above (Text-figs 22, 23); second recurrent vein slightly inclivous, almost straight, weakly sinuate centrally, probably with two bullae; nervulus strongly postfurcal, distance between basal vein and nervulus equal to half of nervulus length. (Lithapechtis Cockerell)...... go to 7.

- Areolet (if present) quadrangular or pentagonal, sometimes pointed above but without distinct petiole (Textfigs 5,8); second recurrent vein straight or arcuate, not sinuate centrally, with one or two bullae; nervulus interstitial or weakly postfurcal (except for Hypsicera anglica with this vein strongly postfurcal)....... go to 8 .

7 - Second recurrent vein distinctly inclivous (Text-fig. 23); areolet with long petiole; second discoidal cell 1.7-1.75 times as long as wide; discocubitus stronger curved; nervulus strongly inclivous $=$ Lithapechtis salmacidus sp. nov.

- Second recurrent vein subvertical (Text-fig. 22); areolet with short petiole; second discoidal cell 1.9 times as long as wide; discocubitus moderately curved; nervulus weakly inclivous $=$ Lithapechtis fumosus Cockerell.

8 - Areolet complete (except for Eusterinx humalai sp. nov. which has no areolet), quadrangular, more or less pointed above (Text-figs 4-6, 8-10); second recurrent vein moderately to strongly arcuate (except for Eusterinx vectensis which has this vein almost straight); nervulus interstitial or slightly postfurcal...... go to 9 .

- Areolet incomplete (open distally), pentagonal, not pointed above (Text-figs 11-15); second recurrent vein straight or arcuate; nervulus sometimes far postfurcal. ...... go to 14 .

9 - Second recurrent vein strongly arcuate and areolet weakly to strongly oblique (Text-figs 3-6). (Pimplinae). .... go to 10 .

- Second recurrent vein almost straight and areolet weakly oblique (subrhombic), or areolet absent (Text-fig. 10). (Orthocentrinae)...... go to 12.

10 - Nervulus postfurcal, distinctly inclivous (Text-fig. 5); discocubitus very weakly curved ?=Itoplectis saxosa Cockerell.

- Nervulus interstitial, slightly inclivous or subvertical. Discocubitus distinctly curved......go to 11 .

11 - Areolet strongly oblique (Text-fig. 6); first intercubitus much shorter than second intercubitus; postnervulus intercepted high $=$ Scambus fossilis sp. nov.

- Areolet weakly oblique (Text-fig. 4); first intercubitus subequal to second intercubitus; postnervulus intercepted low. $=$ Exeristes gurnetor sp. nov.

12 - Forewing without areolet; first section of radius straight; discocubitus very slightly curved; nervulus inclivous; postnervulus intercepted low = Eusterinx humalai sp. nov.

- Forewing with areolet; first section of radius more or less curved; discocubitus distinctly curved; nervulus vertical; postnervulus intercepted low...... go to 13 .

13 - Areolet large, first intercubitus long; discocubitus moderately curved $=$ Eusterinx vectensis (Cockerell). 
- Areolet small, oblique, first intercubitus very short; discocubitus strongly curved $=$ Eusterinx arcuatus (Cockerell).

14 - Nervulus strongly postfurcal and strongly inclivous (Text-fig. 11); second recurrent vein straight; first intercubitus and abscissa of cubitus between first intercubitus and second recurrent vein long; head globose; body robust; hind coxa and femur thick. (Metopiinae) = Hypsicera anglica (Cockerell).

- Nervulus interstitial or slightly postfurcal, weakly inclivous. Second recurrent vein usually arcuate. First intercubitus and abscissa of cubitus between first intercubitus and second recurrent vein usually much shorter. (Cryptinae)...... go to 15 .

15 - Postnervulus intercepted in its $0 \cdot 35$; posterior section vertical; discocubitus very slightly curved; small insect with forewing length $2.7 \mathrm{~mm}=$ Stilpnus oligocenus Cockerell.

- Postnervulus sometimes intercepted higher; posterior section inclivous; discocubitus distinctly curved; forewing usually longer...... go to 16 .

16 - Second recurrent vein strongly inclivous, almost straight, not curved near subdiscoideus; nervulus interstitial; postnervulus strongly inclivous, angle between posterior section and brachius $50^{\circ}$; discocubitus slightly and evenly curved $=$ Hemiteles dirus sp. nov.

- Second recurrent vein inclivous, roundly curved, stronger curved near subdiscoideus; nervulus more or less postfurcal; posterior section of postnervulus less inclivous; discocubitus usually stronger curved...... go to 17 .

17 - Discocubitus at most very weakly curved anteriorly and posteriorly, and strongly curved near the middle; nervulus very slightly inclivous, distinctly postfurcal; radial cell 2.5 times as long as wide; second discoidal cell $2 \cdot 15$ times as long as wide $=$ Hemiteles acourti (Cockerell).

- Discocubitus more or less evenly curved; nervulus distinctly inclivous, somewhat postfurcal; radial cell $2 \cdot 2$ times as long as wide; second discoidal cell 1.8 times as long as wide $=$ Hemiteles protervus $\mathrm{sp}$. nov.

3.8.9. Discussion. Taxonomic composition of Ichneumonidae of the Bembridge Marls gives little information about ecological and climatic conditions. Orthocentrinae indicate humid forests; other subfamilies do not show clear biotopic preferences. Parasites of Lepidoptera (Metopiinae, and probable Pimplinae and Cryptinae), mycetophagous Diptera (Orthocentrinae) and probable ants (Paxylommatidae) are found.

The Bembridge Marls ichneumonid fauna is generally closest to that of Baltic amber, both being dominated by Cryptinae and Townesitinae with presence of Paxylommatinae. Cryptinae are abundant in many Cenozoic insect sites, but Townesitinae are known only from the Bembridge Marls and Baltic amber. However, these two assemblages differ strikingly in two respects. First, the extinct subfamily Pherhombinae is rather common in the Baltic and Rovno ambers (Kasparyan 1988b, Tolkanitz et al. 2005) but not recorded in the Bembridge Marls (nor in any other Cenozoic deposits). Secondly, the subfamily Pimplinae dominates in the Bembridge Marls assemblage and is rather common in other Cenozoic deposits since the Paleocene, but is not recorded in the Baltic amber. The lack of Pherhombinae in the Bembridge Marls indicates it is somewhat younger than Baltic amber.

Both the Bembridge Marls and the Baltic amber deposits are apparently older than the Florissant beds. This inference is based on the subfamily Ichneumoninae, a relatively progressive group of Ichneumonidae (Gokhman 1992) which is abundant in the Florissant and recorded neither in the Bembridge Marls nor in the Baltic amber. Additionally, the Florissant assemblage lacks the fossil subfamily Townesitinae which constitutes an appreciable part of both the Bembridge Marls and the Baltic amber ichneumonid assemblages. Many Recent subfamilies are recorded from the Florissant which are absent from the Bembridge Marls (Brues 1910), but that material deserves revision before being used in more detailed comparisons.

\subsection{Family Braconidae Nees, 1812}

[By Sergey A. Belokobylskij.]

The oldest fossils of Braconidae are known from the Cretaceous Period (Carpenter et al. 1937; Zherikhin 1978; Rasnitsyn 1983; Basibuyuk et al. 1999; Perrichot et al. 2007, 2009; Ortega-Blanco et al. 2009), but the most numerous and diverse members of this family were discovered and described from Cenozoic (Oligocene, Miocene and Eocene) ambers in different parts of the World (Baltic: Brues 1923, 1933, 1939; Tobias 1987; Dominican: Zuparko \& Poinar 1997; Achterberg 2001; Engel \& Bennett 2008; Mexican: Muesebeck 1960; Chinese: Hong 2001, 2002), and different rock deposits (Cockerell 1919, 1920a, 1921a; Brues 1906; Statz 1936, 1938).

In spite of the quite extensive published information about braconid fossils, the positions of many taxa are very problematic, because they were not described by braconid experts. As a result, many fossils have been described in incorrect genera and subfamilies. Unfortunately, the largest collection of Baltic amber from Königsberg University, with numerous types of Hymenoptera, was mostly destroyed during the Second World War. This includes the Braconidae described by Brues and now it is almost impossible to check and correct the attribution of many of Brues' taxa because of incomplete descriptions and often insufficiently informative figures. Undoubtedly, revision of the all available described taxa is one of the main steps toward the real estimation of the taxonomic position of fossil Braconidae.

All the types of species described by Cockerell (1921a) from the Bembridge Marls of the Isle of Wight are kept in good condition in the collection of the Palaeontological Department of the Natural History Museum in London. The study of this collection has enabled the modern taxonomic position of these taxa to be established. Additional material from this collection shows that the diversity of the braconid fossil assemblage is wide and includes several additional subfamilies not recorded previously.

Most of the fossils studied show meso- and metasoma preserved three-dimensionally (including depth), and their study requires observations from different visual angles. As a result, several characters mentioned in the descriptions cannot be seen on photos or line drawings. Also, the sex of the fossils under study is often unknown, because the respective characters are not available due to incomplete preservation.

The venational terminology and symbols follow that of Achterberg (1979) (see Text-fig. 29B and additions in Textfigs 26 and 43A).

3.9.1. Subfamily Agathidinae Foerster, 1862. Koinobiont endoparasitoids of lepidopteran larvae of the subfamily Agathidinae are not abundant in the fossil record, including amber. Three species of Agathis Latreille, 1804 (A. juvenilis Brues, 1910, A. saxatilis Brues, 1910 and A. velatus Brues, 1910) described by Brues (1910) from the Florissant beds are now considered as uppermost Eocene (Evanoff et al. 2001). Of these taxa, A. saxatilis is undoubtedly a species of the genus Earinus Wesmael, 1837 because of the presence of the distinct and complete $1-\mathrm{SR}+\mathrm{M}$ in the forewing. Two others are probably species of Bassus Fabricius, 1804, judging from the head being figured as not elongate in its lower half and with the mouth apparatus short. Two species with broad second submarginal cell 
in the forewing from the Florissant (Microdus miocenicus Cockerell, 1927) and from the Baltic amber (M. quadrangularis Brues, 1933) belong to the genus Bassus in the modern sense as well. The generic position of Cremnops florissanticola Cockerell, 1919 (Cockerell 1919; Brues 1933) from the Florissant needs verification: its wing venation as figured is very close to that of other fossil Bassus with the enlarged second submarginal cell. Lastly, Snellenius succinalis Brues, 1933 described in this subfamily, but in the microgastrine genus Snellenius Westwood, 1882 (Brues 1933), is not an agathidine: its taxonomic position needs revision.

Two well preserved forewings discovered in the collection from the Bembridge Marls are described below. Several agathidine genera (Cremnops Foerster, 1862, Labagathis Enderlein, 1920, Zacremnops Sharkey \& Wharton, 1985), as well as some species of other genera (Bassus, Agathis, Euagathis Szepligeti, 1900, Braunsia Kriechbaumer, 1894) have similar venation. That is why the new species are provisionally included in Bassus as one of the less derived agathidine genera, and additionally because a number of species of comparable age and with similar wing venation are already known to belong to Bassus (see above).

Genus Bassus Fabricius, 1804

Bassus magnareola Belokobylskij, sp. nov. Plate 9, fig. 1; Text-fig. 25A

Etymology. From magnus, the Latin for large, and areola, the Latin for cell, because of the enlarged second submarginal cell of forewing.

Holotype. NHMUK In.17127, Bembridge Marls, NW Isle of Wight, UK, Smith Collection; isolated forewing.

Diagnosis. Similar to B. quadrangularis (Brues, 1933) in large second submarginal cell but differs in having 1-R1 shorter than pterostigma, second submarginal cell very weakly narrowed above, and $r$ much shorter than 3-SR. Differs from insufficiently described B. miocenicus (Cockerell, 1927) (= Microdus miocenicus Cockerell, 1927, Florissant), comb. nov., in having subsquare second submarginal cell.

Description. Forewing length $c .3 \cdot 3 \mathrm{~mm}$. $\mathrm{C}+\mathrm{SC}+\mathrm{R}$ thick. Pterostigma subtriangular, wide, rather short, $c .2 \cdot 5$ times as long as maximum width. $1-\mathrm{R} 10.75$ times as long as pterostigma, almost as long as distance from apex of marginal cell to wing apex; $r$ arising almost from middle of pterostigma, short, c. $0 \cdot 2$ times as long as maximum pterostigmal width, 0.5 times as long as 3-SR. Marginal cell much shortened, narrow, pointed apically, 4.5 times as long as maximum width. 3-SR $0 \cdot 15$ times as long as weakly concave SR1, 0.6 times as long as 2-SR; $\mathrm{r}-\mathrm{m}$ distinctly sclerotised, weakly broken in anterior 0.4 . Second submarginal cell subsquare, weakly narrowed anteriorly, 0.9 times as long as wide, its anterior side 0.8 times as long as posterior side. Short basal and apical sections of $1-\mathrm{SR}+\mathrm{M}$ developed; $\mathrm{m}-\mathrm{cu}$ distinctly antefurcal, as long as 2-SR, 0.7 times as long as weakly curved 1-M and subparallel to it; $\mathrm{cu}-\mathrm{a}$ distinctly postfurcal. Colour: Forewing hyaline; pterostigma and $\mathrm{C}+\mathrm{SC}+\mathrm{R}$ dark brown; remaining veins brown to pale brown.

Bassus quadrangularis (Brues, 1933), comb. nov. Plate 9, fig. 2; Text-fig. 25B

1933 Microdus quadrangularis Brues, 95. Baltic amber; Upper Eocene. lost).
Material examined. NHMUK In.24958, Bembridge Marls, NW Isle of Wight, UK, Hooley Collection; isolated forewing with basal part lost.

Diagnosis. Similar to B. magnareola sp. nov. but differs in having 1-R1 almost as long as pterostigma, second submarginal cell distinctly narrowed above, and $\mathrm{r}$ almost as long as 3-SR.

Description. $\mathrm{C}+\mathrm{SC}+\mathrm{R}$ thick. Pterostigma subtriangular, wide, rather short, $c .2 \cdot 5$ times as long as maximum width. 1$\mathrm{R} 1$ almost as long as pterostigma, c. 1.3 times as long as distance from apex of marginal cell to wing apex; $r$ arising almost from middle of pterostigma, short, c. 0.4 times as long as maximum width of pterostigma, almost as long as 3-SR. Marginal cell distinctly shortened, narrow, pointed apically, almost five times as long as maximum width. 3-SR $0 \cdot 1$ times as long as the straight SR1, 0.4 times as long as 2-SR; r-m distinctly sclerotised, weakly broken in anterior $0 \cdot 3$. Second submarginal cell trapezoid, narrowed anteriorly, about 0.8 times as long as wide, its anterior side 0.6 times as long as posterior side. Short basal and apical sections of $1-\mathrm{SR}+\mathrm{M}$ present; $\mathrm{m}$-cu distinctly antefurcal, almost as long as 2-SR, 0.6 times as long as distinctly curved $1-\mathrm{M}$ and weakly divergent from it. $\mathrm{Cu}-\mathrm{a}$ postfurcal, distant from $1-\mathrm{M}$ for $0 \cdot 3$ times cu-a length. Subdiscal cell wide, c.3.0 times as long as wide; CU1b absent.

Remarks. According to the short original description of the forewing, the present fossil shows no differences from $B$. quadrangularis. I prefer to use this name until new material is available.

3.9.2. Subfamily Brachistinae Foerster, 1862. Brachistinae are ovo-larval parasitoids of various beetles. One of the main features discriminating this group from the closely related subfamily Helconinae is the absence of $\mathrm{r}-\mathrm{m}$ and, as a result, of the second submarginal cell. Unfortunately, not every fossil has its forewing preserved well enough to permit reliable identification. This results in tentative placement of insufficiently preserved fossils.

In the fossil record, the subfamily is represented by only a few species of two genera. These are Eubazus crassicornis (Brues, 1933) and E. gracilicornis (Brues, 1939) (originally described in Blacus: Achterberg 1982), E. normalis Brues, 1923, comb. nov. and E. wilmattae Brues, 1910, comb. nov. (originally described in Brachistes and Calyptus respectively) and Triaspis anomala Brues, 1939 (all from the Baltic amber, except for E. wilmattae from the Florissant). Described from the Florissant, Urosigalphus aternus Brues, 1910 is possibly also a member of the brachistine genera Triaspis or Schizoprymnus. Calyptoides veternus Cockerell, described putatively as a brachistine wasp (Cockerell 1921a), actually belongs to subfamily Helconinae (see below).

Five new species of the genus Eubazus are described from the Insect Limestone, Bembridge Marls, in this study. The subgeneric position of these new species is not clear because of insufficient morphological information available from these rock fossils.

Genus Eubazus Nees, 1816

Eubazus ? brodiei Belokobylskij, sp. nov. Plate 9, fig. 4; Text-fig. 26

Etymology. After P.B. Brodie, whose collection includes the holotype.

Holotype. NHMUK I.9239, Bembridge Marls, NW Isle of Wight, UK, Brodie Collection; wasp in dorsoventral aspect lacking antennae, legs, forewings, and metasomal apex. 

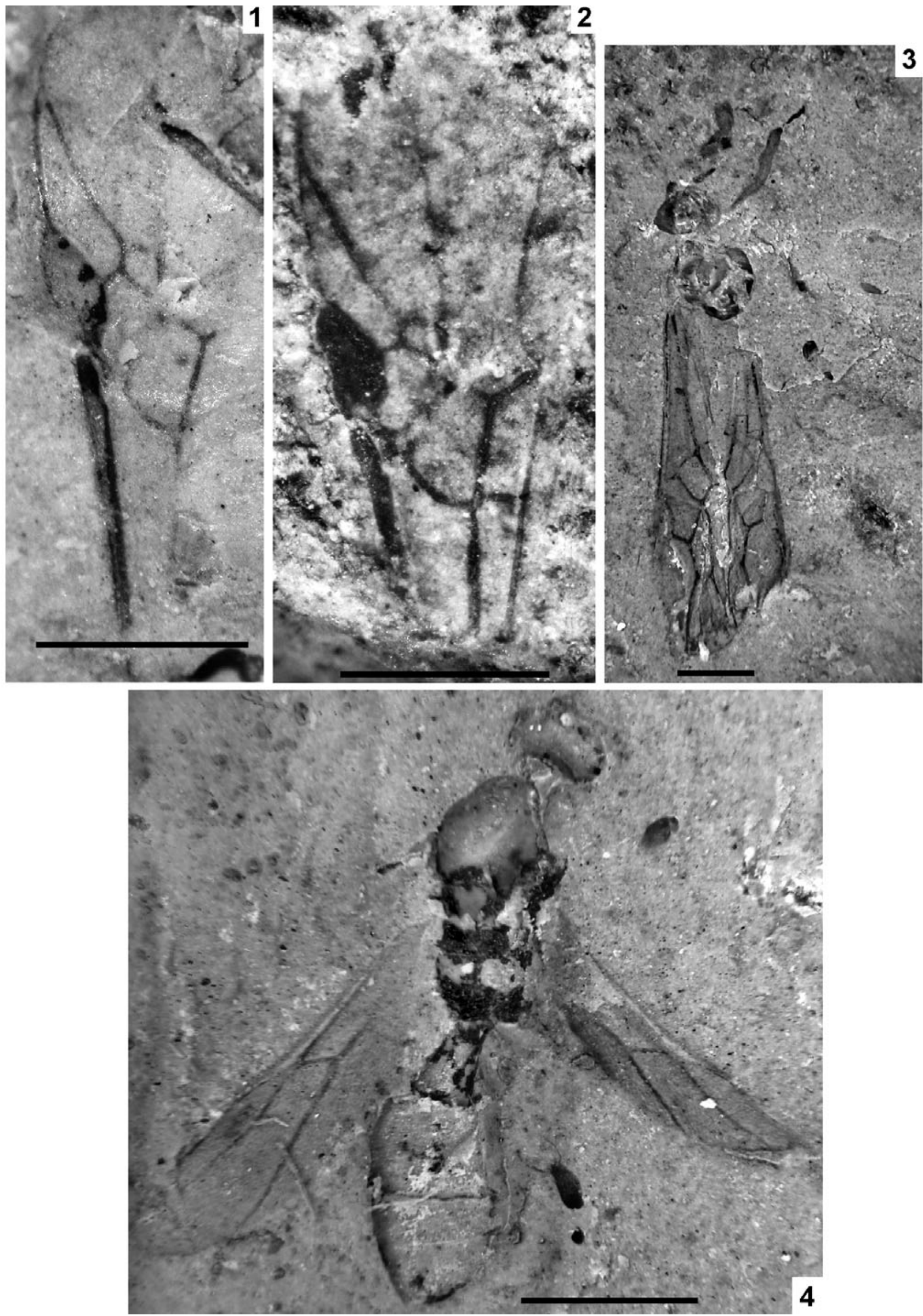

Plate 9 (1) Bassus magnareola sp. nov., holotype, NHMUK In.17127. (2) Bassus quadrangularis (Brues), NHMUK In.24958. (3) Bracon ? antefurcalis sp. nov., holotype, NHMUK I.9061. (4) Eubazus ? brodiei sp. nov., holotype, NHMUK I.9239. Scale bars $=1 \mathrm{~mm}$. 


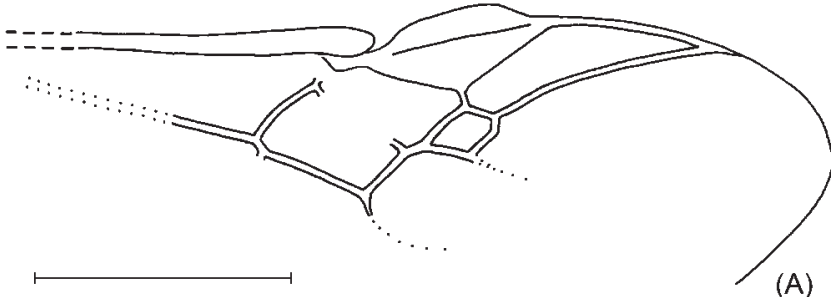

(A)

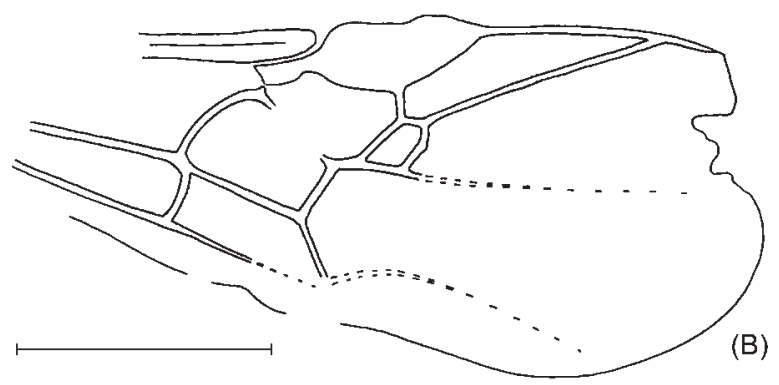

Text-figure 25 (A) Bassus magnareola sp. nov., holotype, NHMUK In.17127. (B) B. quadrangularis (Brues), NHMUK In.24958. Scale bars $=1 \mathrm{~mm}$.

Diagnosis. Characteristic of the species is the propodeum lacking delineated areas and the first tergite long and with high dorsal carinae.

Description. Length of body $3.8 \mathrm{~mm}$, mesosoma $1.5 \mathrm{~mm}$, metasoma $1.7 \mathrm{~mm}$. Head transverse, about twice as wide as median length, rather strongly and somewhat roundly narrowed behind the eyes. Occipital carina complete dorsally. Mesosoma about 2.5 times as long as maximum width. Median lobe of mesoscutum distinctly protruding forwards and rounded anteriorly. Notauli complete, rather deep, more or less narrow entirely, fused one with another shortly before prescutellar depression. Prescutellar depression wide, deep, with high medial carina, possibly weakly sculptured. Scutellum convex. Metanotum medially with two fine carinae convergent posteriorly, and with high and rather large tubercle in posterior half. Propodeum long, irregularly rugose-reticulate, possible smooth basilaterally. Hind wing with sub basal cell large; $\mathrm{M}+\mathrm{CU} 3.0$ times as long as $1-\mathrm{M}$. Basal cell rather narrow, almost seven times as long as its maximum width. Marginal cell weakly widened in basal half and then weakly narrowed towards apex. Metasoma 1.1 times as long as mesosoma. First tergite elongate, regularly and not strongly widened towards apex, with high and weakly convergent dorsal carinae developed in basal 0.8 of tergite, dorsope small or almost indistinct; length of tergite 1.5 times its apical width, apical width 1.6 times its basal width. Second suture absent. Combined median length of second and third tergites 1.4 times basal width of second tergite and 0.8 times their maximum width. Following segments distinctly protruding behind third one. Colour: mesosoma and first metasomal tergite black; rest of metasomal tergites possibly brown; hind wing hyaline; veins brown.

Remarks. The absence of forewings is a serious problem for understanding the real taxonomic position of this fossil because similar morphological structures are known in subfamilies Brachistinae and Helconinae (Diospilini). On the base of hind wing venation, structures of the dorsal part of mesosoma and the first metasomal tergite, the new species is included tentatively in the genus Eubazus.

Eubazus flavistigma Belokobylskij, sp. nov. Plate 10, fig. 1; Text-fig. 27A

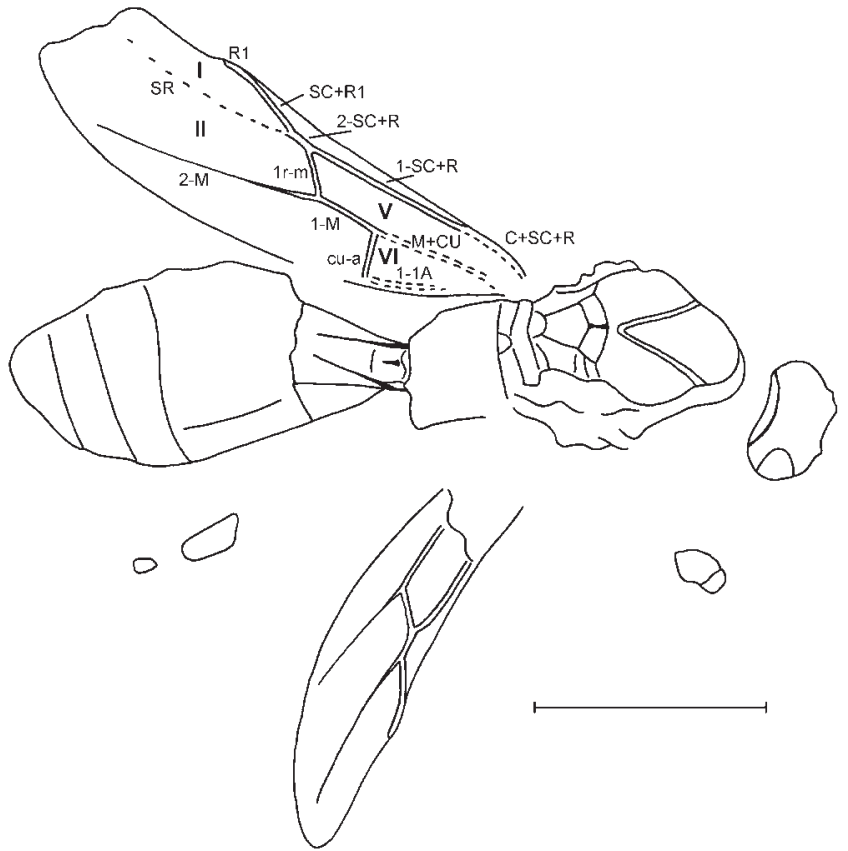

Text-figure 26 Eubazus ? brodiei sp. nov., holotype, NHMUK I.9239. Scale bars $=1 \mathrm{~mm}$.

Etymology. From flavus, the Latin for yellow, and pterostigma, referring to its colouration.

Holotype. NHMUK In.17244, Bembridge Marls, NW Isle of Wight, UK, Smith Collection; incomplete fossil showing head in dorsal view, with antennal bases, mesosoma in oblique dorsal-lateral view, and forewings, one lacking base and another without fore and distal parts.

Diagnosis. The present species differs distinctly from the all other fossil Eubazus in yellow coloration of pterostigma.

Description. Length of mesosoma $1.6 \mathrm{~mm}$, forewing 3.0 $\mathrm{mm}$. Head behind eyes rather strongly and roundly narrowed. Scapus thick, 1.4 times as long as wide, almost twice as long as pedicel. Mesosoma 1.5 times as long as maximum height. Mesoscutum highly and roundly elevated above pronotum. Notauli complete, very deep, wide anteriorly and narrow posteriorly. Prepectal carina distinct. Sternauli deep and wide medially, smooth, situated in anterior 0.8 of mesopleuron. Propodeum possibly without areolation. Forewing 2.6 times as long as maximum width. Pterostigma subtriangular, wide, 2.6 times as long as maximum width. 1-R1 1.25 times as long as pterostigma, 2-R1 distinct. Marginal cell weakly shortened, pointed apically, 2.6 times as long as maximum width; $r$ arising a little behind midlength of pterostigma, 0.7 times as long as maximum pterostigmal width. SR $1+3-\mathrm{SR}$ distinctly curved in basal $0 \cdot 3$, otherwise almost straight, $5 \cdot 8$ times as long as $\mathrm{r}, 3 \cdot 8$ times as long as 2-SR. 2-SR 1.5 times as long as r, 1.2 times as long as $\mathrm{m}-\mathrm{cu}$. $1-\mathrm{SR}+\mathrm{M}$ straight. Discal cell sessile anteriorly, 1.5 times as long as wide; $\mathrm{m}-\mathrm{cu}$ distinctly antefurcal; $\mathrm{cu}-\mathrm{a}$ postfurcal, distant from 1-M for half cu-a length. Subdiscal cell wide, closed antero-posteriorly by $\mathrm{CU} 1 \mathrm{~b}, 2.5$ times as long as wide. CU1a arising from posterior 0.25 of distal side of subdiscal cell. Colour: head and possibly mesosoma pale brown; wings faintly infuscate; pterostigma entirely yellow; veins brown.

Eubazus? grandareola Belokobylskij, sp. nov. Plate 10, fig. 2; Text-fig. 27B

Etymology. After grandis, the Latin for large, and areola, referring to the propodeum with large areola. 

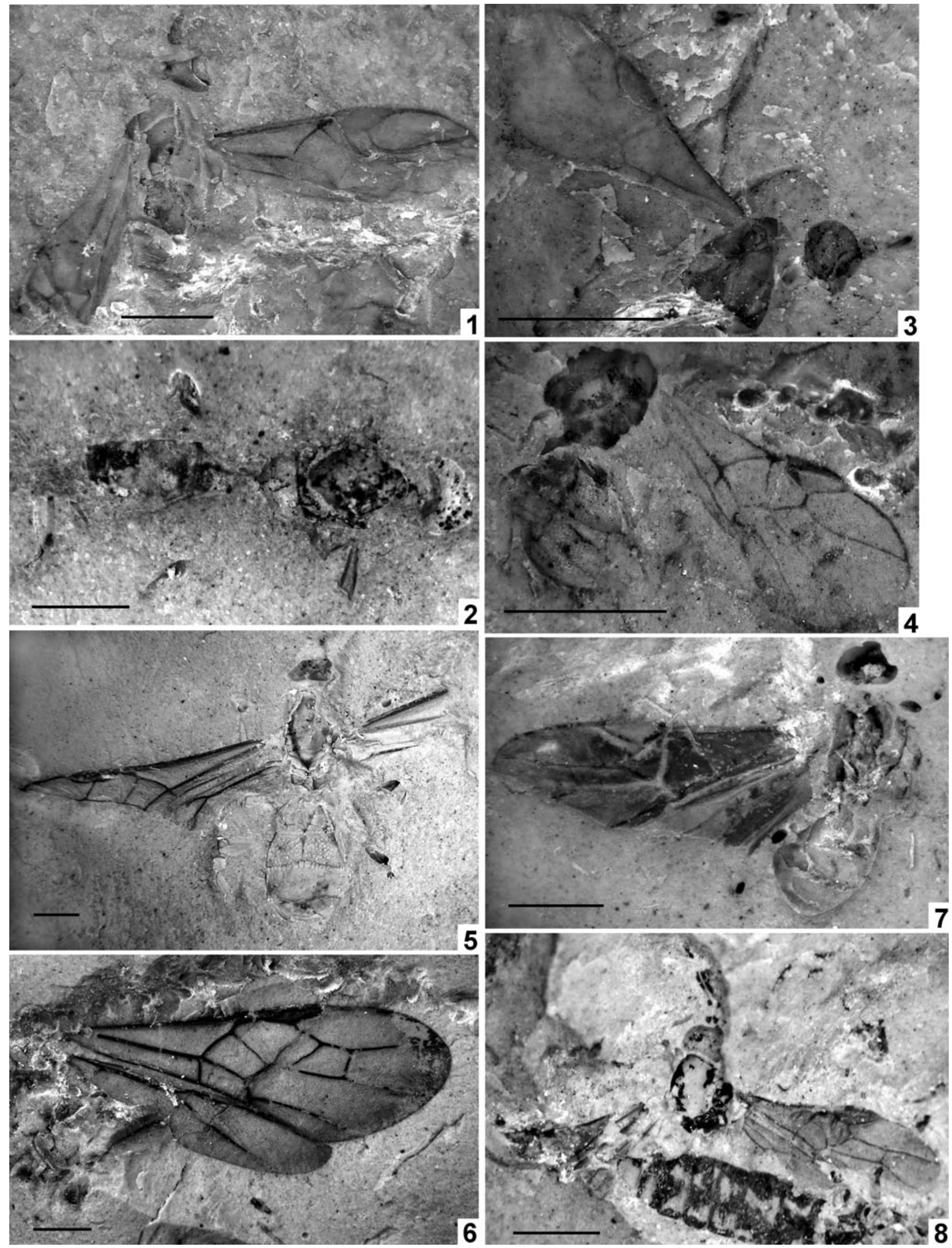

Plate 10 (1) Eubazus flavistigma sp. nov., holotype, NHMUK In.17244. (2) Eubazus ? grandareola sp. nov., holotype, NHMUK I.8754. (3) Eubazus ? hooleyi sp. nov., holotype, NHMUK In.24790. (4) Eubazus nanus sp. nov., holotype, NHMUK I.10108. (5) Bembracon acourtsmithi sp. nov., holotype, NHMUK In.17224. (6) Bembracon medialis sp. nov., holotype, NHMUK Pl II.2760. (7) Bracon brodiei sp. nov., holotype, NHMUK I.9351. (8) Bracon micrarche (Cockerell), holotype, NHMUK I.9026. Scale bars $=1 \mathrm{~mm}$. 

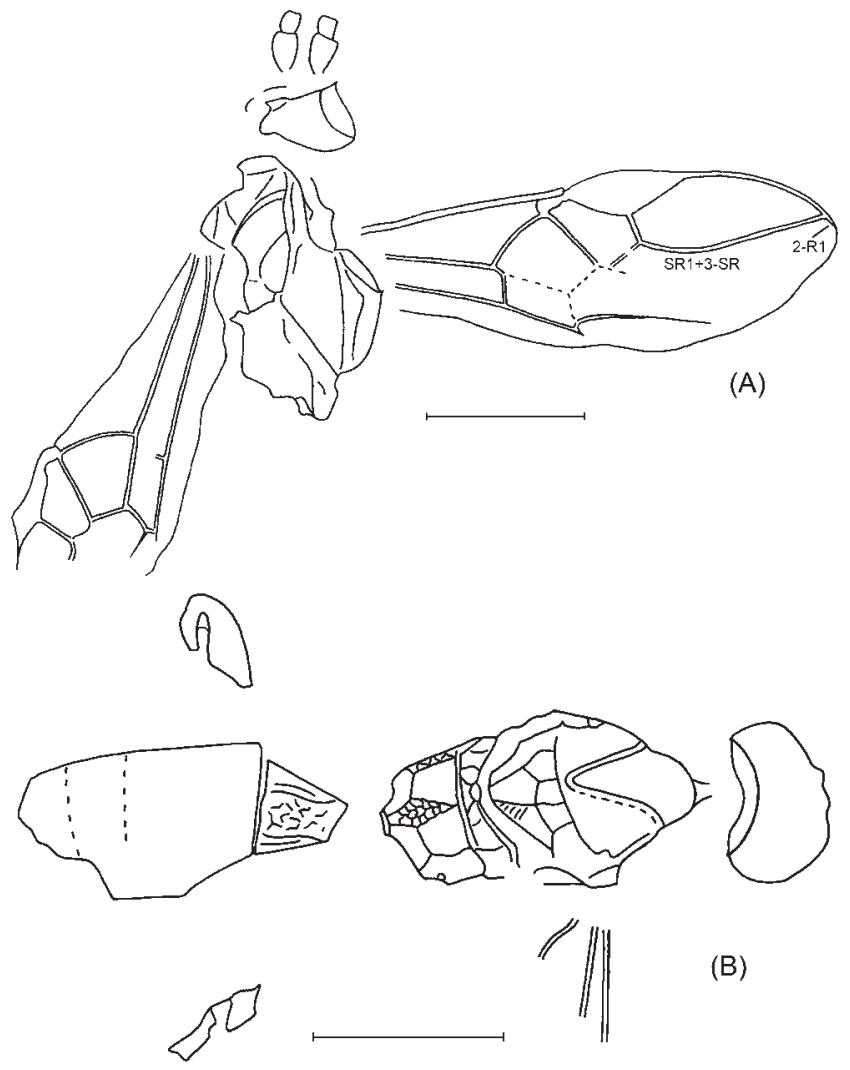

Text-figure 27 (A) Eubazus flavistigma sp. nov., holotype, NHMUK In.17244. (B) E. ? grandareola sp. nov., holotype, NHMUK I.8754. Scale bars $=1 \mathrm{~mm}$

Holotype. NHMUK I.8754, Bembridge Marls, NW Isle of Wight, UK, Brodie Collection; body in dorsoventral view, lacking antennae, wings, almost all legs, and rear part of metasoma.

Diagnosis. The present species is very similar to Charmon, but differs in presence of sternauli. It differs distinctly from the all other fossil Eubazus in its short temple and large propodeal areola.

Description. Length of body $4.5 \mathrm{~mm}$ (mesosoma $1.7 \mathrm{~mm}$, metasoma $1.7 \mathrm{~mm}$ ). Head transverse, about twice as wide as median length. Occipital carina dorsally complete. Mesosoma $2 \cdot 3$ times as long as maximum width. Mesoscutum 1.15 times as long as maximum width. Median lobe of mesoscutum distinctly protruding forwards and rounded anteriorly. Notauli complete, rather deep, more or less wide throughout, crenulated, fused shortly before prescutellar depression. Prescutellar depression wide, deep posteriorly, with high median carina, possibly weakly sculptured. Scutellum convex, without transverse posterior depression. Metanotum medial with two fine carinae weakly convergent posteriorly, and with high and rather large tubercle in posterior half. Propodeum long, possibly finely and irregularly rugose-reticulate at least in part, with distinct areolation, areola large, long subrhomboid, distinctly narrowed posteriorly, 2.6 times as long as maximum width, with very short basal carina; petiolar area short and semicircular, distinctly separated by carina from areola. Metasoma: First tergite relatively short, regularly and strongly widened towards apex, with high and weakly convergent dorsal carinae in basal half of tergite, with strongly convex and wide median area; length of tergite 0.9 times its apical width, apical width about 2.5 times its basal width. Second suture absent. Combined median length of second and third tergites 1.2 times basal width of second tergite and 0.9 times their maximum

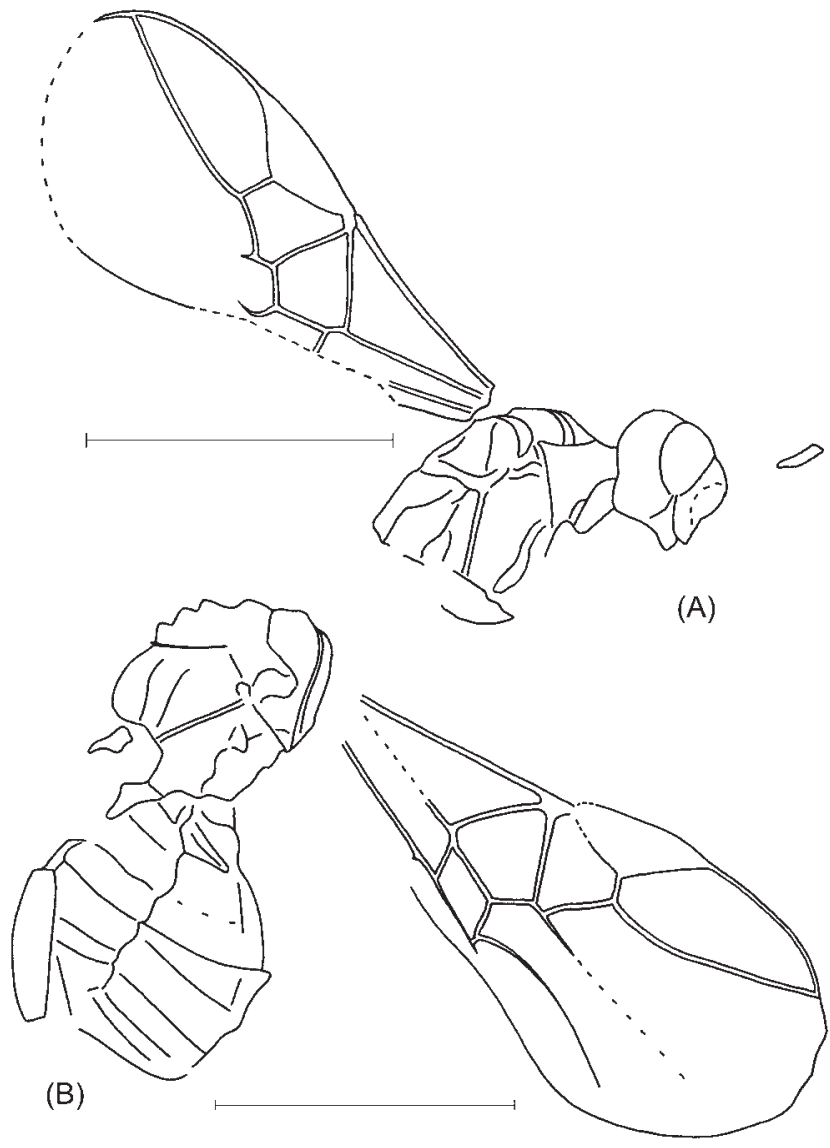

Text-figure 28 (A) Eubazus ? hooleyi sp. nov., holotype, NHMUK In.24790. (B) E. nanus sp. nov., holotype, NHMUK I.10108. Scale bars $=1 \mathrm{~mm}$.

width. Following segments distinctly protruding behind third one. Colour: head and mesosoma black; metasoma brown, dark brown posteriorly.

Remarks. Characteristic of the species is the propodeum, with its rather large and long areola which almost reaches the basal margin of the propodeum. In the absence of information about wing morphology, the species is tentatively attributed to Eubazus for the same reasons as E. brodiei sp. nov.

\section{Eubazus? hooleyi Belokobylskij, sp. nov.} Plate 10, fig. 3; Text-fig. 28A

Etymology. After R.W. Hooley, who compiled the collection including the holotype.

Holotype. NHMUK In.24790, Bembridge Marls, NW Isle of Wight, UK, Hooley Collection; head and incomplete mesosoma in side view, and one forewing lacking part of hind and apical margin.

Diagnosis. The main diagnostic characters of this species are long temple, deep and S-shaped sternauli, distinctly shortened marginal cell, and long 2-R1.

Description. Length of head $0.35 \mathrm{~mm}$, mesosoma $0.8 \mathrm{~mm}$, forewing $1.9 \mathrm{~mm}$. Head 1.2 time as high as long. Temple rather long, eye almost as long as temple. Occipital carina present at least laterally. Clypeus convex. Mesosoma high, 1.35 times as long as maximum height. Mesoscutum high, roundly elevated above pronotum. Notauli apparently present. Scutellum weakly convex. Subalar depression rather deep and narrow. Prepectal carina present. Sternauli deep, rather narrow, S-shaped, oblique, long, almost smooth. Forewing $2 \cdot 3$ times as long as wide. Pterostigma subtriangular, wide, $2 \cdot 8$ times as 

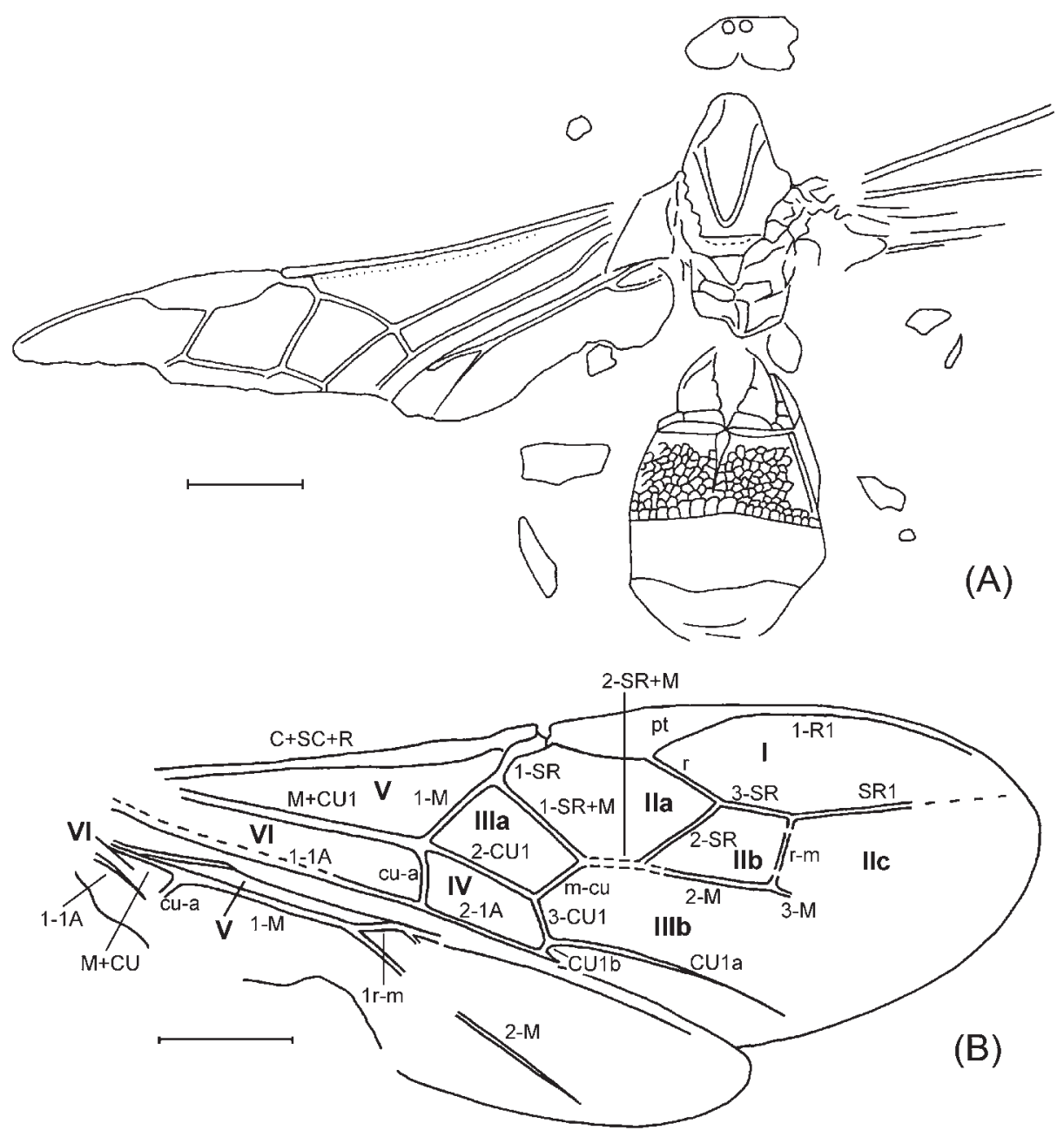

Text-figure 29 (A) Bembracon acourtsmithi sp. nov., holotype, NHMUK In.17224. (B) B. medialis sp. nov., holotype, NHMUK P 1.II2760. Cells: I = marginal; II = submarginal; III = discal; IV = subdiscal; V = basal; $\mathrm{VI}=$ sub basal; a, b, and c indicate first, second and third cell, respectively. Scale bars $=1 \mathrm{~mm}$.

long as maximum width, almost as long as 1-R1. Marginal cell distinctly shortened, $2 \cdot 7$ times as long as maximum width. 2$\mathrm{R} 1$ rather long; $\mathrm{r}$ arising from middle of pterostigma, $0 \cdot 6$ times as long as maximum pterostigmal width. SR1+3-SR weakly curved anteriorly and almost straight posteriorly, c. $6 \cdot 0$ times as long as r. 2-SR twice as long as r, 4.7 times as long as 2$\mathrm{SR}+\mathrm{M}, 1.6$ times as long as $\mathrm{m}-\mathrm{cu}$. $1-\mathrm{SR}+\mathrm{M}$ straight. Discal cell shortly sessile anteriorly, almost as long as wide; $\mathrm{cu}-\mathrm{a}$ postfurcal, distant of 1-M for 0.6 times cu-a length. Colour: head black; wings hyaline; pterostigma (possibly) and veins brown.

Remarks. Wing venation, particularly the shape of SR1+3$\mathrm{SR}$, and presence of sternauli and notauli, suggest attribution of the species to subfamily Brachistinae. The absence of the metasoma does not permit certain identification to genus, so I ascribe it tentatively to Eubazus.

Eubazus nanus Belokobylskij, sp. nov. Plate 10, fig. 4; Text-fig. 28B

Etymology. After nanus, the Greek for dwarf, referring to the very small body size.

Holotype. NHMUK I.10108, Bembridge Marls, NW Isle of Wight, UK, Brodie Collection; meso- and metasoma in side view with hind femur and one forewing.
Diagnosis. The main diagnostic characters of this new taxon are sternauli shallow, propodeum without delineated areas, forewing short, discal cell narrow, and marginal cell shortened.

Description. Length of metasoma $0.9 \mathrm{~mm}$, forewing 1.9 mm. Mesosoma c. 1.2 times as long as maximum height. Mesoscutum highly and roundly elevated above pronotum. Notauli complete, deep and rather narrow in anterior 0.7 , deeper and rather wide in posterior $0 \cdot 3$, fused just before prescutellar depression. Prescutellar depression rather wide, deep, finely sculptured at least partly, with distinct median keel. Prepectal carina present laterally, possibly very fine ventrally. Sternauli very shallow, wide, almost smooth, situated along almost whole length of lower part of mesopleuron. Metapleural suture distinctly and shortly crenulated. Propodeum short, almost not narrow in anterior $0 \cdot 3$ (lateral view) and strongly and almost linearly abrupted in posterior 0.7 , without marginal areas, almost entirely and rather finely rugosereticulate. Forewing 2.2 times as long as maximum width. Pterostigma subtriangular, wide, 2.5 times as long as maximum width. 1-R1 1.1 times as long as pterostigma; 2-R1 short. Marginal cell shortened, pointed apically, $2 \cdot 8$ times as long as maximum width; $r$ arising almost from middle of pterostigma, 0.45 times as long as maximum pterostigmal width. SR $1+3-$ SR weakly and evenly curved in basal 0.5 and weakly Sshaped in apical $0 \cdot 5,8 \cdot 3$ times as long as $\mathrm{r}, 3 \cdot 5$ times as long 
as 2-SR. 2-SR 2.4 times as long as $\mathrm{r}, 1.35$ times as long as $\mathrm{m}-\mathrm{cu}$. 1-SR $+\mathrm{M}$ almost straight. Discal cell shortly sessile anteriorly, $1 \cdot 1$ times as long as wide; $\mathrm{m}-\mathrm{cu}$ distinctly antefurcal, $3 \cdot 3$ times as long as 2-SR+M; cu-a postfurcal, distant from 1-M for half $\mathrm{cu}-\mathrm{a}$ length. Subdiscal cell wide, closed anteroposteriorly by CU1b, 2.4 times as long as wide. CU1a arising from posterior 0.25 of distal side of subdiscal cell. a present and unsclerotised. Hind femur about 4.0 times as long as maximum width. Metasoma not forming carapace, tergites rather soft, apical segments distinctly protruding behind third tergite. Second suture very fine. Second tergite almost as long as third tergite. Colour: mesosoma and possibly metasoma almost entirely dark brown; wing hyaline; entire pterostigma and veins brown.

Remarks. The position of this species in the genus Eubazus is clear from the venation of the forewing, the mesosoma with prepectal carina and sternauli, and the structure of the metasoma. The new species is very similar to $E$. crassicornis (Brues) described from Baltic amber (Brues 1933) and redescribed by Achterberg (1982) in having the widely sessile discal cell of the forewing, the short first metasomal tergite and the wide hind femur. Unfortunately, the supporting characters of the fossil are not numerous, which hinders the comparison of the taxa, but E. nanus sp. nov. possibly differs in having the subdiscal cell wide and short, 2-SR long, first and second metasomal tergites short, and forewing short. E. nanus sp. nov. differs from $E$. hooleyi sp. nov. in having the discal cell short and narrow sessile anteriorly, 3-SR mostly straight, pterostigma and sternauli narrow; from E. flavistigma sp. nov. in having pterostigma dark colourated, discal cell narrow and widely sessile, and $r$ short.

3.9.3. Subfamily Braconinae Nees, 1812. The subfamily Braconinae is one of the largest and most diverse groups of idiobiont braconids, with numerous extant genera described from tropical and subtropical regions (Quicke 1987). Used for designation of these genera, the special characters of antennae, mesosomal and metasomal tergites are usually not visible in rock fossils. This presents problems in the identification of the taxonomic position of these fossils.

Only a few Cenozoic Braconinae have been described so far. Their generic names have changed with time; I prefer to include the majority of described taxa, especially those described by old authors, to the polymorphic genus Bracon used in the broad sense, until future revisions have been undertaken. These are Bracon cockerelli Brues, 1910 (Florissant, USA), B. diffusiventre Théobald, 1937 (Oligocene of Kleinkembs, Germany), B. laceolatus Zhang, 1989 (Miocene of Shangwang, China), B. macrostigma Heyden, 1858 (Oligocene of Sieblos, Germany), B. praeteritus Foerster, 1891 (Oligocene of Brunstatt, Germany), B. rottensis Meunier, 1915 (Rott, Germany), possibly also B. abstractus Brues, 1910 and B. resurrectus Brues, 1910 from Florisant, as well as B. micrarche (Cockerell, 1921), comb. nov., from the Bembridge Marls. The status of Bracon laminarium Scudder, 1878 from Green River (USA) is unclear and perhaps it does not belong to the Braconidae (A. P. Rasnitsyn, pers. comm. 2006). According to the figure, Bracon pallidus Heer, 1867 is not of the subfamily Braconinae, but its correct taxonomic position is obscure and requires restudy of the type. Unfortunately, most of the aforementioned species of this genus described in the 19th or beginning of the 20 th centuries have no distinct descriptions with correct modern diagnostic features, and it is quite possible some of these species belong to other genera or subfamilies. There is only one braconine species described from a rock fossil that can be identified with greater confidence, Ipobracon vectensis Cockerell, 1921a, apparently belonging to the genus Cyanopterus (see below).
Worth mentioning is that all Bembridge Marls Braconinae, except those attributed to a new genus, have distinctly curved $1-\mathrm{SR}+\mathrm{M}$.

Genus Bembracon Belokobylskij, gen. nov.

Etymology. After Bembridge and genus Bracon. Gender masculine.

Type species. Bembracon acourtsmithi sp. nov., by present designation.

Diagnosis. Differs from extant genera in the combination of the following characters: notauli distinct and complete; prescutellar depression wide and deep; first tergite with median area distinctly and acutely narrowed towards apex; and with apico-lateral transverse areas delineated by carina.

Description. Head with antennal sockets separated by only half their diameter. Mesoscutum long, with notauli distinct, complete and anteriorly deep. Prescutellar depression wide, oblique anteriorly, almost vertical posteriorly. Pterostigma rather narrow; $r$ arising from middle of pterostigma; $r-m$ present. Discal cell distinctly petiolate anteriorly; cu-a interstitial or a little antefurcal; $\mathrm{m}-\mathrm{cu}$ distinctly antefurcal. Second submarginal cell short and wide. Subdiscal cell closed by CU1b in posteriodistal corner. Hind wing with basal cell very narrow and sub basal cell very small. First metasomal tergite with median area wide, pointedly narrowed posteriorly, and with two apicolateral transverse areas delineated by carinae. Second tergite moveably connected with first tergite, with very narrow and long triangle median area following to second suture. Second suture deep and wide, coarsely crenulated.

Remarks. The genus is tentatively included in the subfamily Braconinae, because the studied fossils present no information about the occipital and prepectal carinae. At the same time, the new genus shows unique characters, unknown for Braconinae, in the structure of the first metasomal tergite, which has a pointedly narrowed posterior median area and delimited apico-lateral transverse areas. These characters, taken together with the distinct and complete notauli and deep and the wide prescutellar depression, might allow proposing a separate tribe or even subfamily for the new genus. However, this seems premature until more information is accumulated for this interesting group.

\section{Bembracon acourtsmithi Belokobylskij, sp. nov. Plate 10, fig. 5; Text-fig. 29A}

Etymology. After the collector's name.

Holotype. NHMUK In.17224, Bembridge Marls, NW Isle of Wight, UK, Smith Collection; head (damaged) and body in dorsal aspect with incomplete wings (missing hind and apical areas) and small leg fragments.

Diagnosis. Differs from the second species of this genus, $B$. medialis sp. nov., in having $\mathrm{R}$ and particularly $2-\mathrm{SR}+\mathrm{M}$ short, and 1-SR short.

Description. Length of metasoma $2.7 \mathrm{~mm}$. Mesosoma: Mesoscutum long, 1.4 times as long as maximum width. Notauli present, complete, shallow. Prescutellar depression almost smooth. Propodeum smooth, possibly with complete high longitudinal keel. Forewing: pterostigma oval triangular, c.4.0 times as long as maximum width; $r$ arising from middle of pterostigma and distinctly oblique in respect to it, 1.6 times as long as maximum pterostigmal width, 0.65 times as long as 2-SR. 1-SR $+\mathrm{M}$ almost straight; $\mathrm{m}-\mathrm{cu} 0.7$ times as long as 2-SR, 0.6 times as long as $1-\mathrm{SR}+\mathrm{M}$ and $1-\mathrm{M}$. Discal cell 1.7 times as long as wide. 1-M about 5.0 times as long as 1-SR; $\mathrm{m}-\mathrm{cu}$ distinctly antefurcal. Subdiscal cell wide. Hind wing: 

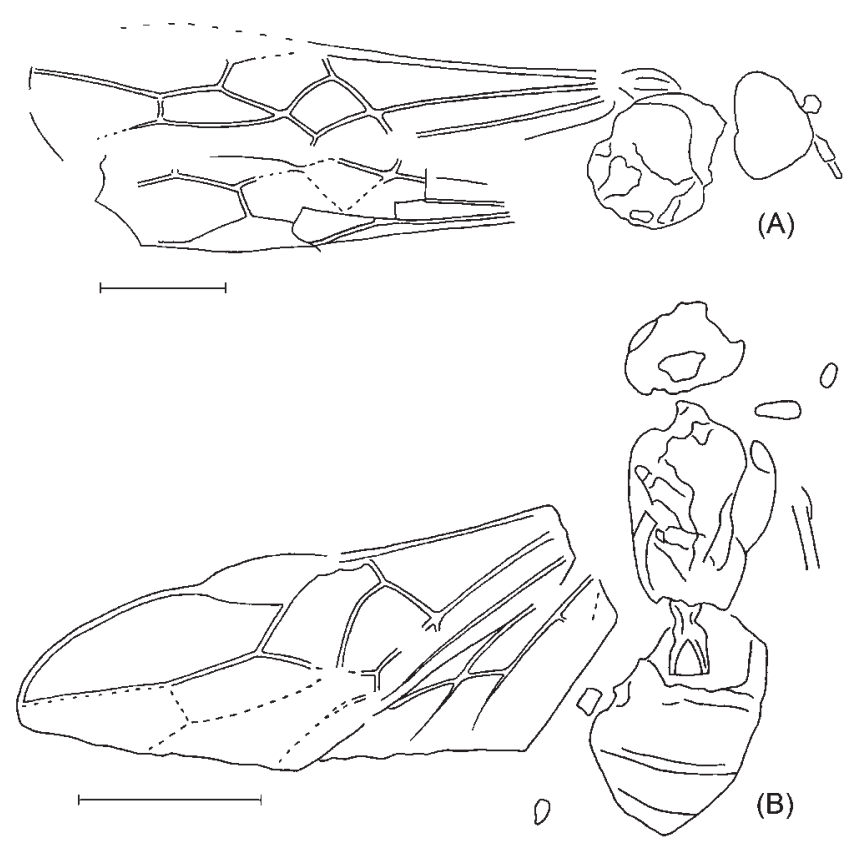

Text-figure 30 (A) Bracon ? antefurcalis sp. nov., holotype, NHMUK I.9061. (B) B. brodiei sp. nov., holotype, NHMUK I. 9351. Scale bars $=1 \mathrm{~mm}$

$\mathrm{m}-\mathrm{cu}$ absent. Basal cell subparallel-sided. $\mathrm{M}+\mathrm{CU} 0.4$ times as long as 1-M. Legs: hind femur wide. Metasoma 1.65 times as long as maximum width. First tergite wide, 0.75 times as long as wide apically, with median area subtriangular (2.4 times as long as maximum width), smooth except narrowly areolate laterally. Second tergite almost entirely rather densely and subroundly areolate; median length of tergite (without suture) 0.5 times its basal width, 0.8 times length of third tergite. Second suture rather narrow laterally and wide medially, weakly curved. Third tergite entirely smooth. Posterior tergites shortly protruding behind third one. Colour: wings entirely infuscate; pterostigma and veins black.

Bembracon medialis Belokobylskij, sp. nov. Plate 10, fig. 6; Text-fig. 29B

Etymology. After medial vein, which is distinctive in the length of its 2-SR $+\mathrm{M}$.

Holotype. Pl II2760a, b (part and counterpart), north end of Thorness Bay. Collected by R. Szadziewski, 23/05/05; joined fore and hind wings.

Diagnosis. Differs from the type species in having $\mathrm{r}$ and particularly 2-SR $+\mathrm{M}$ long, 1-SR long, and the discal cell less widened basally.

Description. Length of forewing $7.3 \mathrm{~mm}$, hind wing $5.2 \mathrm{~mm}$. Forewing length 2.7 times its maximum width. Pterostigma narrow, oval-triangular, $4 \cdot 3$ times as long as maximum width; $\mathrm{r}$ arising weakly before middle of pterostigma and distinctly oblique in respect to it, 1.85 times as long as maximum pterostigmal width, 0.9 times as long as 2-SR. Marginal cell not shortened; 1-R1 1.25 times as long as pterostigma. 3-SR 0.85 times as long as $\mathrm{r}, 0.3$ times as long as SR $1,0.75$ times as long as 2-SR, 1.1 times as long as $\mathrm{r}-\mathrm{m}$. 2-SR 1.45 times as long as $\mathrm{r}-\mathrm{m}$; latter with two bullae. Second submarginal cell short, 1.8 times as long as maximum width, almost as long as discal cell. 1-SR $+\mathrm{M}$ straight. 2-SR+M long, 0.6 times as long as 2-SR, 0.9 times as long as $\mathrm{m}-\mathrm{cu} ; \mathrm{m}-\mathrm{cu} 0.7$ times as long as 2-SR, 0.5 times as long as $1-\mathrm{SR}+\mathrm{M}$ and 0.7 times as long as 1-M. Discal cell 1.85 times as long as wide. 1-M c. 3.0 times as long as 1-SR; $\mathrm{m}$-cu strongly antefurcal; cu-a very weakly antefurcal. Subdiscal cell wide, 2.5 times as long as wide. Hind wing: $\mathrm{m}-\mathrm{cu}$ absent. Basal cell very narrow and subparallel-sided. $\mathrm{M}+\mathrm{CU} 0.45$ times as long as 1-M.

Genus Bracon Fabricius, 1804

Bracon? antefurcalis Belokobylskij, sp. nov. Plate 9, fig. 3; Text-fig. 30A

Etymology. After the antefurcal position of the forewing $\mathrm{cu}-\mathrm{a}$.

Holotype. NHMUK I.9061, Bembridge Marls, NW Isle of Wight, UK, Brodie Collection; poorly preserved head with scape and pedicel and partial mesosoma in lateral view, two damaged forewings and badly damaged hind wing.

Description. Length of head $0.6 \mathrm{~mm}$, of forewing $4.6 \mathrm{~mm}$. Head 1.3 times as high as long. Face rather convex and short. Hypoclypeal cavity rather large. Occipital carina absent. Antenna: scape rather wide and short; pedicel possibly very short. Mesosoma possibly with prepectal carina absent. Forewing: pterostigma subtriangular, rather narrow, 3.8 times as long as maximum width. Marginal cell not shortened, pointed apically, almost 3.0 times as long as maximum width. 1-R 1 c. $1 \cdot 2$ times as long as pterostigma; $r$ arising almost from middle of pterostigma, 0.9 times as long as maximum pterostigmal width, forming distinct obtuse angle with 3-SR. 3-SR twice as long as $\mathrm{r}, 0.5$ times as long as the almost straight SR 1, almost as long as 2-SR; $\mathrm{r}-\mathrm{m}$ present and distinct, 0.35 times as long as 2-SR. Second submarginal cell 3.2 times as long as width, about 1.8 times as long as subdiscal cell. $1-\mathrm{SR}+\mathrm{M}$ straight basally, curved in apical half; $\mathrm{m}-\mathrm{cu}$ distinctly antefurcal, $3 \cdot 7$ times as long as 2-SR $+\mathrm{M}, 0.6$ times as long as 2-SR. Discal cell long petiolate anteriorly, 1.8 times as long as width. 1-SR almost 0.5 times as long as $1-\mathrm{M}$; cu-a distinctly antefurcal, distant from 1-M for 0.35 times cu-a length. Subdiscal cell wide. Hind wing with sub basal cell short, $\mathrm{m}-\mathrm{cu}$ possibly absent. Colour: head possibly brown; mesosoma brown; wings almost hyaline; pterostigma brown, veins dark brown.

Remarks. I tentatively include this new species in the genus Bracon until additional information about its morphology is known. The most important characters of this taxon are the distinctly antefurcal position of $\mathrm{cu}-\mathrm{a}$, the equal lengths of 3SR and 2-SR, the relatively narrow pterostigma and the second submarginal cell. Antefurcal position of $\mathrm{cu}-\mathrm{a}$ is known for braconine species of the genus Euurobracon Ashmead, 1900, but the new species distinctly differs from Euurobracon, besides its small body size, in the different shape and large size of the second submarginal cell.

\section{Bracon brodiei Belokobylskij, sp. nov. Plate 10, fig. 7; Text-fig. 30B}

Etymology. After P.B. Brodie who compiled the collection which includes the holotype.

Holotype. NHMUK I.9351, Bembridge Marls, NW Isle of Wight, UK, Brodie Collection; dorsal aspect of poorly preserved head and mesosoma and better preserved metasoma, incomplete wings (lacking base and posteroapical area) and leg fragments.

Diagnosis. Very similar to B. micrarche (Cockerell, 1921), but differs in having $\mathrm{r}$ and the second submarginal cell long, and the 1-SR short. Additional material is necessary to decide if the above difference is really of specific importance.

Description. Length of body $c .3 \cdot 0 \mathrm{~mm}$, mesosoma $c .1 \cdot 1$ $\mathrm{mm}$, forewing $3.2 \mathrm{~mm}$. Head more or less transverse, distinctly and convex-roundly narrowed behind eyes. Antennal 


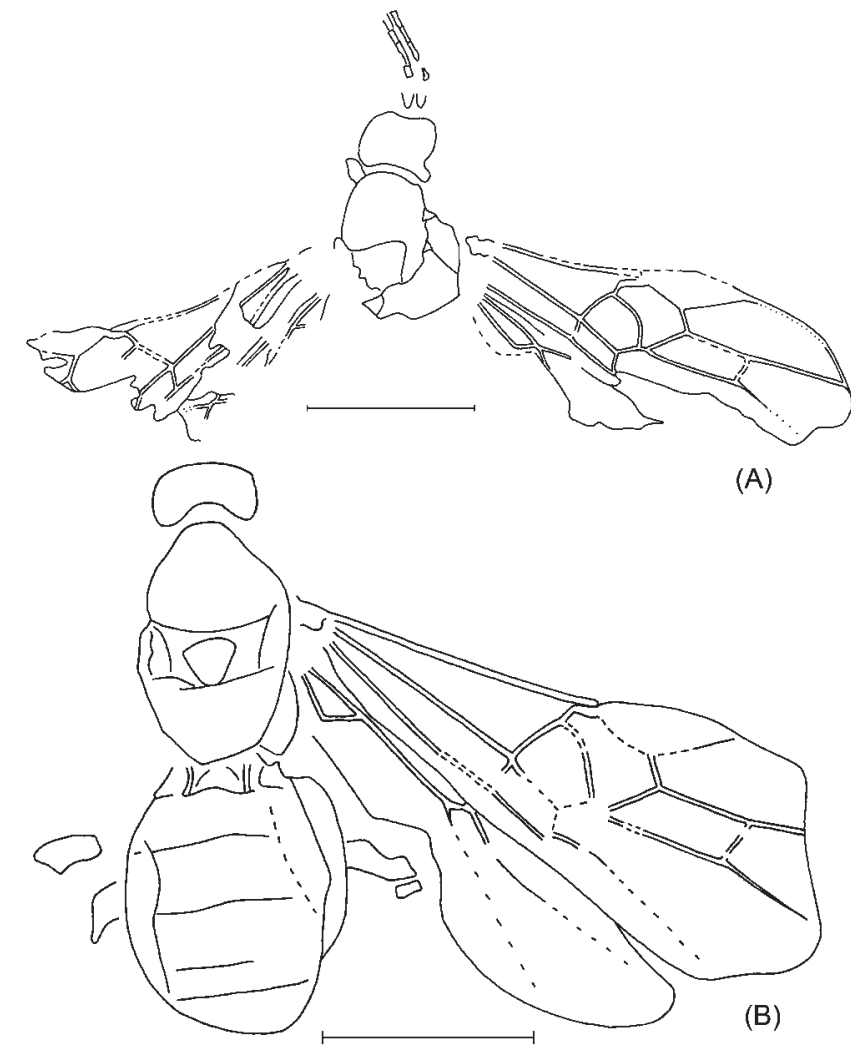

Text-figure 31 Bracon micrarche (Cockerell): (A) holotype NHMUK I.9026/I.9760; (B) NHMUK I.9182. Scale bars = $1 \mathrm{~mm}$.

sockets large, separated for almost their diameters and c.1.8 times distance between socket and eye. Transverse diameter of eye 1.6 times length of temple. Ocelli weakly enlarged. Mesosoma 1.4 times as long as maximum width. Forewing $2 \cdot 8$ times as long as maximum width. Pterostigma subtriangular, wide, 2.8 times as long as maximum width. 1-R 11.4 times as long as pterostigma; $\mathrm{r}$ arising from basal 0.4 of pterostigma and oblique in respect to it, almost as long as maximum pterostigmal width. Marginal cell not shortened, pointed apically, $3 \cdot 4$ times as long as maximum width. 3-SR about twice as long as $\mathrm{r}, 0.75$ times as long as SR $1,1.5$ times as long as 2$\mathrm{SR} ; \mathrm{r}-\mathrm{m}$ possibly sclerotised medially and with two short bullae subanteriorly and subposteriorly, 0.6 times as long as 2-SR. Second submarginal cell long, 3.4 times as long as wide, 1.7 times as long as subdiscal cell. $1-\mathrm{SR}+\mathrm{M}$ strongly curved in basal half and almost straight in apical half; $\mathrm{m}-\mathrm{cu}$ antefurcal, 0.6 times as long as 2-SR, 0.9 times as long as $r$, 0.3 times as long as 2-M. Discal cell distinctly petiolate anterior, 1.6 times as long as wide. 1-M almost 3.0 times as long as 1-SR; cu-a interstitial. Subdiscal cell rather wide, closed antero-posteriorly by $\mathrm{CU} 1 \mathrm{~b}, 3 \cdot 0$ times as long as wide. CU1a arising from posterior 0.3 of distal side of subdiscal cell. Hind wing: SR arising from $2-\mathrm{SC}+\mathrm{R}$ very closely to $1 \mathrm{r}-\mathrm{m}$. Basal cell weakly widened anteriorly. Marginal cell widened in basal half. Sub basal cell short; M+CU 0.6 times as long as 1-M. Metasoma: first tergite rather long and more or less narrow, its length about 1.3 times apical width, with distinct convex basal area separated by rather deep lateral furrows, moveably connected with second tergite. Colour: head and mesosoma black; metasoma light reddish brown; wings distinctly infuscate, paler distally; pterostigma and veins dark brown.

Bracon micrarche (Cockerell, 1921), comb. nov. Plates 10, fig. 8, 11, fig. 1; Text-fig. 31
Holotype. NHMUK I.9026/I.9760 (part and counterpart), Bembridge Marls, NW Isle of Wight, UK, Brodie Collection; dorso-ventral view of head with incomplete antennae and damaged mesosoma, and damaged wings.

Other material. NHMUK I.9182, Bembridge Marls, NW Isle of Wight, UK, Brodie Collection; sublateral view of head and dorso-ventral aspect of body lacking appendages except slightly incomplete fore and hind wings and leg fragments.

Diagnosis. Characteristic of this species is the distinctly curved 1-SR $+\mathrm{M}$. This species differs from B. cockerelli Brues, 1910 from Florissant in having the wings less strongly infuscate, 3-SR and second submarginal cell longer, and $\mathrm{m}-\mathrm{cu}$ distinctly antefurcal.

Description of holotype. Length of mesosoma $c .0 .8 \mathrm{~mm}$, forewing $2.4 \mathrm{~mm}$. Head 1.3 times as high as maximum length. Occipital carina absent. Scape short and rather thick, 1.3 times as long as wide. Sub-basal segments $2 \cdot 8-3 \cdot 0$ times as long as wide. Mesosoma: notauli absent. Prescutellar depression narrow. Scutellum wide, its width 1.2 times median length. Propodeum entirely smooth. Forewing $c .3 \cdot 0$ times as long as maximum width. Pterostigma subtriangular, rather wide, 2.8 times as long as maximum width. $1-\mathrm{R} 11 \cdot 3$ times as long as pterostigma; $r$ arising distinctly before middle of pterostigma (interior distance between parastigma and $\mathrm{r} 0.7$ times interior distance between $\mathrm{r}$ and apex of pterostigma), distinctly oblique in respect to pterostigma, 0.6 times as long as maximum pterostigmal width. Marginal cell not shortened, pointed apically, 3.0 times as long as maximum width. 3-SR $3 \cdot 2$ times as long as $\mathrm{r}, 0.75$ times as long as the almost straight SR 1, 1.5 times as long as 2-SR; $\mathrm{r}-\mathrm{m}$ sclerotised, with two short bullae subanteriorly and subposteriorly, 0.6 times as long as 2-SR. Second submarginal cell long, about 3.0 times as long as wide, about twice as long as rather wide subdiscal cell. 1$\mathrm{SR}+\mathrm{M}$ more or less distinctly and rather strongly and evenly curved; $\mathrm{m}-\mathrm{cu}$ antefurcal, 0.5 times as long as $2-\mathrm{SR}, 0.2$ times as long as $2-\mathrm{M}$. Discal cell distinctly petiolate anteriorly, 1.6 times as long as wide. 1-M about 2.5 times as long as 1-SR; $\mathrm{cu}-\mathrm{a}$ almost interstitial. Subdiscal cell rather wide, closed antero-posteriorly by $\mathrm{CU} 1 \mathrm{~b}, c$. 3.0 times as long as wide. CU1a arising from posterior $0 \cdot 3$ of distal side of subdiscal cell. Hind wing: $\mathrm{m}-\mathrm{cu}$ absent. Basal cell widened anteriorly. Marginal cell widened in basal $0 \cdot 3$, then weakly narrowed. Colour: head, antennae and mesosoma black; wings distinctly infuscate, paler distally; pterostigma entirely brown; veins brown.

Non-type specimen. Generally similar to holotype, but differs in the following characters. Length of mesosoma $c .1 \cdot 1$ $\mathrm{mm}$, metasoma $1.2 \mathrm{~mm}$, forewing c. $2.8 \mathrm{~mm}$. Mesosoma 1.6 times as long as maximum width. Mesoscutum 0.85 times as long as maximum width. Notauli absent. Width of scutellum 1.3 times its median length. Forewing $c .2 \cdot 5$ times as long as maximum width as preserved. Pterostigma 2.7 times as long as maximum width. 3-SR 2.9 times as long as $\mathrm{r}, 1.6$ times as long as 2-SR; $\mathrm{r}-\mathrm{m} 0.7$ times as long as 2-SR. Second submarginal cell 1.8 times as long as subdiscal cell. $1-\mathrm{SR}+\mathrm{M}$ rather strongly curved in basal half and almost straight in apical half; $\mathrm{m}-\mathrm{cu} 0.25$ times as long as 2-M. Discal cell 1.4 times as long as width. Subdiscal cell 2.8 times as long as wide. In hind wing, sub basal cell short, $\mathrm{M}+\mathrm{CU} 0.6$ times as long as 1-M. Metasoma c. 1.5 times as long as wide. First tergite incompletely preserved, with median area distinct at least basally, moveably connected with second tergite. Second suture more or less distinct. Second tergite medially as long as third tergite. Metasoma light reddish brown.

Genus Cyanopterus Haliday, 1835

Cyanopterus vectensis (Cockerell, 1921), comb. nov. Plate 11, fig. 2; Text-fig. 32 


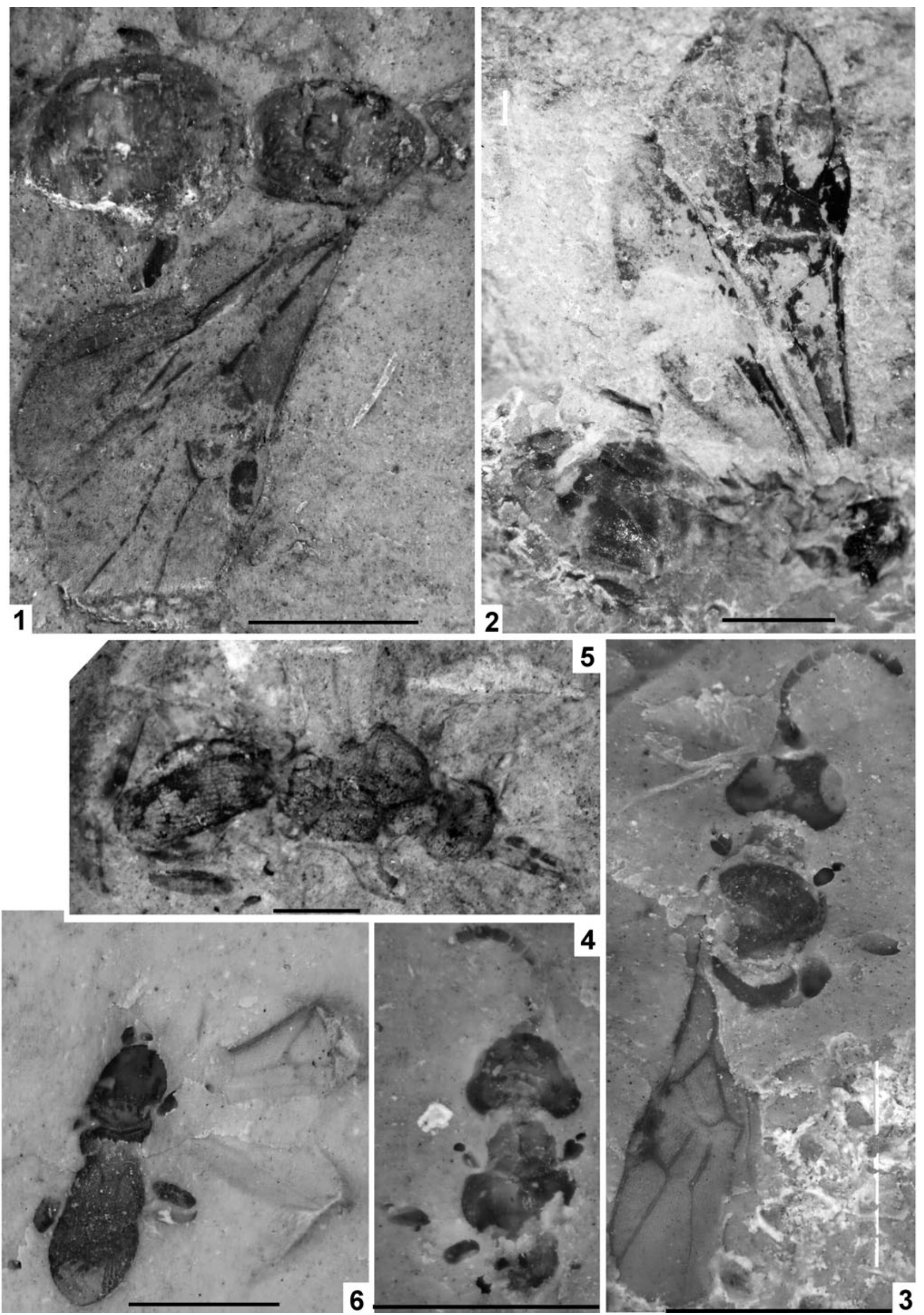

Plate 11 (1) Bracon micrarche (Cockerell), NHMUK I.9182. (2) Cyanopterus vectensis (Cockerell), holotype, NHMUK I.9415. (3-4) Ascogaster (Ascogaster) pygmaea sp. nov., holotype, NHMUK In.17379: (3) part;

(4) counterpart. (5) Ascogaster (Syntaphus) wheeleri (Donisthorpe), holotype, NHMUK I.8744. (6) Ascogaster (Ascogaster) brodiei sp. nov., holotype, NHMUK I. 9924. Scale bars $=1 \mathrm{~mm}$. 


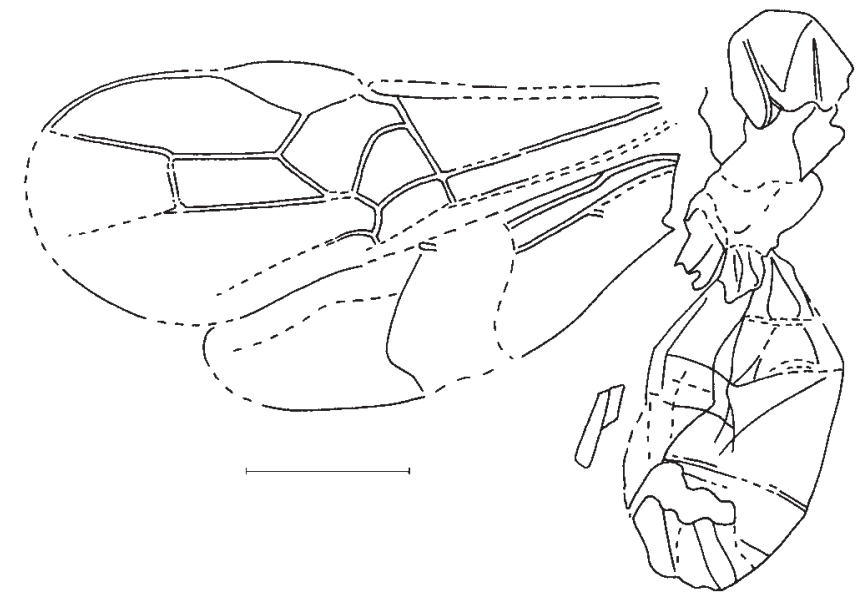

Text-figure 32 Cyanopterus vectensis (Cockerell), holotype NHMUK I.9415. Scale bar $=1 \mathrm{~mm}$.

Holotype. NHMUK I.9415, Bembridge Marls, NW Isle of Wight, UK, Brodie Collection; headless body in sublateral view with incomplete wings.

Diagnosis. Differs from extant species in the strongly curved $1-\mathrm{SR}+\mathrm{M}$ in the forewing.

Description. Length of mesosoma $1.4 \mathrm{~mm}$, metasoma $2 \cdot 0$ $\mathrm{mm}$, forewing $3.9 \mathrm{~mm}$. Mesosoma: mesoscutum possible finely and densely punctulate with very fine granulation on median lobe, with distinct, not deep, narrow notauli, fused posteriorly. Propodeum smooth throughout. Forewing 2.4 times as long as maximum width. Pterostigma subtriangular, wide, 2.7 times as long as maximum width. 1-R1 1.3 times as long as pterostigma; $\mathrm{r}$ arising distinctly before middle of pterostigma, distinctly oblique in respect to it, 0.9 times as long as maximum pterostigmal width. Marginal cell very weakly shortened, pointed apically, $3 \cdot 1$ times as long as maximum width. 3-SR 2.3 times as long as $\mathrm{r}, 0.9$ times as long as the straight SR 1, 1.4 times as long as 2-SR; $r-m$ sclerotised, possibly with two short bullae subanteriorly and subposteriorly, 0.7 times as long as 2-SR. Second submarginal cell long, $3 \cdot 3$ times as long as wide, about twice as long as subdiscal cell. 1-SR $+\mathrm{M}$ strongly and somewhat irregularly curved. 2-SR $+\mathrm{M}$ about 0.8 times as long as $\mathrm{m}-\mathrm{cu}, 0.2$ times as long as 2-M. M-cu 0.4 times as long as 2$\mathrm{SR}, 0 \cdot 2$ times as long as $2-\mathrm{M}$. Discal cell distinctly petiolate anteriorly, 1.45 times as long as wide. 1-M 2.5 times as long as $1-\mathrm{SR}$; $\mathrm{m}-\mathrm{cu}$ weakly antefurcal; cu-a interstitial. Subdiscal cell rather wide, closed antero-posteriorly by CU1b, 2.4 times as long as wide. CU1a arising from posterior 0.3 of subdiscal cell; 3-CU1 distinctly curved. In hind wing, sub basal cell weakly widened anteriorly; marginal cell weakly narrowed submedially. Metasoma: first tergite with distinctly subtriangular median area delineated by rather deep furrows. Second tergite with rather distinct lateral furrows, oblique and divergent posteriorly. Second suture present. Colour: mesosoma black; metasoma pale brown; wings distinctly infuscate; entire pterostigma and veins dark brown.

Remarks. This species belongs to Cyanopterus (senior synonym of Ipobracon Thomson, 1892) based on the presence of relatively distinct lateral divergent furrows on the second tergite combined with the absence of the median subtriangular area.

3.9.4. Subfamily Cheloninae Foerster, 1862. The subfamily Cheloninae is one of the most specialised groups within the microgasteroid phylogenetic branch of Braconidae. The members of this subfamily are easily recognised by the coarsely sclerotised and immoveably fused three anterior metasomal tergites, together with some features of forewing venation (such as $r-m$ present, marginal cell usually shortened, $\mathrm{r}$ often arising from the anterior third of pterostigma, $\mathrm{m}-\mathrm{cu}$ usually postfurcal, 3SR often short), basically reticulate-areolate sculpture of mesosoma and the presence of a postpectal carina.

The chelonine wasps are common as fossils, particularly as inclusions in the Eocene Baltic amber (Brues 1933; Tobias 1987). It is noteworthy that they mainly belong to the genus Ascogaster, one of the less derived groups in the subfamily (A. adentata Tobias, 1987, A. dilatata Brues, 1933, A. gracilicornis Brues, 1933, A. longicauda Tobias, 1987, A. pentagona Brues, 1933, A. pinicola Brues, 1933, A. praevolans Brues, 1933, A. robusta Brues, 1933, A. rutilipes Tobias, 1987, A. submersa Brues, 1933, A. sylvestris Brues, 1933, and A. thoracica Tobias, 1987). Syntaphus wheeleri Donisthorpe, 1920 described from the Bembridge Marls as an ant belongs here as well (see below). Moreover, all three species of the genus Chelonus Jurine, 1801 described from Florissant (Chelonus depressus Brues, 1910, C. muratus Brues, 1910 and C. solidus Brues, 1910) show no reliable features that would discriminate Chelonus from $A s$ cogaster. Hence, no reliable records of the fossil Chelonus are known so far.

Only two species of Phanerotoma Wesmael, 1838 (P. baltica, Brues, 1933 and $P$. extensa Brues, 1933) have been recorded from Baltic amber (Brues 1933). The genus Diodontogaster Brues, 1933 (type species D. bidentata Brues, 1933 in Baltic amber) is the third chelonine genus in the fossil record which is venationally similar to Ascogaster and differs from it only in the presence of a pair of conical lobes on the posteroventral sides of the carapace (Brues 1933). The genus Anacanthobracon Brues, 1933 (type species A. femorator Brues, 1933) was described in the subfamily Doryctinae (Brues 1939), but its position is debatable: the good published figure shows no hypoclypeal cavity characteristic of that subfamily. This feature, together with the structure of the metasoma and very specific forewing venation, indicates this genus belongs to the subfamily Cheloninae. Finally, the genus Chelonohelcon Brues, 1933, described originally in the subfamily Helconinae, has been recently transferred to Cheloninae in the monobasic tribe Chelonohelconini (Tobias 1987).

The position of the genus Eobracon Cockerell, 1920 (type species E. cladurus Cockerell, 1920a) described in the subfamily Cheloninae from the Eocene of Colorado (Cockerell 1920; Brues 1933) is also disputable. According to the wing venation (supposing that $\mathrm{r}-\mathrm{m}$ is correctly shown there: see Cockerell 1920 a, p. 259), this genus may be a specialised member of Helconinae.

Four genera and 20 species are known in the fossil record for Cheloninae. Three additional species of Ascogaster are described here. Worth mentioning is that all known fossil Cheloninae have a less derived forewing venation of the Ascogaster type (with 1-SR $+\mathrm{M}$ developed), supposing that the earlier authors (Gravenhorst 1834; Brischke 1886) have erroneously recorded Chelonus sp. in Baltic amber.

\section{Genus Ascogaster Wesmael, 1835}

Remarks. The species of Ascogaster are the most abundant fossil Cheloninae. They show striking variation of several important characters recorded in the described species, e.g., petiolate anterior to sessile basal cell and postfurcal vs. interstitial position of $\mathrm{m}-\mathrm{cu}$ in the forewing (Brues 1933), or presence vs. absence of the first suture on the carapace (Tobias 1987). This suggests the need for care in assessing the real position of these taxa.

Development of both metasomal sutures is a previously unknown character for Ascogaster. The only species with clear 


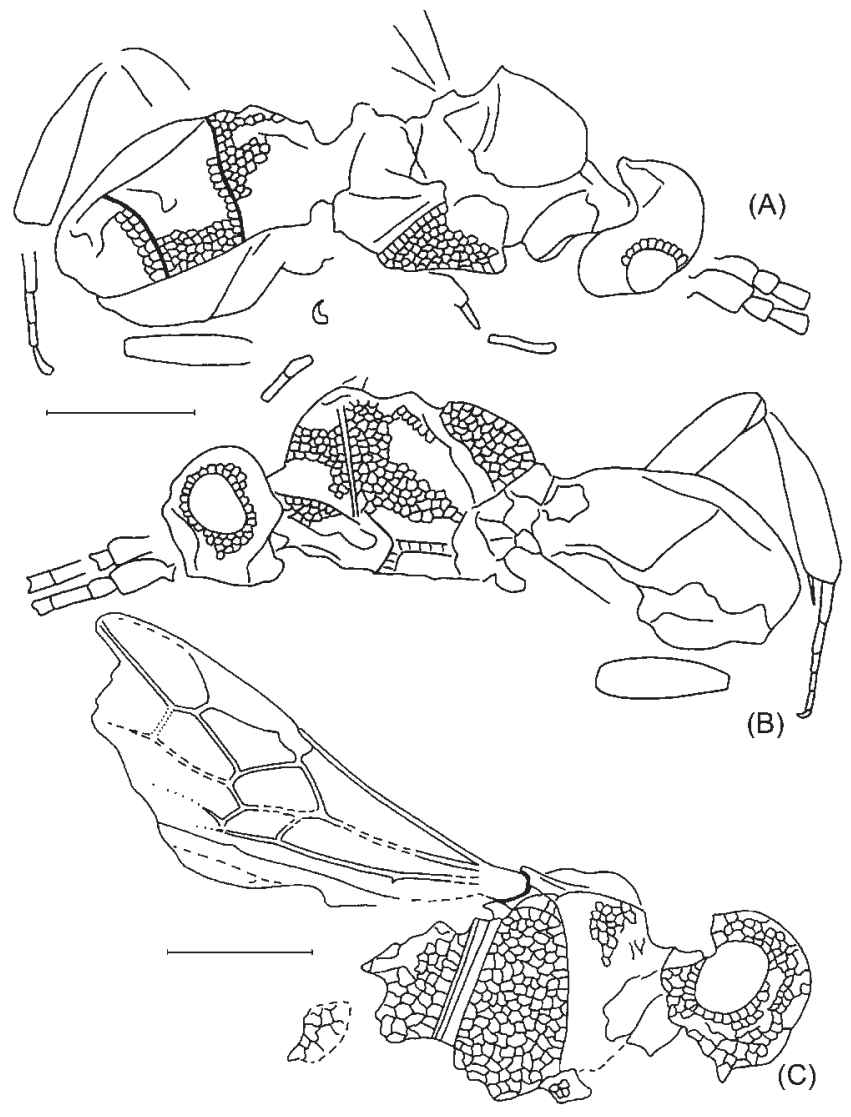

Text-figure 33 Ascogaster (Syntaphus) wheeleri (Donisthorpe): (A, B) holotype, NHMUK I.8744: (A) part; (B) counterpart, sculpture partially drawn; (C) paratype, NHMUK I.9325. Scale bars $=1 \mathrm{~mm}$.

sutures was described as an ant under the generic name Syntaphus Donisthorpe, 1920 (see below). Otherwise, a few extant and fossil species of Ascogaster have at most the first suture more or less developed (Tobias 1987). Nevertheless, I prefer to retain Syntaphus as a subgenus of Ascogaster.

The presence of two deep metasomal sutures is the main diagnostic character of the chelonine tribe Phanerotomini. The discovery of a similar character in Ascogaster reduces the gap between these genera, but does not close it. In fact, species of Ascogaster have the discal cell petiolate and body predominantly dark coloured, in contrast to Phanerotoma which have the discal cell distinctly and more-or-less widely sessile anteriorly and body colour basically pale. It is of importance that several species from Baltic amber described by Brues (1933) in Ascogaster (A. dilatata Brues, 1933, A. gracilicornis Brues, 1933, A. praevolans Brues, 1933, A. pentagona Brues, 1933, A. sylvestris Brues and A. submerse Brues) have the discal cell sessile or subsessile. However, his descriptions do not mention the presence or absence of metasomal sutures. All species described by Tobias (1987) have the discal cell distinctly petiolate.

\section{Subgenus Syntaphus Donisthorpe, 1920, stat. nov.}

Type species. $S$. wheeleri Donisthorpe, 1920, by monotypy. Diagnosis. Differs from the nominate subgenus in having the metasomal carapace with two sutures developed.

Ascogaster (Syntaphus) wheeleri (Donisthorpe, 1920), comb. nov.

Plate 11, fig. 5; Text-fig. 33

1920 Syntaphus wheeleri Donisthorpe, p. 84, plate V. fig. 1, 2.
Holotype. NHMUK I.8744/I. 9936 (part and counterpart), Bembridge Marls, NW Isle of Wight, UK, Brodie Collection; practically wingless body in sublateral aspect with partial antenna, hind leg and small fragments of other legs.

Paratype. NHMUK I.9325, Bembridge Marls, NW Isle of Wight, UK, Brodie Collection; head and incomplete mesosoma in side view, and incomplete forewing.

Description of holotype. Length of body $4.3 \mathrm{~mm}$. Head subcircular, entirely covered by coarse and irregularly areolate sculpture of chelonine type. Longitudinal diameter of eye 1.4 times its transverse diameter. Scape large, $2 \cdot 0-2 \cdot 3$ times as long as wide, $2 \cdot 7$ times as long as pedicel. First flagellar segment 2.3-2.5 times as long as wide. Mesosoma 1.3-1.4 times as long as high, covered by chelonine type sculpture including propodeum but excluding apparently smooth mesosternum. Mesopleuron 1.6 times as high as maximum width. Notauli rather wide and shallow. Prescutellar depression rather shallow and short. Sternauli indistinct. Propodeum with rather long dorsal process (tooth) subacute apically. Hind femur rather wide, about $3 \cdot 3$ times as long as wide. Hind tibia strongly widened, 4.6 times as long as maximum width, 1.5 times as long as hind femur. Hind tarsus 0.8 times as long as hind tibia. Ratio of hind tarsal segments is 16:7:5:4:5. Carapace of metasoma with two rather distinct sutures, entirely covered by sculpture of chelonine type, $2 \cdot 0-2 \cdot 2$ times as long as width. First and second tergites of equal median length and $1 \cdot 1$ times as long as third tergite. Colour: antenna black; mesosoma at least partly, and metasoma entirely, black; hind leg brown.

Paratype is generally similar to holotype, but differs in the following characters (the wing is absent in the holotype). Length of head and mesosoma (with spine of propodeum) $2 \cdot 1$ $\mathrm{mm}$; mesosoma $1.4 \mathrm{~mm}$. Longitudinal diameter of eye 1.3 times its transverse diameter. Mesopleuron about twice as high as maximum width. Propodeum with long dorsal subpointed apical tooth and short rather thick rounded ventral tubercle. Forewing (distal part absent): pterostigma subtriangular, wide, about $3 \cdot 0$ times as long as maximum width. 1-R1 0.9 times as long as pterostigma; $r$ arising distinctly behind middle of pterostigma (internal distance of pterostigma between parastigma and $r$ about twice internal distance between $r$ and apex of pterostigma), distinctly oblique to pterostigma, 0.4 times as long as maximum pterostigmal width. Marginal cell distinctly shortened, pointed apically, 2.7 times as long as maximum width, 1.15 times as long as pterostigma. 3-SR 1.9 times as long as $\mathrm{r}, 0.25$ times as long as weakly curved SR 1, 0.4 times as long as 2-SR; $\mathrm{r}-\mathrm{m}$ unsclerotised, 0.5 times as long as 2-SR. Second submarginal cell rather long, about twice as long as wide, 1.4 times as long as subdiscal cell. 1$\mathrm{SR}+\mathrm{M}$ weakly S-shaped. 2-SR $+\mathrm{M} 0.6$ times as long as $\mathrm{m}-$ cu, 0.15 times as long as $2-\mathrm{M} ; \mathrm{m}-\mathrm{cu} 0.4$ times as long as 2SR, 0.3 times as long as 2-M. Discal cell shortly petiolate anteriorly, 1.85 times as long as wide. 1-M about 8.0 times as long as $1-\mathrm{SR}$; $\mathrm{m}-\mathrm{cu}$ distinctly postfurcal; $\mathrm{cu}-\mathrm{a}$ inclined posteroapically, distinctly postfurcal, distant from 1-M for 0.65 times cu-a length. Subdiscal cell wide, closed antero-posteriorly by $\mathrm{CU} 1 \mathrm{~b}$, about twice as long as wide. CU1a arising from posterior 0.25 of subdiscal cell; 3-CU1 straight. 2A present and sclerotised at most part. Hind wing absent. Wings infuscate; entire pterostigma and veins dark brown.

\section{Subgenus Ascogaster Wesmael, 1835 s. str.}

Type species. A. instabilis Wesmael, 1835

Species included. About 100 species are known in the world fauna, including 15 fossil ones (Brues 1933; Huddleston 1984; Tobias 1987, 2000). 

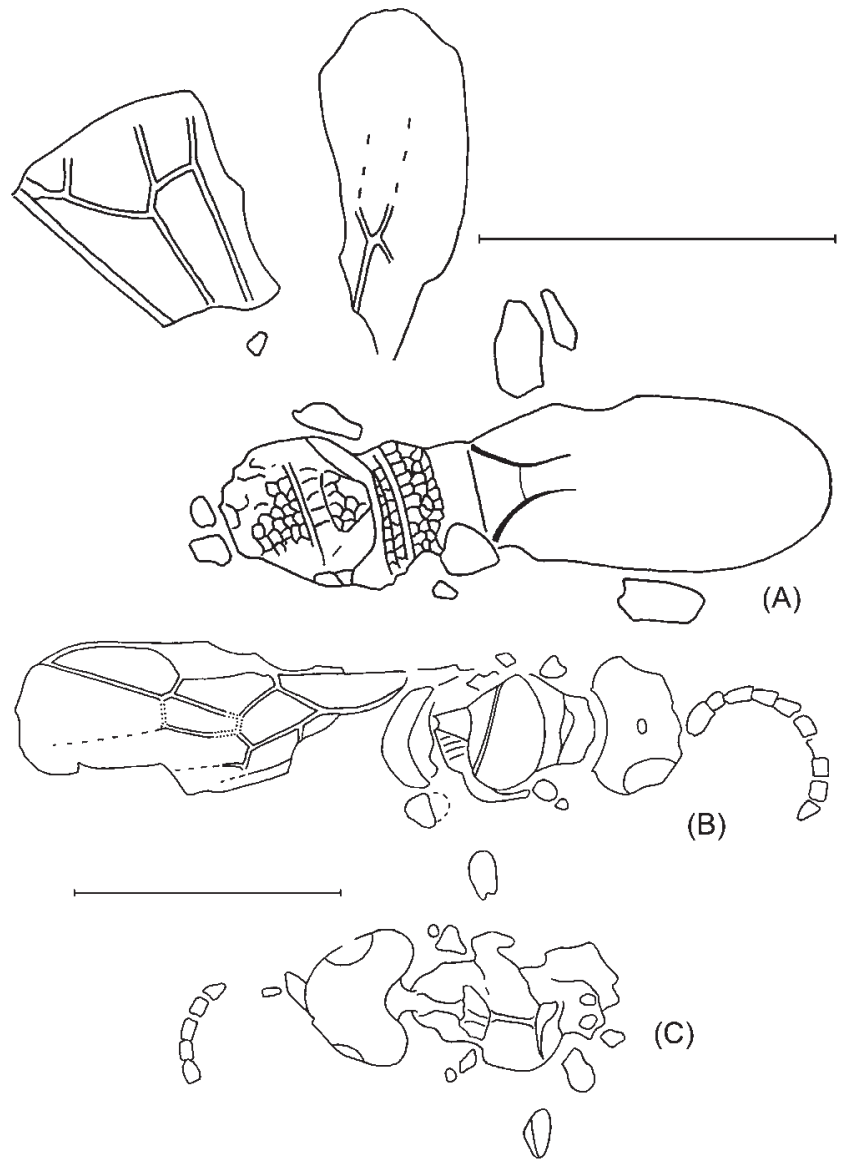

(B)

Text-figure 34 (A) Ascogaster (Ascogaster) brodiei sp. nov., holotype, NHMUK I.9924; (B, C) Ascogaster (Ascogaster) pygmaea sp. nov., holotype NHMUK In.17379: (B) part; (C) counterpart. Scale bars = 1 $\mathrm{mm}$.

\section{Ascogaster (Ascogaster) brodiei Belokobylskij, sp. nov. Plate 11, fig. 6; Text-fig. 34A}

Etymology. After P.B. Brodie, who compiled the collection which includes the holotype.

Holotype. NHMUK I.9924, Bembridge Marls, NW Isle of Wight, UK, Brodie Collection; incomplete headless body in dorsoventral aspect, incomplete wings and leg fragments.

Diagnosis. The new species is similar to A. robusta Brues, 1933 with petiolate discal cell but differs in having the carapace long, narrow and apparently pale in basal part, and the propodeum without tubercles. The new species differs from A. pinicola Brues, 1933, another fossil species with a petiolate discal cell, in having notauli indistinct, scutellum areolate, carapace lacking longitudinal sculpture, and propodeum without a transverse carina. From all Ascogaster species described by Tobias (1987) in Baltic amber, this new species differs by the absence of the first metasomal suture. Comparison with described recent species is not possible because of the limited number of diagnostic characters available.

Description. Length of mesosoma $1.1 \mathrm{~mm}$. Mesosoma including propodeum covered by coarse and irregularly areolate sculpture of chelonine type, scutellum less strongly sculptured. Mesoscutum without notauli. Prescutellar depression wide and distinctly crenulated. Propodeum without any teeth or tubercles, with rather distinct semicircular transverse carina submedial. Forewing: discal cell distinctly petiolate. 1-SR 0.2 times as long as $1-\mathrm{M}$; cu-a distinctly postfurcal, inclined posteroapically, distant from 1-M for 0.7 times cu-a length. Carapace of metasoma rather long and narrow, twice as long as wide,

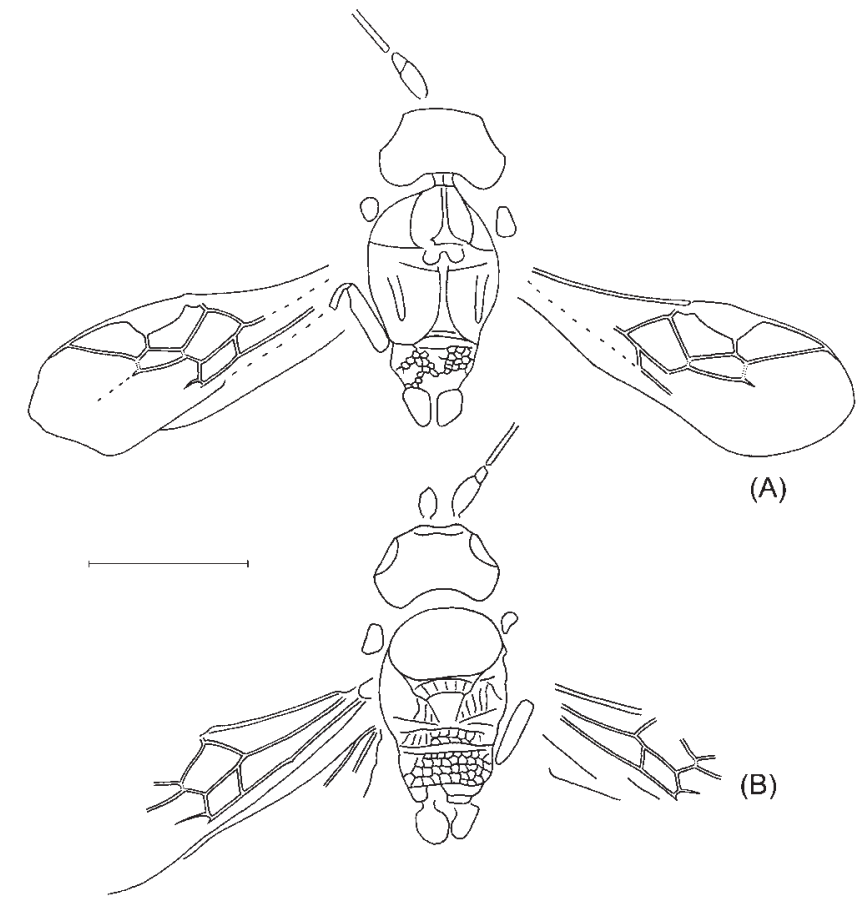

Text-figure 35 Ascogaster (Ascogaster) yulei sp. nov., holotype NHMUK I.9209/I. 9379 (A) part; (B) counterpart. Scale bar $=1 \mathrm{~mm}$.

rather distinctly roundly narrowed in posterior quarter, without sutures, entirely densely reticulate-areolate with elongate areolae, without distinct striation. Basal carinae distinct, convergent in their anterior half (where connected by distinct transverse carina), then subparallel for rather long distance. Colour: mesosoma black, metasoma black; possibly pale in wide basomedial area; forewing almost hyaline in basal half.

\section{Ascogaster (Ascogaster) yulei Belokobylskij, sp. nov. Plate 12, figs 1, 2; Text-fig. 35}

Etymology. After A. Yule, who has collected a lot of important fossil specimens in Bembridge Marls.

Holotype. NHMUK I.9209/I.9379 (part and counterpart), Bembridge Marls, NW Isle of Wight, UK, Brodie Collection; showing head with incomplete antenna and mesosoma with forewings and leg fragments in dorsal and ventral aspects.

Diagnosis. Different types of preservation of the present and previous species make them difficult to compare, leaving only larger body size, shorter prescutellar depression and presence of a transverse propodeal carina in A. yulei to discriminate them. The new species is also very similar to $A$. pinicola Brues, 1933, except that it has notauli indistinct, scutellum finely reticulate-areolate, propodeum lacking teeth, 3-SR almost equal to $\mathrm{r}$, and $\mathrm{m}-\mathrm{cu}$ distinctly postfurcal. A. yulei differs from $A$. wheeleri, besides the supposed absence of the metasomal sutures, in having 3-SR short and almost equal to r, and the sternauli present. The new species differs from all the Ascogaster species described by Tobias (1987) from Baltic amber in having temple large, notauli indistinct, and 1-R1 shorter than pterostigma.

Description. Median length of head $0.4 \mathrm{~mm}$, mesosoma $1.25 \mathrm{~mm}$, forewing $2.2 \mathrm{~mm}$. Head almost twice as wide as long medially, 1.5-1.6 times as wide as maximum length. Head behind eyes distinctly roundly narrowed. Transverse diameter of eye 0.9-1.0 times length of temple. Occipital carina distinct, complete dorsally, fused with hypostomal carina above base of mandible. Malar space about as long as basal width of mandible. Antenna: scape rather long, almost twice as long as maximum width. Basal segments of flagellum rather slender. 
Mesosoma 1.55-1.65 times as long as maximum width. Notauli absent. Mesoscutum rather long, its length 0.65 times as long as maximum width, finely areolate. Prescutellar depression rather deep, more or less short, with five carinae. Scutellum finely reticulate-areolate. Sternauli shallow, weakly S-shaped, distinctly crenulated. Mesopleuron apparently almost smooth in lower half. Propodeum without any distinct teeth or tubercles, with rather distinct semicircular transverse submedial carina. Wings: forewing 2.6 times as long as wide. Pterostigma wide, rather short and almost semicircular, $2 \cdot 3$ times as long as maximum width. Marginal cell strongly shortened, almost twice as long as wide. $1-\mathrm{R} 10.9$ times as long as pterostigma, 1.3 times as long as distance from apex of marginal cell to apex of wing; $r$ arising almost from posterior 0.3 of pterostigma, about half as long as maximum pterostigmal width. 3SR almost equal to $\mathrm{r}, 0 \cdot 2$ times as long as the straight SR 1 . Second submarginal cell rather long, 2.6 times as long as wide; $\mathrm{m}-\mathrm{cu}$ distinctly but not strongly postfurcal. Discal cell distinctly petiolate, about 1.5 times as long as wide, almost as long as second submarginal cell. 1-SR c. $0 \cdot 2$ times as long as 1$\mathrm{M}$; cu-a distinctly postfurcal, inclined posteroapically, distant from 1-M for 0.6-0.65 times cu-a length. Subdiscal cell wide, closed antero-posteriorly by CU1b, almost twice as long as wide. CU1a arising from posterior 0.3 of subdiscal cell; 3CU1 straight. Colour: head and mesosoma black. Forewing faintly infuscate. Pterostigma and veins brown to dark brown.

\section{Ascogaster (Ascogaster) pygmaea Belokobylskij, sp. nov.} Plate 11, figs 3, 4; Text-fig. 34B, C

Etymology. After pygmaeus, the Latin for tiny, referring to small body size of the species.

Holotype. NHMUK In.17379 (part and counterpart), Bembridge Marls, NW Isle of Wight, UK, Smith Collection; dorsoventral aspect of head with incomplete antenna and partial mesosoma with incomplete forewing and leg fragments.

Diagnosis. The new species differs distinctly from all known fossil Ascogaster species in its small size, with forewing length $1.7 \mathrm{~mm}$. It is similar to A. pinicola Brues, 1933 in small body size and discal cell petiolate anteriorly, but differs in having the basal segments of the antenna short and thick, $\mathrm{m}-\mathrm{cu}$ distinctly postfurcal, marginal cell long, and 3-SR less strongly shortened. A. pygmaea is similar to A. pentagona Brues, 1933 in the shape of the second submarginal cell, but distinctly differs by having the forewing faintly infuscate, the notauli absent, the mesonotum without striation, and the discal cell distinctly petiolate anteriorly. It differs from $A$. thoracica Tobias, 1987 in having the basal flagellar segments short and thick, the notauli indistinct, the propodeum without teeth, and 3-SR long. Comparison with A. brodiei is limited, because of their different states of preservation, yet they can be discriminated by the small size and distinctly transverse mesoscutum in the present species. A. pygmaea can be distinguished from $A$. yulei by the narrower head, short temple, wide mesoscutum, weakly shortened marginal cell, and long discal cell.

Description. Median length of head $0.25-0.3 \mathrm{~mm}$, mesosoma $0.8-0.85 \mathrm{~mm}$, forewing $1.7 \mathrm{~mm}$. Head about twice as wide as long medially, 1.2 times as wide as maximum length, distinctly convex and roundly narrowed behind eyes. Transverse diameter of eye 1/1-1.2 times length of temple. Occipital carina distinct, fused below with hypostomal carina. Clypeus distinctly convex. Ocelli weakly enlarged. Antenna thick basally. Scape long and rather thick, 1.8 times as long as maximum width, 2.5 times as long as pedicel. First flagellar segment twice as long as apical wide, 1.1 times as long as second segment. Seventh flagellar segment thickened, 1.35-1.45 times as long as maximum width. Mesosoma 1.5 times as long as maximum width. Pronotum distinctly elongate. Mesoscutum 0.55 times as long as maximum width, finely areolate. Notauli absent. Prescutellar depression rather deep, wide, with several carinae. Sternauli indistinct. Mesopleuron distinctly finely areolate. Prepectal and postpectal carinae present. Forewing 2.8 times as long as wide. Pterostigma wide, rather long, subtriangular, $2 \cdot 7$ times as long as maximum width. Marginal cell weakly shortened, 2.8 times as long as wide. 1-R1 1.1 times as long as pterostigma, about 3.0 times as long as distance from apex of marginal cell to apex of wing; $r$ arising from posterior 0.3 of pterostigma, about half as long as maximum pterostigmal width. 3-SR 0.8 times as long as $\mathrm{r}, 0.15$ times as long as the straight SR 1, $0 \cdot 25$ times as long as 2-SR. Second submarginal cell rather long, $2 \cdot 3$ times as long as wide; $\mathrm{m}-\mathrm{cu}$ strongly postfurcal. Discal cell distinctly petiolate, about twice as long as wide, $1 \cdot 1$ times as long as second submarginal cell. 1-SR $0 \cdot 25$ times as long as 1-M; cu-a distinctly postfurcal, inclined posteroapically, distant from 1-M for 0.8 times cu-a length. Subdiscal cell wide, closed antero-posteriorly by CU1b, $2 \cdot 3$ times as long as wide. CU1a arising from posterior 0.25 of subdiscal cell; 3-CU1 straight. Colour: head and mesosoma dark reddish brown; forewing faintly infuscate; pterostigma and veins brown to dark brown.

3.9.5. Subfamily Doryctinae Foerster, 1862. Doryctinae is one of the most diversified subfamilies of idiobiont Braconidae (Belokobylskij et al. 2004b), with more than 200 known genera.

Many doryctine taxa have been described or recorded as fossils. The most species (eight) were described in the genus Doryctes Haliday, 1836 (s.l., including Ontsira Cameron, 1900) (Brues 1933; Statz 1938; Zhang 1989). In many cases, it is not easy to establish the modern generic position for these taxa because of insufficient descriptions and/or preservation state. The position of most of the species described by Brues in the genus Doryctes (D. contectus Brues, 1933, D. filiformis Brues, 1933, D. hyalinus Brues, 1933, and D. succinalis Brues, 1933 ) seems to be correct, but D. minutus Brues, 1933 is hardly a member of this genus, judging from its different wing venation and the absence of basiventral tubercles on the hind coxa. The species described in the genus Clinocentrus (C. microps Brues, 1933, C. caudatus Brues, 1933 and C. debilis Brues, 1933) probably also belong to Ontsira or Doryctes (Belokobylskij 1995). The three species described by G. Statz (1938) from the Aquitanian (latest Oligocene or earliest of Miocene) of Rott in Germany as Doryctes. D. conjectus Statz, 1938 and D. rotundatus Statz, 1938 have a correct position in this genus, but $D$. longulus Statz is not a Doryctinae, because its forewing discal cell is sessile, the hind wing sub basal cell is very long and the $\mathrm{m}-\mathrm{cu}$ is absent. D. huadongensis Zhang, 1989 from the Middle Miocene of Shanwang, China, is perhaps a real Doryctes (Zhang 1989). Three species from Rott have been described in the genus Spathius Nees, 1818 (S. pedicularis Statz, 1936, S. longicornis Statz, 1938 and S. macroradialis Statz, 1938) the first two of them probably belong to Doryctes, and the last one to subfamily Opiinae. The elongate first metasomal tergite not transformed into a real petiole can be found in some species of doryctine genera (including Doryctes), as well as in other braconid groups, and especially in males (cf. S. pedicularis). Brues suggested Ichneumon petrinus Scudder, 1890 from White River, Colorado (USA) to be a member of Spathius (Brues, 1910) or Rhaconotus Ruthe, 1854 (Brues, 1933), but these suggestions need verification. Finally, two braconid wasps from the Bembridge Marls, Phanomeris colenutti Cockerell, 1921a and Xenarcha distracta Cockerell, 1921a should be transferred to the genus Ontsira (see below).

Two genera of the tribe Hecabolini are mentioned in the fossil record as well. The diagnostic characters of Hecabolus 
gladiator Statz, 1936 described from Rott (forewing discal cell sessile anteriorly, subdiscal cell closed apico-posteriorly, shape of body with long ovipositor) suggest its position rather in the brachystine genus Eubazus. Real diagnostic characters of the genus Polystenus Foerster, 1862 have been obscured for long time (Papp 1984). As a result, P. obduratus Brues, 1933 from the Baltic amber is actually not a member of this genus (if it is a real member of Doryctinae). The description, even if supported with no illustration, indicates this species should form a genus of its own, based on the described combination of characters: occiput very faintly margined above; malar space long; hind coxa with no basiventral tubercle; $\mathrm{m}-\mathrm{cu}$ antefurcal; and cu-a far postfurcal.

Very interesting is the discovery of specialised genera of the tribe Ecphylini Ecphylus oculatus Muesebeck, 1960 and Aivalykus dominicanus Zuparko \& Poinar, 1997, in the Miocene Mexican and Dominican ambers. Genus Heterospilus Haliday, 1836 from the Santonian (Late Cretaceous) Taimyr amber is reported by Zherikhin (1978), but this information needs verification. The record of the genus Rhaconotus Ruthe, 1854 (as Hormiopterus Girault, 1869: Scudder 1890; Brues 1910) in the Florissant (latest Eocene of Colorado) is doubtful as well.

There are taxa erroneously described in Doryctinae. The genus Promonolexis Brues, 1933 (type species P. klebsi Brues, 1933) from the Eocene Baltic amber (Brues 1933) is most probably a junior synonym of Blacus Nees. The characters shared by these genera are: discal cell sessile (the character state practically unknown in Doryctinae); ovipositor thickened and strongly curved down (practically unknown in doryctines and more characteristic of Euphorinae s. 1.); antenna 18segmented (characteristic of some species of Blacus); and long and narrow mesonotum and metasoma slender basally (also the characters often met in Blacus). The genus Semirhytus Szepligeti, 1902, having been included in Rogadinae by Brues (1933), may differ radically from the modern one. Then $S$. caudatus Brues, 1933 from the Baltic amber is probably a member of the tribe Clinocentrini (Exothecinae s.1.) rather than of Doryctinae. Lastly, Anacanthobracon Brues, 1939 described in Doryctinae, also from the Baltic amber, is apparently a member of Cheloninae (see above).

The taxonomic position of one doryctine fossil is not yet clear. Doryctomorpha tertiaria Brues, 1933 (Baltic amber) was described in the genus Doryctomorpha Ashmead, 1900, which is now included in Rhyssalinae (Belokobylskij et al. 2004a). The original description is insufficient, so progress in understanding that species depends on finding the type or new material.

Only three doryctine species are recorded from the Bembrige Marls, all belonging to the genus Ontsira.

\section{Genus Ontsira Cameron, 1900}

Remarks. This is the first reliable fossil record of the genus Ontsira, because all earlier records appearing under the name Doryctes are not easy to fit to these genera based on their original descriptions.

Ontsira colenutti (Cockerell, 1921), comb. nov. Plate 12, fig. 3; Text-fig. 36

1921a Phanomeris (?) colenutti Cockerell, p. 18, fig. 20.

Holotype. NHMUK I.9702/ I.9096 (part and counterpart), Bembridge Marls, NW Isle of Wight, UK, Brodie Collection; head and mesosoma in lateral aspect with forewing and incomplete legs.
Diagnosis. The species differs from all known fossil Doryctes s.l. (Ontsira included) in having mesosoma short and high.

Description. Length of mesosoma $1.5 \mathrm{~mm}$, hind femur 0.85 $\mathrm{mm}$, forewing $3.5 \mathrm{~mm}$. Head behind eyes roundly narrowed. Occipital carina present below. Mesosoma short and high, 1.45 times as long as maximum height. Mesoscutum highly and almost roundly elevated above pronotum. Notauli complete, wide anterior and narrow posterior. Scutellum distinctly convex. Prepectal carina distinct. Sternauli deep, rather wide, crenulated at least partly, situated in anterior 0.6 of mesopleuron. Propodeum with basilateral areas delineated by carinae. Forewing 2.7 times as long as maximum width. Pterostigma subtriangular, rather wide, 3.0 times as long as maximum width. 1-R1 1.4 times as long as pterostigma, 2-R1 very short; $\mathrm{r}$ arising almost from middle of pterostigma, 0.8 times as long as maximum pterostigmal width. Marginal cell not shortened, pointed apically, 3.0 times as long as maximum width. 3-SR twice as long as $\mathrm{r}, 0.5$ times as long as the almost straight $\mathrm{SR} 1,1.2$ times as long as 2-SR; $\mathrm{r}-\mathrm{m}$ present, weakly sclerotised, 0.6 times as long as 2-SR. Second submarginal cell 2.3 times as long as wide, 1.25 times as long as subdiscal cell. 1$\mathrm{SR}+\mathrm{M}$ straight, 9.0 times as long as 2-SR + M. 2-SR + M $0 \cdot 15$ times as long as 2-SR, $0 \cdot 2$ times as long as $\mathrm{m}-\mathrm{cu}, 0 \cdot 1$ times as long as sclerotised part of 2-M. Discal cell distinctly petiolate anterior, 1.8 times as long as wide; $\mathrm{m}-\mathrm{cu}$ distinctly antefurcal. $\mathrm{Cu}-\mathrm{a}$ postfurcal, distant from 1-M for 0.4 times $\mathrm{Cu}-\mathrm{a}$ length. Subdiscal cell wide, $3 \cdot 0$ times as long as width; cula arising from posterior 0.3 of distal margin of subdiscal cell, rather distinctly pigmented in about its basal half. Legs: hind coxa with basiventral tubercle, 1.3 times as long as wide (tubercle included). Hind femur widened, $3 \cdot 3$ times as long as wide. Hind tibia not thickened, 1.6 times as long as femur, 2.5 times as long as hind basitarsus. Colour: head pale brown; mesosoma brown to pale brown; hind leg brown; hind tibia pale in basal $0 \cdot 3$; wings almost hyaline; pterostigma brown, pale basally and apically; veins brown.

Remarks. The position of this species in Ontsira is justified by the following characters: prepectal carina and sternauli present, notauli distinct and complete, hind coxa with basiventral tooth, hind femur thick, propodeum with basilateral areas delineated by carinae.

Ontsira distracta (Cockerell, 1921), comb. nov. Plate 12, fig. 4; Text-fig. 37

\section{1a Xenarcha (?) distracta Cockerell, 15, fig. 16.}

Holotype. NHMUK I.9099, Bembridge Marls, NW Isle of Wight, UK, Brodie Collection; insect in side view lacking hind wings and with incomplete antenna and legs.

Diagnosis. The species differs from the other known fossil Ontsira species in having body size small, basilateral areas of propodeum short, forewing distinctly infuscate and with anterior position of CU1a.

Description. Length of body $2.0 \mathrm{~mm}$, mesosoma $0.8 \mathrm{~mm}$, metasoma 0.95 , hind femur $0.5 \mathrm{~mm}$, forewing $1.6 \mathrm{~mm}$. Head rather long, 1.3 times as high as long. Occipital carina developed. Hypoclypeal depression distinct, rather wide. Face transversely striate. Occipital carina distinct, fused below with hypostomal carina distinctly above mandibular base. Eye $c .1 .5$ times as long as temple in lateral view. Segments in apical half of antenna elongate but rather thick, c. 3.0 times as long as wide. Mesosoma 1.7 times as long as maximum height. Mesoscutum highly and roundly elevated above pronotum. Scutellum convex. Prepectal carina distinct. Sternauli rather wide, situated 

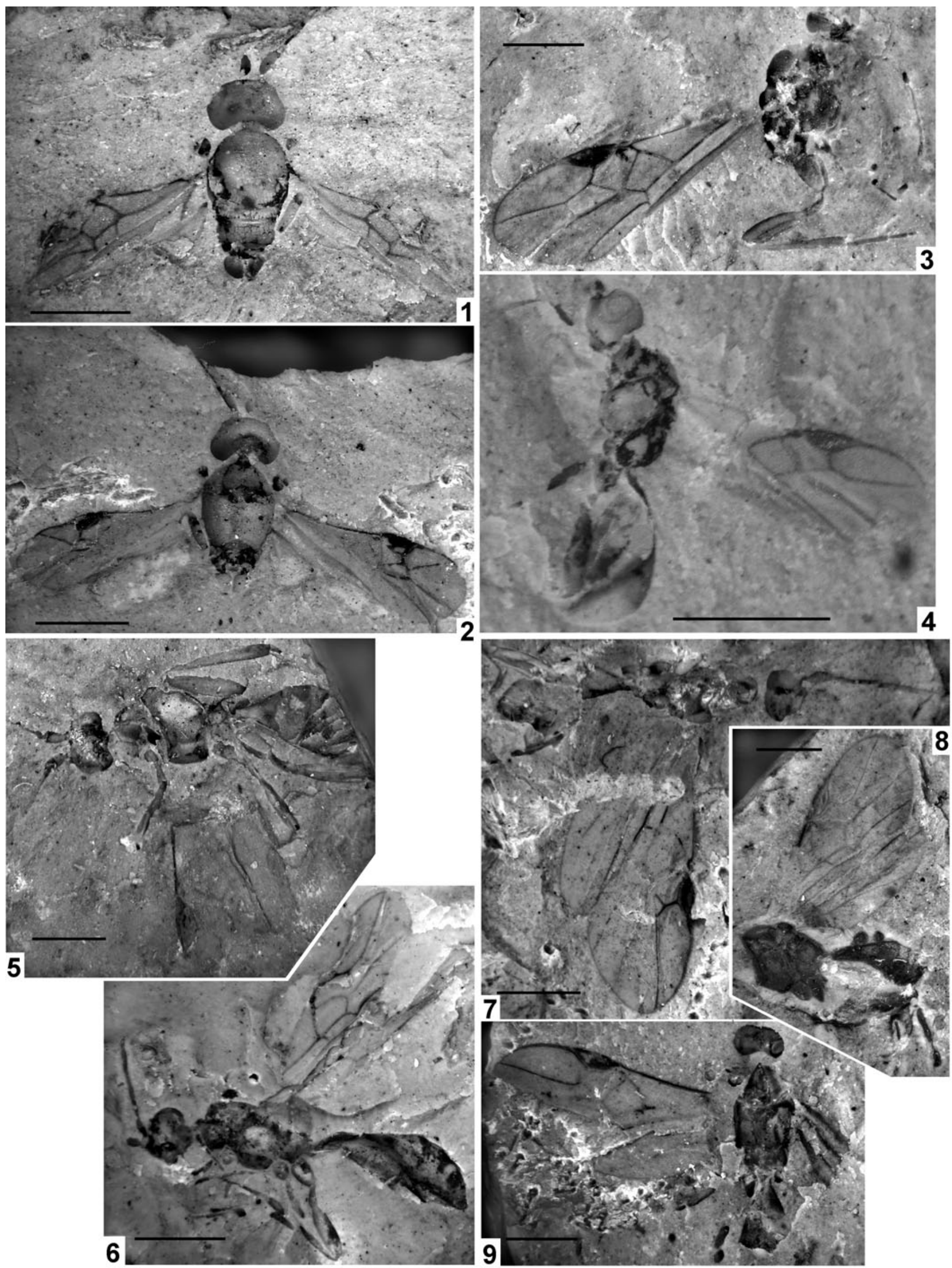

Plate 12 (1-2) Ascogaster (Ascogaster) yulei sp. nov., holotype, NHMUK I.9209/I.9379: (1) part; (2) counterpart. (3) Ontsira colenutti (Cockerell), holotype, NHMUK I.9702 (part). (4) Ontsira distracta (Cockerell), holotype, NHMUK I.9099. (5) Meteorus crassitergum sp. nov., holotype, NHMUK I.9065. (6) Ontsira cenozoica sp. nov., holotype NHMUK I.9601. (7-9) Meteorus applanatus sp. nov.; (7) holotype, NHMUK I.9656; (8) paratype, NHMUK I.8894; (9) paratype, NHMUK I.8674. Scale bars $=1 \mathrm{~mm}$. 


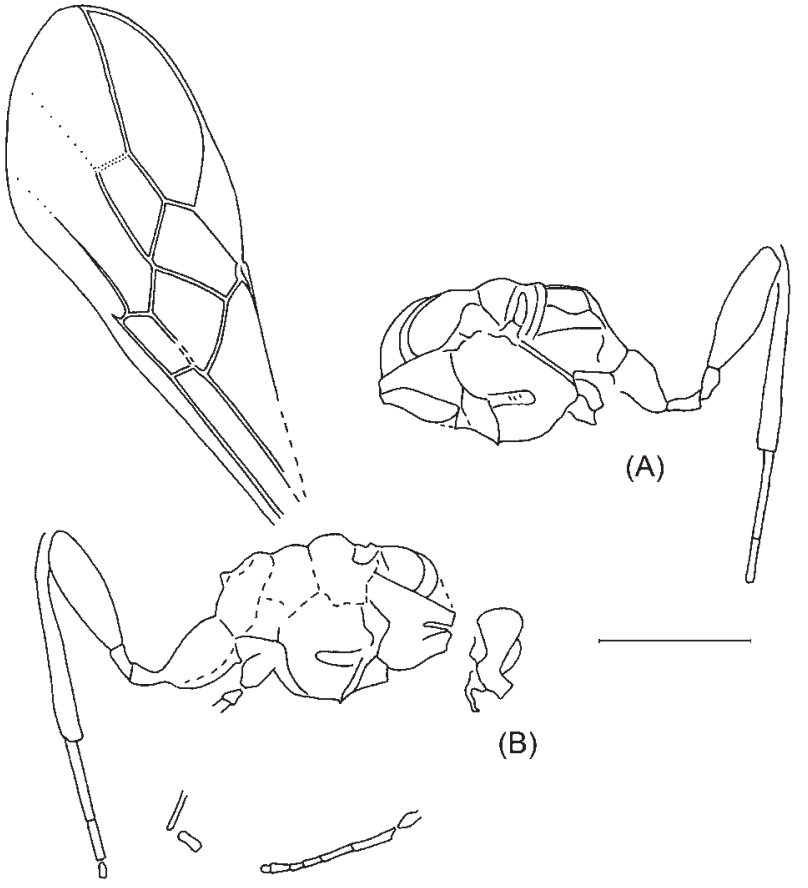

Text-figure 36 Ontsira colenutti (Cockerell), holotype: (A) NHMUK I.9702 (part); (B) NHMUK I.9096, mesosoma and hind leg (countpart) Scale bar $=1 \mathrm{~mm}$.

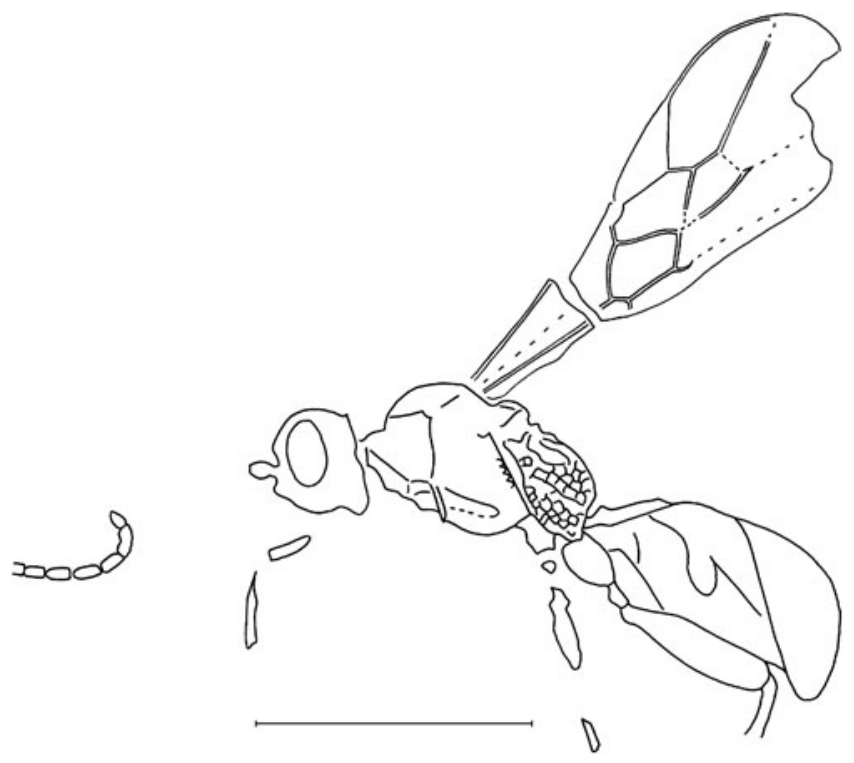

Text-figure 37 Ontsira distracta (Cockerell), holotype, NHMUK I.9099. Scale bar $=1 \mathrm{~mm}$.

in anterior 0.7 of mesopleuron. Mesopleural suture distinctly crenulated. Metapleura areolate throughout. Propodeum almost entirely finely areolate, with rather small basilateral areas more or less delineated by carinae. Forewing 2.8 times as long as maximum width. Pterostigma subtriangular, rather wide, 2.8 times as long as maximum width. Parastigma rather thick. 1R1 1.2 times as long as pterostigma, 5.5 times as long as distance from apex of marginal cell to apex of wing; 2-R1 almost absent; $r$ arising near middle of pterostigma, shortly unsclerotised apically (unless damaged there), not perpendicular to pterostigma, 0.75 times as long as maximum pterostigmal width. Marginal cell weakly shortened, pointed apically, 2.6 times as long as maximum width. 3-SR $1 \cdot 15$ times as long as r, 0.25 times as long as regularly and weakly curved SR 1, 0.6

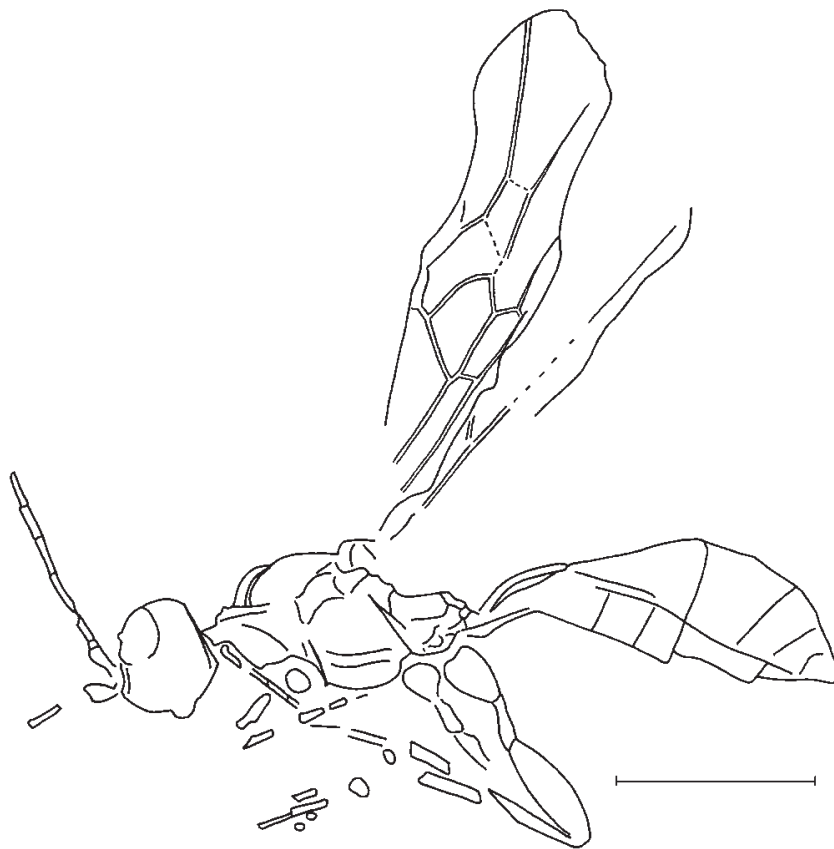

Text-figure 38 Ontsira cenozoica sp. nov., holotype, NHMUK I.9601. Scale bar $=1 \mathrm{~mm}$.

times as long as 2-SR; $\mathrm{r}-\mathrm{m}$ present, faintly sclerotised, 0.55 times as long as 2-SR. Second submarginal cell $2 \cdot 25$ times as long as wide, 1.2 times as long as subdiscal cell. 1-SR $+\mathrm{M}$ weakly $\mathrm{S}$-shaped. $2-\mathrm{SR}+\mathrm{M}$ very short. $\mathrm{M}-\mathrm{cu} 0.7$ times as long as 2-SR, 0.45 times as long as sclerotised part of 2-M. Discal cell distinctly petiolate anteriorly, 1.7 times as long as wide. 1-M about 3.0 times as long as $1-\mathrm{SR}$; $\mathrm{m}-\mathrm{cu}$ weakly antefurcal; cu-a distinctly postfurcal. Subdiscal cell narrow. CU1a arising close to anterior side of subdiscal cell, weakly curved basally. Legs: hind coxa possibly with small basiventral tubercle, 1.4 times as long as wide. Hind femur distinctly widened, about 3.0 times as long as wide. Metasoma with no characters to describe. Colour: head possible entirely black; mesosoma black; first metasomal tergite black; laterotergites and sternites of metasoma light brown; hind leg brown; wings distinctly infuscate; pterostigma entirely dark brown, pale basally and apically; veins brown.

Remarks. The position of this species in the genus Ontsira is tentative, because several important characters (structure of notauli, subdiscal cell, second metasomal tergite, etc.) are not preserved.

Ontsira cenozoica Belokobylskij, sp. nov. Plate 12, fig. 6; Text-fig. 38

Etymology. After Cenozoic.

Holotype. NHMUK I.9601, Brodie Collection; insect in side view with incomplete antenna, wings and legs.

Diagnosis. Differs from $O$. colenutti (Cockerell) in having mesosoma long, second submarginal cell short and narrow, and 1-SR $+\mathrm{M}$ distinctly curved. Of Brues' species of Doryctes, the new species is similar to D. hyalinus Brues in having long and slender basal antennal segments, but differs in having the temple long, first metasomal tergite not strongly convex above, 3-SR long, $\mathrm{m}$-cu distinctly antefurcal, and 2-SR and $\mathrm{r}-\mathrm{m}$ not strongly convergent anteriorly. O. oligocenica differs from $D$. filiformis Brues in having the first metasomal tergite long and not strongly convex above, the second tergite without a basal area, $\mathrm{cu}-\mathrm{a}$ less distinctly postfurcal, and $\mathrm{m}-\mathrm{cu}$ 


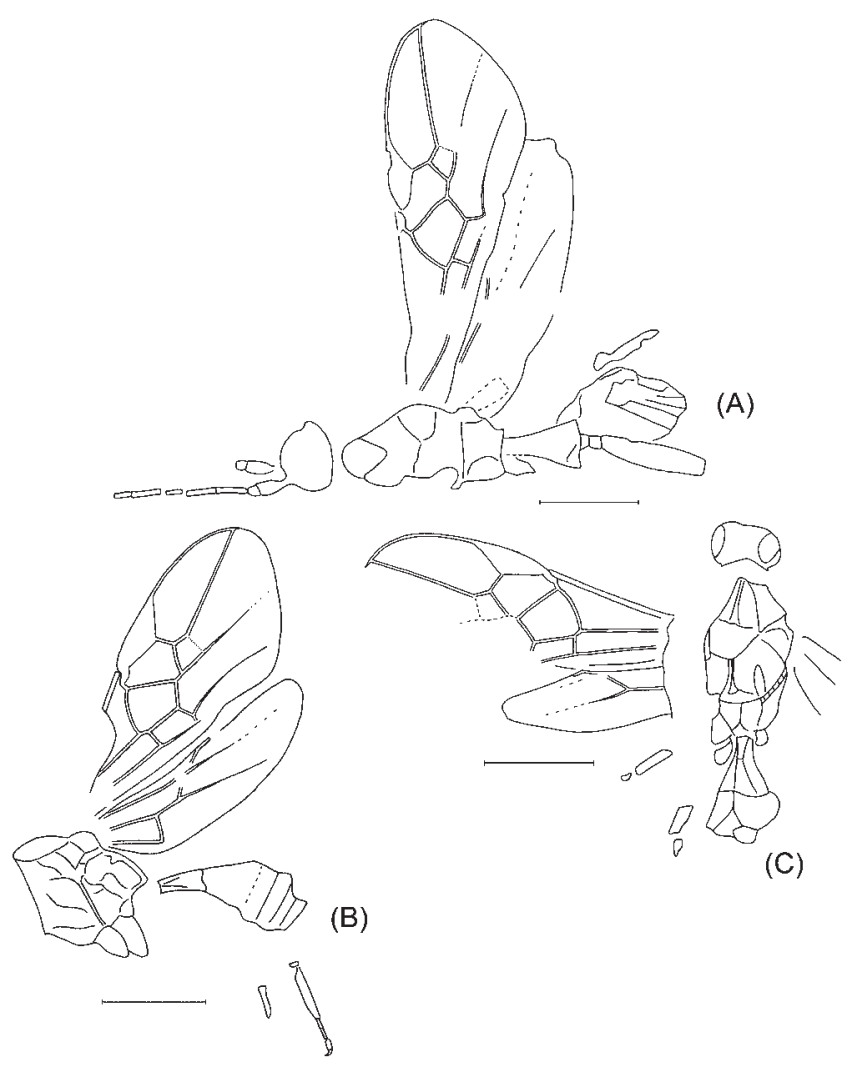

Text-figure 39 Meteorus applanatus sp. nov.: (A) holotype, NHMUK I.9656; (B) paratype, NHMUK I.8894; (C) paratype, NHMUK I.8674. Scale bars $=1 \mathrm{~mm}$

distinctly antefurcal. Differs from Spathius longicornis Statz in having $\mathrm{m}-\mathrm{cu}$ distinctly antefurcal and hind femur thick.

Description. Length of body $3.6 \mathrm{~mm}$, mesosoma $1.3 \mathrm{~mm}$, metasoma $1.9 \mathrm{~mm}$, forewing $2.6 \mathrm{~mm}$. Head strongly convex dorsally, 1.2 times as high as long in lateral view. Occipital carina present. Temple in lateral view about half as long as eye. Face rather weakly convex. Antenna rather slender. Scape convex, 1.6 times as long as wide, $2 \cdot 2$ times as long as pedicel. First flagellar segment 4.3 times as long as wide apically, 1.2 times as long as second segment. Mesosoma long and rather high, about twice as long as maximum height. Pronotum convex dorsally. Mesoscutum rather highly and roundly elevated above pronotum. Notauli present at least in anterior half. Scutellum convex. Prepectal carina distinctly developed. Sternauli present but shallow. Forewing about 3.5 times as long as maximum width. Pterostigma ill-preserved. 2-R1 almost absent. Marginal cell weakly shortened, pointed apically, c.3.5 times as long as maximum width. 3-SR 1.5 times as long as r, 0.35 times as long as the almost straight SR1, 0.9 times as long as 2-SR; $\mathrm{r}-\mathrm{m}$ weakly sclerotised, 0.55 times as long as 2-SR. Second submarginal cell rather short, $2 \cdot 3$ times as long as wide, as long as subdiscal cell. 1-SR $+\mathrm{M}$ distinctly convex, 4.5 times as long as $2-\mathrm{SR}+\mathrm{M}$. 2-SR+M $0 \cdot 35$ times as long as 2-SR, $0 \cdot 5$ times as long as $\mathrm{m}-\mathrm{cu}, 0 \cdot 2$ times as long as $2-\mathrm{M}$. Discal cell distinctly petiolate anterior, twice as long as wide; $\mathrm{m}-\mathrm{cu}$ distinctly antefurcal; cu-a postfurcal, distant from 1-M for 0.7 times cu-a length. Subdiscal cell wide, 3.5 times as long as wide. CU1a arising from posterior 0.25 of distal margin of subdiscal cell, rather distinctly pigmented basally. Legs: hind coxa with basiventral tubercle, without processes dorsally, 1.65 times as long as wide; hind femur wide, 3.3 times as long as wide. Metasoma: first tergite rather long; 0.8 times as long as hind femur; second and following tergites smooth. Colour: body brown or black; forewing faintly infuscate; pterostigma and veins brown or dark brown.
3.9.6. Subfamily Euphorinae Foerster, 1862. The subfamily Euphorinae is a diverse group of koinobiont braconid wasps with a wide spectrum of hosts and stages (Tobias 1965, 1966; Shaw 1985). The members of this group are common and almost cosmopolitan.

Several euphorine taxa are recorded as fossils, mainly in amber (Brues 1933, 1939; Carpenter et al. 1937; Tobias 1987). Besides the tribe Blacini, which is sometimes considered as a separate subfamily (Achterberg 1982,1988), species of the tribes Meteorini, Oncometeorini, Perilitini, Centistini, Euphorini, Prosyntretini and Neoneurini are recorded as fossils. Among them are five species of Meteorus Haliday, 1835: M. brevis Brues, 1933, M. crassicornis Brues, 1933, M. elongatus Brues, 1933 and M. interstitialis Brues, 1933 from the Baltic amber, and "Meteorus" longicornis Statz, 1938 from Rott, near the Oligicene/Miocene boundary in Germany. The position of the amber species is clear, but the status of $M$. longicornis needs verification. Fushunobracon orientalis Hong, 2001 from the Eocene Fushun amber in China might also be a member of the tribe Meteorini.

Two genera of the tribe Centistini are recorded as fossils: Pygostolus Haliday, 1833 and Parasyrrhizus Brues, 1933. The position of Pygostolus from the Canadian and Baltic ambers is not clear, because both described species, P. clavatus Brues, 1933 and $P$. patriarchicus Brues, 1937, particularly the last one, differ considerably from extant species of this genus. The forewing venation of $P$. patriarchicus, especially the shape of discal cell, is very similar to the extant genus Korecnomis Park \& Achterberg, 1994. Described from Baltic amber is the genus Parasyrrhizus Brues, 1933 (type species P. ludens Brues, 1933), similar to extant Spathicopis Achterberg, 1977 in forewing venation and the presence of notauli, but it apparently differs in having the sternauli absent, the body stout, and the antenna short and stout (shape of the first tergite is unclear). Three species and two genera were described by Brues (1933, 1939 ) in the tribe Perilitini: Perilitus (Microctonus) nanus (Brues, 1933), comb. nov., and two possibly related species with petiolate first tergite in two monotypic genera Onychoura Brues, 1933 (type species O. petiolata Brues, 1933) and Meteorites Brues, 1939 (type species M. inopinata Brues, 1939). A single species, Euphorus indurescens Brues, 1910, was described in the tribe Euphorini on the basis of a poorly preserved fossil from Florissant (Brues 1910).

There is an undoubtedly a remarkable discovery in the Baltic amber of the specialised euphorine tribe Neoneurini, represented there by a monotypic extinct genus Elasmosomites Brues, 1933 (type species E. primordialis Brues, 1933), and the monotypic and exclusively Eocene tribes Oncometeorini Tobias, 1987 (Oncometeorus aduncus Tobias, 1987 with abnormally hook-shaped ovipositor) and Prosyntretini Tobias, 1987 (Prosyntretus calcaratus Tobias, 1987).

Composition of the euphorine fossils in the Bembridge Marls is much more modest, with only two identifiable species of Meteorus described below.

Genus Meteorus Haliday, 1835

Remarks. Described fossil species of Meteorus (Brues 1933; Statz 1938) have $\mathrm{m}-\mathrm{cu}$ distinctly postfurcal (entering the second submarginal cell) or at most interstitial. In contrast, all Bembridge Meteorus have $\mathrm{m}-\mathrm{cu}$ far antefurcal (entering the first submarginal cell well before its apex).

Meteorus applanatus Belokobylskij, sp. nov. Plate 12, figs 7-9; Text-fig. 39 


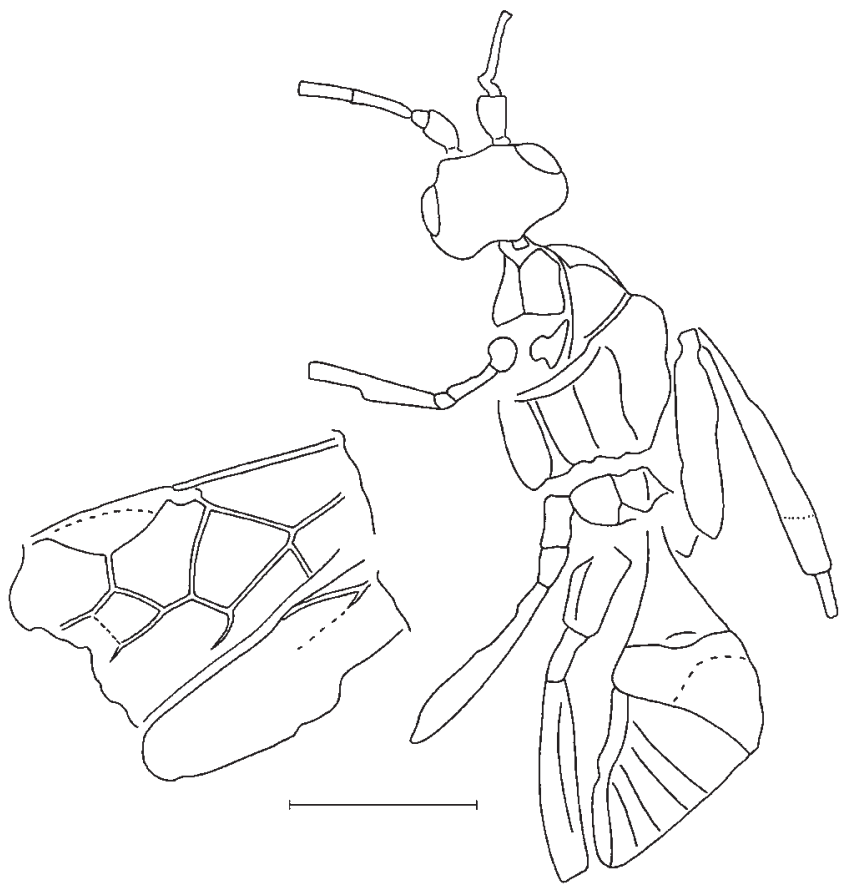

Text-figure 40 Meteorus crassitergum sp. nov., holotype, NHMUK I.9065. Scale bar $=1 \mathrm{~mm}$.

Etymology. After applanatus, the Latin for flattened, referring to shape of fossil.

Holotype. NHMUK I.9656, Bembridge Marls, NW Isle of Wight, UK, Brodie Collection; dorsal aspect of insect with each head, meso- and metasoma, antennae, wings and legs more or less incomplete.

Paratypes. NHMUK I.8674, lateral aspects of incomplete mesosoma and metasoma with wings and partial legs; NHMUK I.8894 ventral aspect of head, mesosoma, metasomal base, incomplete wings and leg fragments. All from Bembridge Marls, NW Isle of Wight, UK, Brodie Collection.

Diagnosis. The new species differs from M. crassitergum sp. nov. in having $\mathrm{r}$ arising weakly behind the middle of the pterostigma, first metasomal tergite less wide apically, and 1$\mathrm{M}$ weakly curved. Comparison with extant species of Meteorus is complicated by insufficient preservation.

Description of holotype. Body length $c .4 .2 \mathrm{~mm}$; length of head, mesosoma and first metasomal tergite combined $3 \cdot 1$ $\mathrm{mm}$, mesosoma $1.6 \mathrm{~mm}$, forewing $3.9 \mathrm{~mm}$. Head in lateral view 1.3 times as high as maximum length. Antenna: scape large, 1.6 times as long as maximum width, twice as long as pedicel. First flagellar segment c.5.0 times as long as maximum width, almost as long as second segment. Mesosoma 2.4 times as long as maximum width at level of mesoscutum. Median lobe of mesoscutum distinctly convex anteriorly; notauli present. Forewing 2.6 times as long as maximum width. Pterostigma subtriangular and wide, 2.7 times as long as maximum width; $\mathrm{r}$ arising slightly beyond middle of pterostigma, 0.8 times as long as maximum pterostigmal width. Marginal cell slightly shortened, 1-R 1 about 1.3 times as long as pterostigma. 3-SR 0.9 times as long as $\mathrm{r}, 0.15$ times as long as the straight SR1, 0.6 times as long as 2-SR, about as long as $\mathrm{r}-\mathrm{m}$. Second submarginal cell 1.2 times as long as wide, 0.6 times as long as subdiscal cel. 1-SR $+\mathrm{M}$ weakly curved; $\mathrm{m}-\mathrm{cu}$ strongly antefurcal, almost twice as long as 2-SR+M. Discal cell distinctly and shortly petiolate anteriorly, 1.4 times as long as wide. 1$\mathrm{M}$ distinctly convex; cu-a postfurcal, distant from 1-M for 0.45 times cu-a length. Legs: hind femur 4.0 times as long as maximum width, with rather wide and long transverse protuberance along lower 0.6. Metasoma: first tergite distinctly and almost linearly widened towards apex, without spiracular tubercle, its length 1.6 times apical width, apical width about 3.5 times its basal width. Colour: propodeum and first metasomal tergite black or dark brown; rest of metasoma possibly brown or pale brown; wings hyaline; pterostigma and veins dark brown.

Additional characters from paratypes. Forewing length $3 \cdot 1-3 \cdot 5 \mathrm{~mm}$. Head transverse, about twice as wide as long, evenly roundly narrowed behind eyes. Eye rather large, transverse diameter of eye in dorsal view about twice as long as temple. Occipital carina distinct. Sides of pronotum almost entirely smooth. Prepectal carina distinct. Mesopleuron 1.41.5 times as high as long, with more or less distinct, wide and almost smooth sternaulus. Scutellum distinctly convex. Subalar depression rather deep and narrow. Forewing $c .2 \cdot 2$ times as long as wide. Pterostigma $3 \cdot 0-3 \cdot 3$ times as long as maximum width; $\mathrm{r}$ 0.7-0.8 times as long as maximum width of pterostigma. 1-R1 $1 \cdot 2-1 \cdot 3$ times as long as pterostigma. 3-SR $0 \cdot 7-0.8$ times as long as $\mathrm{r}, 0 \cdot 13-0 \cdot 15$ times as long as SR 1 , $0 \cdot 45-0.5$ times as long as 2-SR, 0.7 times as long as $\mathrm{r}-\mathrm{m}$. Second submarginal cell $1 \cdot 05-1 \cdot 2$ times as long as width; $\mathrm{m}-\mathrm{cu}$ $2 \cdot 0-2 \cdot 5$ times as long as $2-\mathrm{SR}+\mathrm{M}$. 1-SR $+\mathrm{M}$ almost straight. Discal cell $1 \cdot 2-1 \cdot 3$ times as long as wide; cu-a postfurcal, distant from 1-M for $0 \cdot 3-0 \cdot 4$ times cu-a length. Ventral margins of first tergite possibly separated.

\section{Meteorus crassitergum Belokobylskij, sp. nov. Plate 12, fig. 5; Text-fig. 40}

Etymology. After crassus, the Latin for thick, and tergum, referring to width of the first metasomal tergite.

Holotype. NHMUK I.9065, Bembridge Marls, NW Isle of Wight, UK, Brodie Collection; subventral aspect of insect with antennae, wings, legs and metasoma incompletely preserved.

Diagnosis. Similar to extant M. oculatus Ruthe, 1862 (Huddleston 1980) in having hind tibia distinctly thickened, but differs in having the temple long, head behind the eyes rounded and less strongly narrowed, second submarginal cell and 2-SR + M long. Differs from M. corax Marshall, 1898 in having the first tergite wide apically, flagellar segments long, hind femur and tibia distinctly wider, and $2-\mathrm{SR}+\mathrm{M}$ of forewing long.

Description. Length of head, mesosoma and first metasomal tergite combined $2.8 \mathrm{~mm}$, of mesosoma $1.6 \mathrm{~mm}$. Head weakly transverse, 1.6 times as wide as median length. Head behind eyes weakly convex anteriorly and roundly narrowed posteriorly. Transverse diameter of eye in dorsal view about as long as temple. Antenna: Scape large, 1.6 times as long as maximum width. First flagellar segment 3.3 times as long as apical width, almost as long as second segment. Mesosoma 1.8 times as long as wide. Scutellum more or less convex. Prepectal carina present. Sternauli shallow and wide, almost smooth. Forewing: pterostigma subtriangular, wide, 2.8 times as long as maximum width; $r$ arising distinctly behind middle of pterostigma, 0.7 times as long as maximum pterostigmal width. 3-SR $0 \cdot 85$ times as long as r, 0.55 times as long as 2-SR, 0.7 times as long as $\mathrm{r}-\mathrm{m}$. Second submarginal cell about as long as wide, $0 \cdot 6$ times as long as subdiscal cell. 1-SR $+\mathrm{M}$ weakly curved; $\mathrm{m}-\mathrm{cu}$ strongly antefurcal, almost twice as long as $2-\mathrm{SR}+\mathrm{M}$. Discal cell distinctly and shortly petiolate anteriorly, 1.3 times as long as wide; $\mathrm{cu}-\mathrm{a}$ postfurcal, distant from 1-M for 0.6 times $\mathrm{cu}-\mathrm{a}$ length. Legs: hind femur 4.5 times as long as maximum width; hind tibia distinctly thickened towards apex, 8.6 times as long as wide, its maximum width 0.7 times width of femur. 
Metasoma: first tergite distinctly and almost linearly widened towards apex, without spiracular tubercle, its length c.1.2 apical width, apical width 3.5 times its basal width. Colour: head, mesosoma at least in part, and metasoma dark brown to black; wings hyaline; pterostigma and veins brown.

3.9.7. Subfamily Exothecinae Foerster, 1862, s. I. Subfamily Exothecinae s. 1. is one of the most disputed groups in the Braconidae, and several of its tribes now have the rank of subfamily (Achterberg 1993). The real taxonomic and phylogenetic positions of these taxa require special study using modern morphological, anatomical and molecular data. For the present, I prefer to use the subfamily in the broad sense.

A few exothecine genera and species have been recorded as fossils, although in many cases their taxonomic position needs re-study. Two species are described in the genus Cantharoctonus Viereck, 1912 (tribe Rhysipolini): C. oligocenicus Brues, 1933 from the Eocene Baltic amber (Brues 1933) and C. bruesii Statz, 1936 from near the Oligocene/Miocene boundary (Statz 1936), but their positions are problematic. C. oligocenicus was originally included in the Spathiini (Doryctinae) and characterised as having its first tergite petiolate, second metasomal tergite very long and covering almost entirely the following tergites, and CU1a arising near the middle of the distal margin of the closed subdiscal cell. C. bruesii was originally described as having the first tergite short and not petiolate, and CU1a arising far behind middle of the distal side of the subdiscal cell. Both descriptions are not enough to identify positions of these species with reasonable confidence. Colastes abrogatus (Brues, 1910) (originally Exothecus abrogatus: Brues 1910) shows characters unusual for extant species of Colastes Haliday, 1833, such as the extremely slender antenna, almost petiolate metasoma, interstitial position of both $\mathrm{cu}-\mathrm{a}$ and $\mathrm{m}-\mathrm{cu}$, and large second submarginal cell distinctly widened towards its apex. Rhysipolis distinctus Théobald, 1937 described from the French Oligocene (Théobald 1937) also deserves verification of its generic placement.

Three genera of the tribe Hormiini have been reported from the Taimyr and Baltic ambers. The specialised extinct genus Parahormius has been mentioned as found in the Cretaceous Taimyr amber (Zherikhin 1978). Hormius submersus (Brues, 1933) was described (as Hormiellus submersus) from the Baltic amber (Brues, 1933). It has a venation of the Hormius type, but several other characters as described raise some doubts as to this placement: vertex, mesoscutum and scutellum chagrined; maxillary palpi long; pterostigma narrow; $\mathrm{cu}-\mathrm{a}$ strongly postfurcal. One more fossil from Baltic amber has been described as the extinct monotypic genus Prochremylus Brues, 1933 (type species P. brevicornis Brues, 1933), also with Hormius-type forewing venation, but generically distinct from Hormius species in having short and thick antenna, subcircular head, enlarged femora, and indistinct sternauli.

Only one species of this group is recorded from the Bembridge Marls.

Genus Chremylus Haliday, 1833

Chremylus infuscatus Belokobylskij, sp. nov.

Plate 13, fig. 1; Text-fig. 41

Etymology. After infuscatus, the Latin for infuscate, referring to colouration of the forewing.

Holotype. NHMUK I.9066, Bembridge Marls, NW Isle of Wight, UK, Brodie Collection; headless body with incomplete forewings and legs in dorsoventral view.

Diagnosis. Differs from the type species C. elaphus Haliday in having second and third tergites long, $\mathrm{m}-\mathrm{cu}$ distinctly postfurcal, and forewing distinctly infuscate.
Description. Length of metasoma $0.9 \mathrm{~mm}$, forewing 1.4 $\mathrm{mm}$. Mesosoma: prepectal carina present. Sternauli narrow, rather deep, situated in basal 0.6 of mesopleuron. Mesopleuron 1.5 times as high as long. Forewing c.2.5 times as long as wide. Pterostigma subtriangular, wide, $3 \cdot 2$ times as long as maximum width; $r$ arising from middle of pterostigma, 1.1 times as long as maximum pterostigmal width. Marginal cell not shortened, 1-R1 1.2 times as long as pterostigma. 3SR 1.2 times as long as $\mathrm{r}, 0.4$ times as long as the straight SR1, almost as long as 2-SR, 1.4 times as long as $\mathrm{r}-\mathrm{m}$. Second submarginal cell $2 \cdot 2$ times as long as width, $0 \cdot 9$ times as long as discal cell; $\mathrm{m}-\mathrm{cu}$ distinctly postfurcal, $3 \cdot 0$ times as long as $2-\mathrm{SR}+\mathrm{M}, 0 \cdot 7$ times as long as $2-\mathrm{SR}$. $1-\mathrm{SR}+\mathrm{M}$ weakly $\mathrm{S}-$ shaped. Discal cell shortly petiolate anterior, 1.6 times as long as wide. 1-M and $\mathrm{m}-\mathrm{cu}$ convergent posterior. Subdiscal cell closed posterior, rather narrow, $3 \cdot 5$ times as long as wide. CU1a not interstitial, arising distinctly before middle of distal side of subdiscal cell; cu-a postfurcal, distant from 1-M for about cu-a length. Legs: middle femur rather thick, 4.3 times as long as its width. Metasoma oval. First tergite strongly and almost linearly widened towards apex, its length 0.7 times apical width. Tergites behind first one rather soft, smooth, their combined length 1.5 times maximum width. Second suture indistinct. Median length of second and third tergites combined 1.15 times basal width of second tergite, 0.8 times maximum width of these tergites. Colour: propodeum and possibly all mesosoma dark brown; metasoma brown to dark brown; wings distinctly infuscate; pterostigma and veins brown to dark brown.

Remarks. The position of this species in Chremylus is not certain because of insufficient preservation, but seems acceptable for the present. The new species shares the following characters with Chremylus: second and third metasomal tergites enlarged; 1-M and $\mathrm{m}$-cu distinctly convergent posteriorly; cu-a distinctly postfurcal; $\mathrm{m}$-cu postfurcal (often almost interstitial in the type species of Chremylus); CU1a arising before middle of distal margin of subdiscal cell; sternauli distinct. These characters differentiate the new species from Prochremylus.

3.9.8. Subfamily Helconinae Foerster, 1862. The subfamily Helconinae is one of the less derived groups of koinobiont parasitoids developing inside of the larvae of xylophagous beetles. The taxa of this subfamily are relatively common in various kinds of fossil assemblages. One of the interesting results of the study of helconine wasps in the Baltic amber was the discovery of Acampsohelcon rasnitzini Tobias, 1987, with the carapace-like structure of the metasoma, which has been placed in Acampsohelconini, a tribe of its own (Tobias 1987) and later (Achterberg 2000) elevated at the subfamily rank. Wing venation of Eobracon Cockerell is similar to that of Acampsohelcon, but carapace tergites in this genus are possibly fused and the ovipositor is much longer (see also discussion in Cheloninae). Sinobracon speciosus Hong, 1974 described from the Fushun amber (Eocene of China) is possibly also a member of this subfamily.

The largest number of helconine fossil species were described in the genus Aspicolpus Wesmael, 1838. Venational characters used in the current taxonomy of Helconinae suggest the fossil Aspicolpus should be split into several groups of generic rank. However, this idea is not easily realised because of the incomplete descriptions and insufficiently informative figures, if any. That is why I suggest these fossils form three groups in the genus Aspicolpus. One of them includes A. clarus Brues, 1933 and $A$. perditellus Brues, 1933, which have short to very short 3-SR (not longer than r) and possibly smooth second and third metasomal tergites (known only for the first species; unknown in the extant species of Aspicolpus). A. fraternus Brues, 1933 is characterised by the discal cell petiolate anteriorly (unknown in Recent Aspicolpus), second submarginal cell distinctly narrowed 


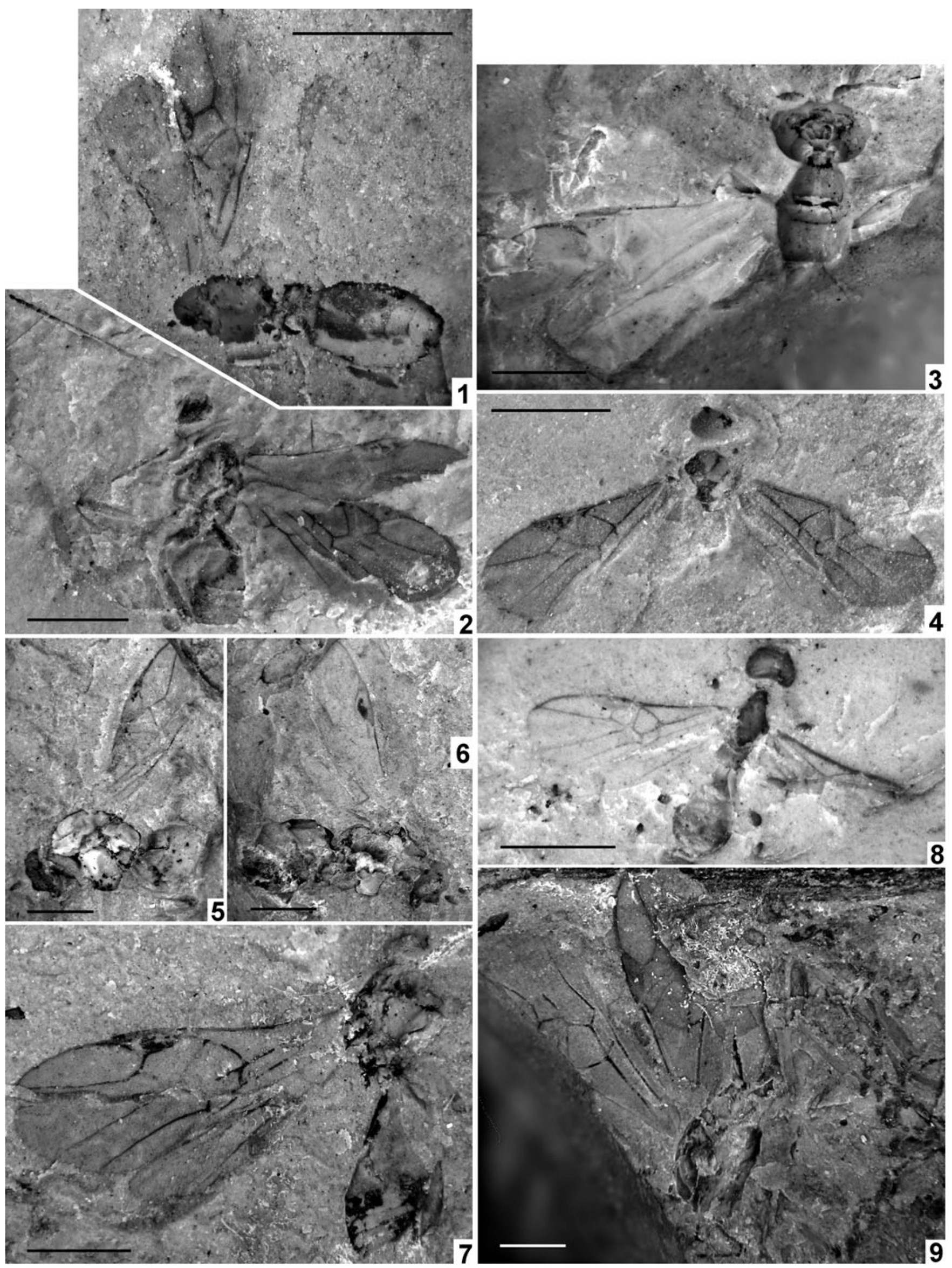

Plate 13 (1) Chremylus infuscatus sp. nov., holotype, NHMUK I.9066. (2) Calyptoides veternus Cockerell, holotype, NHMUK I.9722. (3) Aspicolpus temporalis sp. nov., holotype, NHMUK I.9935. (4) Diospilus acourti Cockerell, holotype, NHMUK I.9071. (5-6) Diospilus curtithorax sp. nov., holotype, NHMUK I.9286/I.9025: (5) part; (6) counterpart. (7) Hellenius ? kozlovi sp. nov., holotype, NHMUK In.17298. (8) Taphaeus cervicalis (Cockerell), holotype, NHMUK I.9199. (9) Homolobus rasnitsyni sp. nov., holotype, NHMUK In.20545. Scale bars $=1 \mathrm{~mm}$ 


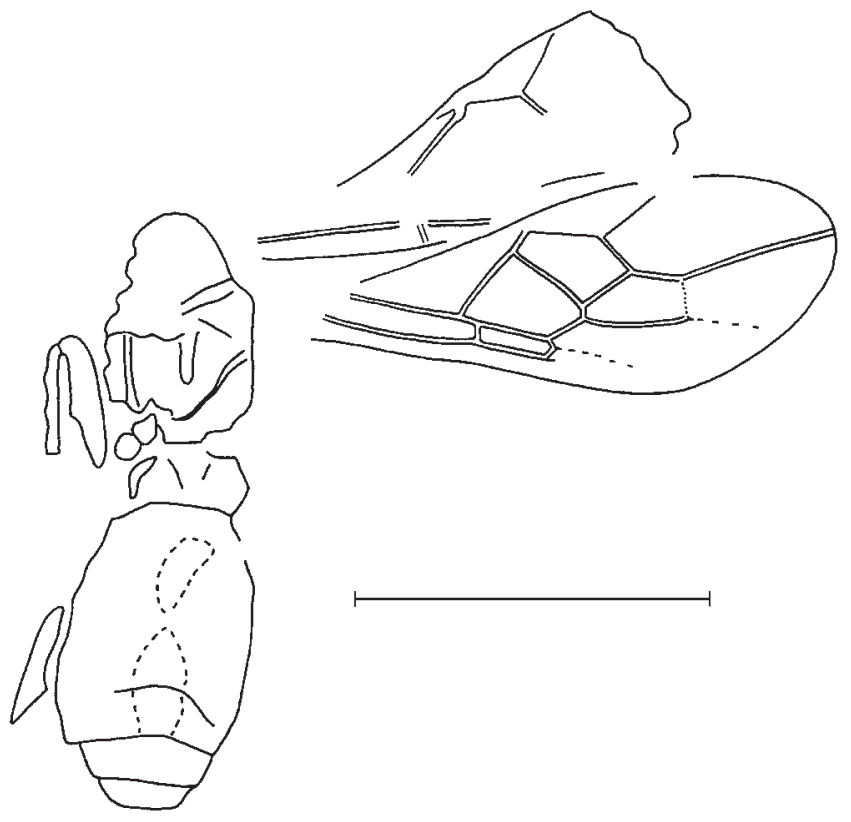

Text-figure 41 Chremylus infuscatus sp. nov., holotype, NHMUK I.9066. Scale bar $=1 \mathrm{~mm}$.

distally, and $\mathrm{r}$ arising distinctly behind middle of the pterostigma. The third group is composed of A. moniliformis Brues, 1933 and A. similis Brues, 1933, which have a quite short second submarginal cell but, judging from other described features, they are probably the only real members of Aspicolpus. Based on wing venation, and particularly shape and size of the second submarginal cell, and because of rather long first metasomal tergite, Aspicolpus longicornis Statz, 1936 from near the Oligocene/Miocene boundary of Rott in Germany (Statz 1936) can be transferred to the genus Taphaeus. Several species similar to Aspicolpus in having rather long and not triangular second submarginal cell species were described by Brues (1933) in the genus Microtypus Ratzeburg, 1848. The status of all these taxa needs conformation: it is possible that some of them deserve transfer to Helconinae, Macrocentrinae or Homolobinae.

There is no morphological reason to include $A$. minor Brues, 1933 in Austrohelcon Turner, except perhaps for the absence of a deep frontal cavity (Brues 1933). This species, together with the one described as Gymnoscelis klebsi Brues, 1933, deserves transfer to the genus Helcon Nees, in spite of several special features of wing venation in the latter (second submarginal cell subsquare with almost parallel 2-SR and $\mathrm{r}-\mathrm{m}, \mathrm{cu}-\mathrm{a}$ interstitial, only $2 \mathrm{~A}$ present). One peculiar species from Baltic amber has been described in the genus Eumacrocentrus Ashmead, 1900 (E. similis Brues, 1933).

The sole true member of the genus Diospilus Haliday, 1833, D. acourti Cockerell, 1921, has been described from the Bembridge Marls (Cockerell 1921a). According to the description of the forewing venation, and particularly the shape of the second submarginal cell, Diospilus repertus Brues, 1910 from the Florissant (Brues 1910) probably belongs to Aspicolpus as well, despite the description lacking several diagnostic characters of this genus. The very peculiar wing venation of Diospilus allani Brues, 1937 described from the Cretaceous Canadian amber (Brues 1937) suggests that it belongs to Rhyssalinae rather than Helconinae, even if the shape of the clypeus is unknown and the hind wing is insufficiently described. Similar venation is described in the extant ryssaline genus Pseudobathystomus Belokobylskij, 1986 as well as in some species of Oncophanes Foerster, 1862. Lastly, D. verus Théobald, 1937 from the Oligocene of France (Théobald 1937) is a quite distinct member of the subfamily Helconinae, but the shape of the second submarginal cell in the forewing indicates its position in the genus Taphaeus.

Taphaeus precox Brues, 1923 is apparently a true species of that genus from Baltic amber (Brues 1923). Sigalphus cervicalis Cockerell, 1921 from the Bembridge Marls (see below) and Aspicolpus longicornis Statz (see above) also deserve transfer to Taphaeus Wesmael, 1835. Peculiar wing venation similar to Ascogaster species is known for three species of the Eocene helconine genus Electrohelcon Brues, 1933 (E. grandis Brues, 1933, E. minor Brues, 1933 and E. foveatus Brues, 1933).

The status of Discoletes soporatus Brues, 1910 from the Florissant (Brues 1910) is not clear, because it has interstitial $\mathrm{m}-\mathrm{cu}$ and pale yellowish brown pterostigma, which are unknown or rare in extant Helconinae. The taxonomic position of Calyptoides veternus Cockerell, 1921 from the Bembridge Marls is discussed below.

\section{Genus Calyptoides Cockerell, 1921}

Type species. C. veternus Cockerell, 1921

Diagnosis. Similar to Taphaeus Wesmael, 1835. Differs from that and all other genera of Helconinae in having a long and thick process on the dorsal surface of the hind coxa.

Description. Antennae long and slender. Mesosoma short and high, mesoscutum highly and almost vertically elevated above pronotum. Sternauli deep and wide. Prepectal carina probably developed. In forewing, pterostigma subtriangular and rather wide. 1-R1 longer than pterostigma; $r$ arising almost from middle of pterostigma. Marginal cell not shortened, pointed apically. 3-SR shorter than r; r-m present. Second submarginal cell subtrapezoid and rather narrow. Discal cell shortly sessile anteriorly; $\mathrm{m}-\mathrm{cu}$ far antefurcal; cu-a distinctly postfurcal. Subdiscal cell closed apico-posteriorly. 2A and a indistinct. Sub-basal cell of hind wing large. Legs slender and long. Hind coxa with rather thick, more or less pointed and rearward directed dorso-posterior process. First metasomal tergite as long as second and third tergites combined. Second metasomal suture absent.

Calyptoides veternus Cockerell, 1921

Plate 13, fig. 2; Text-fig. 42

1921a Calyptoides veternus Cockerell, p. 13, fig. 13.

1992 Calyptoides veternus Cockerell, 1921: Carpenter, p. 478.

Holotype. NHMUK I.9722, Bembridge Marls, NW Isle of Wight, UK, Brodie Collection; lateral aspect of insect with appendages incompletely preserved.

Diagnosis. As for genus.

Description. Body length $2.1 \mathrm{~mm}$, mesosoma $0.8 \mathrm{~mm}$, hind femur $0.6 \mathrm{~mm}$, metasoma $0.9 \mathrm{~mm}$, forewing $2.2 \mathrm{~mm}$. Head elongated below, its height 1.5 times maximum width. Antenna rather long, as preserved 0.9 times as long as forewing. Subapical antennal segment c.4.0 times as long as wide. Mesosoma 1.2 times as long as maximum height. Scutellum distinctly convex. Forewing $c .2 \cdot 8$ times as long as maximum width. Pterostigma 3.0 times as long as maximum width. $1-\mathrm{R} 11 \cdot 2$ times as long as pterostigma, 2-R1 short. Marginal cell 3.0 times as long as maximum width. $\mathrm{R} 0.6$ times as long as maximum width of pterostigma. 3-SR 0.8 times as long as $\mathrm{r}, 0 \cdot 1$ times as long as weakly curved SR1, 0.4 times as long as 2-SR; r-m unsclerotised, 0.7 times as long as 2-SR. Second submarginal cell about as long as wide. $1-\mathrm{SR}+\mathrm{M}$ straight, 3.5 times as long as $2-\mathrm{SR}+\mathrm{M}$. 2-SR $+\mathrm{M} 0.4$ times as long as 2-SR, 0.5 


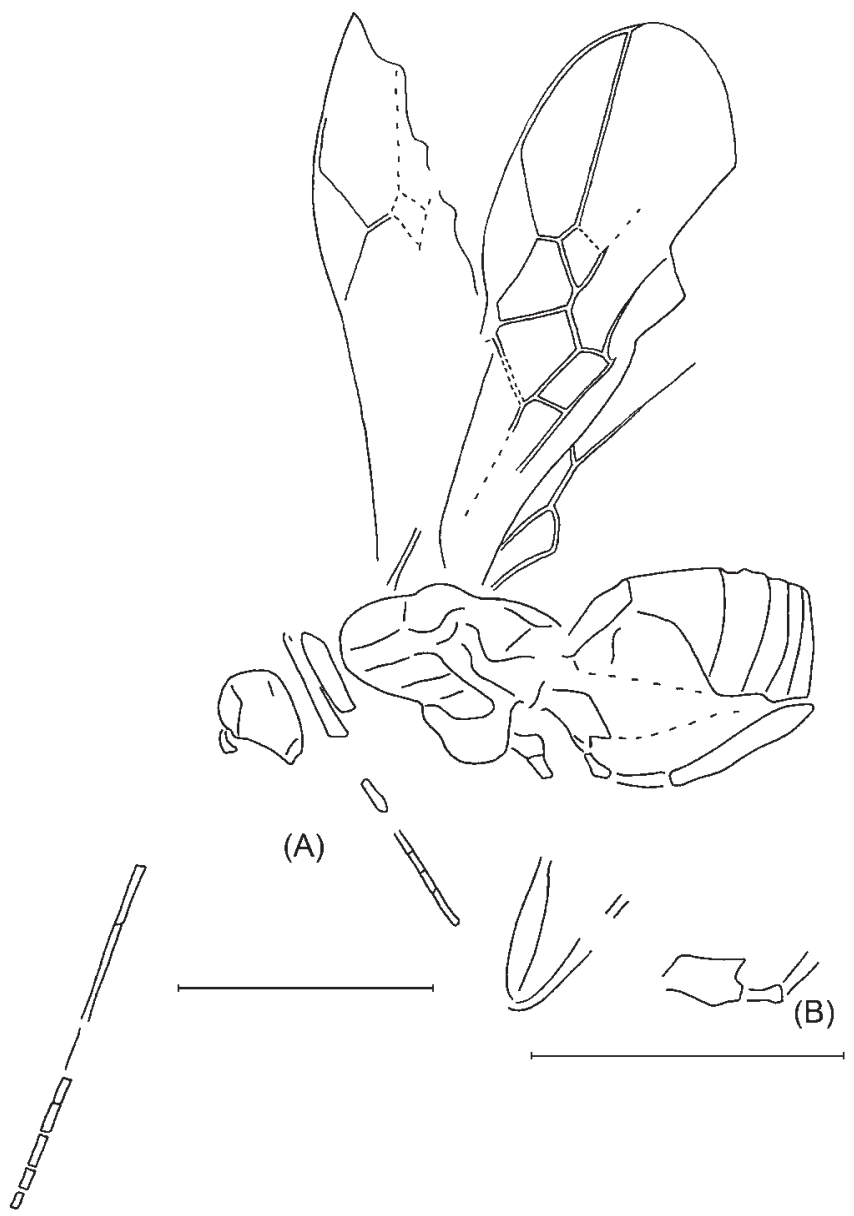

Text-figure 42 Calyptoides veternus Cockerell: (A) holotype, NHMUK I.9722; (B) same, hind coxa. Scale bars $=1 \mathrm{~mm}$.

times as long as $\mathrm{m}-\mathrm{cu}, 0.4$ times as long as sclerotised part of 2-M. Discal cell 1.3 times as long as wide. Distance from 1-M for $0 \cdot 35$ times cu-a length. Subdiscal cell wide, $2 \cdot 3$ times as long as wide; CU1b distinct. CU1a arising from posterior $0 \cdot 3$ of distal side of subdiscal cell, rather distinctly sclerotised in about its basal half. Hind wing: $\mathrm{M}+\mathrm{CU} 0.45$ times as long as $1-\mathrm{M}, 1 \cdot 3$ times as long as $\mathrm{m}-\mathrm{cu}$. Legs: middle femur $6 \cdot 2$ times as long as width; hind coxa rather elongate; hind femur 5.5 times as long as width. Metasoma 1.2 times as long as mesosoma. Second and third tergite long; following tergites short and distinctly protruding behind third one. Colour: possibly entirely black head; mesosoma dorsally and first tergite; metasoma behind first tergite brown; wings hyaline; pterostigma and veins brown.

Genus Aspicolpus Wesmael, 1838

Aspicolpus temporalis Belokobylskij, sp. nov.

Plate 13, fig. 3; Text-fig. 43A

Etymology. After temporalis, the Latin for temporal, referring to long temples.

Holotype. NHMUK I.9935, Bembridge Marls, NW Isle of Wight, UK, Brodie Collection; ventral aspect of head with incomplete antennae, pro- and mesothorax with incomplete wings and legs.

Diagnosis. Distinctly differs from $A$. moniliformis Brues and A. similis Brues (Brues, 1933) in having long 3-SR and second submarginal cell.

Description. Length of head $0.7 \mathrm{~mm}$, pro- and mesothorax combined c. $1.0 \mathrm{~mm}$, forewing $3.3 \mathrm{~mm}$. Head distinctly transverse, 1.6 times as wide as maximum length, 1.4 times as wide

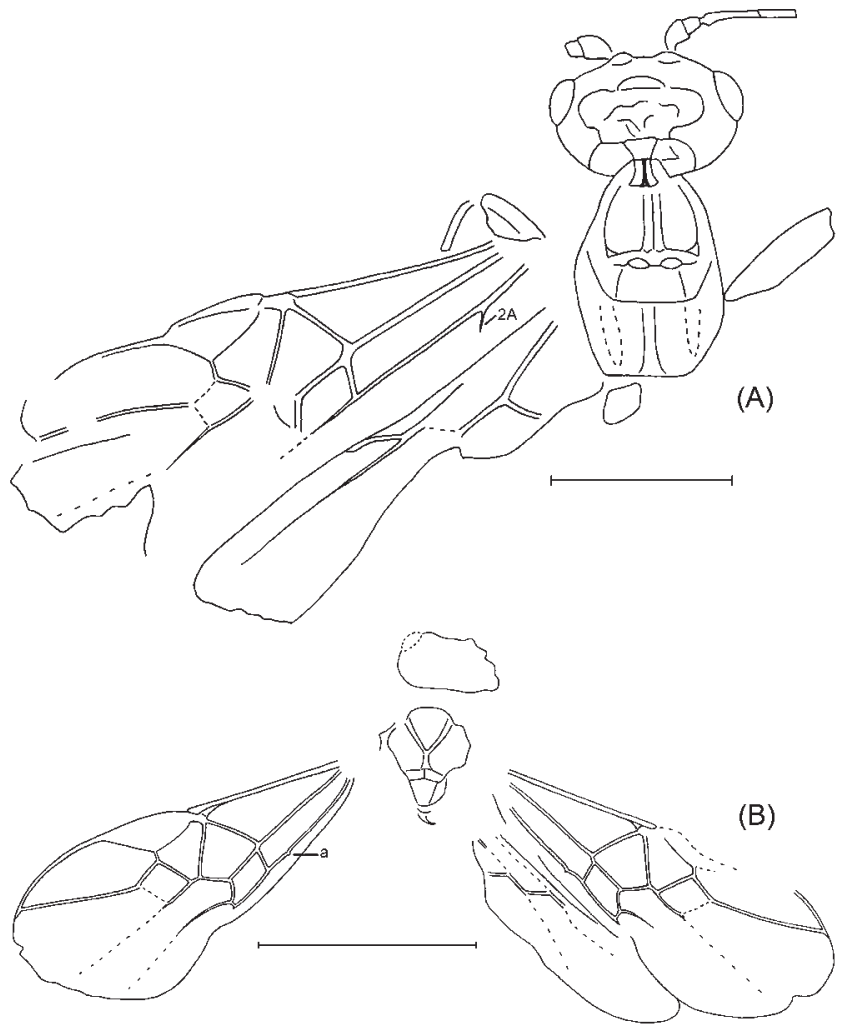

Text-figure 43 (A) Aspicolpus temporalis sp. nov., holotype, NHMUK I.9935. (B) Diospilus acourti Cockerell, holotype NHMUK I.9071. Scale bars $=1 \mathrm{~mm}$.

as mesosoma. Head behind eyes rather strongly and roundly narrowed, transverse diameter of eye almost as long as temple. Occipital carina distinct, fused below with hypostomal carina distinctly above mandibular base. Malar suture present. Malar space short, 0.4 times as high as basal width of mandible. Clypeus wide and narrow, with weakly and evenly roundly curved posterior margin, 0.7 times as wide as face. Clypeal suture deep laterally and fine above between tentorial pits. Face smooth. Antenna: scape rather short, 1.85 times as long as maximum width, 2.4 times as long as pedicel. First flagellar segment slender, c. 6.0 times as long as wide apically. Mesosoma: propleura convex below. Prepectal carina distinct and rather highly situated laterally. Sternauli very shallow and wide, possibly smooth. Forewing 2.6 times as long as maximum width. Pterostigma partly deformed, subtriangular, rather wide, $2 \cdot 2$ times as long as maximum width; $r$ arising slightly behind middle of pterostigma and almost perpendicular to it, $0 \cdot 35$ times as long as maximum pterostigmal width, forming distinct obtuse angle with 3-SR. 3-SR rather short, 1.4 times as long as $\mathrm{r}, 0.6$ times as long as 2-SR, 0.9 times as long as $\mathrm{r}-\mathrm{m}$; $\mathrm{r}-\mathrm{m}$ distinct, 0.7 times as long as 2-SR. Second submarginal cell $c .1 .2$ times as long as wide, $0 \cdot 6$ times as long as subdiscal cell along posterior margin. 1-SR $+\mathrm{M}$ straight. Discal cell narrowly sessile anteriorly; cu-a postfurcal, distant from basal for 0.4 times cu-a length. Subdiscal cell wide, possibly closed antero-posteriorly by $\mathrm{CU} 1 \mathrm{~b}, c .2 .5$ times as long as maximum width. $2 \mathrm{~A}$ distinct, a absent. Hind wing: $\mathrm{m}-\mathrm{cu}$ absent. $\mathrm{M}+\mathrm{CU}$ about twice as long as 1-M. SR subparallel to wing anterior margin. Basal cell c.5.0 times as long as wide. Legs: fore femur rather wide, 3.6 times as long as wide. Colour: mesosoma possibly dark brown or black; pterostigma and veins brown.

Remarks. The position of this species in Aspicolpus is supported with only $2 \mathrm{~A}$ developed, a long second submarginal cell and 3-SR. 


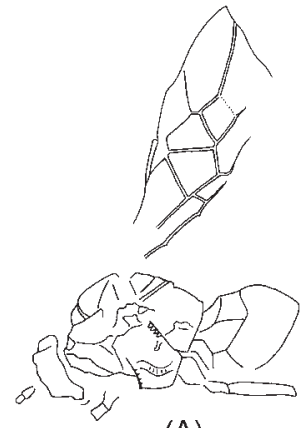

(A)

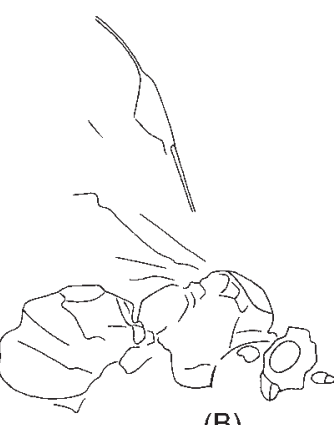

(B)

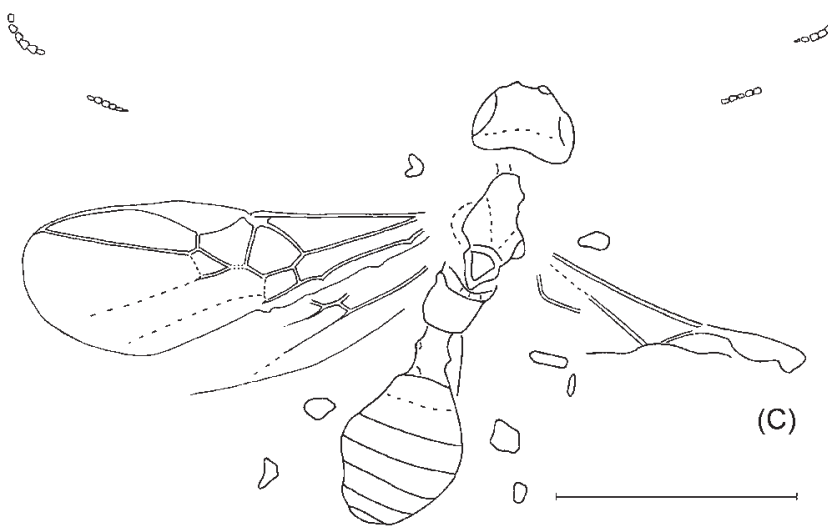

Text-figure 44 (A, B) Diospilus curtithorax sp. nov., holotype, NHMUK I.9286/I.9025: (A) part; (B) counterpart; (C) Taphaeus cervicalis (Cockerell), holotype, NHMUK I.9199. Scale bars $=1 \mathrm{~mm}$.

Genus Diospilus Haliday, 1833

Diospilus acourti Cockerell, 1921

Plate 13, fig. 4; Text-fig. 43B

1921a Diospilus acourti Cockerell, p. 12, fig. 12.

Holotype. NHMUK I.9071/ I.9184 (part and counterpart), Bembridge Marls, NW Isle of Wight, UK, Brodie Collection; head, mesonotum and wings in dorsal view.

Diagnosis. Similar to extant D. oleraceus Haliday, 1833, the widely distributed Palaearctic parasitoid of beetles. Their distinction is difficult based on the limited information available for the fossil.

Description. Combined length of head and mesonotum 0.95 $\mathrm{mm}$, forewing $2.0 \mathrm{~mm}$. Head: subcubical, its width 1.4 times maximum length. Head weakly convex behind eyes, temple length 1.3 times transverse diameter of eye. Mesosoma: mesoscutum wide, its maximum width 1.4 times maximum length, median lobe very weakly rounded anteriorly. Notauli distinct, rather narrow and complete, fused before prescutellar depression. Prescutellar depression rather wide, with medial carina. Forewing 2.4 times as long as maximum width. Pterostigma subtriangular, 2.7 times as long as maximum width. 1-R1 1.2 times as long as pterostigma, 2-R1 short; $\mathrm{r}$ arising almost from middle of pterostigma, $0 \cdot 3$ times as long as maximum pterostigmal width. Marginal cell slightly shortened, pointed apically, 2.6 times as long as maximum width. 3-SR 2.8 times as long as $\mathrm{r}, 0 \cdot 3$ times as long as the straight SR $1,0.7$ times as long as 2-SR; $\mathrm{r}-\mathrm{m}$ present, faintly pigmented, 0.8 times as long as 2-SR. Second submarginal cell weakly widened anteriorly, $1 \cdot 1$ times as long as wide. $1-\mathrm{SR}+\mathrm{M}$ straight, $6 \cdot 5$ times as long as 2-SR+M. 2-SR+M $0 \cdot 2$ times as long as 2-SR, $0 \cdot 3$ times as long as $\mathrm{m}-\mathrm{cu}, 0.2$ times as long as $2-\mathrm{M}$. Discal cell shortly sessile anteriorly, as long as wide; $\mathrm{m}-\mathrm{cu}$ strongly antefurcal; cu-a shortly postfurcal. Subdiscal cell wide, closed

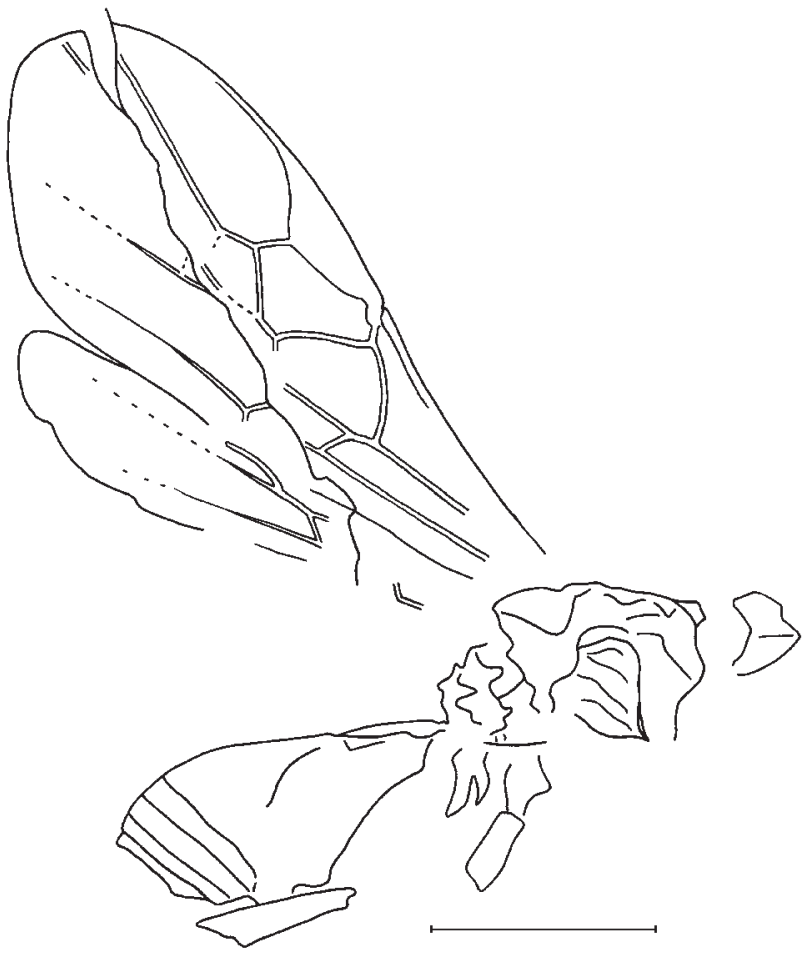

Text-figure 45 Hellenius ? kozlovi sp. nov., holotype, NHMUK In.17298. Scale bar $=1 \mathrm{~mm}$.

apico-posteriorly by CU1b, $2 \cdot 5$ times as long as width. CU1a arising from posterior 0.3 of distal margin of subdiscal cell, rather distinctly sclerotised in basal c.0-3. 3-CU1 distinctly curved. a present, but very indistinct. Hind wing: sub basal cell large; $\mathrm{M}+\mathrm{CU}$ c. 0.5 times as long as $1-\mathrm{M}$ and 1.8 times as long as $\mathrm{m}$-cu. Colour: head, almost entirely, and mesonotum black; wings hyaline; pterostigma and veins brown.

\section{Diospilus curtithorax Belokobylskij, sp. nov.} Plate 13, figs 5, 6; Text-fig. 44A, B

Etymology. From curtus, the Latin for short, and thorax, referring to form of mesosoma.

Holotype. NHMUK I.9286/ I.9025 (part and counterpart), Bembridge Marls, NW Isle of Wight, UK, Brodie Collection; lateral aspect of insect with incomplete appendages and metasoma.

Diagnosis. Very similar to $D$. acourti, but differs by having the second submarginal cell not widened anteriorly, 2-SR $+\mathrm{M}$ short and the mesosoma very short and high.

Description. Length of mesosoma 1.4-1.5 mm, forewing $c$. $3.0 \mathrm{~mm}$. Head: occipital carina distinct. Eye medium size, 1.4 times as high as broad. Malar space short, 0.2 times as high as longitudinal diameter of eye, 0.7 times as high as basal width of mandible. Antenna: scape about as long as wide. Pedicel rather long. Subapical segments 1.4-1.7 times as long as maximum width. Mesosoma short and high, $1 \cdot 1-1 \cdot 15$ times as long as high. Mesoscutum highly and roundly elevated above pronotum, with deep notauli at least anteriorly. Scutellum weakly convex. Mesopleuron about twice as high as long, with deep, curved, rather narrow, long and crenulated sternaulus. Prepectal carina present. Mesopleural suture distinctly crenulated anteriorly. Propodeum largely irregularly areolate at least in posterior half. Forewing: pterostigma triangular, wide and short, 2.5 times as long as maximum width. Marginal cell shortened; $r$ arising slightly behind middle of pterostigma, $0 \cdot 25$ times as long as maximum pterostigmal width, 
forming very obtuse angle with 3-SR. 3-SR 4.0 times as long as $\mathrm{r}, 0.7$ times as long as 2-SR; $\mathrm{r}-\mathrm{m}$ present, faintly pigmented, almost parallel to 2-SR, 0.75 times as long as 2-SR, almost as long as 3-SR. Second submarginal cell not widened anteriorly, subparallel-sided, 1.3 times as long as wide, rather narrow. 1$\mathrm{SR}+\mathrm{M}$ almost straight, 8.5 times as long as 2-SR+M. 2$\mathrm{SR}+\mathrm{M} 0 \cdot 15$ times as long as 2-SR, $0 \cdot 2$ times as long as 2-M. Discal cell shortly but distinctly sessile anteriorly, almost as long as wide; $\mathrm{m}-\mathrm{cu}$ antefurcal; $\mathrm{cu}-\mathrm{a}$ shortly postfurcal, distant from 1-M for $0 \cdot 3$ times cu-a length. Subdiscal cell closed anteroposteriorly. 2A and a present, but very indistinct. Legs: Middle coxa rather large. Metasoma wide. Colour: head possibly black; mesosoma brown to black; metasoma brown; wings hyaline; pterostigma and veins dark brown.

\section{Genus Hellenius Tobias, 1982}

Remarks. The recently described Palaearctic genus Hellenius (Tobias 1982) includes three extant species. The hosts of this genus are unknown yet, but according to their position in Helconinae they are possibly beetle larvae. This is first fossil record of the genus.

\section{Hellenius ? kozlovi Belokobylskij, sp. nov. Plate 13, fig. 7; Text-fig. 45}

Etymology. After the late Professor Mikhail A. Kozlov, distinguished Russian hymenopterist.

Holotype. NHMUK In.17298, Bembridge Marls, NW Isle of Wight, UK, Smith Collection; lateral view of insect lacking antennae and most of head and legs, and with somewhat incomplete wings.

Diagnosis. Differs from extant ones in having marginal cell not shortened and with straight SR1, and rather long pterostigma.

Description. Length of mesosoma $1.2 \mathrm{~mm}$, meso- and metasoma combined $2.8 \mathrm{~mm}$, forewing $3.1 \mathrm{~mm}$. Mesosoma about 1.5 times as long as high. Mesoscutum distinctly and roundly elevated above pronotum. Notauli deep and possibly complete. Subalar depression rather deep and wide. Sternauli deep and wide. Prepectal carina possibly present. Propodeum at least partly with coarse areolate-reticulate sculpture. Forewing 2.6 times as long as maximum width. Pterostigma subtriangular, rather wide, $3 \cdot 3$ times as long as maximum width; $r$ arising distinctly behind middle of pterostigma, oblique in respect to it, 0.65 times as long as maximum pterostigmal width, forming very obtuse angle with 3-SR. 3-SR rather short, almost as long as r, 0.15 times as long as SR1, 0.65 times as long as 2-SR, almost as long as $\mathrm{r}-\mathrm{m}$; $\mathrm{r}-\mathrm{m}$ distinct, 0.65 times as long as 2-SR. Second submarginal cell small, 1.6 times as long as wide. $1-\mathrm{SR}+\mathrm{M}$ almost straight. Discal cell long petiolate anterior, 1.7 times as long as maximum width; $\mathrm{m}-\mathrm{cu}$ strongly antefurcal, almost as long as 2-SR+M; cu-a postfurcal, distant from 1-M for half cu-a length. Subdiscal cell wide, closed antero-posteriorly by CU1b. 2A unsclerotised but rather distinct. Hind wing: $1 \mathrm{r}-\mathrm{m}$ as long as 2-SC + R. Marginal cell narrow; SR subparallel to anterior margin of wing. Hind femur rather narrow. Metasoma: first tergite rather long, about 0.9 times as long as second and third tergites combined, following segments rather weakly protruding behind third tergite. Colour: mesosoma almost entirely black; metasoma black dorsally, brown ventrally; forewing faintly infuscate; pterostigma and veins dark brown.

Remarks. Wing venation is practically the same as in extant Hellenius, including petiolate discal cell, small second sub- marginal cell, and strongly antefurcal $\mathrm{m}$-cu. Unfortunately, the comparison in structure of meso- and metasoma is not possible because of poor preservation.

Genus Taphaeus Wesmael, 1835

Taphaeus cervicalis (Cockerell, 1921), comb. nov. Plate 13 fig. 8; Text-fig. 44C

\section{1a Sigalphus (?) cervicalis Cockerell, p. 15, fig. 15}

Holotype. NHMUK I.9199, Bembridge Marls, NW Isle of Wight, UK, Brodie Collection; dorsal aspect of insect with incomplete antennae, right wings and fragmentary legs.

Diagnosis. The species is similar to extant $T$. hiator (Thunberg, 1822) but differs in having discal cell widely sessile, 3SR short, cu-a distinctly postfurcal, and first tergite narrow and long. Differs from T. praecox Brues, 1923 from the Baltic amber in having forewing faintly infuscate, temple short, and $\mathrm{r}$ arising from middle of pterostigma. Differs from T. longicornis (Statz, 1936), comb. nov. from Rott in having discal cell widely sessile, marginal cell weakly shortened, and $\mathrm{m}-\mathrm{cu}$ distinctly antefurcal.

Description. Length of body $1.8 \mathrm{~mm}$, mesosoma $0.65 \mathrm{~mm}$, metasoma $0.75 \mathrm{~mm}$, forewing $1.6 \mathrm{~mm}$. Head weakly transverse, distinctly widened behind eyes, 1.3 times as wide as long medially, 1.35 times as wide as maximum length. Eye 2.2 times as long as temple in dorsal view, measured along straight line. Mesosoma rather long and slender, c. 3.0 times as long as maximum width. Notauli present, complete, rather narrow. Forewing 2.7 times as long as maximum width. Pterostigma subtriangular, $3 \cdot 3$ times as long as maximum width. 1-R 1 about as long as pterostigma, $5 \cdot 2$ times as long as $2-\mathrm{R} 1,3 \cdot 5$ times as long as distance from apex of marginal cell to apex of wing; $r$ arising before middle of pterostigma (internal distance of pterostigma between parastigma and $r$ 0.85 times internal distance between $\mathrm{r}$ and apex of pterostigma), not strictly perpendicular to pterostigma, 0.55 times as long as maximum pterostigmal width. Marginal cell shortened, pointed apically, 4.0 times as long as maximum width. 3-SR short, 0.4 times as long as r, 0.05 times as long as the straight SR1, 0.25 times as long as $2-\mathrm{SR} ; \mathrm{r}-\mathrm{m}$ present, strongly desclerotised, 0.8 times as long as 2-SR. Second submarginal cell about as long as wide, 0.7 times as long as subdiscal cell. 1-SR $+\mathrm{M}$ straight. $2-\mathrm{SR}+\mathrm{M}$ almost as long as $\mathrm{r}, 0.6$ times as long as 2-SR, 0.7 times as long as $\mathrm{m}-\mathrm{cu}, 0.6$ times as long as sclerotised part of 2-M; $\mathrm{m}-\mathrm{cu} 0.7$ times as long as 2SR, 0.85 times as long as sclerotised part of 2-M. Discal cell distinctly sessile anterior, 1.1 times as long as wide; $\mathrm{m}-\mathrm{cu}$ strongly antefurcal; cu-a distinctly postfurcal, distant from 1$\mathrm{M}$ for 0.65 times cu-a length. Subdiscal cell wide, closed antero-posteriorly by CU1b. CU1a arising from posterior 0.3 of distal side of subdiscal cell. Hind wing: $\mathrm{m}-\mathrm{cu}$ absent; $\mathrm{M}+\mathrm{CU}$ about twice as long as 1-M. Metasoma egg-shaped, rather wide, 1.7 times as long as maximum width. First tergite narrow, with distinct spiracular tubercles in basal $0.3,1.6$ times as long as wide at level of spiracular tubercles, 2.3 times as long as minimum width before tubercles. Colour: head and mesosoma brown; metasoma light brown; wings faintly infuscate; pterostigma entirely pale brown; veins brown.

3.9.9. Subfamily Homolobinae Achterberg, 1979. The koinobiont braconid wasps of the subfamily Homolobinae, parasitoids of lepidopteran larvae, have not been previously recorded as fossils (Achterberg 1979). Members of this subfamily are absent even from the well known Baltic amber assemblage. 


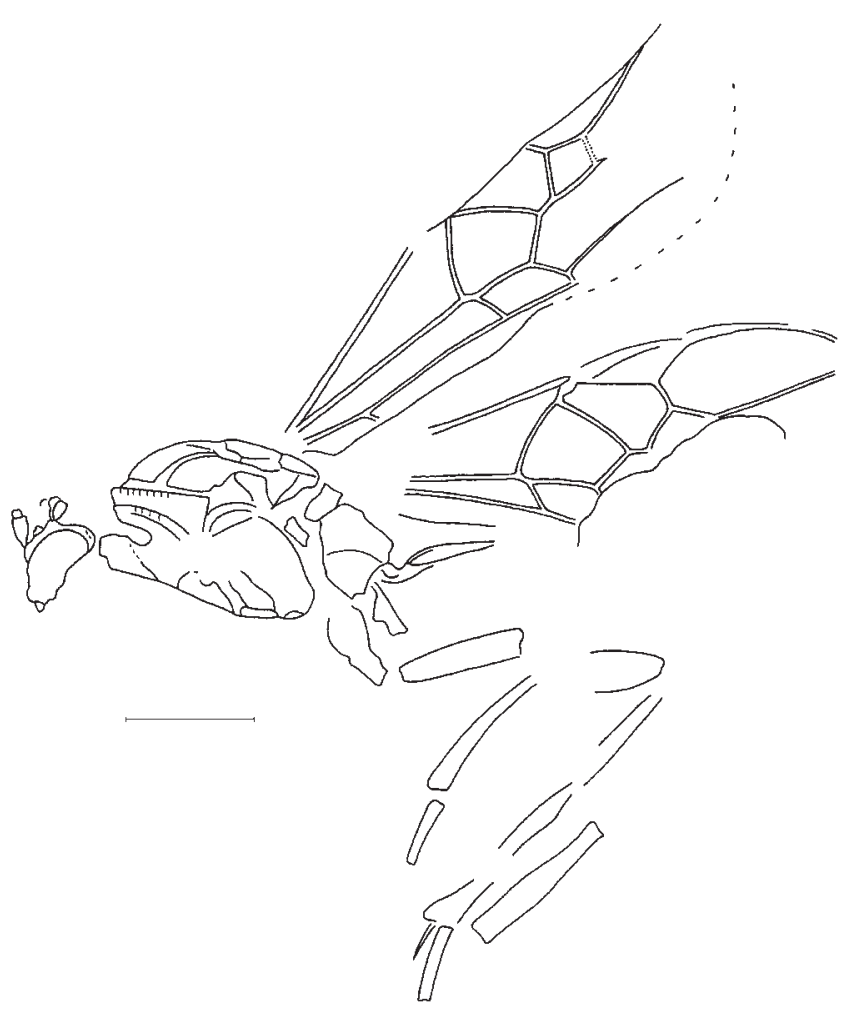

Text-figure 46 Homolobus rasnitsyni sp. nov., holotype, NHMUK In.20545. Scale bar $=1 \mathrm{~mm}$.

Genus Homolobus Foerster, 1862

Homolobus rasnitsyni Belokobylskij, sp. nov. Plate 13, fig. 9; Text-fig. 46

Etymology. In honor of A.P. Rasnitsyn, Russian palaeoentomologist.

Holotype. NHMUK In.20545, Bembridge Marls, NW Isle of Wight, UK, Smith Collection; lateral aspect of partial head with antennal bases, mesosoma with incomplete forewings, mid and hind legs, and metasomal base.

Diagnosis. Characteristic of the species are eyes and possibly ocelli enlarged, discal cell shortly petiolate, $r$ arising distinctly behind middle of pterostigma, cu-a strongly proclined, and hind tibia distinctly widened apically.

Description. Mesosoma length $2.3 \mathrm{~mm}$, forewing $4.9 \mathrm{~mm}$. Head: eye large. Possibly enlarged ocelli present. Scape rather large. Mesosoma: length 1.7 times height. Oblique depression on sides of pronotum rather narrow and crenulated. Notauli very deep and complete. Scutellum almost flat. Subalar depression deep and narrow. Propodeum distinctly rugose-reticulate at least in posterior half. Wing: pterostigma subtriangular, wide, rather long, $3 \cdot 3$ times as long as maximum width. Marginal cell weakly shortened, 2.4 times as long as maximum width. 1-R1 1.2 times as long as pterostigma; $\mathrm{r}$ arising distinctly behind middle of pterostigma (internal distance of pterostigma between parastigma and r 1.5 times internal distance between $r$ and apex of pterostigma), forming very obtuse angle with 3-SR, 0.75 times as long as maximum pterostigmal width. 3-SR 1.3 times as long as r, 0.25 times as long as SR 1 , 0.85 times as long as 2-SR, 1.3 times as long as $\mathrm{r}-\mathrm{m}$. Second submarginal cell short, narrowed posteriorly, 1.2 times as long as maximum width, about 0.7 times as long as subdiscal cell; $\mathrm{m}-\mathrm{cu}$ distinctly antefurcal, almost twice as long as 2$\mathrm{SR}+\mathrm{M}$, almost as long as 2-SR. 1-SR+M weakly S-shaped. Discal cell very shortly petiolate anteriorly, $1 \cdot 2$ times as long as width. 1-M and $\mathrm{m}-\mathrm{cu}$ more or less distinctly convergent posteriorly. Subdiscal cell wide, closed posteriorly, its length along posterior margin $2 \cdot 3$ times maximum width. CU1a almost entirely sclerotised, arising from posterior 0.2 of distal side of subdiscal cell; cu-a strongly inclined posteroapically, subparallel to 3-CU1, postfurcal, distance from $1-\mathrm{M}$ is $0 \cdot 3$ times cu-a length. Basal part of 1-1A straight. 2A present. Legs: middle coxa of medium size, weakly elongate; hind femur rather wide; middle and hind tibiae widened posteriorly, with long and pointed spurs; hind basitarsus thickened. Metasoma: first tergite long, with more or less distinct spiracular tubercle in basal $0 \cdot 2$, with sharp lateral border. Colour: mesosoma light reddish brown, propodeum darker; first metasomal tergite dark brown; pterostigma possibly brown, veins dark brown.

Remarks. Subgeneric position of the new species is not clear because of insufficient preservation: structure of hind wing, tarsal claws, antennal segments and ovipositor is unknown, as well as some details concerning the head, mesosoma and metasoma.

3.9.10. Subfamily Microgastrinae Foerster, 1862. The subfamily Microgastrinae is one of the most specialised braconid groups. The extant members are exclusively koinobiont parasitoids of larvae of various Lepidoptera. Mason (1981) has made a reclassification of the former large genus Apanteles Foerster, 1862 and erected several additional genera. Unfortunately the characters used for their diagnoses are rarely available for rock fossils, so I have used the old nomenclature from Nixon (1965).

Only a few fossil microgastrine taxa are described so far, although they are among the most abundant parasitoids in Recent biocenoses. Two fossil species of Apanteles are described by Statz (1938). The attribution of A. macrophthalmus Statz, 1938 looks convincing, unlike that of another species $A$. concinna Statz, 1938 which shows a distinct $\mathrm{r}-\mathrm{m}$ on forewing and so should be transferred elsewhere, possibly to Microplitis Foerster, 1862. The latter genus has two described fossil species, Microplitis elegans Timon-David, 1944 from the Oligocene of Camoins in France (Timon-David 1944) and $M$. vesperus Brues, 1910 from the Florissant. M. vesperus has a distinctly enlarged second submarginal cell (cf. Brues 1910, p. 102, fig. 85) suggesting a different generic position (possibly in Eocardiochiles Brues, 1933 or Semionis Nixon, 1965). The status of Microgaster primordialis Brues, 1906 from the Florissant also needs verification, because of the peculiar shape and size of its second submarginal cell.

Several described fossil genera have distinctly or strongly elongate 3-SR and correspondingly enlarged second submarginal cell. Described in Cardiochilinae is Eocardiochiles Brues, 1933 (with type species E. fritschii Brues, 1933) later transferred to Microgastrinae (Mason 1981). This genus, together with Semionis Nixon (including Eocene Semionis nixoni Tobias, 1987) and New World Pelicope Mason, 1981, now form the tribe Semionini (Tobias 1987). The similar shape of the second submarginal cell has been also indicated for Oligoneuroides Brues, 1910 (type species O. destructus Brues), described in Microgastrinae from the latest Eocene of the Florissant (Brues 1910). However, the number of antennal segments (25 or 26) recorded for this genus strongly testifies against Microgastrinae and suggests rather in favour of the subfamily Cardiochilinae. The genus Miracoides Brues, 1933 (type species M. proteus Brues, 1933), described from the Baltic amber in Microgastrinae as well, is very similar to the Recent Mirax Haliday, 1833 and should be included in the subfamily Miracinae.

The species Dacnusites sepultus Cockerell, 1921 and D. reductus Cockerell, 1921 were originally described in the new genus Dacnusites Cockerell, 1921 as a member of the subfamily Alysiinae (Dacnusini) (Cockerell 1921a). The present 
study reveals their position as members of the subfamily Microgastrinae (see below).

Three genera and four species of Microgasterinae are currently recorded in the Bembridge Marls of the Isle of Wight.

\section{Genus Dacnusites Cockerell, 1921}

Type species. D. sepultus Cockerell, 1921 (by original designation).

Remarks. This genus was described in the subfamily Alysiinae (Dacnusini). Re-study of forewings of both constituent species, D. sepultus and D. reductus Cockerell, 1921, undoubtedly indicates its position in Microgastrinae rather than in Alysiinae.

The enlarged second submarginal cell with distinctly developed 3-SR and closed by $\mathrm{r}-\mathrm{m}$, together with large hind coxa, are known in extant genera Microgaster Latreille, 1804, Hygroplitis Thomson, 1895 and Paroplitis Mason, 1981. Unfortunately, the diagnostic characters of these genera (venation of the hind wing, shape and sculpture of three basal metasomal tergites, length and shape of ovipositor sheaths) cannot be seen on the fossils at hand. Therefore I have to retain Dacnusites as a morphogenus of Microgastrinae with the above diagnostic characters, until better preserved fossils are available for study.

\section{Dacnusites sepultus Cockerell, 1921}

Plate 14, fig. 1; Text-fig. 47B

1921a Dacnusites sepultus Cockerell, p. 19, fig. 21.

1992 Dacnusites sepultus Cockerell, 1921: Carpenter, p. 478.

Holotype. NHMUK In.17176, Bembridge Marls, NW Isle of Wight, UK, Smith Collection; lateral view of body with incomplete antennae and one forewing.

Diagnosis. Very similar to $D$. reductus Cockerell, differs in having 1-SR short and in having discal cell respectively lower.

Description. Length of mesosoma $1.05 \mathrm{~mm}$, metasoma c. $1.0 \mathrm{~mm}$, forewing $2.3 \mathrm{~mm}$. Head rather small. Antennae thick, flagellar segments divided medially in two parts by rather distinct constriction; sub-basal segments 2.0-2.2 times as long as maximum width. Mesosoma short and high, about 1.2 times as long as high. Notauli absent. Sternauli present, rather wide, situated in anterior 0.7 of mesopleuron. Forewing 2.2 times as long as maximum width. Pterostigma subtriangular, 2.5 times as long as maximum width. $\mathrm{C}+\mathrm{SC}+\mathrm{R}$ thick. Sclerotised part of 1-R1 almost as long as pterostigma. Marginal cell not shortened; $r$ arising almost from middle of pterostigma, almost perpendicular to it, 0.7 times as long as maximum pterostigmal width, almost twice as long as sclerotised 3-SR, as long as 2-SR. SR1 strongly desclerotised, weakly visible; $\mathrm{r}-\mathrm{m}$ present, desclerotised, enclosing small second submarginal cell. Second submarginal cell almost as wide as long, subtriangular. 1-SR $+\mathrm{M}$ weakly curved, $3 \cdot 5$ times as long as 2-SR + M. 2-SR + M 0.7 times as long as $\mathrm{r}, 0.7$ times as long as 2-SR, 0.65 times as long as $\mathrm{m}-\mathrm{cu}$ and sclerotised part of 2-M. Discal cell rather shortly petiolate anteriorly, almost as long as wide. 1-M weakly curved, 5.5 times as long as 1-SR; $\mathrm{m}-\mathrm{cu}$ strongly antefurcal; cu-a strongly postfurcal, distant from 1-M for cu-a length. Subdiscal cell wide, almost twice as long as wide; CU1b indistinct; subdiscal cell open apico-posteriorly because 2-1A desclerotised distally. 2A indistinct. Legs: hind coxa rather large and long, about twice as long as maximum width; hind femur rather wide. Metasoma without carapace. Colour: head, antennae, mesosoma, middle and hind coxa and hind femur black; metasoma brown; forewing almost hyaline; pterostigma almost black; veins brown. Dacnusites reductus Cockerell, 1921
Plate 14, fig. 2; Text-fig. 47A

1921a Dacnusites reductus Cockerell, p. 19, fig. 22.

Holotype. NHMUK In.24338, Bembridge Marls, NW Isle of Wight, UK, Hooley Collection; isolated forewing.

Diagnosis. Very similar to the type species, differs in having longer 1-SR and higher discal cell.

Description. Forewing $2.0 \mathrm{~mm}$ long, almost twice as long as maximum width. Pterostigma subtriangular, 2.6 times as long as maximum width. $\mathrm{C}+\mathrm{SC}+\mathrm{R}$ thick. Sclerotised part of 1-R1 almost as long as pterostigma. Marginal cell not shortened; $r$ arising almost from middle of pterostigma, almost perpendicular to pterostigma, 0.7 times as long as maximum pterostigmal width, 2.5 times as long as sclerotised 3-SR, 0.9 times as long as 2-SR. SR1 much desclerotised but visible; $r-m$ present, not sclerotised, enclosing small second submarginal cell. Second submarginal cell almost as wide as long, subtriangular. 1-SR $+\mathrm{M}$ weakly curved, 4.0 times as long as 2-SR $+\mathrm{M}$. 2-SR $+\mathrm{M} 0.6$ times as long as $\mathrm{r}, 0.5$ times as long as 2-SR, 0.55 times as long as $\mathrm{m}-\mathrm{cu}$ and sclerotised part of 2-M. Discal cell rather long and petiolate anteriorly, 1.1 times as long as wide. 1-M almost straight, $3 \cdot 2$ times as long as $1-\mathrm{SR} ; \mathrm{m}-\mathrm{cu}$ strongly antefurcal; cu-a strongly postfurcal, distance from 1M 1.2 times $\mathrm{cu}-\mathrm{a}$ length. Subdiscal cell wide, 1.7 times as long as wide; CU1b present; subdiscal cell open apico-posteriorly because 2-1A desclerotised distally. 2A and a indistinct. Colour: forewing almost hyaline; pterostigma light brown; veins light brown.

Genus Palaeomicrogaster Belokobylskij, gen. nov.

Etymology. After palaios, the Greek for ancient, and genus Microgaster. Gender masculine.

Type species. Palaeomicrogaster oculatus sp. nov., by present designation and monotypy.

Diagnosis. Similar to Microgaster Latreille and related genera, but differs in having eyes very long, distinctly narrowed below and almost reaching mandibular base, and hind wing SR arising from $1 \mathrm{r}-\mathrm{m}$. The latter character appears in a few microgastrine taxa including species of Choeras Mason; the new genus distinctly differs from all such Microgastrinae in the peculiar eye shape.

Description. Head more or less transverse. Eyes very long, distinctly and regularly narrowed downward and possibly reaching base of mandible. Occipital carina absent. Frons distinctly concave. Ocelli enlarged. Notauli, prepectal carina and sternauli absent. Propodeum without delineated areas; $r-m$ of forewing present, enclosing rather small second submarginal cell. Discal cell petiolate anteriorly; cu-a strongly postfurcal and evenly curved. In hind wing, SR arising from $1 \mathrm{r}-\mathrm{m}$, distinctly convex in anterior half and almost straight in posterior half. Marginal cell with distinct desclerotised submedial crossvein; $\mathrm{r}-\mathrm{m}$ present enclosing long and rather narrow submarginal cell. Hind coxa large. Hind femur wide; hind tibia slender basally and distinctly widened towards apex. Metasoma short and wide, more or less depressed. First tergite possibly long.

Palaeomicrogaster oculatus Belokobylskij, sp. nov. Plate 14, figs 4, 5; Text-fig. 48

Etymology. From oculatus, the Latin for 'having an eye', referring to peculiar shape of eyes.

Holotype. NHMUK I. 9853/I. 10187 (part and counterpart), Bembridge Marls, NW Isle of Wight, UK, Brodie 

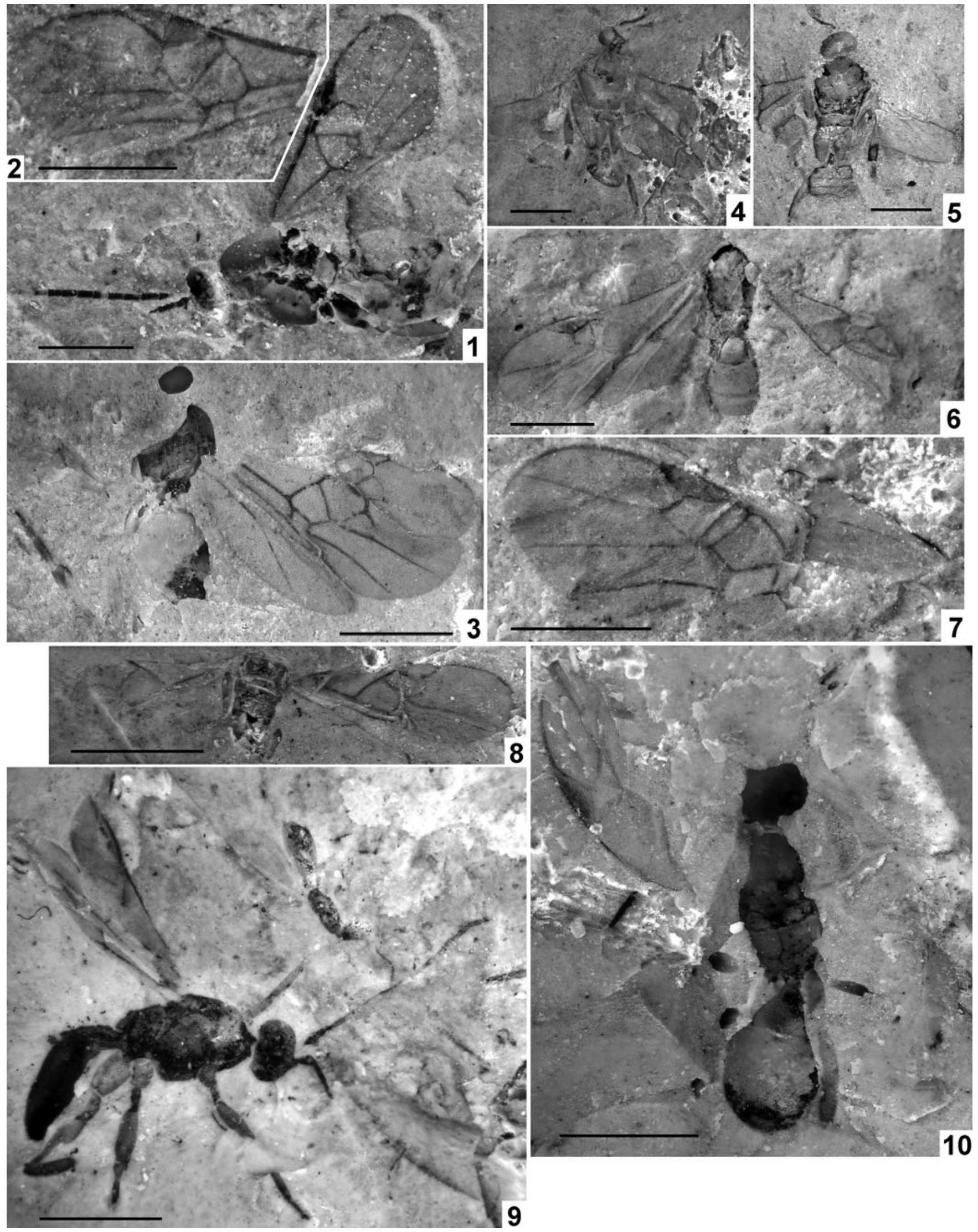

Plate 14 (1) Dacnusites sepultus Cockerell, holotype, NHMUK In.17176. (2) Dacnusites reductus Cockerell, holotype, NHMUK In.24338. (3) Semionis wightensis sp. nov., holotype, NHMUK In.17081. (4-5) Palaeomicrogaster oculatus sp. nov., holotype, NHMUK I.9853/I.10187: (4) part; (5) counterpart. (6) Biosteres peritus (Cockerell), holotype, NHMUK I.9671. (7) Microtypus hooleyi (Cockerell), holotype, NHMUK In.24337. (8) Oncophanes andrewrossi sp. nov., holotype, NHMUK I.10252. (9) Rhyssalus bruesi sp. nov., holotype, NHMUK I.9468. (10) Dolopsidea ? intermedia sp. nov., holotype, NHMUK I.9615. Scale bars $=1 \mathrm{~mm}$. 


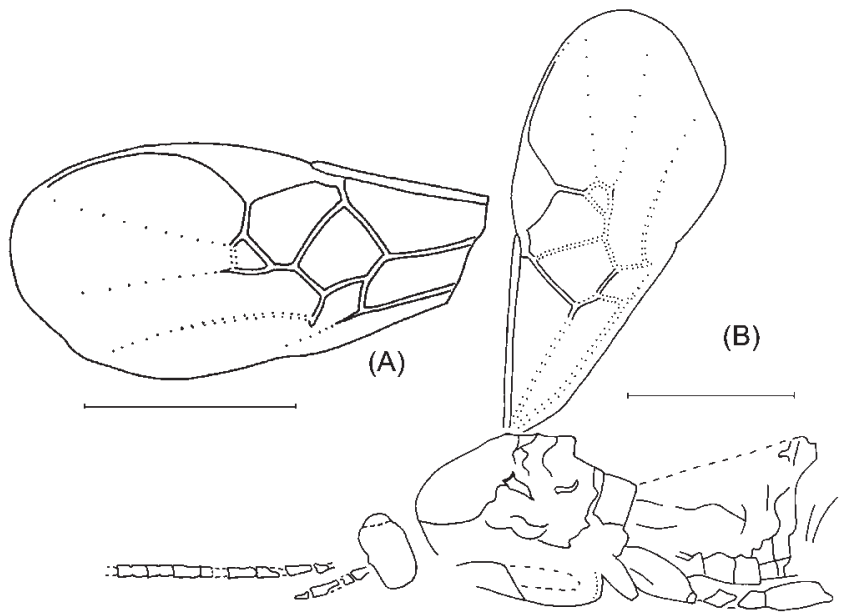

Text-figure 47 (A) Dacnusites reductus Cockerell, holotype, NHMUK In.24338. (B) D. sepultus Cockerell, holotype, NHMUK In.17176. Scale bars $=1 \mathrm{~mm}$

Collection; dorso-ventral aspect of insect with antennae, wings and legs incomplete.

Description. Body length $2.7 \mathrm{~mm}$, mesosoma $1.05 \mathrm{~mm}$, metasoma $1.1 \mathrm{~mm}$, forewing $c .2 .5 \mathrm{~mm}$. Head 2.2 times as broad as median length. Frons with shallow but distinct median longitudinal furrow. Head distinctly and roundly narrowed behind eyes. Transverse diameter of eye in dorsal view about as long as temple. Ocelli subcircular, arranged in triangle with base 1.2 times its side; postocellar line equal to ocellar diameter. Antennae rather thick. Mesosoma short and wide, 1.4 times as long as wide. Lateral sides of pronotum with shallow vertical furrow. Mesosternal suture absent. Mesoscutum 0.8 times as long as maximum width. Prescutellar depression distinct and narrow. Scutellum with no subposterior transverse furrow. Metanotum medially with rather large subcircular area delineated by carinae laterally and distinct convex protuberance posteriorly. Propodeum smooth, with distinct lateral longitudinal carinae and rather large spiracles in basal 0.3 $0 \cdot 4$. Forewing $2 \cdot 2$ times as long as maximum width; $r$ arising possibly behind middle of pterostigma and almost perpendicular to it, about 0.9 times as long as maximum pterostigmal width, 2.5 times as long as sclerotised 3 -SR, 1.2 times as long as $2-\mathrm{SR} ; \mathrm{r}-\mathrm{m}$ distinctly pigmented. Small second submarginal cell 1.25 times as long as maximum width, rather narrow. 1$\mathrm{SR}+\mathrm{M}$ weakly curved. Discal cell rather long and petiolate anteriorly, $1 \cdot 1$ times as long as wide. 1-M weakly curved; $\mathrm{m}$ $\mathrm{cu}$ antefurcal; cu-a strongly postfurcal, distant from 1-M for 0.9 times $\mathrm{cu}-\mathrm{a}$ length, 0.65 times distance from $\mathrm{cu}-\mathrm{a}$ to $\mathrm{m}-\mathrm{cu}$. Subdiscal cell wide, 1.6 times as long as wide. Hind wing wide, c. 3.0 times as long as maximum width. Submarginal cell $3 \cdot 2$ times as long as wide. Legs: hind coxa about twice as long as wide, 0.7 times as long as hind femur; hind femur 3.4 times as long as maximum width; maximum width of hind tibia 0.7 times maximum width of hind femur. Metasoma without carapace, visible tergites (behind hind coxae) rather short and strongly transverse. Colour: head, antennae, mesosoma and metasoma black; hind tibia black (at least on widened part and base of hind tarsus); hind femur brown; forewing almost hyaline; pterostigma pale with distinctly darkened margins; veins pale brown.

\section{Genus Semionis Nixon, 1965}

Remarks. Wing venation with large second submarginal cell is recorded in three genera of the tribe Semionini Tobias, 1987: extant South African and fossil Semionis; extant New
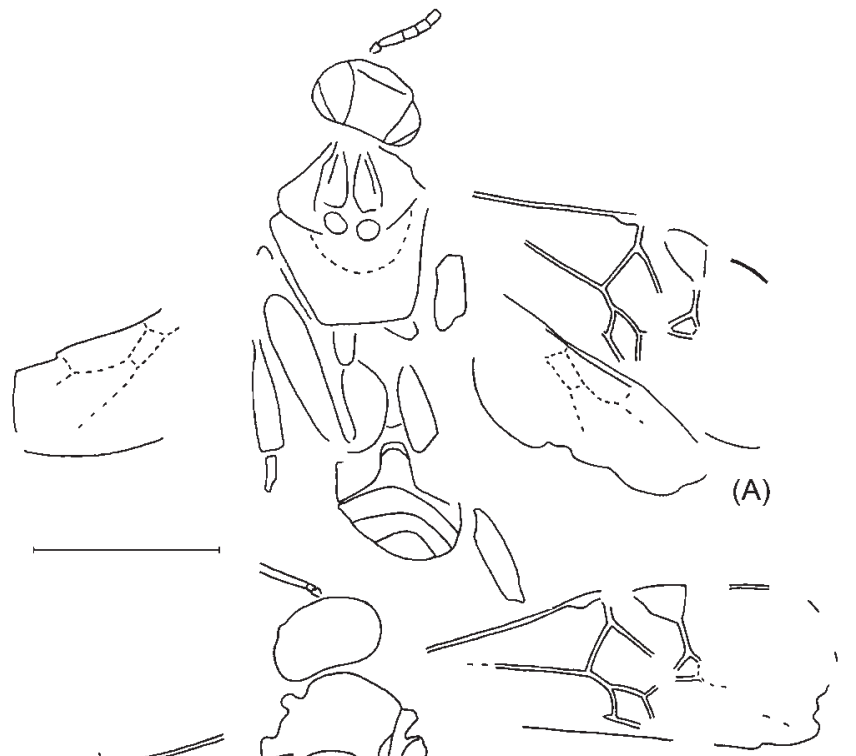

(B)

Text-figure 48 Palaeomicrogaster oculatus sp. nov., holotype NHMUK I 9853/I.10187: (A) part; (B) left forewing; (C) counterpart. Scale bar $=1 \mathrm{~mm}$.

World Pelicope Mason, 1981; and fossil Eocardiochiles Brues, 1933 (Mason 1981; Tobias 1987). Additionally characteristic of these genera is the absence of the hind wing $2 \mathrm{r}-\mathrm{m}$, one of the unique microgastrine features.

A combination of the absence of the hind wing $2 r-m$ with the enlarged forewing submarginal cell is diagnostic of the worldwide Cardiochilinae Ashmead, 1900 and even African Khoikhoinae Mason, 1983. Unfortunately, the unique fossil under description below does not display several important morphological features (antennae, metasomal tergites, etc.) which could help improve understanding of its taxonomic position.

Semionis wightensis Belokobylskij, sp. nov. Plate 14, fig. 3; Text-fig. 49

Etymology. After the Isle of Wight.

Holotype. NHMUK In.17081, Bembridge Marls, NW Isle of Wight, UK, Smith Collection; lateral aspect of head fragment, incomplete mesosoma and wings, hind leg and metasoma.

Diagnosis. Similar to S. nixoni Tobias, 1987 from the Baltic amber, but differs in having cu-a much more postfurcal, 1-SR long, 3-M almost straight, SR of hind wing subparallel to anterior margin of wing, 3-SR short, and the hind tibia with wide, pale coloration.

Description. Length of body c.2.0 mm, mesosoma $0.8 \mathrm{~mm}$, metasoma $0.9 \mathrm{~mm}$, forewing $2.2 \mathrm{~mm}$. Mesosoma 1.2 times as long as high. Mesoscutum highly and roundly elevated above pronotum. Notauli absent. Prescutellar depression very narrow and rather deep. Sternauli shallow and wide. Prepectal carina possibly present. Propodeum possibly entirely with coarse 


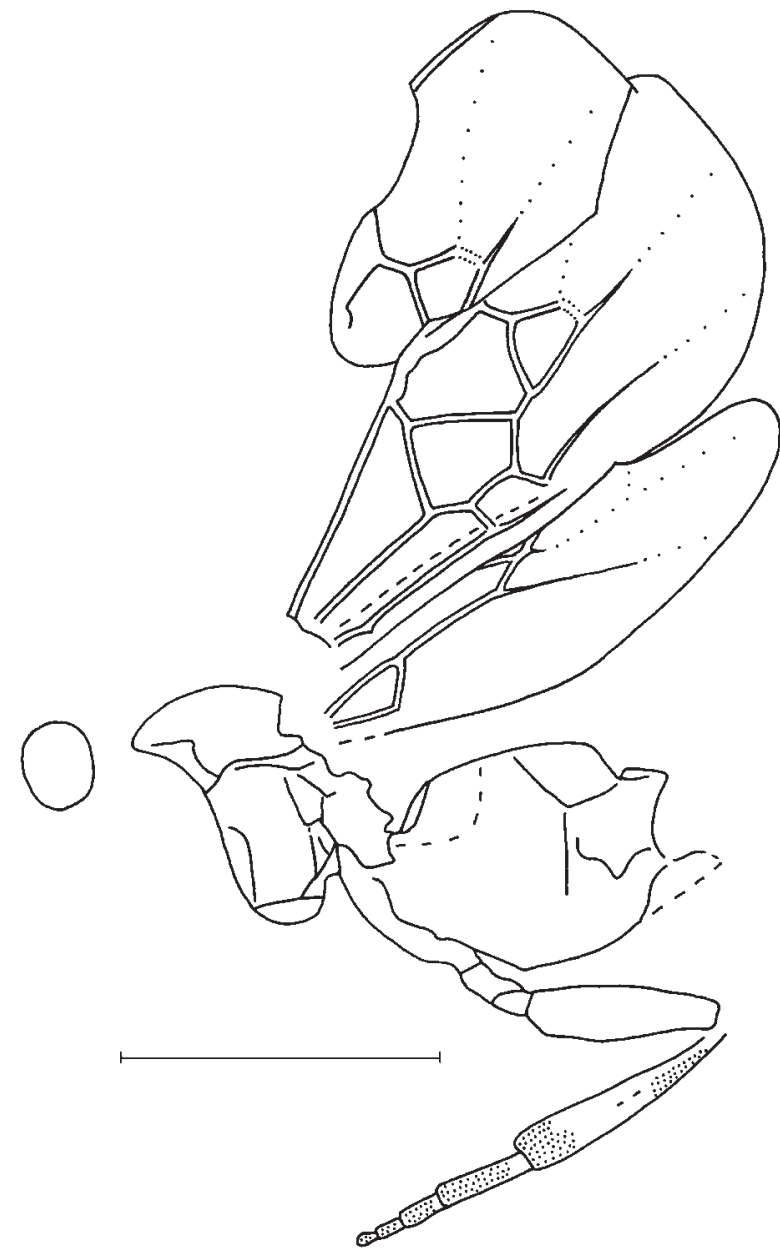

Text-figure 49 Semionis wightensis sp. nov., holotype, NHMUK In.17081. Scale bar $=1 \mathrm{~mm}$.

areolate-reticulate sculpture. Forewing 2.4 times as long as maximum width. Pterostigma subtriangular, rather wide. Sclerotised part of 1-R1 long, protruding almost to apex of wing; $\mathrm{r}$ arising distinctly behind middle of pterostigma and almost perpendicular to it. 3-SR long, 1.4 times as long as $\mathrm{r}, 0.75$ times as long as 2-SR. SR1 not at all sclerotised but visible and distinctly curved; r-m present, desclerotised, enclosing rather large second submarginal cell. Second submarginal cell 1.5 times as long as wide. 1-SR $+\mathrm{M}$ straight, 4.5 times as long as $2-\mathrm{SR}+\mathrm{M}$; $\mathrm{m}-\mathrm{cu}$ almost twice as long as $2-\mathrm{SR}+\mathrm{M}, 0.7$ times as long as 2-SR, 1.3 times as long as r. Discal cell long petiolate anterior, 1.3 times as long as wide. 1-M very weakly curved, $3 \cdot 5$ times as long as $1-\mathrm{SR}$; $\mathrm{m}$-cu strongly antefurcal. $\mathrm{Cu}-\mathrm{a}$ strongly postfurcal, distant from 1-M for almost cu-a length, 0.6 times distance from $\mathrm{cu}-\mathrm{a}$ to $\mathrm{m}-\mathrm{cu}$. Subdiscal cell wide, 1.7 times as long as width; CU1b absent. $2 \mathrm{~A}$ present but very strongly desclerotised. CU1a and 3-M distinctly pigmented. Hind wing 4.0 times as long as wide. Basal cell narrow. Sub basal cell rather large; $\mathrm{M}+\mathrm{CU}$ almost equal to 1-M; cu-a weakly S-shaped. 2-M and SR distinctly divergent, without $2 \mathrm{r}-\mathrm{m}$. SR subparallel to anterior margin of wing; marginal cell with indistinct oblique cross-vein submedially. Legs: hind coxa of medium size; hind femur 3.8 times as long as wide; hind tibia distinctly widened, c.5.0 times as long as wide, 1.2 times as long as hind femur. Metasoma wide and rather short. Colour: head, most part of mesosoma and metasoma, at least in posterior third, almost black; hind leg pale; hind tibia distinctly infuscate in apical $0 \cdot 25$; hind tarsus dark brown; forewing faintly infuscate; pterostigma entirely brown; veins dark brown.

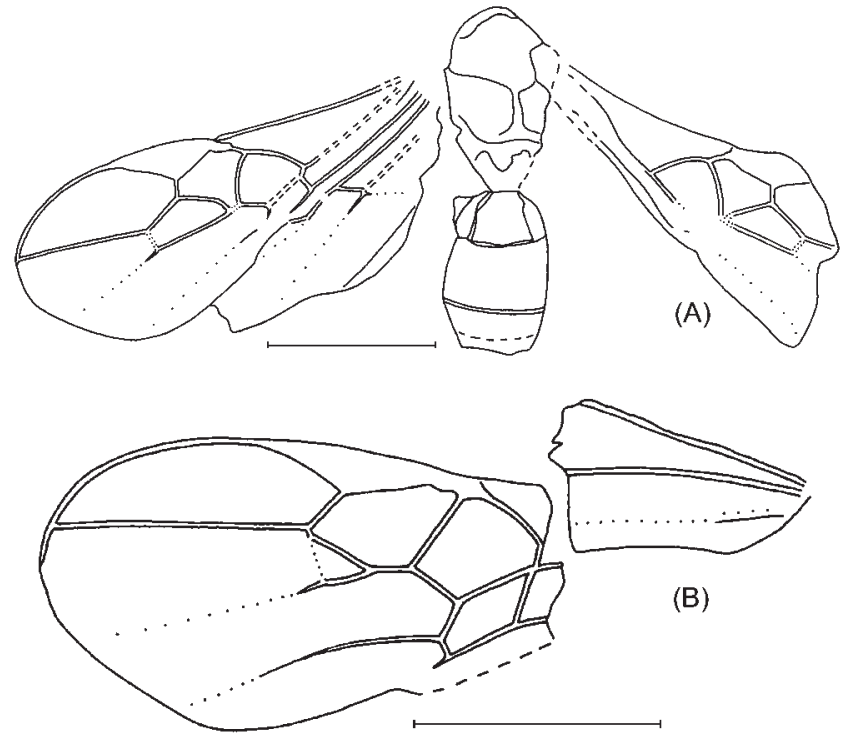

Text-figure 50 (A) Biosteres peritus (Cockerell), holotype, NHMUK I.9671. (B) Microtypus hooleyi (Cockerell), holotype, NHMUK In.24337. Scale bars $=1 \mathrm{~mm}$.

3.9.11. Subfamily Opiinae Foerster, 1862. The members of Alysiinae and Opiinae, parasitoids of various families of Diptera, are very rare as fossils. Nine species of four genera (Alysia exigua Brues, 1910, A. latifrons Statz, 1938, A. meunieri Théobald, 1937, A. petrina Brues, 1910, A. ruskii Cockerell, 1913, Pentapleura (?) filicornis Statz, 1938, P. longipennis Statz, 1938, Tanycarpa interstitialis Statz, 1938, and Aspilota (?) stigmalineata Statz, 1938) were described only as fossils from Florissant, Rott and Aix-en-Provence (Brues 1910; Cockerell 1913; Théobald, 1937, Statz 1938). Unfortunately, the above alysiine fail to show the main alysiine character - shape and position of mandibles. Identification of Alysiinae based on other characters is difficult and deserve verification. Two species of Dacnusites described as a member of the tribe Dacnusini (Alysiinae) (Cockerell 1921a) are found to belong to the subfamily Microgastrinae (see above).

Subfamily Opiinae has the only fossil record Bathystomus (?) peritus Cockerell, 1921. Although several important opiine characters cannot be seen in the unique fossil, evaluation of those available (absence of prepectal carina and presence of hind wing $\mathrm{m}-\mathrm{cu}$, as well as some details of forewing venation) would agree with its position in Opiinae but in a different genus, Biosteres Foerster, 1862.

Genus Biosteres Foerster, 1862

Biosteres peritus (Cockerell, 1921), comb. nov. Plate 14, fig. 6; Text-fig. 50A

1921a Bathystomus peritus Cockerell, p. 16, fig. 17.

Holotype. NHMUK I.9671, Bembridge Marls, NW Isle of Wight, UK, Brodie Collection; dorsal view of headless body with no appendages but partially incomplete wings.

Diagnosis. Characteristic of the new species are the second submarginal cell rather long and narrowed towards apex, not shortened marginal cell, antefurcal $\mathrm{m}-\mathrm{cu}$, wide second metasomal suture, and perhaps the entirely smooth three anterior metasomal tergites.

Description. Length of mesosoma and metasoma combined $1.9 \mathrm{~mm}$, mesosoma $0.95 \mathrm{~mm}$, metasoma $0.95 \mathrm{~mm}$, forewing $2.4 \mathrm{~mm}$. Mesosoma 1.7 times as long as maximum width. Prepectal carina absent. Forewing 2.5 times as long as maximum 
width. Pterostigma subtriangular, wide, almost 3.0 times as long as maximum width. 1-R1 1.3 times as long as pterostigma. Marginal cell not shortened, pointed apically, $2 \cdot 5$ times as long as maximum width; $r$ arising behind middle of pterostigma (internal distance of pterostigma between parastigma and $\mathrm{r} 0.6$ times internal distance between $\mathrm{r}$ and apex of pterostigma), $0 \cdot 7$ times as long as maximum pterostigmal width. 3SR twice as long as r, 0.4 times as long as weakly S-shaped SR1, 0.8 times as long as 2-SR; $r-m$ present and weakly sclerotised, $0 \cdot 3$ times as long as $2-\mathrm{SR}$. Second submarginal cell $2 \cdot 3$ times as long as wide, 1.6 times as long as subdiscal cell. $1-\mathrm{SR}+\mathrm{M}$ distinctly curved; $\mathrm{m}-\mathrm{cu} 0.6$ times as long as 2-SR and 1-SR $+\mathrm{M}$. Discal cell distinctly petiolate anterior, 1.4 times as long as width; $\mathrm{m}-\mathrm{cu}$ antefurcal; $\mathrm{cu}-\mathrm{a}$ postfurcal. Subdiscal cell rather wide, about 3.0 times as long as wide. $2 \mathrm{~A}$ and a probably absent. Basal cell of hind wing distinctly widened distally; $\mathrm{m}-\mathrm{cu}$ present, weakly postfurcal, almost straight. Metasoma: first tergite distinctly and slightly roundly widened towards apex, with clear spiracular tubercle in basal $0 \cdot 3$; length of tergite about equal to its apical width; apical width $c .2 \cdot 5$ times its basal width. Second tergite 0.8 times as long as basal width, 1.4 times as long as visible third tergite. Combined median length of second and third tergites almost equal to its maximum width, 1.3 times basal width of second tergite. Colour: mesosoma brown; metasoma yellow; wings almost hyaline; pterostigma brown, pale basally and possibly apically; veins brown.

Remarks. Position of this species in the genus Biosteres is not definite, and additional material might help to understand the real status of this taxon. It is not easy to find related species from extant taxa of this genus.

3.9.12. Subfamily Orgilinae Ashmead, 1900 (= Microtypinae Szepligeti, 1908). Subfamily Orgilinae (including tribe Microtypini which some authors consider as a separate subfamily, Achterberg 1993) is a small group of koinobiont braconids, endoparasitoids of lepidopteran larvae, widely distributed on almost all continents.

Only three species of Orgilus Haliday, 1833, recently transferred to this genus from Blacus Nees, 1818 (Achterberg 1982), are known as fossils: O. ashmeadii (Brues 1933), O. grandior (Brues 1933) and O. longicornis (Brues 1933). The majority of the fossil Orgilinae were described in Microtypus Ratzeburg, 1848 (Brues 1933, 1939). Because the morphological limits of this genus in Brues' view were very broad, only three species (M. brevicornis Brues, 1933, M. triangulifer Brues, 1933 and M. verticalis Brues, 1933) out of ten described by him from Baltic amber had the real Microtypus-type triangular second submarginal cell and only two radial abscissae $r$ and SR1+3SR (see also discussion for subfamily Helconinae).

Cockerell described the new genus and species Diospiloides hooleyi Cockerell, 1921 from the Bembridge Marls and considered it as possibly related to Diospilini (Helconinae). Restudy of the type has shown it belongs to the genus Microtypus (see below). Thus, Diospiloides Cockerell, 1921 is a junior synonym of Microtypus Ratzeburg, 1848.

Only one genus and species of the subfamily Orgilinae is recorded in the Bembridge Marls of the Isle of Wight.

Genus Microtypus Ratzeburg, 1848

= Diospiloides Cockerell (type species D. hooleyi Cockerell, 1921), syn. nov.

Microtypus hooleyi (Cockerell, 1921), comb. nov. Plate 14, fig. 7; Text-fig. 50B

1921a Diospiloides hooleyi Cockerell, p. 14, fig. 14.

1992 Diospiloides hooleyi Cockerell, 1921: Carpenter, p. 478.
Holotype. NHMUK In.24337, Bembridge Marls, NW Isle of Wight, UK, Hooley Collection; isolated forewing.

Diagnosis. Very similar to M. brevicornis Brues, 1933 but differs in having $\mathrm{r}$ arising distinctly behind middle of pterostigma, $\mathrm{m}-\mathrm{cu}$ distinctly longer than $2-\mathrm{SR}+\mathrm{M}$, and $\mathrm{cu}-\mathrm{a}$ less strongly postfurcal.

Description. Forewing length $c .3 \cdot 0 \mathrm{~mm} ; 2.8$ times as long as maximum width. Pterostigma subtriangular, $3 \cdot 5$ times as long as maximum width. 1-R 11.75 times as long as pterostigma, $8 \cdot 2$ times as long as 2-R1. Marginal cell not shortened, pointed apically, 3.6 times as long as maximum width; $r$ arising distinctly behind middle of pterostigma (internal distance of pterostigma between parastigma and $\mathrm{r} 1.4$ times internal distance between $\mathrm{r}$ and apex of pterostigma), 1.1 times as long as maximum pterostigmal width, 0.2 times as long as 3-SR, 0.65 times as long as 2-SR; r-m present, strongly desclerotised, enclosing second submarginal cell. Second submarginal cell 1.5 times as wide as long, narrow, triangular, shortly petiolate anterior. 1-SR $+\mathrm{M}$ very weakly $\mathrm{S}$-shaped, about twice as long as 2-SR + M. 2-SR + M 0.9 times as long as $\mathrm{r}, 0.6$ times as long as 2-SR, 0.7 times as long as $\mathrm{m}-\mathrm{cu}$, 0.6 times as long as sclerotised part of 2-M. Discal cell shortly sessile anteriorly, 1.4 times as long as wide; $\mathrm{m}-\mathrm{cu}$ strongly antefurcal; cu-a very shortly postfurcal. Subdiscal cell wide, 2.3 times as long as wide; CU1b distinct, closing subdiscal cell. CU1a arising from posterior 0.3 of distal margin of subdiscal cell, distinctly sclerotised on about basal half of its length. 2A and a indistinct. Colour: forewing hyaline; pterostigma very pale, narrowly brown marginally and almost black shortly anteriorly; veins mostly pale brown and partly brown.

3.9.13. Subfamily Rhyssalinae Foerster, 1862. The members of subfamily Rhyssalinae were for a long time included in other subfamilies, such as Rogadinae and Exothecinae s.l. This subfamily was re-instated by Quicke \& Achterberg (1990), after a special study of the inner structures of the ovipositor and venom apparatus, and now includes the genera Rhyssalus Haliday, 1833, Oncophanes Foerster, 1862, Dolopsidea Hincks, 1944, Pseudobathystomus Belokobylskij, 1986 and possibly several subtropical and tropical genera (Doryctomorpha Ashmead, 1900, Caenopachyella Szepligeti, 1908, Metaspathius Brues, 1922).

Two genera of this subfamily were described from the Baltic amber as Rogadinae (Brues 1933). Descriptions and figures of both species of Rhyssalus (R. brevicornis Brues, 1933 and $R$. rugosus Brues, 1933) show their position to be unequivocally not of this genus. This opinion is supported by the sculptured second and third metasomal tergites, the granulate sculpture of mesoscutum, the reduced number of antennal segments and, for the second species only, not clavate male hind tibia. If really cyclostomate braconids, these species are possibly members Exothecinae (because of areolate propodeum). The same taxonomic position should also include Palaeorhyssalus Brues, 1933 (with $P$. dubitosus Brues, 1933) from the Baltic amber. At the same time, Diospilus allani Brues, 1937 from the Upper Cretaceous Canadian amber is very similar venationally to the extant Pseudobathystomus Belokobylskij, or some species of Oncophanes Foerster (see discussion above under Helconinae).

New species of Dolopsidea, Rhyssalus and Oncophanes described below are the first reliable members of Rhyssalinae in the fossil record.

Genus Dolopsidea Hincks, 1944

Dolopsidea ? intermedia Belokobylskij, sp. nov.

Plate 14, fig. 10; Text-fig. 51A 

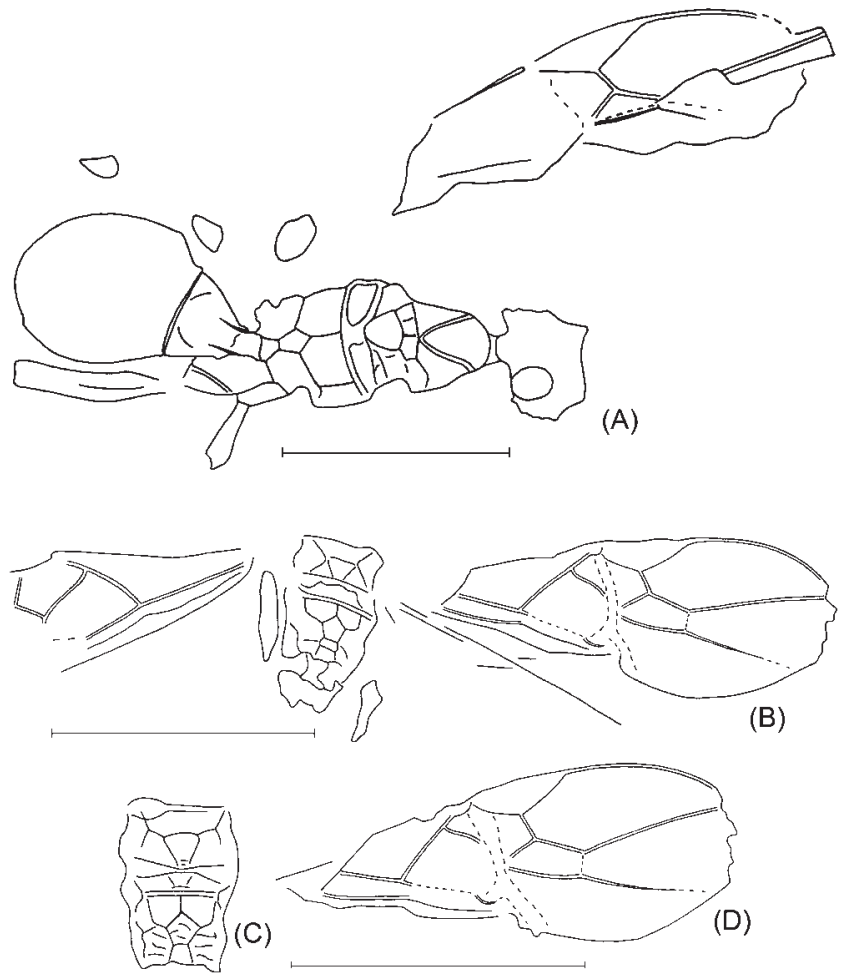

Text-figure 51 (A) Dolopsidea ? intermedia sp. nov., holotype, NHMUK I. 9615. (B-D) Oncophanes andrewrossi sp. nov., holotype, NHMUK I.10252. Scale bars $=1 \mathrm{~mm}$.

Etymology. After intermedius, the Latin for intermediate, referring to a position of this species between several subfamilies.

Holotype. NHMUK I.9615, Bembridge Marls, NW Isle of Wight, UK, Brodie Collection; dorsal aspect of incomplete head, meso- and metasoma with deformed forewing and fragmentary legs.

Diagnosis. Differs from the extant species $D$. indagator (Haliday, 1836) in having the propodeum smooth between carinae, the first metasomal tergite short and wide, and the mesoscutum distinctly rounded anteriorly.

Description. Length of body $2.5 \mathrm{~mm}$, mesosoma $1.0 \mathrm{~mm}$, metasoma $1.1 \mathrm{~mm}$, forewing c. $2.0 \mathrm{~mm}$. Head rather transverse, distinctly and roundly narrowed behind eyes. Eyes rather large. Ocelli small, arranged in triangle with base $1 \cdot 3$ times its sides. Distance between antennal sockets almost equal to distance between socket and eye. Frons more or less distinctly concave, without medial furrow or keel. Occipital carina complete dorsally. Mesosoma 1.8 times as long as maximum width. Median lobe of mesoscutum weakly protruding forwards and rounded anterior. Notauli complete, shallow particularly posteriorly, fused with each other on border of prescutellar depression. Prescutellar depression wide, deep, without medial carina, weakly sculptured. Scutellum convex, rather short, without transverse depression posteriorly. Sternauli shallow and wide, almost smooth, situated in anterior 0.6 of mesopleuron. Metanotum with fine medial carina. Propodeum more or less short, almost entirely smooth, with rather distinct and wide lateral tubercles, with distinct areas delineated by high carinae, basal carina 1.7 times as long as anterior fork, areola 1.6 times as long as width, petiolate area rather long and separated from areola by distinct carina. Forewing: pterostigma 2.6 times as long as maximum width. 1-R1 1.3 times as long as pterostigma. Marginal cell not shortened, pointed apically, 2.7 times as long as maximum width; $r$ arising from middle of pterostigma, 0.8 times as longas maximum pterostigmal width. 3-SR 1.7 times as long as $\mathrm{r}, 0.3$ times as long as SR1, about 1.5 times as long as 2$\mathrm{SR} ; \mathrm{m}-\mathrm{cu}$ shortly antefurcal. Legs: hind coxa without dorsal processes; hind femur rather wide. Metasoma wide, 1.8 times as long as maximum width, 1.1 times as long as mesosoma. First tergite moveably connected with second tergite, short and wide, distinctly convex and rugulose-striate mostly on wide and subcircular area, regularly and strongly widened towards apex, with high and weakly convergent dorsal carinae in basal 0.3 of tergite, dorsope small; length of tergite 0.9 times its apical width, apical width about 3.0 times its basal width. Second suture absent. Second and third tergites strongly sclerotised, smooth, their combined median length about 1.8 times basal width of second tergite and 1.25 times their maximum width. Colour: body entirely black; hind femur possibly brown; forewing faintly infuscate; pterostigma and veins brown.

Remarks. With the limited information available, the species is tentatively included in the genus Dolopsidea Hincks, based on the forewing with the $\mathrm{r}-\mathrm{m}$ and second submarginal cell, mesoscutum with notauli, propodeum with distinct peculiar areolation, short first tergite with basal carinae, and absence of the second metasomal suture.

Genus Oncophanes Foerster, 1862

Oncophanes andrewrossi Belokobylskij, sp. nov. Plate 14, fig. 8; Text-fig. 51B-D

Etymology. In honour of Dr Andrew Ross, palaeontologist at National Museums Scotland, Edinburgh.

Holotype. NHMUK I.10252, Bembridge Marls, NW Isle of Wight, UK, Brodie Collection; dorsal aspect of incomplete mesosoma and wings with leg fragments.

Diagnosis. Differs from the type species O. minutus (Wesmael, 1838) in having 1-R1 much longer than pterostigma, forewing infuscate, propodeal areola less narrowed posteriorly, and possibly the $\mathrm{m}-\mathrm{cu}$ postfurcal.

Description. Length of forewing $1.6 \mathrm{~mm}$. Mesosoma: scutellum about as wide as median length. Metanotum medially with two carinae convergent posteriorly and fused with transverse posterior protuberance. Propodeum distinctly areolated with carinae. Areola wide, pentagonal, short, 1.2 times as long as wide, 1.6 times as long as petiolate area, distinctly separated from wide and long petiolate area by carina, basilateral areas rather short and almost smooth, other parts of propodeum rugose-reticulate. Wings: forewing 2.8 times as long as wide. Pterostigma subtriangular, wide, small, about 3.0 times as long as maximum width. Marginal cell not shortened, 1-R1 1.6 times as long as pterostigma; $r$ long, almost as long as maximum width of pterostigma, arising almost from middle of pterostigma. 3-SR 1.5 times as long as $\mathrm{r}, 0.3$ times as long as the straight SR1, about 1.5 times as long as 2-SR and $\mathrm{r}-\mathrm{m}$. Second submarginal cell rather wide, 2.4 times as long as width, almost as long as subdiscal cell; $\mathrm{m}-\mathrm{cu}$ possibly postfurcal, $3 \cdot 7$ times as long as $2-\mathrm{SR}+\mathrm{M}, 1 \cdot 3$ times as long as 2-SR. 1-SR +M weakly S-shaped. Discal cell distinctly petiolate anteriorly, 1.6 times as long as wide. 1-M and $\mathrm{m}-\mathrm{cu}$ subparallel, weakly convergent posteriorly. Subdiscal cell narrow. CU1a not interstitial. Colour: mesosoma dark brown to black; wings faintly infuscate; pterostigma (possibly) and veins brown.

Remarks. Propodeal areolation with long and distinctly delineated petiolate area and forewing venation confirm position of the species in Oncophanes despite the poor preservation of the holotype.

Genus Rhyssalus Haliday, 1833

Rhyssalus bruesi Belokobylskij, sp. nov.

Plate 14, figure 9; Text-fig. 52 


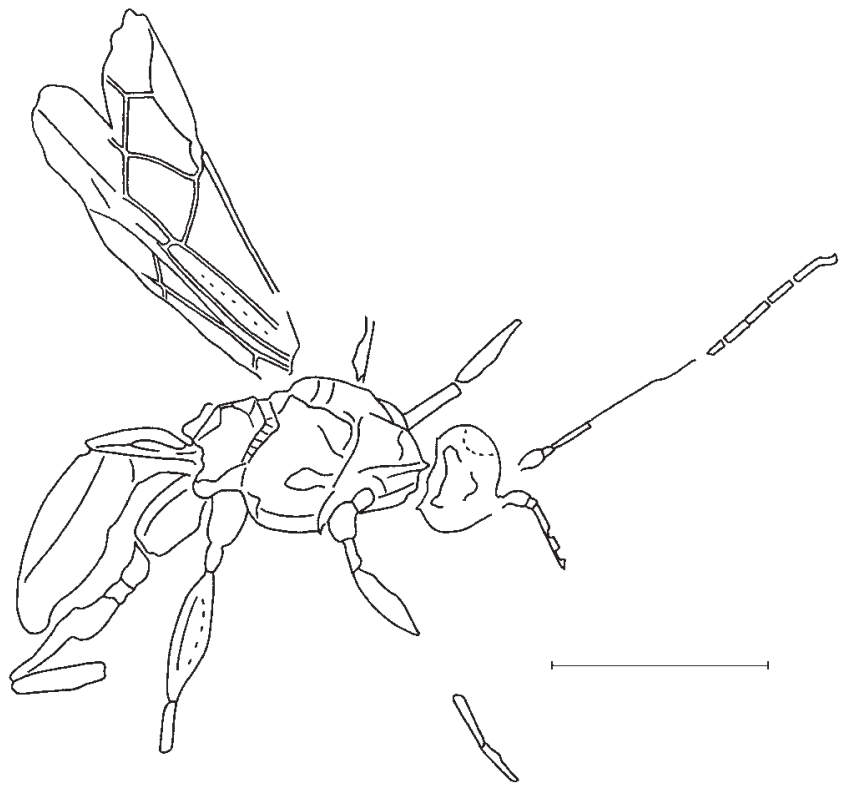

Text-figure 52 Rhyssalus bruesi sp. nov., holotype, NHMUK I.9468. Scale bar $=1 \mathrm{~mm}$.

Etymology. After C.T. Brues, well-know hymenopterist and researcher of the hymenopteran fauna of Baltic amber.

Holotype. NHMUK I.9468, Bembridge Marls, NW Isle of Wight, UK, Brodie Collection; male, lateral aspect of insect with antennae, wings and legs incomplete.

Diagnosis. Differs from all extant congeners in having the fore and middle femora thick, the first tergite elongate, $r$ arising almost from the middle of pterostigma, and $\mathrm{m}-\mathrm{cu}$ a little antefurcal.

Description. Body length $2.6 \mathrm{~mm}$, mesosoma $1.1 \mathrm{~mm}$. Head 1.65 times as high as maximum length. Occipital carina present. Antennae slender, rather long. Scape 1.8 times as long as maximum width, $2 \cdot 2$ times as long as pedicel. First flagellar segment about 5.0 times as long as apical width, $1 \cdot 1$ times as long as second segment. Subapical segment about $3 \cdot 0$ times as long as wide. Mesosoma: length 1.6 times height. Notauli present at least anteriorly and deep. Prepectal carina present. Sternauli rather distinct, more or less short, rather wide. Subalar depression deep and wide. Mesopleural suture crenulated. Basilateral areas of propodeum delineated by carinae. Wings: pterostigma subtriangular, wide, rather long, 3.6 times as long as maximum width; $r$ arising almost from middle of pterostigma, forming almost straight line with 3-SR, almost as long as maximum pterostigmal width, about 0.5 times as long as 2-SR; $\mathrm{m}-\mathrm{cu}$ shortly antefurcal, 0.7 times as long as 2-SR. $1-\mathrm{SR}+\mathrm{M}$ distinctly $\mathrm{S}$-shaped. Discal cell distinctly petiolate anteriorly, almost twice as long as wide. 1-M and $\mathrm{m}-\mathrm{cu}$ weakly convergent posteriorly. Subdiscal cell rather wide, possibly closed posteriorly, $3 \cdot 5$ times as long as wide. CU1a not interstitial; cu-a postfurcal, distant from 1-M almost for $\mathrm{cu}-\mathrm{a}$ length. Hind wing: sub-basal cell shortened; $\mathrm{M}+\mathrm{CU}$ shorter than $1-\mathrm{M} ; \mathrm{m}-\mathrm{cu}$ present and weakly antefurcal. Legs rather robust. Legs: middle femur wide; hind coxa without basiventral corner, 1.4 times as long as wide; visible basal part of hind tibia thickened. Metasoma: first tergite rather long. Colour: head, mesosoma and at least first metasomal tergite almost black; pterostigma and veins dark brown.

Remarks. The position of this species in Rhyssalus is somewhat unreliable, because of the lack of information about the hypoclypeal cavity and incomplete wing venation. Nevertheless, the thickened hind tibia, areolated propodeum, thick femora, short sub basal cell of hind wing, and developed $\mathrm{m}-\mathrm{cu}$ support the attribution of this species to Rhyssalus.

3.9.14. Discussion. The studied material from the Bembridge Marls includes members of many subfamilies previously recorded as fossils. Undoubtedly interesting is the first discovery from this locality of the subfamily Homolobinae.

Living members of most of braconid taxa recorded in the Bembridge Marls, and particularly Agathidinae, Cheloninae, Exothecinae, Homolobinae, Microgastrinae, Orgilinae, partly Rhyssalinae, and possibly Euphorinae (Meteorus), are known as parasitoids of various Lepidoptera. This information is interesting, because their lepidopteran hosts are very rare in the Bembridge Marls fossil assemblage. The abundance of lepidopteran parasitoids, both in the Bembridge and Baltic amber assemblages, suggests the same abundance for moths since at least the late Eocene, in spite of their poor fossil record which is apparently due to taphonomic processes. Interesting is the presence, in both assemblages (see Brues 1933 and Tobias 1987 for Baltic amber), of plenty of Ascogaster, a specialised egg-larval parasitoid of micro-Lepidoptera, and particularly the species of very small size indicative of their development at the expense of leaf miners (for example, A. pinicola Brues or A. pygmaea sp. nov.). Microlepidopteran hosts, mainly of the families Tortricidae, Gelechiidae and Pyralidae, are known also for Bassus, Microtypus, Chremylus (as well as some Coleoptera: Shenefelt 1975), Oncophanes and possibly Microgastrinae genera. However, the latter group is known to prefer to parasitise gregarious macrolepidopteran caterpillars. Equally Homolobus and some Meteorus are often dependent on macrolepidopterans, mainly the families Geometridae, Noctuidae and Lasiocampidae.

Several groups of Bembridge Marls braconids belong to subfamilies today displaying larval or egg-larval parasitism of beetles, the supposed groundplan host group of Braconidae (Telenga 1952). These are mostly the plesiomorphic subfamilies Rhyssalinae, Doryctinae, Helconinae and Brachistinae, with the exception of Braconinae, which includes quite specialised genera (Bracon, Cyanopterus and especially Bembracon). Larval parasitism is known for the rhyssaline Rhyssalus and possibly Dolopsidea, the doryctine Ontsira (one from the less derived genus in subfamily Doryctinae) and braconine genera. Some of the recorded genera of Helconinae (Taphaeus and Diospilus) and Brachistinae (Eubazus) are known to include egg-larval parasitoids of beetles (Anobiidae, Cerambycidae, Nitidulidae, Curculionidae etc.). Worth mentioning is that the most primitive species of the euphorine genus Meteorus (for example, $M$. corax species group) are also parasitoids of beetle larvae, and it is possible that the Bembridge Marls species of this genus might be a coleopteran and not lepidopteran entomophage.

The fossil record of the subfamilies Alysiinae and Opiinae, parasitoids of flies, is doubtful because of the insufficient preservation of the respective fossils (see discussion under Opiinae above). In that connection, of importance is the first reliable record of Opiinae (Biosteres peritus (Cockerell)) in the Bembridge Marls. At the same time, it is surprising that not a single specimen of Aphidiidae (or Aphidiinae in Braconidae: Achterberg 1993), the obligate parasitoids of aphids, is found here (as well as in Florissant) in contrast to Oligocene and Miocene fossil sites (Stary 1973). Noteworthy is the absence of Euphorinae, specialised (often nymphal or imaginal) as parasitoids of various insects; these genera are described from Baltic amber and Florissant.

The majority of genera recorded in the Bembridge Marls (Bassus, Eubazus, Ascogaster, Diospilus, Taphaeus, Homolobus, Biosteres, Microtypus etc.) are very common and usually abundant today in the northern hemisphere temperate zone, with 
species richness undoubtedly increasing in its southern parts. Conversely, the morphologically peculiar taxa such as Bembracon gen. nov. with a number of original metasomal apomorphies, Semionis (of South African distribution now), species of Bracon and Cyanopterus with the forewing venation unusual for boreal taxa, Ontsira distracta (Cockerell) and Chremylus infuscatus sp. nov. with deviant wing venation and body structures, are more characteristic of at least a subtropical fauna. Thus the climatic inferences from Braconidae are somewhat contradictory, but indicate a warmer and possibly less humid past climate compared with today.

Composition of the braconid taxa in the Bembridge Marls and their host preferences implies the presence of large open and possibly rather wet grassland, or possibly wetlands, as the source environment. A number of specialised beetle parasitoids indicates the presence of at least isolated trees over these open lands. Alternatively, broadleaf forests might exist nearby, allowing the braconid parasitoids of beetles to enter the grasslands actively (for additional feeding) or passively (by wind), to reach a target water body for burial.

The most diverse Cenozoic braconid faunas are described from the Baltic amber (Brues 1923, 1933, 1939; Tobias, 1987) and the Florissant beds (Cockerell 1913; Brues 1906, 1910). The Baltic fauna is the best studied in respect to the hymenopterans. Despite taxonomic problems with several taxa, 18 subfamilies are recorded, including the endemic Diospilitinae Tobias, 1987 (Acampsohelconinae Tobias, 1987 is now recorded as living: Achterberg 2002), embracing 52 genera and 101 species. All species and 19 genera were described from this amber, and two genera (Bracon and Chelonus) are reported, based on unidentified species. Compared with that of the Baltic amber, the Bembridge Marls braconid fauna is less rich, displaying only 13 subfamilies (lacking Diospilitinae, Acampsohelconinae, Ichneutinae, Macrocentrinae, Miracinae and Aphidiidae, but with the addition of Homolobinae and Opiinae). Out of 23 Bembridge genera, only 11 are the same as in the Baltic amber and four endemic taxa, and only 39 species were identified. Of interest is that the subfamily Braconinae is more diverse in the Bembridge Marls yielding three genera and six species, $v$ s. one genus with no identified species in the Baltic amber. In contrast, the diversity of Euphorinae (including Blacini) is much restricted here (one genus and two species vs. ten genera and 17 species in the Baltic assemblage); the same holds true for Doryctinae (one genus, three species vs. four genera and about ten species) and Orgilinae (one genus, one species vs. two genera and 13 species, some of which are of obscure taxonomic position).

The fauna of the Florissant beds is much less studied, and includes only ten subfamilies, 17 genera (with one endemic, Oligoneuroides Brues, 1910) and 24 species. Investigated almost a century ago, its taxonomic composition is problematic now in respect of several taxa (see discussions under subfamilies). Nevertheless, it is possible to conclude that the Florissant fauna includes the subfamily Alysiinae, which is absent from the Bembridge Marls. Several genera recorded from the Florissant (Agathis, Cremnops, Iphiaulax, Chelonus, Discoletes etc.) are unknown in the Bembridge Marls, but their identity is not certain because of imperfection of either preservation or description. A reliable comparison of the Bembridge Marls and Florissant braconid assemblages requires a taxonomic revision of the latter.

\subsection{Aculeata Scopoli, 1763}

[By Alexander V. Antropov]

Eleven specimens of aculeate wasps and bees were studied. Of them, three represent the type material of Polybia ? anglica
Cockerell, 1921, Polybia ? oblita Cockerell, 1921 and Sceliphron (?) brevior Cockerell, 1921, and six more fossils are described herein for the first time. Two other fossils are attributed only to the family level, because of their poor preservation and lack of data necessary for more precise determination. The twelfth fossil, named Philoponites clarus Cockerell, 1915 is redescribed below based on a photograph of the holotype. The thirteenth fossil, Mesitius? rectinervis Cockerell, 1921, was not re-studied and is included herein for the sake of completeness.

Morphological terminology of the wing venation in general follows a traditional approach, with several additions concerning separate segments of longitudinal veins $\mathrm{M}$ and $\mathrm{Cu}$.

\subsubsection{Superfamily Chrysidoidea Latreille, 1802}

Family Bethylidae Haliday, 1839

Genus Mesitius Spinola, 1853

Mesitius? rectinervis Cockerell, 1921. Plate 15, fig. 1

1921a Mesitius? rectinervis Cockerell, 1921, p. 21, fig. 25.

Holotype. NHMUK I.9352, Bembridge Marls, NW Isle of Wight, UK, Brodie Collection.

Remarks. The type was not re-studied and its taxonomic position is not confirmed.

\subsubsection{Superfamily Vespoidea Laicharting, 1781}

Family Vespidae Laicharting, 1781

Remarks. Four fossils considered below are attributed to Vespidae because of their very long and narrow forewing basal cell $(\mathrm{m})$, discal cell I (1mcu) much longer than subdiscal cell (2cua) in three samples, deeply emarginate inner eye orbits and the pronotum exceeding the tegula posteriorly in the last one.

\subsubsection{Subfamily Polistinae Lepeletier, 1836}

Genus Palaeopolybia Antropov, gen. nov.

Etymology. After palaeus, the Greek for old, and genus Polybia. Gender feminine.

Type species. Polybia?anglica Cockerell, 1921; by present designation and monotypy.

Diagnosis (based on the forewing venation). Forewing with prStg less than half as long as ptStg and only slightly shorter than 1 RS which is 0.21 times as long as $\mathrm{M}$ and 0.37 times as long as RS+M, 2RS S-like bent, 3RS much shorter than 4RS, $4 \mathrm{RS}$ somewhat longer than $3 \mathrm{M}, 2 \mathrm{r}-\mathrm{m}$ practically straight, recurrent veins $1 \mathrm{~m}-\mathrm{cu}$ and $2 \mathrm{~m}-\mathrm{cu}$ joining $2 \mathrm{rm}$ near its posterior corners, $2 \mathrm{rm}$ wider than long and than $2 \mathrm{RS}, 2 \mathrm{M} 1$ and 2M3 almost equal; cu-a strongly postfurcal, half as long as $2 \mathrm{M}+\mathrm{Cu}, 1 \mathrm{Cu} 1$ and $1 \mathrm{Cu} 2$ joined at right angle.

Remarks. The type and only species was described as a questionable Polybia by Cockerell (1921a) who stated that the specimen "agrees in general with Polybia". He also compared it with the genus Apoica. This viewpoint was discussed by Carpenter \& Grimaldi (1997), who concluded that illustrations of the forewing venation of "Polybia" anglica showed "no particular resemblance to either genus - or to any polistine".

This new study of the part and counterpart holotype shows that its forewing marginal cell (r) touches apically the anterior margin of the wing (more or less separated from the wing margin in Masarinae and Eumeninae). There is a comparatively short pterostigma (ptStg) (comparatively long in Eumeninae 

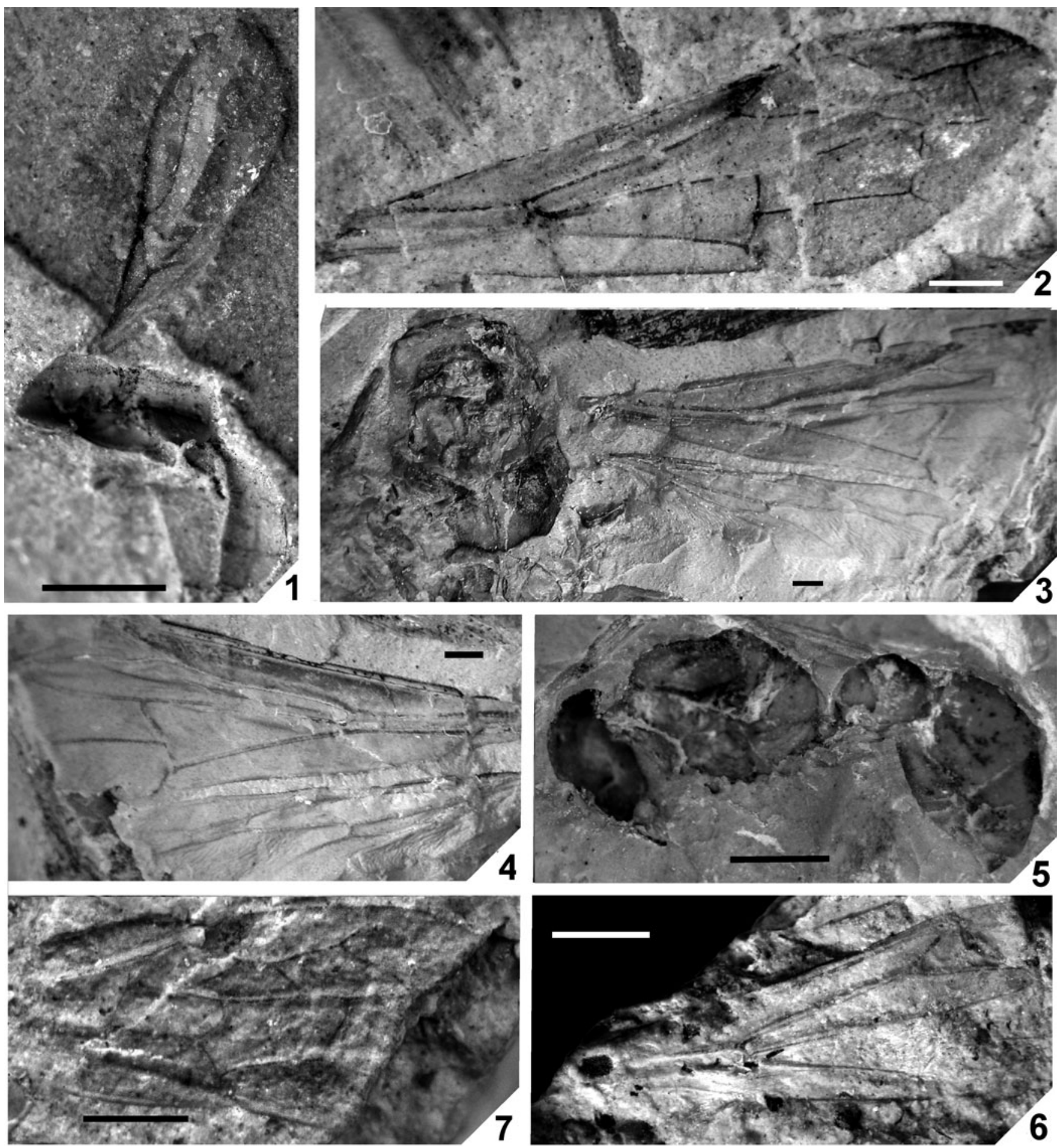

Plate 15 (1) Mesitius? rectinervis Cockerell, holotype, NHMUK I.9352. (2) Palaeopolybia anglica (Cockerell), holotype, forewing, NHMUK In.24339. (3-4) Protopolistes oblitus (Cockerell), holotype, NHMUK In.20530/ In.17166: (3) head, thorax and wings, part; (4) wings, counterpart. (5) Sphaerancistrocerus petiolatus sp. nov., holotype, body, NHMUK In.8967. (6) Subfamily Eumeninae Leach, incertae sedis, forewing, NHMUK In.43416. (7) Philoponites clarus Cockerell, holotype, forewing, USNM No 61409. Scale bars $=1 \mathrm{~mm}$.

and Stenogastrinae), both recurrent veins join $2 \mathrm{rm}(2 \mathrm{~m}-\mathrm{cu}$ joining $3 \mathrm{rm}$ in Priorivespinae and some Euparagiinae). There is a right angle between veins $2 \mathrm{M} 1$ and $2 \mathrm{RS}$ (very obtuse in Vespinae), strongly postfurcal vein cu-a (antefurcal in Masarinae; interstitial or slightly postfurcal in Euparagiinae, Priorivespinae and Stenogastrinae; slightly postfurcal in Vespinae), and also short vein $\mathrm{cu}-\mathrm{a}$ and unmodified subdiscal cell $(2 \mathrm{cu}-\mathrm{a})(\mathrm{cu}-\mathrm{a}$ long and $2 \mathrm{mcu}$ narrowed and projecting apically in Euparagiinae). These features place this species in the subfamily Polistinae (Carpenter \& Rasnitsyn 1990; Brothers \& Finnamore, 1993).

Diagnosis. In comparison with fossil genera, the forewing radial area of Palaeopolybia is most similar to that of Palaeovespa Cockerell, 1906 (Vespinae) in the relatively long prestigma, both recurrent veins joining the $2 \mathrm{rm}$ near its posterior corners, and $2 \mathrm{rm}$ wider than long.

However, Palaeopolybia differs from Palaeovespa in the following features (mainly in comparison with $P$. socialis Poinar, 


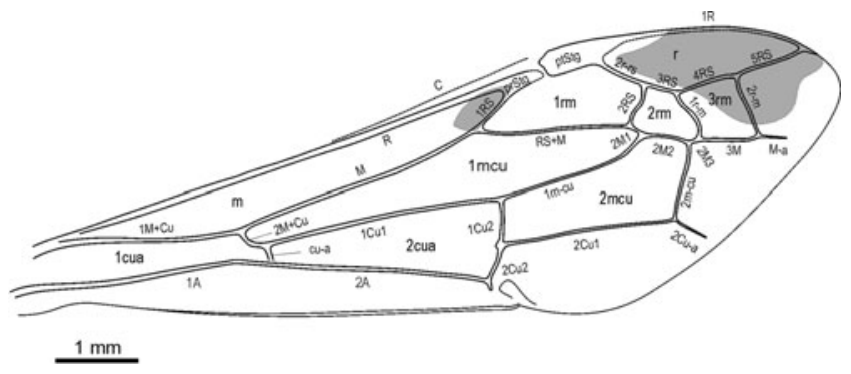

Text-figure 53 Palaeopolybia anglica (Cockerell), line drawing of holotype forewing, NHMUK In.24339.

2005, in which forewing venation has been described in detail): prStg somewhat shorter than ptStg (prStg almost equal to ptStg in Palaeovespa); 1RS 0.21 times as long as M $(0.38$ times in Palaeovespa); 1RS 0.37 times as long as $\mathrm{RS}+\mathrm{M}$ (1.37 times in Palaeovespa); 2RS S-shaped (straight in Palaeovespa); 3RS much shorter than 4RS (almost equal to 4RS in Palaeovespa); 4RS somewhat longer than vein 3M (much shorter than $3 \mathrm{M}$ in Palaeovespa); $2 \mathrm{r}-\mathrm{m}$ practically straight (strongly S-shaped in Palaeovespa); $2 \mathrm{M} 1$ almost equal to 2M3 (shorter than 2M3 in Palaeovespa); cu-a strongly postfurcal (slightly postfurcal in Palaeovespa); cu-a half as long as $2 \mathrm{M}+\mathrm{Cu}$ (almost equal to $2 \mathrm{M}+\mathrm{Cu}$ in Palaeovespa); angle between $1 \mathrm{Cu} 1$ and $1 \mathrm{Cu} 2$ right (acute in Palaeovespa); angle between 2Cu1 and 2m-cu obtuse (right in Palaeovespa).

In comparison with extant genera, no similarity in the basic features is found between Palaeopolybia and Polybia Lepeletier, 1836. The two genera differ in the following features: $r$ roundly acute apically (strongly acute in Polybia); prStg shorter than ptStg and almost as long as 1RS (1RS at least 2-3 times as long as ptStg, which is still longer comparing prStg in Polybia); $2 \mathrm{r}-\mathrm{rs}$ equal to $2 \mathrm{RS}(1 \cdot 2-1.5$ times as long as $2 \mathrm{RS}$ in Polybia); $1 \mathrm{RS}$ c. $0 \cdot 2$ times as long as $\mathrm{M}(0 \cdot 3-0 \cdot 37$ times as long as $1 \mathrm{M}$ in Polybia); 2RS S-shaped (2RS straight or slightly curved outward in Polybia); 2RS and 2M1 join at right angle (at obtuse angle in Polybia); 3RS approximately half as long as 4RS (34 times shorter than 4RS in Polybia); 4RS almost equal to 5RS (1.5-2 times shorter than 5RS in Polybia); 4RS slightly longer than $3 \mathrm{M}$ (distinctly shorter than $3 \mathrm{M}$ in Polybia); 5RS approximately equal to $2 \mathrm{r}-\mathrm{m}$ (c. 1.5 times as long as $2 \mathrm{rs}-\mathrm{m}$ in Polybia); $2 \mathrm{rm}$ wider than long (distinctly longer than wide in Polybia); 2M2 almost three times as long as $2 \mathrm{M} 1$ and $2 \mathrm{M} 3$ (subequal to 2M1 and 2M3 in Polybia); 3rm longer than wide (distinctly wider than long in Polybia); cu-a approximately half as long as $2 \mathrm{M}+\mathrm{Cu}(0 \cdot 12-0 \cdot 14$ times as long as $2 \mathrm{M}+\mathrm{Cu}$ in Polybia); $1 \mathrm{Cu} 2$ not curved (S-shaped in Polybia); $1 \mathrm{Cu} 2$ approximately equal to $2 \mathrm{Cu} 2$ (distinctly longer than $2 \mathrm{Cu} 2$ in Polybia).

Instead, Palaeopolybia shows some resemblance to Apoica Lepeletier, 1836, for example, in that: prStg is longer than wide, $2 \mathrm{rm}$ not longer than wide, $2 \mathrm{rm}$ and $3 \mathrm{rm}$ of comparable width; $5 \mathrm{RS}$ as long as $2 \mathrm{r}-\mathrm{m} ; 1 \mathrm{Cu} 2$ straight. At the same time, the two genera are different in a number of important features: marginal cell roundly acute apically (distinctly acute in Apoica); ptStg distinctly wider (very narrow in Apoica); prStg only slightly shorter than 1RS (less than two thirds as long as 1RS in Apoica); $2 \mathrm{r}$-rs equal to 2RS (twice as long as 2RS in Apoica); $2 \mathrm{r}$-rs hardly longer than 3RS (almost 2.5 times as long as $3 \mathrm{RS}$ in Apoica); $2 \mathrm{r}-\mathrm{rs}$ shorter than 5RS (2r-rs more than 1.5 times as long as 5RS in Apoica); 3RS c. 0.5 times as long as 4RS (only slightly shorter than 4RS in Apoica); 3RS 2 times longer than 2M3 (3RS shorter than 2M3 in Apoica); 4RS approximately equal to 5RS (distinctly shorter than 5RS in Apoica); $4 \mathrm{RS}$ slightly longer than $3 \mathrm{M}$ (distinctly shorter than $3 \mathrm{M}$ in
Apoica); 1r-m S-shaped (straight in Apoica); $2 \mathrm{M} 2$ almost three times as long as $2 \mathrm{M} 1$ and $2 \mathrm{M} 3(0.67$ times as long as $2 \mathrm{M} 1$ and 0.4 times as long as $2 \mathrm{M} 3$ in Apoica); M only slightly longer than vein $1 \mathrm{Cu} 1$ (almost 1.5 times as long as $1 \mathrm{Cu} 1$ in Apoica); $\mathrm{RS}+\mathrm{M}$ only slightly shorter than vein $1 \mathrm{~m}-\mathrm{cu}(\mathrm{RS}+\mathrm{M}$ c. $0 \cdot 7$ times as long as $1 \mathrm{~m}-\mathrm{cu}$ in Apoica); $2 \mathrm{~m}$-cu straight (curved outward in Apoica); $2 \mathrm{~m}-\mathrm{cu} c$. half as long as $2 \mathrm{Cu} 1$ (almost one third as long as $2 \mathrm{Cu} 1$ in Apoica); $1 \mathrm{~m}-\mathrm{cu}$ c. 6 times as long as its maximum width (almost eight times as long as its maximum width in Apoica); cu-a $c$. half as long as $2 \mathrm{M}+\mathrm{Cu}$ (one sixth to one seventh as long as $2 \mathrm{M}+\mathrm{Cu}$ in Apoica); $1 \mathrm{cu}-\mathrm{a}$ not shorter than subdiscal cell (distinctly shorter than subdiscal cell in Apoica).

The above comparison justifies generic level distinction of the fossil under consideration.

The combination of other venational features of Palaeopolybia is otherwise unknown in Polistinae, in which prestigma (prStg) is several times shorter than ptStg (slightly shorter only in Apoica Lepeletier, 1836), 2rm is not wider than long nor wider than $3 \mathrm{rm}$, both recurrent veins $(1 \mathrm{~m}-\mathrm{cu}$ and $2 \mathrm{~m}-\mathrm{cu})$ never joining $2 \mathrm{rm}$ near its posterior corners, and vein $\mathrm{cu}-\mathrm{a}$ is much shorter than vein $2 \mathrm{M}+\mathrm{Cu}$, often almost nonexistent.

Palaeopolybia anglica (Cockerell, 1921), new combination Plate 15, fig. 2; Text-fig. 53

1921a Polybia ? anglica Cockerell, p. 20, fig. 23.

1997 Polybia ? anglica Cockerell: Carpenter \& Grimaldi, p. 2 .

Holotype. NHMUK In. 24339; Bembridge Marls, NW Isle of Wight, UK, Hooley Collection. A piece of rock $43.8 \times 28.6$ $\mathrm{mm}$ with almost complete impression of the forewing lacking its base, apex of prestigma and base of pterostigma near its widest side. Convex veins and concave membrane of the discal cell I indicate that the fossil is the obverse impression (the part as opposed to the counterpart) of the right forewing.

Description (based on the forewing venation). Forewing with prStg less than half as long as ptStg and only slightly shorter than $1 \mathrm{RS}$, which is 0.21 times as long as $\mathrm{M}$ and 0.37 times as long as RS+M; 2RS S-like bent; 3RS much shorter than 4RS; 4RS somewhat longer than $3 \mathrm{M} ; 2 \mathrm{r}-\mathrm{m}$ practically straight; recurrent veins $1 \mathrm{~m}-\mathrm{cu}$ and $2 \mathrm{~m}-\mathrm{cu}$ joining $2 \mathrm{rm}$ near its posterior corners; $2 \mathrm{rm}$ wider and longer than $2 \mathrm{RS} ; 2 \mathrm{M} 1$ and $2 \mathrm{M} 3$ almost equal; cu-a strongly postfurcal, half as long as $2 \mathrm{M}+\mathrm{Cu} ; 1 \mathrm{Cu} 1$ and $1 \mathrm{Cu} 2$ joined at right angle. Two darkened spots are present: the larger one covering almost whole marginal cell and also anteriodistal half of $3 \mathrm{rm}$ and anterior half of the free cell corresponding to $4 \mathrm{rm}$, and the smaller spot in the distal corner of basal cell.

Vein measurements in mm: R1 $1.63 ; 2$ r-rs 0.53 ; 1 RS 0.62 ; 2RS $0.48 ; 3 R S ~ 0.38 ; 4 R S ~ 0.72 ; 5 R S ~ 0.78 ; 2 \mathrm{M}+\mathrm{Cu} 0.46 ; \mathrm{M}$ 2.98; RS+M 1.75; 2M1 0.18; 2M2 0.55; 2M3 0.15; 3M 0.68; M-a $0.60 ; 1 \mathrm{Cu} 12.65 ; 1 \mathrm{Cu} 20.50 ; 2 \mathrm{Cu} 20.44 ; 1 \mathrm{~m}-\mathrm{cu} 1.78$; 2m-cu 0.89; $1 \mathrm{r}-\mathrm{m} 0.58 ; 2 \mathrm{r}-\mathrm{m} 0.73$; cu-a $0.22 ; 2 \mathrm{Cu} 12.03$; $2 \mathrm{Cu}-\mathrm{a} 0 \cdot 50 ; 2 \mathrm{~A} 2 \cdot 38$. Total forewing length $c .9 \cdot 6 \mathrm{~mm}$.

\section{Genus Protopolistes Antropov, gen. nov.}

Etymology. After protos, the Greek for previous, and genus Polistes. Gender masculine.

Type species. Polybia oblita Cockerell, 1921, by present designation and monotypy.

Diagnosis (based on wing venation). Forewing with prStg only slightly shorter than 1RS, M c. 3 times as long as $1 \mathrm{RS}$ and practically equal to $1 \mathrm{Cu} 1 ; 1 \mathrm{~m}-\mathrm{cu}$ at least twice as long as 


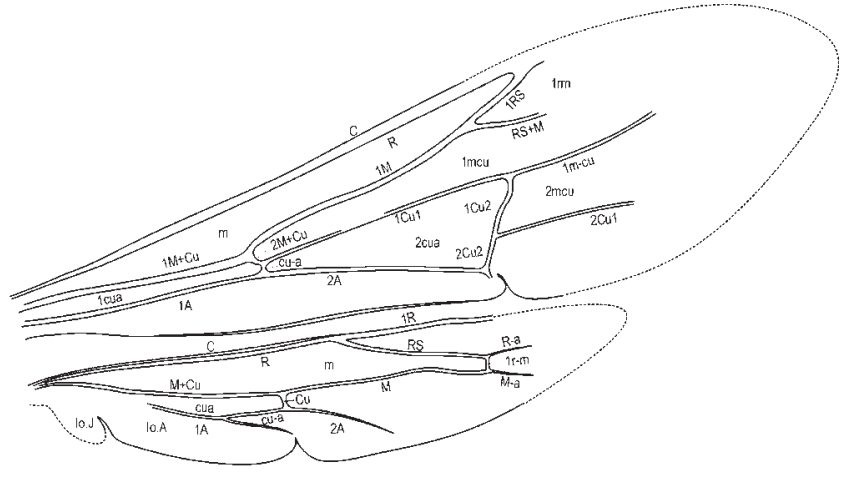

(A)

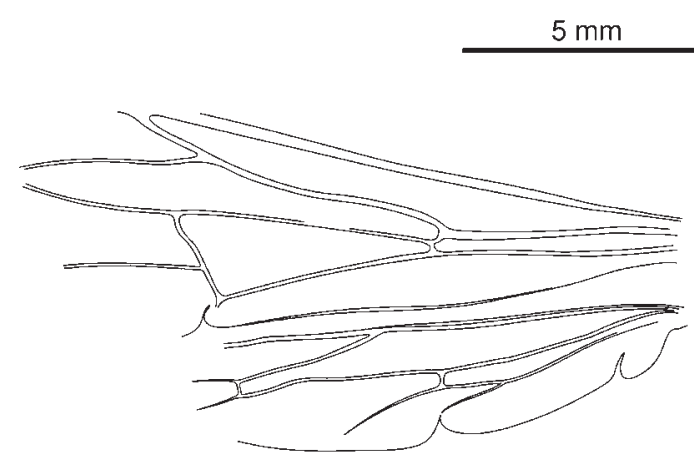

(B)

Text-figure 54 Protopolistes oblitus (Cockerell), line drawings of holotype forewings: (A) part, NHMUK In.20530; (B) counterpart, NHMUK In.17166.

$1 \mathrm{Cu} 2 ; 1 \mathrm{Cu} 1$ and $1 \mathrm{Cu} 2$ joined at acute angle; cu-a slightly postfurcal, as long as $2 \mathrm{M}+\mathrm{Cu}$. Hindwing with $\mathrm{RS}$ somewhat shorter than $\mathrm{M}$ and much longer than half of $\mathrm{M}$; cua as long as jugal and anal lobes together; cu-a c. 4.5 times as long as $\mathrm{Cu}$; jugal lobe present.

Remarks. The type species was compared with Polistes Latreille, 1802, but neither description nor illustration have shown features justifying attribution it to that genus. In the opinion of Carpenter \& Grimaldi (1997), "it is not possible to conclude with certainty that either fossil is even a polistine".

Nevertheless, in spite of incomplete preservation of the type material, the structures available make it possible to compare the new genus to other Vespidae and to reveal its distinction at the generic level.

Diagnosis. In comparison with fossil genera, among fossil vespid wasps the slightly postfurcal or sometimes interstitial position of the forewing $\mathrm{cu}-\mathrm{a}$ is characteristic of subfamilies Euparagiinae (Curiosivespa Rasnitsyn, 1975), Priorivespinae (Priorivespa Carpenter \& Rasnitsyn, 1990), and Vespinae (Vespa Linnaeus, 1758, Palaeovespa). Curiosivespa differs from the new genus in $\mathrm{cu}-\mathrm{a}$ distinctly longer than $2 \mathrm{M}+\mathrm{Cu}$ and in forewing $1 \mathrm{CuA}$ strongly produced dorsoapically. Priorivespa differs in forewing $2 \mathrm{cu}-\mathrm{a}$ shorter than comparatively wide $1 \mathrm{cu}-\mathrm{a}$, in $\mathrm{M}$ shorter than $\mathrm{RS}+\mathrm{M}$, and in somewhat longer cu-a. Vespa, and Palaeovespa, (Vespinae) differ from the new genus in lacking the hindwing jugal lobe. Additionally, Vespa unlike Protopolistes has prStg longer than 1RS. Protopolistes differs from Palaeopolybia by cu-a not longer than $2 \mathrm{M}+\mathrm{Cu}$, $1 \mathrm{Cu} 1$ longer than $2 \mathrm{~A}$ and $1 \mathrm{Cu} 2$ longer than $2 \mathrm{Cu} 2$ and, finally, by an almost twice as long forewing.

In comparison with extant genera, among recent Vespidae the weakly postfurcal position of $\mathrm{cu}-\mathrm{a}$ and its similar length subequal to $2 \mathrm{M}+\mathrm{Cu}$ are characteristic of only a limited number of taxa, including Vespa and Provespa Ashmead, 1903 (Vespi- nae) and Stenogastrinae. On the contrary, characteristic of Polistinae are a strongly postfurcal $\mathrm{cu}-\mathrm{a}$ and its small length up to almost complete loss. The hindwing RS, which is only a little shorter than $\mathrm{M}(\mathrm{M}>\mathrm{RS} \gg 0.5 \mathrm{M})$, is known in some genera of Stenogastrinae, in Vespinae (Vespa, Provespa) and in Polistinae (Polistes, but not Polybia which has $R S \approx 0.5 \mathrm{M}$ ). However, presence of the jugal lobe definitely excludes Vespinae and so leaves only Stenogastrinae and Polistinae for further consideration. However, Protopolistes differs from Stenogastrinae in the following features: 1RS slightly longer than prStg (several times longer in Stenogastrinae); hindwing cu-a equal to jugal and anal lobes together (distinctly longer in Stenogastrinae); $\mathrm{M}$ approximately three times as long as 1RS (at least four times so in Stenogastrinae); $\mathrm{M}$ approximately equal to $1 \mathrm{Cu} 2$ (distinctly shorter than $1 \mathrm{Cu} 2$ in Stenogastrinae); $1 \mathrm{~m}-\mathrm{cu}$ at least 2 times as long as $1 \mathrm{Cu} 2$ (less than 1.5 times in Stenogastrinae).

As a result, the new genus should be left within Polistinae and compared to Polistes, which differs at the generic level in the distinctly shorter prStg and strongly postfurcal and very short $\mathrm{cu}-\mathrm{a}$ in the forewing, and the hindwing cua which is shorter than the jugal and anal lobes combined.

\section{Protopolistes oblitus (Cockerell, 1921), new combination} Plate 15, figs 3, 4; Text-fig. 54

1921b Polybia? oblita Cockerell, pp 542-545, fig. 5.

1997 Polybia ? oblita Cockerell: Carpenter \& Grimaldi, p. 2.

Holotype. NHMUK In.20530/In.17166, (part and counterpart, respectively), Bembridge Marls, NW Isle of Wight, UK, Smith Collection. Sex unknown. The part is a piece of rock $63.2 \times 52 \cdot 1 \mathrm{~mm}$ with the incomplete impressions of the head, thorax, fragments of the left antenna, of the middle and hind femora and tibiae and of the right wings, and very small parts of the left wings. Apical part of the forewing, including marginal cell, submarginal cells, and outer part of discal cell II are not preserved. The counterpart is a piece of rock $40.0 \times 28.6 \mathrm{~mm}$, bearing impressions of fragments of the head, scutum and right wings.

Description (based on wing venation). Forewing with prStg only slightly shorter than 1RS; M c. 3 times as long as 1RS and practically equal to $1 \mathrm{Cu} 1 ; 1 \mathrm{~m}-\mathrm{cu}$ at least twice as long as $1 \mathrm{Cu} 2 ; 1 \mathrm{Cu} 1$ and $1 \mathrm{Cu} 2$ joined at acute angle; cu-a slightly postfurcal, as long as $2 \mathrm{M}+\mathrm{Cu}$. Hindwing with $\mathrm{RS}$ somewhat shorter than $\mathrm{M}$ and much longer than half of $\mathrm{M}$; cua as long as jugal and anal lobes together; $\mathrm{cu}-\mathrm{a} c .4 .5$ times as long as $\mathrm{Cu}$, jugal lobe present.

Vein measurements in $\mathrm{mm}$ : Forewing: $1 \mathrm{M}+\mathrm{Cu} 4.75$; $2 \mathrm{M}+\mathrm{Cu} 0 \cdot 38 ; \mathrm{M} 5 \cdot 20 ; 1 \mathrm{RS} 1.60 ; 1 \mathrm{Cu} 15 \cdot 25 ; 1 \mathrm{Cu} 21.25$; $2 \mathrm{Cu} 20.77 ; 2 \mathrm{~A} 4.48$. Hind wing: $1 \mathrm{~A} 2.80 ; 2 \mathrm{~A} 2.23$; $\mathrm{Cu} 0.28$; cu-a 1.28; M 4.23; M-a 0.93, 1r-m 0.28; RS-a 0.95; RS 3.03. Total length: forewing c. $16.8 \mathrm{~mm}$; hind wing $12.4 \mathrm{~mm}$.

3.10.2.2. Subfamily Eumeninae Leach, 1815. The following two fossils are attributed to Eumeninae because of the deeply emarginate inner eye orbits, the deeply emarginate pronotum exceeding the tegula posteriorly, the developed scutal parategulae in the first, and a very long and narrow forewing basal cell, enlarged ptStg and $1 \mathrm{~m}-\mathrm{cu}$ much longer than $2 \mathrm{cu}-\mathrm{a}$ in the second.

Genus Sphaerancistrocerus Antropov, gen. nov.

Etymology. After sphaera, the Greek for ball, sphere, and genus Ancistrocerus. Gender masculine.

Type species. Sphaerancistrocerus petiolatus sp. nov.; by present designation and monotypy. 


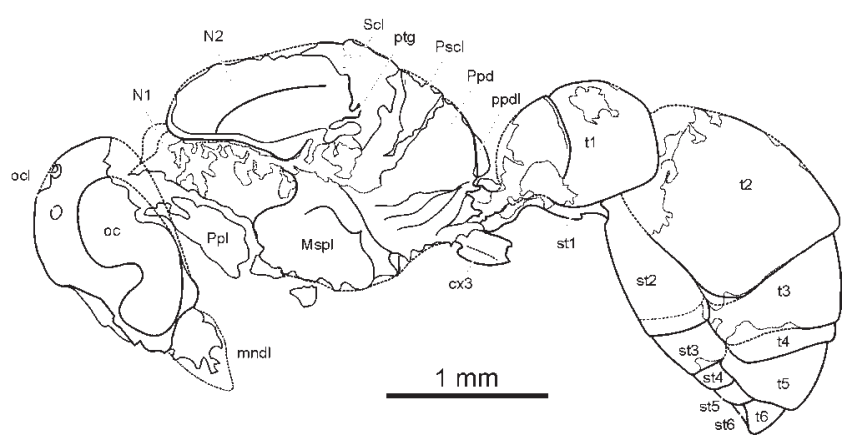

Text-figure 55 Sphaerancistrocerus petiolatus sp. nov., line drawing of holotype body, NHMUK In.8967. Body parts: cx3 = metacoxa; mndl = mandible; $\mathrm{Mspl}=$ mesopleuron; $\mathrm{N} 1=$ pronotum; $\mathrm{N} 2=$ mesonotum; oc = compound eye; ocl = ocelli; $\mathrm{Ppd}=$ propodeum; ppdl = propodeal lamella; $\mathrm{Pscl}=$ postscutellum; $\mathrm{ptg}=$ parategula; $\mathrm{Scl}=$ scutellum; st $1-6=$ metasomal sternites I-VI (abdominal sterna II-VII); t1-6 = metasomal tergites I-VI (abdominal terga II-VII).

Diagnosis. Several eumenine genera with a transverse carina on metasomal tergite I, including fossils Ancistrocerus berlandi Piton, 1840, Ancistrocerus eocenicus Piton, 1840 and Symmorphus senex Carpenter, 2000 are known. They differ from Sphaerancistrocerus gen. nov. in having a distinct bend dividing anterior and posterior parts of tergite I. The only known eumenine genus with a uniformly rounded first metasomal segment is the fossil Rotundipetiolus longiantennus Zhang, 1989, which distinctly differs from Sphaerancistrocerus gen. nov. in its much larger body size and the absence of a transverse carina on tergite I.

Sphaerancistrocerus petiolatus Antropov, sp. nov. Plate 15, fig. 5; Text-fig. 55

Etymology. After petiolus, the Latin for petiole.

Holotype. NHMUK I.8967, Bembridge Marls, NW Isle of Wight, UK, Brodie Collection. Female. The part is a piece of rock $41.5 \times 37.0 \mathrm{~mm}$ with impression of the partially preserved head, thorax, propodeum, hind coxa, and metasoma. Antennae, legs and wings not preserved.

Description (based on body structure). Head with front significantly convex, noticeably stronger than occiput; vertex noticeably convex; ocelli in at least right-angled triangle; pronotal collar moderately roundly convex, without transverse carina; scutum convex anteriorly, with rest surface flattened; adlateral lines almost reaching scutal posterior margin; scutellum posteriorly and postscutellum flattened; metacoxa with outer longitudinal carina; propodeum uniformly rounded, without anterior teeth, with oval apical lamellae; 1st metasomal segment with short petiole not longer than metacoxa; dorsal surface of metasomal tergite I uniformly convex, with transverse carina but without distinct bend between anterior and posterior parts; metasomal sternite I with broad transverse apical depression; metasomal tergite II 1.25 as long as metasomal tergite I, uniformly convex, without isolated border.

Length of body parts in $\mathrm{mm}$ : head 0.83 ; scutum 1.18; scutellum $0 \cdot 38$; postscutellum $0 \cdot 29$; mesosoma $2 \cdot 06$; petiolus $0 \cdot 15$; metasomal tergite I $1 \cdot 11$; anterior part of metasomal tergite I 0.49 ; posterior part of metasomal tergite I 0.54 ; metasomal tergite II 1.21; metasomal tergites II-VI 2.07. Total body length $c .6 \cdot 0 \mathrm{~mm}$.

\subsubsection{Subfamily Eumeninae Leach, 1815, incertae sedis}

Plate 15, fig. 6; Text-fig. 56

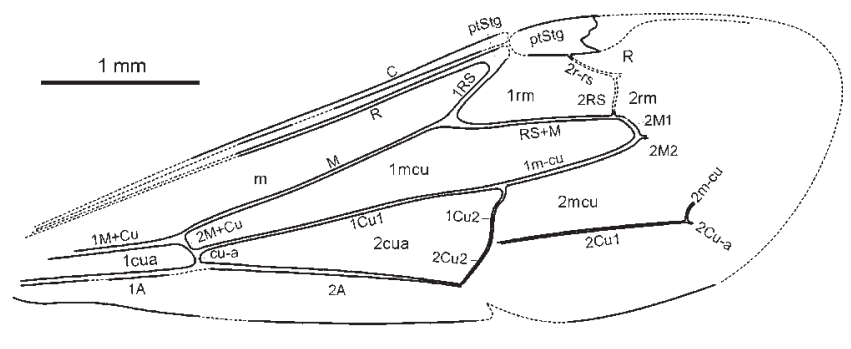

Text-figure 56 Subfamily Eumeninae Leach, incertae sedis, line drawing of forewing, NHMUK In.43416.

Material studied. NHMUK In.43416, Bembridge Marls, NW Isle of Wight, UK, Hooley Collection. Sex unknown. The piece of rock $34.8 \times 26.7 \mathrm{~mm}$ with an impression of the partially preserved forewing. Distal part of the wing including marginal and submarginal cells, and discal cell II not preserved.

Description. Vein measurements in $\mathrm{mm}$ : prStg $0 \cdot 17$, ptStg $0.79,2 \mathrm{M}+\mathrm{Cu} 0 \cdot 13 ; \mathrm{M} 1.86 ; 1 \mathrm{RS} 0,50 ; \mathrm{RS}+\mathrm{M} 1.05 ; 2 \mathrm{M} 1$ $0 \cdot 23$; cu-a $0.08 ; 1 \mathrm{Cu} 11.78 ; 1 \mathrm{Cu} 20 \cdot 36 ; 2 \mathrm{Cu} 20 \cdot 33 ; 1 \mathrm{~m}-\mathrm{cu}$ $1 \cdot 15 ; 2 \mathrm{Cu} 11 \cdot 27$; $2 \mathrm{~A} 1 \cdot 68$. Total forewing length ?. $5.3 \mathrm{~mm}$.

Remarks. Though the form of basal, discal I, and subdiscal cells and enlarged pterostigma attribute the specimen to the subfamily Eumeninae, absence of the most important cells of the submarginal sector prevents its placement even to genus.

\subsubsection{Family Tiphiidae Leach, 1815}

\subsubsection{Subfamily Tiphiinae Leach, 1815}

\section{Genus Philoponites Cockerell, 1915}

Type species. Philoponites clarus Cockerell, 1915; by monotypy.

Diagnosis (based on forewing venation). Forewing with complete marginal (r), three submarginal (1 $\mathrm{rm}, 2 \mathrm{rm}$, and $3 \mathrm{rm}$ ), two discal (1mcu and $2 \mathrm{mcu}$ ), basal (m), sub-basal (1cua), and subdiscal (2cua) cells. Marginal cell not strongly elongate, probably rounded or truncate apically; $2 \mathrm{rm}$ equal to $1 \mathrm{rm}$; $3 \mathrm{rm}$ more than 1.3 times as long as $2 \mathrm{rm} ; 2 \mathrm{mcu} 1.5$ times as long as $1 \mathrm{mcu}$; 2 cua longer than $1 \mathrm{mcu}$; ptStg enlarged, oval, somewhat longer than prStg; $2 \mathrm{r}-\mathrm{m}$ at least twice as long as $5 \mathrm{RS}$; $\mathrm{M}$ almost straight; $1 \mathrm{~m}-\mathrm{cu}$ strongly curved outwards, received by $2 \mathrm{rm} ; 2 \mathrm{~m}-\mathrm{cu}$ almost straight, received by $3 \mathrm{rm}$; $\mathrm{cu}-\mathrm{a}$ antefurcal, oblique, longer than $2 \mathrm{M}+\mathrm{Cu} ; 2 \mathrm{Cu}-\mathrm{a}$ short, not reaching wing margin.

Remarks. Philoponites was described by Cockerell (1915) as a member of "Philanthidae" and compared venationally with Philoponus Kohl, 1889 (junior synonym of Pseudoscolia Radoszkowski, 1876). I had no opportunity to study the holotype kept at the USNM (No 61409); however, I did study a photograph, which unfortunately does not display all necessary details. For example, not clearly visible are the apex of the marginal cell and posterior part of $2 \mathrm{RS}$ near $\mathrm{RS}+\mathrm{M}$. The form and the relative sizes of ptStg, $1 \mathrm{mcu}, 2 \mathrm{mcu}$, and $1 \mathrm{rm}$ of the type species do not correspond to those of Philanthidae sensu Cockerell (1915), nor Philanthinae sensu Bohart \& Menke (1976). Particularly, 1m-cu strongly curved outwards does not occur in Crabronidae or generally in digger wasps. On the contrary, the forewing venation of Philoponites clarus is similar to that of some tiphiid wasps of the subfamily Tiphiinae. Furthermore, if the posterior part of 2RS of Philoponites clarus was not reaching $\mathrm{RS}+\mathrm{M}$, its venation becomes practically identical to that of Paratiphia praefecta Cockerell, 1907 (Upper Eocene shales of Florissant).

However, both of these species essentially differ from extant representatives of the genus Paratiphia Saussure \& Sichel, 


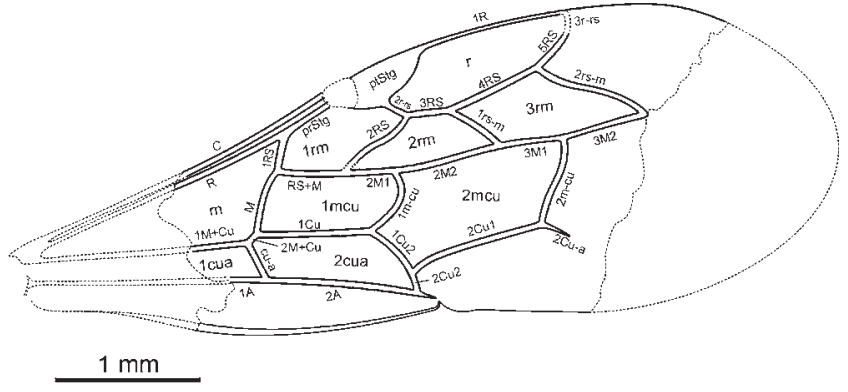

Text-figure 57 Philoponites clarus Cockerell, line drawing of holotype forewing, USNM No 61409.

1864 in the form of the marginal cell, with its simple narrowed apex touching the wing margin; whereas Paratiphia species have the marginal cell either broadly rounded apically and not reaching the wing margin, or entirely opened anteriorly. In any case, the marginal cell of Paratiphia has a short apical vein Rs-a, which is not present in either Paratiphia praefecta or Philoponites clarus. As a result, I consider, that P. praefecta Cockerell, 1907 should be transferred from the genus Paratiphia to Philoponites, thus becoming Philoponites praefectus (Cockerell), comb. nov., and the genus Philoponites should be included in the family Tiphiidae.

\section{Philoponites clarus Cockerell, 1915} Plate 15, fig. 7; Text-fig. 57

1915 Philoponites clarus Cockerell, pp 482, 499, plate 64, figure 2.

1976 Philoponites clarus Cockerell: Bohart \& Menke, p. 31.

1992 Philoponites clarus Cockerell: Carpenter, p. 496.

Holotype. USNM No 61409; sex unknown. Lacoe Coll. 7620. Incomplete impression of the right forewing missing distal part of outer membrane and proximal parts of wing and of pterostigma.

Description (based on forewing venation). Forewing with complete marginal (r), three submarginal (1 rm, 2rm, and $3 \mathrm{rm}$ ), two discal (1mcu and $2 \mathrm{mcu}$ ), basal (m), sub-basal (1cua), and subdiscal (2cua) cells. Marginal cell not strongly elongate, probably rounded or truncate apically; $2 \mathrm{rm}$ equal to $1 \mathrm{rm} ; 3 \mathrm{rm}$ more than 1.3 times as long as $2 \mathrm{rm} ; 2 \mathrm{mcu} 1.5$ times as long as 1mcu; 2cua longer than 1mcu; ptStg enlarged, oval, somewhat longer than prStg; $2 \mathrm{r}-\mathrm{m}$ at least twice as long as $5 \mathrm{RS}$; $\mathrm{M}$ almost straight; $1 \mathrm{~m}-\mathrm{cu}$ strongly curved outwards, received by $2 \mathrm{rm} ; 2 \mathrm{~m}-\mathrm{cu}$ almost straight, received by $3 \mathrm{rm}$; $\mathrm{cu}-\mathrm{a}$ antefurcal, oblique, longer than $2 \mathrm{M}+\mathrm{Cu} ; 2 \mathrm{Cu}-\mathrm{a}$ short, not reaching wing margin.

Vein measurements in mm: ptStg 0.66; 1R 0.98; 3r-rs 0.15; 2r-rs $0 \cdot 18$; 1RS $0 \cdot 28$; 2RS $0 \cdot 60$; 3RS $0 \cdot 28$; 4RS 0.68; 5RS $0.30 ; 1 \mathrm{r}-\mathrm{m} \quad 0.43 ; 2 \mathrm{r}-\mathrm{m} \quad 0.80 ; \mathrm{RS}+\mathrm{M} 0.44 ; \mathrm{M} 0.45 ; 2 \mathrm{M} 1$ $0.35 ; 2 \mathrm{M} 20.75 ; 3 \mathrm{M} 10.44 ; 3 \mathrm{M} 2 \quad 0 \cdot 58 ; 2 \mathrm{M}+\mathrm{Cu} 0.08 ; \mathrm{cu}-\mathrm{a}$ $0 \cdot 28 ; 1 \mathrm{Cu} 10.76 ; 2 \mathrm{Cu} 10.78 ; 1 \mathrm{Cu} 20.41 ; 2 \mathrm{Cu} 20 \cdot 14 ; 1 \mathrm{~m}-\mathrm{cu}$ $0.45 ; 2 \mathrm{~m}-\mathrm{cu} 0 \cdot 60 ; 2 \mathrm{Cu}-\mathrm{a} 0 \cdot 18 ; 2 \mathrm{~A} 1 \cdot 00$. Total forewing length $c .5 .8 \mathrm{~mm}$.

\subsubsection{Subfamily Dryophiinae Antropov, nov.}

Type genus. Dryophia Antropov, gen. nov.; by present designation and monotypy.

Diagnosis. Subfamily Dryophiinae nov. somewhat resembles females of Dryinidae (Chrysidoidea), differing from them in having frons flattened and head strongly narrowed and elongate behind the eyes, and by the non-specialised mesosoma and more complete forewing venation.
Subfamily Dryophiinae is more similar to Tiphiidae (Vespoidea) in having the pronotum deeply U-like excised and reaching the tegulae posteriorly, and in the structure of the mesosoma, contiguous metacoxae, and sessile metasoma.

Among Tiphiidae, the new subfamily is most similar to Myzininae in the presence of a frontal tubercle, comparatively large eyes and structure of the scutellum, postscutellum and propodeum, but differs in its head elongate and narrowed behind the eyes, narrow pronotal collar, deeply emarginate pronotum, tegulae ending posteriorly at transscutal furrow, absence of scutal adlateral lines, hind femora not widened, and in absence of metasomal intersegmental constrictions and a pygidial plate.

\section{Genus Dryophia Antropov, gen. nov.}

Etymology. After generic names Dryinus and Tiphia. Gender feminine.

Type species. Dryophia oculata Antropov, sp. nov.; by present designation and monotypy.

Diagnosis. As for subfamily.

Dryophia oculata Antropov, sp. nov. Plate 16, fig. 1; Text-fig. 58

Etymology. After oculatus, the Latin for goggle-eyed.

Holotype. NHMUK In.17086, Bembridge Marls, NW Isle of Wight, UK, Smith Collection. Female. The holotype is a piece of rock $40.0 \times 39.7 \mathrm{~mm}$ with impressions of the head, mesosoma, metasoma and partially preserved left femur, tibia and left forewing. Antennae, other legs, right wings and left hind wings not preserved.

Description. Compound eyes very large and convex, head behind eyes strongly narrowed and elongate; frons flat, not broader than eye, with indistinct tubercle below; vertex weakly convex; ocelli small, round, in equilateral triangle between eyes; occipital carina distinct at least dorsally; pronotal collar short, weakly concave anteriorly, with strong lateral corners; pronotum deeply emarginate, U-shaped posterior and reaching tegulae posterolaterally; notauli almost reaching transscutal furrow; adlateral lines absent; scutellum large and flat, rounded posteriorly; tegulae semicircular, not enlarged, but ending at transscutal furrow posteriorly; forewings somewhat shortened, probably scarcely reaching metasomal middle; 1 cua only scarcely narrower than $1 \mathrm{rm}$; hind coxae not enlarged; hind femora and tibiae not widened; propodeum somewhat elongate, oval, without dorsal enclosure and lateral and posterior carinae or furrows; metasoma sessile, without elongate petiole, and constrictions between tergites; apical tergite without pygidial plate.

Body parts measurements in mm: head length 1.67 ; eye length 0.68 ; eye height 0.99 ; mesomal length 2.81 ; pronotal collar length $0 \cdot 21$; pronotal length 0.93 ; pronotal width 1.25 ; scutal length 0.93 ; scutellar length 0.56 ; postscutellar length $0 \cdot 17$; propodeal length $0 \cdot 82$; pronotal collar width $0 \cdot 96$; scutal width $1 \cdot 13$; scutellar width $0 \cdot 85$; metasomal width $1 \cdot 53$; metasomal length 3.99 ; 1st metasomal segment 0.90 ; 2nd metasomal segment $0 \cdot 79$. Total body length $c .8 .54 \mathrm{~mm}$. Forewing veins measurements in $\mathrm{mm}: 2 \mathrm{M}+\mathrm{Cu} 0 \cdot 04$; cu-a $0 \cdot 21$; $\mathrm{M} \mathrm{0.36}$; $\mathrm{RS}+\mathrm{M} 0 \cdot 29 ; 1 \mathrm{Cu} 10 \cdot 37 ; 1 \mathrm{~m}-\mathrm{cu} 0 \cdot 22$.

\subsubsection{Family Scoliidae Leach, 1815}

3.10.4.1. Subfamily Palaeoscoliinae Antropov, nov.

Type genus. Palaeoscolia gen. nov., by present designation and monotypy.

Diagnosis. Subfamily Palaeoscoliinae differs from Archaeoscoliinae Rasnitsyn, 1993 in its broad and corrugated outer 

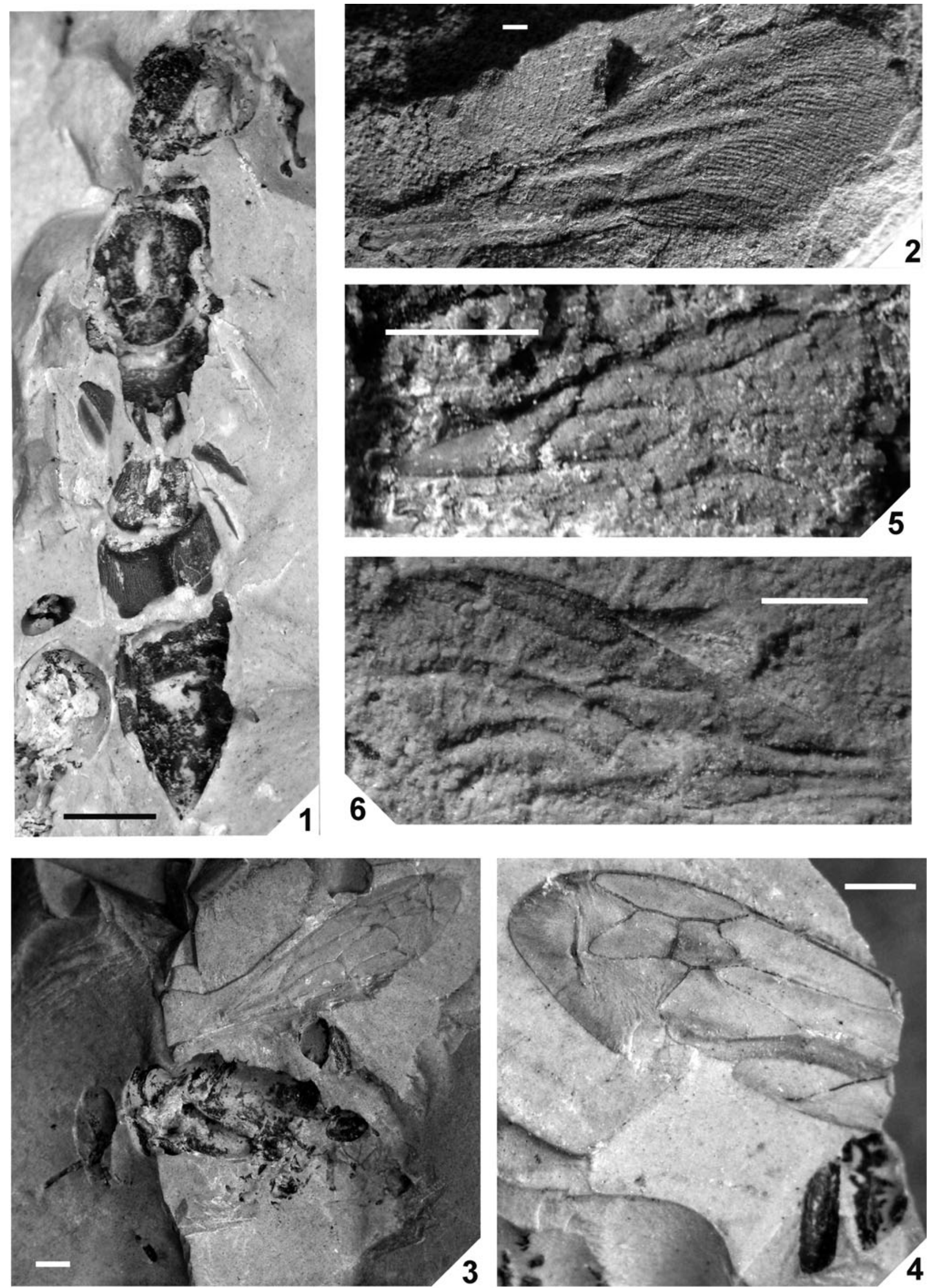

Plate 16 (1) Dryophia oculata sp. nov., holotype, body, NHMUK In.17086. (2) Palaeoscolia relicta sp. nov., holotype, forewing, NHMUK In.24527. (3-4) Protosceliphron brevior (Cockerell), holotype, NHMUK In.17472/In.24340: (3) head, thorax, wings, and anterior part of metasoma, part; (4) apical parts of wings and hind femur and tibia, counterpart. (5) Tytthopsen nanus sp. nov., holotype, forewing, NHMUK In.25568. (6) Plisomena gigantea sp. nov., holotype, forewing, NHMUK In.24789. Scale bars $=1 \mathrm{~mm}$. 


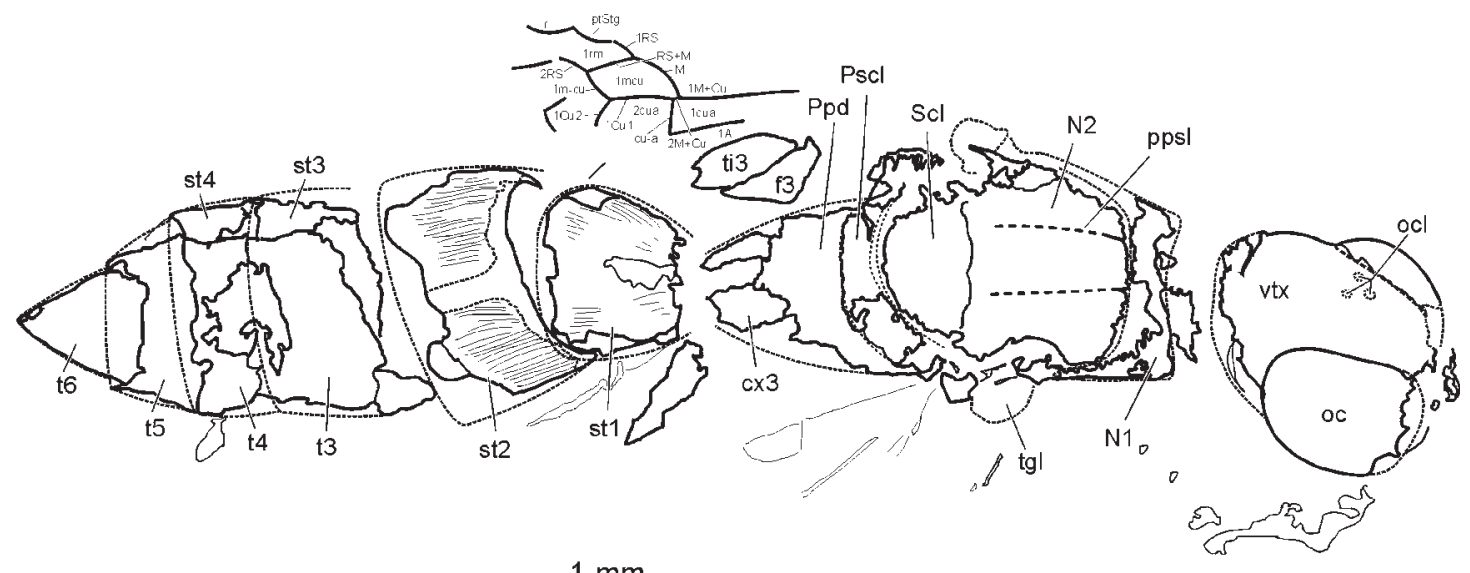

$1 \mathrm{~mm}$

Text-figure 58 Dryophia oculata sp. nov., line drawing of holotype body, NHMUK In.17086. Body parts: $\mathrm{cx} 3=$ metacoxa; $\mathrm{f} 3=$ hind femur; $\mathrm{N} 1=$ pronotum; $\mathrm{N} 2=$ mesonotum; $\mathrm{oc}=$ compound eye; ocl = ocelli; $\mathrm{Ppd}=$ propodeum; ppsl = parapsidal line; Pscl = postscutellum; Scl = scutellum; st1-4 = metasomal sternites I-IV (abdominal sterna II-V); t3-6 = metasomal tergites III-VI (abdominal terga IV-VII); ti3 = hind tibia; tgl = tegula; $\mathrm{vtx}=$ vertex. Wing cells: 1 cua $=$ sub-basal; $\mathrm{r}=$ marginal; $1 \mathrm{rm}=$ submarginal I; $1 \mathrm{mcu}=$ discal I; 2 cua $=$ subdiscal.

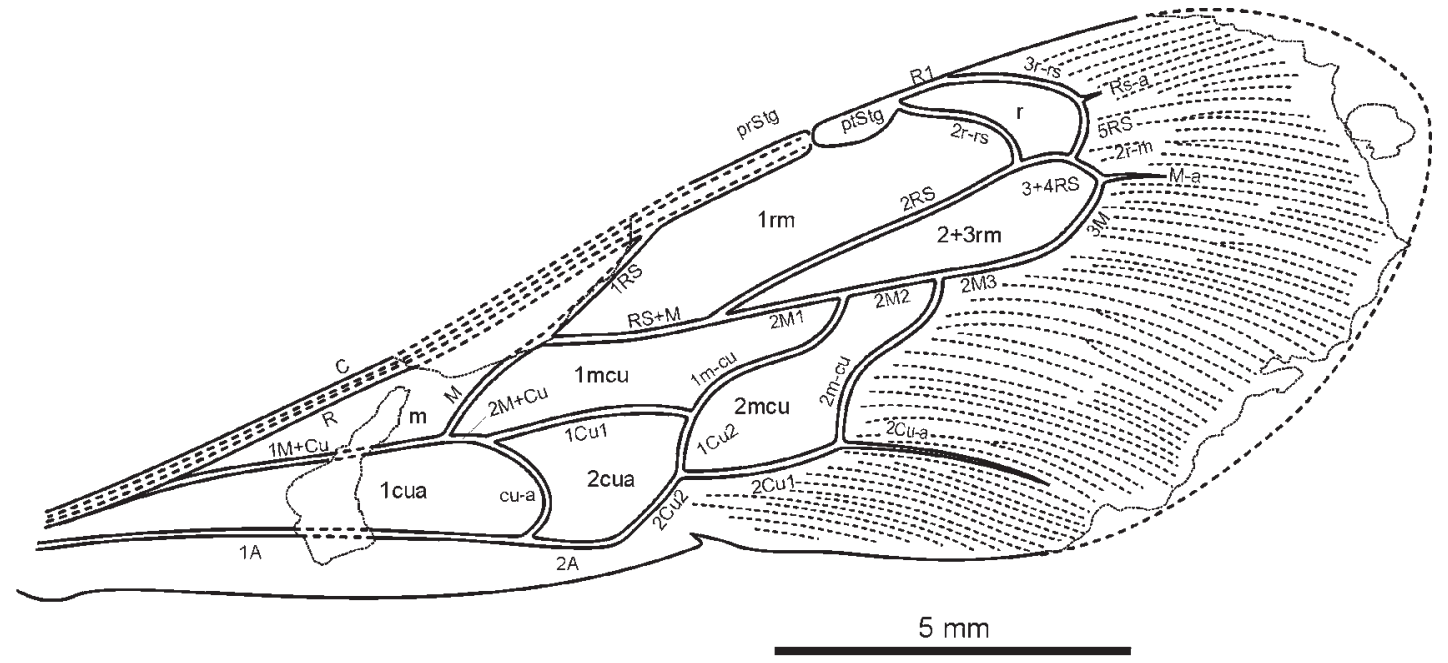

Text-figure 59 Palaeoscolia relicta sp. nov., line drawing of holotype forewing, NHMUK In.24527.

forewing membrane, not elongate ptStg half as long as prStg, short marginal cell, two closed submarginal cells $(2+3 \mathrm{rm}$ formed by merged $2 \mathrm{rm}$ and $3 \mathrm{rm}$ ), and distinctly postfurcal and curved distal cu-a. Palaeoscoliinae also differs from Proscoliinae Rasnitsyn, 1977 in having ptStg not strongly enlarged (half as long as prStg), 2RS straight, bearing no inner appendicular vein, 2RS and 2r-m non-convergent anteriorly, $1 \mathrm{mcu}$ shorter than $2+3 \mathrm{rm}$ and twice as long as $2 \mathrm{cua}, 1 \mathrm{~m}-\mathrm{cu}$ and $2 \mathrm{~m}$-cu S-shaped, and cu-a strongly postfurcal.

Subfamily Palaeoscoliinae is more similar to Scoliinae Latreille, 1802 and particularly to the genera Campsoscolia Betrem, 1933 and Campsomeris Guérin, 1838, but differs in having a wide and comparatively short costal prStg, a notch separating a distinct and not strongly elongate ptStg from prStg, and S-curved $1 \mathrm{~m}-\mathrm{cu}$.

\section{Genus Palaeoscolia Antropov, gen. nov.}

Etymology. After palaeus, the Greek for old, and genus Scolia. Gender feminine.

Type species. Palaeoscolia relicta Antropov, sp.nov.; by present designation and monotypy.

Diagnosis. As for the subfamily.
Palaeoscolia relicta Antropov, sp. nov. Plate 16, fig. 2; Text-fig. 59

Holotype. NHMUK In.24527; Bembridge Marls, NW Isle of Wight, UK, Hooley Collection. A piece of rock $44.8 \times 28.6$ $\mathrm{mm}$ with almost complete impression of the forewing lacking its base, middle part of anterior margin and distal margin of membrane. Preservation rather poor because of salt crystals covering rock surface (strong oblique illumination can somewhat improve visibility of the fossil).

Description (based on forewing venation). Forewing with marginal (rR), two submarginal (1 rm and $2+3 \mathrm{rm})$, two discal (1 $\mathrm{mcu}$ and $2 \mathrm{mcu}$ ), basal (m), sub-basal (1cua), and subdiscal cells (2cua); ptStg distinct, oval, half as long as prStg; costal notch between ptStg and prStg distinct; marginal cell strongly shortened, rounded apically; second and third submarginal cells united; $1 \mathrm{rm}$ strongly elongate, longer and broader than $2+3 \mathrm{rm}$; 2RS straight, without inner appendix vein, not strongly convergent with $2 \mathrm{rs}-\mathrm{m}$ anteriorly; 5RS 1.6 times as long as 2rs-m; $\mathrm{M}$ almost straight, $0 \cdot 8$ times as long as $\mathrm{RS}+\mathrm{M} ; 2 \mathrm{M} 1$ $1 \cdot 3$ times as long as $2 \mathrm{M} 2,1 \cdot 2$ times as long as $2 \mathrm{M} 3,1.4$ times as long as $3 \mathrm{M}$; $1 \mathrm{mcu}$ twice as long as $2 \mathrm{cua} ; 1 \mathrm{~m}-\mathrm{cu}$ and $2 \mathrm{~m}-\mathrm{cu}$ strongly $\mathrm{S}-$ shaped, both received by $2+3 \mathrm{rm}$; cu-a postfurcal, 
roundly curved distally, $2 \cdot 5$ times as long as $2 \mathrm{M}+\mathrm{Cu} ; 2 \mathrm{~A} 0 \cdot 8$ times as long as cu-a, 1.4 times as long as $1 \mathrm{Cu} 2$, and 0.9 times as long as $2 \mathrm{Cu} 2 ; 2 \mathrm{Cu}-\mathrm{a}$ long, but not reaching wing margin.

Vein measurements in mm: prStg 2.62; ptStg 1.27; 1R 0.78; 3r-rs 1.86; 2r-rs 1.90; 1RS 2.13; 2RS 4.75; 3+4RS 0.77; 5RS $0 \cdot 80 ; 2 \mathrm{r}-\mathrm{m}$ 0.50; RS+M 2.44; M 1.97; $2 \mathrm{M} 1$ 1.84; $2 \mathrm{M} 2$ 1.37; $2 \mathrm{M} 31.53 ; 3 \mathrm{M} 1.26 ; 2 \mathrm{M}+\mathrm{Cu} 0.61 ; \mathrm{cu}-\mathrm{a} 1.46 ; 1 \mathrm{Cu} 12.90$; $2 \mathrm{Cu} 12 \cdot 25 ; 1 \mathrm{Cu} 20 \cdot 84 ; 2 \mathrm{Cu} 21.40 ; 1 \mathrm{~m}-$ cu $2.73 ; 2 \mathrm{~m}-\mathrm{cu} 2.74$; 2A 1.20 ; Rs-a $0 \cdot 31 ; \mathrm{M}-\mathrm{a} 0 \cdot 90 ; 2 \mathrm{Cu}-\mathrm{a} 3 \cdot 01$. Total forewing length $c .20 \cdot 8 \mathrm{~mm}$.

\subsubsection{Superfamily Apoidea Latreille, 1802}

\subsubsection{Family Sphecidae Latreille, 1802}

Subfamily Sceliphrinae Ashmead, 1899

Tribe Protosceliphrini Antropov, nov.

Type genus. Protosceliphron gen. nov., by present designation and monotypy.

Diagnosis. Protosceliphrini tribe nov. resembles Sceliphrini in the forewing venation, but differs from all Sphecidae in the postfurcal hind wing cu-a and particularly in the metasomal segment I lacking a petiole.

The unique species of the type genus has been described as Sceliphron (?) brevior Cockerell, 1921 based mainly on the forewing venation. Forewing venation and structure of the thorax and propodeum (mesosoma), as preserved, do generally correspond to those of extant representatives of the genus Sceliphron Klug, 1801, except that 5RS is uniformly curved outwards in the new tribe and not S-shaped as usually in Sceliphron, and that $1 \mathrm{Cu} 1$ is more curved forwards than in Sceliphron. Hind wing shows a greater difference in the postfurcal position of $\mathrm{cu}-\mathrm{a}$, which is interstitial in Sceliphrini.

Most striking is, however, structure of the metasomal segment I of the new tribe, which lacks a long petiole of entirely sternal nature which is otherwise a universal feature of Sphecidae.

The visible metasomal segment I of all known members of Sceliphrini have a more or less elongate tubular petiole, formed by metasomal sternite I, while metasomal tergite I is divided into a larger convex posterior part, embracing laterally the posterior end of sternite I, and a broadly separated minute acrotergite I. The last forms, above the anterior end of the sternal petiole, a dorsal part of the metasomal joining plate connecting the metasoma with the propodeum. Some extant genera of Sphecinae (Stangeellini: Stangeella Menke, 1962) or related to Chloriontinae (Chlorion Latreille, 1809) have a comparatively short petiole, which is not longer than the hind coxa, but with the posterior part of metasomal tergite I separated from its acrotergite. Chalybion mortuum Cockerell, 1907 (Sceliphrinae, Sceliphrini) from the Upper Eocene shales of Florissant, Colorado has a short but distinct petiole. Hoplisidia kohliana Cockerell, 1906 (Sceliphrinae, Sceliphrini) also from Upper Eocene shales of Florissant, Colorado described in "Nyssonidae" and attributed to Tiphiidae (Evans 1966) and later to Sceliphrini (Menke \& Rasnitsyn 1987) also have a short petiole, though its precise structure is not visible in the type specimen.

The holotype of the only known species in the new tribe has a sclerite lying directly behind the propodeal apex which, judging from its form and size, represents metasomal tergite I or at least the main fragment of its anterior part. It has a distinct rectangular prominence at the anterior margin which obviously represents its acrotergite forming a joining plate, but not separated from the posterior part of the tergite. Thus, the metasoma of Protosceliphron is sessile and has no elongate sternal petiole, as characteristic of the subfamily Sceliphrinae and the family Sphecidae in general.
Genus Protosceliphron Antropov, gen. nov.

Etymology. After protos, the Greek for previous, and genus Sceliphron. Gender neuter.

Type species. Sceliphron (?) brevior Cockerell, 1921, by present designation and monotypy.

Diagnosis. As for the tribe.

Protosceliphron brevior (Cockerell, 1921), new combination Plate 16, figs 3, 4; Text-fig. 60

1921a Sceliphron (?) brevior Cockerell, pp 20-21, fig. 24.

1976 Sceliphron (?) brevior Cockerell: Bohart \& Menke, p. $31,106$.

Holotype. NHMUK In.17472/In. 24340 (part and counterpart), Bembridge Marls, NW Isle of Wight, UK, Smith/ Hooley Collections. The part is a piece of rock $57.6 \times 41.4$ $\mathrm{mm}$ with impression of the partially preserved head, thorax, metasomal base, fragments of antennae, hind femur and tibia, almost complete right forewing, and base of right hind wing. The counterpart is a piece of rock $24.4 \times 18.7 \mathrm{~mm}$ with the partially preserved hind femur and tibia, and apical half of the right forewing.

Description. Head flattened, with vertex strongly broadened; mandibles long, almost straight, acute apically; palpal segments elongate; hind femora stout; forewing venation almost like that of Sceliphron, with complete basal, marginal, three submarginal, two discal, sub-basal, and subdiscal cells; forewing $1 \mathrm{Cu} 1$ distinctly curved forwards; hind wing cu-a postfurcal; metasomal tergite I complete, with acrotergite not separated from posterior part; sternal petiole not developed.

Vein measurements in $\mathrm{mm}$ : Forewing: prStg 1.78; ptStg 0.94; R1 1.34; 1RS 0.40; 2RS 0.70; 3RS 0.55; 4RS 0.75; 5RS 0.68; RS+M 2.61; M 1.18; 2M1 0.40; 2M $20.41 ; 2 \mathrm{M} 3$ $0 \cdot 36 ; 3 \mathrm{M} 1 \cdot 33 ; 2 \mathrm{M}+\mathrm{Cu} 0 \cdot 16,1 \mathrm{Cu} 12 \cdot 30 ; 2 \mathrm{Cu} 11 \cdot 90,1 \mathrm{Cu} 2$ $0 \cdot 66 ; 2 \mathrm{Cu} 20 \cdot 18,2 \mathrm{~A} 2 \cdot 53 ; 2 \mathrm{r}-\mathrm{rs} 0.48,3 \mathrm{r}$-rs $0 \cdot 29 ; 1 \mathrm{r}-\mathrm{m} 0.60$, $2 \mathrm{r}-\mathrm{m} 1.00 ; 1 \mathrm{~m}-\mathrm{cu} 1.65 ; 2 \mathrm{~m}-\mathrm{cu} 0.93$; cu-a $0.25 ; 2 \mathrm{Cu}-\mathrm{a} 0.47$. Hindwing: $\mathrm{Cu} 0 \cdot 21 ; \mathrm{cu}-\mathrm{a} 0 \cdot 28$. Total forewing length $c .10 \cdot 1$ $\mathrm{mm}$, hindwing $6.8 \mathrm{~mm}$.

Remark. Judging from the length of the left basal and right apical antenomeres and the relative length of antennae, the studied specimen is a female.

\subsubsection{Family Crabronidae Latreille, 1802}

Subfamily Pemphredoninae Dahlbom, 1835

Tribe Psenini A. Costa, 1858

Genus Tytthopsen Antropov, gen. nov.

Etymology. After tytthos, the Greek for smallest, and genus Psen. Gender masculine.

Type species. Tytthopsen nanus sp. nov., by present designation and monotypy.

Diagnosis. The complete forewing venation of the type genus, with the elongate marginal cell which touches the wing margin with its acuminate apex, indicates it probably belongs to the crabronid subfamily Pemphredoninae.

In comparison with fossil genera, only two species of fossil pemphredonines are known to have three submarginal cells: Palanga succinea Budrys, 1993 and Eomimesa rasnitsyni Budrys, 1993, both from the Upper Eocene Baltic amber. Of them, Palanga differs from Tytthopsen in the following features: prStg at most one third as long as ptStg; $2 \mathrm{r}-\mathrm{rs}$ received by outer third of ptStg and 1.5 times as long as 4RS; $\mathrm{M}$ and $1 \mathrm{~m}-\mathrm{cu}$ practically straight; $1 \mathrm{~m}-\mathrm{cu}$ received by $1 \mathrm{rm}, 2 \mathrm{~m}-\mathrm{cu}$ 


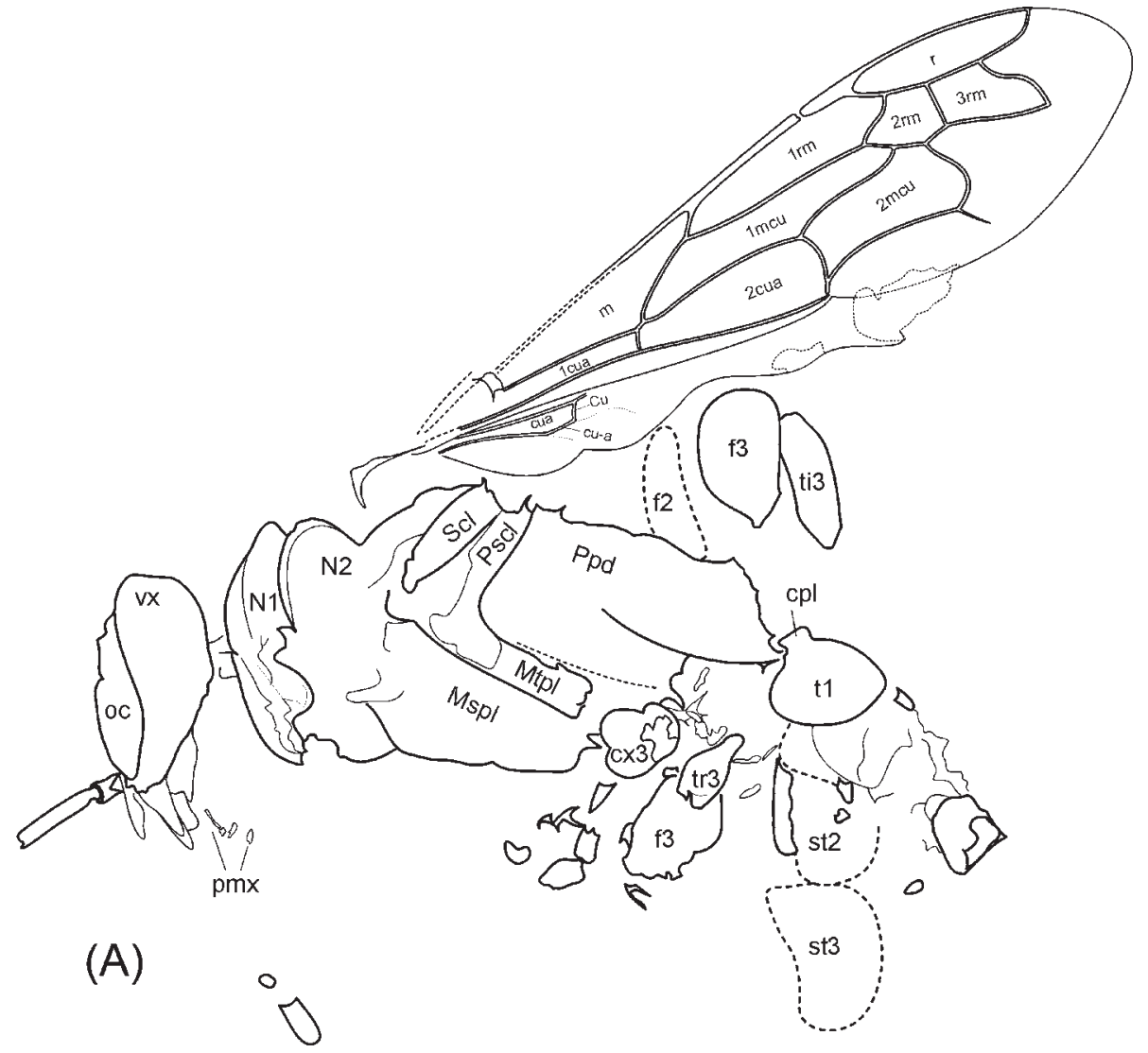

$1 \mathrm{~mm}$

(B)

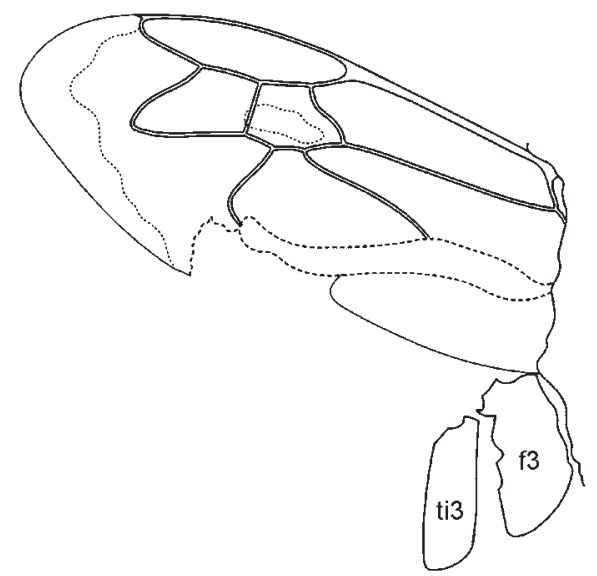

Text-figure 60 Protosceliphron brevior (Cockerell), line drawing of holotype NHMUK In.17472/In. 24340: (A) part; (B) counterpart. Body parts: $\mathrm{cpl}=$ connecting plate; $\mathrm{cx} 3=$ metacoxa; $\mathrm{f} 2=$ mid femur; $\mathrm{f} 3=$ hind femur; $\mathrm{Mspl}=$ mesopleuron; $\quad \mathrm{Mtpl}=$ metapleuron; $\quad \mathrm{N} 1=$ pronotum; $\quad \mathrm{N} 2=$ mesonotum; $\quad$ oc $=$ compound $\quad$ eye; $\mathrm{pmx}=$ maxillary palpus; $\mathrm{Ppd}=$ propodeum; $\mathrm{Pscl}=$ postscutellum; $\mathrm{Scl}=$ scutellum; st $2=$ sternite II; st $3=$ sternite III; $\mathrm{t} 1=$ metasomal tergite $\mathrm{I}$ (abdominal tergum II); $\mathrm{t} 3=$ hind tibia; $\mathrm{vx}=$ vertex. Wing cells: $\mathrm{m}=$ basal; 1 cua $=$ sub-basal; $\mathrm{r}=$ arginal; $1 \mathrm{rm}=$ submarginal $\quad \mathrm{I} ; \quad 2 \mathrm{rm}=$ submarginal $\quad$ II; $2, \quad 3 \mathrm{rm}=$ submarginal $\quad$ III; $1 \mathrm{mcu}=$ discal $1 ; 2 \mathrm{mcu}=$ discal $2 ; 1$ cua $=$ subdiscal $1 ; 2$ cua $=$ subdiscal 2.

by $3 \mathrm{rm} ; 1 \mathrm{rm}$ c. $0 \cdot 67$ times as long as marginal cell, more than four times as long as $2 \mathrm{rm}$ and at least three times as long $3 \mathrm{rm}$.

Eomimesa differs from Tytthopsen in having prStg at most 0.25 times as long as ptStg; 2 r-rs received by outer third of ptStg and almost half as long as 4RS; $\mathrm{M}$ and $1 \mathrm{~m}-\mathrm{cu}$ practically straight; $1 \mathrm{~m}-\mathrm{cu}$ and $2 \mathrm{~m}-\mathrm{cu}$ received by $2 \mathrm{rm}$ near its angles; $\mathrm{M}-\mathrm{a}$ and $2 \mathrm{Cu}-\mathrm{a}$ reaching outer wing margin; $1 \mathrm{rm}$ approximately 0.67 times as long as marginal cell, more than three times as long as $2 \mathrm{rm}$ and approximately 1.5 times as long as $3 \mathrm{rm} ; 1 \mathrm{mcu}$ c.4 times as long as its maximum width.
In comparison with extant aculeates, the following living aculeates are similar to Tytthopsen in combining an apically acuminate marginal cell touching the wing margin, three submarginal cells, $1 \mathrm{~m}-\mathrm{cu}$ received by $2 \mathrm{rm}$, and $2 \mathrm{~m}-\mathrm{cu}$ received by $3 \mathrm{rm}$ :

1. Male Myrmosa Latreille, 1796 (Mutillidae: Myrmosinae) differ from Tytthopsen in distinctly enlarged ptStg, marginal cell not strikingly acuminate apically and elongate (5RS not longer than $2 \mathrm{r}-\mathrm{m}$ ); in $\mathrm{M}-\mathrm{a}$ and $2 \mathrm{Cu}-\mathrm{a}$ reaching 


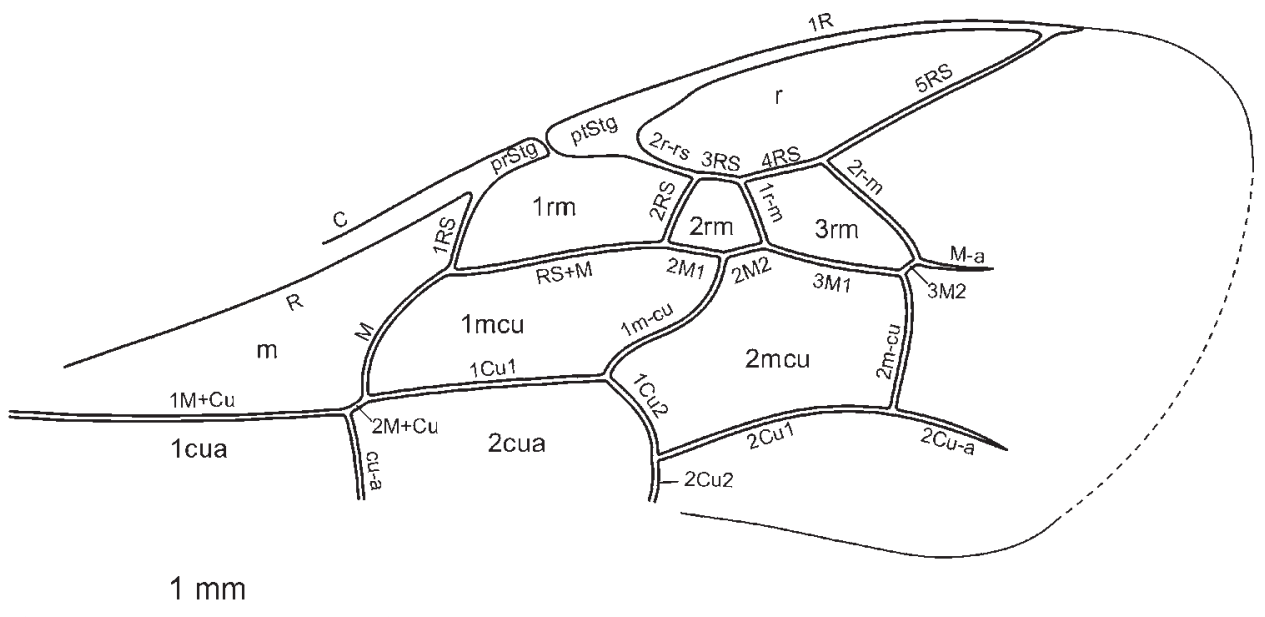

Text-figure 61 Tytthopsen nanus sp. nov., line drawing of holotype forewing, NHMUK In.25568.

outer wing margin, in $2 \mathrm{~m}-\mathrm{cu}$ received by $3 \mathrm{rm}$ nearer to cell base than to its middle; in straight $\mathrm{M}$; and in interstitial cu-a;

2. Pompilidae often have similar venation pattern, but differ in marginal cell less elongate and acuminate apically (5RS usually not longer or hardly longer than $2 \mathrm{r}-\mathrm{m}$ ); in $2 \mathrm{~m}-\mathrm{cu}$ received by $3 \mathrm{rm}$ nearer to cell middle than to its apex; in usually clearly elongate $1 \mathrm{mcu}$ (more than three times as long as wide); in usually straight $\mathrm{M}$; and in postfurcal or rarely interstitial $\mathrm{cu}-\mathrm{a}$;

3. Ampulicidae Dolichurus Latreille, 1809 (Dolichurini) differs in marginal cell less elongate (5RS not longer or hardly longer than $2 \mathrm{r}-\mathrm{m}$ ); in $2 \mathrm{~m}-\mathrm{cu}$ received by $3 \mathrm{rm}$ nearer to cell middle than to its apex; and in straight $\mathrm{M}$;

4. Crabronidae, Ammopsen Krombein, 1959 (Psenini) is similar in prStg not enlarged and slightly curved $\mathrm{M}$, but differs in marginal cell less elongate (5RS not longer or hardly longer than $2 \mathrm{r}-\mathrm{m}$ ) and in $2 \mathrm{~m}-\mathrm{cu}$ received by $3 \mathrm{rm}$ nearer to cell base than to its middle. Psenulus Kohl, 1897 (Psenini) is similar in marginal cell acuminate and elongate (5RS longer than $2 \mathrm{r}-\mathrm{m})$, but differs in enlarged prStg; in $2 \mathrm{~m}-\mathrm{cu}$ received by $3 \mathrm{rm}$ nearer to cell base than to its middle; and in straight $\mathrm{M}$;

5. Andrena Fabricius, 1775 (Apidae, Andreninae) is similar in acuminate and elongate marginal cell, but differs in $2 \mathrm{~m}-\mathrm{cu}$ receiving $3 \mathrm{rm}$ nearer to cell middle than to its apex; in the straight $\mathrm{M}$; and in cu-a postfurcal or interstitial;

6. Halictus Latreille, 1804 (Apidae, Halictinae) is similar in the form of marginal cell and $\mathrm{M}$, in the position of $1 \mathrm{~m}-\mathrm{cu}$, $2 \mathrm{~m}-\mathrm{cu}$ and $\mathrm{cu}-\mathrm{a}$, but differs in enlarged $\mathrm{ptStg}$; in $2 \mathrm{rm}$ insignificantly smaller than $3 \mathrm{rm}$; and in $1 \mathrm{mcu}$ not larger than $1 \mathrm{rm}$.

It is possible to conclude that Tytthopsen is most similar venationally and supposedly most close taxonomically to Ammopsen and therefore can be attributed to Crabronidae (Psenini).

Tytthopsen nanus Antropov, sp. nov. Plate 16, fig. 5; Text-fig. 61

Etymology. Nanus is the Latin for dwarfish, alluding to the small size of the species.

Holotype. NHMUK In.25568; Bembridge Marls, NW Isle of Wight, UK, Hooley Collection. Sex unknown. The holotype is a piece of rock $26.5 \times 23.4 \mathrm{~mm}$ with an almost complete left forewing, but lacking the proximal and lower parts, including the anal veins. Judging by concave veins, the fossil is a counterpart of the left forewing.

Description. Forewing with marginal, three submarginal and two discal cells. Marginal cell elongate, with acuminate apex touching wing margin; $1 \mathrm{rm} c$.half as long as marginal cell, more than twice as long as $2 \mathrm{rm}$ and c.1.5 times as long as $3 \mathrm{rm} ; 1 \mathrm{mcu} c$.twice as long as its maximum width and scarcely longer than 2mcu; prStg longer than a half of ptStg; $2 \mathrm{r}-\mathrm{rs}$ received by middle of ptStg and almost as long as 4RS; $\mathrm{M}$ curved posteriad; $1 \mathrm{~m}-\mathrm{cu}$ S-shaped and received by $1 \mathrm{RS}$ slightly beyond its middle; $2 \mathrm{~m}-\mathrm{cu}$ received by $2 \mathrm{RS}$ almost at its apex; cu-a postfurcal; $\mathrm{M}-\mathrm{a}$ and $2 \mathrm{Cu}-\mathrm{a}$ ending far from outer wing margin.

Vein measurements in mm: ptStg $0.45 ; 1 \mathrm{R} 1.05 ; 2 \mathrm{r}-\mathrm{rs} 0 \cdot 23$; 3RS 0.13 ; 4RS 0.23 ; $5 \mathrm{RS} 0.73 ; 1 \mathrm{M}+\mathrm{Cu} 0.93 ; 2 \mathrm{M}+\mathrm{Cu} 0.08$; M $0.43 ; 1 \mathrm{RS} 0 \cdot 24 ; \mathrm{RS}+\mathrm{M} 0 \cdot 59 ; 2 \mathrm{M} 10 \cdot 18 ; 2 \mathrm{M} 20 \cdot 11 ; 3 \mathrm{M} 1$ $0.38 ; 3 \mathrm{M} 20.05 ; \mathrm{M}-\mathrm{a} 0.21 ; 1 \mathrm{Cu} 10.66 ; 1 \mathrm{Cu} 20.27 ; 1 \mathrm{~m}-\mathrm{cu}$ $0.47 ; 2 \mathrm{~m}-\mathrm{cu} 0.38 ; 2 \mathrm{RS} 0 \cdot 21 ; 1 \mathrm{r}-\mathrm{m} 0 \cdot 19 ; 2 \mathrm{r}-\mathrm{m} 0.38 ; 2 \mathrm{Cu} 1$ $0 \cdot 66 ; 2 \mathrm{Cu}-\mathrm{a} 0 \cdot 33$. Total forewing length $c .3 \cdot 7 \mathrm{~mm}$.

Tribe Pemphredonini Dahlbom, 1835

Subtribe Spilomenina Menke, 1989

Genus Plisomena Antropov, gen. nov.

Etymology. The generic name is an anagram of Spilomena. Gender feminine.

Type species. Plisomena gigantea sp. nov., by present designation and monotypy.

Remarks. Like in the case of Tytthopsen, elongate marginal cell with acuminate apex touching the wing margin indicates the new genus is a member of Pemphredoninae (Crabronidae). Within that subfamily, reduced forewing venation is characteristic of the tribe Pemphredonini.

Diagnosis. In comparison with fossil genera, four genera having similar forewing venation with two submarginal and single discal cells are described from the Albian Burmese amber (Cretospilomena Antropov, 2000a), the Upper Cretaceous Cedar Lake amber (Lisponema Evans, 1969), the Upper Cretaceous New Jersey amber (Psolimena Antropov, 2000b), and the Upper Eocene Baltic amber (Eopinoecus Budrys, 1993). Cretospilomena, Lisponema and Psolimena differ from Plisomena in enlarged ptStg. Additionally, Lisponema and Psolimena differ in marginal cell truncate apically. Moreover, in all known Pemphredoninae with similar venation, ptStg is enlarged, longer than prStg and comparable in length with $2 \mathrm{rm}$, which is markedly smaller than $1 \mathrm{rm}$. Only Eopinoecus has a less enlarged ptStg. The four above mentioned genera additionally 


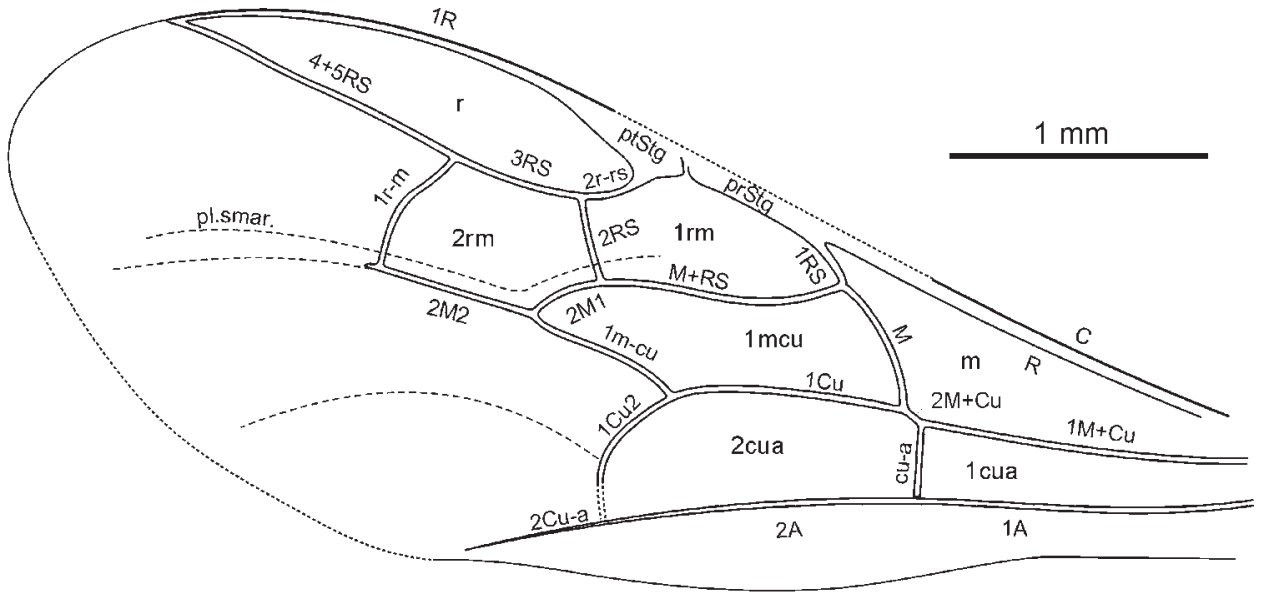

Text-figure 62 Plisomena gigantea sp. nov., line drawing of holotype forewing, NHMUK In.24789.

differ from Plisomena in having $1 \mathrm{~m}-\mathrm{cu}$ received by $1 \mathrm{rm}$, which is markedly larger than $2 \mathrm{rm}$.

In comparison with extant genera, wing venation of Plisomena is almost typical for the subtribes Spilomenina and Stigmina. Among them only several species of the genus Spilomena Shuckard, 1838 (Spilomenina) have $1 \mathrm{~m}-\mathrm{cu}$ received by 2rm: S. argentina Antropov, 1992; S. catamarca Antropov, 1992; S. willinki Antropov, 1992; S. kimseyae Antropov, 1993; S. nasuta Antropov, 1993; S. schlingeri Antropov, 1993; and S. tungurachua Antropov, 1993. However, unlike Plisomena, all these species have a distinct angle between $\mathrm{RS}+\mathrm{M}$ and 2M1. Additionally, the type species of Plisomena has its forewing more than $5 \mathrm{~mm}$ long, that is at least twice as long as even in the largest species of Spilomena.

\section{Plisomena gigantea Antropov, sp. nov.} Plate 16, fig. 6; Text-fig. 62

Etymology. After giganteus, the Latin for giant.

Holotype. NHMUK In.24789, Bembridge Marls, NW Isle of Wight, UK, Hooley Collection. Sex unknown. The holotype is a piece of rock $28.3 \times 31.9 \mathrm{~mm}$, with an almost complete impression of the forewing. Judging by concave veins and convex submarginal wrinkle (Platesmar.), the fossil is a counterpart of the right forewing.

Description. Diagnosis. Forewing with single marginal, two submarginal and single discal cells: marginal cell with apex acuminate and touching wing margin; $1 \mathrm{rm}$ almost half as long as marginal cell and slightly longer than $2 \mathrm{rm}$; $1 \mathrm{mcu}$ approximately twice as long as its maximum width and 1.5 times as long as $1 \mathrm{rm}$; RS+M and $2 \mathrm{M} 1$ smoothly joining (not angulated); $1 \mathrm{~m}-\mathrm{cu}$ received by $2 \mathrm{rm}$ approximately $1 / 3$ its length from 2RS; cu-a antefurcal.

Vein measurements in mm: prStg 0.60; ptStg 0.60; 1R 1.50; 2r-rs 0.27 ; 1 RS 0.22 ; 2RS 0.35 ; 3RS $0.52 ; 4+5 \mathrm{RS} 1.23$; $2 \mathrm{M}+\mathrm{Cu} 0 \cdot 10 ; \mathrm{M} 0 \cdot 52 ; \mathrm{RS}+\mathrm{M} 0.93 ; 2 \mathrm{M} 10 \cdot 28 ; 2 \mathrm{M} 20.62 ;$ $1 \mathrm{Cu} 10.90 ; 1 \mathrm{Cu} 20.36 ; 2 \mathrm{Cu} 20.23 ; 1 \mathrm{~m}-\mathrm{cu} 0.63 ; 1 \mathrm{r}-\mathrm{m} 0.51$; cu-a $0 \cdot 30 ; 2 \mathrm{Cu}-\mathrm{a} 0.53 ; 2 \mathrm{~A} 1.22$. Total length of forewing c. $5 \cdot 2 \mathrm{~mm}$.

\subsubsection{Family Apidae Latreille, 1802}

Subfamily Apinae Latreille, 1802 Tribe ?Bombini Latreille, 1802

Genus Oligobombus Antropov, gen. nov.
Etymology. After Oligocene and genus name Bombus. Gender masculine.

Type species. Oligobombus cuspidatus sp. nov., by present designation and monotypy.

Diagnosis. Forewing distinctly pointed apically with complete venation, including marginal cell (r), three submarginal cells (1rm, 2rm, 3rm), basal (m), sub-basal (1 cua), subdiscal (2cua), and two discal cells (1mcu, $2 \mathrm{mcu})$; marginal cell elongate, distinctly longer than distance between its apex and wing tip, with non-parallel veins $5 \mathrm{RS}$ and $1 \mathrm{R}$, 5RS uniformly curved backwards, and roundly truncate apex bearing appendicular vein Rs-a; forewing distal membrane distinctly papillate; ptStg comparatively short, with straight margin within marginal cell, 4.0 times as long as prStg, slightly longer than 3RS, but shorter than 4RS; $2 \mathrm{r}-\mathrm{rs}$ arising from distal part of ptStg after its midpoint, as long as $3 R S$ and 0.77 times as long as 4RS; 3RS shorter than 4RS; 4RS half as long as 5RS; $2 \mathrm{RS}$ practically straight; $1 \mathrm{r}-\mathrm{m} 0.45$ times as long as $3 \mathrm{M} 1$; $\mathrm{RS}+\mathrm{M}$ as long as $2 \mathrm{M} 1$; angle between $1 \mathrm{r}-\mathrm{m}$ and $2 \mathrm{M} 2$ acute; angle between $1 \mathrm{r}-\mathrm{m}$ and $3 \mathrm{M} 1$ obtuse; $2 \mathrm{M} 1$ slightly shorter than 2M2; $2 \mathrm{M} 2$ almost 1.5 times shorter than 3M1; 3M1 almost 1.5 times as long as $4 \mathrm{RS}$, almost 7.0 times as long as $3 \mathrm{M} 2$; $1 \mathrm{rm}$ with an oblique translucent vein $\mathrm{rs}$ and not wider than $2 \mathrm{rm} ; 2 \mathrm{rm}$ shorter than $3 \mathrm{rm}$, the widest submarginal cell; $1 \mathrm{~m}-$ cu slightly curved anteriorly; $2 \mathrm{~m}$-cu uniformly curved outwards; distance between anterior ends of $1 \mathrm{~m}-\mathrm{cu}$ and $2 \mathrm{~m}-\mathrm{cu}$ distinctly exceeding their length; $1 \mathrm{Cu} 2$ twice as long as $2 \mathrm{Cu} 2$; $2 \mathrm{Cu} 1$ uniformly curved inwards; cu-a postfurcal, vertical and longer than $2 \mathrm{M}+\mathrm{Cu}$.

Diagnosis. Forewing venation complete, including marginal cell $(r)$, three submarginal cells of approximately equal sizes (1rm, 2rm, 3rm), basal (m), sub-basal (1cua), subdiscal (2cua), and two discal cells $(1 \mathrm{mcu}, 2 \mathrm{mcu})$; marginal cell elongate, distinctly longer than distance between its apex and wing tip, with non-parallel veins $1 \mathrm{R}$ and 5RS, with 5RS uniformly curved backwards, and with roundly truncate apex bearing appendix Rs-a; ptStg comparatively short, with a straight margin within marginal cell; ptStg with straight margin within marginal cell, 4.0 times as long as prStg; $3 \mathrm{RS}$ shorter than $4 \mathrm{RS} ; 1 \mathrm{rm}$ with an oblique translucent vein rs; $2 \mathrm{RS}$ straight basally; angle between $1 \mathrm{r}-\mathrm{m}$ and $2 \mathrm{M} 2$ acute; $2 \mathrm{rm}$ shorter than $3 \mathrm{rm} ; 1 \mathrm{~m}-\mathrm{cu}$ slightly curved anteriorly; distance between anterior ends of $1 \mathrm{~m}-\mathrm{cu}$ and $2 \mathrm{~m}-\mathrm{cu}$ distinctly exceeding their length; $2 \mathrm{~m}-\mathrm{cu}$ uniformly curved outwards; forewing distal membrane distinctly papillate.

Remarks on the tribal position. The complete forewing venation (including closed elongate marginal cell narrowed and not touching anterior wing margin apically, three submarginal 
cells of approximately equal size, basal, sub-basal, subdiscal, and two discal cells) with comparatively short pterostigma and distance between anterior ends of recurrent veins distinctly exceeding their length allows the attribution of the studied specimen to the apid subfamily Apinae Latreille, 1802.

According to the last revision (Engel 2001), apines are divided into four extant tribes: Euglossini Latreille, 1802, Bombini Latreille, 1802, Apini Latreille, 1802 and Meliponini Lepeletier, 1836; and three fossil tribes: Electrobombini Engel, 2001, Electrapini Engel, 2001 and Melikertini Engel, 2001. The tribe Meliponini should be excluded because of its reduced venation and usually opened apex of the marginal cell. The tribe Apini should be also excluded because of its strongly elongate and parallel-sided marginal cell, strongly narrowed and obliquely elongate $3 \mathrm{rm}$, and antefurcal cu-a.

The distinctly papillate forewing distal membrane of the studied specimen is characteristic of Electrobombini, Bombini and Euglossini, but not of Electrapini or Melikertini.

The marginal cell vein 5RS of the studied specimen is slightly curved outwards, as it is characteristic of Electrobombini, some Electrapini (Thaumastobombus Engel, 2001), and Melikertini (Melikertes Engel, 1998), but not of other Electrapini (some Protobombus Cockerell, 1908), Melikertini (Succinapis Engel, 2001, Melissites Engel, 2001) and the extant tribes Euglossini (5RS curved inwards) and Bombini (5RS curved inwards or sometimes almost straight).

An oblique translucent vein rs dividing $2 \mathrm{RS}$ of the studied specimen is characteristic of Electrobombini, Electrapini and Bombini, but not of Melikertini or Euglossini.

First transverse submarginal vein (2RS) of the studied specimen is practically straight as in Melikertini (Succinapis and Melikertes) and Euglossini, while it is S-curved basally in Melissites (Melikertini), Electrapini, Electrobombini, and all Bombini (2RS is even angular in many subgenera).

Submarginal cell II $(2 \mathrm{rm})$ of the studied specimen is distinctly narrower than submalginal cell III (3rm) as in Melikertini, Electrapini, Electobombini and Euglossini, but not in Bombini, characterised by $2 \mathrm{rm}$ wider than $3 \mathrm{rm}$.

The recurrent vein I $(1 \mathrm{~m}-\mathrm{cu})$ of the studied specimen is only slightly curved outwards preapically, as in Electrapini and Electrobombini, while it is strongly curved roundly in Electrapini (some Protobombus), Melikertini (Succinapis Engel, 2001, Melissites Engel, 2001) and some Euglossini and Bombini (for example, in subgenera Bombias Robertson, 1903, Kallobombus Dalla Torre, 1880, or Thoracobombus Dalla Torre, 1880), or distinctly angular in some Melikertini (Melikertes Engel, 1998), Euglossini and Bombini (for example, in subgenera Alpinobombus Skorikov, 1914, Bombus Latreille, 1802, Exilobombus Skorikov, 1922, Megabombus Dalla Torre, 1880, Melanobombus Dalla Torre, 1880, Pyrobombus Dalla Torre, 1880, or Subterraneibombus Vogt, 1911).

The recurrent vein II $(2 \mathrm{~m}-\mathrm{cu})$ of the studied specimen is uniformly curved outwards, as in Electrapini, Melikertini and Euglossini, while it is S-shape in Electrobombini and almost all Bombini (excluding subgenera Alpinobombus or Kallobombus).

The studied specimen also differs from Electrobombini in $1 \mathrm{rm}$ not wider than $2 \mathrm{rm}$, ptStg only slightly longer than $3 \mathrm{RS}$, $2 \mathrm{r}-\mathrm{rs}$ arising from distal part of ptStg after its midpoint, Rs-a present, 2Cu1 uniformly curved anterior, and $\mathrm{cu}-\mathrm{a}$ longer than $2 \mathrm{M}+\mathrm{Cu}$.

The studied specimen differs from Bombini (characters in brackets) in marginal cell distinctly longer than distance between its apex and wing tip (as long as, or somewhat longer), with 5RS uniformly curved backwards (usually curved forwards), ptStg 4.0 times as long as prStg (shorter to slightly longer than prStg), 2RS almost straight (curved or angulate basally), 3RS shorter than 4RS (as long as, or longer than 4RS), 1m-cu weakly curved anteriorly (roundly curved or distinctly angulate), and $2 \mathrm{~m}$-cu uniformly curved outwards (S-shaped).

Finally, an angle between $1 \mathrm{r}-\mathrm{m}$ and $2 \mathrm{M} 2$ in the studied specimen is acute, while it is right or obtuse in all other apine tribes; excluding Apini, which distinctly differs in the form of strongly elongate marginal cell and submarginal cell II and strongly narrowed and obliquely elongate submarginal cell III. It is very likely that acute outer angles of $2 \mathrm{rm}$ in these two tribes have separate origin.

Thus, the forewing venation of the studied specimen is characterised by a set of features which, taken separately, can be found in different fossil and extant tribes of the apine bees, but taken together do not occur in any of them. At the same time, though the forewing venation of the studied specimen is generally similar to that of the extant tribe Bombini, absence of the most important features of the head, legs and mesosoma prevents identification of its exact tribal position.

Diagnosis. In comparison with fossil genera, the forewing venation of Oligobombus gen. nov. is similar to that of the monotypical genus Electrobombus Engel, 2001 from the Baltic amber (Electrobombini) in the papillate distal membrane, short ptStg with a straight margin within marginal cell, 2M1 almost equal to or slightly shorter than $2 \mathrm{M} 2$, and also in non-parallel veins $1 \mathrm{R}$ and 5RS.

Oligobombus gen. nov. differs from Electrobombus (characters in brackets) in having forewing longer than $13 \mathrm{~mm}(10.50 \mathrm{~mm}$ in Electrobombus samlandensis Engel, 2001, which is the largest known bee species preserved in amber of any deposit); marginal cell roundly truncated apically (acutely rounded); ptStg slightly longer than 3RS but shorter than 4RS (ptStg appreciably longer than $3 \mathrm{RS}$ and somewhat longer than $4 \mathrm{RS}$ ); $2 \mathrm{r}-\mathrm{rs}$ arising from distal part of ptStg after its midpoint, equal to $3 \mathrm{RS}$ and 0.77 times as long as 4RS (2r-rs arising from proximal part of ptStg before its midpoint, distinctly longer than $3 \mathrm{RS}$ and equal to 4RS); 4RS half as long as 5RS (c. 0.33 times); Rs-a present (absent); $1 \mathrm{rm}$ not wider than $2 \mathrm{rm}$ (distinctly wider); angle between $1 \mathrm{r}-\mathrm{m}$ and $2 \mathrm{M} 2$ acute (obtuse); $\mathrm{RS}+\mathrm{M}$ as long as $2 \mathrm{M} 1$ (1.5 times longer); $2 \mathrm{M} 1$ slightly shorter than $2 \mathrm{M} 2$ (as long as 2M2); $3 \mathrm{M} 1$ almost 1.5 times as long as $4 \mathrm{RS}$ (c. 2.0 times); $1 \mathrm{~m}$-cu 1.7 times as long as $2 \mathrm{M} 1$ (more than twice so); $2 \mathrm{~m}-\mathrm{cu}$ uniformly curved outwards (S-shaped); $1 \mathrm{Cu} 2$ twice as long as $2 \mathrm{Cu} 2$ (at least 4.0 times); 2Cu1 uniformly curved anterior (2Cu1 straight); and $\mathrm{cu}-\mathrm{a}$ longer than $2 \mathrm{M}+\mathrm{Cu}$ (the veins are equal).

Oligobombus gen. nov. is also similar to Protobombus Cockerell, 1909, Electrapis Cockerell, 1909 and Thaumastobombus Engel, 2001 (Electrapini), all from the Late Eocene Baltic amber, in the roundly truncate apex of marginal cell bearing an appendix Rs-a and approximately equal veins $\mathrm{RS}+\mathrm{M}$ and $2 \mathrm{M} 1$.

Oligobombus differs from Protobombus (in brackets) in the forewing longer than $13 \mathrm{~mm}(3.9-7.4 \mathrm{~mm})$; ptStg with straight margin within marginal cell (convex); ptStg slightly longer than $3 \mathrm{RS}$ and shorter than 4RS (at least twice as long as $3 \mathrm{RS}$ and distinctly longer than $4 \mathrm{RS}$ ); $2 \mathrm{r}$-rs arising from distal part of ptStg after its midpoint (from the midpoint of ptStg); 2r-rs equal in length to 3RS (distinctly longer than 3RS); 2 r-rs 0.77 times as long as 4RS (almost equal in length to $4 \mathrm{RS}$ ); $2 \mathrm{RS}$ almost straight (S-shaped); $4 \mathrm{RS}$ half as long as 5RS (c. $0.33-0.4$ so); $1 \mathrm{rm}$ not wider than $2 \mathrm{rm}$ (distinctly wider); angle between $1 \mathrm{r}-\mathrm{m}$ and $2 \mathrm{M} 2$ acute (right or obtuse); $2 \mathrm{M} 1$ somewhat shorter than 2M2 (distinctly longer); 3M1 almost 1.5 times as long as 4RS (c. twice as long as); $1 \mathrm{~m}-\mathrm{cu}$ 1.7 times as long as $2 \mathrm{M} 1$ (not more than 1.3 times so); $1 \mathrm{~m}$ cu slightly curved preapically (angulate preapically); $2 \mathrm{~m}-\mathrm{cu}$ uniformly curved outwards (angulate preapically); $1 \mathrm{Cu} 2$ twice 
as long as $2 \mathrm{Cu} 2(2 \cdot 5-3 \cdot 0$ times longer); and $\mathrm{cu}-\mathrm{a}$ longer than $2 \mathrm{M}+\mathrm{Cu}$ and postfurcal ( $\mathrm{cu}-\mathrm{a}$ still longer or interstitial).

Oligobombus gen. nov. also differs from Electrapis and Thaumastobombus (in brackets) in having forewing longer than $13 \mathrm{~mm}(6 \cdot 38-9.17 \mathrm{~mm}$ in Electrapis and $4.45 \mathrm{~mm}$ in Thaumastobombus); small ptStg (enlarged) with straight margin within marginal cell (with convex margin within marginal cell) and longer than 3RS and shorter than 4RS (slightly longer than 3RS and 4RS); 4RS half as long as 5RS (at least 0.4 times as long as $5 \mathrm{RS}$ ); $2 \mathrm{r}$-rs equal in length to $3 \mathrm{RS}$ (distinctly shorter than 3RS in Electrapis and somewhat longer than 3RS in Thaumastobombus); $1 \mathrm{rm}$ with an oblique translucent vein rs ( $1 \mathrm{rm}$ without $\mathrm{rs}$ ); $1 \mathrm{rm}$ not wider than $2 \mathrm{rm}$ (slightly wider); 2RS almost straight (more or less S-shaped in Electrapis and angulate inwards in Thaumastobombus); 2M1 somewhat shorter than 2M2 (distinctly longer); angle between $1 \mathrm{r}-\mathrm{m}$ and $2 \mathrm{M} 2$ acute (obtuse); $1 \mathrm{~m}-\mathrm{cu} 1.7$ times as long as $2 \mathrm{M} 1$ (not more than 1.2 times so); $2 \mathrm{~m}$-cu uniformly curved outwards (sometimes straight in Thaumastobombus); $1 \mathrm{Cu} 2$ twice as long as $2 \mathrm{Cu} 2(2 \cdot 5-3 \cdot 0$ times so in Electrapis); and cu-a vertical (posterior end of $\mathrm{cu}-\mathrm{a}$ moved distally in Electrapis and distinctly moved proximally in Thaumastobombus).

Finally, Oligobombus gen. nov. also differs from Succinapis, Melikertes and Roussyana (Manning, 1961) (all Melikertini) in the not narrowed anteriorly submarginal cell II (2r-rs as long as 3RS).

In comparison with extant genera, the forewing venation of Oligobombus gen. nov. is generally similar to that of extant members of the genus Bombus Latreille, 1802 in papillate distal membrane; in short ptStg with a straight margin within $\mathrm{R}$; in $2 \mathrm{r}-\mathrm{rs}$ arising distally from the midpoint of $\mathrm{ptStg}$; and in abscissa 2M1 almost equal in length or only slightly shorter than 2M2. Oligobombus gen. nov. differs from Bombus (in brackets) in marginal cell distinctly longer than distance from its apex to the wing tip, wider and with non-parallel $1 \mathrm{R}$ and 5RS, with $5 \mathrm{RS}$ almost straight or uniformly curved backwards, and roundly truncate apex (marginal cell narrow, somewhat longer than distance from its apex to the wing tip, with almost parallel $1 \mathrm{R}$ and $5 \mathrm{RS}$, which is curved forwards basally, or sometimes almost straight, and rounded apically); ptStg almost four times longer than prStg (ptStg little if any longer than prStg); 2r-rs equal in length to 3RS (2r-rs distinctly shorter than 3RS); $2 \mathrm{RS}$ almost straight (curved or angulate basally); $3 R S$ only slightly shorter than $4 \mathrm{RS}$ (3RS 0.67 times as long as 4RS); 4RS half as long as $5 \mathrm{RS}(0 \cdot 26-0.29$ times as long as 5RS); $1 \mathrm{r}-\mathrm{m} 0.45$ times as long as $3 \mathrm{M} 1$ (practically equal in length); $2 \mathrm{rm}$ narrower than $3 \mathrm{rm}$ ( $2 \mathrm{rm}$ mainly wider than $3 \mathrm{rm}$ ), $3 \mathrm{rm}$ less narrowed anterior and the widest among submarginal cells ; (3rm strongly narrowed anteriorly, and $2 \mathrm{rm}$ is the widest submarginal cell); $2 \mathrm{M} 20.7$ times as long as $3 \mathrm{M} 1$ (practically equal to $3 \mathrm{M} 1$ ); angle between $1 \mathrm{r}-\mathrm{m}$ and $2 \mathrm{M} 2$ acute (obtuse or sometimes right); $3 \mathrm{M} 1$ almost 1.5 times as long as $4 \mathrm{RS}$ (c. $2 \cdot 0$ times as long as 4RS); $3 \mathrm{M} 1$ almost seven times as long as $3 \mathrm{M} 2$ (c. 2.5-3.0 times as long as $3 \mathrm{M} 2$ ); $1 \mathrm{~m}-$ cu weakly curved anteriorly (roundly curved or distinctly angulate); $2 \mathrm{~m}-\mathrm{cu}$ uniformly curved outwards (S-shaped); and $1 \mathrm{Cu} 2$ twice as long as $2 \mathrm{Cu} 2$ (approximately equal in length).

\section{Oligobombus cuspidatus Antropov, sp. nov.} Plate 17, figs 1-2; Text-fig. 63

Etymology. After cuspidatus, the Latin for pointed, alluding to the form of the wing tip.

Holotype. NHMUK In.17349 (part and counterpart), Smith Collection. Sex unknown. The part is a piece of rock $65 \cdot 2 \times$ $23.6 \mathrm{~mm}$, with the impression of the well preserved middle and apical parts of the right forewing. The counterpart is a piece of rock $67.4 \times 24.8 \mathrm{~mm}$, with the impression of the well preserved middle part of the right forewing.

Description. Forewing distinctly pointed apically with complete venation, including marginal cell $(\mathrm{r})$, three submarginal cells (1rm, 2rm, 3rm), basal (m), sub-basal (1 cua), subdiscal (2cua), and two discal cells (1mcu, $2 \mathrm{mcu}$ ); marginal cell elongate, distinctly longer than distance between its apex and wing tip, with non-parallel veins $5 \mathrm{RS}$ and $1 \mathrm{R}, 5 \mathrm{RS}$ uniformly curved backwards, and roundly truncate apex bearing appendicular vein Rs-a; forewing distal membrane distinctly papillate; ptStg comparatively short, with straight margin within marginal cell, four times as long as prStg, slightly longer than 3RS, but shorter than 4RS; $2 \mathrm{r}-\mathrm{rs}$ arising from distal part of ptStg after its midpoint, as long as $3 \mathrm{RS}$ and 0.77 times as long as 4RS; 3RS shorter than 4RS; 4RS half as long as 5RS; $2 \mathrm{RS}$ practically straight; $1 \mathrm{r}-\mathrm{m} 0.45$ times as long as $3 \mathrm{M} 1$; $\mathrm{RS}+\mathrm{M}$ as long as $2 \mathrm{M} 1$; angle between $1 \mathrm{r}-\mathrm{m}$ and $2 \mathrm{M} 2$ acute; angle between $1 \mathrm{r}-\mathrm{m}$ and $3 \mathrm{M} 1$ obtuse; $2 \mathrm{M} 1$ slightly shorter than 2M2; $2 \mathrm{M} 2$ almost 1.5 times shorter than $3 \mathrm{M} 1 ; 3 \mathrm{M} 1$ almost 1.5 times as long as 4RS, almost seven times as long as $3 \mathrm{M} 2$; $1 \mathrm{rm}$ with an oblique translucent vein rs and not wider than $2 \mathrm{rm} ; 2 \mathrm{rm}$ shorter than $3 \mathrm{rm}$, the widest submarginal cell; $1 \mathrm{~m}-$ $\mathrm{cu}$ slightly curved anteriorly; $2 \mathrm{~m}$-cu uniformly curved outwards; distance between anterior ends of $1 \mathrm{~m}-\mathrm{cu}$ and $2 \mathrm{~m}-\mathrm{cu}$ distinctly exceeding their length; $1 \mathrm{Cu} 2$ twice as long as $2 \mathrm{Cu} 2$; $2 \mathrm{Cu} 1$ uniformly curved inwards; cu-a postfurcal, vertical and longer than $2 \mathrm{M}+\mathrm{Cu}$.

Vein measurements in mm: prStg 0.20; ptStg 0.83; 1R 3.70; 2r-rs $0.75 ; 3$ r-rs 0.35 ; $1 \mathrm{RS} 0.60 ; 2 \mathrm{RS} 0 \cdot 80 ; 3 \mathrm{RS} 0.75 ; 4 \mathrm{RS}$ $0.95 ; \quad 5 \mathrm{RS} 2.00 ; \quad 2 \mathrm{M}+\mathrm{Cu} 0.20 ; \mathrm{M} 2.60 ; \mathrm{RS}+\mathrm{M} \quad 1.20$; 2M10.76; $2 \mathrm{M} 2$ 0.97; 3M11.40; 3M2 0.21; $1 \mathrm{Cu} 12.60 ; 1 \mathrm{Cu} 2$ $0.84 ; 2 \mathrm{Cu} 12.75 ; 2 \mathrm{Cu} 20.40 ; 1 \mathrm{r}-\mathrm{m} 0.63 ; 2 \mathrm{r}-\mathrm{m} 1.26 ; 1 \mathrm{~m}-\mathrm{cu}$ $1.37 ; 2 \mathrm{~m}-\mathrm{cu} 1.27$; cu-a $0.36 ; 2$ A 2.85 ; Rs-a $0.42 ; \mathrm{M}-\mathrm{a} 0.46$; $2 \mathrm{Cu}-\mathrm{a} 0 \cdot 47$. Forewing apex is distinctly pointed. Total length of forewing $c .13 .25 \mathrm{~mm}$.

\subsubsection{Family Apidae Latreille, 1802}

\section{Subfamily Megachilinae Latreille, 1802 Megachilinae incertae sedis Plate 17, fig. 3; Text-fig. 64}

Material studied. NHMUK I.10012, Bembridge Marls, NW Isle of Wight, UK, Brodie Collection. Sex unknown. A piece of rock $42.3 \times 30.8 \mathrm{~mm}$, with an impression of the partially preserved mesosoma, metasoma, fore coxae and fore and mid femora, a poorly preserved head, and a few longitudinal veins of forewings.

Description. Cuticle black, distinctly punctate; fore coxae, fore and mid femora, hind tibiae and tarsi reddish-brown; mesosoma rounded, with very short propodeum; metasoma robust, with middle tergites at least twice wide as long; constrictions between metasomal tergites distinct. Length of body parts in mm: scutum 1.17; mesosoma $c$. 1.66; metasoma $c$. $2 \cdot 05$. Scutal width 1.55 ; metasomal width $1 \cdot 78$. Total body length $c .4 .7 \mathrm{~mm}$.

Remarks. The flattened and moderately widened hind tibiae and basal tarsomeres and robust metasoma with convex tergites, separated by distinct constrictions, attribute the specimen to several genera of the subfamily Megachilinae Latreille, 1802 , but absence of the most important features of wing venation and structure of the head and mesosoma prevents identification of its generic position.

3.10.6. Discussion. A comparison of the studied fauna of Aculeata, in the vicinity of the Eocene/Oligocene boundary, of Bembridge Marls, Isle of Wight, England, with two faunas 

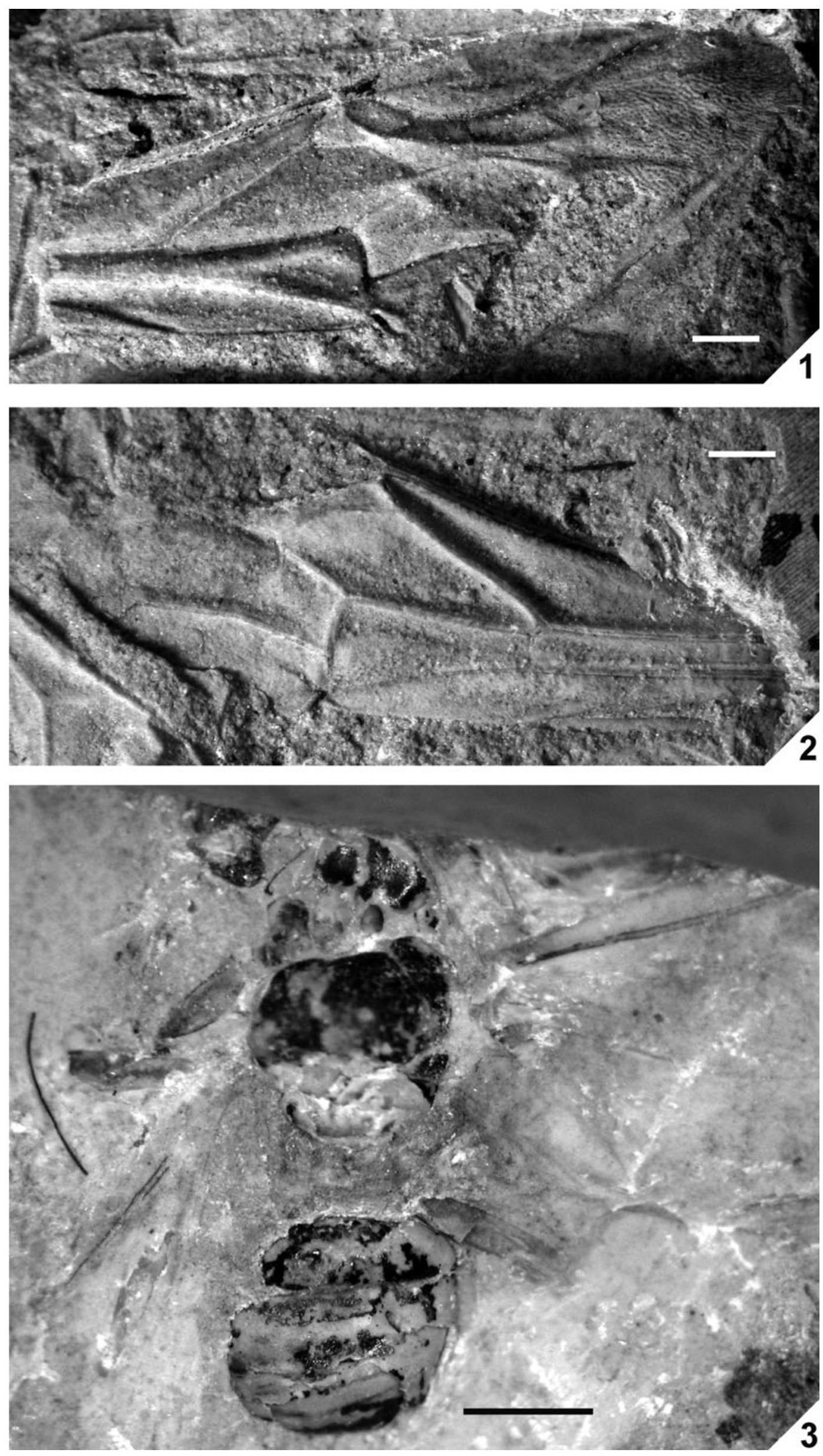

Plate 17 (1-2) Oligobombus cuspidatus sp. nov., holotype forewing NHMUK In. 17349: (1) part; (2) counterpart. (3) Family Megachilidae Latreille, 1802, incertae sedis, head, thorax, middle part of metasoma, fore and mid femora, and hind tibia and tarsus, NHMUK In.10012. Scale bars $=1 \mathrm{~mm}$. 

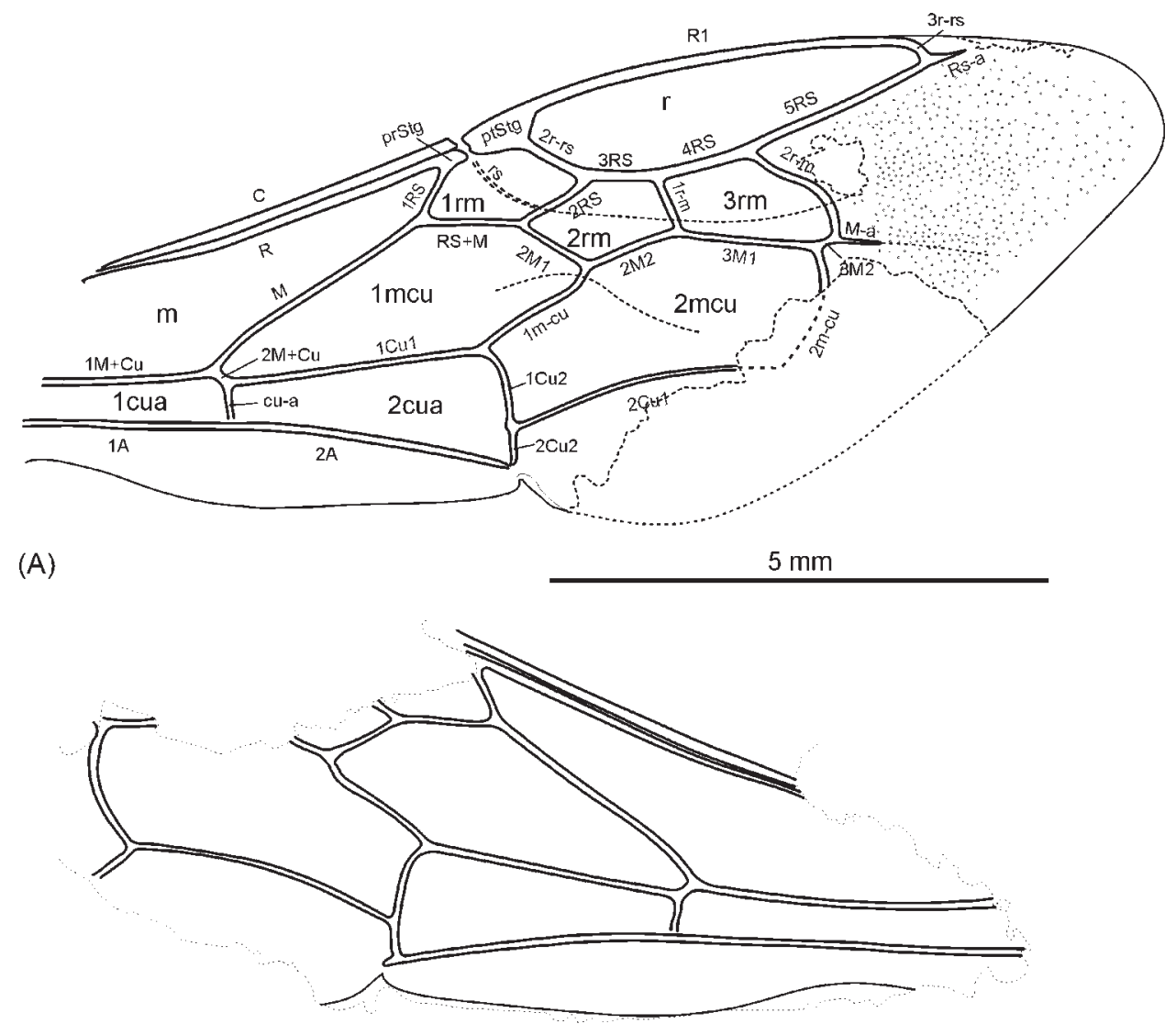

(B)

Text-figure 63 Oligobombus cuspidatus sp. nov., line drawings of holotype forewings, NHMUK In.17349: (A) part; (B) counterpart.

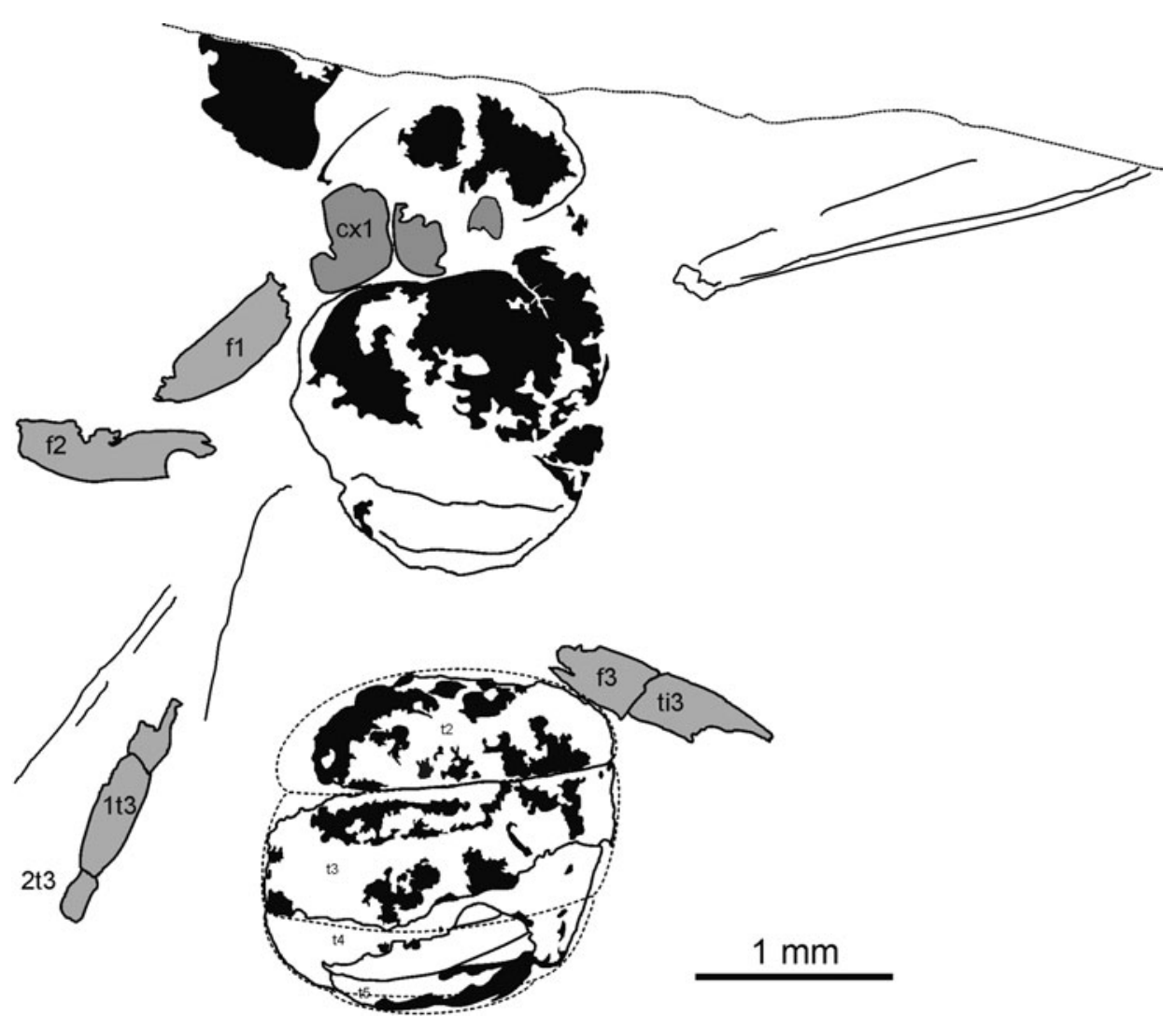

Text-figure 64 Family Megachilidae Latreille, incertae sedis, line drawing of body, NHMUK In.10012. Body parts: $\mathrm{cx} 1=$ procoxae; $\mathrm{f} 1-3=$ fore, mid and hind femora; ti $3=$ hind tibia; $1 \mathrm{t} 3=$ hind tarsomere $1 ; 2 \mathrm{t} 3=$ hind tarsomere $2 ; \mathrm{t} 2-5=$ metasomal tergites II-V (abdominal terga III-VI). 
of similar age: the Upper Eocene Baltic amber and the uppermost Eocene shales of Florissant (USA, Colorado) are of obvious interest.

Various xylobionts are common in Baltic amber. Species of the genera Vespa, Palaeovespa and Polistes (Vespidae) probably built their nests on or inside trees and prey directly in their crowns. Several genera of Apidae (Electrobombus, Electrapis, Protobombus, Thaumastobombus) were also discovered in Baltic amber and, though nothing is known about their nesting habits, they were probably forest inhabitants which could build underground nests as do extant species of Bombini. It is necessary to take into consideration that Vespidae and Apidae are not particular xylobionts, because their provisioning territories may spread far from the nest, and their chances of being fossilised in resin depend directly on the density of populations. Representatives of the families Ampulicidae (Protodolichurus Nemkov, 1988, Dolichurus Latreille, 1809) and Crabronidae (Eopinoecus, Eoxyloecus, Passaloecus Shuckard, 1837, Pison Jurine, 1808, Tracheliodes A. Morawitz, 1866 and, judging from the absence of foretarsal digging rakes, Palanga and Eomimesa) also hunt in the same biotopes. Species of Ampulicidae used available cracks of the tree trunks for concealing their prey, and species of Crabronidae, as well as comparatively small bees of the families Megachilidae (Glyptapis Cockerell, 1909, Ctenoplectrella Cockerell, 1909, Glaesosmia Engel, 2001), like their extant relatives, built their nests either in wood or inside old borings of various xylophagous insects. Obviously, these groups are closely linked to trees and had more chances to be fossilised in resin. The only exception to the rule is Tiphia (?) sp., which was mentioned by Brischke (1886) from the lost collection of Menge.

The more diverse fauna of the Florissant beds is somewhat different. Though Vespidae (Palaeovespa, Polistes) and even real xylobionts (Crabronidae, Pemphredoninae - Passaloecus) are present here, the prevailing groups are connecting with prey inhabiting soil (Tiphiidae, Myzininae - Lithotiphia Cockerell, 1906, Geotiphia Cockerell, 1906; Tiphiinae - Paratiphia; Scoliidae, Archaeoscoliinae - Floriscolia Rasnitsyn, 1993); with digging underground nests (Sphecidae, Ammophilinae - Ammophila Kirby, 1798; Crabronidae, Crabroninae - Tracheliodes, Ectemnius Dahlbom, 1845, Mellininae - Mellinus Fabricius, 1790, Bembicinae - Gorytes Latreille, 1805 (?Psammaletes Pate, 1936), Psammaecius Lepeletier, 1832, Philanthinae - Philanthus Fabricius, 1790, Prophilantus Cockerell, 1906); or so-called "mud-daubers", who use moist clay from near water for building their nests (Sphecidae, Sceliphrinae - Chalybion Dahlbom, 1843, Hoplisidia Cockerell, 1906; Crabronidae, Crabroninae Pison). Many other groups of Hymenoptera found in Florissant shales inhabited the shore territories of the fresh water lakes and also included ground-nesting or often weakly flying forms.

The composition of the aculeate wasp and bee fauna found in the Bembridge Marls, Isle of Wight, England, demonstrates wider generic diversity than is characteristic of the contemporary Palaearctic region. The studied fauna includes both xylobionts (Palaeopolybia, Protopolistes, Sphaerancistrocerus, Tytthopsen, Plisomena, a megachilid bee and, probably, Dryophia) and ground-dwelling forms (Philoponites, Palaeoscolia, Protosceliphron, and Oligobombus). The most interesting fact is the high level of endemicity; none of the discovered taxa were previously known from other formations. Another peculiarity is the presence of archaic forms, for instance the polistine wasp Palaeopolybia, which retains a vespine-like structure of its forewing submarginal area; Protosceliphron - the only known Sphecidae with a sessile metasoma lacking sternal petiole; and Plisomena - the only known Spilomenina with plesiomorphic (not enlarged) pterostigma. Presence of such a generalised feature as a weak degree of costalisation of the anterior ends of recurrent veins in Palaeopolybia, Tytthopsen, Plisomena and Oligobombus is also a very remarkable peculiarity of the studied fauna, because it is more archaic than those of the earlier resembling taxa. I think that it was a locally endemic fauna, probably isolated from the surrounding regions.

There are comparatively low numbers of Aculeata in Bembridge Marls (excluding winged ants, whose quantity is much more than of all other groups of Aculeata) and parasitic Hymenoptera. The first group perished in mass after swarming, while the second could easily be blown from the coast because of its comparatively weak flying abilities. However, this cannot explain the low quantity of Aculeates in the adjacent territories, because actively flying aculeate wasps and bees are not connected with a sea coast, where they can get neither prey nor building materials. That is why the probability of their fossilisation in such conditions was quite low. Nevertheless, the discovery of such taxa as Tiphiidae, Scoliidae and Apidae indicates that large meadows with grasses and long-flowered herbs were present near the region of fossilisation. The occurrence of Spilomenina and small eumenine wasps occupying pre-existing borings in wood suggests the presence of broad-leaved trees. The comparatively weak degree of costalisation of the wing venation and significant sizes of the marginal cell in the discovered pemphredonines also testifies to their living in forest or forest-steppe regions. Furthermore, some taxa of apparently tropical affinities (Palaeopolybia) indicate a warm climate. I suggest that the region of fossilisation was a coastal plain with a warm climate, resembling the modern subtropical habitats of the Mediterranean region.

\subsection{Superfamily Formicoidea Latreille, 1802 \\ [By Gennady M. Dlussky and Ksenia S. Perfilieva.]}

3.11.1. Family Formicidae Latreille, 1802. Ants are the most abundant group of insects in the Bembridge Marls. The first brief report on a finding of ants in the Bembridge Marls, with no description of species, appeared in the late 19th Century (Brodie 1875). A few years later Woodward (1879) referred to identifications by F. Smith and noted that ants from these deposits belong to genera Myrmica Latreille, 1804, Formica Linnaeus, 1758 and Camponotus Mayr, 1861. Donisthorpe (1915) reproduced this information. The same year, Cockerell (1915) finished the study of a small collection from the Bembridge Marls collected by Brodie (transferred to the United States National Museum as a part of the Lacoe collection) and published the first descriptions of species. His descriptions were based mainly on measurements of cells and veins of forewings of a few specimens. He described eight species and referred them to four subfamilies: Ponera hypolitha Cockerell, 1915 (Ponerinae); Leptothorax gurnetensis Cockerell, 1915 (Myrmicinae); Dolichoderus britannicus Cockerell, 1915, D. anglicus Cockerell, 1915, and D. ovigerus Cockerell, 1915 (Dolichoderinae); and Oecophylla atavina Cockerell, 1915, O. perdita Cockerell, 1915, and O. megarche Cockerell, 1915 (Formicinae).

Donisthorpe (1920) undertook revision of a large collection of fossils from the Bembridge Marls, collected by P. B. Brodie, E. J. A'Court Smith and R. W. Hooley and kept at the Natural History Museum, London. In this article, he demonstrated that the species described by Cockerell as Leptothorax gurnetensis actually belongs to the subfamily Formicinae, and placed it in a new genus Leucotaphus Donisthorpe, 1920. He also described seven new species: Syntaphus wheeleri Donisthorpe, 1920; Euponera (Mesoponera) crawleyi Donisthorpe, 1920; Ponera minuta Donisthorpe, 1920, Emplastus emeryi Donisthorpe, 1920 (Ponerinae); Dolichoderus gurnetensis Donisthorpe, 


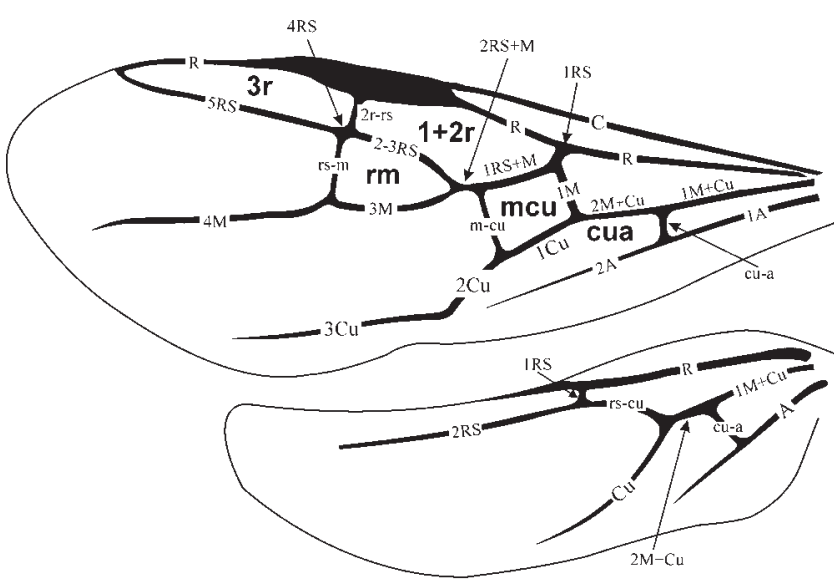

Text-figure 65 Wing venation of Emplastus britannicus, to show venational symbols used. Capitalised are longitudinal veines; dashed are cross-veins; neither of above are cells.

1920 (Dolichoderinae); Leucotaphus cockerelli Donisthorpe, 1920; and Camponotus (Colobopsis) brodiei Donisthorpe, 1920 (Formicinae). Later Cockerell (1927) described one more species, Leucotaphus permaneus Cockerell, 1927. There are no later publications about the ant fauna of the Bembridge Marls.

We studied 1136 specimens of fossil ants kept at the NHMUK including all of Donisthorpe's type specimens. We were able to study all of Cockerell's types, stored at the USNM (15 specimens) as well. It has only been possible to identify 105 of the specimens up to family level, due to insufficient preservation. The remaining 1031 specimens have been identified up to genus and 630 to species level. Digital photos have been prepared for 245 of the best preserved fossils, and some of them served as a base for line drawings.

Among the studied material, 234 specimens were earlier identified by Donisthorpe. Fifteen of them are not ants, and the references of 13 other fossils to ants seem doubtful. During the present revision, we found that Donisthorpe's article (1920) contains a number of mistakes, both in respect to definition of specimens and to taxonomic position of described species. There is an example, which can attest to the quality of this work: Donisthorpe described specimen NHMUK I.8675 as the holotype of Euponera (Mesoponera) crawleyi (Ponerinae) and identified its counterpart (I.8539) as Leucotaphus gurnetensis, hence referring it to another subfamily (Formicinae).

Some species described by Cockerell and Donisthorpe have been either synonymised or excluded from Formicidae, with only ten of 17 described species currently accepted, and the taxonomic status of six of them is changed. Additionally we describe ten new species below.

Preservation of the Bembridge fossils is unusual. In fact, they are not impressions but cavities. As a result, we see an insect from the inside, unlike other deposits where fossils are seen from the outside. This creates additional difficulties for interpretation. In particular, the fossils rarely split along the middle plane and as a result the insect contour looks deformed. It is rarely possible to combine part and counterpart. Also, measurements and their ratios are more variable than it is expected from intact ants.

In the line drawings, lines trace visible sclerite boundaries, dashed lines trace supposed sclerite boundaries, and dotted lines - visible margins of incomplete sclerites. Filled contours denote sclerites with the original matter preserved, even if chemically modified. Wing morphometrics were analysed using standard methods (cf. Bookstein 1991; Rohlf \& Marcus 1993; Danforth 1989; Rust 1999). Measurements of larger structures

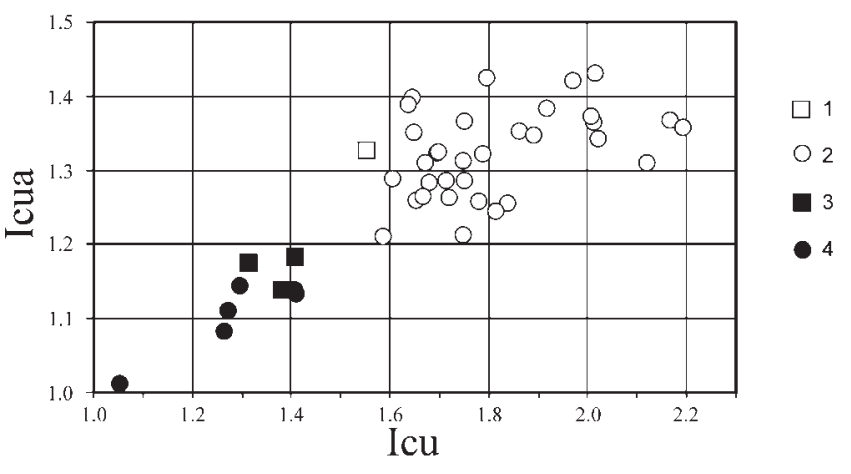

Text-figure 66 Differences of position of cross-vein cu-a in Aneuretinae, Dolichoderinae and Ponerinae from Bembridge Marls. Symbols: $1=$ Britaneuretus anglicus (Aneuretinae); $2=$ Dolichoderinae; $3=$ Taphopone petrosa (Ponerinae); 4 = other Ponerinae.

(total body length, length of alitrunk, forewing, etc.) were made using an ocular micrometer. Smaller details (petiole length, height and width, maximum eye diameter, etc.) were measured from digital pictures.

Abbreviations of measurements taken: $\mathrm{AL}=$ alitrunk (mesosoma) length from junction with head to that with petiole; $\mathrm{AW}=$ maximum alitrunk width; $\mathrm{BL}=$ total body length; $\mathrm{ED}$ $=$ maximum eye diameter; $\mathrm{F} 1=$ fore femur length; $\mathrm{F} 3=$ hind femur length; FWL = forewing length; FWW = forewing width measured between the pterostigmal base and indention of wing hind margin next to junction of sections $2 \mathrm{Cu}$ and $3 \mathrm{Cu}$ (Text-fig. 65 ); $\mathrm{HL}=$ head length without mandibles; $\mathrm{HW}=$ maximum head width; $\mathrm{n}=$ number of specimens measured; $\mathrm{PtL}=$ petiole length; $\mathrm{PtH}=$ maximum petiole height; $\mathrm{PtW}=$ maximum petiole width; $\mathrm{SL}=$ scape length; $\mathrm{ScL}=$ scutum length; $\mathrm{ScW}=$ scutum width; SctlL = scutellum length; SctlW = scutellum width.

Nomenclature of the wing venation (Text-fig. 65) is as in our previous publications (Dlussky 1983; Perfilieva 2002; Dlussky \& Perfilieva 2003). Two indices are used to help discriminate ant subfamilies: these concern relative position of cross-vein $\mathrm{cu}-\mathrm{a}$ and are calculated as follows:

$$
\begin{gathered}
\mathrm{Icu}=[1 \mathrm{Cu}+(2 \mathrm{M}+\mathrm{Cu})] / 1 \mathrm{Cu}, \\
\text { Icua }=[(1 \mathrm{M}+\mathrm{Cu})+(2 \mathrm{M}+\mathrm{Cu})] /(1 \mathrm{M}+\mathrm{Cu}) .
\end{gathered}
$$

They are particularly helpful in the distinguishing of Ponerinae and Dolichoderinae (Text-fig. 66). The second index is more precise, because Icu depends not only on the position of cu-a but also on the size of cell mcu. However, Icu is indispensable in the case of incomplete wings when Icua is not available for consideration.

Other terminology of ant morphology follows Bolton (1994). Statistics of the living and extinct genera and species are after Bolton (1995), corrected to consider overlooked and subsequent publications.

\subsubsection{Subfamily Aneuretinae Emery, 1913}

Taxa included. Subfamily Aneuretinae includes the unique extant species Aneuretus semoni Emery, 1893 that inhabits Sri Lanka (Wilson et al. 1956). Seven fossil species attributed to Aneuretinae were also described: Cananeuretus occidentalis Engel \& Grimaldi, 2005 (Upper Cretaceous, Canadian amber); Aneuretellus deformis Dlussky, 1988 (Paleocene, Sakhalin amber); Protaneuretus succineus Wheeler, 1915, Paraneuretus longicornis Wheeler 1915 and P. tornquisti Wheeler, 1915 (Late Eocene, Baltic amber); Mianeuretus mirabilis Carpenter, 1930 (latest Eocene, Florissant); and M. eocenicus Dlussky \& Rasnitsyn, 2002 (Middle Eocene, Green River). The incomplete 
Burmomyrma rossi Dlussky, 1996 (mid-Cretaceous, Burmese amber) may also belong to this subfamily.

Genus Britaneuretus Dlussky \& Perfilieva, gen. nov.

Etymology. After Britain and genus Aneuretus. Gender masculine.

Type species. Dolichoderus anglicus Cockerell, 1915.

Diagnosis. Female. Propodeum with a pair of short, obtuse teeth. Petiole elongate, without scale or distinct node. Forewing with cells $1+2 \mathrm{r}, \mathrm{rm}$, mcu and most likely $3 \mathrm{r}$ closed. $1 \mathrm{RS}$ and $2 \mathrm{r}$-rs vertical to $\mathrm{R}$. Cell mcu medium sized (visually about half area of cell $1+2 \mathrm{r}$ or little less), far distant of pterostigmal base level. Icu $>1.5$, Icua $>1.2$. Gaster oval, without constriction between first and second segments.

Remarks. Differs from Cananeuretus Engel \& Grimaldi, 2005 from the Upper Cretaceous Canadian amber, Protaneuretus Wheeler, 1915 and Paraneuretus Wheeler, 1915 from the Late Eocene Baltic amber, Mianeuretus Carpenter, 1930 from the Middle and latest Eocene of North America, and from extant Aneuretus Emery, 1893 by absence of petiolar node. Protaneuretus and Cananeuretus have no propodeal teeth. Aneuretellus Dlussky, 1988 from the Palaeocene Sakhalin amber has no petiolar node but, unlike the new genus, has no propodeal teeth. The only known species $A$. deformis is of very small size (body length about $3 \mathrm{~mm}$, alitrunk length $0.88 \mathrm{~mm}$ ).

Although no sting is visible in the fossil, a combination of petiole form and features of forewing venation indicate position of the new genus in Aneuretinae with sufficient confidence.

Britaneuretus anglicus (Cockerell, 1915), comb. nov. Plate 18, fig. 1; Text-fig. 67.

1915 Dolichoderus anglicus Cockerell, p. 484, plate 65. fig. 8. 1978 Dolichoderus anglicus Cockerell; Burnham, p. 112.

1995 Dolichoderus anglicus Cockerell; Bolton, p. 172.

Holotype. USNM 61415, Lacoe Coll. Bembridge Marls, Isle of Wight, UK.

Description. Female. Propodeum angular in side view, with blunt teeth on boundary of propodeal dorsum and declivity; propodeal dorsum longer than propodeal declivity. Petiole 1.7 times as long as high and about half as long as propodeum. Anterior part of petiolar dorsum almost flat, posterior one feebly rounded in side view. Petiole with maximal height behind its midlength. Forewing: distance from $1 \mathrm{RS}$ to pterostigma more than 1.5 times as long as $\mathrm{RS}+\mathrm{M}$. $1 \mathrm{M}$ inclined and parallel to $\mathrm{m}-\mathrm{cu}$. RS $+\mathrm{M}$ nearly 0.65 as long as $2-3 \mathrm{RS}$. Cell mcu trapezoid ( $\mathrm{RS}+\mathrm{M}$ and $1 \mathrm{Cu}$ noticeably longer than $\mathrm{m}-\mathrm{cu}$ and $1 \mathrm{M}) . \mathrm{Icu}=1 \cdot 6$, Icua $=1 \cdot 3$.

Measurements of holotype, $\mathrm{mm}: \mathrm{AL} \sim 2 \cdot 6 ; \mathrm{FWL} \sim 8$; $\mathrm{PtL}=1 \cdot 2 ; \mathrm{PtH}=0 \cdot 7$.

Remarks. Cockerell described Dolichoderus anglicus using only characters of forewing venation and ignored preserved body fragments. The wing venation is characteristic not only of Dolichoderus, but also of many other genera. At the same time, the form of the propodeum and petiole of the fossil is strictly unlike that of Dolichoderinae and particularly of Dolichoderus.

Cross-vein 2r-rs occurring distally in respect to rs-m appears to be an aberration in ant wings, being present often in only one wing of the pair. Therefore, we consider this feature as an aberration of the holotype and not as a diagnostic character of the taxon.

3.11.1.2. Subfamily Dolichoderinae Forel, 1878

Genus Dolichoderus Lund, 1831
Type species. Formica attelaboides Lund, 1831, by monotypy.

Other species. The genus Dolichoderus comprises 110 species in the modern fauna, the vast majority of which are distributed in the Neotropical (54) and Indo-Australian and Australian (41) regions. Only nine species are known from the Oriental region, four from the Nearctic region, two from the Palearctic region, and none were recorded from the Afrotropical region. The oldest species, D. kohlsi Dlussky \& Rasnitsyn, 2002, is recorded in the Middle Eocene Formation Green River, USA. Sixteen species are described from the Late Eocene Baltic and Rovno ambers (Dlussky 2002; Dlussky \& Perkovsky 2002) seven species from the near-boundary Eocene/Oligocene deposits: two from Florissant, USA (Carpenter 1930), five from the Isle of Wight, UK (Donisthorpe 1920), and six species from the Oligocene of continental Europe (Théobald 1937). Thirteen species are described from the Miocene of Central Europe (Radoboj, Croatia) and East Europe (Kerch, Ukraine), Eastern Asia (Shanwang, Shandong, China) and Central America (Dominican amber) (Mayr 1867; Dlussky 1981a; Wilson 1985; Zhang 1989; Zhang et al. 1994). However, after revision of the European fossil species, this number will undoubtedly change. As shown below, only one of five species described as Dolichoderus from the Bembridge Marls belongs there.

Diagnosis (for rock fossils of females and workers). Female. Head elliptical or oval, widest behind midlength of head sides; sometimes retort-shaped or subrectangular with rounded occipital corners, but never rectangular and longer than wide as in Protazteca Carpenter. Eyes of moderate size. Mandibles triangular, dentate. Propodeum bispinate, bidentate, or distinctly angular in side view, always with concave declivity. Petiole with scale proclined, or triangular in side view. Integument thick, often coarsely sculptured. Forewing with cells $1+2 \mathrm{r}, 3 \mathrm{r}$, $\mathrm{rm}$ and mcu closed; rm usually triangular. $1 \mathrm{RS}$ vertical to $\mathrm{R}$ or slightly proclined. Cell $3 \mathrm{r}$ touching wing margin, crossveins $2 r-r s$ and $r s-m$ coincide on $R S$, or $r s-m$ slightly distal. Cell mcu medium-sized, rhomboid or trapezoid (1Cu appreciably longer than $\mathrm{RS}+\mathrm{M}$ ). Gaster oval, without constriction between first and second segments. Integument thick, often coarsely sculptured.

Remarks. Almost all modern species of the genus are dendrobiotic, and there are no reasons to consider the present fossils as different.

Dolichoderus vectensis Donisthorpe, 1920 Plate 18, figs 2-3; Text-fig. 68A-C.

1920 Dolichoderus vectensis Donisthorpe, p. 88, plate V. fig. 6. 1978 Dolichoderus vectensis Donisthorpe; Burnham, p. 112. 1995 Dolichoderus vectensis Donisthorpe; Bolton, p. 177.

Holotype. NHMUK I.9198, , Bembridge Marls, NW Isle of Wight, UK, coll. P. B. Brodie (Plate 18, fig. 2; Text-fig. 68A).

Other material. Two females and four forewings in NHMUK collection, including well preserved lateral imprint of the female NHMUK In.24934 (Text-fig. 68B) and forewing NHMUK I.9373 (Plate 18, fig. 3; Text-fig. 68C). Bembridge Marls, NW Isle of Wight, UK,

Diagnosis. Similar to extant and extinct species of D. quadripunctatus group, particularly to D. tertiarius (Mayr 1868) from the Baltic amber and D. polessus Dlussky, 2002 from the Rovno amber (Late Eocene), but differs from both in the rougher sculpture of the scutum and propodeum.

Description. Female. BL 4-4.5 mm. Head wide, with convex sides, rounded occipital corners and concave occipital 

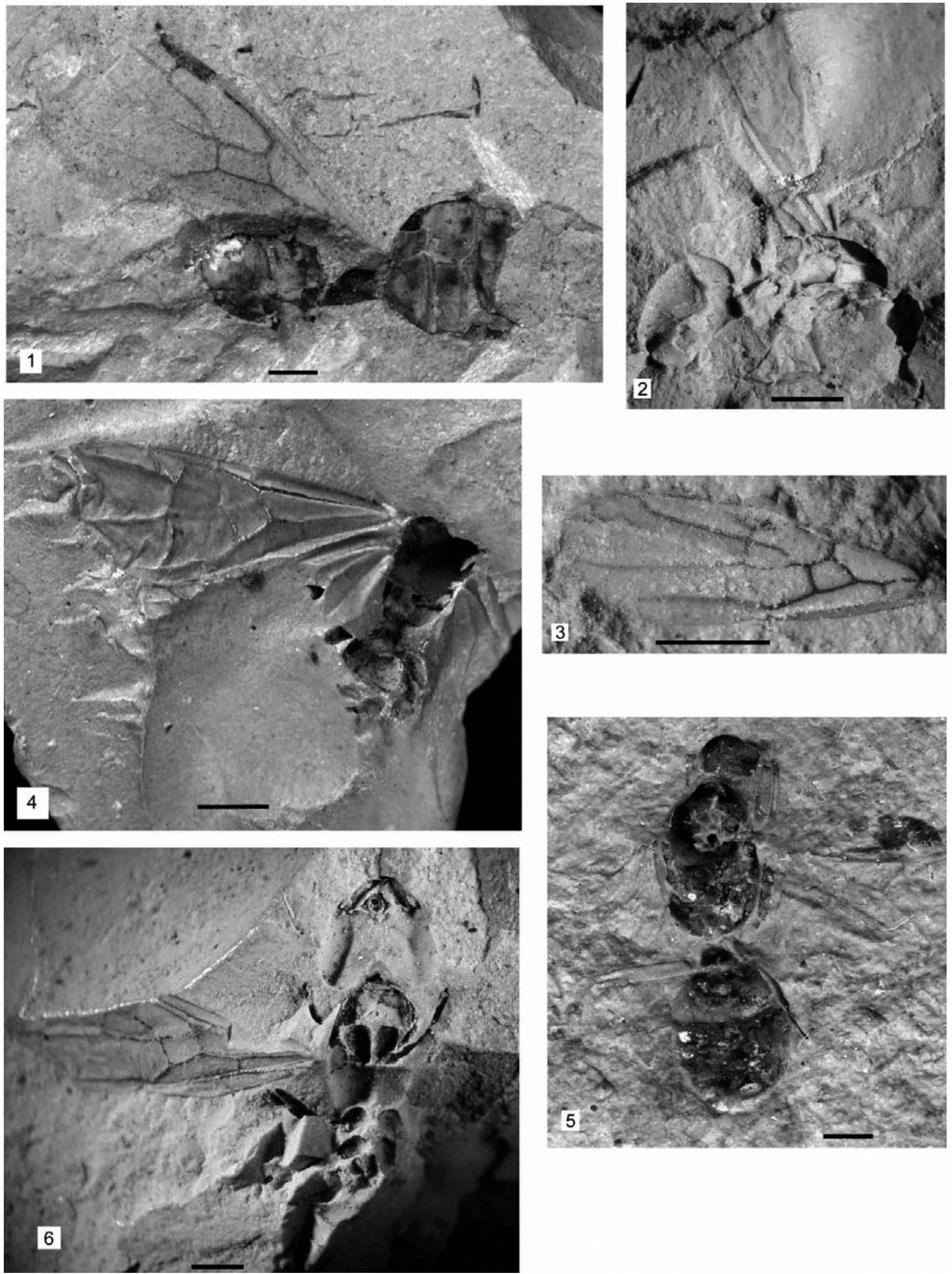

Plate 18 (1) Britaneuretus anglicus (Cockerell) comb. nov., holotype of Dolichoderus anglicus Cockerell, USNM 61415. (2-3) Dolichoderus vectensis Donisthorpe: (2) holotype, NHMUK I.9198; (3) forewing, NHMUK I.9373. (4-6) Emplastus britannicus (Cockerell), comb. nov.: (4) holotype of Dolichoderus britannicus Cockerell, USNM 61413; (5) holotype of Dolichoderus ovigerus Cockerell USNM 61416; (6) holotype of Emplastus emeryi Donisthorpe, NHMUK In.24367. Scale bars $=1 \mathrm{~mm}$. 


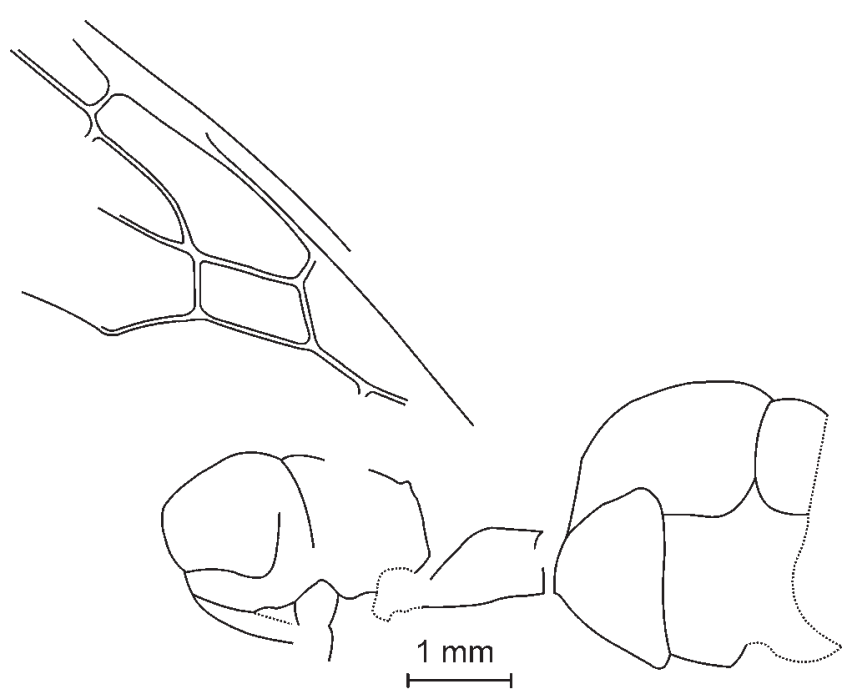

Text-figure 67 Britaneuretus anglicus (Cockerell), holotype of Dolichoderus anglicus Cockerell, USNM 6145.
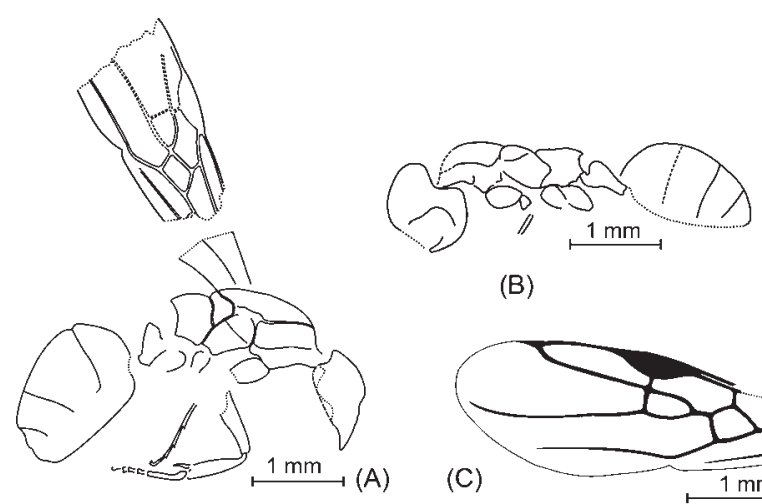

(B)

Text-figure 68 Dolichoderus vectensis Donisthorpe: (A) $\circ$, holotype, NHMUK I.9198; (B) ㅇ, NHMUK In.24934; (C) forewing, NHMUK I.9373.

margin. Mandibles well developed, triangular. Scutum feebly convex, not overhanging pronotum. Mesopleurae with distinct longitudinal furrow. Propodeum angular, with distinct carina separating propodeal dorsum and declivity; propodeal dorsum convex, propodeal declivity concave in side view. Legs rather short and thick. Petiole with rounded node, 1.5-1.8 times as long as high. At least scutum and propodeal sides with rather rough sculpture consisting of large isolated foveolae. Mesopleurae with no noticeable sculpture. Forewing: FWL 3·3-4 $\mathrm{mm}$. 1RS and $2 \mathrm{r}-\mathrm{rs}$ vertical to R. Cross-veins $2 \mathrm{r}-\mathrm{rs}$ and $\mathrm{rs}-\mathrm{m}$ coincide on RS, or rs-m shifted distally for about its width. Cell $\mathrm{rm}$ triangular, usually with distinct or (in holotype) short stem. Cell mcu of medium size. Icu $=1.55-2.0 \mathrm{~mm}$; Icu $=1.4$ $\mathrm{mm}$.

Measurements in mm. NHMUK I.9198 (क, holotype): $\mathrm{BL}=4.4 ; \quad \mathrm{AL}=1.6 ; \quad \mathrm{HL} \sim 0.8 ; \quad \mathrm{FWL} \sim 3.5 . \quad$ NHMUK In.24934 (९): $\mathrm{BL} \sim 4 ; \quad \mathrm{AL}=1.6 ; \quad \mathrm{HL} \sim 0.8 ; \quad \mathrm{HW} \sim 0.9$; $\mathrm{PtL}=0 \cdot 52 ; \mathrm{PtH}=0 \cdot 30$. Other specimens $(\mathrm{n}=3): \mathrm{FWL}=3.3-$ 4.0; FWW $=0.8-1.1$.

Remarks. Donisthorpe (1920) erroneously identified specimen I.9231 as Leucotaphus gurnetensi: all visible characters of this specimen including form of the propodeum are similar to the holotype of $D$. vectensis.

\section{Morphogenus Emplastus Donisthorpe, 1920}

1915 Dolichoderus; Cockerell, p. 483 (nec Lund, 1831).
1915 Ponera; Cockerell, p. 483 (nec Latreille, 1804).

1920 Dolichoderus; Donisthorpe, p. 87 (pars) (nec Lund, 1831). 1920 Emplastus Donisthorpe, p. 86.

Type species. Emplastus emeryi Donisthorpe, 1920 (=Dolichoderus britannicus Cockerell, 1915), by original designation.

Other species. E. britannicus (Cockerell, 1915), E. hypolithus (Cockerell, 1915), E. gurnetensis (Donisthorpe, 1920), and E. kozlovi sp. nov. Bembridge Marls, Isle of Wight, UK.

Diagnosis. Fossil ants not preserved well enough to fit orthotaxa, and with following combination of traits: size medium, head subrectangular with rounded occipital corners; mandibles triangular with denticulate masticatory margin; propodeum rounded in side view, petiole in side view with thick scale (females) or triangular (males). Forewing with cells $1+2 \mathrm{r}, 3 \mathrm{r}$, rm and mcu closed; cell $3 \mathrm{r}$ with apex touching wing fore margin, $1 \mathrm{RS}$ vertical to $\mathrm{R}$ or slightly proclined. Icu $>1.45 \mathrm{~mm}$, Icua $>1.2 \mathrm{~mm}$. Gaster without constriction between first and second segments.

Remarks. Donisthorpe (1920) placed this genus in the subfamily Ponerinae and considered it similar to the modern Myopias Roger, 1861. In his opinion Emplastus, as well as Myopias, has mandibles without teeth. In fact, the holotype has the masticatory margin of mandibles hidden. Specimen NHMUK In.24461, similar to E. emeryi in the body proportions and other visible characters, has masticatory margin of mandibles with blunt teeth. The position of cross-vein $\mathrm{cu}-\mathrm{a}$ in the type species $(\mathrm{Icu}=1.7)$ differs clearly from that of Ponerinae. In contrast, all characters visible on the holotype of Emplastus emeryi are identical to those of Dolichoderus britannicus Cockerell, and so justify synonymy of the former under the latter species name.

Cockerell (1915) and Donisthorpe (1920) described several species now included in Emplastus, based on the Dolichoderuslike forewing venation (characteristic of several other dolichoderine genera). However, this character is combined with the propodeum rounded in side view and not angular or bispinate with concave hind contour, as in all living and fossil Dolichoderus.

The morphogenus Emplastus may embrace representatives of various dolichoderine genera, particularly those earlier included into Iridomyrmex (Anonichomyrma Donisthorpe, 1947, Ctenobethylus Brues, 1939, and Iridomyrmex Mayr, 1862). Emplastus differs from Liometopum Mayr, 1861 (Late Eocenepresent) in the apex of cell $3 \mathrm{r}$ of the forewing touching the wing margin (distant from it in Liometopum). As mentioned above, Emplastus differs from females of Dolichoderus in the form of the propodeum.

Emplastus britannicus (Cockerell, 1915), comb. nov. Plate 18, figs 4-6; Text-figs 65, 69A-G, 88C

1915 Dolichoderus britannicus Cockerell, pp 483-484, plate 65, figs. 6-7.

1915 Dolichoderus ovigerus Cockerell, p. 484, plate 65, fig. 9; syn. nov.

1920 Dolichoderus britannicus Cockerell; Donisthorpe, pp 8788.

1920 Dolichoderus ovigerus Cockerell; Donisthorpe, p. 88.

1920 Emplastus emeryi Donisthorpe, p. 86, plate V. fig. 5; syn. nov.

1978 Dolichoderus britannicus Cockerell; Burnham, p. 112.

1978 Dolichoderus ovigerus Cockerell; Burnham, p. 112.

1978 Emplastus emeryi Donisthorpe; Burnham, p. 109.

1992 Emplastus emeryi Donisthorpe; Carpenter, p. 492. 


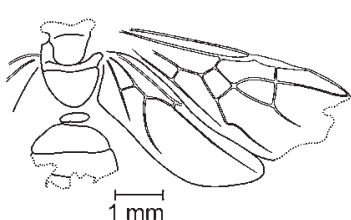

(A)
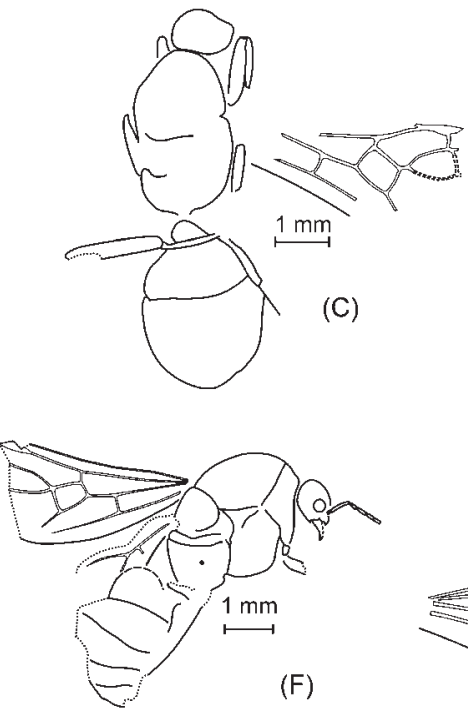

(F)
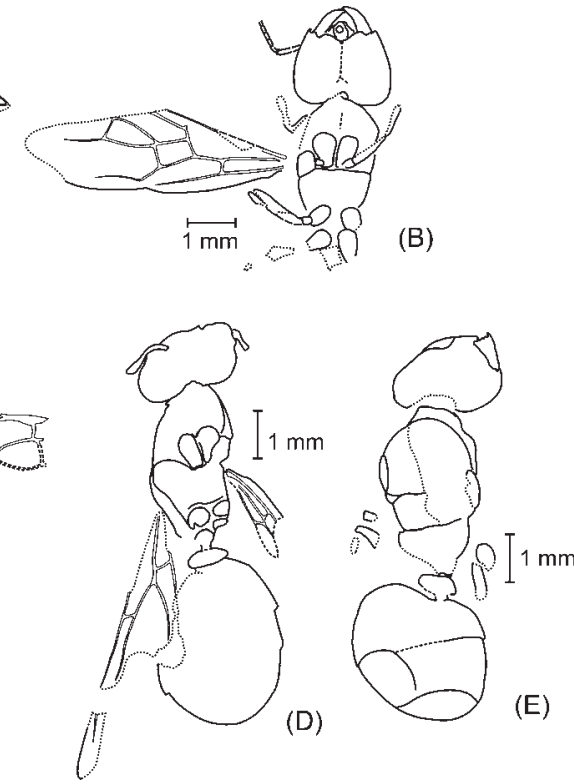

(E)

Text-figure 69 Emplastus britannicus (Cockerell): (A) 9 . USNM 61413 (holotype of Dolichoderus britannicus

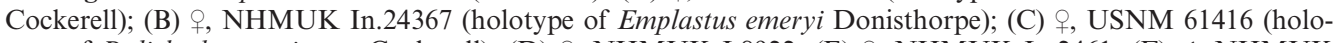
type of Dolichoderus ovigerus Cockerell); (D) + , NHMUK I.8922; (E) + , NHMUK In.2461; (F) ô, NHMUK I.10142; (G) forewing, NHMUK In.25083.

1995 Dolichoderus britannicus Cockerell; Bolton, p. 173.

1995 Dolichoderus ovigerus Cockerell; Bolton, p. 175.

1995 Emplastus emeryi Donisthorpe; Bolton, p. 188.

Holotype. USNM 61413, part and counterpart, Bembridge Marls, NW Isle of Wight, UK; \& (Plate 18, fig. 4; Text-fig. 69A).

Paratype. USNM 61414, Bembridge Marls, NW Isle of Wight, UK, Lacoe coll., + .

Other material. Holotype of Dolichoderus ovigerus, USNM 61416, Bembridge Marls, NW Isle of Wight, UK, coll. Lacoe, + (Plate 18, fig. 5; Text-fig. 69C). Holotype of Emplastus emeryi, NHMUK In.24367, Bembridge Marls, NW Isle of Wight, UK, coll. R. W. Hooley, क (Plate 18, fig. 6; Text-fig. 69B). Fifteen females, two males and 27 forewings in NHMUK collection and one forewing in CAMSM collection, including well preserved dorsal (NHMUK In.24461, Text-fig. 69E) and ventral (NHMUK I.8922, Text-fig. 69D) imprints of females, lateral imprint of male (NHMUK I.10142, Textfig. 69F) and completely preserved imprint of forewing (NHMUK In.25083, Text-fig. 69G). Bembridge Marls, Isle of Wight, UK.

Description. Female. BL 6-8.5 mm, AL 2.5-3.5 mm, FWL 6-7 mm. Head wide $(\mathrm{HW} / \mathrm{HL}=1.2)$, as wide as alitrunk, broader behind than in front, with feebly convex sides, rounded occipital corners and concave occipital margin. Scape short, not reaching occipital margin. Mandibles massive, triangular, with few blunt teeth on masticatory margin. Alitrunk c. 1.8 times as long as wide. Scutum flat dorsally, rounded anteriorly, nearly as long as wide; not overhanging pronotum. Scutellum feebly convex, 1.7-1.9 times as wide as long. Propodeum evenly rounded in side view. Legs rather short and thick. Petiole with scale wide and thick, scale $2 \cdot 5-3$ times as wide as thick. Gaster oval. Body integument matter preserved with chagrined surface.

Male. BL c. $6 \mathrm{~mm}$, AL c. $3 \mathrm{~mm}$, FWL 5.5-6 mm. Head small, clearly narrower than alitrunk. Eyes oval, situated slightly before midlength of head sides. Scape short, not reaching occipital margin, about as long as two or three flagellomeres. Mandibles well developed, triangular. Pronotum narrow, along midline less than 0.25 as long as scutum. Scutum and scutellum feebly convex, scutum half as long as alitrunk. Propodeum rounded in side view. Legs rather long and thin. Petiole triangular in side view, with rounded top, higher than long. As preserved, surface sculpture similar to, but finer than, in female.

Forewing 1RS slightly proclined or, sometimes, vertical to R. Cross-veins $2 r-r s$ and $r s-m$ coincide on RS or, rarely, $\mathrm{rs}-\mathrm{m}$ distal for cross-vein width. Cell $\mathrm{rm}$ triangular, not pedunculate or with very short stem, comparatively wide (1.62.1 times as long as wide). Cell mcu medium-sized, trapezoid or, rarely, rhomboid. Icu $=1 \cdot 55-2 \cdot 2$, Icua $=1 \cdot 2-1 \cdot 4$. Hindwing with two longitudinal veins $\mathrm{RS}$ and $\mathrm{Cu}$ and well developed 1RS. Cross-vein rs-cu concave, longer than r-rs and $2 \mathrm{Cu}$. Cross-vein $\mathrm{cu}-\mathrm{a}$ more close to $\mathrm{rs}-\mathrm{cu}$ than to wing base.

Measurements in mm. Types: USNM 61413 ( + , holotype of Dolichoderus britannicus): AW $=1.3 ; \mathrm{PtW}=0.66 ; \mathrm{FWL} \sim 6$. USNM 61414 ( 9 , paratype of Dolichoderus britannicus): $\mathrm{BL}=5.7 ; \mathrm{AL}=2.7, \mathrm{FWL}=6.2 . \mathrm{USNM} 61416$ ( $\%$, holotype of Dolichoderus ovigerus): $\mathrm{BL}=6.9 ; \mathrm{AL}=2.9, \mathrm{AW}=1.6$. NHMUK In.24367 Emplastus emeryi): $\mathrm{AL}=3.3 ; \mathrm{HL}=1.6$; $\mathrm{HW}=2.0$. Other specimens: females: $\mathrm{AL}=2.7-3.55(\mathrm{n}=4)$; $\mathrm{HW}=1.9-2,1 \quad(\mathrm{n}=3) ; \mathrm{ScL}=1.4-1.5 \quad(\mathrm{n}=3) ; \mathrm{SctW}=1.6$ $1.7 \quad(\mathrm{n}=2) ; \quad$ SctlL $=0.65-0.7 \quad(\mathrm{n}=3) ; \quad$ PtW $=0.6-0.85$; $\mathrm{FWL}=6.0-7.05 \quad(\mathrm{n}=3) . \quad$ Males: $\mathrm{AL}=2.5-3.2 \quad(\mathrm{n}=2)$; $\mathrm{HL}=1.0 \quad(\mathrm{n}=1) ; \quad \mathrm{SL}=0.4 \quad(\mathrm{n}=1) ; \quad \mathrm{ED}=0.25 \quad(\mathrm{n}=1) ;$ 
$\mathrm{FWL}=6.8(\mathrm{n}=1) ; \mathrm{FWW}=1.9-2,1 \quad(\mathrm{n}=2)$. Isolated forewings: $\mathrm{FWL}=5.4-7.3(\mathrm{n}=13) ; \mathrm{FWW}=1.6-2.1(\mathrm{n}=11)$.

Remarks. Three specimens (NHMUK I.8922, NHMUK In.17067/NHMUK In.17074, NHMUK In.24461) were found in the NHMUK collection with the general appearance and available characters identical to those of the holotype of Emplastus emeryi. There are a significant number of incomplete fossils as well that form a complete transition between Emplastus emeryi Donisthorpe, Dolichoderus britannicus Cockerell and D. ovigerus Cockerell. Cockerell (1915) wrote that $D$. ovigerus had "Structure, including petiole, essentially as in $D$. britannicus, from which it may not be distinct" (Cockerell 1915, p. 484). The only indicated differences between these species are details in the forewing venation, particularly the pedunculate cell $\mathrm{rm}$ in D. ovigerus. However, this character is variable: for example, the specimen NHMUK In.25085 has cell $\mathrm{rm}$ long pedunculate in the right wing and with very short stem in the left one. This justifies synonymy of the three species resulting in the valid name Emplastus britannicus (Cockerell 1915).

There are ovoid bodies seen inside the abdomen of the holotype female of $D$. ovigerus. Cockerell described them as eggs. However, we observed similar structures inside the head and alitrunk of some other specimens, so we consider them to have a mineral origin.

Of the specimens listed by Donisthorpe (1920), we failed to find specimens NHMUK I.10257, NHMUK I.9347, NHMUK H.114, NHMUK H.262, NHMUK H.440, and NHMUK H.497, and found NHMUK I.9198 designated as the holotype of Dolichoderus vectensis Donisthorpe.

Donisthorpe (1920) erroneously identified specimen NHMUK I.8922 as Oecophylla sp. In fact, the specimen is very similar to the holotype of Emplastus emeryi and not to Oecophylla. $\mathrm{He}$ also identified a poorly preserved specimen NHMUK In.24410 (coll. R. W. Hooley) as Oecophylla, which probably belongs also to E. britannicus. Donisthorpe (1920, p. 84) cited W. M. Wheeler as having identified specimens NHMUK In.17074 and NHMUK In.24461 = NHMUK H.127 doubtfully as Liometopum queens.

Females of Emplastus britannicus have a general appearance similar to those of Ctenobethylus Brues, 1939 from Late Eocene ambers, and Liometopum Mayr, 1861 (Late Eocene-present). However, the key diagnostic characters of these genera (form of anterior margin of clypeus, presence or absence of ocelli, position of propodeal spiracles, etc.) are not visible on the studied specimens. Females of $E$. britannicus differ from $C$. goepperti in the wide petiole scale and from Liometopum in the wing venation (position of top of cell $\mathrm{rm}$ ) and in the short antennal scape. Construction of the cranio-mandibular system of all of these females indicates that they built their nests most likely in rotten wood, similar to modern Liometopum and Lasius (subgenus Dendrolasius Ruzsky, 1912).

Emplastus hypolithus (Cockerell, 1915), comb. nov. Plate 19, figs 1-2; Text-fig. 70A-C.

1915 Ponera hypolitha Cockerell, p. 483, plate 64, figs. 3-4.

1978 Ponera hypolitha Cockerell; Burnham, p. 109.

1964 Poneropsis hypolitha (Cockerell); Taylor, 139.

1995 Poneropsis hypolitha (Cockerell); Bolton, p. 363.

Holotype. USNM 61411, Bembridge Marls, NW Isle of Wight, UK, coll. Lacoe; forewing (Plate 19, fig. 1; Text-fig. $70 \mathrm{~A})$.

Other material. NHMUK In.17311, Bembridge Marls, NW Isle of Wight, UK, coll. E. J. A'Court Smith; male (Plate 19, fig. 2; Text-fig. 70C) and 13 forewings (including NHMUK In.24368, Text-fig. 70B) in NHMUK collection. Bembridge Marls, Isle of Wight, UK.

Diagnosis. Differs from E. britannicus, the most common species of Emplastus in the Bembridge Marls, in form of the forewing cell $\mathrm{rm}$ and in position of $2 \mathrm{r}-\mathrm{rs}$.

Description. Male. BL 6,5 mm, AL $3 \mathrm{~mm}$, FWL 5-6 mm. Head small, distinctively narrower than alitrunk. Eyes oval, situated slightly before midlength of head sides. Scape short, not reaching occipital margin, as long as three flagellomeres. Mandibles well developed, triangular. Pronotum comparatively wide, along midlength $0 \cdot 33$ times as long as scutum. Scutum feebly convex, half as long as alitrunk. Propodeum evenly rounded in side view. Legs rather long and thin. Petiole higher than long, in side view its anterior surface feebly concave, posterior surface straight, top rounded. Preserved remnants of body integuments chagrined.

Forewing. Cell rm triangular, not pedunculate, rarely quadrangular, comparatively narrow $(2 \cdot 5-2 \cdot 8$ times as long as wide). Cross-vein $\mathrm{rs}-\mathrm{m}$ usually distal of $2 \mathrm{r}-\mathrm{rs}$, rarely coinciding. Cell mcu of medium size, trapezoid. Icu $=1 \cdot 6-2 \cdot 1$, Icua $=1 \cdot 3-$ 1.4 .

Measurements in mm. USNM 61412 (holotype of Ponera hypolitha): FWL 6. NHMUK In.17311 (今): $\mathrm{BL}=6.5$; $\mathrm{AL}=3.0 ; \mathrm{HL} \sim 1.1 ; \mathrm{F} 3 \mathrm{~L}=1.7$; FWL $\sim 6$. Other specimens: $\mathrm{FWL}=5.0-5.8(\mathrm{n}=7) ; \mathrm{FWW}=1.2-1.5(\mathrm{n}=4)$.

Remarks. Cockerell (1915) described this species as Ponera hypolitha based on a fragment of the forewing (holotype, USNM 61412) and a poorly preserved hind wing (paratype, USNM 61412). Position of cross-vein cu-a in the holotype $(\mathrm{Icu}=1.6)$ clearly indicates the fossil belongs to Dolichoderinae. A complete male (NHMUK In.17311) apparently conspecific with the holotype permits the assignment of the species to the morphogenus Emplastus. Paratype hind wing has no visible venation: structures considered by Cockerell to be veins are in fact wing folds. There are no features justifying attribution of the paratype to either Ponera or Emplastus; it is therefore considered to be Formicidae incertae sedis.

Donisthorpe erroneously identified specimens NHMUK In.17311, NHMUK In.24368 and NHMUK In.24373 as Dolichoderus britannicus, and NHMUK In.9347 as D. ovigerus, in spite of their forewing venation and particularly position of $2 r-$ $r s$ and form of $r m$ which show no similarity to E. britannicus.

Emplastus gurnetensis (Donisthorpe, 1920), comb. nov. Plate 19, fig. 3; Text-fig. 71

1920 Dolichoderus gurnetensis Donisthorpe, p. 88, plate V. fig. 7.

1978 Dolichoderus gurnetensis Donisthorpe; Burnham, p. 112.

1995 Dolichoderus gurnetensis Donisthorpe; Bolton, p. 174.

Holotype. NHMUK: I.9755, Bembridge Marls, NW Isle of Wight, UK, coll. P. B. Brodie;, q (Plate 19, fig. 3; Text-fig. 71A).

Other material: Female, two males (including I.9510; Textfig. 71B) and four forewings in NHMUK collection. Bembridge Marls, Isle of Wight, UK.

Diagnosis. The species occupies an intermediate position between E. britannicus and E. hypolithus. Forewing venation is similar to E. hypolithus, and males are similar in general appearance to E. britannicus, but differing in smaller size. The female holotype differs from females of E. britannicus in head proportions and in form of petiole. Body fossils of female $E$. hypolithus are unknown, but male E. hypolithus is 1.5 times as long as female E. gurnetensis and therefore these two cannot be conspecific. 

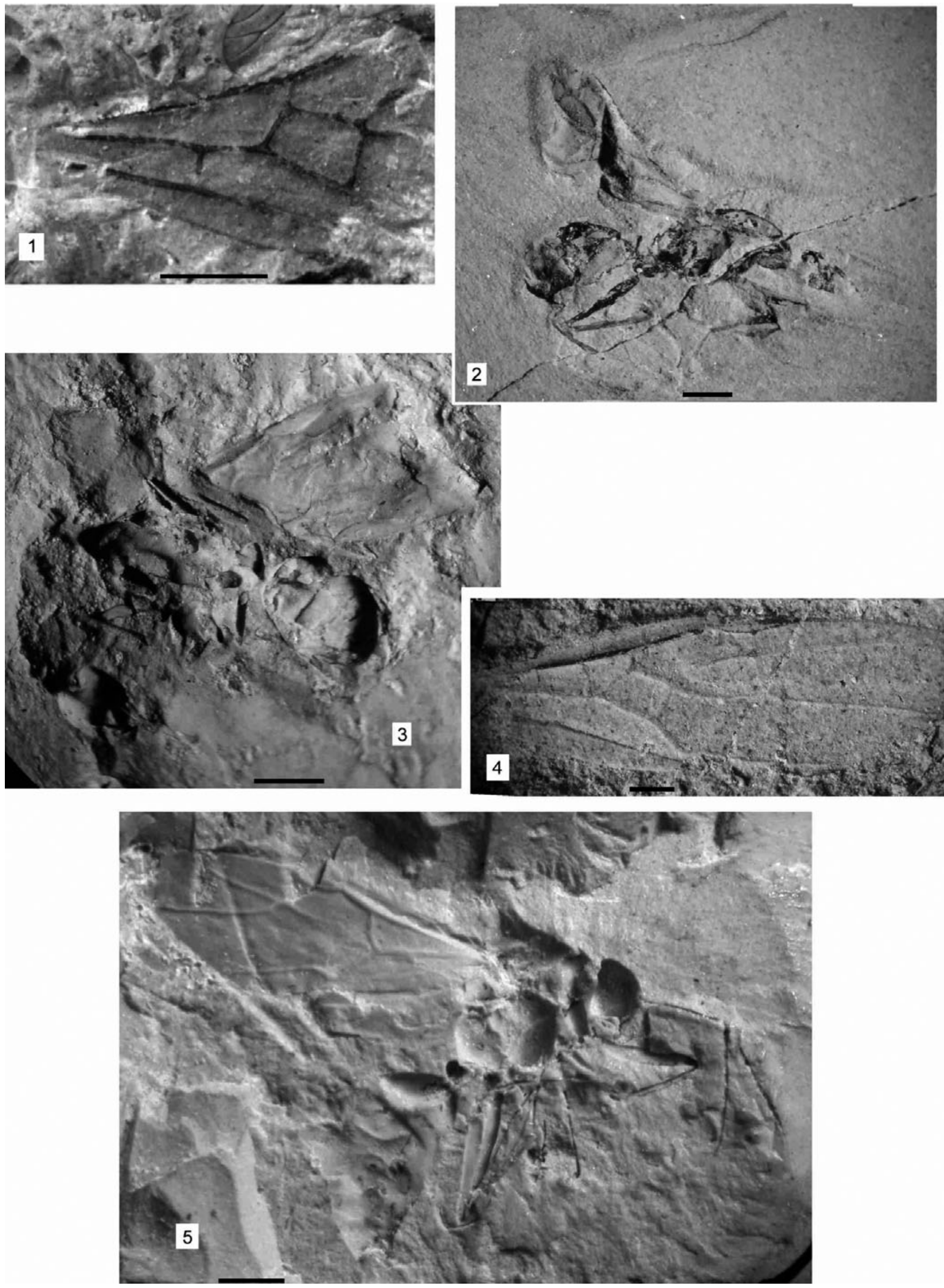

Plate 19 (1-2) Emplastus hypolithus (Cockerell) comb. nov.: (1) holotype of Ponera hypolitha Cockerell, USNM 61411; (2) o, NHMUK In.17311. (3) Emplastus gurnetensis (Donisthorpe), comb. nov., holotype of Dolichoderus gurnetensis Donisthorpe, NHMUK I.9755. (4) Emplastus kozlovi Perfilieva, sp. nov., holotype, NHMUK PI II.2784. (5) Camponotus cockerelli (Donisthorpe) comb. nov., holotype of Leucotaphus cockerelli Donisthorpe, NHMUK I.8517. Scale bars $=1 \mathrm{~mm}$. 

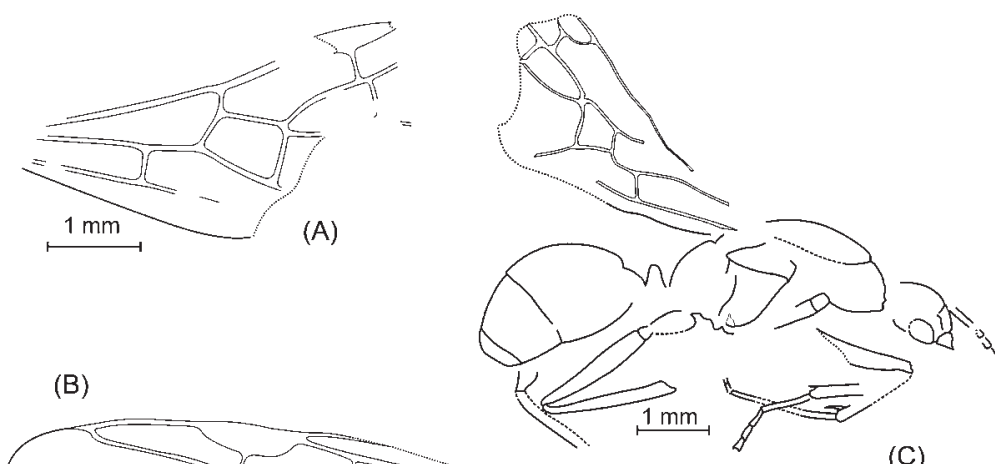

(B)

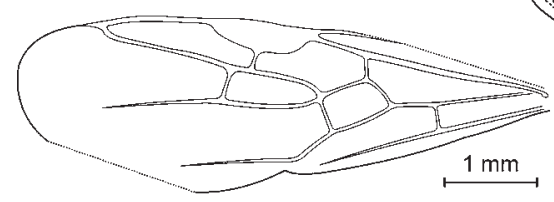

(C)

Text-figure 70 Emplastus hypolithus (Cockerell): (A) forewing, holotype of Ponera hypolitha Cockerell, USNM 61411; (B) forewing, NHMUK In.24368; (C) ô, NHMUK In.17311.

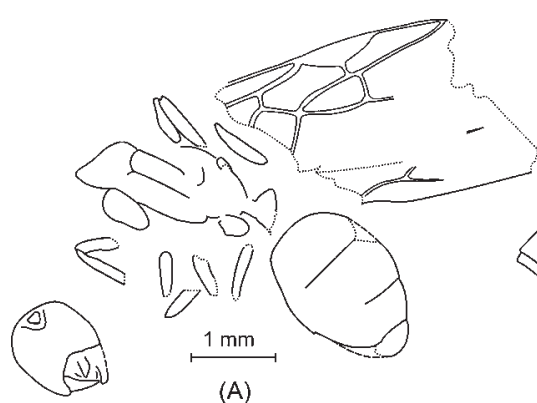

(A)

Text-figure 71 Emplastus gurnetensis (Donisthorpe): (A) + , holotype of Dolichoderus gurnetensis Donisthorpe, NHMUK I.9755; (B) ô, NHMUK I.9510.

Description. Female. BL c. $5 \cdot 5 \mathrm{~mm}, \mathrm{AL}$ c. $2 \mathrm{~mm}$, FWL 5.5$6 \mathrm{~mm}$. Head longer than wide (HL:HW =1.07), about half as long as alitrunk, rectangular with slightly convex sides, rounded occipital corners and straight or feebly convex occipital margin. Mandibles massive, triangular. Propodeum evenly rounded in side view. Legs rather short and thick. Petiole with scale low, triangular in side view, about as long as high. Gaster oval. Body integument matter preserved with chagrined surface.

Male. BL c. $4 \mathrm{~mm}$, AL 1.8-1.9 mm, FWL 3-4 mm. Head small. Alitrunk 2.5 times as long as head. Ocelli large (visible in NHMUK I.9082). Pronotum narrow, along midline less than 0.25 times as long as scutum. Scutum and scutellum convex in side view, scutum about half as long as alitrunk. Propodeum rounded in side view. Legs rather long and thin. Petiole in side view triangular, slightly higher than long. Body integument matter preserved with chagrined surface.

Forewing cell $\mathrm{rm}$ triangular, not pedunculate or with short stem 2.2-2.4 times as long as high. Cross-vein rs-m distal of $2 \mathrm{r}-\mathrm{rs}$. Cell mcu of medium size, rhomboid or trapezoid. $\mathrm{Icu}=1 \cdot 7-2 \cdot 0$, Icua $=1 \cdot 24-1 \cdot 38$. Hind wing with three longitudinal veins $(\mathrm{RS}, \mathrm{M}, \mathrm{Cu}) .1 \mathrm{M}$ and $\mathrm{rs}-\mathrm{m}$ of roughly same length. Cross-vein $\mathrm{cu}-\mathrm{a}$ closer to rs-cu than to wing base.

Measurements in mm. NHMUK I.9755 ( + holotype): BL $\sim 5 \cdot 5 ; \quad \mathrm{AL}=2 \cdot 1 ; \quad \mathrm{HL}=1.01 ; \quad \mathrm{HW}=0.94 ; \quad \mathrm{FWL} \sim 5.7$. NHMUK I.8723: FWL $=6 \cdot 1$; FWW $=1.7$. Males: $\mathrm{AL}=1.8$ $1.9 \quad(\mathrm{n}=2) ; \quad \mathrm{HL}=0.75-0.8 \quad(\mathrm{n}=2) ; \quad \mathrm{ScL}=0.9 \quad(\mathrm{n}=1) ;$ $\mathrm{SctL}=0 \cdot 54 \quad(\mathrm{n}=1) . \quad$ Forewings: $\mathrm{FWL}=4 \cdot 0-6 \cdot 3 \quad(\mathrm{n}=2)$; $\mathrm{FWW}=2 \cdot 1(\mathrm{n}=1)$.

Remarks. Donisthorpe identified specimen NHMUK I.9082 as Leucotaphus gurnetensis (Cockerell), but it is larger and differs in body proportions. He also identified forewing NHMUK In.24373 as Dolichoderus britannicus in spite of its venational difference (in position of $\mathrm{r}-\mathrm{rs}$ and in form of $\mathrm{rm}$ ).

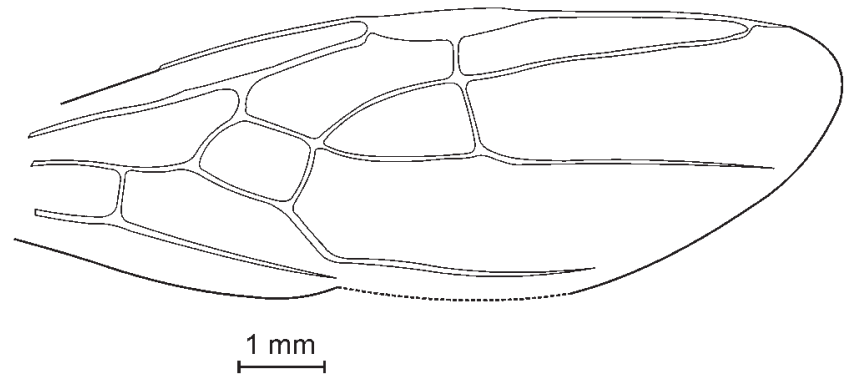

Text-figure 72 Emplastus kozlovi Perfilieva, sp. nov., holotype, NHMUK PI II.2784.

Emplastus kozlovi Dlussky \& Perfilieva, sp. nov. Plate 19 fig. 4; Text-fig. 72

Etymology. In memory of Mikhail Kozlov, who collected the holotype.

Holotype. NHMUK PI II.2784 a, b, Bembridge Marls, Burnt Wood, Isle of Wight, UK, collected by Belokobylsky, Khalaim, and Kozlov 24.05.2005; forewing, (Plate 19, fig. 4; Text-fig. 72).

Paratypes. NHMUK In. 24372, NHMUK In.24936, NHMUK In.25112, NHMUK In.25141, forewings, Bembridge Marls, NW Isle of Wight, UK, coll. R. W. Hooley.

Diagnosis. Venationally similar to E. britannicus, but differs in larger size (7-9 $\mathrm{mm}$ in males and 11-12 $\mathrm{mm}$ in females; in contrast to, respectively, 5.5-6 $\mathrm{mm}$ and 6-7 $\mathrm{mm}$ in $E$. britannicus) and in relatively long cell $\mathrm{rm}$.

Description. FWL $11-12 \mathrm{~mm}$ in females, $7 \cdot 8-8 \cdot 8 \mathrm{~mm}$ in males. $1 \mathrm{RS}$ and $2 \mathrm{r}-\mathrm{rs}$ vertical to $\mathrm{R}$ and $\mathrm{RS}$, respectively. Cell $\mathrm{rm}$ triangular, with no stem, rarely with very short stem, $2 \cdot 2-$ 2.5 times as long as wide. Cross-veins rs- $\mathrm{m}$ and $2 \mathrm{r}-\mathrm{rs}$ coinciding. Cell $\mathrm{mcu}$ of medium size, trapezoid. Icu $=1 \cdot 6-1 \cdot 8$, Icua $=1 \cdot 3-1 \cdot 5$.

Measurements in mm. NHMUK: PI II.2784 (holotype): $\mathrm{FWL}=11 \cdot 3, \quad \mathrm{FWW}=3 \cdot 4 ; \quad$ paratypes: $\mathrm{FWL}=7 \cdot 8-11 \cdot 0$, $\mathrm{FWW}=1 \cdot 8-3 \cdot 0(\mathrm{n}=4)$.

Remarks. Donisthorpe erroneously identified forewing NHMUK In.24372 as E. britannicus.

\subsubsection{Subfamily Formicinae Latreille, 1809}

Genus Camponotus Mayr, 1861

Type species. Formica ligniperda Latreille, 1802, by subsequent designation by Bingham (1903). 


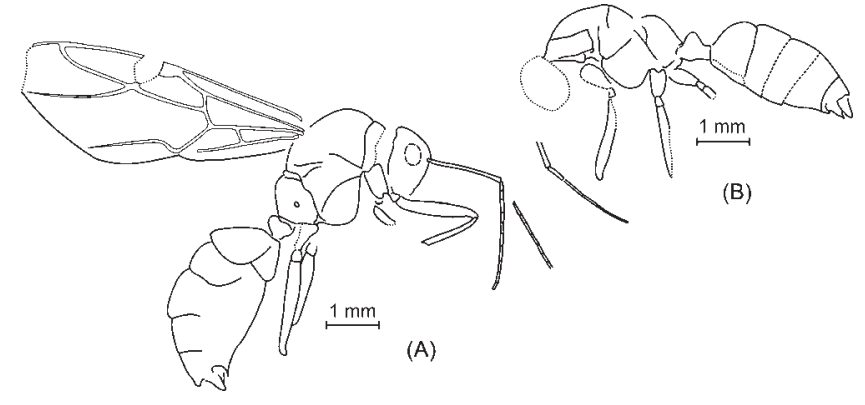

Text-figure 73 Camponotus cockerelli (Donisthorpe): (A) ô, holotype of Leucotaphus cockerelli Donisthorpe, NHMUK I.8517; (B) $\hat{0}$, NHMUK In.17280.

Other species. In the modern fauna Camponotus totals $c$. 950 species distributed on all continents from forest-tundra in the north of Eurasia and Boreal America to Tierra del Fuego in the south. The majority of species frequent humid arboreal ecosystems, but occur also in deserts and savannas, where they build underground nests.

Bolton (1995) listed 23 fossil species of Camponotus. He missed nine species described by Zhang (1989) from the Miocene deposits of China (Shanwang). Zhang further reported (apparently erroneously) three extant species there: $C$. festinus F. Smith, 1857; C. luteus F. Smith, 1858; and C. mitis F. Smith, 1858. There are also indications of findings of unidentified Camponotus in the Oligocene of Camoin-les Bains in France (Timon-David 1944), in the Miocene of the Dominican amber (Wilson 1985) and in the rock fossils of Bakhioti in Georgia and Chon-Tuz in Kirghizia (Dlussky 1981a). One more species is described below.

As a result, c. 40 species of fossil Camponotus are currently known. However, only a subset of them can be attributed to the genus with reasonable confidence. C. mengei Mayr, 1868, described from the Baltic amber, as well as those from the Miocene of Georgia and Kirghizia are undoubtedly Camponotus. C. fuscipennis Carpenter, 1930 (latest Eocene, Florissant, USA), ?. shanvangensis Hong, 1984, C. longus Zhang, 1989, C. plenus Zhang, 1989 and C. ambon Zhang, 1989 (Miocene, Shanwang, China) also belong to this genus, based on their figures and descriptions. Preservation and/or quality of descriptions of other species leave some doubts about their identification. Until re-examination of the types, these species should be either attributed to morphogenus Camponotites Dlussky, 1981 (wings and winged fossils), or considered Formicidae incertae sedis.

Diagnosis (for rock fossils). Size medium to large, head subrectangular with rounded occipital corners; male and female antennae geniculate, scape attached at some distance from posterior clypeal margin; mandibles triangular with denticulate masticatory margin; petiole with scale thick (females) or triangular in side view (males). Forewing with cells $1+2 \mathrm{r}$, 3r; closed rm and mcu lost; RS usually convex downwards within cell $3 \mathrm{r}, 5 \mathrm{RS}$ and $4 \mathrm{M}$ join basally (rs $-\mathrm{m}$ lost). $1 \mathrm{M}$ and $1 \mathrm{RS}$ form smooth, almost straight, distinctly reclined vein. Crossvein $2 \mathrm{r}-\mathrm{rs}$ distinctly reclined in respect to RS. Icua $>1.3$. Hindwing with two longitudinal veins $\mathrm{RS}$ and $\mathrm{Cu}$. Gaster without constriction between first and second segments.

Camponotus cockerelli (Donisthorpe, 1920), comb. nov. Plate 19, fig. 5; Text-fig. 73A, B

1920 Leucotaphus cockerelli Donisthorpe, pp 90-91, Plate V, fig. $10(\hat{o})$.

1978 Leucotaphus cockerelli Donisthorpe; Burnham, p. 111.

1995 Leucotaphus cockerelli Donisthorpe; Bolton, p. 246.
Holotype. NHMUK I.8517, Bembridge Marls, NW Isle of Wight, UK, coll. P. B. Brodi; ô (Plate 19, fig. 5; Text-fig. 73 A).

Other material. Four males (including well preserved lateral imprint) NHMUK In.17280; (Text-fig. 73B) and eight forewings in NHMUK collection, and two males in CAMSM collection. Bembridge Marls, Isle of Wight, UK.

Description. Male. BL 6-7.5 mm. Head about half as long as alitrunk. Eyes oval, situated above the midlength of head sides. Antennae geniculate, scape attached at some distance from clypeus; extending more than half its length beyond occipital margin. Scutum feebly convex in side view. Propodeum with dorsal surface short, convex, forming rounded blunt angle at junction with longer and almost straight declivous surface. Legs long and thin. Petiole triangular, a little longer than high in side view. Gaster cylindrical. Genital stipes short, narrow, rounded apically.

Forewing length of female $6.5-8 \mathrm{~mm}$, male 5-6.5 $\mathrm{mm}$. $2+3 R S$ and $5 \mathrm{RS}$ both convex downward, not S-like. Distance between $1 \mathrm{M}$ and $\mathrm{cu}-\mathrm{a}$ not longer than joint length $1 \mathrm{M}$ and $1 \mathrm{RS}$. Icua $=1.3-1.6$. Hindwing with two longitudinal veins $\mathrm{RS}$ and $\mathrm{Cu}$. Section rs-cu about as long as $2 \mathrm{M}+\mathrm{Cu}$. Crossvein $\mathrm{cu}-\mathrm{a}$ near wing base.

Measurements in mm. Holotype $\hat{o}$ NHMUK I.8517: $\mathrm{BL}=7 \cdot 5 ; \mathrm{AL}=2 \cdot 6 ; \mathrm{HL} \sim 1 \cdot 3 ; \mathrm{SL}=1 \cdot 4 ; \mathrm{ScL}+\mathrm{SctlL}=1.9$; FWL $\sim 6 ; \quad \mathrm{F} 3=1.8 ; \quad$ NHMUK I.9225 (§) $) \quad \mathrm{AL}=1.9 ;$ NHMUK In.17280 (§): $\mathrm{BL}=7 \cdot 5 ; \quad \mathrm{AL}=2 \cdot 7 ; \quad \mathrm{ScL}=1 \cdot 3$; $\mathrm{PtL}=0 \cdot 6$.

Remarks. Donisthorpe described Leucotaphus cockerelli based on two specimens: holotype ô NHMUK I.8517 and paratype + NHMUK I.9028. The holotype is described as having the forewing cell mcu closed, but figured with crossvein $\mathrm{m}-\mathrm{cu}$ closing this cell and represented by a dotted line. The holotype examined shows no trace of $\mathrm{m}-\mathrm{cu}$ and so with no closed cell mcu, which is not a wing anomaly. In case of aberrative loss of $\mathrm{m}-\mathrm{cu}$ in a species with $\mathrm{cu}-\mathrm{a}$ normally present, the wing retains a trace of the formerly closed cell mcu in form of a distinct angulation at the junction of $1 \mathrm{RS}$ and $1 \mathrm{M}$ : the holotype has this composite vein smooth. Additionally, Bembridge Leucotaphus exhibits a more proximal position of $\mathrm{cu}-\mathrm{a}$ in comparison with the present specimen. However, the strongest evidence of the species belonging to Camponotus is the scape attached to the head distinctly above the clypeus.

The paratype NHMUK I.9028 is actually Diptera indet. Instead we have found the specimen NHMUK I.9731 labelled erroneously as the holotype of Leucotaphus cockerelli which fits the description of the paratype, including measurements (body length $5.5 \mathrm{~mm}$ ), and apparently represents the female paratype. We identify it as Leucotaphus gurnetensis (Cockerell).

Thirteen more specimens fit the diagnosis of Camponotus cockerelli and are found in the NHMUK collection. Of them, specimens NHMUK I.8692, NHMUK I.9225 and NHMUK In.17280 are misidentified by Donisthorpe (1920) as Oecophylla sp., and NHMUK In.17066 as Leucotaphus gurnetensis. The petiole form of NHMUK I.8692 and NHMUK I.9225 is not characteristic for Oecophylla; the posterior margin of cell rm, formed by RS of wing impression NHMUK In.17066 is convex (concave in Oecophylla); cell mcu is closed in NHMUK In.17066. Specimen NHMUK In.17280, a male body with poorly preserved wings, is almost identical to the holotype. Other specimens are forewings of Camponotini of a size similar to that of the holotype.

Forewing length of the studied fossils varies from $5 \mathrm{~mm}$ to $8 \mathrm{~mm}$. The range is wide enough to suppose it covers more than a single species and sex. In living Camponotus, male wings are narrower than those of the female (Perfilieva 2005). The present material shows Iw (ratio of forewing length to width) range as $2 \cdot 9-4 \cdot 3$, indicating the presence of both sexes. 
Wing morphometrics were analysed using standard methods (see above). Two comparatively uniform groups have been identified, apparently representing males and females. Moreover, the results indicate the presence of two species, one including males NHMUK I.8517 (holotype, FWL $=5.6 \mathrm{~mm}$; $\mathrm{Iw}=2.9)$ and NHMUK In.24794 (FWL $=6.5 \mathrm{~mm})$, and female NHMUK In.24931 (FWL $=8.0 \mathrm{~mm}$; Iw $=4.3)$; and another with males NHMUK I.8692 (FWL $=5.0 \mathrm{~mm}$; Iw $=3.0)$ and NHMUK I.9359 (FWL $=6.0 \mathrm{~mm})$ and females NHMUK In.24842 $(\mathrm{FWL}=6.5 ; \quad \mathrm{Iw}=3 \cdot 7), \quad$ NHMUK In.24881 (FWL $=7.5 \mathrm{~mm} ; \mathrm{IW}=3.6)$ and NHMUK In.25175 $(\mathrm{FWL}=7.7 \mathrm{~mm})$. Unfortunately, the material is too limited to justify formal description of a new species.

\section{Morphogenus Leucotaphus Donisthorpe, 1920}

Type species. Leptothorax gurnetensis Cockerell, 1915, by original designation.

Other species. Leucotaphus gurnetensis (Cockerell, 1915), L. permaneus Cockerell, 1927, L. donisthorpei sp. nov., Bembridge Limestone, Isle of Wight, UK.

Diagnosis. Fossil ants not well enough preserved to fit orthotaxa, and with following combination of traits: mandibles triangular; male antennae geniculate; scape articulate to the posterior margin of clypeus; female and male scape protruding beyond the occipital margin of the head; propodeum rounded or angulate in side view; petiole with high scale (†) or triangular (ठ) in side view; gaster without constriction between the first and second gastal (III and IV abdominal) segments. Forewing with cells $1+2 \mathrm{r}, 3 \mathrm{r}$ and mcu and not rm closed. $2-3 \mathrm{RS}$ convex, rarely feebly arching, 5RS convex. Cell $3 \mathrm{r}$ with apex touching wing margin. Sections 5RS and 4M with joint start (rs-m lost). Cell mcu trapezoid ( $\mathrm{RS}+\mathrm{M}$ appreciably shorter than $1 \mathrm{Cu}$ ), small (in terms of area, less than half cell $1+2 \mathrm{r}$ ). Icu $>1.5$, Icua $>1.2$. Hindwing with two longitudinal veins $\mathrm{RS}$ and $\mathrm{Cu}$, $1 \mathrm{RS}$ lost (2RS and rs-cu join at R). Cross-vein cu-a near wing base.

Remarks. Many genera of formicine ants from the tribes Formicini and Lasiini (in particular, Formica Linnaeus, 1758 and Lasius Fabricius, 1804) fit the diagnosis of Leucotaphus. Undoubtedly many fossil species described as Formica and Lasius from poorly preserved impressions deserve transfer into this morphogenus. Leucotaphus would range at least from the Paleocene (undescribed wings from Tadushi Formation in the Russian Far East) up to the Miocene (Lasius vetulus Dlussky, 1981).

Leucotaphus gurnetensis (Cockerell, 1915) Plate 20, figs 1-3; Text-figs 74A-E, 88B

1915 Leptothorax gurnetensis Cockerell, p. 485, plate 65, figs. 4, 5 (wing).

1920 Leucucotaphus gurnetensis (Cockerell): Donisthorpe, p. 89 , Plate V, fig. 8,9 (male).

1978 Leptothorax gurnetensis Cockerell: Burnham, p. 111.

1992 Leptothorax gurnetensis Cockerell: Carpenter, p. 492.

1995 Leucotaphus gurnetensis (Cockerell): Bolton, p. 246.

Holotype. USNM 61417, Bembridge Marls, NW Isle of Wight, UK, coll. Lacoe (holotype of Leptothorax gurnetensis Cockerell); ô (Plate 20, fig. 1; Text-fig. 74A).

Other material USNM 61418 (ð̋, Lacoe Coll., designated by Cockerell as Leptothorax gurnetensis var. a), 100 males, ten females, and 36 isolated forewings (32 0 and four 9 ) in the NHMUK collection, and four of forewings in the CAMSM collection, including: NHMUK I.9731 ( + , which is the para- type of Leucotaphus cockerelli Donisthorpe, 1920); NHMUK I.9744 ( $\hat{\alpha}$, designated by Donisthorpe (1920) as ergatotype of Leucotaphus gurnetensis, Text-fig. 74E); NHMUK I.9756 (今ે, designated by Donisthorpe (1920) as plesiotype of Leucotaphus gurnetensis); a well preserved dorsal imprint of female NHMUK I.8733 (Plate 20, fig. 2; Text-fig. 74B); and lateral imprints of males NHMUK I.10040 (Text-fig. 74C) and NHMUK I.9796 (Plate 20, fig. 3; Text-fig. 74D). Four males in CAMSM collection.

Description. Male. BL 2.2-3.8 mm, AL 1.0-1.7 mm, FWL 2.2-3.7 mm. Head subtrapezoid, narrower in front than behind, longer than wide, occipital corners rounded, occipital margin feebly convex. Eyes oval, situated slightly before midlength of head sides; maximum eye diameter $2 \cdot 6-3 \cdot 1$ times less than head length. Scape slightly protrudes beyond the occipital margin of the head; scape length a little less than head length. Mandibles well developed, triangular; mandibular teeth not visible in any specimen. Alitrunk 1.2-1.4 times as wide as head, twice as long as wide and 1.3-1.5 times as long as high. In side view scutum feebly convex, propodeum rounded or with the poorly expressed angle, in which case propodeal dorsum much shorter than declivity. Legs rather thin and long. Petiole in side view triangular, with rounded top, higher than long. Gaster oviform, narrowed behind. Genitals slightly exposed, with stipes short, narrow, rounded at the top.

Female. BL 5.0-6.5 mm, AL 2.2-3.2 mm, FWL 5-5.5 $\mathrm{mm}$. Head narrower than alitrunk. Alitrunk 1.8-1.9 times as long as wide, $1 \cdot 3-1.5$ as long as high. In side view scutum rounded in front, flat behind. Propodeal dorsum and declivity forming rounded blunt angle at junction. Petiole 2.2-2.4 times as high as long, with scale high and wide, $2 \cdot 5-3$ times as wide as thick. Gaster oval.

Forewing length c. $5 \mathrm{~mm}$ (†), 2.5-3.7 mm (ô). Icu 2.0-3.6 (mean $2.51 \pm 0.09, \mathrm{n}=17$ ), varying widely because of variable size of cell mcu which is always small (in terms of area far less than half cell $1+2 \mathrm{r}$ ). Icua $=1 \cdot 2-2 \cdot 2$. Hind wing with cross-vein rs-cu almost straight, comparatively short (clearly shorter than $2 \mathrm{M}+\mathrm{Cu})$.

Measurements in mm. USNM 61417 (ô, holotype): $\mathrm{BL}=3 \cdot 05 ; \mathrm{AL}=1 \cdot 2 ; \mathrm{FWL} \sim 2 \cdot 6$. Other specimens: Males: $\mathrm{BL}=2 \cdot 2-3 \cdot 8 \quad($ average $=2 \cdot 92, \quad$ std $=0 \cdot 330, \quad \mathrm{n}=40) ;$ $\mathrm{AL}=1 \cdot 0-1 \cdot 7 \quad($ average $=1 \cdot 35, \quad$ std $=0 \cdot 166, \quad \mathrm{n}=40) ;$ $\mathrm{HL}=0.44-0.69$ (average $=0.54$, std $0.09, \mathrm{n}=8$ ); $\mathrm{HW}=0.54$ $(\mathrm{n}=1) ; \quad \mathrm{SL}=0.54 \quad(\mathrm{n}=1) ; \quad \mathrm{ED}=0.18-0.24 \quad(\mathrm{n}=4) ;$ $\mathrm{ScL}=0.57-0,87 \quad($ average $=0,67, \quad \mathrm{std}=0.10, \quad \mathrm{n}=7)$; $\mathrm{SctL}=0.27-0,45 \quad(\mathrm{n}=4) ; \mathrm{FWL}=2 \cdot 2-3 \cdot 7 \quad$ (average $=3 \cdot 05$, std $=0356, \mathrm{n}=55)$. Females: $\mathrm{AL}=2.4-3.2$ (average $=2.68$, $\mathrm{std}=0.34, \mathrm{n}=7) ; \mathrm{AW}=1.3-1.6(\mathrm{n}=3) ; \mathrm{ScL}=1.1(\mathrm{n}=1)$; $\mathrm{ScW}=1.3(\mathrm{n}=1) ; \mathrm{PtW}=0.58-0.65(\mathrm{n}=5)$.

Remarks. When describing the holotype forewing (USNM 61417), Cockerell (1915) referred to the very small size of cell mcu as a key diagnostic character. The second studied specimen of this species (USNM 61418), with large mcu, he considered to be probably an individual variation. We found the holotype $\mathrm{Icu}=3 \cdot 1$, Icua $=1 \cdot 7$, and the specimen USNM $61418 \mathrm{Icu}=2 \cdot 1$, Icua $=1 \cdot 6$. Cell $\mathrm{mcu}$ is really variable in size in L. gurnetensis: sometimes it is larger than even in var. $\alpha$, sometimes it is less than in the holotype, and the majority of studied specimens it is of intermediate size.

Male L. gurnetensis is quite variable in size, with the forewing length distribution being bimodal: based on 55 measured wings, we found maximums at $2 \cdot 8-2 \cdot 9 \mathrm{~mm}$ and $3 \cdot 2-3 \cdot 3 \mathrm{~mm}$. It can be excluded that the material represents a mixture of two different species. No discrete differences were revealed to discriminate the composing species. The current taxonomic concept of L. gurnetensis is best left until more knowledge is obtained. 

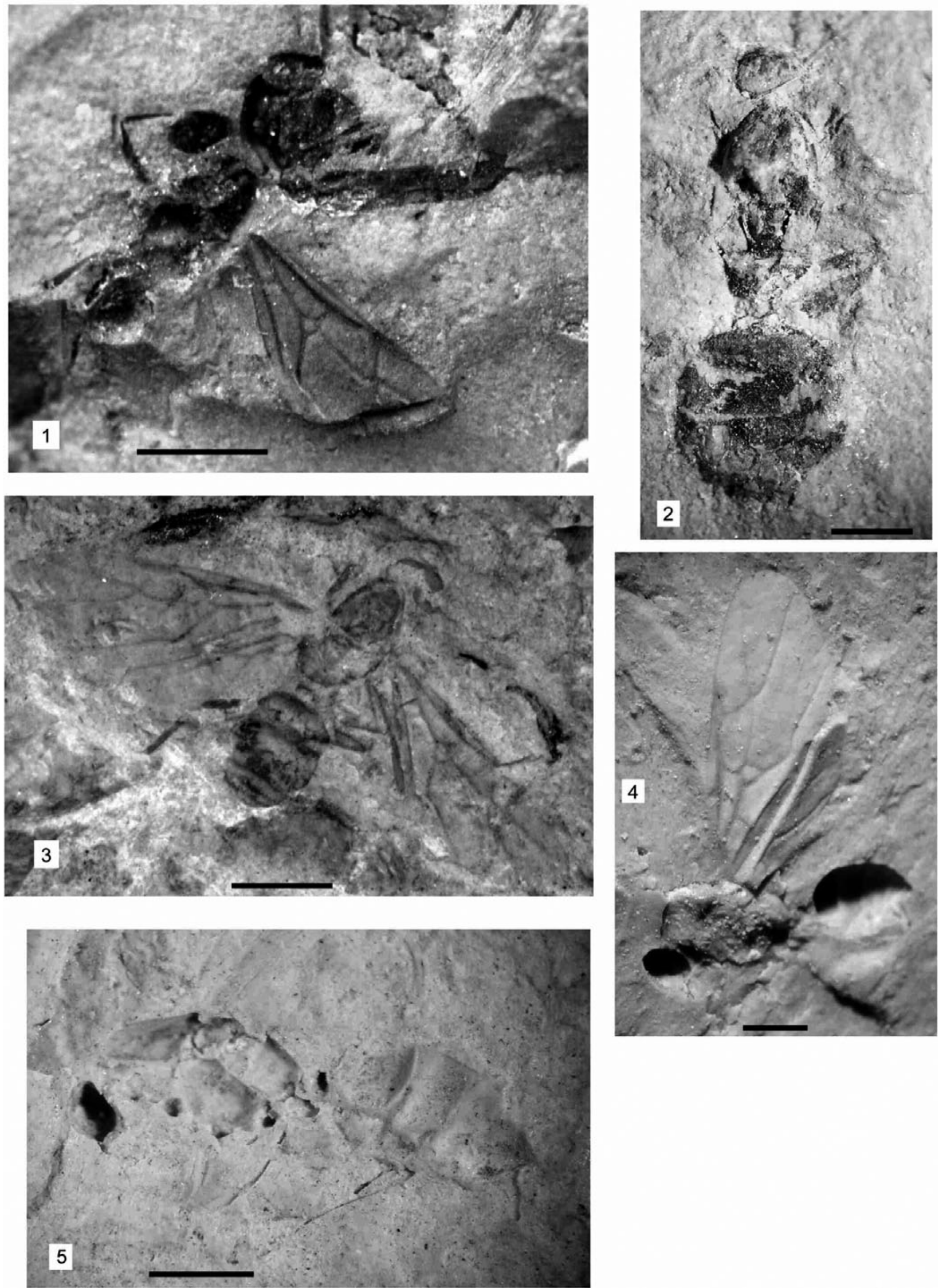

Plate 20 (1-3) Leucotaphus gurnetensis (Cockerell): (1) holotype of Leptothorax gurnetensis Cockerell, USNM 61417; (2) ㅇ, NHMUK I.8733; (3) ô, NHMUK I.9796. (4-5) Leucotaphus donisthorpei Dlussky, sp. nov.: (4) holotype, NHMUK I.8765; (5) paratype, NHMUK I.10097. Scale bars $=1 \mathrm{~mm}$. 


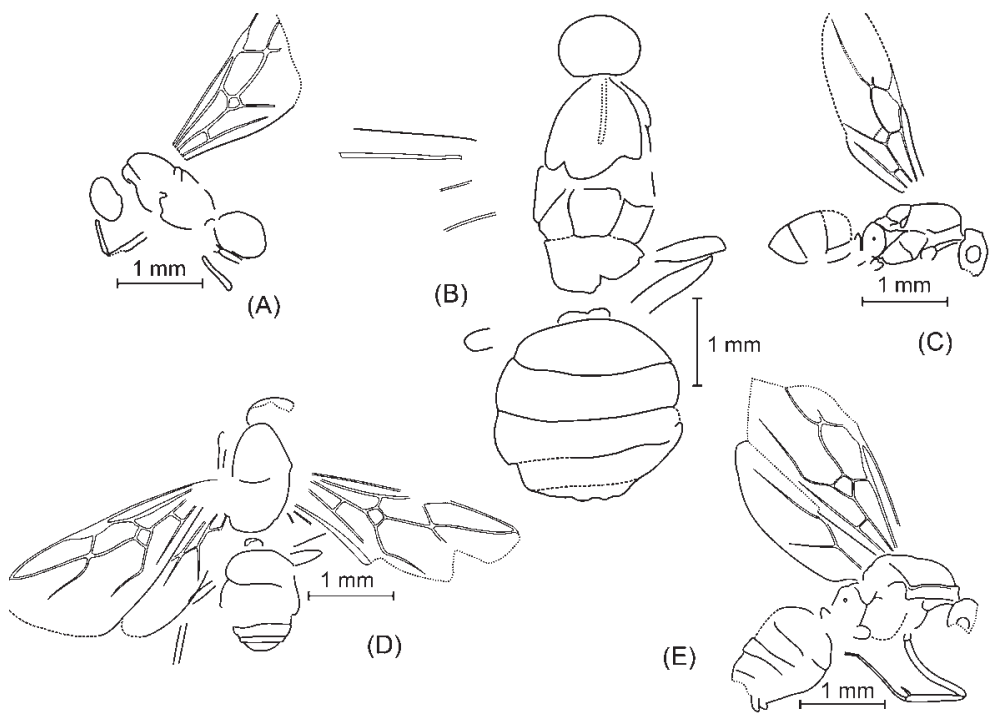

Text-figure 74 Leucotaphus gurnetensis (Cockerell): (A) ô, holotype of Leptothorax gurnetensis Cockerell,

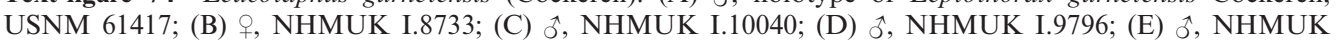
I.9744.

Donisthorpe (1920) listed 116 specimens identified as Leucotaphus gurnetensis. We have found two more specimens labelled and not listed (NHMUK I.9343, NHMUK I.9827), but have failed to locate 24 listed specimens: NHMUK I.7286, NHMUK I.8764, NHMUK NHMUK I.8889, NHMUK I.8927, NHMUK I.9142, NHMUK I.9184, NHMUK I.9246, NHMUK I.9266, NHMUK I.9351, NHMUK I.9356, NHMUK I.9386, NHMUK I.9526, NHMUK I.9593, NHMUK I.9718, NHMUK I.9688, NHMUK I.10005, NHMUK I.10018, NHMUK I.10120, NHMUK I.1026, NHMUK In.17202, NHMUK In.17203, NHMUK In.17298, NHMUK In.19602 (= H.189). As a result, we were able to study 94 specimens identified by Donisthorpe. Most of them were really males of Leucotaphus gurnetensis, but some were found either to be of poor preservation, permitting only identification as Formicidae incertae sedis (NHMUK I.8994, NHMUK I.9281, NHMUK I.9677, NHMUK I.9958, NHMUK I.10265, NHMUK In.24376), or to be misidentified and belonging in fact to Dolichoderus vectensis (NHMUK I.9231), Emplastus gurnetensis sp. (NHMUK I.9082), Camponotus cockerelli (NHMUK In.17066), Leucotaphus donisthorpei (NHMUK I.8678, NHMUK I.8737, NHMUK I.8765, NHMUK I.10097), Oecophylla atavina (NHMUK In.17213), Ponerites crawleyi (NHMUK I.8539, NHMUK I.8684, NHMUK I.8759, NHMUK I.9406, NHMUK I.9774,), Ponerites hooleyi (NHMUK I.9602, NHMUK I.9869), Ponerites antropovi (NHMUK I.9996), Ponerites sp. (NHMUK I.10123) and Taphopone microptera (NHMUK I.9763, NHMUK In.24378).

Wheeler identified specimen NHMUK In.24380 (=H.334) as a worker of Camponotus sp. (Donisthorpe 1920, p. 84). Actually, the constitution of its alitrunk, well developed and with scutum and scutellum separated, clearly specifies the fossil as a wingless female and not a worker. Specimen NHMUK I.8731 is designated by Donisthorpe as the paratype of Leucotaphus cockerelli. As shown above, the holotype of this species is actually a male of Camponotus. The specimen NHMUK I.8731 has the petiolar scale high and narrow, attesting it as a female, with size and body proportions fitting Leucotaphus gurnetensis.

Re-describing the male of Leucotaphus gurnetensis, Donisthorpe $(1920$, p. 90$)$ noted that "there are several larger specimens, which may be the females of this species, this sex being, on that view, larger than the male, as in some of the subgenera of Acanthomyops; some are dealated, others winged. One specimen (NHMUK I.10097) is very perfect, showing well the segments of the thorax and gaster." Actually, this specimen has clearly visible male genitals. It is described below as a paratype of Leucotaphus donisthorpei.

Donisthorpe also described a cocoon and workers of Leucotaphus gurnetensis. Concerning workers he wrote (p. 89): "I have seen some eight workers, nearly all of them being on the same piece of rock as winged specimens. The head is small, the scale distinct, and some parts of the legs are present, but the general outline is not very clear. The length is $2-2.7 \mathrm{~mm}$ ". We have studied four of eight samples listed by him and found no workers. Sample NHMUK I.10248 includes poorly preserved impression of an insect other than an ant, samples NHMUK I.8722 and NHMUK I.9744 include only impressions of male Leucotaphus gurnetensis, and sample NHMUK In.17250 is poorly preserved fragments of Oecophylla sp. In general, ant workers and the more so their cocoons have very low chance of being preserved as rock fossils.

Leucotaphus gurnetensis is the third most abundant species (after two Oecophylla species) in the Bembridge Marls ant assemblage. It comprises $25 \%$ of all ant fossils identified to the species level. This ant is similar to the Recent Lasius Fabricius, 1804 in general appearance, and perhaps really belongs to this genus. However the level of preservation does not allow any sight of key characters that differ Lasius from other genera of Formicinae. It is also very similar to fossil ants described as Lasius from other deposits: L. schiefferdeckeri Mayr, 1868 (Late Eocene Baltic amber), L. peritulus (Cockerell, 1927) (latest Eocene, Florissant, USA), L. epicentrus Théobald, 1937 (Oligocene Aix-en-Provence, France), L. redtenbacheri (Heer, 1849) and others (Miocene, Radoboj, Croatia), L. vetulus Dlussky, 1981 (Vishnevaja Balka, Russia) and others. Like $L$. gurnetensis these ants are numerous in their taphocenoses $(11 \%$ in Baltic amber, 25\% in Florissant, 33\% in Radoboj, 34\% in Vishnevaja Balka).

Leucotaphus donisthorpei Dlussky \& Perfilieva, sp. nov. Plate 20, figs 4-5; Text-fig. 75A, B

Etymology. In honour of Horace St. J. K. Donisthorpe.

Holotype. NHMUK I.8765, Bembridge Marls, NW Isle of Wight, UK, coll. P. B. Brodie, ô (Plate 20, fig. 4; Text-fig. $75 \mathrm{~A})$. 

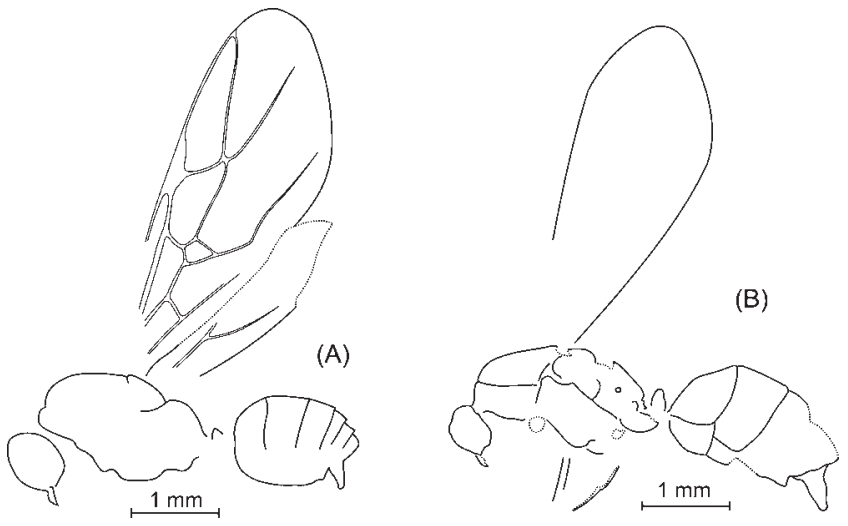

Text-figure 75 Leucotaphus donisthorpei sp. nov.: (A) ڤ̂, holotype, NHMUK I.8765; (B) ڤै, paratype, NHMUK I.10097.

Paratypes. NHMUK: I.8678, I.8750, I.8948, I.10097, Bembridge Marls, NW Isle of Wight, UK, coll. P. B. Brodie; 今ิ ô (Plate 20, fig. 5; Text-fig. 75 B); NHMUK In 25124, Bembridge Marls, NW Isle of Wight, UK, coll. R. W. Hooley; 우 forewing.

Other material. Three males, three male forewings, and two female forewings in NHMUK collection. Bembridge Marls, Isle of Wight, UK.

Diagnosis. Differs from the type species in larger wing size.

Description. Male. BL 4.0-4.5 mm, AL 1.4-2..0 mm, FWL 3.8-4.5 mm. Head small, narrower than alitrunk. Scape longer than head, distinctly surpassing occipital margin. Mandibles well developed, triangular. Alitrunk 1.4-1.6 times as long as high. Scutum in side view rounded in front and flat behind. Propodeum in side view rounded. Petiole higher than long, with thick scale, narrowed upward, with rounded top. Gaster oviform. Genitals strongly exposed, with stipes long, triangular, rounded at apex.

Forewing length $+c .7 .5 \mathrm{~mm}$, o $3.8-4.5 \mathrm{~mm}$, Icu $=1.9$ $2 \cdot 3$, Icua $=1 \cdot 35-1 \cdot 55$. Fore and hind wing venation as in $L$. gurnetensis.

Measurements in mm. NHMUK I.8765 ( $\hat{o}$, holotype): $\mathrm{BL}=4 \cdot 0 ; \mathrm{AL}=1 \cdot 9 ; \mathrm{HL}=0 \cdot 75 ; \mathrm{FWL}=4 \cdot 5$. Other specimens $(\widehat{\jmath} \widehat{o}) ; \mathrm{AL}=1 \cdot 5-2 \cdot 8(\mathrm{n}=6) ; \mathrm{HL}=1 \cdot 1(\mathrm{n}=1) ; \mathrm{FWL}=3.8-$ $4.3(\mathrm{n}=4)$.

Remarks. There are two forewings (NHMUK In.24920 and NHMUK In.25124) with forewing venation characteristic for Leucotaphus, but larger than female forewings of L. gurnetensis. We assume that they belong to females of $L$. donisthorpei. Forewing fragment NHMUK I.9549 may also be a male of that species.

Donisthorpe erroneously identified specimens NHMUK I.8737, NHMUK I.8765, NHMUK I.8678, and NHMUK I.10097 as Leucotaphus gurnetensis, and NHMUK I.8673 as Oecophylla sp.

\section{Genus Oecophylla F. Smith, 1860}

Type species. Formica virescens Fabricius, 1775, a junior synonym of Oecophylla smaragdina (Fabricius, 1775), by subsequent designation of Bingham, 1903.

Other species. There are two extant species of this genus: Oecophylla smaragdina (Fabricius 1775) in the Oriental and Indo-Australian Regions, and O. longinoda (Latreille 1802) in the Afrotropical Region. Fifteen fossil species are described, the most ancient being the Middle Eocene: O. longiceps Dlussky in Dlussky et al., 2008 from Grube Messel, Germany, and O. eckfeldiana Dlussky, in Dlussky et al. 2008 from Eckfeld,
Germany (Dlussky et al., 2008); and the Late Eocene: $O$. brischkei Mayr, 1868 and O. crassinoda Wheeler, $1922(=O$. brevinodis Wheeler, 1915) from the Baltic amber, O. praeclara Foerster (Brunstadt, Germany), O. atavina Cockerell, 1915, O. perdita Cockerell, 1915 and O. megarche Cockerell, 1915, from Bembridge, Isle of Wight, UK and O. bartoniana Cockerell, $1920 \mathrm{~b}$ from the Eocene Bagshot Beds, Bournemouth, UK. Two species are described from European Oligocene deposits: O. superba Théobald, 1937 (Haut-Rhin, France) and O. sicula Emery, 1905 (Sicilian amber). Also, four species are known from Miocene deposits: O. obesa (Heer 1849), O. radobojana (Heer 1849) (Radoboj, Croatia), O. leakeyi Wilson \& Taylor, 1964 (Victoria, Kenya) and O. xiejiaheensis (Hong, 1984) (Shanwang, China). However, the real number of fossil species is less. O. xiejiaheensis is transferred to the morphogenus Camponotites Dlussky, 1981 (Dlussky et al. 2008), and O. perdita is synonymised herein under $O$. atavina. $O$. bartoniana and $O$. praeclara were described from detached forewings, so they may be conspecific with other species known from complete fossils.

Diagnosis (for rock fossils). Size large, head subrectangular with rounded occipital corners; antennae geniculate in both sexes; scape attached at some distance from clypeus; mandibles large, triangular, with sharp teeth on the masticatory margin; petiole elongate, without scale, or nodiform (only at females); gaster without constriction between first and second gastral (III and IV abdominal) segments; forewing with closed cells $1+2 \mathrm{r}, 3 \mathrm{r}$, with no closed $\mathrm{rm}$ and $\mathrm{mcu}$; posterior margin of cell $3 r$ (formed by $\mathrm{RS}$ ) always concave.

Remarks. Both modern species of the genus ("weaver ants") live in the crown of trees of tropical forests and construct nests from leaves, fastened by silk secreted by the larvae. Morphology of Oecophylla agrees with their mode of life. Long legs and antennae allow them to step or jump in the crown from one leaf to another. The original petiole construction is connected with their ability to lift the gaster upwards, providing large maneuverability during leaps (Dlussky 1981b). Large flat mandibles with sharp teeth are adapted to cutting leaves for construction of the nest. The morphological resemblance of extinct and extant species allows confidence to assert that their modes of life also were similar. It proves to be true also from the fossilised nest of $O$. leakeyi in the Miocene deposits of Kenya (Wilson \& Taylor 1964). However, their tropical preference should not be considered as strict, because of their discovery in the European Miocene which had a subtropical to warm temperate rather than a tropical climate.

Oecophylla are the most numerous ants in Bembridge Marls assemblage comprising $69.8 \%$ of all ant fossils identified to the generic level. However, this proportion is obviously overestimated. Firstly, large fossils such as Oecophylla, the largest ant in the assemblage, are better preserved and easier to collect. Secondly, the original shape and structure of these ants, jointly with their large size, helps identification, even from small fragments that are usually not noticed in the case of other ants. When comparing only more complete fossils identifiable to the species level, the proportion of Oecophylla falls to $51 \cdot 8 \%$, and yet remains higher than that of any other ant (Leucotaphus gurnetensis 24.9\%; Emplastus britannicus $10 \%)$.

Cockerell (1915) described three Oecophylla species from the Bembridge Marls: O. atavina, O. perdita and O. megarche. $\mathrm{He}$ distinguished them by using small details of forewing venation, which lie well within the range of intraspecific variability. Donisthorpe (1920) distinguished only O. megarche based on the very large size, and wrote about other species: "They are all smaller than specimens of $O$. megarche. A chart of the measurements allows that they vary in every possible 
$\mathrm{n}$

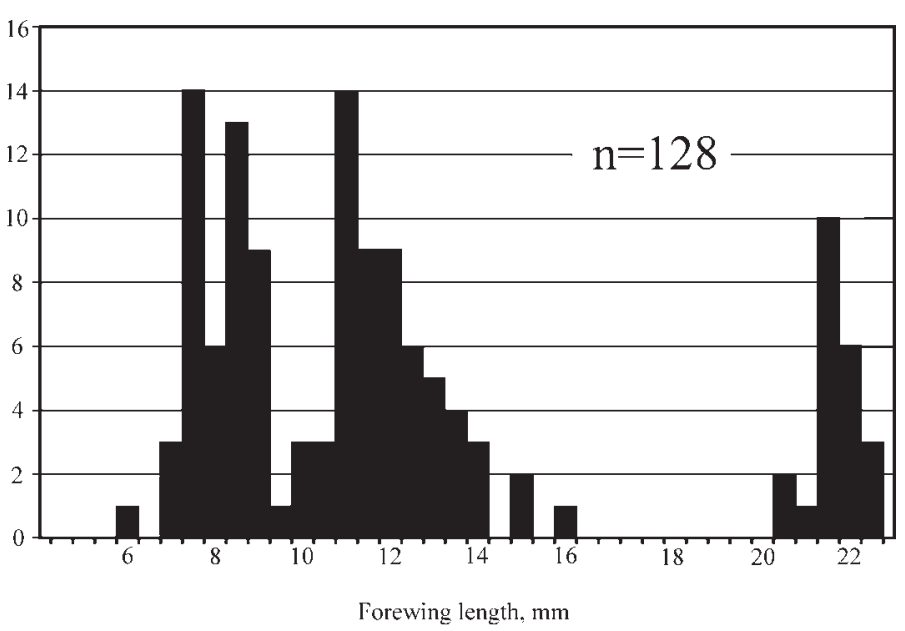

Text-figure 76 Frequency distributions of forewing length classes among Oecophylla.

way - in size, size of wings, and all other measurements. Nor does it appear to me that any good purpose would be served by creating a number of new species, which would probably embrace or overlap Cockerell's $O$. atavina and O. perdita" (p. 92).

Initially we supposed that all Oecophylla fossils belong to one species. However, when we made a diagram of frequency distribution of forewing size, we found it three-modal (Textfig. 76). All specimens can be divided into three distinct clusters: the small ones, with FWL 6.0-9.4 mm, mode $7.5 \mathrm{~mm}$; the medium ones (FWL 9.5-16 mm, mode $11 \mathrm{~mm}$ ); and the large ones (FW 21-23 mm). The ranges of variation are, respectively, $3.5 \mathrm{~mm}$ (47\% of modal wing length), $6.5 \mathrm{~mm}$ $(59 \%)$, and $2.0 \mathrm{~mm}(9 \%)$. The studied samples of living Formicinae (Perfilieva 2005) show variation ranges of forewing length as some $17 \%$ and not above $40 \%$ (in case of polymorphic females). This indicates that the present middle and, less certainly, smaller clusters are probably of a mixed nature.

Small specimens with bodies preserved are mostly males, including $\hat{\sigma}$ holotype of $O$. atavina, $\mathrm{FWL}=7.6 \mathrm{~mm}$ and $\hat{\sigma}$ paratype of $O$. perdita, $\mathrm{FWL}=6.8 \mathrm{~mm}$; except the only female NHMUK In. 24400 with FWL $=8.5 \mathrm{~mm}$. Large fossils, including the holotype of $O$. megarche with $\mathrm{FWL}=23 \mathrm{~mm}$, are mainly represented by isolated wings; except the paratype of O. megarche USNM 61425, which shows additionally a head and a fragment of alitrunk. However there is no doubt that all of them belong to females. In contrast, specimens of the medium group with bodies preserved represent both males and females. Holotype (,$+ \mathrm{FWL}=12.7 \mathrm{~mm}$ ) and one paratype ( $\circ \mathrm{FWL}=11.8 \mathrm{~mm}$ ) of $O$. perdita belong to this group. Standard morphometrtic analysis (see above) of wings $9-17 \mathrm{~mm}$ long for characters discriminating male and female ant wings (Perfilieva 2005) reveals two distinct clusters. This makes it possible to appreciate two species of Oecophylla present in the Bembridge Marls ant assemblage, with the small species (AL 2.0-2.8 mm; FWL 6.0-9.5 mm; क AL 3.5-4.5 mm; FWL $8 \cdot 5-13.7 \mathrm{~mm}$ ) being Oecophylla atavina Cockerell, 1915 (=O. perdita Cockerell, 1915), and the large species (ô AL 4-5.5 mm; FWL 10-15.9 mm; o FWL 20.7-23.0 mm) Oecophylla megarche Cockerell, 1915.

We have identified 195 specimens as O. atavina, and 122 specimens as $O$. megarche. 366 incomplete fossils (fragments of bodies and wings) in the NHMUK collection and 37 in the CAMSM collection are left identified as Oecophylla sp.
Oecophylla atavina Cockerell, 1915

Plate 21, figs 1-5; Text-figs 77, 88A

1915 Oecophylla atavina Cockerell, p. 485, plate 64, fig. 7 (ङ)

1915 Oecophylla perdita Cockerell, pp 485-486, plate 64, figs. 5-6 (우) syn. nov.

1920 Oecophylla megarche Cockerell; Donisthorpe, pp 91-92, (partim, quoad Plate V, fig. 12).

1978 Oecophylla atavina Cockerell; Burnham, p. 114.

1978 Oecophylla perdita Cockerell; Burnham, p. 114.

1995 Oecophylla atavina Cockerell; Bolton, p. 298.

1995 Oecophylla perdita Cockerell; Bolton, p. 298.

2008 Oecophylla atavina Cockerell; Dlussky et al., p. 616

Holotype. USNM 61419, Bembridge Marls, NW Isle of Wight, UK; $\hat{\jmath}$ (Plate 21, figs 1, 2; Text-fig. 77A).

Other material. USNM 61420, + , forewing, holotype of Oecophylla perdita Cockerell (Plate 21, fig. 5; Text-fig. 77B); USNM 61421, + , paratype of Oecophylla perdita Cockerell; USNM 61422 ô, forewing, paratype of Oecophylla perdita Cockerell), coll. Lacoe (Plate 21, fig. 5); 156 males and 29 females in the NHMUK collection and six males in the CAMSM collection, including NHMUK I.8702,, , designated by Donisthorpe (1920) as the plesiotype of $O$. megarche Cockerell (Text-fig. 77D), NHMUK I.8711 ( + , identified by Donisthorpe as $O$. megarche Cockerell, Plate 21, fig. 4; Textfig. 77C), NHMUK I.8768 (Text-fig. 77E), NHMUK I.9143 (Plate 21, fig. 3; Text-fig. 77G) and NHMUK I.9345 (ふో) (Text-fig. 77F). All from Bembridge Marls, Isle of Wight, UK.

Diagnosis. Smaller species: ${ }^{\top} \mathrm{AL} 2 \cdot 0-2.8 \mathrm{~mm}$; FWL $6 \cdot 0$ $9.5 \mathrm{~mm}$; ㅇ AL 3.5-4.5 mm; FWL 8.5-13.7 mm.

Description. Female. BL 8-12 mm, AL 3.5-4.5 mm, FWL 8.5-13.7 mm. Head subtrapezoidal, narrower in front than behind, about as long as wide. Occipital corners rounded, occipital margin feebly convex. Anterior margin of clypeus rounded. Eyes comparative small, oval, situated slightly behind midlength of head sides; maximum eye diameter about $0 \cdot 3$ head length. Mandibles large, triangular with large sharp teeth. Scape protrudes far beyond the occipital margin of the head, about twice as long as head. Alitrunk massive, a little wider than head. Scutum wider than long (in NHMUK I.8527, ScW/ScL $=1 \cdot 2$ ), flat above, rounded anteriorly, overhanging pronotum in dorsal view. Propodeum feebly convex in 

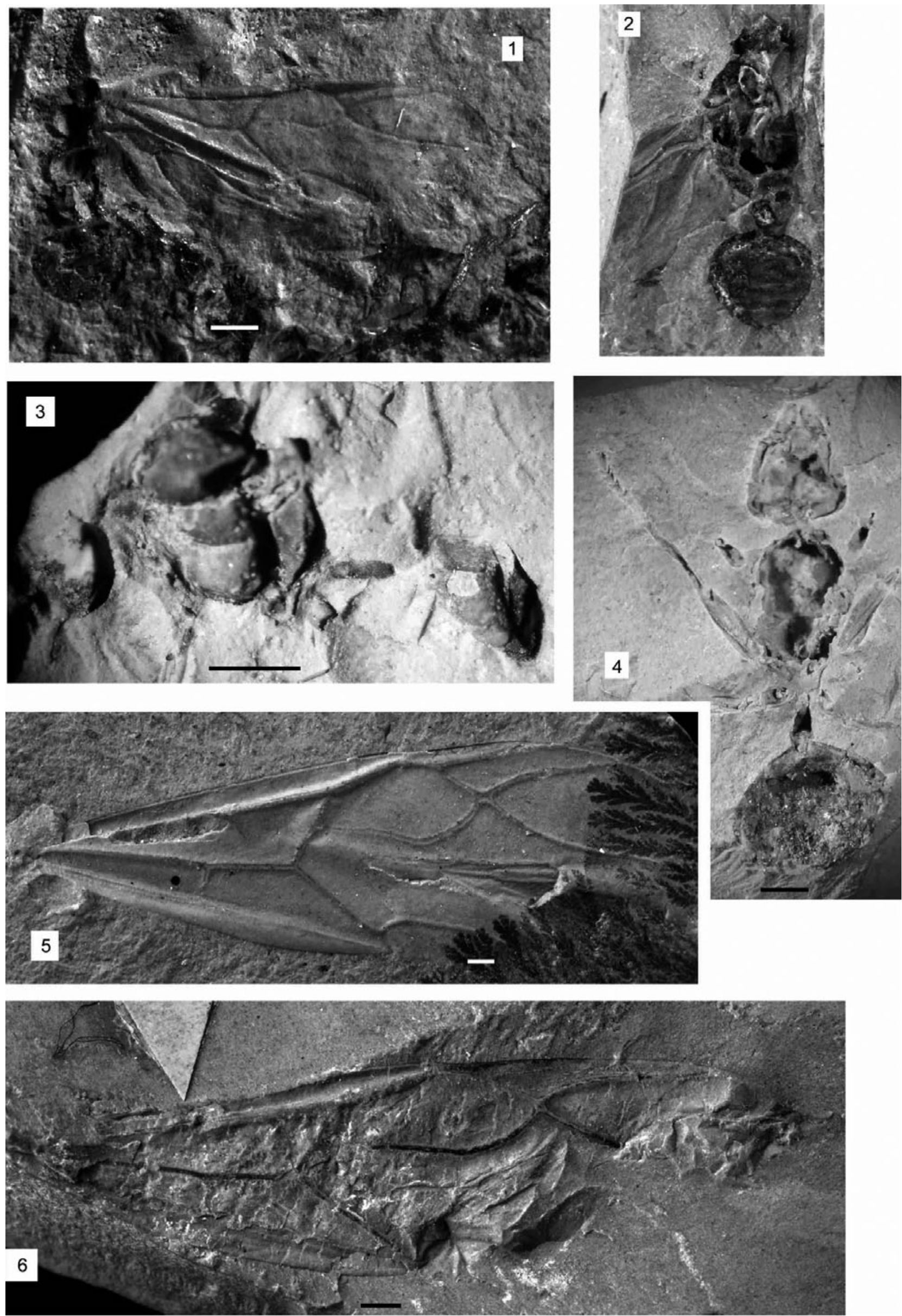

Plate 21 (1-5) Oecophylla atavina Cockerell: (1-2) holotype, USNM 61419 (part and counterpart); (3) ô, NHMUK I.9143; (4) +, NHMUK I.8711; (5) holotype of Oecophylla perdita Cockerell, USNM 61420. (6) Oecophylla megarche Cockerell, holotype, USNM 61423. Scale bars $=1 \mathrm{~mm}$. 

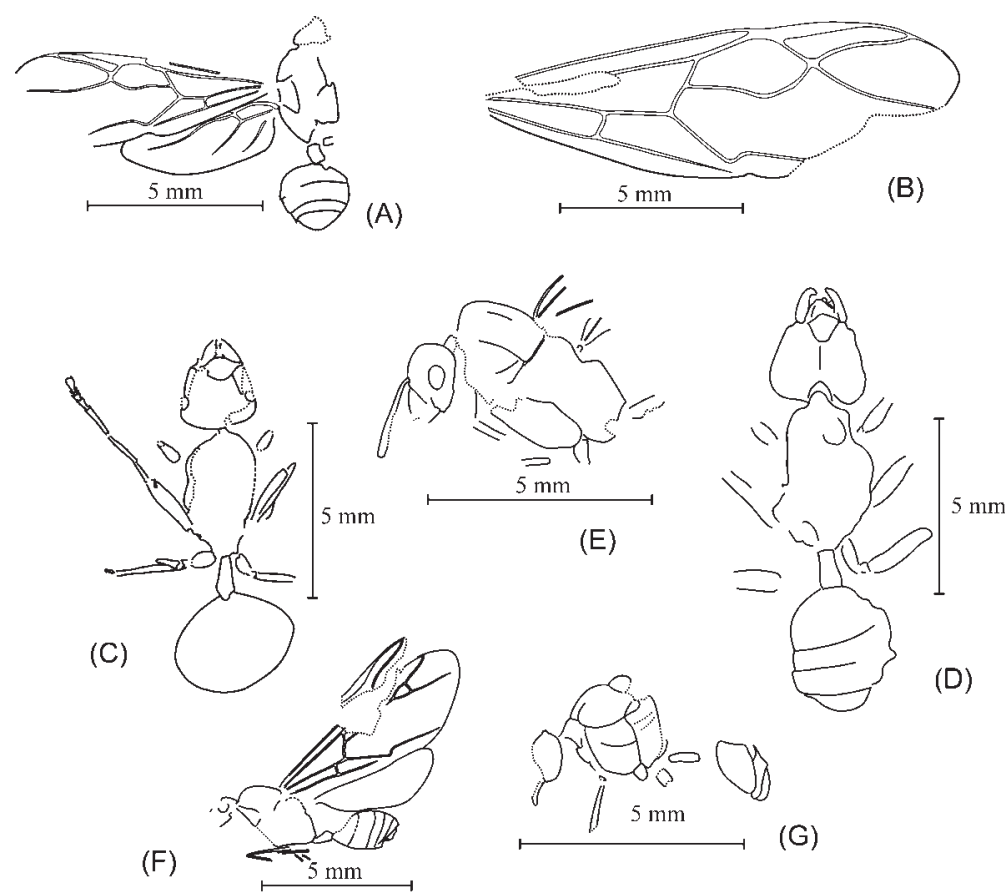

Text-figure 77 Oecophylla atavina Cockerell: (A) ô, holotype, USNM 61419; (B) forewing, holotype of Oecophylla perdita Cockerell, USNM 61420; (C) + , NHMUK I.8711; (D) + , NHMUK I.8702; (E) + , NHMUK I.8968; (F) §̊, NHMUK I.9345; (G) §ે, NHMUK I.9143.

side view. Legs rather short and thick; hind femur shorter than alitrunk. Petiole without scale or node, narrowed anteriorly, twice as long as wide and high. Gaster oval.

Male. BL 5-6.3 mm, AL 2.0-2.8 mm, FWL 6-9.5 mm. Head comparatively small, considerably narrower than alitrunk. Eyes convex. Alitrunk short and high (in NHMUK I.9143, 1.2 times as long as high). Scutum convex, a little longer than wide. Propodeum feebly convex or straight in side view. Legs rather long and thin. Petiole without scale or node, narrowed anteriorly, 2.5-3 times as long as wide and high. Gaster oviform, narrowed behind. Posterior margin of subgenital plate uniformly concave. Genitals small, poorly exposed from gaster. Genital stipes with rounded apex, about 1.5 times as long as wide.

Forewing 1RS proclined, forming acute angle with R, 2r-rs proclined. Cell $3 \mathrm{r}$ comparatively narrow, $5 \mathrm{RS}$ bent into $3 \mathrm{r}$. Section $2-3 R S$ (delimiting cell $1+2$ r from below) bent. $3 \mathrm{Cu}$ convex. Hind wing with two longitudinal veins RS and $\mathrm{Cu}$. 1RS distinct, short. Section rs-cu concave, much longer than $2 \mathrm{M}+\mathrm{Cu}$. Cross-vein cu-a about as long as rs-cu, placed near it.

Measurements in mm. USNM 61419 ( $\hat{o}$, holotype): $\mathrm{BL}=5 \cdot 9 ; \mathrm{AL}=2 \cdot 7 ; \mathrm{FWL}=7 \cdot 6$. USNM 61420 ( + , holotype of $O$. perdita): $\mathrm{FWL}=12 \cdot 7$. USNM 61421 ( + , paratype of $O$. perdita): $\mathrm{FWL}=11 \cdot 8$. USNM 61422 ( $\hat{O}$, paratype of $O$. perdita): $\mathrm{HW}=0 \cdot 90 . \mathrm{SL}=0 \cdot 94 . \mathrm{FWL}=6 \cdot 8$. Other specimens: Males: $\mathrm{BL}=5.0-6.3 \quad$ (average $=5.61, \quad$ std $=0.46, \quad \mathrm{n}=16$ ). $\mathrm{AL}=2.0-2.8($ average $=2.44, \mathrm{std}=0.35, \mathrm{n}=11) . \mathrm{PtL}=0.6-$ $0.75(\mathrm{n}=3) . \mathrm{FWL}=6 \cdot 0-9.4 \quad$ (average $=7.66 . \mathrm{std}=0.723$, $\mathrm{n}=81) . \quad$ Females: $\mathrm{BL}=8.2-12.1 \quad(\mathrm{n}=20) . \quad \mathrm{AL}=2.6-4.6$ (average $=4.0, \quad$ std $=0.69, \quad \mathrm{n}=8) . \quad \mathrm{HL}=1.5-2.8 \quad(\mathrm{n}=5)$. $H W=2.8(n=1) . S L=1.9(n=1) . \quad E D=0.4-0.5 \quad(n=2)$. $\mathrm{PtL}=0.9-1.1 \quad(\mathrm{n}=4) . \quad \mathrm{FWL}=10 \cdot 0-15 \cdot 9 \quad($ average $=11 \cdot 72$, $\mathrm{std}=1.408, \mathrm{n}=22)$.

Remarks. Donisthorpe (1920) identified the wingless females NHMUK I.8702 and NHMUK I.8711 as O. megarche, and even designated the former a plesiotype and represented it on PI.V. fig. 12. However, their size (AL 4.6 and $3.7 \mathrm{~mm}$, respectively) indicates their FWL is not above $13 \mathrm{~mm}$, well below the range of $O$. megarche.
Oecophylla megarche Cockerell, 1915

Plate 21, fig. 6; Text-fig. 78A-E

1915 Oecophylla megarche Cockerell, p. 486, plate 65, figs. 1-3. 1920 Oecophylla megarche Cockerell; Donisthorpe, pp 91-92 (part., quoad fig. 11).

1978 Oecophylla megarche Cockerell; Burnham, p. 114.

1995 Oecophylla megarche Cockerell; Bolton, p. 298.

Holotype. USNM 61423, Bembridge Marls, NW Isle of Wight, UK, coll. Lacoe); 9 forewing (Plate 21, fig. 6; Textfig. 78A).

Paratypes. USNM 61424, Bembridge Marls, NW Isle of Wight, UK; hind wing of 9 ; USNM 61425, Bembridge Marls, NW Isle of Wight, UK, coll. Lacoe; क (Text-fig. 78B).

Other material. 46 males and 68 females in the NHMUK collection and on male and four females in the CAMSM collection, including: NHMUK I.8729 (Text-fig. 78D); NHMUK In.24391 (Text-fig. 78C); NHMUK In.24909 (Text-fig. 78E). All from Bembridge Marls, Isle of Wight, UK,

Diagnosis. Bigger species: ô AL 4-5.5 mm, FWL 10-15.9 $\mathrm{mm}$, o FWL 20.7-23.0 mm.

Description. Male. AL 4-5.5 mm, FWL 10-16 mm. Similar to $O$. atavina, except for larger size, shorter petiole and longer genital stipes. Scutum a little longer than wide (1.1 times as long as wide in NHMUK I.8670). Petiole 1.8-2.1 times longer than wide. Genital stipes twice as long as wide.

Female. FWL 20-24 mm. Based on proportions of $O$. atavina and living $O$. smaragdina, apparently $\mathrm{AL} \mathrm{c.} 6 \mathrm{~mm}$, $\mathrm{BL}>15 \mathrm{~mm}$. The only known head about as long as wide and c. 3.5 times as long as maximum eye diameter (paratype USNM 61425, Text-fig. 37).

Wing venation of fore and hind wings as in $O$. atavina.

Measurements in mm. USNM 61423 ( + , holotype): $\mathrm{FWL}=20.7$. USNM 61424 ( + , paratype): hind wing 16.8 . USNM 61425 (ㅇ, paratype): HW =3·2. NHMUK I.8703

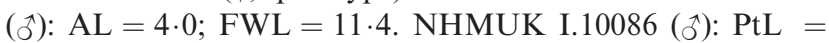
1.3. Other specimens: 命: $\mathrm{FWL}=10 \cdot 0-15 \cdot 9$ (average $=$ $11 \cdot 74$, std $=1 \cdot 408, \mathrm{n}=40$ ). 우: $\mathrm{FWL}=20 \cdot 7-23 \cdot 0$ (average $=$ $21 \cdot 94, \operatorname{std}=0 \cdot 767, \mathrm{n}=25$ ). 

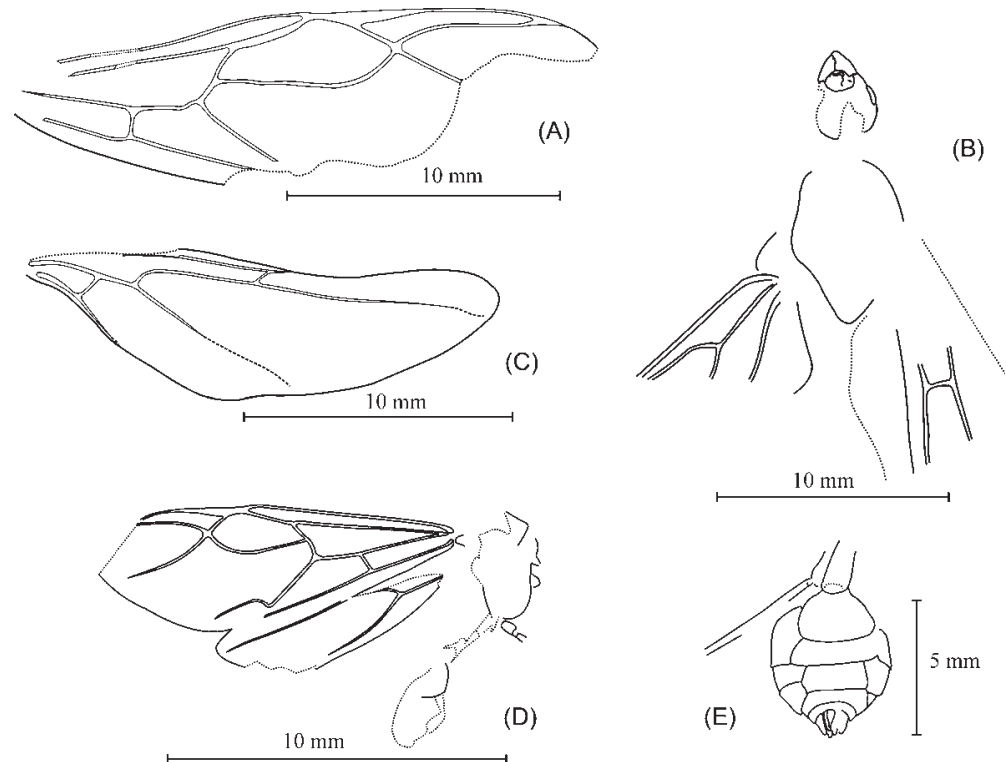

Text-figure 78 Oecophylla megarche Cockerell: (A) $\uparrow$ forewing, holotype, USNM 61423; (B) $\uparrow$, paratype, USNM 61425; (C) hind wing of 9 , NHMUK In.24391; (D) s, NHMUK I.8729; (E) gaster of of from above, NHMUK In.24909.

\subsubsection{Subfamily Ponerinae Lepeletier, 1836}

Morphogenus Ponerites Dlussky \& Rasnitsyn, 2002

Type species. Ponerites eocenicus Dlussky \& Rasnitsyn, 2002 , by original designation.

Other species. P. coloradensis Dlussky \& Rasnitsyn, 2002 and $P$. hypoponeroides Dlussky \& Rasnitsyn, 2002 from the Green River Formation, Middle Eocene of USA (Dlussky \& Rasnitsyn 2002), P. umbrus (Popov 1932) from the Middle Miocene of North Caucasus, and P. crawleyi (Donisthorpe, 1920) and two new species from the Bembridge Marls described below. Some European Miocene and Oligocene ants described as Ponera also apparently deserve placement here.

Diagnosis. Fossil ants not well enough preserved to fit orthotaxa, and with following combination of traits: size small to medium, head subrectangular with rounded occipital corners; eyes comparatively small, situated before midlength of head sides; mandibles triangular with denticulate masticatory margin; promesonotal and mesopropodeal sutures present in workers; sculpture conspicuous, head, alitrunk and waist with no denticles or spines; petiole with thick scale; gaster with constriction between first and second segments of gaster (III and IV abdominal segments); second gastral tergite and sternite subequal, apex of the gaster not directed downwards; sting well developed. Forewing with closed cells $1+2 \mathrm{r}, 3 \mathrm{r}$, rm and mcu; cross-vein cu-a sutated near mcu, so usually Icu $<1.45$ and Icu $<1.2$.

Remarks. Key traits used to distinguish extant genera of the tribe Ponerini (shape of ventral petiolar lobe, dentition of mandibular masticatory margin, number of spurs of middle and hind tibiae) are not visible in most rock fossils of small, nonspecialised Ponerinae. Taylor (1964) designated these fossils as "Ponera (?)", and the informal name "Ponerites" was later coined for them (Dlussky 1981a). Later Dlussky \& Rasnitsyn (2002) proposed to use the latter name as valid for a morphogenus with the above diagnosis.

The extant genera Ponera Latreille, 1804, Hypoponera Santschi, 1938 and, partially, Pachycondyla F. Smith, 1858 and perhaps some other ponerine genera agree with the diagnosis of Ponerites.
Ponerites crawleyi (Donisthorpe, 1920), comb. nov. Plate 22, fig. 1; Text-fig. 79A-E

1920 Euponera (Mesoponera) crawley Donisthorpe, p. 85, plate V. fig. 3.

1978 Euponera (Mesoponera) crawley Donisthorpe: Burnham, p. 109.

1995 Pachycondyla crawleyi (Donisthorpe): Bolton, p. 304.

Holotype. NHMUK I.8675/I.8539 print and conterprint, Bembridge Marls, NW Isle of Wight, UK, coll. P. B. Brodie; q (Plate 22, fig. 1, Text-fig. 79A, B)

Other material. Three females and three males in the NHMUK collection, including NHMUK I.8759 (ㅇ) (Textfig. 79C), NHMUK I.9406 (ô) (Text-fig. 79E) and NHMUK I.9774, coll. P. B. Brodie; ô (Text-fig. 79D); all from Bembridge Marls, Isle of Wight, UK.

Description. Female. BL c. $4 \mathrm{~mm}$, AL c. $1.5 \mathrm{~mm}$. Head elongate, longer than wide, with parallel sides, rounded occipital corners, and feebly concave occipital margin. Eyes oval, strongly displaced forward, length of cheek less than scape diameter. Scape reaching occipital margin or perhaps slightly protruding beyond it. Mandibles well developed, triangular, with numerous small teeth on masticatory margin. Scutum feebly convex, not overhanging pronotum anteriorly. Scutum and scutellum separated with distinct impression in side view. Mesopleural suture well developed. Propodeum angulated in side view with dorsum somewhat shorter than declivity. Petiole 1.6-1.7 times as high as long, with high scale, in side view, with almost parallel anterior and posterior surfaces and smoothly rounded top. Rear part of petiole with ventral rounded lobe. No spurs preserved with fragments of middle and hind tibiae as preserved in holotype. Tubular articulation between first and second gastral segments well developed (preserved in specimens NHMUK I.8539 and NHMUK I.8759). First gastral segment higher than long. Sting short and sharp. Preserved organic integument of alitrunk and gaster with very fine shagreened sculpture.

Male. BL 3-3.5 mm. Eyes of moderate size, oval, displaced a little forward. Antenna filiform, long, deflexed back reaching 

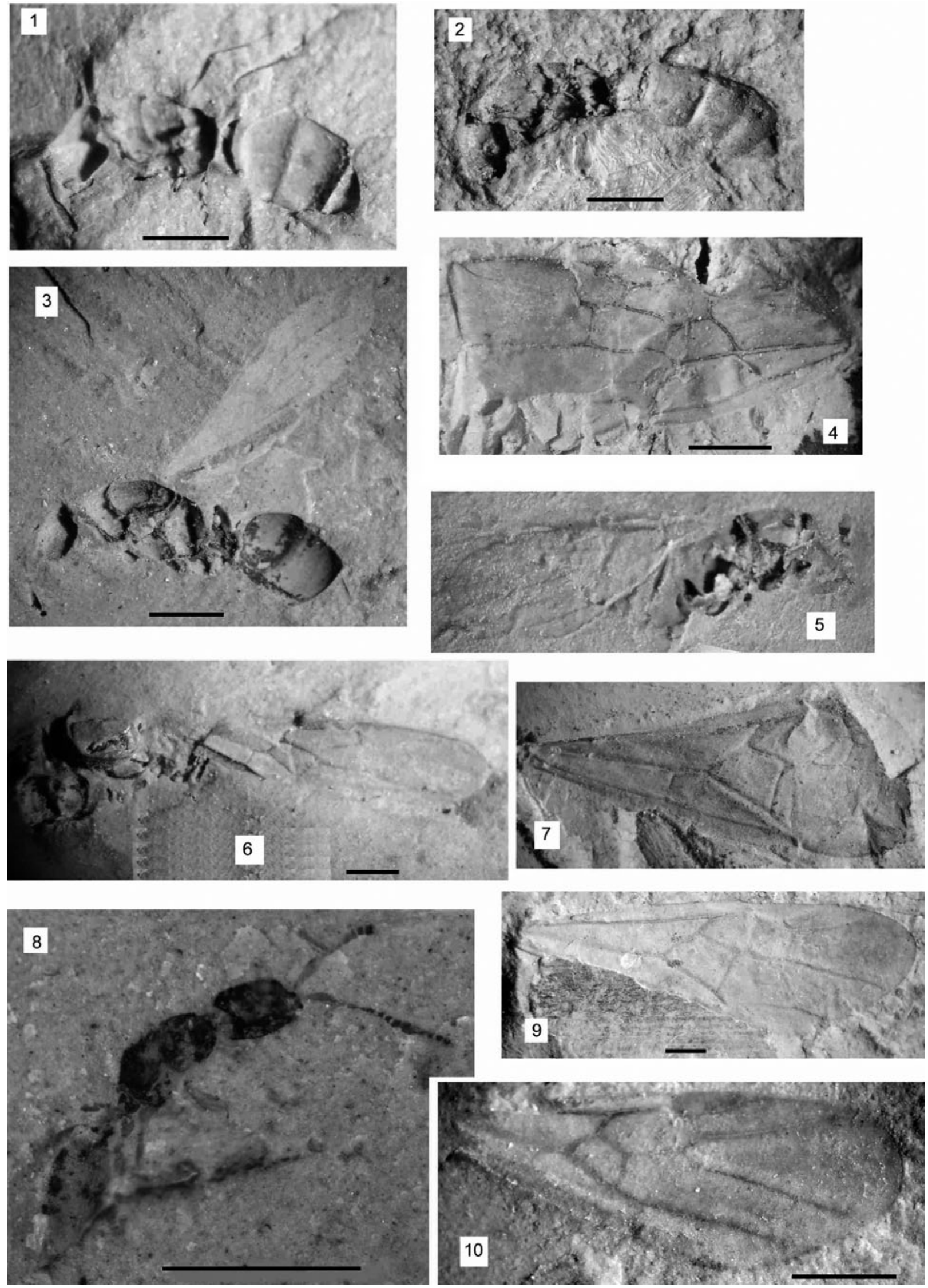

Plate 22 (1) Ponerites crawleyi (Donisthorpe), comb. nov., holotype (Euponera crawleyi Donisthorpe), NHMUK I.8675. (2) Ponerites antropovi Dlussky, sp. nov., holotype, NHMUK I.9996. (3) Ponerites hooleyi Dlussky \& Perfilieva sp. nov., holotype, NHMUK In.24971. (4-5) Taphopone macroptera Perfilieva,1 sp. nov.: (4) holotype, NHMUK I.9494; (5) paratype, NHMUK In.24378. (6) Taphopone petrosa Perfilieva, sp. nov., holotype, NHMUK In.24369. (7) Taphopone aberrans Perfilieva, sp. nov., paratype, NHMUK In.24910. (8) Solenopsites rossi Dlussky, sp. nov., holotype, NHMUK I.9968. (9) Taphopone aberrans Perfilieva, sp. nov., holotype, NHMUK In.24917. (10) Paraphaenogaster hooleyana Perfilieva, sp. nov., holotype, NHMUK In.24963. Scale bars $=1 \mathrm{~mm}$. 


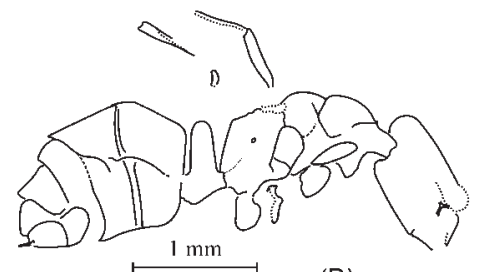

(B)

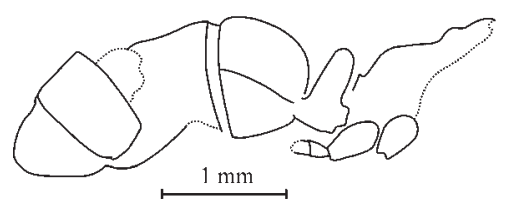

(C)

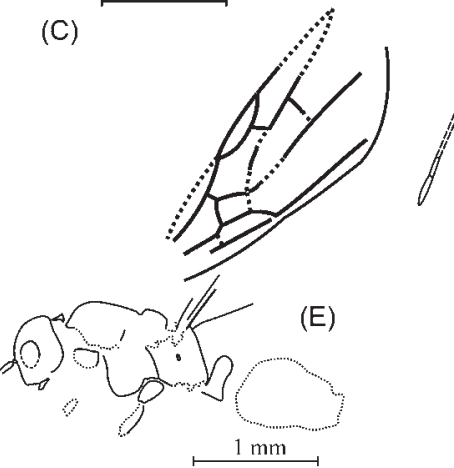

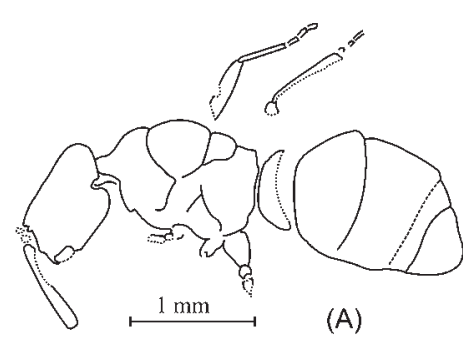

(A)<smiles>C1CC1</smiles>

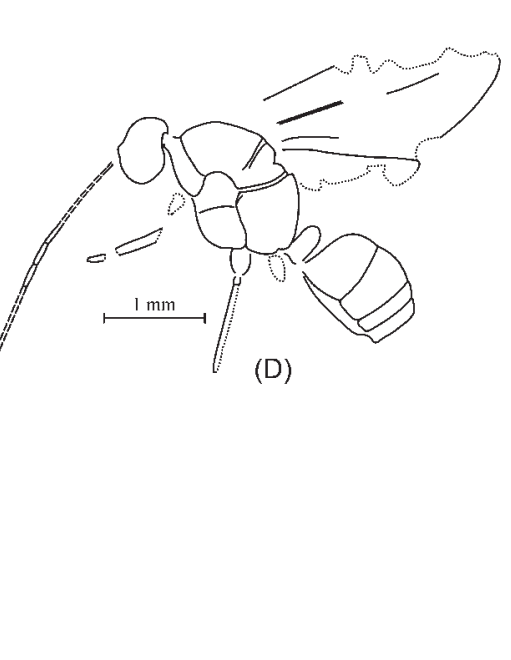

Text-figure 79 Ponerites crawleyi (Donisthorpe): (A) + , holotype of Euponera crawleyi Donisthorpe, NHMUK I.8675; (B) counterprint of the same specimen, identified by Donisthorpe as Leucotaphus gurnetensis (Cockerell);

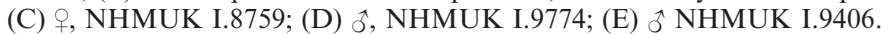

middle of gaster. Scape very short, flagellomeres elongate, four times as long as thick in middle of flagellum. In side view, scutum uniformly convex, propodeum gradually rounded. Propodeal spiracles small, oval. Legs rather long and thin. Petiole with high scale, in side view, with almost parallel anterior and posterior surfaces and smoothly round top. Constriction between first and second gastral segments poorly expressed.

Forewing (known only for males) with closed cells $1+2 \mathrm{r}$, rm, mcu (specimen NHMUK I.9406), and supposedly 3r. $1 \mathrm{RS}$ perpendicular to R. 1M more than twice as long as $1 \mathrm{RS}$. Cross-vein $2 \mathrm{r}-\mathrm{rs}$ slightly proclined, $\mathrm{rs}-\mathrm{m}$ more distal than $2 \mathrm{r}$ rs, a little distal comparing level of pterostigmal apex. Cell rm triangular, not pedunculate. Cell mcu of medium size, rhomboid, reaching level of pterostigmal base. Cross-vein $\mathrm{cu}-\mathrm{a}$ joining $1 \mathrm{M}+\mathrm{Cu}$ near $\mathrm{mcu}$. Icu $=1 \cdot 25-1.3$, Icua $=1 \cdot 1$.

Measurements in mm. NHMUK I.8675 ( + , holotype): $\mathrm{BL}=3 \cdot 6 ; \quad \mathrm{AL}=1 \cdot 5 ; \quad \mathrm{HL}=0 \cdot 9 ; \quad \mathrm{SL}=0 \cdot 75 ; \quad \mathrm{ScL}=0 \cdot 5 ;$ $\mathrm{SctL}=0.23 ; \mathrm{PtL}=0.31 ; \mathrm{PtH}=0.60$. NHMUK I.8759 (क): $\mathrm{PtL}=0.39 ; \mathrm{PtH}=0.69$. NHMUK I.9774 (今) $: \mathrm{AL}=1.6$; $\mathrm{ScL}=0.7 ; \quad$ AntL $=2.7 ; \quad \mathrm{PtH}=0.4$. NHMUK I.9406 (ふ̋): $\mathrm{AL}=1 \cdot 3 ; \mathrm{HL}=0 \cdot 55 ; \mathrm{FWL}=2 \cdot 9 ; \mathrm{PtH}=0 \cdot 34$.

Remarks. Donisthorpe (1920) misidentified specimens NHMUK I.8539, NHMUK I.8684, NHMUK I.8759, NHMUK I.9406 and NHMUK I.9774 as Leucotaphus gurnetensis. Constriction between first and second gastral segments, the key character of Ponerinae, is clearly visible on specimens NHMUK I.8539, NHMUK I.8759 and NHMUK I.9774. Furthermore, NHMUK I.8539 represents a counterpart of NHMUK I.8675, the holotype of Euponera crawleyi. Forewings of NHMUK I.9406 show cross-vein cu-a near cell mcu $(\mathrm{Icu}=1 \cdot 3$; Icua $=1 \cdot 1)$, which is equally a key character of Ponerinae. Male NHMUK I.9774 has filiform antennae unlike males of Leucotaphus, which have geniculate antennae.

Unfortunately there is no diagnostic character discriminating Ponera, Hypoponera or Pachycondyla (= Euponera) (tibial spur formula, ventral lobe of petiole, dentation of mandibles etc.) preserved in the material available, thus forcing us to refer this species to the morphogenus Ponerites.

\section{Ponerites antropovi Dlussky \& Perfilieva, sp. nov.} Plate 22, fig. 2; Text-fig. 80

Etymology. After Alexander V. Antropov who was the first to identify this ant as Ponerinae.

Holotype. NHMUK I.9996, Bembridge Marls, NW Isle of Wight, UK, coll. P. B. Brodie; + (Plate 19, fig. 22; Text-fig. 80).

Diagnosis. Differs from P. crawleyi and P. hooleyi in position of eyes near the middle of head sides, propodeum rounded in side view, scale with fore-surface feebly convex, and in elongated first gastral segment.

Description. Female. BL $4.5 \mathrm{~mm}$. Eyes round, situated near the middle of head sides. Scutum feebly convex, not overhanging pronotum anteriorly. Scutellum feebly convex. Propodeum rounded in side view. Petiole with high scale, fore-surface of scale feebly convex, back surface feebly concave, top rounded. Gaster with distinct constriction between first and second segments showing well preserved tubular rings, first gastral segment a little longer than high.

Male unknown.

Measurements of holotype in mm. $\mathrm{AL}=1.65 ; \mathrm{HL}=1.0$; $\mathrm{ED}=0 \cdot 25$.

Remarks. Donisthorpe misidentified the holotype as Leucotaphus gurnetensis. During preliminary study of the material, Dr Alexander Antropov correctly identified it as Ponerinae. The new species is attributed to the morphogenus Ponerites because the diagnostic characters of the genera Ponera, Hypoponera or Pachycondyla (=Euponera) (tibial spur formula, ventral lobe of petiole, dentation of mandibles etc.) cannot be seen in the current material. 


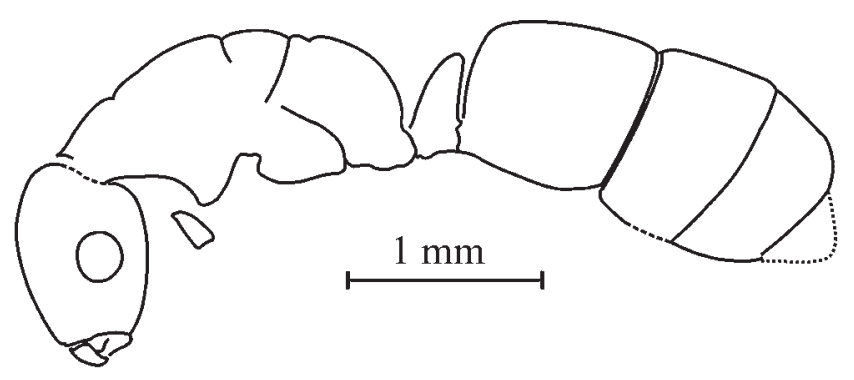

Text-figure 80 Ponerites antropovi Dlussky, sp. nov., + , holotype, NHMUK I.9996.

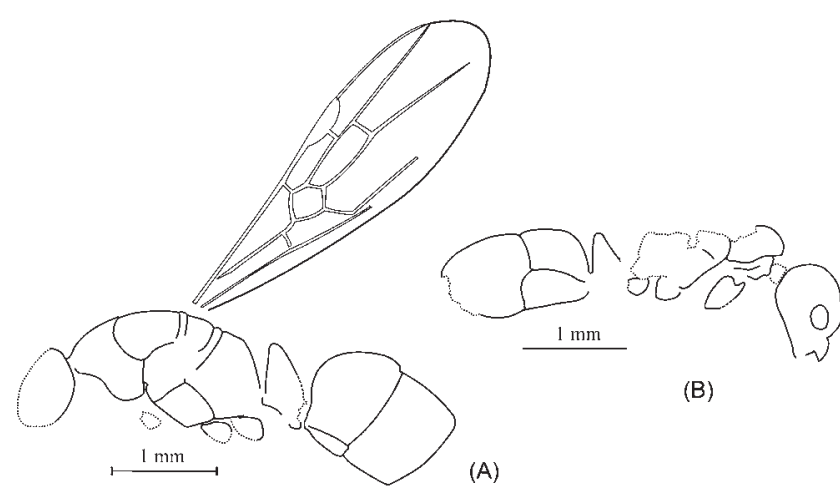

Text-figure 81 Ponerites hooleyi Dlussky et Perfilieva, sp. nov.: (A) $\uparrow$, holotype, NHMUK In.24971; (B) + , paratype, NHMUK I.9869.

Ponerites hooleyi Dlussky \& Perfilieva sp. nov. Plate 22, fig. 3; Text-fig. 81A, B.

Etymology. In honour of R. W. Hooley, collector of the type specimen.

Holotype. NHMUK In.24971, Bembridge Marls, NW Isle of Wight, UK, coll. R. W. Hooley; $q$ (Plate 22, fig. 3; Textfig. 81A).

Paratypes. NHMUK I.9602 (ふ઼),NHMUK I.9869 (ㅇ) (Text-fig. 81B); both from Bembridge Marls, NW Isle of Wight, UK, coll. P. B. Brodie.

Diagnosis. Differs from $P$. crawleyi by high scale, in side view, clearly narrowed upwards with a narrowly round top; in propodeum angulate, in side view, eyes displaced forward; differs from $P$. antropovi by the above position of eyes and short first segment of the gaster.

Description. Female. BL about 4-5 mm. Eyes oval, displaced forward; length of cheek similar to maximal diameter of eye. Scutum rather small, feebly convex, not over-hanging pronotum anteriorly. Scutellum feebly convex. Mesopleural suture well developed. Propodeum in side view angulated; propodeal dorsum much shorter than propodeal declivity. Petiole more high than long, with high scale, in side view clearly narrowed upwards with the narrowly round top. Gaster with distinct constriction between first and second segments. First segment of the gaster higher than long.

Male. BL about $3 \mathrm{~mm}$. Head absent in both paratypes. Scutum and scutellum are feebly convex. Propodeum rounded in side view. Petiole in side view triangulate, with rounded top. Gaster with weak constriction between first and second segments.

Forewing. 1RS and 2r-rs perpendicular to R. Cell $3 \mathrm{r}$ comparatively long, more than four times as long as wide, its apex touching wing margin. Cell rm quadrangular. Cross-vein rs-m far distal in respect of $2 \mathrm{r}-\mathrm{rs}$, but not distal of level of pterostigmal apex. Cell mcu pentagonal, in terms of area more than half as large as $1+2$ r. $2 \mathrm{M}$ and $\mathrm{RS}+\mathrm{M}$ of subequal length. Cell mou not reaching level of pterostigmal base. $1 \mathrm{M}$ more than twice as long as $1 \mathrm{RS}$. Cross-vein $\mathrm{cu}-\mathrm{a}$ meeting $1 \mathrm{M}+\mathrm{Cu}$ near mcu. Icu $=1 \cdot 4$, Icua $=1 \cdot 13$.

Measurements in mm. NHMUK In.24971 ( $\odot$, holotype): $\mathrm{AL}=1.9 ; \quad \mathrm{FWL}=3 \cdot 75$. NHMUK I.9859 (क, paratype): $\mathrm{AL}=1 \cdot 5 ; \mathrm{HL}=0 \cdot 9 ; \mathrm{ED}=0 \cdot 23$. NHMUK I.9602 (ô, paratype): $\mathrm{BL}=3 \cdot 1, \mathrm{AL}=1 \cdot 25$. NHMUK In.24378 (今ึ, paratype): $\mathrm{AL}=1 \cdot 5, \mathrm{FWL}=3 \cdot 0$.

Remarks. Donisthorpe (1920) identified specimens NHMUK I.9602, NHMUK I.9869, and NHMUK In.24378 as Leucotaphus gurnetensis. However, the presence of a constriction between the first and second segments of NHMUK I.9602 and NHMUK I.9869 and the presence of closed cell rm and position of cross-vein cu-a on forewing of NHMUK In.24378 indicate these ants belong to subfamily Ponerinae.

As no diagnostic characters separating the genera Ponera, Hypoponera or Pachycondyla (tibial spur formula, ventral lobe of petiole, dentation of mandibles etc.) can be seen on impressions, we include this species in the morphogenus Ponerites.

Morphogenus Taphopone Dlussky \& Perfilieva, gen. nov.

Etymology. From Greek taphos for grave and genus Ponera. Gender feminine.

Types species. "Ponerites" karaganensis Dlussky, 1981, Miocene, Vishnevaya Balka, Stauropol reg., Russia.

Other species. Attributed with confidence to this morphogenus are Taphopone karaganensis (Dlussky, 1981), comb. nov. (= "Ponerites" karaganensis) and Taphopone stauropolitana (Dlussky, 1981), comb. nov. (= "Ponerites" stauropolitanus) from the Miocene of Stavropol region (Russia) and four species described below. Most likely, some other species from other Miocene deposits of Europe, described in genera Ponera Latreille, 1804 and Poneropsis Heer, 1867 and included in the morphogenus Poneropsis Heer, 1867 by Taylor (1964), may also deserve transfer to this genus.

Diagnosis. Isolated ant forewings with closed cells $1+2 \mathrm{r}, 3 \mathrm{r}$, $\mathrm{rm}$ and $\mathrm{mcu}$, and with distal position of cross-vein $\mathrm{cu}-\mathrm{a}$ (usually with Icu $<1.4$ ). Cross-vein $1 \mathrm{r}-\mathrm{rs}$ (subdividing cell $1+2 \mathrm{r}$ on two separated cells), or its rudiment, lost (unlike some Armaniidae and Sphecomyrminae). Cells 3r, rm and mcu are not grouped in the central part of the wing (unlike Formicium Westwood, 1854, subfamily Formiciinae).

Remarks. While revising the genus Ponera Latreille, 1804, Taylor (1964) placed 19 species described previously from forewing fossils from the Miocene of Europe as Ponera Latreille and Poneropsis Heer, as well as Ponera hypolitha Cockerell from the Bembridge Marls, in the morphogenus Poneropsis. Taylor's re-definition of Poneropsis resulted in its much wider application for all detached ant wings with complete venation. This is because Taylor overlooked some important traits, particularly the position of cross-vein $\mathrm{cu}-\mathrm{a}$, which can be used to distinguish forewings of Ponerinae and several other primitive ant subfamilies (Armaniinae, Sphecomyrminae, Myrmeciinae, Amblyoponinae, Ectatomminae, Cerapachyinae, Ecitoninae) from the venationally advanced subfamilies Myrmicinae, Aneuretinae, Dolichoderinae and Formicinae. As a result, Poneropsis sensu Taylor can accommodate the majority of the ant wing fossils. The name Poneropsis further causes confusion. Mayr (1867) re-examined three specimens identified as Ponera fuliginosa (type species of genus Poneropsis) by Heer and found that they had a two-segmented waist and might be females of Aphaenogaster Mayr, 1853, a genus of Myrmicinae. Therefore we propose a new morphogenus for impressions of ant forewings with closed cells $1+2 \mathrm{r}, 3 \mathrm{r}$, rm and mcu, and 


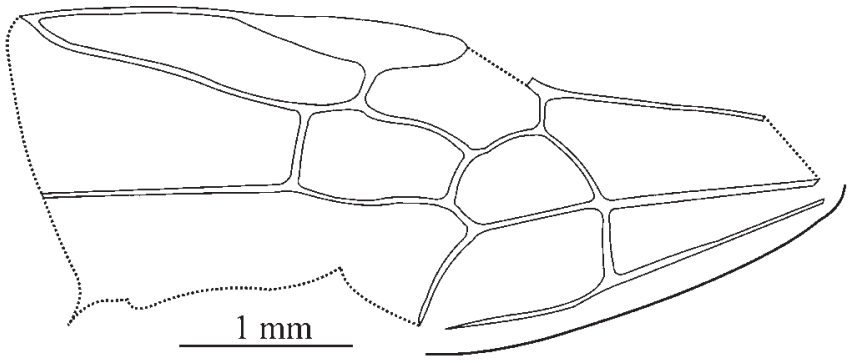

Text-figure 82 Taphopone macroptera Perfilieva, sp. nov., forewing, holotype, NHMUK I.9494.

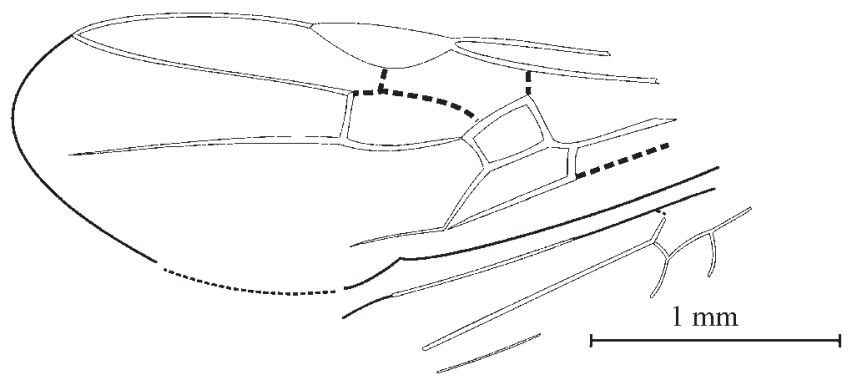

Text-figure 83 Taphopone microptera Perfilieva, sp. nov., forewing, holotype, NHMUK In.9763.

with a distal position to cross-vein $\mathrm{cu}-\mathrm{a}(\mathrm{Icu}<1.4)$, which certainly belong to Ponerinae or other venationally-primitive ant subfamilies. We also include some additional characters in the diagnosis which exclude the most archaic (Armaniidae, Sphecomyrminae) and aberrant ants (Formiciinae).

The new species are diagnosed in the key below (section 3.11.3)

\section{Taphopone macroptera Dlussky \& Perfilieva, sp. nov.} Plate 22, fig. 4; Text-fig. 82

Etymology. Macroptera is Latin for "large wings".

Holotype. NHMUK I.9494, Bembridge Marls, NW Isle of Wight, UK, coll. P. B. Brodie; forewing (Plate 22, fig. 4; Text-fig. 82).

Paratype. NHMUK I.10172, Bembridge Marls, NW Isle of Wight, UK, coll. P. B. Brodie; forewing (Plate 22, fig. 5).

Description. FWL c.5.5-6 mm. 1RS slightly reclined, not strictly perpendicular to R. Cell $3 \mathrm{r}$ comparatively short (less than four times as long as wide), its apex touching wing margin. Cell $\mathrm{rm}$ quadrangular, $\mathrm{rs}-\mathrm{m}$ distal in respect to $2 \mathrm{r}-\mathrm{rs}$, but not in respect of pterostigmal apex. $2 \mathrm{r}-\mathrm{rs}$ somewhat proclined. Cell mcu large (more than half cell $1+2 \mathrm{r}$ in terms of area), pentagonal, $2 \mathrm{M}$ shorter than $\mathrm{RS}+\mathrm{M}$. Cross-vein $\mathrm{m}-\mathrm{cu}$ surpassing level of pterostigmal base. $1 \mathrm{M}$ more than twice as long as 1RS. Cell cua well developed. Crossvein cu-a almost reaching $\mathrm{mcu}(2 \mathrm{M}+\mathrm{Cu}$ practically lost $) . \mathrm{Icu}=1 \cdot 05$, Icua $=1 \cdot 01$ (holotype; paratype Icu $=1.09$ ).

Remarks. The holotype is labelled as Pachycondyla sp., however Donisthorpe did not mention this specimen in his paper. This might well be correct, but cannot be reasonably confirmed because of the absence of diagnostic characters (cf. above). That is why the new species is included in the morphogenus Taphopone.

T. macroptera is venationally similar to Ponerites hooleyi, but differs in having a larger wing (3-4 $\mathrm{mm}$ in the latter).

\section{Taphopone microptera Dlussky \& Perfilieva, sp. nov. Text-fig. 83}

Etymology. Microptera is Latin for "small wings".
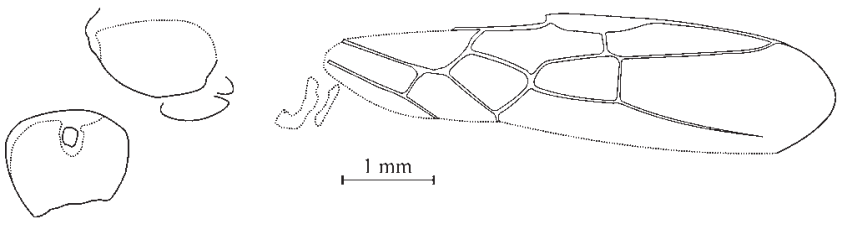

Text-figure 84 Taphopone petrosa Perfilieva, sp. nov., holotype, NHMUK In.24369

Holotype. NHMUK I.9763, Bembridge Marls, NW Isle of Wight, UK, coll. P. B. Brodie; forewing (Text-fig. 83).

Paratype. NHMUK In.24378 Bembridge Marls, NW Isle of Wight, UK, coll. R. W. Hooley; forewing.

Description. FWL c. $3 \mathrm{~mm}$. Cell $3 \mathrm{r}$ comparatively long (four times as long as wide), touching wing margin. Cell rm quadrangular. Cross-vein $\mathrm{rs}-\mathrm{m}$ far distal in relation to $2 \mathrm{r}-\mathrm{rs}$ but not distal of pterostigmal apex. Cell mcu pentagonal, reaching level of pterostigmal base. Cross-vein $\mathrm{m}-\mathrm{cu}$ and $1 \mathrm{M}$ shorter than $1 \mathrm{Cu}$. Cell cua well developed. Cross-vein cu-a almost reaching mcu $(2 \mathrm{M}+\mathrm{Cu}$ practically lost $) . \quad \mathrm{Icu}=1 \cdot 1-1 \cdot 3$, Icua $=1 \cdot 1$ (holotype)

Hindwing (holotype) with three longitudinal veins RS, M, and $\mathrm{Cu} .1 \mathrm{RS}$ and $\mathrm{rs}-\mathrm{m}$ of near equal length, $\mathrm{m}-\mathrm{cu}$ longitudinal, longer than $\mathrm{rs}-\mathrm{m}$.

Measurements in mm (holotype): $\mathrm{AL}=1 \cdot 55 ; \mathrm{FWL}=3 \cdot 1$; $\mathrm{FWW}=0 \cdot 9$.

Remarks. Donisthorpe misidentified both forewings of this species as Leucotaphus gurnetensis, even though they have cell $\mathrm{rm}$ closed and forewing cross-vein $\mathrm{cu}-\mathrm{a}$ takes distal position.

Taphopone petrosa Dlussky \& Perfilieva, sp. nov. Plate 22, fig. 6; Text-fig. 84

Etymology. petrosa is Latin for stony.

Holotype NHMUK In.24369, Bembridge Marls, NW Isle of Wight, UK, coll. R. W. Hooley; + (Plate 22, fig. 6, Text-fig. 84).

Paratypes. NHMUK In.24927; NHMUK In.24949 (forewings); NHMUK In.25006 (two forewings), coll. R. W. Hooley; CAMSM X.50140.21 (TN 71) (forewing). All from Bembridge Marls, Isle of Wight, UK,

Description. Female. FWL 6-7.5 mm. Head subrectangular, wider than long, with convex sides and rounded occipital corners.

Forewing. 1RS reclined. Apex of cell $3 \mathrm{r}$ touching wing margin. Cell $\mathrm{rm}$ triangular with short stem or not pedunculate, $2 \cdot 2-2 \cdot 4$ times as long as wide. Cross-vein rs-m level with $2 \mathrm{r}-$ rs, or more distal than that but not more than for vein width. Cell mcu trapezoid, of medium size, $1 \mathrm{M}$ shorter than $\mathrm{m}-\mathrm{cu}$. $\mathrm{M}+\mathrm{Cu}$ distinctly bent at junction with $\mathrm{cu}-\mathrm{a}$. Cross-vein $\mathrm{cu}-\mathrm{a}$ near cell mcu. Icu 1·3-1·4, Icua 1·14-1·18.

Measurements in mm. Holotype: $\mathrm{HW}=1.45 ; \mathrm{FWL}=6 \cdot 1$. Paratype NHMUK In.24927: FWL $=6 \cdot 1 ; \mathrm{FWW}=2 \cdot 1$. Paratype NHMUK In.24949: FWL $=7 \cdot 2 ; \mathrm{FWW}=1 \cdot 9$

Remarks. Donisthorpe (1920) misidentified the holotype as Dolichoderus britannicus, even though the distal position of cross-vein $\mathrm{cu}-\mathrm{a}$ indicates clearly that it belongs to Ponerinae.

Taphopone aberrans Dlussky \& Perfilieva, sp. nov. Plate 22, figs 7, 9; Text-fig. 85

Etymology. Aberrans is Latin for aberrant.

Holotype. NHMUK In.24917, Bembridge Marls, NW Isle of Wight, UK, coll. R. W. Hooley; forewing (Plate 22, fig. 9; Text-fig. 85).

Paratypes. Forewings. NHMUK I.8574, coll. P. B. Brodie; NHMUK In.24847; NHMUK In.24910 (Plate 22, fig. 7); 


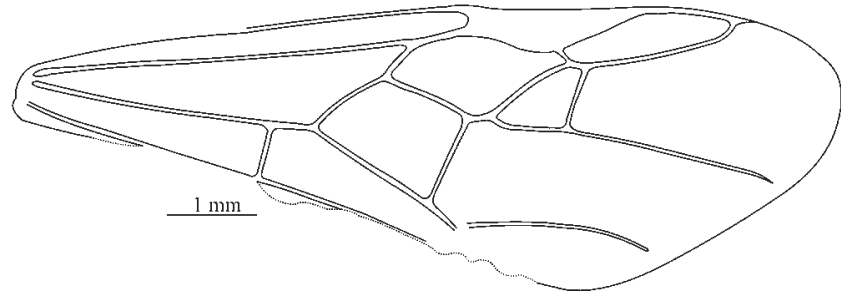

Text-figure 85 Taphopone aberrans Perfilieva, sp. nov., forewing, holotype, NHMUK In.24917.

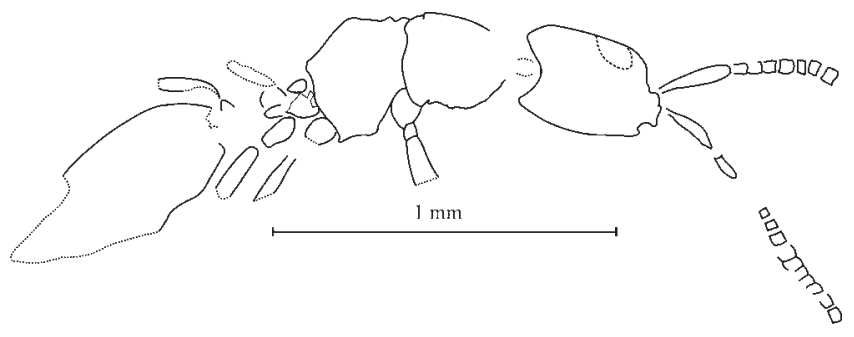

Text-figure 86 Solenopsites rossi Dlussky, sp. nov., + , holotype, NHMUK I.9968.

NHMUK In.24917; NHMUK In.24960, coll. R. W. Hooley; CAMSM: X.50140.117 (TN.173). All from Bembridge Marls, Isle of Wight, UK,

Description. Forewing. FWL $c .9 \mathrm{~mm}$. 1RS distinctly reclined. Cell 3r short, less than three times as long as wide, its apex touching wing margin. Cell $\mathrm{rm}$ rather small, triangular, usually with long stem. Cross-vein $2 \mathrm{r}-\mathrm{rs}$ reclined, cross-vein $\mathrm{rs}-\mathrm{m}$ somewhat distal in respect to $2 \mathrm{r}-\mathrm{rs}$, but not beyond pterostigmal apex, often meeting $\mathrm{M}$ more proximal than RS. Cell mcu large, subequal to $1+2 \mathrm{r}$ in terms of area, trapezoid ( $\mathrm{RS}+\mathrm{M}$ and $1 \mathrm{M}$ shorter than $\mathrm{m}-\mathrm{cu}$ and $1 \mathrm{Cu}$, respectively). $1 \mathrm{M}$ more than twice as long as 1RS. Cross-vein $\mathrm{m}$-cu placed distal of level of pterostigmal base. Cross-vein cu-a meeting $1 \mathrm{M}+\mathrm{Cu}$ near cell mcu. Icu $=1 \cdot 3-1 \cdot 45$, Icua $=1 \cdot .13-1 \cdot 14$.

Measurements in mm. FWL $=9 \cdot 1$ (holotype).

Remarks. The distal position of $\mathrm{cu}-\mathrm{a}$ indicates the wing belongs to a representative of Ponerinae but differs from other Bembridge Ponerinae in the form of cell $\mathrm{rm}$.

\subsubsection{Subfamily Myrmicinae Lepeletier de Saint-Fargeau, 1836}

\section{Morphogenus Solenopsites Dlussky \& Rasnitsyn, 2002}

Type species. Solenopsites minutus Dlussky \& Rasnitsyn, 2002, by original designation.

Other species. S. minutus (Middle Eocene, Green River Formation, USA) and $S$. rossi sp. nov. (Bembridge Marls, Isle of Wight, UK).

Diagnosis. Ant rock fossils with waist two-segmented and long (more than half as long as gaster and nearly half as long as the alitrunk), with propodeum unarmed, petiole pedunculate and postpetiole narrowly attached to gaster, which cannot be identified more precisely.

Remarks. This morphogenus can include all poorly preserved impressions of small Myrmicinae without propodeal spines or teeth and with a pedunculate petiole, but really belong to many different orthotaxa.

Solenopsites rossi Dlussky \& Perfilieva, sp. nov. Plate 22, fig. 8; Text-fig. 86

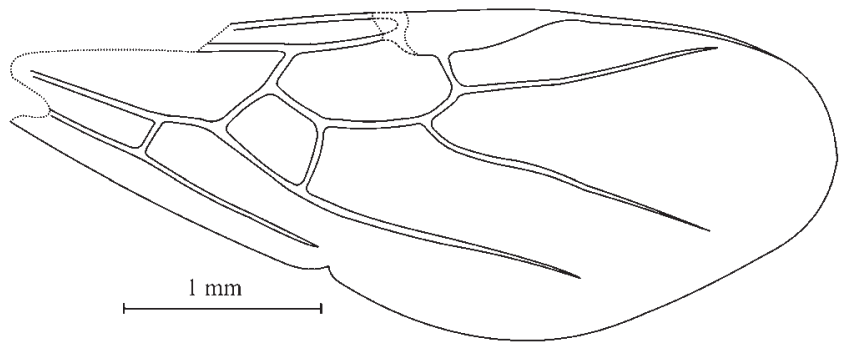

Text-figure 87 Paraphaenogaster hooleyana Perfilieva, sp. nov., forewing, holotype, NHMUK In.24963.

Etymology. In honour of Dr Andrew Ross, appreciating his help in preparing this work.

Holotype NHMUK I.9968, Bembridge Marls, NW Isle of Wight, UK, coll. P. B. Brodie, ( (Plate 22, fig. 8; Text-fig. 86).

Description. Wingless female. BL about $2 \mathrm{~mm}$. Head subrectangular, longer than wide, with feebly convex sides, rounded occipital corners and concave occipital margin. Eyes oval, strongly displaced forward. Antennae geniculate, scape thick and short, not reaching the occipital margin, middle flagellomeres thicker than long. Propodeum angulate in side view, without spines or teeth. Legs short and thick.

Measurements in mm. $\mathrm{AL}=0 \cdot 65 ; \mathrm{HL}=0 \cdot 39, \mathrm{HW}=0 \cdot 29$; $\mathrm{SL}=0 \cdot 23$.

Remarks. Despite the waist being only partially preserved, position of the alitrunk, gaster and preserved fragments of the waist indicate two-segmented waist. The new species differs from all other ants in the Bembridge assemblage in its small size, and from $S$. minutus in the form of head.

\section{Morphogenus Paraphaenogaster Dlussky, 1981}

Type species. Paraphaenogaster microphthalmus Dlussky, 1981, by original designation.

Other species. P. hooleyana sp. nov. Aphaenogaster shanwangensis (Hong, 1984), A. lapidescens Zhang, and A. paludosa Zhang from the Middle Miocene of Shanwang (Shandong, China) are similar venationally (Zhang, 1989) and might belong there as well.

Diagnosis. Isolated ant wings with cells $1+2 \mathrm{r}$ and $\mathrm{mcu}$, cell $3 \mathrm{r}$ open at apex, and $\mathrm{r}-\mathrm{m}$ present, apical sections of $\mathrm{RS}$ and $\mathrm{M}$ leaving cell $1+2 \mathrm{r}+\mathrm{rm}$ separately.

Remarks. Similar venation is characteristic of some Myrmicinae: Pheidolini (a part of Aphaenogaster Mayr) and Solenopsidini (Solenopsis Westwood, Oligomyrmex Mayr).

Paraphaenogaster hooleyana Dlussky \& Perfilieva, sp. nov. Plate 22, fig. 10; Text-fig. 87

Etymology. After Mr. R. W. Hooley.

Holotype. NHMUK In.24963, Bembridge Marls, NW Isle of Wight, UK, coll. R. W. Hooley; forewing (Plate 22, fig. 10).

Paratype NHMUK In.25082, Bembridge Marls, NW Isle of Wight, UK, coll. R. W. Hooley; forewing.

Description. Forewing. Cell mcu trapezoid $(1 \mathrm{Cu}$ appreciably longer than $1 \mathrm{M}$ and $\mathrm{RS}+\mathrm{M}$ ), of medium size (not more than half of cell $1+2 \mathrm{r}$ in terms of area), not reaching level of pterostigmal base. $4 \mathrm{M}$ leaving $\mathrm{RS}+\mathrm{M}$ basal of $2 \mathrm{r}-\mathrm{rs}$ and at level of pterostigmal base in holotype (slightly more distal in paratype). 1RS reclined. Cross-vein cu-a well distant from mcu. Icu $=1 \cdot 5-1 \cdot 7$, Icua $\sim 1 \cdot 2$.

Remarks. Holotype and paratype wings differ in size significantly, restored values being $4.6 \mathrm{~mm}$ and $3.8 \mathrm{~mm}$, respectively. Position of base of apical section of $\mathrm{M}$ on cell $\mathrm{rm}$, relative length of $1 \mathrm{M}$ and $1 \mathrm{RS}$, and inclination of $2 \mathrm{r}-\mathrm{rs}$ differ as 
well. Nevertheless they may be the same species, supposing the holotype is a female and paratype a male.

There is also a poorly preserved wing NHMUK In.25081 of apparently similar venation, but differing in still smaller size (FWL $\sim 3 \mathrm{~mm}$ ).

3.11.2. Species doubtfully and erroneously described as Formicidae

Camponotus brodiei Donisthorpe, 1920

1920 Camponotus brodiei Donisthorpe, p. 93, plate V. fig. 13. 1995 Camponotus brodiei Donisthorpe, Bolton, p. 89.

Holotype NHMUK I.9551, Bembridge Marls, NW Isle of Wight, UK, coll. P. B. Brodie.

Remarks. The holotype is possibly an ant but so poorly preserved that it does not permit attribution to a subfamily. We refer it to as Formicidae incertae sedis.

\section{Leucotaphus permaneus Cockerell, 1927}

1927 Leucotaphus permaneus Cockerell, p. 165 (footnote).

The original description is short and of little help, and the holotype is lost from the USNM collection. We propose to consider this species as nomen dubium.

Ponera minuta Donisthorpe, 1920

Remarks. Belongs to Agaonidae (see Donisthorpe 1920, p. 17).

Syntaphus wheeleri Donisthorpe, 1920

Remarks. Belongs to Braconidae (see Donisthorpe 1920, p. 69).

3.11.3. Keys for the identification of ant fossils from the Bembridge Marls. Preservation of ant fossils in Bembridge Marls is variable: forewings are unknown for some species (Solenopsites rossi, Ponerites antropovi) and are the only known parts of some others (Emplastus kozlovi, Paraphaenogaster hooleyana and all Taphopone species). This meant that separate keys had to be constructed for bodies and for forewings.

\subsubsection{Key to bodies with or without wings}

1 - Waist with one segment (petiole); forewing with closed cell 3r...... go to 2 .

- Waist with two segments (petiole and postpetiole); forewing often with opened cell 3r (Myrmicinae). The only myrmicine species with a preserved body is Solenopsites rossi $\mathrm{sp}$. nov. $\mathrm{BL} \sim 2 \mathrm{~mm}$. Head longer than width, subrectangular, with slightly convex sides and concave occipital margin. Wing venation unknown.

2 - Gaster with constriction between first and second segments; male antennae filiform, with very short scape; forewing with closed cells $1+2 \mathrm{r}, 3 \mathrm{r}$, rm and mcu; crossvein $\mathrm{cu}-\mathrm{a}$ close to cell $\mathrm{mcu}$, so usually Icu $<1.45$ and Icua $<1 \cdot 2$ (Ponerinae)...... go to 3 .

- Gaster without constriction between first and second segments; cross-vein cu-a displaced proximally, so usually Icu $>1.5$ and Icua $>1 \cdot 2 \ldots$ go to 5 .

3 - Petiole with high scale, in side view with almost parallel anterior and posterior surfaces and smoothly round top; forewing with triangular cell rm; BL 3-3.5 mm. o : eyes oval; strongly displaced forward, so length of cheek less than scape diameter; propodeum in side view angular, with dorsum somewhat shorter than declivity. ot: eyes of moderate size, oval, less displaced forward; propodeum evenly rounded in side view. $=$ Ponerites crawley $i$ (Donisthorpe).
- Petiole with high scale, in side view clearly narrowed upwards with narrowly rounded top; cheek about as long as eye diameter or longer. BL $4-4.5 \mathrm{~mm}$...... go to 4 .

4 - First gastral tergite longer than high; eyes oval, slightly displaced forward; $q$ cheek about as long as maximum eye diameter; wing venation unknown $=$ Ponerites antropovi sp. nov.

- First gastral tergite shorter than high; eyes rounded, situated near the middle of head sides; o cheek longer than eye diameter; forewing with cell rm quadrangular $=$ Ponerites hooleyi sp. nov.

5 - Propodeum angular, with distinct carina separating propodeal dorsum and declivity, with dorsum convex and declivity concave in side view.; petiole with rounded node, $1.5-1.8$ times as long as high; forewing with closed cells $1+2 \mathrm{r}, 3 \mathrm{r}$, rm and mcu; BL 3-3.5 mm; FWL $3 \cdot 5-4 \mathrm{~mm}$. (Dolichoderinae $)=\uparrow$ Dolichoderus vectensis Donisthorpe.

- Propodeum gradually rounded or angular in side view, with straight or feebly convex propodeal declivity; petiole of other form...... go to 6 .

6 - Petiole elongate, longer than wide, without node or scale...... go to 7 .

- Petiole with scale (†) or triangular in side view (ふ) $). .$. .. go to 11 .

7 - Propodeum angular in side view, with blunt teeth on the border of propodeal dorsum and declivity, with dorsum longer than declivity; petiole 1.7 times as long as high and about half as long as propodeum; anterior part of petiolar dorsum almost straight, and posterior feebly rounded in side view; maximum petiole height is behind its midlength; forewing with closed cells $1+2 \mathrm{r}, \mathrm{rm}$, mcu and apparently $3 \mathrm{r}$; FWL about $8 \mathrm{~mm}$. (Aneuretinae) $=$ Britaneuretus anglicus (Cockerell).

- Propodeum feebly convex or straight in side view; petiole narrowed anteriorly, 1.8-3 times as long as wide and high. scape extending far beyond occipital margin; o mandibles large, triangular, with large sharp teeth; forewings with closed cells $1+2 \mathrm{r}$ and $3 \mathrm{r}$ and not $\mathrm{rm}$ and $\mathrm{mcu}$; $5 \mathrm{RS}$ and $4 \mathrm{M}$ leaving the same point (no cross-vein rs-m). (Formicinae, Oecophylla)...... go to 9.

8 - BL 5-6.3 mm; AL 2-3 mm; FWL 6-9.5 mm; petiole 2.5-3 times as long as wide and high; scutum a little longer than wide $=$ o Oecophylla atavina Cockerell.

- AL > $3.5 \mathrm{~mm}$; FWL usually $>9.5 \mathrm{~mm}$; petiole about twice as long as wide... go to 9 .

9 - FWL 19-25 mm, restored BL more than $16 \mathrm{~mm}=$ ? Oecophylla megarche Cockerell.

- FWL 10-16 mm; BL < $10 \mathrm{~mm}$...... go to 10.

10 - Scutum a little longer than wide; alitrunk short and high, a little longer than high; gaster with six segments and exposed genitals; AL 3.5-4.5 mm; FWL 8.3-16

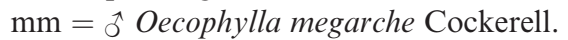

- Scutum a little wider than long; alitrunk longer, nearly twice as long as high; gaster with five segments; AL 4$5.55 \mathrm{~mm}$; FWL $8.5-13.7 \mathrm{~mm}=$ + Oecophylla atavina Cockerell.

$11-$ Forewing with closed cells $1+2 \mathrm{r}, 3 \mathrm{r}$, rm and mcu; male antennae filiform with very short scape. (Dolichoderinae)...... go to 12 .

- Forewing without closed cell $\mathrm{rm}$; $5 \mathrm{RS}$ and 4M starting from the same point (cross-vein rs-m lost). Antennae geniculate in both sexes, scape always extending beyond occipital margin. (Formicinae)...... go to 16 .

12 - Head about as wide as alitrunk or a little narrower; antennae geniculate; gaster with five segments (qo) ......go to 13 . 
- Head distinctly narrower than alitrunk; antennae filiform, with very short scape; petiole triangular in side view; gaster with six segments $(\hat{o} \widehat{o}) \ldots . .$. go to 14 .

13 - Head wider than long; scape short, not reaching occipital margin; petiole with scale 2.5-3 times as wide as thick; cell $\mathrm{rm}$ comparatively wide $(1 \cdot 6-2 \cdot 1$ times as long as wide); cross-veins $2 \mathrm{r}-\mathrm{rs}$ and $\mathrm{rs}-\mathrm{m}$ aligned at RS (4RS absent), or rs-m slightly distal, leaving 4RS as long as about vein thickness; BL 6-8.5 mm; AL 2.5-3.5 mm; FWL 6-7 $\mathrm{mm}=$ +Emplastus britannicus (Cockerell).

- Head longer than wide; petiole with low scale (about as long as high), triangular in side view; cell rm $2 \cdot 2-2 \cdot 4$ times as long as wide; cross-veins rs-m noticeable distal on RS than $2 \mathrm{r}-\mathrm{rs}$, 4RS much longer than vein thickness; BL 5-6.5 mm; AL 2.2-3.2 mm; FWL 5-5.5 $\mathrm{mm}=$ ? Emplastus gurnetensis (Donisthorpe).

14 - Cell rm 1·6-2.1 times as long as wide; cross-veins 2r-rs and $\mathrm{rs}-\mathrm{m}$ aligned at RS, 4RS lost, or rs- $\mathrm{m}$ a little more distal, leaving 4RS about as long as vein thickness; BL $\sim 6 \mathrm{~mm}$; $\mathrm{AL} \sim 3 \mathrm{~mm}$; FWL 5-5.6 mm = ô Emplastus britannicus (Cockerell).

- Cell rm 2.2 -2.8 times as long as wide; cross-vein rs-m noticeably distal on RS in respect of $2 \mathrm{r}-\mathrm{rs}$, 4RS distinctly longer than vein thickness......go to 15 .

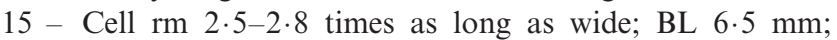
AL $3 \mathrm{~mm}$; FWL 5-6 $\mathrm{mm}=\hat{0}$ Emplastus hypolithus (Cockerell).

- Cell rm 2.2 -2.4 times as long as wide; BL $4 \mathrm{~mm}$; AL sim;2 mm; FWL 4 mm. = ô Emplastus gurnetensis (Donisthorpe).

16 - Scape attached distant from posterior margin of clypeus; forewing lacking closed cell $\mathrm{mcu}=$ Camponotus cockerelli (Donisthorpe).

- Scape attached at the posterior clypeal margin. Cell mcu present....... go to 17 .

17 - ㄱ: BL 2.2-3.8 mm; AL 1.0-1.7 mm; FWL 2.2-3.7 $\mathrm{mm}$; petiole triangular in side view; genitals poorly exposed, with stipes short, narrow, rounded at top. ㅇ: BL 5.0-5.7 mm; AL 2.2-3.2 mm; FWL 5-5.5 mm; petiole with scale high and wide, $2 \cdot 2-2 \cdot 4$ times as high as long and $2 \cdot 5-3$ times as wide as thick $=$ Leucotaphus gurnetensis (Cockerell).

- 今: BL 4.0-4.5 mm; AL 1.4-2.0 mm; FWL 3.8-4.5 $\mathrm{mm}$; petiole triangular in side view; genitals well exposed, with stipes long, triangular, rounded at top. ㅇ: FWL 7.4-7.5 $\mathrm{mm}=$ Leucotaphus donisthorpei $\mathrm{sp}$. nov.

\subsubsection{Key to wings}

1 - Forewings with cells $1+2 \mathrm{r}, 3 \mathrm{r}$, rm and mcu closed..... go to 2 .

- Closed cell rm absent......go to 13 .

2 - Cross-vein cu-a near cell mcu, so usually Icu $<1.45$ and Icua $<1.2$ (Ponerinae)... go to 3 .

- Cross-vein cu-a displaced proximal, so usually Icu $>1 \cdot 5$ and Icua $>1 \cdot 2 \ldots$.go to 8 .

3 - Cell rm triangular...... go to 4 .

- Cell rm quadriangular......go to 6 .

4 - Cell rm small, pedunculate, with long stem; FWL c. 9 $\mathrm{mm} ; \quad$ Icu $=1 \cdot 3-1 \cdot 45 ; \quad$ Icua $=1 \cdot 13-1 \cdot 14=$ Taphopone aberrans sp. nov.

- Cell rm with no or very short stem..... go to 5 .

5 - Cross-vein 2r-rs clearly proximal of rs-m; FWL c. 3 $\mathrm{mm}$; Icu $1 \cdot 25-1 \cdot 3$; Icua $1 \cdot 1=$ Ponerites crawleyi (Donisthorpe).

- Cross-veins 2r-rs and rs-m coinciding on RS (4RS is absent) or $\mathrm{rs}-\mathrm{m}$ a little distal leaving 4RS about as long as vein thickness; FWL c. $7 \mathrm{~mm}$; Icu 1.3-1.4; Icua $1 \cdot 14-1 \cdot 18=$ Taphopone petrosa sp. nov.
6 - Cell cua lost; cross-vein cu-a distant from cell mcu, so as $2 \mathrm{M}+\mathrm{Cu}$ well developed and $\mathrm{Icu} \geq 1 \cdot 4$; Icua $\geq 1 \cdot 13$; FWL 3-4 $\mathrm{mm}=$ Ponerites hooleyi $\mathrm{sp}$. nov.

- $2 \mathrm{Cu}$ leaving cell mcu at clear angle forming distinct cell cua; cross-vein cu-a close to mcu, resulting in $\mathrm{Icu} \leq 1$ $\cdot 3$; Icua $\leq 1 \cdot 1 \ldots$. go to 7 .

7 - Cell $3 \mathrm{r}$ comparatively short, four times as long as wide; FWL 5.5-6 mm; Icu = 1.05; Icua $=1 \cdot 01$ (holotype) $=$ Taphopone macroptera sp. nov.

- Cell 3r more than four times as long as wide; FWL c.3 $\mathrm{mm}$; Icu $=1 \cdot 1-1 \cdot 3$; Icua $=1 \cdot 08-1 \cdot 10$; Hind wing with three longitudinal veins $(\mathrm{RS}, \mathrm{M}$ and $\mathrm{Cu})=$ Taphopone microptera sp.nov

8 - Cross-vein $2 \mathrm{r}-\mathrm{rs}$ distal of $\mathrm{rs}-\mathrm{m}$ (possibly an aberration, for normally it is rs-m which can be more distal); FWL c. $8 \mathrm{~mm}$; Icu $=1.6$; Icua $=1.3=$ Britaneuretus anglicus (Cockerell) (Aneuretinae).

- Cross-vein 2r-rs either proximal of, or coinciding with, rs-m. (Dolichoderinae)...... go to 9.

9 - FWL 3-3.5 mm. Cell rm triangular, pedunculate (rarely with stem very short). Cross-vein $2 \mathrm{r}-\mathrm{rs}$ coinciding with rs $-\mathrm{m}$ or a little distal of it $=$ Dolichoderus vectensis Donisthorpe.

- FWL $>4.5 \mathrm{~mm} . . .$. .go to 10 .

10 - Cell rm 1.5-2.1 times as long as wide; cell rm triangular with very short or no stem; cross-veins $2 \mathrm{r}-\mathrm{rs}$ and $\mathrm{rs}-\mathrm{m}$ coinciding on RS (4RS absent), or rs-m distal a little (4RS about as long as vein thickness); FWL 5.5-7 mm; Icu 1.55-2.2; Icua 1.2-1.4; hindwing with two longitudinal vein $(\mathrm{RS}$ and $\mathrm{Cu})=$ Emplastus britannicus (Cockerell).

Cell rm 2.2-2.8 times as long as wide...... go to 11 .

11 - Cell rm 2.5-2.8 times as long as wide; cell rm quadrangular or triangular, not pedunculate; cross-vein rs-m noticeably distal on RS compared to $2 \mathrm{r}-\mathrm{rs}$; 4RS distinctly longer than vein thickness, rarely $\mathrm{rs}-\mathrm{m}$ and $2 \mathrm{r}-$ rs coinciding on RS; FWL 5-6 mm; Icu 1.6-2.1; Icua $1 \cdot 3-1 \cdot 4=$ Emplastus hypolithus (Cockerell).

- Cell rm 2.2-2.5 times as long as wide. Cell rm triangular without stem......go to 12 .

12 - Cross-vein rs-m distinctly distal on RS compared to $2 \mathrm{r}-$ rs, 4RS distinctly longer than vein thickness; FWL 4-6 $\mathrm{mm}$; Icu $=1 \cdot 8$; Icua $=1 \cdot 25$; hindwing with three longitudinal veins $(\mathrm{RS}, \mathrm{M}$ and $\mathrm{Cu}=$ Emplastus gurnetensis (Donisthorpe).

- Cross-veins 2r-rs and rs-m coinciding on RS; FWL 7.8-12 mm; Icu 1.6-1.8; Icua 1.3-1.5=Emplastus kozlovi sp. nov.

13 - Cell mcu closed..... go to 14.

- Cell mcu absent (Formicinae)...... go to 18 .

14 - 4M leaving cell $1+2 \mathrm{r}$ long before $2 \mathrm{r}-\mathrm{rs}$ and $5 \mathrm{RS}$; cell $3 \mathrm{r}$ open apically, even if sometimes very narrowly and inconspicuously; FWL 3.5-4.5 mm; Icu 1.5-1.7; Icua c. $1 \cdot 2$ = Paraphaenogaster hooleyana sp. nov. (Myrmicinae).

- $5 \mathrm{RS}$ and $4 \mathrm{M}$ with joint origin (no rs-m); cell 3r always closed; Icu 2.0-3·6; Icua 1·2-2.2 (Leucotaphus, Formicinae)...... go to 15 .

15 - FWL 2.2-3.7 $\mathrm{mm}=$ ^ L. gurnetensis (Cockerell).

- FWL $>3.7 \mathrm{~mm} . .$. . go to 16 .

16 - FWL 3.8-4.5 $\mathrm{mm}=\widehat{\jmath}$ L. donisthorpei $\mathrm{sp}$. nov.

- FWL $>4.5 \mathrm{~mm}$...... go to 17.

17 - FWL 5-5.5 mm = + L. gurnetensis (Cockerell).

- FWL c. $7.5 \mathrm{~mm}=\widehat{\jmath}$ L. donisthorpei sp. nov.

18 - 5RS always convex (cell 3r bent outward); FWL 5-8 $\mathrm{mm}$; hindwing with cross-vein $\mathrm{rs}-\mathrm{cu}$ subequal to $2 \mathrm{M}+\mathrm{Cu}$, cross-vein $\mathrm{cu}-\mathrm{a}$ near to wing base compared to rs-cu $=$ Camponotus cockerelli (Donisthorpe). 
Table 2 Taxonomic composition (numbers and \% of total) of ants in the Bembridge Marls.

\begin{tabular}{|c|c|c|c|c|}
\hline \multirow[t]{2}{*}{ Taxa } & \multicolumn{2}{|c|}{ All fossils } & \multicolumn{2}{|c|}{ Identified up to species level } \\
\hline & $\mathrm{n}$ & $\%$ & $\mathrm{n}$ & $\%$ \\
\hline \multicolumn{5}{|l|}{ Aneuretinae } \\
\hline Britaneuretus anglicus (Cockerell) & 1 & $0 \cdot 1$ & 1 & $0 \cdot 2$ \\
\hline \multicolumn{5}{|l|}{ Dolichoderinae } \\
\hline Dolichoderus vectensis Donisthorpe & 7 & $0 \cdot 6$ & 6 & $1 \cdot 1$ \\
\hline Emplastus britannicus (Cockerell) & 52 & $4 \cdot 6$ & 52 & $8 \cdot 3$ \\
\hline Emplastus hypolithus (Cockerell) & 15 & $1 \cdot 3$ & 15 & $2 \cdot 4$ \\
\hline Emplastus gurnetensis (Donisthorpe) & 8 & $0 \cdot 7$ & 8 & $1 \cdot 3$ \\
\hline Emplastus kozlovi Perfilieva, sp. nov. & 5 & $0 \cdot 4$ & 5 & $0 \cdot 8$ \\
\hline Emplastus sp. & 1 & $0 \cdot 1$ & & \\
\hline \multicolumn{5}{|l|}{ Formicinae } \\
\hline Camponotus cockerelli (Donisthorpe) & 15 & $1 \cdot 3$ & 15 & $2 \cdot 4$ \\
\hline Camponotus sp. & 1 & $0 \cdot 1$ & & \\
\hline Leucotaphus gurnetensis (Cockerell) & 158 & $13 \cdot 9$ & 158 & $25 \cdot 1$ \\
\hline Leucotaphus donisthorpei Dlussky, sp. nov. & 16 & 1.4 & 16 & $2 \cdot 5$ \\
\hline Leucotaphus sp. & 1 & $0 \cdot 1$ & & \\
\hline Oecophylla atavina Cockerell & 199 & $17 \cdot 5$ & 199 & $31 \cdot 6$ \\
\hline Oecophylla megarche Cockerell & 124 & $10 \cdot 9$ & 124 & $19 \cdot 7$ \\
\hline Oecophylla sp. & 397 & $34 \cdot 9$ & & \\
\hline \multicolumn{5}{|l|}{ Ponerinae } \\
\hline Ponerites crawleyi (Donisthorpe) & 7 & $0 \cdot 6$ & 7 & $1 \cdot 1$ \\
\hline Ponerites hooleyi Dlussky et Perfilieva, sp. nov. & 3 & $0 \cdot 3$ & 4 & $0 \cdot 5$ \\
\hline Ponerites antropovi Dlussky, sp. nov. & 1 & $0 \cdot 1$ & 1 & $0 \cdot 2$ \\
\hline Ponerites sp. & 1 & $0 \cdot 1$ & & \\
\hline Taphopone macroptera Perfilieva, sp. nov. & 2 & $0 \cdot 2$ & 2 & $0 \cdot 3$ \\
\hline Taphopone microptera Perfilieva, sp. nov. & 2 & $0 \cdot 2$ & 2 & $0 \cdot 3$ \\
\hline Taphopone petrosa Perfilieva, sp. nov. & 6 & $0 \cdot 5$ & 6 & $1 \cdot 0$ \\
\hline Taphopone aberrans Perfilieva, sp. nov. & 6 & $0 \cdot 5$ & 6 & $1 \cdot 0$ \\
\hline Taphopone sp. & 1 & $0 \cdot 1$ & 1 & $0 \cdot 2$ \\
\hline \multicolumn{5}{|l|}{ Myrmicinae } \\
\hline Solenopsites rossi Dlussky, sp. nov. & 1 & $0 \cdot 1$ & 1 & $0 \cdot 2$ \\
\hline Paraphaenogaster hooleyana Perfilieva, sp. nov. & 2 & $0 \cdot 2$ & 2 & $0 \cdot 3$ \\
\hline Paraphaenogaster sp. & 1 & $0 \cdot 1$ & & \\
\hline Formicidae indet. & 105 & $9 \cdot 2$ & & \\
\hline TOTAL & 1136 & $100 \cdot 1$ & 630 & $100 \cdot 5$ \\
\hline
\end{tabular}

- 5RS always concave (bent into cell 3r); hindwing with rs-cu much longer than $2 \mathrm{M}+\mathrm{Cu}$ and with $\mathrm{cu}-\mathrm{a}$ more close to rs-cu than to wing base...... go to 19.

19 - FWL 6-9.5 $\mathrm{mm}=$ ô Oecophylla atavina Cockerell.

- FWL > 9.5 mm......go to 20.

20 - FWL 20-23 mm = q Oecophylla megarche Cockerell.

- FWL 10-16 mm.....go to 21.

21 - Apical corner of cell $1+2 \mathrm{r}$ obtuse, rarely c. 90ff; FWL $10-16 \mathrm{~mm}=$ ô Oecophylla megarche Cockerell

- Apical corner of cell 1+2 more acute; FWL 8.5-13.7 $\mathrm{mm} .=+$ Oecophylla atavina Cockerell.

3.11.4. Discussion. The Bembridge Marls Insect Bed has yielded 20 ant species belonging to ten genera and five subfamilies (Table 2). The most striking feature of the assemblage is the hyperabundance of Oecophylla, not recorded in any other circumstance in the past. Oecophylla fossils represent $63.4 \%$ of all the ants collected and $69.8 \%$ of those identified up to genus level. There is no question that the figures are exaggerated, because these ants are generally of larger size and rather striking general appearance, which make them easier to be collected and identified, even from small fragments. The collecting bias is not easy to account for; unlike the identification bias, which can be partially taken into account due to considering only the better preserved fossils which permit species level identification. This approach excludes 403 fossils identified as Oeco- phylla sp. and 111 as Formicidae indet. The resulting figures are a bit lower, with Oecophylla making up $51 \cdot 3 \%$ of ants $(31.6 \%$ - O. atavina and $19.7 \%$ - O. megarche) while the second most abundant species, Leucotaphus gurnetensis, comprises $25 \cdot 1 \%$, and the fourth, Emplastus britannicus is $8 \cdot 3 \%$. The general appearance of females of the most abundant ant species are reconstructed in Text-figure 88. All remaining species identified in the assemblage are much rarer, each with its share being under $3 \%$ of the ant fauna.

The above data make it possible to draw some inference on the environments near the target water body of the Bembridge Marls insect burial. No doubt the landscape was rich in forest, as the abundance of dendrobiotic ants suggests. These dendrobionts form the most common three species (both species of Oecophylla and Emplastus britannicus) whose joint share is $59.5 \%$ of all ants. Their morphology discussed above, as well as the biology of their living relatives or analogues, indicates their dendrobiotic habits with considerable confidence. Judging from habits of extant relatives, Dolichoderus vectensis and Camponotus cockerelli were dendrobiotic as well: they are responsible for $3 \cdot 5 \%$ of the ant assemblage.

Bembridge Ponerinae, which make up $4 \cdot 3 \%$ of the assemblage, were most probably forest floor dwellers, judging from both their morphology (forward position of female eyes) and analogy with Ponerinae in the Baltic amber and other late 
Table 3 Composition ( $\%$ of total) of ant subfamilies in better known fossil assemblages

\begin{tabular}{|c|c|c|c|c|c|c|c|c|}
\hline \multirow[t]{2}{*}{ Subfamily } & \multirow{2}{*}{$\begin{array}{l}\text { Late Cretaceous } \\
\text { (all data) }\end{array}$} & \multicolumn{4}{|l|}{ Eocene } & \multirow{2}{*}{$\begin{array}{l}\text { Oligocene } \\
\text { Sicilian } \\
\text { amber }\end{array}$} & \multicolumn{2}{|l|}{ Miocene } \\
\hline & & $\begin{array}{l}\text { Green } \\
\text { River }\end{array}$ & $\begin{array}{l}\text { Baltic } \\
\text { amber }\end{array}$ & $\begin{array}{l}\text { Bembridge } \\
\text { Marls }\end{array}$ & Florissant & & Radoboj & $\begin{array}{l}\text { Visnevaja } \\
\text { balka }\end{array}$ \\
\hline Aneuretinae & $1 \cdot 9$ & $3 \cdot 1$ & $0 \cdot 3$ & $0 \cdot 2$ & $0 \cdot 02$ & 0 & 0 & 0 \\
\hline Dolichoderinae & $1 \cdot 9$ & $75 \cdot 0$ & $64 \cdot 1$ & $13 \cdot 8$ & $62 \cdot 6$ & $7 \cdot 7$ & $13 \cdot 1$ & $3 \cdot 9$ \\
\hline Formicinae & $1 \cdot 9$ & $3 \cdot 1$ & $32 \cdot 8$ & $81 \cdot 3$ & $32 \cdot 5$ & $35 \cdot 9$ & $64 \cdot 2$ & $52 \cdot 6$ \\
\hline Ponerinae & $1 \cdot 9$ & $10 \cdot 4$ & $0 \cdot 7$ & $4 \cdot 3$ & $0 \cdot 04$ & $5 \cdot 1$ & 0.7 & $2 \cdot 6$ \\
\hline Cerapachyinae & 0 & 0 & $0 \cdot 1$ & 0 & 0 & 0 & 0 & 0 \\
\hline Myrmeciinae & 0 & $6 \cdot 3$ & $0 \cdot 1$ & 0 & 0 & 0 & 0 & 0 \\
\hline Pseudomyrmecinae & 0 & 0 & $0 \cdot 2$ & 0 & $0 \cdot 04$ & 0 & 0 & 0 \\
\hline Myrmicinae & $1 \cdot 9$ & $2 \cdot 1$ & $1 \cdot 7$ & $0 \cdot 5$ & $4 \cdot 8$ & $51 \cdot 3$ & $21 \cdot 9$ & $40 \cdot 8$ \\
\hline Armaniidae & $36 \cdot 9$ & 0 & 0 & 0 & 0 & 0 & 0 & 0 \\
\hline Sphecomyrminae & $47 \cdot 2$ & 0 & 0 & 0 & 0 & 0 & 0 & 0 \\
\hline Brownimeciinae & $3 \cdot 8$ & 0 & 0 & 0 & 0 & 0 & 0 & 0 \\
\hline
\end{tabular}

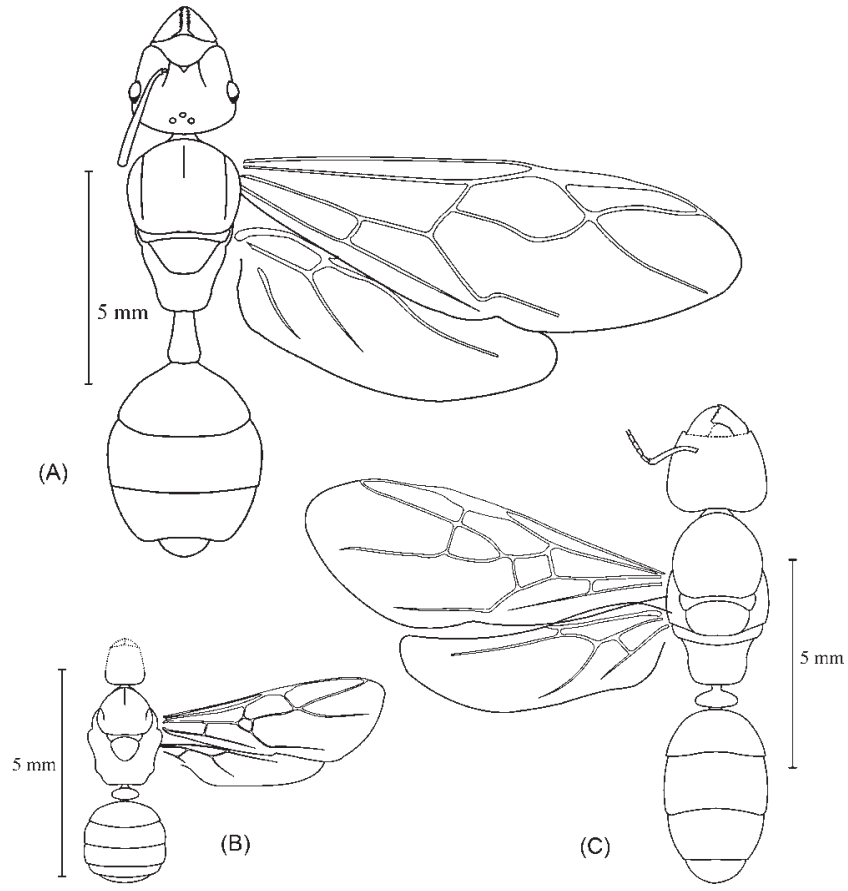

Text-figure 88 Restored general appearance of female ants most common in the Bembridge Marls: (A) Oecophylla atavina Cockerell; (B) Leucotaphus gurnetensis (Cockerell); (C) Emplastus britannicus (Cockerell).

Eocene European ambers, which certainly formed in forested areas. Of all Ponerinae found (except for Bradoponera meieri Mayr, 1867), 94\% are winged sexual forms, which implies that their workers do not normally visit tree trunks and kept to the forest floor, unlike sexual forms which probably started their nuptial flight from trees and other high points.

Hence, at least two thirds of the Bembridge ant assemblage consists of forest ants. Of the remaining species, the second most abundant, Leucotaphus gurnetensis, most probably resembles Lasius, which is a eurybiotic ant genus commonly found in forests, meadows and steppe. In the late Eocene European ambers, Lasius schiefferdeckeri Mayr, 1867, is the second most abundant ant species (after Ctenobethylus goepperti (Mayr, 1867)).

The Bembridge ants indicate a warm climate. Extant Oecophylla is characteristic of tropics and southern subtropics. One of the authors (GMD) had a chance to observe O. smaragdina introduced from China to North Caucasus (Lazarevskoye Insectarium, All-Union Institute of Plant Protection). After a successful winter $(1963 / 64)$ spent in a greenhouse, the ants did well during the summer in the open air in a garden, including raising larvae, but they became inactive when the temperature dropped below $18^{\circ} \mathrm{C}$. Unfortunately, they were not returned to the greenhouse in time, so they died out when the temperature dropped below zero. Since Oecophylla makes its nest only from living leaves, they can only populate forests with evergreen angiosperm trees. We have no reason to hypothesise different habits in the past, except that the ants could have existed in a somewhat less hot climate than now: they are found in the late Miocene of Oeningen in Germany, where the climate is reconstructed as warm temperate rather than subtropical (Mai 1995).

The above results enable a possible a comparison of the Bembridge assemblage with some other past ant assemblages. In this comparison, we rely on the following sources: for Late Cretaceous - Dlussky (1975, 1983, 1987, 1996, 1999a,b), Dlussky et al. (2004), Grimaldi et al. (1997), Grimaldi \& Agosti (2000), Engel \& Grimaldi (2005); for Green River (Middle Eocene of western North America) - Dlussky \& Rasnitsyn (2002), for Baltic amber (Russia and Poland, Late Eocene) - Wheeler (1915) and our unpublished observations; for Florissant (latest Eocene, Colorado, USA) - Carpenter (1930); for Sicilian amber (Upper Oligocene of Italy) - Emery (1891); for Radoboj (Lower Miocene of Croatia) - Mayr (1867) with our additions; for Vishnevaja Balka (Middle Miocene of Stavropol, Russia) - Dlussky (1981a).

The comparison traditionally refers to composition of past assemblages at the subfamily level (Table 3). It has been shown (Dlussky 1983, 1987; Dlussky \& Rasnitsyn 2002) that the Late Cretaceous assemblages were dominated by extinct Armaniidae and Sphecomyrminae, with extant subfamilies Aneuretinae, Dolichoderinae, Formicinae, Ponerinae and Myrmicinae known from rare (usually unique) plesiomorphic fossils. Since the end of the Late Cretaceous, Armaniidae and Sphecomyrminae are no longer found in the fossil record; which starts containing only extant subfamilies, with the sole exception of the short-living (Early and Middle Eocene only) monotypical giant Formiciinae, and subfamilies became the highest-level changes in composition of the ant assemblages. The Palaeocene (Sakhalin amber), Eocene (Green River and European ambers) and possibly in Oligocene (except the zoogeographically different - Afrotropical - Sicilian amber, and 


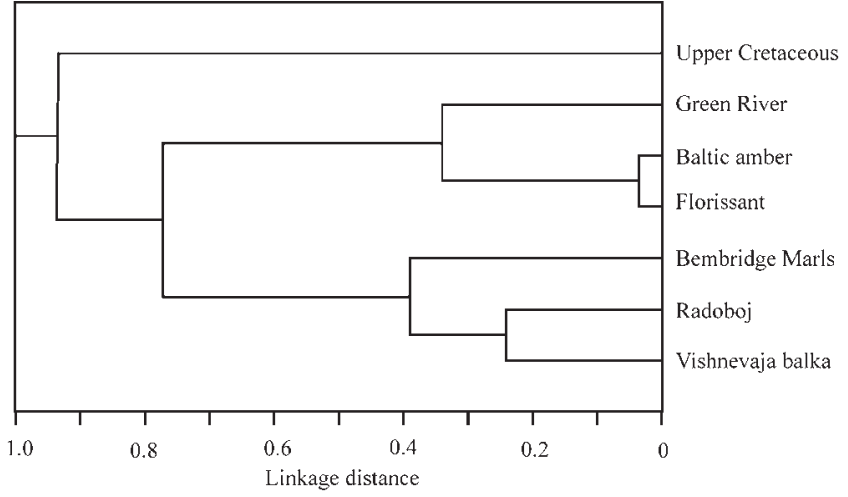

Text-figure 89 Dendrogram of similarity of the subfamily level composition of the best known ant rock fossil assemblages in the unweighted pair-group average.

supposing the Florissant assemblage to be of Oligocene rather than uppermost Eocene in age) are characterised by dominating Dolichoderinae and rare Myrmicinae. It is only in the Miocene (or in the Late Oligocene, if Sicilian amber is taken into consideration) when the subfamily level composition of the ant assemblages approached the contemporary pattern, with dominating Formicinae and Myrmicinae and far subordinated Dolichoderinae.

Table 3 shows that the Bembridge assemblage differs somewhat from the above sequence in that it is strictly dominated by Formicinae $(81 \cdot 3 \%$, the highest percentage ever observed throughout the known ant history), Dolichoderinae far subordinate $(13.8 \%)$, and Myrmicinae $(0.5 \%)$ being the rarest. The dendrogram based on cluster analysis shows this pattern particularly clearly (Text-fig. 89). Cretaceous assemblages are naturally the most distinct, and the Cenozoic ones form two clusters; one composed of the Baltic amber and Florissant, and a little more distant Green River, and the other cluster embracing the Bembridge and Miocene assemblages. The particular similarity of the Baltic amber and Florissant is based on their virtually identical shares of Formicinae and Dolichoderinae; that of the second cluster is the result their high share of Formicinae, and the still higher similarity of Vishnevaya and Radoboj depends on the high participation of Myrmicinae. Hence, the geochronologically similar Bembridge and Florissant faunas reveal quite different relationships - the former closer to Miocene, and the latter to Eocene assemblages.

However, the pattern does not seem convincing, particularly when considering the generic level composition of the assemblages. Indeed, Florissant is dominated by Protazteca $(28 \cdot 2 \%)$ which has no analogue in Baltic amber, and Liometopum $(30 \cdot 4 \%)$ known in Baltic assemblage from two specimens of the same species. Unlike Florissant, the Baltic assemblage is dominated by Ctenobethylus $(47.0 \%)$ unknown at Florissant. This makes it important to make a wider generic level comparison; which is difficult, however, because the Bembridge assemblage is rich in morphogenera not directly comparable to genera in other assemblages.

The problem might be resolved to some extent by relying partly on intuition, comparing the similarity of morphogenera to particular ant orthogenera. In particular, we associate Emplastus with Iridomyrmex s.l. (Iridomyrmex + Anonychomyrma + Ctenobethylus), Leucotaphus gurnetensis with Lasius, Leucotaphus donisthorpei with Prenolepis, and Ponerites + Taphopone with Ponera + Hypoponera + small-sized Pachycondyla. The Cretaceous and Green River assemblages are excluded from consideration because these genera are absent there, and Green River is dominated by the morphogenus

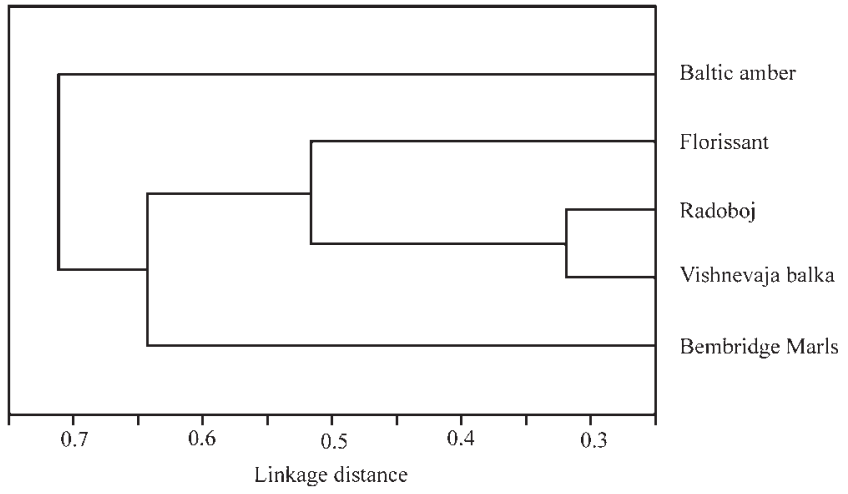

Text-figure 90 Dendrogram of similarity of the genus level composition of the best known ant rock fossil assemblages in the unweighted pair-group average.

Eoformica, which is impossible at present to associate with orthogenera because of poor preservation.

The resulting dendrogram (Text-fig. 90) shows the Baltic amber assemblage to be isolated while Florissant is closer to the Miocene assemblages than Bembridge is; apparently because of a higher share of Lasius (25.0\% in Florissant, 33.3\% in Radoboj and $34 \cdot 2 \%$ in Vishnevaya, as opposed to $13.9 \%$ of Leucotaphus gurnetensis in Bembridge).

The isolated position of the Baltic amber assemblage is apparenly taphonomically based (Dlussky \& Rasnitsyn 2002). The ants trapped in resin are mostly workers running about on tree trunks, with those of smaller size having more chance to be trapped there. As a result, larger ants and soil and litter dwellers have less chance to become amber inclusions. Unlike them, to become impression fossils, an ant has to be buried in the bottom sediments of an ancient lake. The allochthonous insects (those living outside the target lake) find their way to future burial mostly from the air (Zherikhin 1980). That is why the chance to become an impression fossil is higher for winged ants, and particularly for those in aerial swarms (mating flight with copulation starting in air, as opposed to the ground swarm where males and females copulate only after the dispersal flight is over (Kannowski 1963)). Aerial swarms often involve numerous ant sexual forms, travelling far from their start area (swarms can be found tens of kilometres beyond the ants' northern limits as recorded in tundra (Dlussky 1967)). In contrast, ground swarming female ants (for example, Formica L.) execute a comparatively short flight, while males are flying low over the ground to seek females by their pheromones. Thus their potential to become impression fossils is lower.

Hypothesising the burial of ants inhabiting the source environments of the late Eocene European ambers (Baltic and others) in water bodies whose deposits would become fossiliferous rocks, we would expect the resulting ant assemblages to be much different than those in the ambers. Firstly, they would probably have a higher proportion of Oecophylla. Baltic amber has yielded two species of the genus, jointly producing less than $1 \%$ of the assemblage. This is not surprising, as these ants are large and long-legged, and more likely to escape resin traps compared to other ants. Still more importantly, they are tightly connected with angiosperm trees and their workers would have had little reason to visit the amber source trees, which were conifers. Secondly, the proportion of Ctenobethylus would be much lower. Alates of this genus are noticeably rare in amber $-0 \cdot 3 \%(\mathrm{n}=5685$; figures in this paragraph summarise those by Mayr 1868, Wheeler 1915, and our unpublished observations). Other ants, both supposed dendrobiotic and herpetobiotic (forager on the surface of soil), show a higher share of 
their sexual forms: herpetobiotic Lasius schiefferdeckeri Mayr $3.7 \%(\mathrm{n}=1719)$, Formica spp. 9.9\% $(\mathrm{n}=1448)$, Prenolepis henschei Mayr - 10.3\% ( $=715)$; herpetobiotic or dendrobiotic Iridomyrmex geinitzi (Mayr) - 2.6\% ( $\mathrm{n}=1260)$; specialised dendrobiotic Tetraponera spp. $-3 \cdot 3 \%(\mathrm{n}=61)$; and Dolichoderus spp. $-4 \cdot 6 \%(\mathrm{n}=653)$. As to geo- and stratobiotic ants (foraging within soil and leaf litter respectively), their amber inclusions are almost invariably alates: Paratrechina pygmaea (Mayr) - 98\% ( $\mathrm{n}=107)$, Hypoponera atavia (Mayr) - 94\% $(\mathrm{n}=52)$. This is quite natural, because their workers rarely leave the soil and leaf litter, unlike sexual forms that climb use trees to start their nuptial flight.

The exceedingly high proportion of worker inclusions in the case of Ctenobethylus has only one explanation: this ant nested in old conifer trees, had huge families and made very active trails towards colonies of symbiotic aphids. This inference is confirmed by the common syninclusions of these ants with Germaraphis aphids (Perkovsky 2006) and the high proportion of multiple inclusions of Ctenobethylus in a piece of amber. Our observations produced a figure of $9 \cdot 2 \%$ (56 out of 608), with more than one worker per piece (up to 11); and Wheeler (1915) noticed numerous such cases, including seven pieces with more than ten workers each (up to 50). As already mentioned, Ctenobethylus is apparently a close analogue (the closest relative) of Emplastus britannicus, the fourth most common ant in the Bembridge assemblage, with a share of $10 \cdot 1 \%$.

The third most likely feature of the fossil ant assemblage expected in rocks resulting from an ant community populating the amber forest is a lower proportion of Formica. This inference can be deduced from the observation that these ants do not form nuptial swarms and thus have a comparatively low chance of being buried in a target water body. Formica is absent from the Vishnevays Balka, although there is little doubt that these ants lived near the water body of burial. The Bembridge Marls apparently lack ant fossils referable to that genus (there are no large Leucotaphus there comparable to the Formica sexual forms). In contrast, $10 \%$ of the Baltic assemblage are Formica ants, mainly Formica flori Mayr, 1868 and Formica gustawi Dlussky, 1967.

Thus, the expected rock fossil assemblage of ants from the Late Eocene amber forest would show considerable similarity to the Bembridge assemblage. This would then only highlight differences between the European (Baltic and Bembridge) and American (Florissant) assemblages, as follows:

1. Protazteca is the most abundant ant group in Florissant (28.3\%), but neither the genus nor its analogues are known in the present and past in Europe.

2. In contrast, Oecophylla is common in the European Eocene, Oligocene and Miocene, as well as in the contemporary tropics of the Old World, but has never been recorded in the past and present Americas.

3. The Florissant assemblage lacks small Ponerinae dwelling within the leaf litter (Ponera, Hypoponera, Ponerites), which are well represented in the Cenozoic assemblages of Europe.

In contrast, the Bembridge ant assemblage shows significant similarity to those in the European Miocene. As already mentioned, the second most abundant Bembridge species, Leucotaphus gurnetensis, is probably similar to Lasius; the Vishnevaya Balka assemblage has Lasius vetulus Dlussky, 1981, equally the second most common ant there, which probably deserves to be transferred to Leucotaphus. The Bembridge Marls contain ant wings attributable to Paraphaenogaster, which were previously known only from the Miocene of Europe (described from Vishnevays and also identified by GMD in the collections from Oeningan and Parschlung kept at the NHMUK) and China. Aphaenogaster sommerfeldti
Mayr, 1868 from Baltic amber and A. mayri Carpenter, 1930 from Florissant are not attributable to Paraphaenogaster because they have cell rm closed. It is quite possible that the wing described as Camponotites macropterus Dlussky, 1981 in fact represents Oecophylla, otherwise known in the European Miocene of Radoboj and Oeningen (O. obesa (Heer), Mayr, 1867). Dolichoderus vectensis of the Bembridge Marls belongs to the D. quadripunctatus group equally known in Baltic amber (Dlussky 2002) and the European Miocene (D. haueri (Mayr, 1867) from Radoboj, D. tauricus Dlussky, 1981 from Kerch, Ukraine) and not in the present and past Americas.

The above pattern indicates that the widely traceable generic level similarity of the Cenozoic (late Eocene through to Miocene) ant faunas shows its geographic orientation as more distinct than the temporal one. Within the above time interval, the Old World ant faunas are more similar to each other than to the synchronous American assemblages. For insects at least, this is a rather uncommon example of a geographically constrained evolution which inherits features of taxonomic composition of regional faunas for a long time, despite their intense evolution. There are further examples of this sort; e.g., the Myrmicinae ants whose evolution was apparently moslty confined to Africa (Dlussky et al. 2004), or honey bees which are confined to the Old World throughout all their rather long history (Engel 2006). This may indicate that evolution of highly social insects might be particularly geographically constrained compared to other insects. However, more detailed testing of this hypothesis lies far beyond the scope of the present project.

\section{General discussion}

\subsection{Composition of the Bembridge Marls hymenopteran assemblage}

1460 fossils were studied, which yielded a minimum of 118 species, counting those identified to any level, but only those that are evidently different from others identified to the same level. These 118 species represent 20 families and at least 78 genera.

In Ichneumonidae, 32 fossils were studied, including the types of 11 species described by Cockerell (1921a). One new genus and eight new species are described: Exeristes gurnetor Khalaim, sp. nov.; Scambus fossilis Khalaim, sp. nov.; Eusterinx humalai Khalaim, sp. nov.; Hemiteles dirus Khalaim, sp. nov.; Hemiteles protervus Khalaim, sp. nov., Paxylobembra kozlovi Khalaim, gen. et sp. nov.; Marjorietta gigantea Khalaim, sp. nov.; and Lithapechtis salmacidus Khalaim, sp. nov. The genus Acourtia Cockerell, 1921 is transferred to the subfamily Townesitinae. The following new combinations are established: Eusterinx arcuatus (Cockerell, 1921); Hemiteles acourti (Cockerell, 1921); and Marjorietta disrupta (Cockerell, 1921). The most abundant subfamilies are Cryptinae (five specimens), Pimplinae (five specimens), Townesitinae (three specimens) and Orthocentrinae (three specimens), and the genus Lithapechtis Cockerell, 1921 (three specimens) of uncertain subfamily assignment. The subfamilies Metopiinae and Paxylommatinae are known from a single specimen each. Fossil Townesitinae and Paxylommatinae are known from the Bembridge Marls and from Baltic amber only. Townesitinae are quite numerous and are very similar morphologically in both deposits. The ichneumonid fauna of the Bembridge Marls is close to that of the Baltic amber, and these two are apparently older than that of Florissant.

The Braconidae are represented by 13 subfamilies (Agathidinae, Brachistinae, Braconinae, Cheloninae, Doryctinae, Euphorinae, Exothecinae, Helconinae, Homolobinae, Microgastrinae, Opiinae, Orgilinae and Rhyssalinae) and 23 genera and 36 species are recorded. Two new genera and 26 new 
species are described: Bassus magnareola Belokobylskij, sp. nov.; Eubazus ? brodiei Belokobylskij, sp. nov.; E. flavistigma Belokobylskij, sp. nov.; E. ? grandareola Belokobylskij, sp. nov.; E. ? hooleyi Belokobylskij, sp. nov.; E. nanus Belokobylskij, sp. nov.; Bembracon acourtsmithi Belokobylskij, gen. sp. nov.; $B$. medialis Belokobylskij, sp. nov.; Bracon ? antefurcalis Belokobylskij, sp. nov.; B. brodiei Belokobylskij, sp. nov.; Ascogaster (Ascogaster) brodiei Belokobylskij, sp. nov.; A. (A.) yulei Belokobylskij, sp. nov.; A. (A.) pygmaea Belokobylskij, sp. nov.; Ontsira cenozoica Belokobylskij, sp. nov.; Meteorus applanatus Belokobylskij, sp. nov.; M. crassitergum Belokobylskij, sp. nov.; Chremylus infuscatus Belokobylskij, sp. nov.; Aspicolpus temporalis Belokobylskij, sp. nov.; Diospilus curtithorax Belokobylskij, sp. nov.; Hellenius ? kozlovi Belokobylskij, sp. nov.; Homolobus rasnitsyni Belokobylskij, sp. nov.; Palaeomicrogaster oculatus Belokobylskij, gen. sp. nov.; Semionis wightensis Belokobylskij, sp. nov.; Dolopsidea ? intermedia Belokobylskij, sp. nov.; Oncophanes andrewrossi Belokobylskij, sp. nov.; and Rhyssalus bruesi Belokobylskij, sp. nov. The taxonomic status of Syntaphus Donisthorpe, 1920 is reduced to subgeneric level into Ascogaster Wesmael, 1835 (syn. nov.). The genus Diospiloides Cockerell, 1921 is a junior synonym of Microtypus Ratzeburg, 1848 (syn. nov.). The following new combinations are suggested: Bassus quadrangularis (Brues, 1933), Bracon micrarche (Cockerell, 1921), Cyanopterus vectensis (Cockerell, 1921), Ascogaster wheeleri (Donisthorpe, 1920), Ontsira colenutti (Cockerell, 1921), O. distracta (Cockerell, 1921), Taphaeus cervicalis (Cockerell, 1921), Biosteres peritus (Cockerell, 1921), and Microtypus hooleyi (Cockerell, 1921). The genus Calyptoides Cockerell is transferred to the subfamily Helconinae and the genus Dacnusites Cockerell to Microgastrinae. A discussion about contents, validity, generic and species combinations in the aforementioned subfamilies is provided.

In Aculeata s.str., other than ants, two new monotypic genera Palaeopolybia Antropov, gen. nov. for $P$. anglica (Cockerell, 1921), and Protopolistes Antropov, gen. nov. for O. oblitus (Cockerell, 1921) are established in Polistinae, and Sphaerancistrocerus petiolatus Antropov, gen. sp. nov. is described in Eumeninae (Vespidae). Also described are Dryophia oculata Antropov, gen. et sp. nov. (Dryophiinae, Tiphiidae) and Palaeoscolia relicta Antropov, gen. sp. nov. (Palaeoscoliinae Antropov, subfam. nov., Scoliidae), and Oligobombus cuspidatus Antropov, gen. et sp. nov. is described in Apinae (Apidae). Protosceliphrini Antropov, trib. nov. and Protosceliphron Antropov, gen. nov. are described for Sceliphron brevior Cockerell, 1921 in the family Sphecidae. Tytthopsen nanus Antropov, gen. et sp. nov. and Plisomena gigantea Antropov, gen. et sp. nov. are described in Pemphredoninae (Crabronidae).

The ant (Formicidae) assemblage studied includes 20 species, ten genera, and five subfamilies, of which nine species and two genera are described as new: Emplastus kozlovi Dlussky \& Perfilieva, sp. nov.; Leucotaphus donisthorpei Dlussky \& Perfilieva, sp. nov.; Ponerites hooleyi Dlussky \& Perfilieva, sp. nov.; $P$. antropovi Dlussky \& Perfilieva, sp. nov.; Taphopone macroptera Dlussky \& Perfilieva, sp. nov.; T. microptera Dlussky \& Perfilieva, sp. nov.; T. petrosa Dlussky \& Perfilieva, sp. nov.; T. aberrans Dlussky \& Perfilieva, sp. nov.; Paraphaenogaster hooleyana Dlussky \& Perfilieva, sp. nov.; Britaneuretus Dlussky \& Perfilieva, gen. nov.; and Taphopone Dlussky \& Perfilieva, gen. nov. Nine new combinations are proposed: Britaneuretus anglicus (Cockerell, 1915); Emplastus britannicus (Cockerell, 1915); E. hypolithus (Cockerell, 1915); E. gurnetensis (Donisthorpe, 1920); Camponotus cockerelli (Donisthorpe, 1920); Leucotaphus gurnetensis (Cockerell, 1915); Ponerites crawleyi (Donisthorpe, 1920); Taphopone karaganensis (Dlussky, 1981); and Taphopone stauropolitana (Dlussky, 1981). Ants are the most common hyme- nopteran family in the Bembridge Marls, differing from other fossil ant assemblages because of the overwhelming dominance of Oecophylla weaver ants. Composition of the ant assemblage indicates a warm climate, with temperature permanently above $0^{\circ} \mathrm{C}$, and a forested landscape with abundant broad-leaved trees. At a generic level, past ant assemblages have more in common geographically than geochronogically. Also described is Oxyserphus kozlovi Kolyada, sp. nov. (Proctotrupidae).

Thus, the assemblage appears to be one of the richest among the rock fossil hymenopteran assemblages, even if it is second to the Florissant assemblage, which has always attracted much more attention, comprising 291 species, 161 genera and 37 families described but largely not yet revised (Meyer 2003). Out of 52 orthotaxonomical genera named in the Bembridge assemblage 18 are extinct (35\%). Also extinct are all species, two tribes and three subfamilies. All species but one, two tribes and two subfamilies are endemic to the Bembridge Marls hymenopteran fauna, with one species and one tribe endemic jointly to the Bembridge Marls and the Baltic amber. Aculeate wasps and bees are highly endemic, with all genera and several higher taxa known from no other fossil site, nor from any contemporary fauna. Other groups are less specific in distribution. The assemblage is overwhelmingly dominated by winged ants $(84 \%)$, an ordinary feature for the Cenozoic since the Eocene (Dlussky \& Rasnitsyn 2002). These are followed by Braconidae $(5 \cdot 1 \%)$, Ichneumonidae $(2 \cdot 3 \%)$, Diapriidae $(1 \cdot 6 \%)$ and Scelionidae $(0 \cdot 8 \%)$, with the remaining families less than $0.5 \%$ each. The braconid dominance over Ichneumonidae is unusual: this is characteristic of assemblages of amber inclusions, primarily because of the generally smaller size of braconids that are more likely to be stuck in resin traps, as compared with the water surface trap that produces rock fossils. In the Cenozoic rock fossil assemblages, ichneumonid wasps are normally either much more common than the braconid ones (in the Paleocene of Tadushi and in the Eocene/Oligocene of Biamo, the Asian analogue of Florissant, both in the Russian far east; and in the Miocene of Stavropol in Ciscaucasian, personal observation by APR), or of roughly similar proportion (in the Eocene of Green River, western N. America, personal observation by APR; and near the the Oligocene/Miocene boundary of Rott in Germany; Statz 1936).

\subsection{Palaeoenvironmental inferences}

4.2.1. Climate. Palaeoclimatic inferences from hymenopteran fossils are somewhat contradictory, a usual case for the Paleogene (Archibald \& Farrell 2003). Undoubtedly, the climate was warmer than it is now in southern England, as the absence of sawflies suggests, amongst many other indications. However, when looking at the details, we found some fossils of both tropical and warm subtropical affinities (Agaonidae fig pollinators, Oecophylla ants, Polybiini wasps), and those implying temperate conditions (at most a warm temperate climate), particularly the majority of Braconidae and several abundant ant taxa (noticeably Leucotaphus gurnetensis, which is similar to the genus Lasius). This contradiction can be resolved by employing the concept of an equable climate; that is, weakly seasonal even if not very warm, and so suiting both high and low thermophilous taxa (Archibald \& Farrell 2003). This reveals another problem, however: the paradigmatic example of equable climate is that exemplified by the Baltic amber biota, which nevertheless includes an appreciable share of animals depending on a seasonable climate, particularly the aphids. The Bembridge Marls biota shows few aphids and not their specific parasites (Aphidiidae) and so better fits the concept of equability. 
4.2.2. Landscape. Landscape signals from the Bembridge hymenopterans are also contradictory. The contradiction arises from the observation that some groups indicate a heavily forested territory, and the others imply extensive open meadows (A.J. Ross pers. comm., 2010). The former are primarily ants which are dendrobiotic, forming $60 \%$ of the fossil specimens, including those nesting in tree crowns and in tree trunks. 5\% live in the forest floor leaf litter, with the remaining ants being mainly eurytopic. Additionally, fig-pollinating Agaonidae indicate the presence of fig trees, and there are several xylobiotic parasitic and aculeate wasps found there (Gasteruptiidae, some Braconidae and Crabronidae). Ichneumonidae recorded are predominantly forest dwellers, and Orthocentrinae are particularly indicative of humid forests. Diapriidae being more abundant than Scelionidae also suggest a forested environment. In contrast, the majority of Braconidae indicate dominance of open meadows, and about a half of aculeate wasps and bees are ground- and not wood-nesting.

4.2.3. Biotic indication. As already mentioned, Agaonidae wasps infer the presence of fig trees. Oecophylla ants are closely connected to broadleaf trees, and some Braconidae indicate this type of vegetation. Braconid and, to a lesser extent, ichneumonid wasps imply an abundance of moths, both macro- and particularly microlepidopterans, including leaf miners. This confirms the hypothesis that the rarity of the lepidopterans in the Cenozoic rock fossil assemblages is taphonomically caused, and does not necessarily imply their rarity in the source biocenoses. However, Jarzembowski (1980) described 21 moth taxa from the Bembridge Marls. Parasitic wasps infer the presence of various other insect hosts. Noteworthy is the comparative rarity of xylobiotic hosts and an absence of the aphidiid parasites of aphids, and of Alysiinae, the specialised parasites of higher (calyptrate) flies.

4.2.4. Geography. The majority of the fossils are either non-indicative in respect of large-scale biogeography, or otherwise fit the hypothesis of the predominantly Eurasian (Palaearctic + Oriental) character of the past fauna. This holds particularly true of ants that share more taxa with the Eurasian assemblages of different age (e.g. Miocene ones) than with the Florissant assemblage of similar age in N. America. Alternative indications are uncommon, including Ambositrinae (Diapriidae) which are mainly Australasian and Neotropical now, with one species Nearctic, one Afrotropical and three recorded in the Baltic amber, one being very close to the Afrotropical one. Oxyserphys (Proctotrupidae) is also mainly Australian, but known in the Oriental region up to Japan and in Central America as well. Semionis (Braconidae) is now restricted to S. Africa. As in many other cases, the "Gondwanan" distribution of the above taxa results most probably from contraction of the wider past distribution (Eskov 2002). As to the unexpectedly high level of endemism of aculeate wasps and bees in the Bembridge assemblage, which concerns all their genera and a few tribes and subfamilies, this effect shows no parallel in other hymenopteran taxa and so should be considered as characteristic of these aculeates themselves, rather than an indication of the isolated position of the source territory. Indeed, there are many genera there in common with the Baltic amber and Florissant, and one species (Bassus quadrangularis, Braconidae) and one subfamily (Townesitinae, Ichneumonidae) only occur in the Bembridge and Baltic assemblages.

4.2.5. Geochronology. Hymenopteran evolution is comparatively slow during the Cenozoic, with few higher rank taxa going extinct in that interval, and well dated cases of first appearances are uncommon. That is why the geological time correlation signals from the Cenozoic hymenopterans are rarely conclusive. Yet we have some signals of that sort; first of all, the presence of Townesitinae and the absence of Ichneu- moninae (Ichneumonidae) from the Bembridge assemblage. Townesitinae is an extinct subfamily characteristic of Baltic amber and the Bembridge fauna and not recorded in younger strata, including the Florissant beds. Alternatively, Ichneumoninae are recorded neither in the Bembridge Marls, nor in the Baltic amber or in any older fossil sites, but they are common in the Florissant beds and also recorded from the Miocene. The same might also hold true of Alysiinae (Braconidae): this group is recorded in number from the Florissant and Miocene deposits, unlike the Bembridge fauna, the Baltic amber and all the older insect sites. However, all records of Alysiinae badly need revision and so should be used carefully. Also, the higher (calyptrate) Diptera, the alysiine hosts, have a generally similar time range. Taken altogether, these observations suggest that the Bembridge Marls might be older than the Florissant.

\section{Acknowledgements}

The authors are thankful to Andrew J. Ross for his continuous help, to the anonymous reviewer for his very important suggestions and comments, to INTAS for the financial support, to Phil Crabb (NHMUK) for photography and to Bill Crighton (NMS) for checking the English. Additionally, AVA thanks David Notton (NHMUK) for help in the study of the collections of extant aculeates. SAB is indebted to Dr. A.P. Rasnitsyn for valuable consultations and discussion of the early draft of this paper, to Dr. A. Khalaim for important help with preparation of the photos of fossil insects, and to Dr. A. Zaldivar-Riveron for help with literature. SGC thanks Andrew Ross for the invitation to examine this material, and Simon van Noort (Iziko South African Museum, Cape Town) for providing comments on the manuscript. GMD and KSP are thankful to Dr. Conrad Labandeira, who made available for study the ant types by Donistorpe (1920) kept at NMNH, Washington, and to A.P. Rasnitsyn for his primary sorting of NHMUK hymenopteran fossils. AIK appreciates the help by S.A. Belokobylskij and D.R. Kasparyan (ZISP RAS) and A.P. Rasnitsyn (PIN RAS) in the preparation of this paper. APR is thankful to all coauthors for their help, patience and understanding, and to Lubo Masner (Canadian National Collection of Insects, Ottawa), Simon van Noort (South African Museum, Cape Town) and Jean-Yves Rasplus (Institut national de la Recherche Agronomique, France) for help in identification of some platygastroid and agaonid fossils.

The present work contributes to INTAS Project No. 03-514367. It is additionally supported in part by the Russian Foundation for Basic Research: for SAB and AIK, No. 07-0400454 and No. 13-04-00026; and for GMD and KSP, No 0504-49419. For SAB, APR and AIK, it is also supported in part by the Presidium RAS Program "Origin and evolution of Biosphere, Subprogram II".

\section{References}

Achterberg, C. van. 1977. A new Holarctic genus, Spathicopis gen. nov., belonging to the Euphorinae, Centiscini (Hymenoptera: Braconidae). Entomologische Berichten, Amsterdam 37, 27-31

Achterberg, C. van. 1979. A revision of the subfamily Zelinae auct. (Hymenoptera, Braconidae). Tijdschrift voor Entomologie 122, 241-79.

Achterberg, C. van. 1982. The fossil species of the subfamily Blacinae described by C.T. Brues (Hym.: Braconidae). Entomologische Berichten 42, 91-96.

Achterberg, C. van. 1988. Revision of the subfamily Blacinae Foerster (Hymenoptera, Braconidae). Zoologische Verhandelingen Leiden 249, 3-324.

Achterberg, C. van. 1993. Illustrated key to the subfamilies of the Braconidae (Hymenoptera: Ichneumonoidea). Zoologische Verhandelingen Leiden 283, 3-189. 
Achterberg, C. van. 2001. The first known fossil Masoninae (Hymenoptera: Braconidae) from Miocene Dominican amber. Zoologische Mededelingen Leiden 75(21), 393-96.

Achterberg, C. van. 2002. Revision of the genus Canalicephalus Gibson and the recognition of the Acampsohelconinae (Hymenoptrera: Braconidae) as extant. Zoologische Mededelingen Leiden, 76(20), 347-70.

Ahmed, S., Compton, S. G., Butlin, R. K. \& Gilmartin, P. M. 2009 Wind borne insects mediate directional pollen transfer between desert fig trees 160 kilometers apart. Proceedings of the National Academy of Sciences 106, 20342-47.

Antropov, A. V. 1992. Five new neotropical species of the genus Spilomena (Hymenoptera, Sphecidae Pemphredoninae), with additional comments on the previously described species. Russian Entomological Journal 1, 67-73.

Antropov, A. V. 1993. Further supplements to the knowledge of the neotropical fauna of digger wasps of the genus Spilomena (Hymenoptera, Sphecidae Pemphredoninae). Russian Entomological Journal 1, 41-57.

Antropov, A. V. 2000a. Digger Wasps (Hymenoptera, Sphecidae) in Burmese amber. The history, geology, age and fauna (mainly insects) of Burmese amber, Myanmar. Bulletin of The Natural History Museum, Geology Series 56, 59-77.

Antropov, A. V. 2000b. A new digger wasp (Hymenoptera, Sphecidae, Pemphredoninae) from New Jersey amber. In Grimaldi, D. (ed.) Studies on fossils in amber, with particular reference to the Cretaceous of New Jersey, 339-43. Leiden: Backhuys Publishers. Viii $+498 \mathrm{pp}$.

Archibald, S. B. \& Farrell B. D. 2003. Wheeler's dilemma. In Krzeminska E. \& Krzeminski W. (eds) Proceedings of the Second Congress on Paleoentomology "Fossil Insects", Kraków, Poland, 5-9 September 2001. Acta Zoologica Cracoviensia 46 (supplement), 17-23. $440 \mathrm{pp}$.

Ashmead, W. H. 1899. Classification of the entomophilous wasps, or the superfamily Sphegoidea. The Canadian Entomologist 31, 34557.

Ashmead, W. H. 1900. Classification of the Ichneumon flies, or the superfamily Ichneumonoidea. Proceedings of the United States National Museum 23, 1-220.

Ashmead, W. H. 1903. Provespa, a new genus in the Vespidae. Entomological News 14, 182.

Basibuyuk, H. H., Rasnitsyn, A. P., Achterberg, C. Van, Fitton, M. G. \& Quicke D. L. J. 1999. A new putatively primitive Cretaceous fossil braconid subfamily from New Jersey amber (Hymenoptera, Braconidae). Zoologica Scripta 28 (1/2), 211-14

Belokobylskij, S. A. 1986. New braconid genus from the supertribe Exothecidii (Hymenoptera, Braconidae). Entomologicheskoe Oboz renie 65(4), 780-83. [In Russian.]

Belokobylskij, S. A. 1995. Revision of the Palaearctic species of the genus Clinocentrus (Hymenoptera, Braconidae). Journal of Natural History 29, 803-36.

Belokobylskij, S. A., Iqbal, M. \& Austin, A. D. 2004a. Systematics, distribution and diversity of the Australasian doryctine wasps (Hymenoptera, Braconidae, Doryctinae). Records of the South Australian Museum, Monograph Series 8, 1-150.

Belokobylskij, S. A., Zaldivar-Riveron, A. \& Quick, D. L. J. 2004b. Phylogeny of the genera of the parasitic wasps subfamily Doryctinae (Hymenoptera: Braconidae) based on morphological evi dence. Zoological Journal of the Linnean Society 142, 369-404.

Betrem, J. G. 1933. Die Scoliiden der indoaustralischen und palearktischen Region aus dem staatlichen Museum für Tierkunde zur Dresden. Stettiner entomologische Zeitung 94(2), 236-63.

Bingham, C. T. 1903. The fauna of British India, including Ceylon and Burma. Hymenoptera 2. Ants and cuckoo-wasps. London. 506 pp.

Bohart, R. M. \& Menke, A. S. 1976. Sphecid Wasps of the World. A generic revision. Berkeley, Los Angeles, London: University of California Press. 1 colour plate, IX +695 pp.

Bolton, B. A. 1994. Identification Guide to the Ant Genera of the World. Cambridge, MA: Harvard University Press. $222 \mathrm{pp}$.

Bolton, B. A. 1995. New General Catalogue of the Ants of the World. Cambridge, MA: Harvard University Press. 504 pp.

Bookstein, F. L. 1991. Morphometric tools for landmark data: geometry and biology. Cambridge, UK: Cambridge Univ. Press, 198 p.

Bouček, Z. 1997. Agaonidae.. In Gibson, G. A. P., Huber, J. T. \& Woolley, J. B. (eds) Annotated Keys to the Genera of Nearctic Chalcidoidea (Hymenoptera), 117-33. Ottawa, Ontario, Canada: NRC Research Press. 794 pp.

Brischke, D. 1886. Die Hymenopteren des Bernsteins. Schriften der Naturforschenden Gesellschaft in Danzig 6(3), 278-79.

Brodie, P. B. 1875. Tertiary fossil ants in the Isle of Wight. Nature $\mathbf{5 2}$ 570.
Brothers, D. J. \& Finnamore, A.T. 1993. Chapter 8, Superfamily Vespoidea. In Goulet, H. \& Huber, J.T. (eds). Hymenoptera of the world: An identification guide to families, 161-278. Publication 1794/E. Canada Communication Group, Ottawa, Canada. 668 pp.

Brues, C. T. 1906. Fossil parasitic and phytophagous Hymenoptera from Florissant, Colorado. Bulletin of the American Museum of Natural History 22, 491-98.

Brues, C. T. 1910. The parasitic Hymenoptera of the Tertiary of Florissant, Colorado. Bulletin of the Museum of Comparative Zoology at Harvard College 54(1), 4-125.

Brues, C. T. 1922. Some parasitic Hymenoptera from New Zealand. Psyche 29, 216-25.

Brues, C. T. 1923. Some new fossil parasitic Hymenoptera from Baltic amber. Proceedings of the American Academy of Arts and Sciences 58, 327-46.

Brues, C. T. 1933. The parasitic Hymenoptera of the Baltic amber Bernstein Forschungen 3, 4-178.

Brues, C. T. 1937. Superfamilies Ichneumonoidea, Serphoidea, and Chalcidoidea. In Carpenter, F. M., Folsom, J. W., Essig, E. O., Kinsey, A. C., Brues, C. T., Boesel, M. W. \& Ewig H. E. 1937. Insects and arachnids from Canadian amber. University of Toronto Studies. Geological Series 40, 27-44.

Brues, C. T. 1939. New Oligocene Braconidae and Bethylidae from Baltic amber. Annals of the Entomological Society of America 32, 251-63.

Budrys, E. R. 1993. Digger wasps of the subfamily Pemphredoninae (Hymenoptera, Sphecidae) from the Baltic and Taimyr amber. Acta Entomologica Lituanica 2, 34-56.

Burnham, L. 1978. Survey of social insects in the fossil records. Psyche 89, 85-133.

Cameron, P. 1900. Hymenoptera orientalis, or contributions to the knowledge of the Hymenoptera of the Oriental zoological region. Part 9. The Hymenoptera of the Khasia Hills. Part II, Section 1 Memoirs of the Manchester Literary and Philosophical Society 44(15), 1-114.

Carpenter, F. M. 1930. The fossil ants of North America. Bulletin of the Museum of Comparative Zoology 70, 1-66.

Carpenter, F. M. 1992. Superclass Hexapoda. In Moore, R. C. \& Kaesler, R. L. (eds) Treatise on Invertebrate Paleontology, Part $R$, Arthropoda 4, Volume 3 and 4. Boulder, Colorado, and Lawrence, Kansas: The Geological Society of America and the University of Kansas Press. XXII + 655 pp.

Carpenter, F. M., Folsom, J. W., Essig, E. O., Kinsey, A. C., Brues, C. T., Boesel, M. W. \& Ewig H. E. 1937. Insects and arachnids from Canadian amber. University of Toronto Studies. Geological Series 40, 7-62.

Carpenter, J. M. 2000. A vespid wasp from New Jersey Cretaceous amber. In Grimaldi, D. A. (ed.) Studies on fossils in amber, with particular reference to the Cretaceous of New Jersey, 333-37. Leiden, The Netherlands: Backhuys.

Carpenter, J. M. \& Grimaldi, D. A. 1997. Social wasps in amber. American Museum Novitates 3203, 1-7.

Carpenter, J. M. \& Rasnitsyn, A. P. 1990. Mesozoic Vespidae. Psyche 97, $1-20$

Cockerell, T. D. A. 1906. Fossil Hymenoptera from Florissant, Colorado. Bulletin of the Museum of Comparative Zoology 50, 33-58.

Cockerell, T. D. A. 1907. Some fossil arthropods from Florissant, Colorado. Article XXIV. Bulletin of the American Museum of Natural History 23, 605-16.

Cockerell, T. D. A. 1908. Descriptions and records of bees - XX. The Annals and Magazine of Natural History, Series 8 2, 323-34.

Cockerell, T. D. A. 1909. Descriptions of Hymenoptera from Baltic Amber. Mitteilungen aus dem geologisch-palaeontologischen Institut und der Bernsteinsammlung der Universität Königsberg i. Pr. 3 229_ 33.

Cockerell, T. D. A. 1913. Some fossil insects from Florissant, Colorado. The Canadian Entomologist 45, 229-33.

Cockerell, T. D. A. 1915. British fossil insects. Proceedings of the United States National Museum 49, 469-99, plates 60-65.

Cockerell, T. D. A. 1919. Some fossil parasitic Hymenoptera. American Journal of Science, Series 4 47, 376-80.

Cockerell, T. D. A. 1920a. Eocene insects from the Rocky Mountains. Proceedings of the United States National Museum 57, 233-60.

Cockerell, T. D. A. 1920b. Fossil arthropods in the British Museum.1. Annals and Magazine of Natural History, Series 9 5, 273-79.

Cockerell, T. D. A. 1921a. Fossil Arthopods in the British Museum. V. Oligocene Hymenoptera from the Isle of Wight. Annals and Magazine of Natural History, Series 9 7, 1-25.

Cockerell, T. D. A. 1921b. Fossils Arthropods in the British Museum - VII. Annals and Magazine of Natural History, Series 9 8, 54145 . 
Cockerell, T. D. A. 1922. Two families of insects new to British Tertiary strata. The Canadian Entomologist 54, 33-34.

Cockerell, T. D. A. 1927. Fossil insects from the Miocene of Colorado. Annals and Magazine of Natural History, Series 9 19, 161-66.

Cockerell, T. D. A. 1941. Some tertiary insects (Hymenoptera) from Colorado. American Journal of Science 239, 354-56.

Collinson, M. E. 1989. The fossil record of the Moraceae. In Crane, P. R. \& Blackmore, S. (eds) The evolution, systematics and fossil history of the Hamamelidae. Vol. 2, "Higher Hamamelidae", 319-39. Oxford: Oxford University Press.

Compton, S. G., Ball, A. D., Collinson, M. E., Hayes, P., Rasnitsyn, A. P. \& Ross, A. J. 2010. Ancient fig wasps indicate at least 34 Myr of stasis in their mutualism with fig trees. Biology Letters $\mathbf{6}$, $838-42$.

Costa, A. 1858. Fauna del Regno di Napoli ossia Enumerazione di tutti gli Animali che abitano le diverse Regioni di questo Regno e le Acque che le bagnano e Descrizione de 'nuovi o poco esattemente conosciuti con Figure ricevute de Originali viventi e dipinte al naturale. Imenotteri Aculeati. Sfecidei. Napoli: Gaetano Sautto. pp. 1-28, plates $1-$ III

Dahlbom, A. G. 1835. Clavis novi Hymenopterorum systematis anatomia externa, metamorphosi moribusque horum animalium simul consideratis; adjecta synopsi larvarum ejusdem ordinis Scandinavicarum eruciformium. Lundae: Carolus F. Berling. i-v + 40 pp, 1 plate.

Dahlbom, A. G. 1843. Hymenoptera Europaea praecipue borealia; formis typicis nonnullis Specierum Generumve Exoticorum aut Extraneorum propter nexum systematicus associatis; per Familias, Genera, Species et Varietates disposita atque descripta. Tomus: Sphex in sensu Linneano. Officina Lundbergiana, Lund, xliv Fasc. 1, 1-172.

Dahlbom, A. G. 1845. Hymenoptera Europaea praecipue borealia; formis typicis nonnullis Specierum Generumve Exoticorum aut Extraneorum propter nexum systematicus associatis; per Familias, Genera, Species et Varietates disposita atque descripta. Tomus: Sphex in sensu Linneano. Officina Lundbergiana, Lund, xliv Fasc. 3, 353-528, i-xliv, tables.

Dalla Torre, K. W. v. 1880. Unsere Hummel - (Bombus) Arten. Naturhistoriker 2, 40-41.

Dalman, J. W. 1820. Försök till Uppställning af Insect-familjen Pteromalini, i synnerhet med afseen de på de i Sverige funne Arter. Kongliga Svenska Vetenskaps Academiens Nya Handlingar, Stockholm 41, 123-74, 177-82, tab VII-VIII.

Danforth, B. 1989. The evolution of hymenopteran wings: the importance of size. Journal of Zoology 218, 247-76.

Dlussky, G. M. 1967. [Ants of the genus Formica.] Moscow: Nauka Press. 230 pp. [In Russian.]

Dlussky, G. M. 1975. [Superfamily Formicoidea.] In Rasnitsyn, A. P. (ed.) [Hymenoptera Apocrita of the Mesozoic.] Transactions of Paleontological Institute, Academy of Sciences of the USSR 147, 114-22. [In Russian.]

Dlussky, G. M. 1981a. [Miocene ants (Hymenoptera, Formicidae) of the USSR.] In Vishnjakova, V. N., Dlussky, G. M. and Pritykina, L. N. (eds) [New fossil insects from the territory of the USSR,] 6483. Moscow: Nauka Press. 86 pp. [In Russian.]

Dlussky, G. M. 1981b. [Desert ants.] Moscow: Nauka Press. 236 pp. [In Russian.]

Dlussky, G. M. 1983. [A new family of Upper Cretaceous Hymenoptera: an "intermediate link" between the ants and scolioids.] Paleontologicheskiy Zhurnal 1983(3), 65-78. [In Russian; English translation: Paleontological Journal 17, 63-76.]

Dlussky, G. M. 1987. [New Formicoidea from Upper Cretaceous.] Paleontologicheskiy Zhurnal 1987(1), 131-35. [in Russian; English translation: Paleontological Journal 21, 146-50.]

Dlussky, G. M. 1988. [Ants from (Paleocene?) Sakhalin amber.] Paleontologicheskiy Zhurnal 1988(1), 50-61. [In Russian; English translation: Paleontological Journal 22, 50-60.]

Dlussky, G. M. 1996. [Ants (Hymenoptera: Formicidae) from Burmese Amber.] Paleontologicheskiy Zhurnal 1996(3), 83-89. [In Russian; English translation: Paleontological Journal 30, 449-54.]

Dlussky, G. M. 1999a. [The first find of Formicoidea (Hymenoptera) in the Lower Cretaceous of the North Hemisphere.] Paleontologicheskiy Zhurnal 1999(3), 62-66. [in Russian; English translation Paleontological Journal 33, 274-77.]

Dlussky, G. M. 1999b. [New ants (Hymenoptera: Formicidae) from Canadian Amber.] Paleontologicheskiy Zhurnal 1999(3), 73-76. [in Russian; English translation: Paleontological Journal 33, 40912.]

Dlussky, G. M. 2002. [Ants of the genus Dolichoderus Lund (Hymenoptera: Formicidae) from Baltic and Rovno ambers.] Paleontologicheskiy Zhurnal 2002(1), 54-68. [In Russian; English translation: Paleontological Journal 36, 50-63.]
Dlussky, G. M., Brothers, D. \& Rasnitsyn, A. P. 2004. The first Late Cretaceous ants (Hymenoptera: Formicidae) from southern Africa, with comments on the origin of the Myrmicinae. Insect Systematics and Evolution 35, 1-13.

Dlussky, G. M., Wappler, T. \& Wedmann S. 2008. New middle Eocene formicid species from Germany and the evolution of weaver ants. Acta Palaeontologica Polonica 53, 615-26.

Dlussky, G. M. \& Perfilieva, K. S. 2003. [Paleogene ants of the genus Archimyrmex Cockerell, 1923 (Hymenoptera, Formicidae, Myrmeciinae).] Paleontologicheskiy Zhurnal 2003(1), 40-49. [In Russian; English translation: Paleontological Journal 37, 39-47.]

Dlussky, G. M. \& Perkovsky, E. E. 2002. [Ants of Rovno amber.] Vestnik zoologii 36(5), 3-20. [In Russian.]

Dlussky, G. M. \& Rasnitsyn A. P. 2002. Ants (Hymenoptera: Formicidae) of Green River Formation and some other Middle Eocene deposits of North America. Russian Entomological Journal 11, 411-36.

Donisthorpe, H. St. J. K. 1915. British Ants, their Life history and Classification. Plymouth: Brenden \& Son, Ltd. xv +379 pp.

Donisthorpe, H. St. J. K. 1920. British Oligocene ants. Annals and Magazine of Natural History, Ser. 9 6, 81-94.

Donisthorpe, H. St. J. K. 1947 [1946]. Ants from New Guinea, including new species and a new genus. Annals and Magazine of Natural History 11(13), 577-95.

Emery, C. 1891. Le formishe dell'Ambra Siciliana nel Museo Mineralogico dell'Universita di Bologna. Memoire della Reale Accademia delle Scienza dell'Instituto di Bologna, Ser. 5 1, 567-94.

Emery, C. 1893. Voyage de M. E. Simon à l'île de Ceylan (janvierfévrier 1892). Formicides. Annales de la Société Entomologique de France 62, 239-58.

Emery, C. 1905. Deux fourmis de l'Ambre de la Baltique. Bulletin de la Societé Entomologique de France 77, 187-89.

Emery, C 1913 [1912]. Hymenoptera. Fam. Formicidae. Subfam. Dolichoderinae. Genera Insectorum 137, 1-50.

Enderlein, G., 1920. Zur Kenntnis ausserreuropäischer Braconiden. Archiv für Naturgeschihte 84(11), 51-224.

Engel, M. S. 1998. A New Species of the Baltic Amber Bee Genus Electrapis (Hymenoptera: Apidae). Journal of Hymenoptera Research 7(1), 94-101.

Engel, M. S. 2001. A monograph of the Baltic amber bees and evolution of the Apoidea (Hymenoptera). Bulletin of the American Museum of Natural History 259, 192 pp.

Engel, M. S. 2006. A giant honey bee from the middle Miocene of Japan (Hymenoptera, Apidae). American Museum Novitates 3504, $1-12$.

Engel, M. S. \& Bennett, D. J. 2008. Anoblepsis, a new, bizarre braconid wasp genus in Dominican Amber (Hymenoptera: Braconidae). Journal of the Kansas Entomological Society 81(4), 368-72.

Engel, M. S. \& Grimaldi, D. 2005. Primitive new ants in Cretaceous amber from Myanmar, New Jersey and Canada (Hymenoptera: Formicidae). American Museum Novitates 3485, 1-23.

Eskov, K. Y. 2002. Geographical history of insects. In Rasnitsyn, A. P. \& Quicke, D. L. J. (eds) History of Insects, 427-35. Dordrecht: Kluwer Academic Publishers. 517 pp.

Evanoff, E., Mcintosh, W. C. \& Murphey, P. C. 2001. Stratigraphic summary and ${ }^{40} \mathrm{Ar} /{ }^{39} \mathrm{Ar}$ geochronology of the Florissant Formation, Colorado. Proceedings of the Denver Museum of Natural Sciences, Ser. 4 1, 1-16.

Evans, H. E. 1966. The comparative ethology and evolution of the sand wasps. Cambridge, MA: Harvard University Press. xviii +526 pp.

Evans, H. E. 1969. Three new Cretaceous aculeate wasps (Hymenoptera). Psyche 76, 251-61.

Fabricius, J. C. 1775. Systema Entomologiae, sistens Insectorum classes, ordines, genera, species, adiectis synonymis, locis, descriptionibus, observationibus, 1-32. Flensburgi et Lipsiae [= Flensburg and Leipzig]: Kortii. 832 pp.

Fabricius, J. C. 1790. Nova Insectorum genera. Skrivter af Naturhistorie Selskabet, Kjøbnhavn 1, 213-28.

Fabricius, J. C. 1804. Systema Piezatorum. Brunsvigae: Reinchard. $439 \mathrm{pp}$.

Foerster, A. 1856. Hymenopteologische Studien. II Heft. Chalcidiae und Proctotrupii. Aachen: Meer. 152 pp.

Foerster, A. 1862. Synopsis der Familien und Gattungen der Braconen. Verhandlungen des Naturhistorischen Vereines der Preussischen Rheinland und Westphalens 19, 225-88.

Foerster, A. 1869. Synopsis der Familien und Gattungen der Ichneumonen. Verhandlungen des Naturhistorischen Vereins der Preussischen Rheinlande und Westfalens 25(for 1868), 135-221.

Foerster, A. 1891. Die Insekten des "Plattigen Steinmergels" von Brunstatt. Abhandlungen zur geologischen Spezialkarte von ElsassLothringen 3, 333-594. 
Forel, A. 1878. Etudes myrmécologiques en 1878 (première partie) avec l'anatomie du gésier des fourmis. Bulletin de la Société Vaudoise des Sciences Naturelles 15, 337-92.

Girault, J. 1869. Oberservations hyménoptèrologique. III. Des galles d'un Lépidoptère sur le Limoniastrum guyonianum, et des parasites qui les habitant. Annales de la Société Entomologique de France (4) 9, 469-88.

Gokhman, V. E. 1992. [On the origin of endoparasitism in the subfamily Ichneumoninae (Hymenoptera, Ichneumonidae).] Zhurnal Obshchei Biologii 53, 600-08. [In Russian.]

Gravenhorst, J. L. C. 1834. Bericht über die Beschästigungen der entomologischen Section im Jahre 1833. Übersicht der Arbait und Beränderungen der schlesischen Gesellschaft für vaterländische Kultur 1833, 76-80.

Grimaldi, D., Agosti, D. \& Carpenter, J. M. 1997. New and rediscovered primitive ants (Hymenoptera: Formicidae) in Cretaceous amber from New Jersey, and their phylogenetic relationships. American Museum Novitates 3208, 1-43.

Grimaldi, D. \& Agosti, D. 2000. A formicine in New Jersey Cretaceous amber (Hymenoptera: Formicidae), and early evolution of the ants. Proceedings of the National Academy of Sciences of the United States of America 97, 13678-83.

Guérin, M. 1838. Voyage autour de Monde sur la Coquille. Zoologie, II, 1, Divis. 1.

Haliday, A. H. 1833. An essay on the classification of the parasitic Hymenoptera of Britain, which correspond with the Ichneumones minuti of Linnaeus. Entomological Magazine 1, 259-76.

Haliday, A. H. 1835. Essay on parasitic Hymenoptera. Entomological Magazine 3, 20-45.

Haliday, A. H. 1836. Essay on parasitic Hymenoptera. Entomological Magazine 4, 38-59.

Haliday, A. H. 1839. Hymenopterorum synopsis ad methodum clm Fallenii utplurimum accomodata. Addendum to Hymenoptera Brittanica: Alysia. London: Hippolytus Baillière. 4 pp.

Hartig, T. 1840: Naturgeschichte der Gallwespen. Zeitschrift für die Entomologie 2, 176-209.

Hedicke, H. 1939. Aulacidae. In Hedicke, H. (ed.) Hymenopterorum Catalogus 10, 1-27. Junk W. (publ.).

Heer, O. 1849. Die Insektenfauna der Tertiärgebilde von Oeningen und von Radoboj in Croatien. Vol. 2. Heuschrecken, Florfliegen, Alderflügen, Schmetterlinge, und Fliegen. Leipzig: Engelmann. 264 pp.

Heer, O. 1849. 1867. Fossile Hymenopteren aus Oeningen und Radoboj. Neue Denkschriften der allgemeine schweizarische Gesellschaft fürd des gesammten Naturwissenschaften 22, 5-42.

Heyden, C., von. 1858. Fossile Insekten aus der Braunkohle von Sieblos. Palaeontographica 5, 115-20.

Hincks, W. D. 1944. Notes on the nomenclature of some British parasitic Hymenoptera. Proceeding of the Royal Entomological Society of London (B) 13, 30-39.

Hong, Y. 1974. Stratigraphy and paleontology of Fushun coal-field, Liaoning Province. II. Description of new fossil insects and phyllopods. Ti Chih Hsueh Pao 1974, 124-48.

Hong, Y. 1984. [Fossil insects in the diatoms of Shanwang.] Bulletin of the Tjanjin Institute of Geology and Mineral Resources 8, 1-12 [In Chinese.]

Hong, Y. 2001. [Amber insects of China.] Beijing: Beijing Scientific and Technological Publishing House. 653 pp, 48 pls. [In Chinese, with English summary.]

Hong, Y. 2002. [Atlas of amber insects of China.] Henan: Henan Scientific and Technological Publishing House. 394 pp. [In Chinese, with English summary.]

Hooker, J. J., Grimes, S. T., Mattey, D. P., Collinson, M. E. \& Sheldon, N. D. 2009. Refined correlation of the UK Late Eocene-Early Oligocene Solent Group and timing of its climate history. In Koeberl, C. \& Montanari, A. (eds) The Late Eocene Earth Greenhouse, Icehouse, and Impacts. Geological Society of America Special Paper 452, 179-95.

Hope, F. W. 1837. Observations on succinic insects. Transactions of the Entomological Society of London 2, 46-57.

Huddleston, T. 1980. A revision of the Western Palaearctic species of the genus Meteorus (Hymenoptera: Braconidae). Bulletin of the British Museum (Natural History) 41(1), 1-58.

Huddleston, T. 1984. The Palaearctic species of Ascogaster (Hymenoptera: Braconidae). Bulletin of the British Museum (Natural History) 49(5), 341-92.

Humala, A. E. 2003. [Ichneumon-flies of the fauna of Russia and surrounding countries. Subfamilies Microleptinae and Oxytorinae (Hymenoptera: Ichneumonidae).] Moscow: Russian Academy of Science. 175 pp. [In Russian.]

Jarzembowski, E. A. 1976. Report of Easter field meeting: the lower tertiaries of the Isle of Wight, 27-31.III.1975. Tertiary Research $1,11-16$.
Jarzembowski, E. A. 1980. Fossil insects from the Bembridge Marls, Palaeogene of the Isle of Wight, Southern England. Bulletin of the British Museum (Natural History), Geology Series 33, 23793.

Jennings, J. T. \& Austin, A. D. 2000. Higher level phylogeny of Aulacidae and Gasteruptiidae (Hymenoptera). In Austin, A. D. \& Dowton, M. (eds) The Hymenoptera: Evolution, Biodiversity and Biological Control, 155-164. Melbourne: CSIRO Publishing. 480 pp.

Jurine, L. 1801. In Panzer G. W. F. Nachricht von einem neuen entomologischen Werke des Hrn. Prof. Jurine in Geneva. Intelligentzblatt der Litteratur-Zeitung (Erlangen), 161-65.

Jurine, L. 1808. Adnotatio. In Spinola, M. Insectorum Liguriae species novae aut rariores quas in agro Ligustico nuper detexit, descripsit et iconibus illustravit Maximilianus Spinola, adjecto catalogo specierum auctoribus jam enumeratarum, quae in eadem regione passim occurrunt II, 254-56. Genuae: Yves Gravier. ii + 262 pp.

Kannowski, P. B. 1963. The flight activities of formicine ants. Symposia Genetica et Biologica Italica 12, 74-102.

Kasparyan, D.R. (ed.) 1981. [A guide to the insects of the European part of the USSR. Hymenoptera, Ichneumonidae.] Opredelitel po Faune SSSR, Leningrad 3(3). 688 pp. [In Russian.]

Kasparyan, D. R. 1988a. [New taxa of fam. Paxylommatidae (Hymenoptera, Ichneumonoidea) from the Baltic amber.] Trudy Vsesoyuznogo Entomologicheskogo Obshchestva 70, 125-31. [In Russian.]

Kasparyan, D. R. 1988b. [A new subfamily and two new genera of Ichneumonids (Hymenoptera, Ichneumonidae) from Baltic amber.] Proceedings of the Zoological Institute, Leningrad 175, 38-43. [In Russian.]

Kasparyan, D. R. 1994. [Review of Ichneumon flies of the Townesitinae subfam nov. (Hymenoptera, Ichneumonoidea) from the Baltic ambers.] Paleontologicheskiy zhurnal 4, 86-96. [In Russian.]

Kasparyan, D. R. 2001. A new genus and species of the subfamily Ghilarovitinae from Baltic amber (Hymenoptera: Paxylommatidae). Zoosystematica Rossica 10(1), 97-99.

Kasparyan, D. R. \& Humala, A. E. 1995. [A new genus and three new species of Ichneumonids of the subfamily Oxytorinae (Hymenoptera, Ichneumonidae) from Baltic amber.] Entomologicheskoye Obozreniye 74(2), 416-19. [In Russian.]

Khalaim, A. I. 2008. Fossil ichneumon wasps (Hymenoptera: Ichneumonidae) from Biamo (Russia), Oligocene. Alavesia 2, 101-12.

Kirby, W. F. 1798. Ammophila, a new genus of insects in the class Hymenoptera, including the Sphex sabulosa of Linnaeus. Transactions of the Linnean Society 4, 195-212, 1 Plate.

Kirby, W. F 1837. The insects. In Richardson, J. (ed.) Fauna borealiAmericana, or the Zoology of the Northern Parts of British America, containing descriptions of the objects of natural history collected on the late northern land expedition, under command of Capitan Sir John Franklin, 39-325. London: Longman.

Klug, F. 1801. Absonderung einiger Raupentödter und Vereiningung derselben zu einer neuen Gattung Sceliphron. Neue Schriften der Gesellschaft Naturforschender Freunde zu Berlin 3, 555-66.

Kohl, F. F. 1889. Neue Gattungen aus der Hymenopteren-Familie der Sphegiden. Annalen des k.k. Naturhistorischen Hofmuseums 4, 18895, Plate VIII.

Kohl, F. F. 1897. Die Gattungen der Sphegiden. Annalen des k. $k$ Naturhistorischen Hofmuseums 11, 233-516, Plates V-XI

Kozlov, M. A. 1970. Supergeneric groups of the Proctotrupoidea (Hymenoptera). Entomological Review 49, 115-27.

Kriechbaumer, J. 1894. Hymenoptera Ichneumonoidea a medico nautico Dr. Joh. Brauns in itinere ad oras Africae occidintalis lecta. Berliner Entomologische Zeitschrift 39, 43-68.

Krombein, K. V. 1959. A new genus and species of Psenini from the southwestern deserts (Hymenoptera, Sphecidae). Bulletin of the Brooklyn Entomological Society 54, 18-21.

Laicharting, J. N. von. 1781 Verzeichniss und Beschreibung der Tyroler Insecten 1. Zürich: Fuessley. xii +248 pp.

Latreille, P. A. 1796 Précis des Caractères génériques des Insectes, disposes dans un ordre naturel. Bourdeaux: Brive. $210 \mathrm{pp}$.

Latreille, P. A 1802. Histoire naturelle, générale et particulière des Crustacées et des Insectes. T. 3. Paris: Imprimerie F. Dufart. 467 pp.

Latreille, P. A 1804. Tableau méthodique des insectes. Classe huitième. Insectes, Insecta. Nouveau Dictionnaire d'Histoire Naturelle 24, $129-200$.

Latreille, P. A. 1805. Histoire naturelle générale et particulière des Crustacés et des Insectes. Ouvrage faisant suite aux Oeuvres de Leclercq de Buffon, et partie du Cours complet d'Histoire naturelle rédigé par C.S. Sonnini, membre de plusieurs Sociétés savantes 13. Paris: Imprimerie F. Dufart. $432 \mathrm{pp}$

Latreille, P. A. 1809. Genera Crustaceorum et Insectorum secundum ordinem naturalem in familias disposita, iconibus exemplisque 
plurimis explicata 4. Parisiis et Argentorati [= Paris and Strasbourg]: Amand Koenig. 399 pp.

Latreille, P. A 1817. Les Crustacés, les Arachnides et les insectes. In Cuvier, C. (ed.) Le Règne Animal, distribué d'apres son organisation, pour servir de base a l'histoire naturelle des animaux et d'introduction a l'anatmoie comparée 3. Paris: Deterville. $29+653 \mathrm{pp}$

Latreille, P. A 1829. Des Ichneumons (Ichneumon) de Linnaeus. In Cuvier, M. L. B. Le Règne Animal V, Ed. 2a, 282-90. Paris. 556 pp.

Leach, W. E. 1815. Entomology. In Brewster, D. Edinburgh Encyclopaedia 9, pt. 1, 57-172.

Lepeletier De Saint Fargeau, A. L. M. 1832. Mémoire sur le genre Gorytes Latr. Arpactus. Annales de la Société Entomologiques de France 1, 52-79.

Lepeletier De Saint Fargeau, A. L. M. 1836 [1835]. Histoire naturelle des insectes. Hyménoptères. Tome I. Paris: Roret. 547 pp.

Lewis, S. E., Heikes, P. M. \& Lewis, K. L. 1990. Entomofauna from the Brick Yard site (Miocene) near Spokane, Washington. Occasional Papers in Paleobiology St. Cloud State University 4(11), 116.

Linnaeus, C. 1758. Systema Naturae Per Regna Tria Naturae, Secundum Classes, Ordines, Genera, Species, Cum characteribus, differentiis, synonymis, locis 1. Editio Decima, Reformata. Holmiae: Laurentii Salvii. [4], [1-5], 6, 823, [1] pp.

Lund, A. W. 1831. Lettre sur les habitudes de quelques fourmis du Brésil, adressée à M. Audouin. Annales Des Sciences Naturelles 23, 113-38.

Machado, C. A., Jousselin, E., Kjellberg, F., Compton, S. G. \& Herre, E.A. 2001. Phylogenetic relationships, historical biogeography and character evolution of fig-pollinating wasps. Proceedings of the Royal Society, London, Series B 268, 685-94.

Mai, D. H. 1995. Tertiare Vegetationgeschchte Eurropas. Jena: Gustav Fischer Verlag. 692 pp.

Manning, F. J. 1961. A new fossil bee from Baltic amber. XI Internationaler Kongress für Entomologie, Verhandlungen, Wien 1, 306-08.

Marshall, T. A. 1898. Les Braconides. In Andre E. (ed.) Species des Hyménoptères d'Europe et d'Algerie 5bis, 145-288. Cote-d'Or: Beaune. 39, 635 pp.

Masner, L. 1961. Proctotrupidae. Key to the genera of the world (Hymenoptera, Proctotrupoidea). Exploration du Parc National de l'Upemba Mission G.F. de Witte (1946-1949), Brussels 60(4), $37-45$.

Masner, L. 1969. The geographic distribution of recent and fossil Ambositrinae (Hymenoptera: Proctotrupoidea: Diapriidae). Tagungsberichte der Deutsche Akademie der Landwirtschaftwissenschaften zu Berlin 80, 105-09.

Mason, W. R. M. 1981. The polyphyletic nature of Apanteles Foerster (Hymenoptera, Braconidae): a phylogeny and reclassification of Microgastrinae. Memoirs of the Entomological Society of Canada $115,1-147$.

Mason, W. R. M. 1983. A new South African subfamily related to Cardiochilinar (Hymenoptera, Braconidae). Contribution of the American Entomological Institute 20, 49-62.

Mayr, G. 1853. Beiträge zur Kenntniss der Ameisen. Verhandllungen der kaiserlich-kongiglichen zoologish-botanischen Gesellschaft in Wien 3, 101-14.

Mayr, G. 1861. Die europäischen Formiciden. Nach der analytischen Methode bearbeitet. Wien: C. Gerolds Sohn. $80 \mathrm{pp}$.

Mayr, G. 1862. Myrmecologische Studien. Verhandllungen der kaiserlich-kongiglichen zoologish-botanischen Gesellschaft in Wien 12, 649-776.

Mayr, G. 1867. Vorläufige Studien über die Radoboj-Formiciden, in der Sammlung der geologischen Reichsanstalt. Jahrbuch der geologischen Reichsanatal, Wien 17, 47-62.

Mayr, G. 1868. Die Ameisen des Baltischen Bernstein. Beiträge zur Naturkunde Preussens physikalische-ökonomischen Gesellschaft zu Königsberg 1, 1-102.

Menier, J.-J., Nel A., Waller, A. \& Plo?g, G. de. 2004. A new fossil ichneumon wasp of Paris Basin (France), with a checklist of fossil Ichneumonoidea s.l. (Insecta: Hymenoptera: Ichneumonidae: Metopiinae). Geologica Acta 2(1), 83-94.

Menke, A. S. 1962. A new genus of digger wasps from South America (Hymenoptera: Sphecidae). Proceedings of the Biological Society of Washington 75, 303-06.

Menke, A. S. 1989. Arpactophilus reassessed, with three bizarre new species from New Guinea (Hymenoptera: Sphecidae: Pemphredoninae). Invertebrate Taxonomy 2, 737-47.

Menke, A. S. and Rasnitsyn, A. P. 1987. Affinities of the fossil wasp, Hoplisidea kohliana Cockerell (Hymenoptera: Sphecidae: Sphecinae). Psyche 94(1-2), 35-38.

Meunier, M. F. 1915. Über einige fossil Insekten aus den Braunkohlenschichten (Aquitanien) von Rott im Siebengebirge. 3 Teil. Zeitschrift der deutschen geologischen Gesellschaft 67(4), 205-17.
Meyer, H. W. 2003. The Fossils of Florissant. Washington, D.C.: Smithsonian Institution Press. 285 pp.

Morawitz, A. 1866. Einige Bemerkungen über die Crabro-artigen Hymenopteren. Bulletin de l'Académie Impériale des Sciences de St.-Pétersbourg 9, 243-73.

Muesebeck, C. F. W. 1960. A fossil braconid wasp of the genus Ecphylus (Hymenoptera). Journal of Paleontology 34, 495-96.

Nees Von Esenbeck, C. G. 1812. Ichneumonides adsciti, in genera et families divisi. Der Gesellschaft Naturforschender Freunde zu Berlin Magazin für die neuesten Entdeckungen in der gesamten Naturkunde 5, 3-37.

Nees Von Esenbeck, C. G. 1816. Ichneumonides adsciti, in genera et families divisi. Der Gesellschaft Naturforschender Freunde zu Berlin Magazin für die neuesten Entdeckungen in der gesamten Naturkunde 7(4), 243-77.

Nees Von Esenbeck, C. G. 1818. Appendix ad J. I. Gravenhorst conspectun generum et familiarum Ichneumonidum, genera et familias Ichneumonidum adscitorum exhibens. Nova Acta Physicomedica Academiae Caesarea Leopoldino-Carolinae naturae curiosorum 9, 299-310.

Nefdt, R. J. C. \& Compton, S. G. 1996. Regulation of seed and pollinator production in the fig-fig wasp mutualism. Journal of Animimal Ecology 65, 170-82.

Nel, A., Waller, A. \& Plöeg, G. de. 2004. An aulacid wasp in the lowermost Eocene amber from the Paris Basin (Hymenoptera, Evaniidae). Geologica Acta 2, 67-74.

Nemkov, P. G. 1988. Review of the Holarctic species of the genus Tracheliodes A. Morawitz. Horae Societatis Entomologicae Unionis Sovieticae 70, 116-24.

Nixon, G. E. J. 1965. A reclassification of the tribe Microgasterini (Hymenoptera: Braconidae). Bulletin of the British Museum of Natural History (Entomology) 21, 1-34.

Noort, S. van \& Compton, S. G. 1996. Convergent adaptations of fig wasps to the ostiolar morphology of their host figs. Journal of Biogeography 23, 415-24.

Ortega-Blanko, J., Bennett, D. J., Delclòs, X. \& Engel, M. S. 2009 A primitive aphidiine wasp in Albian amber from Spain and a Northern Hemisphere origin for the subfamily (Hymenoptera: Braconidae: Aphidiinae). Journal of the Kansas Entomological Society 82(4), 273-82.

Papp, J. 1984. Contribution to the braconid fauna of Hungary. V. Doryctinae (Hymenoptera: Braconidae). Folia Entomologica Hungarica 45(1), 173-85.

Park, J. S. \& Achterberg, C. van 1994. A new genus of the subfamily Ecnomiinae van Achterberg (Braconidae) from Korea. Zoologische Mededelingen Leiden 68, 49-54.

Pate, V. S. L. 1936. Studies in the Nyssoninae wasps (Gorytini: Sphecidae: Hymenoptera). I. The species of Psammaletes, a new subgenus of Hoplisoides. Transactions of the American Entomological Society 62, 49-56.

Peñalver, E., Engel, M. S. \& Grimaldi, D. A. 2006. Fig wasps in Dominican Amber (Hymenoptera:Agaonidae). American Museum Novitates 3541, 1-16.

Perfilieva, K. S. 2002. [Wing venation in army ants (Hymenoptera, Formicidae) and its importance for phylogenic analysis.] Zoologicheskiy Zhurnal 81, 1239-50 [In Russian; English translation: Entomological Review 82, 1065-76.]

Perfilieva, K. S 2005. [Analysis of interspecies and sexual differences of quantitative wing characters of several ant species.] Ants and Forest Protection. Materials of XII All-Russian Myrmecological Symposium, Novosibirsk, 270-74. [In Russian.]

Perkovsky, E. E. 2006. [Occurrence of ant (Hymenoptera, Formicidae) and aphid (Homoptera, Aphidinea) syninclusions in Saxonian and Rovno ambers.] Paleontologicheskiy Zhurnal 2006(2), 72-74. [In Russian; English translation: Paleontological Journal 40, 190-92.]

Perrichot, V., Néraudeau, D., Nel, A. \& Ploëg, G. de. 2007. A reassessment of the Cretaceous amber deposits from France and their palaeontological significance. African Invertebrates 48(1), 213-27.

Perrichot, V., Nel, A. \& Quicke, D. L. J. 2009. New braconid wasps from French Cretaceous amber (Hymenoptera, Braconidae): synonymization with Eoichneumonidae and implications for the phylogeny of Incheumonoidea. Zoologica Scripta 38, 79-88.

Piton, L. E. 1840. Paléontologie du gisement Eocéne de Menat (Puy-deDóme) (flore et faune). Paris: Paul Lechevalier. 303 pp.

Poinar, G. Jr. 2005. Fossil Trigonalidae and Vespidae (Hymenoptera) in Baltic amber. Proceedings of the Entomological Society of Washington 107(1), 55-63.

Popov, V. 1932. Two new fossil ants from Caucasus (Hymenoptera, Formicidae). Travaux de l'Institute Paleozoologique 2, 17-21.

Quicke, D. L. J. 1987. The Old World genera of braconine wasps (Hymenoptera: Braconidae). Journal of Natural History 21, 43-157. 
Quicke, D. L. J. \& Achterberg, C. van. 1990. Phylogeny of the subfamilies of the family Braconidae (Hymenoptera: Ichneumonoidea). Zoologische Verhandelingen Leiden 258, 1-95.

Radoszkowski, O. 1876. Matériaux pour servir à une faune hyménoptérologique de la Russie. (Suite). Horae Societatis Entomologicae Rossicae 12, 82-110.

Rasnitsyn, A. P. 1975. [Hymenoptera Apocrita of Mesozoic.] Trudy Paleontologicheskogo Instituta AN SSSR [Trans. Paleontol Inst. Acad. Sci. USSR] 147. Moscow: Nauka Press. 134 pp. [In Russian.]

Rasnitsyn, A. P. 1977. [A new subfamily of scoliid wasps (Hymenoptera).] Zoolgicheskiy Zhurnal 56, 522-29. [In Russian, with English summary.]

Rasnitsyn, A. P. 1980. [The origin and evolution of the hymenopteran insects.] Proceedings of Palaeontological Institute, Academy of Sciences of USSR 174. 192 pp. [In Russian.]

Rasnitsyn, A. P. 1983. Ichneumonoidea (Hymenoptera) from the Lower Cretaceous of Mongolia. Contribution of the American Entomological Institute 20, 259-65.

Rasnitsyn, A. P. 1993. Archaeoscoliinae, an extinct subfamily of scoliid wasps (Insecta: Vespida $=$ Hymenoptera: Scoliidae). Journal of Hymenopera Research 2(1), 85-96.

Rasnitsyn, A. P. 2013. Vectevania vetula Cockerell, 1922 from the uppermost Eocene of Bembridge Marls, England, and the system of the family Gasteruptiidae s.l. [Vespida (= Hymenoptera), Evanioidea]. Proceedings of the Russian Entomological Society 84(2), 98-106.

Rasplus, J-Y, Kerdelhué, C., Le Clainche, I. \& Mondor, G. 1998. Molecular phylogeny of fig wasps. Agaonidae are not monophyletic. C. R. Académie des Sciences de Paris, Sciences de la vie 321, 51727.

Ratzeburg, J. T. C. 1848. Die Forstinsekten oder Abbildung und Beschreibung der in den Wäldern Preussens und der Nachbarstaaten als schädlich oder nützlich bekannt gewordenen Insecten; in systematischer Folge und mit besonderer Rücksicht auf die Vertilgung der schädlichsten 2. Berlin: Nicolai. 238 pp.

Robertson, C. 1903. Synopsis of Megachilidae and Bombinae. Transactions of the American Entomological Society 29, 163-78.

Roger, J. 1861. Die Ponera-artigen Ameisen. Berliner Entomologische Zeitschrift 5, 1-54.

Rohlf, F. \& Marcus, L. 1993. A revolution in morphometrics. Trends in Ecology and Evolution 8(4), 129-32.

Rønsted, N., Weiblen, G. D., Cook, J. M., Salamin, N, Machado, C. A. \& Savolainen, V. 2005. 60 million years of co-divergence in the fig wasp symbiosis. Proceedings of the Royal Society, Series B 272, 2593-99.

Rust, J. 1999. Giant ants from the Paleogene of Denmark with a discussion of the fossil history and early evolution of ants (Hymenoptera: Formicidae). Zoological Journal of Linnean Society 125, 331-48.

Ruthe, J. F. 1854. Beitrage zur Kenntnis der Braconiden (Dimeris, Araphis, Trachyusa, Rhaconotus, Alysia). Stettiner Entomologische Zeitung 15, 343-55.

Ruthe, J. F. 1862. Deutsche Braconiden (Meteorus). Berliner Entomologische Zeitung 6, 1-58.

Ruzsky, M. 1912. Mirmekologicheskiya zametki [Myrmecological notices.] Uchenye Zapiski Kazanskago Veterinarago Instituta 29, 629-36.

Santschi, F. 1938. Notes sur quelques Ponera Latr. Bulletin de la Société Entomologique de France 43, 78-80.

Saussure, H. de \& Sichel, J. 1864. Catalogue des espèces de l'ancien genre Scolia, contenant les diagnoses, les descriptions et la synonymie des espèces, avec des remarques explicatives et critiques. Genève et Paris: V. Mason. 358 pp.

Scopoli, J. A. 1763. Entomologia Carniolica exhibens Insecta Carnioliae indigena et distributa in ordines, genera, species, varietates. Methodo Linnaeano. Vindobonae: Typis Ioannis Thomae Trattner. [1-36], 420, [4] pp.

Scudder, S. H. 1878. The fossil insects of the Green River shales. Bulletin of the United States Geological and Geographical Survey of the Territories $\mathbf{4}, 747-76$.

Scudder, S. H. 1890. The Tertiary insects of North America. Report of the United States Geological Survey of the Territories 13, 1-734.

Sharkey, M. J. \& Wharton, R. A. 1985. Redefinition of Megagathis Kriechbaumer, and reassignment of new world species to Zacremnops new genus (Hymenoptera: Braconidae: Agathidinae). The Canadian Entomologist 117, 599-603.

Shaw, S. R. 1985. A phylogenetic study of the subfamilies Meteorinae and Euphorinae (Hymenoptera: Braconidae). Entomography 3, 277-370.

Shenefelt, R. D. 1975. Braconidae 8. Exothecinae. Rogadinae. In Vecht, J. van der \& Shenefelt, R. D. (eds) Hymenopterum Catalogus 12, $1115-262$.
Shuckard, W. E. 1837. Essay on the indigenous fossorial Hymenoptera; comprising a description of all the British species of burrowing sand wasps contained in the metropolitan collections; with their habits as far as they have been observed. London: Richter and Co. XII pp. one Plate, $252+$ [2] pp., pls. 1-4, [4].

Shuckard, W. E. 1838. Descriptions of new exotic aculeate Hymenoptera. Transactions of the Entomological Society of London 2, 6882, Plate VIII.

Skorikov, A. S. 1914. Les formes nouvelles des bourdons (Hymenoptera, Bombidae). VI. Russkoye Entomologicheskoye Obozreniye 14, $119-29$.

Skorikov, A. S. 1922. [Palaearctic bumble bees. Part I. General biology (including zoogeography).] Izvestiya Severnoj oblastnoj stantsyi zashchity rastenij ot vreditelej 4(1), 1-160. [In Russian.]

Smith, F. 1857. Catalogue of the hymenopterous insects collected at Sarawak, Borneo; Mount Ophir, Malacca; and at Singapore, by A. R. Wallace. [part]. Journal of the Proceedings of the Linnean Society. Zoology 2, 42-88.

Smith, F. 1858. Catalogue of hymenopterous insects in the collection of the British Museum. Part VI. Formicidae. London: British Museum. 216 pp.

Smith, F. 1860. Catalogue of hymenopterous insects collected by Mr. A. R. Wallace in the islands of Bachian, Kaisaa, Amboyna, Gilolo and at Dory in New Guinea. Journal of the Proceedings of the Linnean Society. Zoology 5, 93-143.

Spinola, M. 1808. Insectorum Liguriae species novae aut rariores, quae in agro ligustico nuper detexit, descripsit, et iconibus illustratavit 2(2-4). Genuae: Gravier. v + 261 pp.

Spinola, M. 1853. Compte rendue des hyménoptères inédits provenants des voyage entomologique de Mr Ghiliani dans le Parà en 1846. Memoire della Reale Accademia della Scienze di Torino 13(2), 19-94

Stary, P. 1973. A revision of fossil Aphidiidae (Hym.). Annotationes Zoologicae et Botaticae Bratislava 87, 1-22.

Statz, G. 1936. Ueber alte und neue fossile Hymenopterenfunde aus den tertiaren Ablagerungen von Rott am Siebengebirge. Decheniana 93, 256-312.

Statz, G. 1938. Neue Funde parasitischer Hymenopteren aus dem Tertiar von Rott am Siebengebirge. Decheniana 98, 71-144.

Swederus, N. S. 1795. Beskrifning på et nytt genus Pteromalus ibland Insecterna, haerande til Hymenoptera, uti herr arch. och ridd. v. Linnés Systema Naturae. Kungliga Svenska Vetenskapsakademiens Handlingar 16, 201-05.

Szepligeti, G. V. 1900. Braconiden aus Neu-Guinea in der Ungarischen National-Museums. Természetrajzi Füzetek 23, 49-65.

Szepligeti, G. V. 1902. Tropische Cenocoelioniden und Braconiden aus der Sammlung des Ungarischen National-Museums. Természetrajzi Füzetek 25, 39-84.

Szepligeti, G. V. 1908. Braconiden aus der Sammlung des ungarischen National Museums. Annales Historico-Naturales Musei Nationalis Hungarici 6, 297-427.

Taylor, R. W. 1964. Taxonomy and parataxonomy of some fossil ants (Hymenoptera-Formicidae). Psyche 71, 134-41.

Telenga, N. A. 1952. Proiskhozhdenie paraziizma u nasekomykhnaezdnikov i formirovanie ikh fauny v SSSR [Parasitism origin in the parasitic Hymenoptera and formation of their fauna in USSR]. Kiev: Academy of Sciences Ukraine SSR Press. 140 pp.

Théobald, N. 1937. Les insectes fossiles des terrain oligocene de France. Bulletin Mensuelle de la Société Scientifique de Nancy (N.S.) 2bis, 1-473.

Thomson, C. G. 1892. XLIV. Bidrag till Braconidernas kännedom. Opuscula entomológica 16, 1659-751.

Thomson, C. G. 1895. LII. Bidrag till Braconidernas kännedom. Opuscula entomologica 20, 2141-339.

Thunberg, C. P. 1822. Ichneumonidea, insecta Hymenoptera, illustrate. Mémoires de l'Academie imperiale des Sciences de St. Petersbourg 8, 249-81.

Timon-David, J. 1944. Insectes fossiles de 1Oligocene inferieur des Camoins (Bassin de Marseille). II. Hymenopteres. Bulletin de la Société Entomologique de France 49, 40-45.

Tobias, V. I. 1965. [Generic grouping and evolution of parasitic Hymenoptera of the subfamily Euphorinae (Hymenoptera, Braconidae).] I. Entomologicheskoe Obozrenie 44, 841-65. [In Russian.]

Tobias, V. I. 1966. [Generic grouping and evolution of parasitic Hymenoptera of the subfamily Euphorinae (Hymenoptera, Braconidae).] II. Entomologicheskoe Obozrenie 45, 612-33. [In Russian.]

Tobias, V. I. 1982. [On the braconid species described by W. Hellen in the subgenus Taphaeus Wesmael (Hymenoptera, Braconidae).] Entomologicheskoe Obozrenie 61(3), 614-19. [In Russian.]

Tobias, V. I. 1987. [New taxa of braconids (Hymenoptera, Braconidae) from Baltic amber.] Entomologicheskoe Obozrenie 66(2), 845-59. [In Russian.] 
Tobias, V. I. 1988. [The family Paxylommatidae (Hymenoptera) in the fauna of the USSR.] Trudy Vsesoyuznogo Entomologicheskogo Obshchestva 70, 131-43. [In Russian.]

Tobias, V. I. 2000. [Subfamily Cheloninae.] In Lehr, P. A. (ed.). Key to insects of the Russian Far East. Volume 4. Neuropteroidea, Mecoptera, Hymenoptera. Part 4, 426-571. Vladivostok: Dal'nauka. 649 pp. [In Russian.]

Tolkanitz, V. I., Narolsky, N. B. \& Perkovsky, E. E. 2005. [A new species of parasitic wasp of the genus Pherhombus (Hymenoptera, Ichneumonidae, Pherhombinae) from Rovno amber.] Paleontologicheskiy zhurnal 5, 50-52. [In Russian.]

Townes, H. K. 1969. The genera of Ichneumonidae, Part 1. Memoirs of the American Entomological Institute 11. 300 pp.

Townes, H. K. 1970a. The genera of Ichneumonidae, Part 2. Memoirs of the American Entomological Institute 12(for 1969). 537 pp.

Townes, H. K. 1970b. The genera of Ichneumonidae, Part 3. Memoirs of the American Entomological Institute 13(for 1969). 307 pp.

Townes, H. K. 1971. The genera of Ichneumonidae, Part 4. Memoirs of the American Entomological Institute 17. 372 pp.

Townes, H. K. \& Townes, M. 1981. A revision of the Serphidae (Hymenoptera). Memoirs of the American Entomological Institute 32, $1-541$.

Viereck, H. L. 1912. Contribution to our knowlenge of bees and ichneumon-flies, including the description of twenty-one new genera and fifty-seven new species of ichneumon-flies. Proceedings of the United States National Museum 42, 613-648.

Vogt, O. 1911. Studien über das Artproblem. 2. Mitteilung. Über das Variieren der Hummeln. 2. Teil. (Schluss). Sitzungsberichte der Gesellschaft naturforschender Freunde zu Berlin 1911, 31-74

Walker, F. 1846. Descriptions of British Chalcidites. Annals and Magazine of Natural History 4(1), 29-32.

Weiblen, G. D. 2002. How to be a fig wasp. Annual Review Entomology 47, 299-330.

Wesmael, C. 1835. Monographie des Braconides de Belgique. Nouveaux Mémoires de l'Académie Royal des Sciences at Belles-Lettres de Bruxelles 9, 1-252.

Wesmael, C. 1837. Monographie des Braconides de Belgique. Nouveaux Mémoires de l'Académie Royal des Sciences at Belles-Lettres de Bruxelles 10, 5-68.

Wesmael, C. 1838. Monographie des Braconides de Belgique. IV. Nouveaux Mémoires de l'Académie Royal des Sciences at BellesLettres de Bruxelles 11, 1-166.

Wesmael, C. 1845. Tentamen dispositionis methodicae. Ichneumonum Belgii. Nouveaux Mémoires de l'Académie Royale des Sciences, des Lettres et Beaux-Arts de Belgique 18(for 1844), 1-239.
Westwood, J. O. 1854. Contributions to fossil entomology. Quarterly Journal of the Geological Society, London 10, 378-96.

Westwood, J. O. 1882. Description of new or imperfectly known species of Ichneumones adsciti. Tijdschrift voor Entomologie 25, 17-48.

Wheeler, W. M. 1915. The ants of the Baltic Amber. Schriften der physikalische-ökonomischen Gesellschaft zu Königsberg 55, 1-142.

Wheeler, W. M. 1922. Ants of the American Museum Congo expedition. A contribution to the myrmecology of Africa. II. The ants collected by the American Museum Congo Expedition. Bulletin of the American Museum of Natural History 45, 39-269.

Wilson, E. O. 1985. Ants of the Dominican amber (Hymenoptera: Formicidae). The subfamily Dolichoderinae. Psyche 92, 17-37.

Wilson, E. O. Eisner, T., Wheeler, G. C. \& Wheeler, J. 1956. Aneuretus simoni Emery, a major link in ant evolution. Bulletin of the Museum of Comparative Zoology 115, 81-99.

Wilson, E. O. \& Taylor R. W. 1964. A fossil ant colony: new evidence of social antiquity. Psyche 71, 93-103.

Woodward, H. 1879. On the Occurrence of Branchipus (or Chirocephalus) in a Fossil State, associated with Eosphaeroma and with numerous Insect Remains, in the Eocene Freshwater (Bembridge) Limestone of Gurnet Bay, Isle of Wight. Quarterly Journnal of the Geological Society, London 35, 342-50.

$\mathrm{Yu}, \mathrm{D}$. S., Achterberg, K. van \& Horstmann, K. 2005. World Ichneumonoidea 2004. Taxonomy, Biology, Morphology and Distribution. CD/DVD. Vancouver, Canada: Taxapad. www.taxapad.com.

Zhang, Haichun \& Rasnitsyn, A. P. 2003. Some ichneumonids (Insecta, Hymenoptera, Ichneumonoidea) from the Upper Mesozoic of China and Mongolia. Cretaceous Research 24(1), 193-202.

Zhang, Junfeng. 1989. [Fossil Insects from Shanwang, Shandong, China.] Jinan, China: Shandong Science and Technology Publishing House. 459 pp +92 pls. [In Chinese, with English summary.]

Zhang, Junfeng, Sun, B. \& Zhang, X. 1994. [Miocene Insects and Spiders from Shanwang, Shandong.] Beijing: Science Press. 298 pp. [In Chinese, with English summary.]

Zherikhin, V. V. 1978. Development and change of Cretaceous and Cenozoic faunistic complexes. Proceedings of the Palaeontological Institute 165, 1-197.

Zherikhin, V. V. 1980. [Characters of insect burial.] In Rohdendorf, B. B. \& Rasnitsyn, A. P. (eds.) [The Historical Development of the Class Insecta,] 7-18. Trudy Paleontologicheskogo Instituta AN SSSR 175. 269 pp. [In Russian.]

Zuparko, R. L. \& Poinar G. O. Jr. 1997. Aivalykus dominicanus (Hymenoptera: Braconidae), a new species from Dominican amber. Proceedings of the Entomological Society of Washington 99(4), 744-47. 